- TESIS -

\title{
"LA EDUCACIÓN MEDIA ESTATAL EN JUNÍN Y LA CONSTRUCCIÓN DE UNA SOCIEDAD MÁS JUSTA"
}

Facultad de Ciencias Jurídicas y Sociales

Universidad Nacional de La Plata

Maestría en Ciencia Política

Directora de Tesis: Dra. María de las Nieves Cenicacelaya

Maestrando: Ab. Hugo Domingo Ferrari

Junín, 16 de diciembre de 2013 


\section{ÍNDICE}

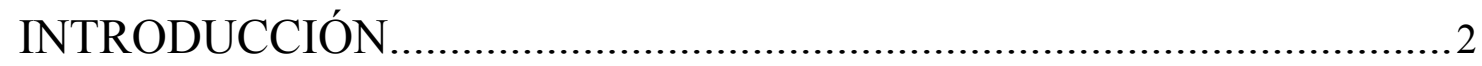

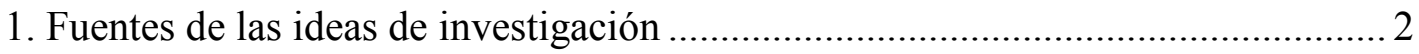

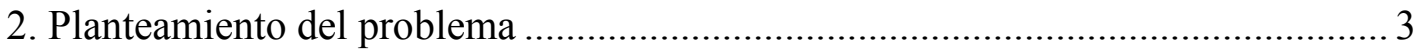

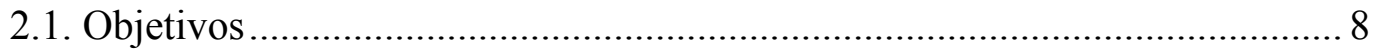

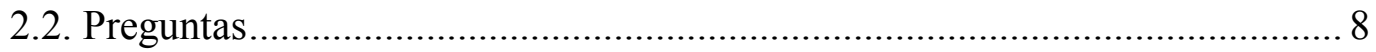

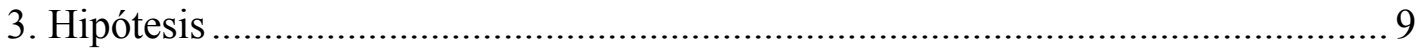

3.1. Definiciones conceptuales de las variables ................................................ 13

Capítulo I. MARCO DE REFERENCIA …...............................................17

1. La existencia humana: aprender y enseñar ......................................................... 17

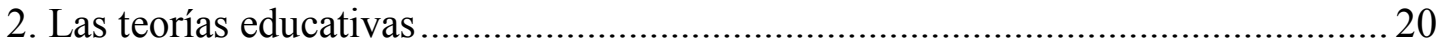

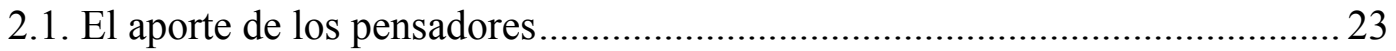

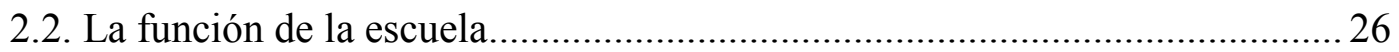

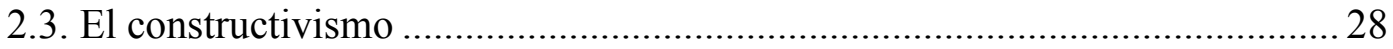

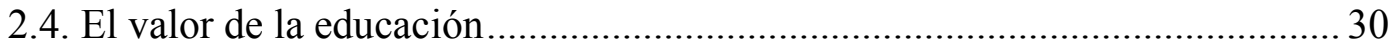

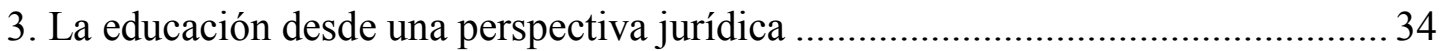

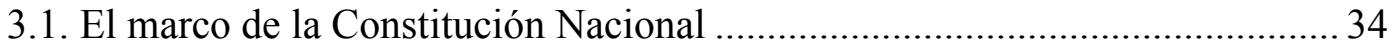

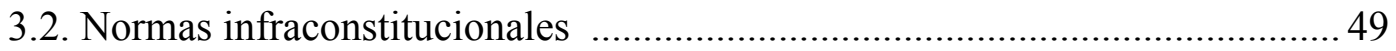

3.2.1. El comportamiento docente en el marco de la ética pública ................. 49

3.2.2. El neoliberalismo y la educación nacional............................................ 51

3.2.3. La responsabilidad del Estado en materia educativa provincial ............. 56

3.2.3.1. Escuelas plurales para sociedades más inclusivas........................... 60

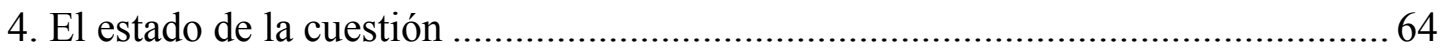

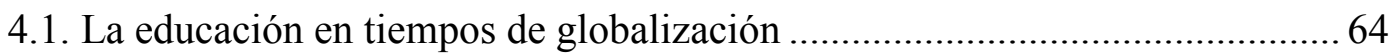

4.2. Principales problemas educativos en América Latina .................................... 66

4.2.1. La sociedad del conocimiento y los agentes socializadores .................. 73

4.2.2. Democracia y valores: creatividad, solidaridad y eficiencia.................. 78

4.2.3. Una educación de calidad para todos ..................................................... 80

4.3. Características del nivel medio del sistema educativo argentino ................... 83

4.3.1. El valor de la escuela para la formación del adolescente y del adulto.... 100

4.3.2. La nueva secundaria en la provincia de Buenos Aires............................ 104 


\section{Capítulo II. EL PROCESO DE INVESTIGACIÓN}

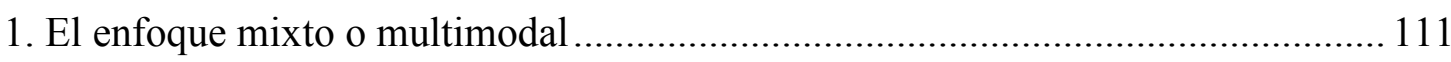

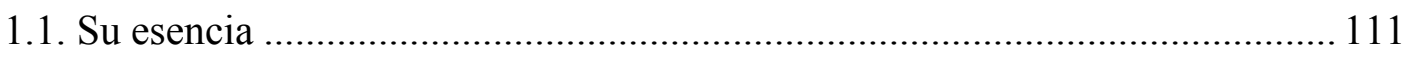

1.2. Definiciones fundamentales que llevaron a su elección .................................. 111

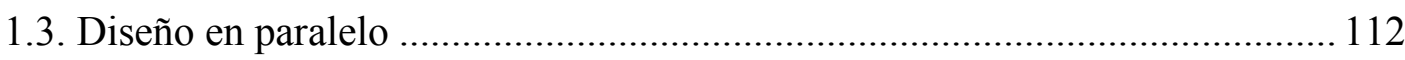

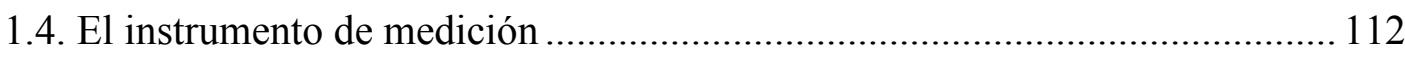

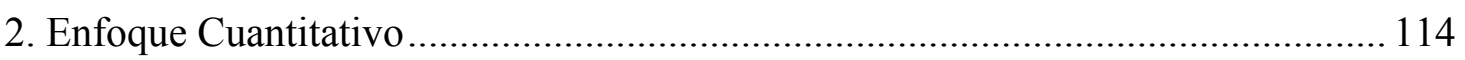

2.1. Egresados de escuelas estatales de nivel medio del Distrito de Junín ............. 115

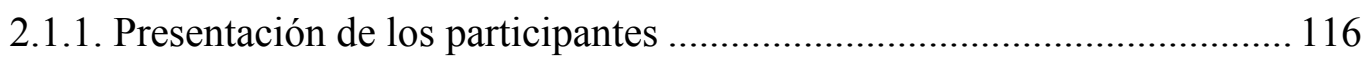

2.1.2. Conceptos preliminares al trabajo de campo ………………………....... 122

2.1.2.1. Estrategia metodológica y diseño muestral ..................................... 122

2.1.2.2. La construcción del instrumento de medición................................... 126

2.1.3. Datos obtenidos al operacionalizar las variables .................................... 132

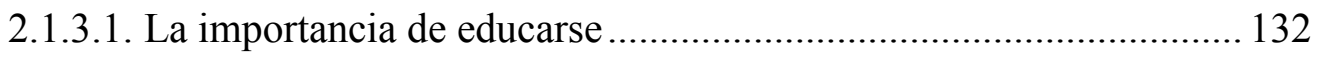

2.1.3.2. Ideas respecto del futuro............................................................... 151

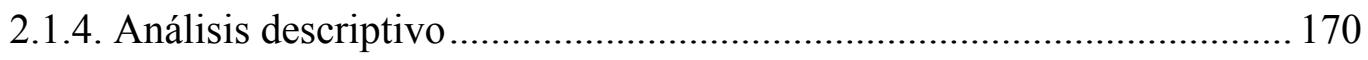

2.2. Responsables de los egresados de escuelas estatales de nivel medio

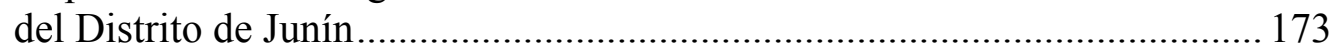

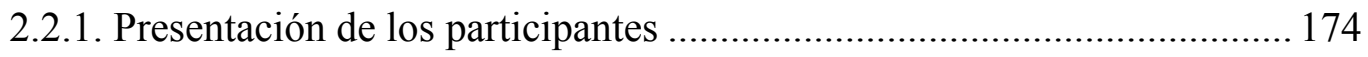

2.2.2. Conceptos preliminares al trabajo de campo ......................................... 176

2.2.2.1. Los responsables y el instrumento de medición............................... 176

2.2.3. Datos obtenidos al operacionalizar las variables ...................................... 177

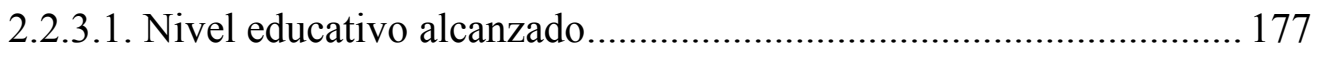

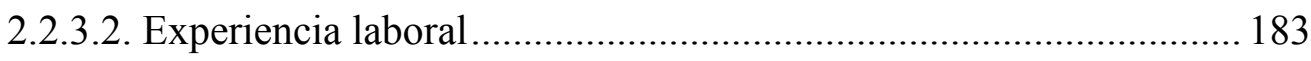

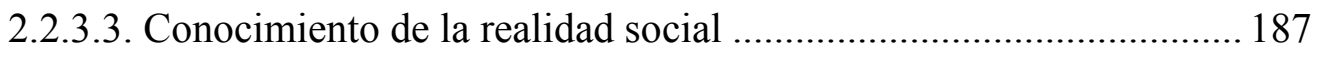

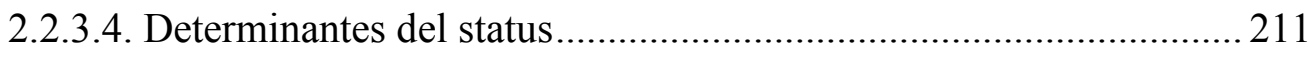

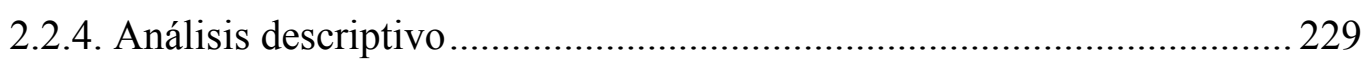

2.3. Profesores de los egresados de escuelas estatales de nivel medio

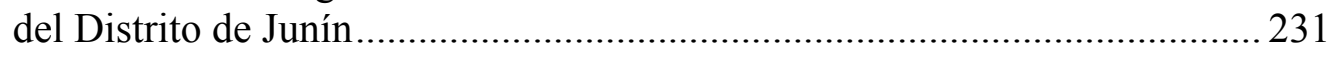

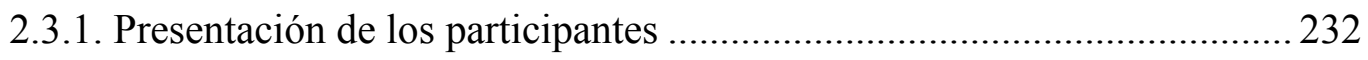

2.3.2. Datos obtenidos al operacionalizar las variables ................................... 236

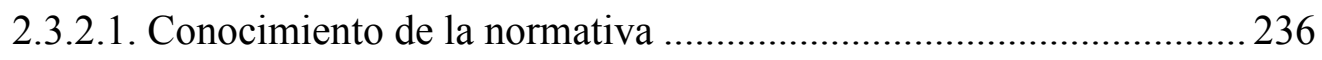

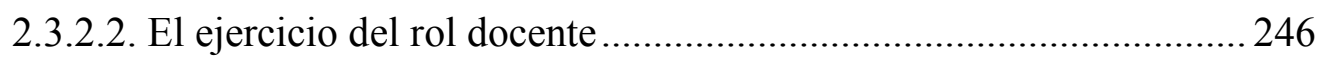

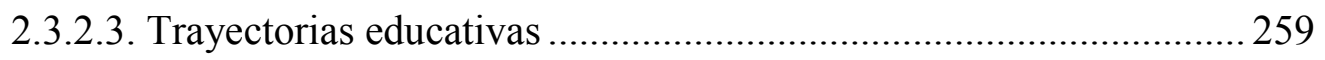


2.3.3. Análisis descriptivo 265

2.4. Directores de escuelas estatales de nivel medio del Distrito de Junín............ 267

2.4.1. Presentación de los participantes 268

2.4.2. Datos obtenidos al operacionalizar las variables 268

2.5. Secretarios de escuelas estatales de nivel medio del Distrito de Junín........... 280

2.5.1. Presentación de los participantes 281

2.5.2. Datos obtenidos al operacionalizar las variables 281

2.5.3. Análisis descriptivo 291

3. Enfoque Cualitativo 298

3.1. Observación 299

3.1.1. Escuelas de adolescentes 300

3.1.1.1. Escuela D: desarrollo de una clase 301

3.1.1.2. Escuela G: horarios 302

3.1.2. Escuelas de adultos 307

3.1.3. Modalidades en varias escuelas: materias que comprenden 308

3.1.4. Alumnos que egresan del nivel medio y finalizan (o no) el mismo 312

3.1.5. El proceso de socialización escolar. 318

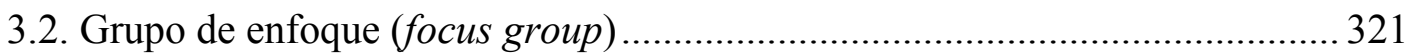

3.2.1. La mirada de los preceptores ............................................................. 322

3.2.2. Otras opiniones sobre la realidad educativa.......................................... 323

3.2.2.1. Cómo ven los profesores a los egresados ........................................ 323

3.2.2.2. Cómo ven los egresados a los profesores ....................................... 324

3.2.2.3. Otros puntos de vista sobre la misma realidad ............................... 325

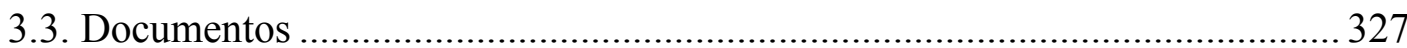

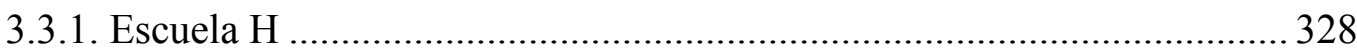

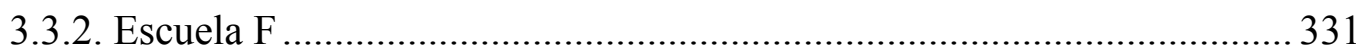

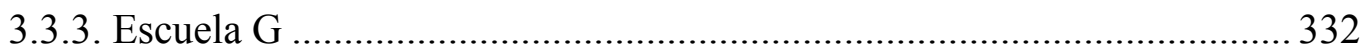

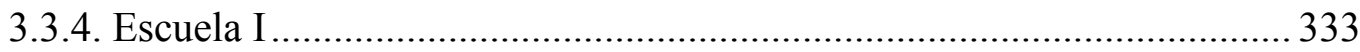

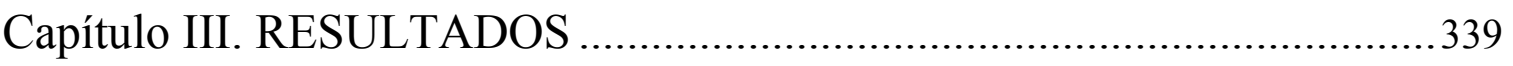

1. Escrutinio empírico para aportar evidencia a favor de las subhipótesis................. 339

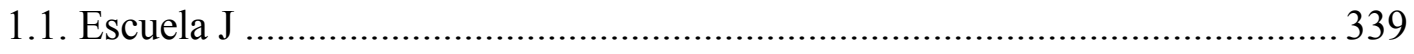

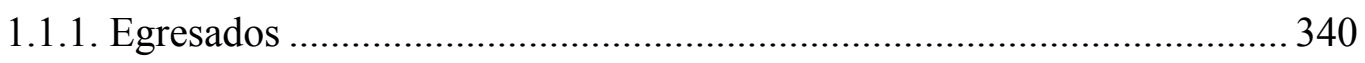

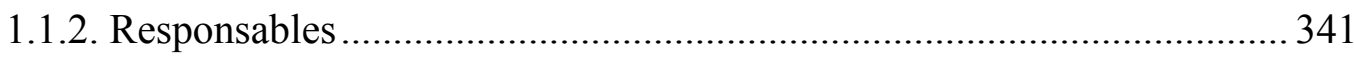




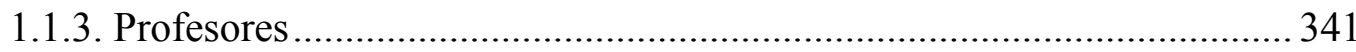

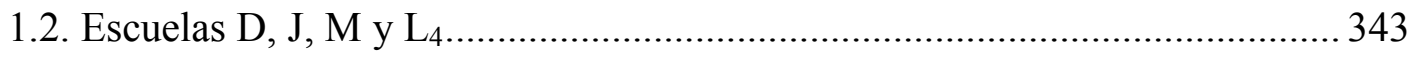

1.2.1. Prueba de la subhipótesis 1 (Egresados) ............................................... 352

1.2.2. Prueba de la subhipótesis 2 (Responsables)........................................... 354

1.2.3. Prueba de la subhipótesis 3 (Profesores)................................................ 357

1.2.4. Prueba de la subhipótesis 4 (Directores)................................................ 360

1.2.5. Prueba de la subhipótesis 5 (Secretarios).................................................... 361

2. Prueba de la Hipótesis General............................................................................. 363

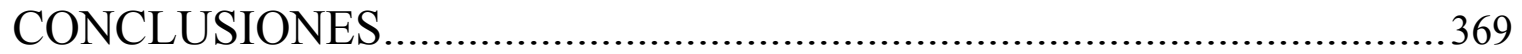

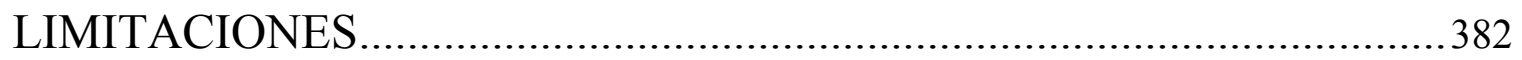

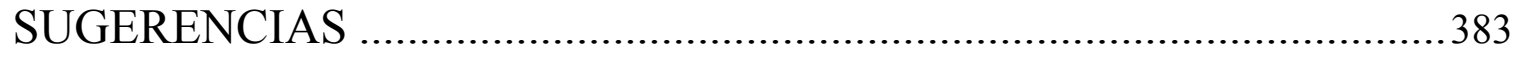

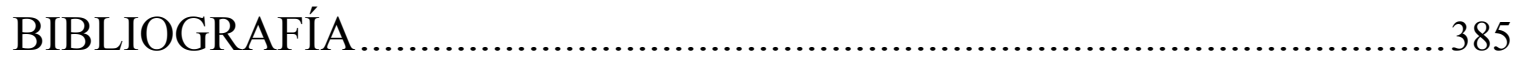

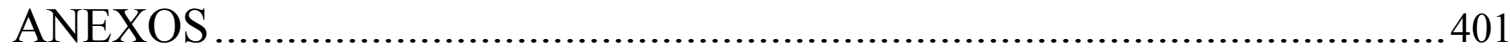


Los diferentes colegios participantes en esta investigación son individualizados con letras mayúsculas del abecedario, en algunos casos mediante subíndices, lo cual se debe a que se trata de un mismo lugar físico donde funcionan una escuela de adolescentes y otra de adultos (ejemplo: A y $\mathrm{A}_{1}$ ). Los colegios $\mathrm{L}, \mathrm{L}_{1}, \mathrm{~L}_{2}, \mathrm{~L}_{3}$ y $\mathrm{L}_{4}$ son una misma escuela para adultos que funciona en cinco espacios físicos diferentes. $L a F_{1.1}$ es una extensión de la $F_{1}$ y se hallan ubicadas en espacios físicos diferentes. A su vez, las escuelas $\mathrm{F}_{\text {y }} \mathrm{F}_{1}$ comparten el mismo edificio.

Presentación de las escuelas estatales de nivel medio del Distrito de Junín

\begin{tabular}{|c|c|c|}
\hline & De Adolescentes & De Adultos \\
\hline $\begin{array}{l}\text { SE ENCUESTÓ } \\
\text { A EGRESADOS }\end{array}$ & $\begin{array}{c}\text { A, B, C, D, E, F, G, H, I y J } \\
\text { Total: } 10 \text { escuelas }\end{array}$ & $\begin{array}{c}\mathrm{A}_{1}, \mathrm{~F}_{1}, \mathrm{H}_{1}, \mathrm{~L}, \mathrm{~L}_{1}, \mathrm{~L}_{2}, \mathrm{~L}_{3} \\
\mathrm{~L}_{4} \mathrm{y} \mathrm{M} \\
\text { Total: } 9 \text { escuelas }\end{array}$ \\
\hline $\begin{array}{l}\text { NO SE ENCUESTÓ } \\
\text { A EGRESADOS }\end{array}$ & $\begin{array}{c}\mathrm{A}_{2}, \mathrm{~A}_{3}, \mathrm{~N}, \mathrm{~N}_{1}, \mathrm{O}, \mathrm{O}_{1}, \mathrm{O}_{2}, \\
\mathrm{O}_{4}, \mathrm{O}_{5} \text { y P } \\
\text { Total: } 10 \text { escuelas }\end{array}$ & $\begin{array}{c}\mathrm{B}_{1}, \mathrm{C}_{1}, \mathrm{~F}_{1.1}, \mathrm{G}_{1}, \mathrm{M}_{1}, \mathrm{M}_{2} \mathrm{y} \mathrm{O}_{3} \\
\text { Total: } 7 \text { escuelas }\end{array}$ \\
\hline & Total: 20 escuelas & Total: 16 escuelas \\
\hline
\end{tabular}

\begin{tabular}{|c|c|c|}
\hline \multicolumn{3}{|c|}{ Escuelas por zonas } \\
\hline & De Adolescentes & De Adultos \\
\hline Urbanas & $\mathrm{B}, \mathrm{C}, \mathrm{D}, \mathrm{E}, \mathrm{F}, \mathrm{G}, \mathrm{O}_{5}, \mathrm{H}$ y J & $\begin{array}{c}\mathrm{B}_{1}, \mathrm{C}_{1}, \mathrm{~F}_{1.1}, \mathrm{G}_{1}, \mathrm{H}_{1}, \mathrm{~L}, \mathrm{~L}_{1}, \mathrm{~L}_{2}, \mathrm{~L}_{3}, \\
\mathrm{~L}_{4}, \mathrm{M}, \mathrm{M}_{1} \mathrm{y} \mathrm{M}_{2}\end{array}$ \\
\hline $\begin{array}{l}\text { En el límite } \\
\text { urbano-suburbano }\end{array}$ & $\mathrm{I}, \mathrm{O}, \mathrm{O}_{1}$ y $\mathrm{O}_{2}$ & $\mathrm{O}_{3}$ \\
\hline Rurales & $\mathrm{A}, \mathrm{O}_{4}, \mathrm{~N}, \mathrm{~N}_{1}$ y $\mathrm{P}$ & $\mathrm{A}_{1}, \mathrm{~A}_{2}$ y $\mathrm{A}_{3}$ \\
\hline
\end{tabular}




\section{INTRODUCCIÓN}

\section{Fuentes de las ideas de investigación}

De niño frecuentemente se escucha cuán importante es estudiar para el futuro. Repetida la frase por padres, responsables y allegados, se va internalizando - escuela mediante- el valor de la educación. Ella se convierte, de a poco, en algo fundamental para la vida de todos en cualquier lugar del planeta y hoy proporciona las primeras ideas para esta investigación. ${ }^{1}$ Esas ideas representan el primer acercamiento a la realidad que aquí se abordará: la educación estatal de nivel medio en el Distrito de Junín, provincia de Buenos Aires, reflejada en los egresados —adolescentes y adultos- del ciclo lectivo 2010.

También existen —en relación al tema- los antecedentes que se pasan a mencionar: las experiencias personales del investigador, materiales escritos (artículos de revistas, disertaciones, libros y notas de periódicos), audiovisuales, programas de radio y de televisión y -últimamente - información disponible en Internet. De todas estas fuentes deviene - a través del tiempo- una firme convicción: ya no es posible concebir la existencia de ningún ser humano sin educación, pero la pregunta que surge inmediatamente es en cuántos países esto aún no es realidad para millones de personas.

En América Latina esta injusticia también se observa y en Argentina (el Distrito de Junín incluido), a pesar del discurso oportunista del gobernante de turno, acontece algo similar. Asimismo, permanentemente se declama por las élites gobernantes de los países caracterizados como desarrollados — por casos, Estados Unidos y Canadá en América del Norte o Alemania, Francia y Gran Bretaña en la más lejana Europa- que la educación es el pilar fundamental sobre el que se asienta el progreso de los pueblos. Existen en dichas naciones millones de habitantes que tienen una muy buena calidad de vida. Datos estadísticos inequívocos sobre tal realidad abundan y son fácilmente cognoscibles merced a la tecnología actual. No obstante, se observan en dichas naciones problemas de diverso tipo y magnitud que

1. Las definiciones del término investigación abundan y aquí se está fuera del alcance de dar cuenta de ellas exhaustivamente. No obstante se adopta la que entiende que: la investigación es un conjunto de procesos sistemáticos y empíricos que se aplican al estudio de un fenómeno. En Hernández Sampieri, Roberto, Fernández Collado, Carlos y Baptista Lucio, Pilar, Capítulo 1 "Similitudes y diferencias entre los enfoques cuantitativo y cualitativo", en Metodología de la investigación. México, Mc Graw Hill Interamericana, Cuarta edición, 2006, página 22. 
preocupan a sus máximos dirigentes. Muchos de ellos están relacionados directamente con la falta de educación o con la baja calidad educativa. También es sabido que existen hoy innumerables analfabetos en las demás naciones. Ni qué hablar de aquellas sociedades del oprobio como - entre otros- Burundi y Congo en África o Haití, en América Central, que muestran estadísticas muy preocupantes referidas a la pobreza y donde la salud, la educación, la vivienda y un trabajo digno ni siquiera llegan a ser un sueño para muchos de sus habitantes. Salvo para una minoría privilegiada detentadora del poder político y económico.

Por otro lado, al leer la historia en los libros se aprende que mucho costó - y aún hoy los reclamos continúan - hacer entender a los poderosos que toda persona, sin distinción alguna, tiene derecho a educarse para llegar a ser alguien en la vida. Fueron necesarios muchos acontecimientos - casi siempre por vía de la fuerza- para que el denominado "pueblo" (entendiéndose por tal la clase humilde) pudiese ejercer plenamente sus derechos; entre ellos el que posibilita la toma de conciencia necesaria para la vida en sociedad: el derecho a la educación. Una educación que debe tener como único límite infranqueable el temporal; esto es, la muerte de quien se educa.

No cabe duda que el solo intento de hacer realidad las ideas antedichas es ya un asunto complejo. Aquellos que han dedicado su vida para alcanzar tal objetivo contribuyeron sobradamente a la toma de conciencia sobre la importancia de la educación. Encontrar indicadores que faciliten su estudio y posibiliten explicaciones sobre el origen de la problemática educativa y su posible evolución es una tarea que conlleva aún mayores dificultades.

Es decir, las ideas para realizar una investigación sobre la educación de nivel medio en el Distrito de Junín surgieron de varias fuentes. A más de lo ya expresado, contribuyeron a dar forma a las ideas originarias los resultados obtenidos en dos trabajos de investigación (uno referido al nivel primario y otro al medio) llevados a cabo en 1990, en el marco del Profesorado en Psicopedagogía cursada en el Instituto Superior de Formación Docente y Técnica (ISFDyT) No 20, ubicado en la ciudad de Junín. También fueron muy importantes las periódicas conversaciones mantenidas con docentes y no docentes preocupados por el futuro de una Argentina que no alcanza a desarrollar plenamente sus recursos, ya sean materiales o humanos.

\section{Planteamiento del problema}

Algo importante tuvo lugar en el siglo XVIII. Constitución había sido un término vacante del que se apropió el constitucionalismo en ese siglo para dar idea de un gobierno de las leyes (no de los hombres. Finiquitado el Absolutismo, a medida que se afirmaban los grandes Estados centralizados comenzó la búsqueda de una palabra que implicase las técnicas aptas 
para controlar el ejercicio del poder estatal. Este vocablo acabó siendo el de constitución. ${ }^{2}$ Alguna doctrina ha expresado en relación al mismo que: "Constitución es aquello en lo que consiste un Estado. Desde este punto de vista la Constitución es equivalente al Estado: éste no tiene una Constitución sino que es una Constitución". ${ }^{3}$

Con el constitucionalismo adviene un proceso histórico-político-jurídico que muestra dos etapas perfectamente marcadas: la primera, que empezó con las revoluciones inglesa de 1688, estadounidense de 1776 y francesa de 1789, originando el constitucionalismo clásico o liberal burgués, con un Estado abstencionista casi absolutamente en lo económico. En ese contexto se sancionó la Constitución Nacional Argentina de 1853. La segunda etapa se plasmó en la Constitución de Querétaro de 1917 (Méjico), en la Declaración de los Derechos del Pueblo Trabajador y Explotado proclamada en 1918 (en la entonces Unión Soviética) y en la Constitución de Weimar de 1919 (Alemania). Surgió así el constitucionalismo social (el Estado interviene fundamentalmente en lo económico) para amenguar las enormes desigualdades sociales producidas por el constitucionalismo clásico.

A su turno, el pensamiento liberal aportó una comprensión totalizadora del mundo, proyectando a la educación como un instrumento que permitía la apertura al talento a partir de dotar capital cultural institucionalizado. Así marcó el camino de construcción de las naciones y el sentimiento de adscripción a ellas en el siglo XIX. La nacionalidad ordenaba las prácticas escolares, ya sea al estilo francés - donde la unión estaba dada por el contrato social en el que el ciudadano incluía dentro de sí la categoría de nacional- o al estilo alemán, donde se adscribía mediante características físicas, históricas y culturales similares que otorgaban al grupo una identidad que lo volvía soberano. ${ }^{4}$

El positivismo, surgido en Francia a inicios del siglo XIX se desarrolló por el resto de Europa en la segunda mitad de dicho siglo. Esta corriente también abonó la causa escolar y son dos los puntos nodales de su aporte: en primer lugar, el reconocimiento de la escuela como institución difusora de la cultura válida (la de la burguesía masculina europea para algunos, la cultura científica para otros o la cultura nacional para terceros) y como instancia de disciplinamiento social que hacía factible el progreso de la humanidad. En segundo lugar -y probablemente ésta sea su contribución fundamental- el positivismo estableció la

2. Sartori, Giovanni, Elementos de Teoría Política. Madrid, Alianza, 2007, página 20.

3. Quiroga Lavié, Humberto, Benedetti, Miguel Ángel y Cenicacelaya, María de las Nieves, Derecho Constitucional Argentino. Santa Fe-Buenos Aires, Rubinzal-Culzoni, 2001, Tomo I, página 11.

4. Pineau, Pablo, Dussel, Inés y Caruso, Marcelo, 1 “PPor qué triunfó la escuela? o la modernidad dijo: 'Esto es educación', y la escuela respondió: 'Yo me ocupo”, en La escuela como máquina de educar: tres escritos sobre un proyecto de la modernidad. Buenos Aires, Paidós, 2001, página 55. 
cientificidad como el único criterio de validación pedagógica. De aquí que toda propuesta educativa debía, para ser considerada aceptable, demostrar que era científica. Corroborada su acientificidad, era motivo suficiente para ser excluida de la discusión. ${ }^{5}$ Respecto del vocablo cientificidad, en esta investigación se toma en cuenta la definición que se aporta desde la psicopedagogía. $^{6}$

Llegada la actualidad, merced a los avances tecnológicos existe la posibilidad de transmitir mensajes a largas distancias en forma simultánea a través del fax, la radio, el teléfono, la televisión o la computadora. Parecería que se está dando un proceso de centralización y monopolización de los medios de comunicación, convertidos en el área a la que apuntan las mayores inversiones económicas en todo el mundo.

Con centro en el nivel medio, en la segunda mitad del siglo $\mathrm{XX}-\mathrm{y}$ como producto del crecimiento económico, la urbanización y el desarrollo tecnológico ya mencionado- la educación tendió a expandirse a la casi totalidad de la población adolescente en países como Japón, Estados Unidos y los de Europa Occidental (con menores inversiones también ello aconteció en naciones de Europa Oriental). Con esta generalización surgió la idea de extender la obligatoriedad de la enseñanza al ciclo básico de la educación secundaria y apareció así la formación básica o general.

En Argentina, en la medida en que se promueva no sólo el desarrollo económico, tecnológico, científico y cultural sino también el educativo, habrá respeto y tutela del derecho a la vida. ${ }^{7}$ La vida es — antes que nada - un hecho biológico que tiene como primera finalidad la conservación de la especie. De modo que ya desde la concepción se requiere la protección del Derecho. Por lo demás, para cierta doctrina se trata "de una educación fundante de la cultura". ${ }^{8}$ Tal opinión no es compartida por el investigador de esta tesis, quien sostiene que es la cultura la que impone determinados contenidos a la educación que tendrá vigencia en un país.

5. Pineau, Pablo, Dussel, Inés y Caruso, Marcelo, op. cit., página 60.

6. Una característica esencial de cualquier conocimiento científico es ser revisable, estar abierto a su reformulación. Un signo de "cientificidad" es la posibilidad de modificar las hipótesis cuando el mundo resiste las interpretaciones o cuando hay problemas no resueltos en su marco interpretativo. Por lo tanto, toda creencia sobre la completitud de una disciplina, toda certeza sobre el carácter definitivo de sus hipótesis, es un obstáculo para el dinamismo de la teoría. En Castorina, José Antonio, Capítulo VII "Los obstáculos epistemológicos en la constitución de la psicopedagogía", en Problemas en psicología genética. Buenos Aires, Niño y Dávila Editores, 1989, página 220.

7. Dromi, Roberto y Menem, Eduardo, La Constitución reformada, comentada, interpretada y concordada. Buenos Aires, Ediciones Ciudad Argentina, 1994, página 182.

8. Dromi, Roberto y Menem, Eduardo, op. cit., página 183. 
Las naciones geográficamente muestran diferencias. Y en otros aspectos, también; entre ellos en su cultura. Si se incluye a la educación dentro de la cultura habrá diferentes contenidos a incorporar plasmados en la política educativa de cada nación. Surge la pregunta sobre qué determina en la educación de un país la existencia de algunas características y de otras no. Y también saber por qué razón diferentes gobiernos incluyen en los presupuestos anuales una mayor o menor cantidad de dinero destinado a la educación de sus poblaciones.

Por otro lado, la gente se resiste a admitir que está decidido de antemano por los organismos financieros internacionales - llámense Fondo Monetario Internacional (FMI) o Banco Mundial (BM) - qué países tendrán una educación de elevada calidad y cuáles no. Se espera que Argentina pase del 6,47 por ciento de su Producto Bruto Interno (PBI) al 10 por ciento. Al mismo tiempo, se desea saber por qué a pesar de dicho porcentaje — uno de los más elevados de América Latina - los resultados en cuanto a calidad de la educación media han ido en retroceso desde 2000 a 2012.

Los últimos informes del Programa Internacional de Evaluación de Alumnos (Pisa, por sus siglas en inglés), financiado por la Organización Mundial para la Cooperación y el Desarrollo Económico (OCDE), colocan al país en un lugar preocupante (en el puesto 58 sobre 65), tanto en los indicadores de rendimiento educativo en Matemática, Lengua y Ciencias como en disciplina escolar. En este último ítem, los estudiantes argentinos aparecen como los más indisciplinados del mundo. ${ }^{9}$

En torno a esta problemática, América Latina muestra una realidad que — si bien se observa en otras regiones del planeta - nunca debiera olvidarse: millones de analfabetos son la cara visible del drama de la injusticia con los más necesitados. Torna perentorio hallar soluciones por existir en las sociedades una mayor conciencia sobre la necesidad de una educación sin menoscabo de la calidad para ningún sector. Esta propuesta enfrenta desafíos tales como incorporar en las políticas educativas un enfoque de la educación como Derecho Humano que posibilite el ejercicio de los demás Derechos Humanos. ${ }^{10}$

Para la realización de esta investigación se eligió partir de un período que tuvo influencias significativas en muchos aspectos de la vida de los argentinos: los años noventa.

9. Carandino, Edgardo. "La prueba Pisa y sus resultados sobre la educación argentina", La Voz, jueves 23 de junio de 2011. <http://www.lavoz.com.ar/opinion/prueba-pisa-sus-resultados-sobreeducacion-argentina $>$. Fecha de consulta: 10 de enero de 2013.

10. Oficina Regional de Educación de la UNESCO para América Latina y el Caribe (OREALC/UNESCO). "El derecho a una educación de calidad para todos en América Latina y el Caribe". 1 "El contexto: los principales desafíos para los sistemas educativos de la región", en Revista Electrónica Iberoamericana sobre Calidad, Eficacia y Cambio en Educación (REICE). Vol. 5 № 3, Santiago, 2007. <http://www.rinace.net/arts/vol5num3/art1_htm.htm>. Fecha de consulta: 1 de septiembre de 2011. 
Las transformaciones producidas desde el gobierno nacional (políticas y económicas) fueron configurando una sociedad fragmentada, impulsando a los sectores altos a posiciones de más privilegio o de consolidación de sus ventajas y provocando el descenso de los sectores medios hacia los márgenes de la pirámide social. Asimismo, produjo la dramática expulsión de los sectores bajos de la misma. También, un importante número de habitantes quedó sin trabajo e innumerables sin poder asistir a la escuela (tanto adolescentes como adultos). La licenciada en Ciencias de la Educación Nadina Poliak manifiesta que en la década de 1990 Argentina “inició un proceso de cambios estructurales que generó una redistribución regresiva del ingreso y modificó en el mismo sentido la estructura social. El signo de la época fue el agravamiento de las desigualdades que afectó a capas enteras de la población". ${ }^{11}$

El problema que se pretende afrontar en esta tesis es determinar si las importantes novedades educativas introducidas por la reforma de 1994 en el texto supremo revelan el interés del Estado nacional en diseñar una política educativa que incluya a todos sus niveles, a fin de legitimar su propia existencia y contar con sujetos de derecho que coadyuven al logro de una sociedad más justa. ${ }^{12}$ Es decir, si más allá de las categóricas afirmaciones de la doctrina en el sentido de que todos los campos de la vida social están comprometidos en este par de derechos civiles (enseñar y aprender), esto se verifica en la realidad o si, por el contrario, ya sea por acción u omisión del poder administrador, por falencias normativas o de otra índole, termina distorsionándose la esencia misma de tales incorporaciones, alterándose en la práctica el sistema educativo en su conjunto - particularmente el nivel medio- con el consiguiente perjuicio para - especialmente- los educandos pertenecientes a los sectores desfavorecidos o desaventajados del país, incluidos los que habitan el Distrito de Junín.

No obstante su reconocimiento expreso en diversos tratados internacionales y en textos normativos supremos, siempre será necesario exigir en cualquier país (Argentina incluida) más y mejor educación para todos, como reaseguro para la permanencia de sociedades con personas libres que aspiran permanentemente a una mejor calidad de vida. Esta es la principal razón por la que se decidió investigar cuál es la realidad en torno a la educación media estatal (tanto de adolescentes como de adultos) en el Distrito de Junín. El propósito será aprehender las características de la educación como instrumento insustituible para el progreso de las personas. Se pretende -asimismo - efectuar un aporte de interés en relación a la

11. Poliak, Nadina, Capítulo 6. "Reconfiguraciones recientes en la educación media: escuelas y profesores en una geografía fragmentada", en Tiramonti, Guillermina (comp.), La trama de la desigualdad educativa: mutaciones recientes en la escuela media. Buenos Aires, FLACSO. Biblioteca del docente. Ediciones Manantial, 2004, página 146.

12. "El derecho a una educación de calidad para todos en América Latina y el Caribe", en REICE. Vol. $5 \mathrm{~N}^{\mathrm{o}}$ 3, Santiago, OREALC/UNESCO, 2007. 
problemática educativa del Distrito mencionado, con la mira puesta en un futuro más justo para todos.

\subsection{Objetivos}

En esta tesis los objetivos generales se orientaron a:

1. Conocer las diferentes realidades sociales y culturales en las que están inmersos los egresados de nivel medio del Distrito de Junín.

2. Comparar el ejercicio del rol entre los diferentes agentes educativos en el proceso enseñanza-aprendizaje llevado a cabo en cada escuela.

3. Analizar cómo recepcionan los agentes educativos los principios de gratuidad y equidad de la educación pública estatal prescriptos en el artículo 75, inciso 19, párrafo $3^{\circ}$, de la Constitución Nacional.

4. Determinar la responsabilidad de los agentes en el proceso educativo de nivel medio del Distrito de Junín.

En tanto, los objetivos específicos se propusieron:

1. Establecer los posibles vínculos entre lo preceptuado en el artículo 75, inciso 19, párrafo $3^{\circ}$ y los resultados de las actividades desarrolladas en escuelas secundarias del Distrito.

2. Cotejar los resultados alcanzados en los diferentes colegios del Distrito.

3. Relacionar los resultados obtenidos de los egresados adolescentes respecto de los alcanzados en los egresados adultos.

4. Comparar las actitudes hacia el estudio y/o el trabajo de los egresados 2010 en las diferentes escuelas.

5. Identificar las trayectorias educativas cumplidas durante 2010 por los egresados de nivel medio del Distrito.

\subsection{Preguntas}

A los fines de lograr los antedichos objetivos se formularon las siguientes preguntas:

1. ¿Las novedades del artículo 75 , inciso 19 , párrafo $3^{\circ}$, revelan el interés estatal en diseñar una política educativa de alcance nacional?

2. ¿Esta actitud evidencia la intención estatal de contar con sujetos de derecho que coadyuven al logro de una sociedad más justa? 
3. ¿Tal propósito estatal se verifica en la realidad?

4. ¿Puede, por diferentes falencias, distorsionarse en la práctica el sistema educativo en su conjunto?

5. ¿A qué sectores sociales pertenecen los egresados de nivel medio del Distrito de Junín que, especialmente, sufrirían los perjuicios si aconteciera lo señalado en la pregunta anterior?

6. ¿El caso de la educación media en el Distrito citado es significativo de los procesos de inclusión/exclusión de los egresados adolescentes y adultos del resto del país?

7. ¿Cuáles son los condicionantes para que un egresado secundario del Distrito mencionado logre ser eje de transformación para una sociedad más justa?

\section{Hipótesis}

El problema planteado y la revisión de la bibliografía estimulan a formular la siguiente hipótesis general ${ }^{13}$ : en relación a países como el nuestro (incluidas provincias como Buenos Aires) una sociedad, como la perteneciente al Distrito de Junín, basada exclusivamente en el uso intensivo del conocimiento produce simultáneamente fenómenos de más igualdad y de más desigualdad, de mayor homogeneidad y de mayor fragmentación sociales. Se desvirtuaría así el rol de las instituciones — particularmente el de la escuela - como lugares clave para actividades al servicio de la construcción de subjetividades activas, capacitadas para motorizar sus propios cambios y aquéllos anhelados por toda sociedad que ansía mayores dosis de justicia.

A los fines de lograr un mayor nivel de operatividad se acudió a varias subhipótesis (o hipótesis específicas), siempre relacionadas con los participantes de esta investigación, integrantes todos de las comunidades educativas. Asimismo, se hará referencia a variables ${ }^{14} \mathrm{y}$

13. Esta hipótesis causal multivariada plantea una relación entre diversas variables independientes y una dependiente (es el caso de padres, profesores, directores y secretarios) y varias independientes con varias dependientes (es el caso de los alumnos). Hernández Sampieri, Roberto; Fernández Collado, Carlos y Baptista Lucio, Pilar, op. cit., página 162.

14. En un experimento, para que una variable se considere independiente debe cumplir tres requisitos: que anteceda a la dependiente, que varíe o sea manipulada y que esta variación pueda controlarse. En esta investigación son independientes, en alumnos las variables 1 y 2; en padres las variables 1,2 y 3 ; en profesores las variables 1 y 2 ; en directores las variables 1 y 2 y en secretarios las variables 1 y 2 . La variable dependiente no se manipula sino que se mide para ver el efecto que la manipulación de la variable independiente tiene en ella. Aquí son dependientes, en alumnos las 
a dimensiones. ${ }^{15}$ Las variables adquieren valor para esta investigación al estar relacionadas entre sí, formando parte de las subhipótesis y de la hipótesis general.

\section{Alumnos}

Subhipótesis 1: Las razones de asistencia a la escuela así como la percepción de aportes de la formación escolar son causas del nivel de conocimientos adquiridos y de las orientaciones de futuro de los egresados.

Variable 1: Razones de asistencia a la escuela

(Cuestionario: pregunta 1)

Dimensiones: a) Asistencia por mandato familiar

b) Asistencia por motivaciones personales

Subdimensiones: $b_{1}$ ) Sociabilidad e inclusión social

$b_{2}$ ) Futuro profesional (estudio y/o trabajo)

$\mathrm{b}_{3}$ ) Desarrollo personal

Variable 2: Percepción de aportes de la formación escolar

(Cuestionario: preguntas 2 a 10)

Dimensiones: a) Percepción del aporte de conocimientos, habilidades y actitudes

b) Contribución de las actividades o espacios organizados por la escuela para la elección educativa y/u ocupacional

Variable 3: Nivel de conocimientos adquiridos

(Cuestionario: preguntas 11 a 17)

Dimensiones: a) Área Lengua Nacional

b) Área Matemática

c) Área Historia

variables 3 y 4; en padres la variable 4; en profesores la variable 3; en directores la variable 3 y en secretarios la variable 3 .

En el caso de variables con varias dimensiones o componentes a medir - como en esta investigación - se incluyen varias preguntas para medir las distintas dimensiones. En Hernández Sampieri, Roberto; Fernández Collado, Carlos y Baptista Lucio, Pilar, Capítulo 7 "Concepción o elección del diseño de investigación", op. cit., página 164.

15. Las dimensiones de las variables son los grandes bloques estructurales de la variable susceptible de ser descompuesta en los indicadores. Los indicadores constituyen el conjunto de actividades o características propias de un concepto o enunciado. En Hernández Sampieri, Roberto, Fernández Collado, Carlos y Baptista Lucio, Pilar, Capítulo 7 "Concepción o elección del diseño de investigación”, op. cit., página 165. 
Variable 4: Orientaciones de futuro

(Cuestionario: preguntas 18 a 23)

Dimensiones: a) Motivación

Subdimensiones: $\mathrm{a}_{1}$ ) Contenido

$a_{2}$ ) Preocupaciones de los estudiantes

b) Evaluación del futuro

Subdimensiones: $b_{1}$ ) Atribuciones causales

$b_{2}$ ) Emociones

\section{Responsables}

Subhipótesis 2: El nivel de escolaridad alcanzado junto a la inclusión en el mercado de trabajo y el conocimiento de la realidad educativa y social, por parte de los responsables del alumno, influyen en la elección de la escuela como estrategia familiar de vida.

Variable 1: Nivel de escolaridad alcanzado

(Cuestionario: preguntas 1 y 2)

Variable 2: Inclusión en el mercado de trabajo

(Cuestionario: preguntas 3.a, 3.b, 3.c y 3.d)

Variable 3: Conocimiento de la realidad educativa y social

(Cuestionario: preguntas 4, 5.a, 5.b, 6, 7 y 8)

Variable 4: Elección de la escuela como estrategia familiar de vida

(Cuestionario: preguntas 9, 10.a, 10.b, 11, 12 y 13)

\section{Profesores}

Subhipótesis 3: El conocimiento de la realidad educativa y social junto al desempeño de su actividad docente inciden en la trayectoria de los estudiantes en su último año del nivel medio.

Variable 1: Conocimiento de la realidad educativa y social

(Cuestionario: preguntas 1 a 4 )

Variable 2: Desempeño de la actividad docente

(Cuestionario: preguntas 5 a 10)

Variable 3: Trayectoria de los estudiantes en su último año del nivel medio

(Cuestionario: preguntas 11 a 13) 


\section{Directores}

Subhipótesis 4: El conocimiento de la realidad educativa así como las interrelaciones escuela-familia determinan la organización de las actividades educativas.

Variable 1: Conocimiento de la realidad educativa

(Cuestionario: preguntas 1, 2, 3, 4 y 5)

Variable 2: Interrelaciones escuela-familia

(Cuestionario: preguntas 6 a 8)

Variable 3: Organización de las actividades educativas

(Cuestionario: preguntas 9 a 17)

\section{Secretarios}

Subhipótesis 5: El conocimiento de la realidad educativa así como las interrelaciones escuela-medio determinan la organización de las actividades educativas.

Variable 1: Conocimiento de la realidad educativa

(Cuestionario: preguntas 1, 2, 3, 4 y 5)

Variable 2: Interrelaciones escuela-medio

(Cuestionario: preguntas 6 y 7)

Variable 3: Organización de las actividades educativas

(Cuestionario: preguntas 8 a 11)

Oportunamente, se definió el alcance de la investigación a realizar, prefiriéndose hablar de esta manera en lugar de considerar tipos de investigación. Así, el diseño, los procedimientos y otros componentes del proceso tuvieron la impronta de un estudio correlacional. Como tal, se midió cada variable presuntamente relacionada y - posteriormente - se midieron y analizaron las correlaciones. Tales correlaciones se sustentaron en una hipótesis general y varias subhipótesis sometidas a prueba referidas a los egresados (adolescentes y adultos), sus responsables, sus profesores, directores y secretarios de escuelas estatales del Distrito de Junín.

En esta investigación se realizó una medición nominal. Las variables nominales utilizadas incluyen dos categorías (y se llaman dicotómicas) o tres o más categorías (denominándose categóricas). Las categorías son las opciones de respuesta o valores de cada ítem (pregunta). Son niveles donde son categorizadas las unidades de análisis (que, en esta 
investigación son los egresados, sus responsables, sus profesores, sus directores y sus secretarios). ${ }^{16}$

\subsection{Definiciones conceptuales de las variables}

Los motivos que impulsaron a adoptarlas fueron, a más de asegurar que las variables puedan ser medidas, evaluar más adecuadamente los resultados de esta investigación. Se trata de definiciones de diccionarios o de libros especializados en educación que describen la esencia o las características de una variable o término. Las definiciones conceptuales (también denominadas constitutivas) corresponden a todas las variables incluidas en las diferentes subhipótesis formuladas. Así:

\section{Alumnos}

Razones de asistencia a la escuela: hoy asistir a la escuela media puede deberse a más de un motivo, no sólo a aquél devenido tradicionalmente, que es estudiar. Las variadas razones de concurrencia a clase inauguran nuevos vínculos pedagógicos del estudiante con los demás integrantes de la comunidad educativa, en una relación más impersonal que la del nivel primario. Se espera que el egresado internalice — al cabo de tres años del Polimodal — los cambios que implica la escuela secundaria en lo que atañe, particularmente, a nuevos horarios y responsabilidades que demandan mayores niveles de autonomía.

Percepción de aportes de la formación escolar: para muchos consiste en dispositivos. Ejemplo: “¿para la formación docente va a haber una formación inicial, una de posgrado o una permanente? Pero hay una segunda acepción de dicho término que aquí interesa: una formación consiste en la implementación de programas y contenidos de aprendizaje. Ejemplo: se sostiene que "en Ingeniería los alumnos reciben una importante formación". Esto significa que se trata de algo que tiene relación con la forma. Formarse es adquirir una cierta forma; una para actuar, para reflexionar y perfeccionarla. Y la escuela media contribuye (aporta, ayuda) a todo ello.

Nivel de conocimientos adquiridos: el conocimiento es la acción y efecto de conocer. Noción, ciencia, sabiduría. El problema del conocimiento es central para la sociedad porque está estrechamente relacionado con la verdad y ésta - a su vez- se vincula con el poder como posibilidad de dominio sobre uno mismo y posibilidad de ejercerlo sobre otros. Conocimiento también es una forma de capacidad intelectiva, de habilidades, destrezas y

16. Hernández Sampieri, Roberto; Fernández Collado, Carlos y Baptista Lucio, Pilar, Capítulo 7 "Concepción o elección del diseño de investigación”, op. cit., página 166. 
competencias que se pueden medir a través de métodos cuantitativos, cualitativos y psicométricos.

Orientaciones de futuro: en la convergencia de las culturas familiares las expectativas juveniles y las formas de socialización escolar se construyen las diferentes experiencias de individualización. En este sentido es posible afirmar que - excepto en algunos sectores bajos del espectro social, sometidos a la tiranía de la necesidad y a la amenaza de la desintegración - en los sectores medios bajos, medios y altos son las variables culturales las que explican las diferentes manifestaciones de la individualización, particularmente aquéllas referidas a las orientaciones de futuro (laboral y/o de estudio) de los egresados.

\section{Responsables}

Nivel de escolaridad alcanzado: qué estudios han culminado (o no) los responsables (padres, madres, tutores u otros) de los egresados. Qué nivel de educación han alcanzado hasta el presente.

Inclusión en el mercado de trabajo: alude a si actualmente los responsables están desarrollando una actividad laboral remunerada (en relación de dependencia o no). En sentido amplio significa desempeñarse en algún ámbito público o privado de manera formal o informal.

Conocimiento de la realidad educativa y social: el conocimiento como una mezcla de experiencias, valores, información y saber hacer, que sirve como marco para la incorporación de nuevas experiencias e información y es útil para la acción. Incluye saber desempeñarse en la vida social.

Elección de la escuela como estrategia familiar de vida: el concepto de estrategia familiar de vida, junto al de estrategia de supervivencia, forma parte de la relación social que se establece entre la estructura social de nivel macrosocial y las acciones individuales a nivel microsocial. Ambos conceptos resultan pertinentes para pensar el lugar que ocupan las familias como espacio articulador entre los individuos y la estructura social a la hora de elegir la escuela a la que asistirán sus hijos.

\section{Profesores}

Conocimiento de la realidad educativa: trátase del conocimiento educativo como derivado de la información, así como ésta deviene de los datos. Informar significa originariamente "dar forma a"; es decir, dar forma a la persona que la obtiene. En tal sentido, un dato es un conjunto discreto de factores objetivos sobre un hecho real. La información educativa se transforma en conocimiento mediante actividades específicas elaboradas por los profesores para guiar las vivencias áulicas de los estudiantes. 
Desempeño de la actividad docente: modo o manera como el docente ejerce su rol. Se relaciona con la posición social (status) que ostenta. Conocimientos y actitudes que los demás esperan o exigen de él. Cualidades que debe reunir para aquéllos que lo consideran un modelo dentro de la sociedad. La docencia es una práctica histórica, con capacidad de originar ciudadanía y cultura en el sentido de la producción de bienes simbólicos. Asimismo, es en la relación Estado-mercado donde se debe resignificar la identidad y la condición de trabajador asalariado del docente.

Trayectoria de los estudiantes en su último año del nivel medio: implica hacer referencia a la temporalidad de las experiencias vividas por los egresados, sus historias sociales y biográficas. En el análisis de sus trayectorias áulicas están presentes elementos estructurales que caracterizan a los grupos y a los individuos (capitales culturales, económicos, simbólicos, pertenencias de género). Son elementos puestos en acción en contextos y situaciones determinadas. Asimismo, las propias trayectorias (con sus aspectos objetivos) van determinando su devenir.

\section{Directores}

Conocimiento de la realidad educativa: se trata del conocimiento educativo como derivado de la información, así como ésta emana de los datos. Informar significa originariamente "dar forma a"; es decir, dar forma a la persona que la obtiene. En este orden de ideas, un dato es un conjunto discreto de factores objetivos sobre un hecho real. La información educativa deviene en conocimiento a través de actividades específicas llevadas a cabo por los directores e incide en la organización escolar.

Interrelaciones escuela-familia: denota, en relación con el vínculo escuela-familia, la alta correspondencia que existe entre ambos universos, situación que refuerza la homogeneidad horizontal a fin de generar una socialización coherente con sus valores, reglas y prácticas.

Organización de las actividades educativas: alude a la responsabilidad de los directores en la elaboración del diseño para la implementación de tareas a llevarse a cabo durante el ciclo lectivo, por parte de la comunidad educativa, a los efectos de dar cumplimiento a la normativa vigente. Y con la finalidad de satisfacer las expectativas de todos los agentes educativos.

\section{Secretarios}

Conocimiento de la realidad educativa: se considera al conocimiento educativo como derivado de la información, así como ésta deviene de los datos. Informar significa originariamente "dar forma a"; es decir: dar forma a la persona que la obtiene. Un dato es un conjunto discreto de factores objetivos sobre un hecho real. La información educativa se 
transforma en conocimiento a través de actividades específicas llevadas a cabo por los secretarios e incide en la organización escolar.

Interrelaciones escuela-medio: la escuela pacta con su entorno un espacio de significación social que es diferente en función de las estrategias que despliega cada grupo social. De esto resulta que la relevancia de las escuelas está dada por la capacidad de cada una de acompañar los procesos de constitución de identidades particulares.

Organización de las actividades educativas: trátase de la responsabilidad de los secretarios en la elaboración del diseño para la implementación de actividades a cumplirse durante el ciclo lectivo - por los integrantes de la comunidad educativa- a los efectos de hacer efectiva la normativa vigente. Y con el propósito de satisfacer las expectativas de todos los agentes educativos. 


\section{Capítulo I \\ MARCO DE REFERENCIA}

Planteado el problema de estudio y evaluadas su relevancia y factibilidad, el siguiente paso consistía en sustentar teóricamente la investigación, etapa que algunos autores también denominan elaboración del marco teórico. Ello implicaba analizar las teorías educativas, las conceptualizaciones, las perspectivas teóricas, las investigaciones y los antecedentes considerados válidos para el correcto encuadre del trabajo.

La elaboración del marco teórico comprendió dos etapas: la revisión de la bibliografía y el desarrollo de una perspectiva teórica o de referencia. Entre los tipos básicos de fuentes informativas para realizar una nueva lectura del material bibliográfico se distinguían las fuentes primarias (directas) que proporcionaron datos de primera mano.

Al seleccionar la información consultada pudo observarse la existencia de teorías educativas ${ }^{17} \mathrm{y}$ varios estudios vinculados directamente - en mayor o en menor grado- con el planteamiento del problema. Seguidamente fueron organizados como antecedentes en forma lógica, destacando lo más relevante en cada caso. Una vez extraídos y recopilados los conocimientos (ideas y datos básicamente de libros, periódicos, revistas especializadas e informes de investigaciones) y operando primordialmente con fuentes primarias (también con el aporte de algunas secundarias, que reprocesan información de primera mano), se pasó a elaborar definitivamente el marco de referencia.

\section{La existencia humana: aprender y enseñar}

Algunas reflexiones que puedan realizarse en torno a la existencia del ser humano abren el camino hacia la comprensión de la educación como una práctica permanente. Se destaca en él su condición histórico-social, experimentando continuamente la tensión de estar siendo

17. Se entiende la teoría educativa como un sistema de hipótesis debidamente verificadas, de leyes científicas y de principios de fundamentación y de organización que se refieren al conocimiento y la transformación del fenómeno educativo y que se extienden a predicciones respecto de sus efectos. En Capella Riera, Jorge. La Educación. Un Enfoque Integral. Segunda edición, Lima, Editorial Cultura y Desarrollo, 1987, página 78. 
para poder llegar a ser y de estar siendo no sólo lo que recibe sino también lo que crea (en ambos casos, nunca en forma mecánica). El ser humano es finito, limitado, inconcluso, pero consciente de todo ello.

Trátase de un ser que teniendo por vocación la humanización se enfrenta -emperocon el desafío de la deshumanización como distorsión de esa vocación. Por otro lado, es un ser preparado para aprender y es justamente en este sentido que el aprender y el enseñar han venido adquiriendo en la historia connotaciones ontológicas, puesto que uno implica al otro sin que jamás uno prescinda normalmente del otro. Aprender y enseñar forman parte del ser humano histórico y social, igual que forman parte del mismo el amor, el asombro, el deseo, el lenguaje y el miedo.

La educación debe ser permanente no porque lo exija determinada línea ideológica, postura política o interés económico. Debe serlo en atención a la finitud del ser humano y - por otro lado - debido a la conciencia que éste tiene de su finitud. Permanentemente las diferentes instituciones -entre las cuales la escuela cumple un rol esencial- como así las nuevas tecnologías, posibilitan adquirir informaciones y conocimientos. El ser humano jamás deja de educarse - aun cuando lo hiciere por fuera de la escolarización- porque la realidad es harto compleja y la apetencia por saber no desaparece mientras vive. En este orden de ideas, en Argentina hasta hace aproximadamente cincuenta años las edades para estudiar estaban prefijadas por la institucionalidad y la costumbre. A cualquier persona que no cumpliere con esas rígidas etapas se le tornaba muy difícil adquirir conocimientos institucionalizados. Completaba el panorama de aquel entonces el autodidacta (hoy en vía de extinción) que era observado como alguien "inquieto" intelectualmente y que gozaba del respeto y de la estima de los demás.

Por otro lado, existían diferencias - aún no desaparecidas totalmente- entre la educación urbana y la rural que coadyuvaron a una mejor formación de los educandos urbanos. Asimismo, es frecuente escuchar expresiones como ésta en el ámbito rural: "desde muy chico/a mis padres me mandaron a trabajar en el campo; de estudiar no se hablaba". Tales palabras no por repetidas dejan de conmover. Cuántos hijos de peones de campo -e incluso de dueños de los mismos - vieron tempranamente definido su futuro: sólo trabajar. Otro dato de interés es que en la ciudad y en el campo (predominantemente aquí) las familias eran muy numerosas (con ocho, nueve, diez o más hijos), donde muy pocos de sus integrantes podían decidir su estilo de vida, su calidad de vida. Pareciera ser que ninguno de ellos hablaba de derechos humanos a pesar de que la Declaración Universal ya existía desde el 10 de diciembre de 1948.

Es por todos conocido que existen quienes no estudiaron porque no tuvieron oportunidad, al tiempo que hoy día se observa a muchos humildes que no estudian porque "no queremos" (afirman), aunque existe el Estado —en cualquiera de sus niveles- que les ofrece distintas 
alternativas como ayuda, incluso hasta el pago total de los estudios. En esta investigación se analizará si, no obstante el reconocimiento constitucional del derecho a la educación, torna difícil el ejercicio del mismo para las clases desfavorecidas o desaventajadas del Distrito de Junín.

Ahora bien, en el mundo existen diferencias culturales de clase, de raza, de género y -como prolongación de todas ellas - han surgido las naciones. Estas distinciones generan de continuo ideologías discriminatorias y de resistencia. Lo que origina la ideología discriminatoria no es la cultura discriminada sino la hegemónica. La cultura discriminada engendra la ideología de resistencia que —en función de su experiencia de lucha- muestra comportamientos pacíficos o violentos. Es imposible comprender todas estas ideologías sin interpretarlas y sin analizar su relación con los poderosos y con los débiles. Las ideologías -no importa si son discriminatorias o de resistencia- encarnan en formas de conducta individual o social que varían de tiempo-espacio a tiempo-espacio. Se expresan en el lenguaje (en la sintaxis y en la semántica), en las formas de actuar, de elegir, de valorar, de andar y de vestir. Asimismo, en la dominación, en la negación del ser humano, en la violencia dirigida en contra de otros hay una inmoralidad radical. Inmoral es el racismo, la violencia de los más fuertes hacia los más débiles, la dominación económica y la dominación sexual. ${ }^{18}$

En Argentina la escuela estatal no es ajena a lo expresado en el párrafo anterior. Muy al contrario de lo manifestado por muchos investigadores sociales, ella misma — según otrostiende a constituirse en un instrumento de reproducción de las diferencias sociales, más allá del discurso oficial acerca de la importante incorporación de educandos al sistema que habría tenido lugar, por ejemplo, en la provincia de Buenos Aires en los últimos años. En una entrevista televisiva, Mariano Nadorowsky (1961-), ex ministro de Educación de la Ciudad Autónoma de Buenos Aires, expresó que “entre 2003 y 2010, excepto Tucumán, en todo el país creció más la matrícula en las escuelas privadas que en las estatales. Incluso en Catamarca se produjo un aumento considerado anormal, ya que fue del 200 por ciento". ${ }^{19}$

Por otro lado, es típico del discurso neoliberal (también llamado a veces posmoderno), para el cual lo que parece importar es la enseñanza puramente técnica, la transmisión de un conjunto de conocimientos necesarios a las clases desfavorecidas al solo efecto de su supervivencia. Tanto como una postura políticamente conservadora es ésta una posición epistemológicamente insostenible y que —además- agrede la naturaleza misma del

18. Savater, Fernando, El valor de educar. Barcelona, Editorial Ariel, Segunda edición, 1997, páginas 68-72.

19. Entrevista a Mariano Nadorowsky en el programa "Código Político", conducido por los periodistas Julio Blanck y Eduardo Van Der Kooy, trasmitida el jueves 14 de abril de 2012, a las 23 horas por el canal de televisión Todo Noticias. 
estudiante, capacitado para aprender algo más profundo que adiestrarse. Así, en la década de 1990 en el Distrito de Junín, se daba en la escuela H, secundaria, ubicada en los límites urbano-suburbano donde la educación quedaba prácticamente reducida al aprendizaje de nociones básicas de Primeros Auxilios y de aquéllas referidas a la puesta en marcha de pequeños emprendimientos. Otras dos - la G y la J-también adolecieron de las exigencias educativas que es dable esperar cuando se pretende que las instituciones escolares sean instrumentos idóneos para la capacitación de los estudiantes. De resultas de ello, un muy bajo porcentaje de egresados de dichos colegios continuó entre 1990 y 1995 estudios terciarios no universitarios (universitarios, ninguno) y los que finalizaron ese nivel fueron pocos. Aquí los datos fueron proporcionados por directivos de las tres escuelas: la $\mathrm{G}$, donde sólo el 18 por ciento de los egresados continuó estudios superiores no universitarios; la escuela $\mathrm{H}$ donde lo hizo el 20 por ciento y la tercera, escuela J, con sólo el 12 por ciento. Estudiaron en el Instituto Superior del Profesorado y en el Instituto Superior de Formación Docente y Técnica $\mathrm{N}^{\mathrm{o}} 20$ y finalizaron su profesorado sólo el 9 por ciento de ellos en el primero de los nombrados y el 6 por ciento en el restante.

\section{Las teorías educativas}

$A b$ initio se impone aclarar que en toda teoría educativa debe existir una unidad de pensamiento que dará coherencia a las respuestas que se ofrezcan a los interrogantes surgidos del proceso educativo. Este importante papel lo desempeña la filosofía de la educación que proporciona la dirección necesaria para no perder el rumbo en el enseñar y en el aprender.

En tal orden de ideas, la mayoría de los autores contemporáneos de diferentes tendencias filosóficas señala la correspondencia que debe existir entre los fines de la educación, las teorías educativas y las técnicas a aplicarse. También se insiste en la libre elección del modelo de hombre al que se aspire, lo cual determinará las teorías educativas y los modos de llevar a cabo el acto educativo en cada sociedad en un momento dado. Esto último implica el respeto hacia todas las culturas (en las que está inmerso - dicho sea de paso- el sistema educativo de cada país) desde las cuales ha de partirse si se desean alcanzar sociedades más democráticas y más justas. Nótese que se enfatiza el respeto por todas las manifestaciones culturales y no la imposición -independientemente del medio que se utilice- de unas sobre otras.

A partir de dilucidar qué es el hombre y de la posición que se asuma acerca de su educabilidad, la filosofía de la educación procurará establecer qué es la educación, para qué se educa al hombre y servir como guía para definir los demás fundamentos pedagógicos. Existen múltiples clasificaciones de los modelos de filosofía de la educación. Aquí se hará referencia a aquélla que los encuadra en tres grupos diferentes: 1) teorías educativas de base filosófica 
idealista objetiva, 2) teorías educativas de base filosófica idealista subjetiva y 3) teoría educativa materialista-dialéctica. En el primer grupo se incluyen las teorías trascendentes, las liberadoras y las neohegelianas. Las trascendentes son primordialmente el neotomismo ${ }^{20}$ y el personalismo $^{21}$ que se fundamentan en el humanismo cristiano. La neotomista (Jacques Maritain (1882-1973) y Víctor García Hoz (1911-1998) son dos de sus principales representantes) se interesa por formar a un hombre atemporal, mientras que el personalismo (Ramón Xirau, 1924; Xavier Zubiri, 1898-1983 y Hugo Darquea López, son algunos de sus exponentes más importantes) se inclina hacia la formación de un hombre personalizado.

Las teorías liberadoras se basan en el personalismo y pueden dividirse en dos ramas: una, que incluye elementos del idealismo subjetivo, del existencialismo y del freudismo (entre cuyos representantes se encuentra Raúl Gutiérrez Saénz, quien desarrolló las características de la pedagogía existencial) y otra que se afilia a corrientes antiinstitucionales y antiescolares (esta última también presenta influencias del socialismo utópico ${ }^{22}$ ). Iván Illich (1926-2002), Christian Baudelot (1938-) y Roger Establet (1938-), aparecen como máximos expositores de esta rama. Las neohegelianas surgen de un esfuerzo encabezado por Giovanni Gentile (1875-1944) para fundamentar la educación en la dialéctica idealista hegeliana. ${ }^{23}$ Su campo de acción ha sido Italia, aunque tiene adeptos en el resto del mundo. Ahora bien, no obstante la validez de otras teorías, a nadie escapa hoy la influencia que han tenido en Occidente - en el siglo XX especialmente- las teorías componentes del primer grupo: las trascendentes se aplicaron fundamentalmente en instituciones educativas de carácter privado, al tiempo que las dos restantes se desarrollaron primordialmente en aquéllas de gestión pública.

Por otro lado, entre las teorías educativas de base filosófica idealista subjetiva se encuentran dos grandes conjuntos: las reproductoras tecnocráticas y el movimiento de la

20. Aplícase de los seguidores de Santo Tomás de Aquino (1225-1274), uno de los grandes pensadores medievales del cristianismo, que fue filósofo y teólogo. Para él la razón humana es muy poderosa pero no puede hacer uso de sus facultades si no está guiada e iluminada por la gracia de Dios.

21. Corriente filosófica que pone énfasis en la persona. Considera al hombre como un ser subsistente y autónomo, esencialmente social y comunitario, libre, trascendente y con un valor en sí mismo que le impide convertirse en un objeto. Un ser moral capaz de amar, de actuar y de definirse a sí mismo considerando siempre la naturaleza que le determina. Se considera a Immanuel Kant precursor del personalismo.

22. Socialismo utópico o primer socialismo es un conjunto heterogéneo de doctrinas de reforma social, previas al auge del siglo XIX, surgidas como respuesta a los serios problemas que acarreaba el triunfo del industrialismo y del liberalismo en Europa.

23. El hegelianismo es el sistema filosófico creado por Georg Wilhelm Friedrich Hegel (1770-1831), según el cual lo "absoluto", que también denomina "idea", se manifiesta evolutivamente bajo las formas de naturaleza y de espíritu. 
Escuela Nueva. El primero está fundado en el positivismo ${ }^{24}$ (Herbert Spencer, 1820-1903), el neopositivismo (Círculo de Viena, representante Bertrand Russell, 1872-1970) y el pragmatismo (John Dewey, 1859-1952). En todos los casos se aspira a un modelo de hombre deshumanizado y resulta una tendencia educativa absolutamente reproductora. Por su lado, el movimiento de la Escuela Nueva se basó inicialmente en el positivismo y el pragmatismo y posteriormente fue sustentado por el humanismo neokantiano, la fenomenología (Edmund Husserl, 1859-1938), el intuicionismo (Henri Bergson, 1859-1941), el existencialismo (Herbert Marcuse, 1898-1979) y el freudismo (Erich Fromm, 1900-1980). En su evolución histórica la Escuela Nueva tuvo como propósito la formación de un hombre sumamente psicologizado (humanizado). Entre sus expositores más encumbrados están Roger Coussinet (1881-1973), Ovide Decroly (1871-1932), María Montessori (1870-1952), Èdouard Claparéde (1873-1940), Célestin Freinet (1896-1966) y Alfredo Miguel Aguayo Sánchez (1866-1948). En la actualidad, sus postulados se mezclan con ideas de Jean Piaget (1896-1980) referidas a las posibilidades que tiene el niño de construir activamente el conocimiento. Valga expresar que paralelamente se ha desarrollado la tendencia constructivista -fundamentalmente orientada por la teoría psicogenética piagetiana- cuyo exponente más destacado es César Coll. El principio básico de la concepción constructivista es que el alumno es quien construye. Vale decir que el educando es quien conoce al realizar una actividad física y también cuando lee o recibe explicaciones. La tarea del maestro es orientar los procesos de construcción del alumno hacia lo que significan y representan los contenidos escolares. El docente guía pero no para que el alumno aprenda lo que él desee sino para que intente engarzar sus procesos de construcción con el saber colectivo culturalmente organizado. ${ }^{25}$

Por su lado, la teoría educativa materialista-dialéctica se ubica, en sus diferentes vertientes, con las que consideran la unidad dialéctica entre lo objetivo y lo subjetivo en la formación del hombre. Se observa — de hecho- una tendencia transformadora. Entre sus mayores representantes están Anton Makarenco (1888-1939), Pavel Petrovich Blonsky (1884-1941), Bogdan Suchodolsky (1907-1992) y Mao Tse-Tung (1893-1976). La educación marxista aspira a la formación del hombre socialista o comunista y tiene como fundamento filosófico al materialismo dialéctico (Karl Marx, 1818-1883; Friedrich Engels, 1820-1895; Vladimir Ilich Lenin, 1870-1924; Joseph Stalin, 1878-1953; Leon Trotsky, 1879-1940; Mao

24. Dícese de la corriente o escuela filosófica la cual afirma que el único conocimiento auténtico es el científico y que éste solamente puede obtenerse de la afirmación de las teorías a través del método científico. Una de las consecuencias del positivismo en educación fue el debate por el establecimiento de un currículo científico.

25. Esta es la posición más progresista del constructivismo. Asimismo, la expresión "aprendizaje significativo" es clave en una concepción constructivista. Por lo demás, no existe —en realidad— una teoría constructivista de la enseñanza y del aprendizaje escolar. 
Tse-Tung y Antonio Gramsci, 1891-1937 son sus más conspicuos expositores). El hombre, al enfrentarse con su medio a través de la comunicación, se apropia individualmente de los contenidos sociales y objetiva socialmente los contenidos individuales. La educación junto a factores ambientales fomenta el proceso de su evolución, por lo que aquélla se presenta con un doble carácter: por una parte es función social y por otra componente del desarrollo de cada individuo.

Por último, la expresión sociedad industrial hace referencia a sociedades caracterizadas por una estructura social moderna. Tal estructura identificó a los países occidentales que produjeron la Revolución Industrial a partir de la transformación de la sociedad preindustrial, premoderna o agraria. En la sociedad industrial la función de la escuela fue explicada de diferentes maneras: para Henri de Saint-Simon (1760-1825), por ejemplo, habría tenido como meta prioritaria la formación de productores, dirigentes y trabajadores. Saint-Simon diferenció dos tipos de educación: aquélla dirigida a la gran masa - consistente en nociones de educación ambiental y un poco de instrucción - frente a la formación especializada de los intelectuales, dirigentes e industriales. Si se aplicara a la utopía neoconservadora la construcción saintsimoniana muy probablemente se observaría lo siguiente: en el futuro la teleinformática estaría al servicio de una educación mediocre y uniforme para la masa, mientras que ciertas élites — resultantes de la ecuación entre el origen social, la capacidad y la herencia política - accederían a un sistema educativo de excelencia en el cual se formarían como gobernantes, científicos e intelectuales. ${ }^{26}$ Esta debería continuar siendo la ecuación vigente para quienes no desean o no aceptan los cambios. No obstante, existen textos que contienen ideas de pensadores cuya finalidad es transformar tal realidad a favor de los desfavorecidos o desaventajados. En esta investigación se intentará aportar datos a los efectos de probar qué visión de la realidad es que la prima en el Distrito de Junín.

\subsection{El aporte de los pensadores}

Han existido pensadores inmersos en diferentes corrientes que -en distintas épocasdejaron aportes de sumo valor ora al conocimiento ora a la educación o a ambos. En primer lugar cabe mencionar a Platón (427-347 a.C.) quien concibió las ideas de manera jerárquica. Suprema es la idea de Dios que, como el Sol en el mito de la caverna, ilumina a todas las demás. En el fondo, su teoría (que algunos denominan doctrina) de las ideas está destinada a explicar el camino por el que se alcanza el conocimiento y también llegar a comprender cómo

26. Puiggrós, Adriana, "Hacia un sistema educativo nacional, de base federal y democrática", en Tedesco, Juan Carlos (compilador), ¿Cómo superar la desigualdad y la fragmentación del sistema educativo argentino? Buenos Aires, Ministerio de Educación, Ciencia y Tecnología, Presidencia de la Nación, 2005, página 84. 
las cosas han llegado a ser lo que son. Sócrates (470-399 a.C.), Platón y Aristóteles (384-322 a.C., el primero maestro de Platón y éste del nacido en Estagira) resumen en muy buena medida el pensamiento griego de la Antigüedad. Empero, sus ideas son prácticamente desconocidas, salvo para las personas ligadas a ellos por alguna razón (por caso profesor de la asignatura "Filosofía" en el nivel medio). Los tres filósofos eran hombres libres (por aquel entonces también existían esclavos en Grecia). Resultaría de interés hoy, pues, considerar la teoría de las ideas de Platón para explicar cómo se formaba el conocimiento en un esclavo. Aunque tal pregunta podría ser objetada porque el esclavo era considerado una cosa, no un ser humano. Entre tantas maravillas y enseñanzas que la Edad Antigua legara a la humanidad, también experimentó el horror de la esclavitud.

René Descartes (1596-1650) hizo de la Matemática el modelo para toda ciencia, aplicando los métodos deductivo y analítico a todos los campos del saber. Reconstruyó el conocimiento sobre una base de certeza al rechazar cualquier creencia, incluso su propia existencia, hasta que pudiera probarse verdadera. Su afirmación "Cogito, ergo sum" ("Pienso, luego existo") le proporcionó el dato cierto a partir del cual pudo deducir la existencia de Dios y de las leyes de la naturaleza. Descartes aplicó la duda como método para aspirar al conocimiento. La duda que, por lo demás, vehiculiza el proceso evolutivo del ser humano. La duda que atenta contra la estructura del pensamiento y que - por lo mismo- evita la deshumanización. La duda que sufre las consecuencias de aquellas corporaciones - las hay de todo tipo en el mundo, Argentina incluida - que ahondan en la sacrosanta obediencia a las jerarquías con absoluto menoscabo - en muchas ocasiones- de la dignidad. Casi cuatrocientos años después de Descartes la duda sigue acompañando al género humano en la búsqueda de un mundo mejor, con una Latinoamérica, una Argentina, un Distrito de Junín más igualitarios. En esta investigación se efectúan diversas actividades tendientes a comprobar las posibilidades de construcción de una sociedad más justa en el citado distrito.

John Locke (1632-1704), uno de los pilares del liberalismo, respecto del cual llegó a definir sus contornos esenciales, expuso la mayoría de los temas que tendrían un pormenorizado desarrollo posteriormente: derechos naturales (humanos); libertades individuales y civiles; gobierno representativo, mínimo y constitucional; separación de poderes; ejecutivo subordinado al legislativo; santidad de la propiedad; laicismo y tolerancia religiosa. ${ }^{27}$ Asimismo, el liberalismo planteó la formación de sujetos libres a través de las prácticas educativas, como condición de existencia del mercado y de la ciudadanía. Derivación necesaria de ello es el interrogante referido a si todos los seres humanos de entonces podían llegar a ser (o eran) libres. Si la respuesta es afirmativa se hablaría de una

27. Locke, John, Segundo tratado sobre el gobierno civil. Madrid, Alianza, traducción, prólogo y notas de Carlos Mellizo, 1991, páginas 28-30. 
educación que permitía la equiparación de aquellos menos afortunados al comienzo de sus vidas. Si es negativa, aquella educación sólo alcanzaba para reproducir las desigualdades de origen. Téngase presente que el fin de la educación liberal fue la constitución del ciudadano como sujeto portador de derechos y obligaciones a partir de la delegación de su soberanía en organismos específicos. De esa manera, el pensamiento liberal enmarcó la educación en un doble juego de derechos y obligaciones: por un lado, derechos de los individuos que la sociedad debía garantizar pero - a su vez- obligaciones de los mismos para con aquélla. Dos de los mayores aportes del liberalismo a la causa de la educación son el Estado docente y la obligatoriedad escolar. Tanto uno como otra constituyen temas de sumo interés, no sólo en los ámbitos académicos. La obligatoriedad escolar ha promovido debates en todas las épocas y obtenidos resultados —en América Latina, especialmente- en beneficio de los más necesitados. Empero, la formación escolar de los niños y los adolescentes que pertenecen a hogares carenciados es - todavía hoy - deficiente. Ello significa que no alcanza para dar el envión que los impulse a salir de la pobreza y/o de la marginalidad. En la presente investigación participan egresados del Distrito de Junín que pertenecen a estos sectores sociales desfavorecidos.

Immanuel Kant (1724-1804) en su Pedagogía — resultado de su curso homónimo dictado en 1803 en la Universidad de Königsberg - retomó el pensamiento pedagógico de los siglos XV al XVII entroncándolo con la Ilustración, lo cual le permitió desarrollar los caracteres de la educación moderna. Kant inicia el texto con la siguiente definición: "El hombre es la única criatura que ha de ser educada, entendiendo por educación los cuidados (sustento y manutención), la disciplina y la instrucción. Según esto, el hombre es niño pequeño, educando y estudiante". ${ }^{28}$ De esta forma concibió a la educación como un fenómeno externo a la realidad dada y a la divinidad. Desde el siglo XX, la psicología (en la que destellan los trabajos de Jean Piaget) viene sosteniendo — con énfasis en los procesos internos- que el niño y el adolescente son seres humanos que atraviesan diferentes etapas evolutivas las cuales incluyen modos particulares de adquisición del conocimiento.

Jean Jacques Rousseau (1712-1778), fijando como premisa la especificidad del niño — concebido no como un adulto pequeño sino como un ser con necesidades y deseos específicos- asignó al educador la misión de observar las capacidades del niño a los efectos de promover su desarrollo. He aquí dos términos — capacidad y desarrollo- que son tomados en cuenta en esta investigación respecto de los egresados adolescentes y adultos, intervinientes en la misma, de escuelas estatales de nivel medio del Distrito de Junín.

28. Kant, Immanuel, Pedagogía. Madrid, Akal Ediciones, 1983, páginas 29 y 30. 
Jean Fréderic Herbart (1776-1841) creó un sistema educativo cuyos principios y método de enseñanza se basan en la experiencia. La educación, tal como la concibió, aspira especialmente a formar a la persona humana. Una educación con un alto sentido ético que, orientada hacia el desarrollo completo de la libertad interna, proclama la moralidad y la virtud como fines supremos de la vida. Actualmente, en los colegios a nivel nacional (incluida la provincia de Buenos Aires) sólo existe una unidad llamada Ética incluida en la asignatura "Filosofía" (la planificación anual de esta materia consta de ocho unidades) dentro de la modalidad Ciencias Sociales. Dicha asignatura tiene una carga horaria semanal baja: dos horas cátedra (ciento veinte minutos con un recreo de diez minutos entre hora y hora). En conversaciones con docentes de nivel medio del Distrito de Junín, la opinión de aquéllos resultó unánime en cuanto a la poca importancia que se le da al tema ético desde los gobiernos nacional y provincial.

Lev Semenovich Vigotsky (1866-1934) otorgó el valor de herramientas psicológicas -por analogía con las herramientas físicas- a los sistemas de signos, particularmente el lenguaje. Mientras los instrumentos físicos se orientan a actuar sobre el mundo externo (colaborando en la transformación de la naturaleza), los instrumentos semióticos parecen estar principalmente orientados hacia el mundo social. Según Vigotsky, la Zona del Desarrollo Próximo (ZDP) es la distancia entre el nivel de desarrollo real determinado por la capacidad del alumno para resolver un solo problema y el nivel de desarrollo potencial establecido bajo la guía de un adulto o en colaboración con otro educando más capaz. Vigotsky plantea tres situaciones diferentes a tener en cuenta: el aprendizaje de la persona sin nadie a su lado, el de ella con la guía de un adulto (profesor o no) y - por último- junto a otro educando más capaz. Si se pusiera atención en los dos últimos casos, podría colegirse que la presencia del otro - que sabe el tema o que es más capaz- actúa como un facilitador para adquirir el conocimiento. En el presente trabajo se realizarán actividades con profesores de egresados adolescentes y adultos de nivel medio del Distrito de Junín referidas a esta problemática.

\subsection{La función de la escuela}

Las teorías educativas tradicionales no ofrecieron bases ciertas para comprender la relación entre conceptos tales como ideología, conocimiento y poder. Esto es, fue eliminado cualquier intento por reflejar en el desarrollo histórico la selección y la legitimación de lo que las escuelas han definido como el conocimiento real. La pregunta ignorada aquí es la manera en que el poder — distribuido en toda la sociedad- funciona para que las ideologías y las formas de conocimiento específicas sostengan los intereses económicos y políticos de las clases sociales. 
Las teorías de la reproducción ${ }^{29}$ abordan el problema del funcionamiento de las escuelas y señalan los beneficios del sector dominante como una característica particular. A diferencia del funcionalismo estructural, rechazan los supuestos de que son instituciones democráticas que promueven la excelencia cultural, el conocimiento exento de valoración y los modos de instrucción objetivos. Estas teorías se ocupan de cómo el poder es utilizado para mediar entre las escuelas y los intereses del capital. Analizan cómo los establecimientos educativos se valen de sus recursos materiales e ideológicos para reproducir las relaciones sociales con el fin de sostener las divisiones del trabajo necesarias para las relaciones de producción. A su turno, las primeras críticas a las teorías de la reproducción señalaron su determinismo unilateral, su visión simplista de la reproducción social y cultural y su periódica forma de teorización ahistórica. ${ }^{30}$

Para Louis Althusser (1918-1990) lo que las escuelas no hacen -como conjunto de instituciones colectivas- es retar las bases estructurales del capitalismo, aunque hay individuos dentro de ellas que realizan fuertes críticas y modos de enseñanza de oposición. Las escuelas, como principal aparato ideológico del Estado, generalmente cumplen acertadamente su función política y suministran a los estudiantes los contenidos y las actitudes apropiados para el trabajo y la ciudadanía.

Por lo demás, en el esquema reduccionista de Althusser, los seres humanos son relegados al papel estático de transportadores de significados ya establecidos, agentes de ideologías hegemónicas inscriptas en sus psiques como cicatrices inamovibles. Consecuentemente, devendría imposible explicar desde esta perspectiva cuáles son los mecanismos que actúan para caracterizar a las escuelas como instituciones relativamente autónomas. En esta investigación se administrarán cuestionarios a egresados de nivel medio del Distrito de Junín donde existen preguntas referidas a las problemáticas del trabajo y de la ciudadanía.

La teoría de Pierre Bourdieu (1930-2002) sobre la reproducción cultural empieza con la suposición de que las sociedades divididas en clases, como las configuraciones ideológicas sobre las que descansan, están mediadas y reproducidas —en parte- por lo que él llama "violencia simbólica". Esto es, el control de la clase gobernante no es el reflejo de la imposición del poder económico a través de la fuerza y de la dominación abiertas. En vez de eso está el más sutil ejercicio del poder simbólico, llevado a cabo por la clase gobernante para imponer una definición del mundo consistente con sus intereses. La cultura se convierte en el vínculo entre los intereses de esa clase y la vida cotidiana. Esto plantea los intereses políticos

29. Véase el Capítulo I, página 21.

30. Giroux, Henry, Capítulo 3 "Reproducción, resistencia y acomodo en el proceso de escolarización", en Teoría y resistencia en educación. Una pedagogía para la oposición. México, Siglo XXI Editores, 1997, páginas 101-103. 
y económicos de las clases dominantes no como arbitrarios e históricamente contingentes sino como elementos necesarios del orden social vigente. ${ }^{31}$ Ahora bien, el valor de la teoría educativa de Bourdieu está en su análisis político de la cultura, en su examen de cómo la cultura dominante es producida en las escuelas y en su intento por desarrollar una noción de psicología que explique parcialmente la pregunta de por qué el dominado toma parte en su propia opresión. Aunque son importantes los avances teóricos de Bourdieu -especialmente en lo que atañe a los modelos de escolarización, liberal y estructural-funcionalista- éstos permanecen atrapados en las nociones de poder y de dominación que son unilaterales y sobredeterminadas.

De 2005 a la fecha se han realizado estudios en diferentes países con la intención de ir más allá de los avances que caracterizan a las teorías de la reproducción social y cultural. Tomando los conceptos de conflicto y de resistencia como punto de partida para sus análisis, estos estudios han buscado redefinir la importancia del poder, de la ideología y de la cultura, como construcciones centrales para entender las complejas relaciones entre la escolarización y la sociedad. Así, el intento neomarxista de vincular a las estructuras sociales con la intervención humana para explorar la forma en que interactúan dialécticamente, representa un avance teórico sobre los supuestos funcional-estructuralistas e interaccionistas. A las teorías neomarxistas de la resistencia también les acosan los problemas. ${ }^{32}$ Lo que está ausente en ellas son los análisis de esas determinantes históricas y culturales que producen un rango de conductas de oposición. Asimismo, las teorías de la resistencia no han brindado suficiente atención al problema de cómo afecta la dominación a la estructura de la personalidad misma. Esto es, existe en el ámbito académico muy poca preocupación por la relación entre comprensión y acción y por qué la una no siempre lleva hacia la otra. Parte de la respuesta podría consistir en descubrir la génesis de esas necesidades socialmente construidas que ligan a la gente a estructuras de dominación más amplias. ${ }^{33}$ En este trabajo se aborda tal problemática mediante actividades individuales y colectivas que serán llevadas a cabo por diferentes agentes de las comunidades educativas de nivel medio del Distrito de Junín.

\subsection{El constructivismo}

Sin mengua de la importancia que en esta investigación se atribuye a las demás teorías, se adhiere a la constructivista porque se reconocen en ella las características de una teoría educativa que permite el pleno desarrollo individual y social. El constructivismo afirma que el

31. Giroux, Henry, Capítulo 3, op. cit., páginas 120-125.

32. Giroux, Henry, Capítulo 3, op. cit., páginas 129-136.

33. Giroux, Henry, Capítulo 3, op. cit., páginas 140-149. 
conocimiento es el resultado de un proceso de construcción o reconstrucción de la realidad que tiene su origen en la interacción entre las personas y el mundo. La idea central es que la elaboración del conocimiento consiste en una modelización más que una descripción de la realidad. Al decir de Tamayo Valencia,

Se tiene que abandonar esa concepción de que el conocimiento se genera a partir de la experiencia, que la única evidencia válida es la empírica y que el conocimiento es un encadenamiento acumulativo de conceptos [...], el aprendizaje ahora se debe ver como una transformación, modificación de un esquema conceptual por la construcción, la comprensión de otra interpretación superior de la realidad ${ }^{34}$.

Como sucede con toda doctrina o teoría, el constructivismo incluye una variedad de orientaciones que mantienen ciertas diferencias de enfoque y de contenido. Así, el constructivismo piagetiano sigue más de cerca los aportes que tienen relación con la epistemología evolutiva; es decir, la forma de construir el conocimiento de acuerdo con las etapas evolutivas del niño y del adolescente. Para Jean Piaget la idea de asimilación es clave ya que la nueva información que llega a una persona es asimilada en función de lo que previamente hubiera adquirido. Muchas veces se necesita luego una acomodación de lo aprendido, por lo que ha de haber una transformación de los esquemas del pensamiento en función de las nuevas circunstancias.

En las décadas de 1960 y de 1970 se observó en muchos países (Argentina incluida) que muchos docentes de los niveles primario y medio utilizaban una nueva forma de enseñar las ciencias, guiada por las contribuciones pedagógicas de Piaget. La aplicación de su teoría como reacción contra la enseñanza tradicional memorística se fundamentó en el aprendizaje por descubrimiento. Una versión extrema de este aporte en el ámbito de las ciencias llevó a centrar la enseñanza en el método científico que se presentaba en muchos textos dogmatizado en pasos o etapas rígidas. Más allá de la discusión sobre un método científico definible como tal, lo cierto es que el aprendizaje por descubrimiento, al girar en torno a la idea de que enseñar algo a un alumno que él podría descubrir por sí solo supone impedirle que lo entienda completamente, llevó a excesos en los procedimientos, lo que hizo perder de vista los contenidos. Por lo demás, a pesar de la fuerte crítica que tuvo esta línea educativa, representó una nueva vía para abordar originalmente la enseñanza de las ciencias. El acento en los alumnos como ejes de su propio proceso de aprendizaje está entre esos logros, al igual que el valor concedido al descubrimiento y a la investigación como formas para construir el conocimiento. En este orden de ideas, según Piaget la enseñanza secundaria se corresponde con el estadio de las operaciones formales. Esta etapa supone en el educando importantes habilidades para el aprendizaje de los contenidos escolares, como la adquisición del

34. Tamayo Valencia, Luis Alfonso, Tendencia de la pedagogía en Colombia, publicado por la Revista Educación y Ciencia. Bogotá, Colombia, 1991, página 12. 
pensamiento hipotético-deductivo. Pero la habilidad cognitiva no se alcanza espontáneamente (al menos, no en forma generalizada). Es importante la educación obligatoria porque desarrolla las habilidades del pensamiento, entre las que se incluyen el razonamiento inductivo, el deductivo y el analógico, así como la capacidad de argumentar y de hacerlo en contrario. A estas habilidades se agregan las propias del pensamiento creativo y todas ellas desarrollarían el pensamiento crítico o la capacidad para reflexionar sobre los procesos del conocimiento.

Otra orientación es el constructivismo humano que surgió de las acotaciones de David Paul Ausubel (1918-2008) sobre el aprendizaje significativo, a las que se añadieron contribuciones neurobiológicas de Joseph Donald Novak (1932-). También es valioso el constructivismo social fundado en la importancia de las ideas alternativas y del cambio conceptual (George Kelly, 1905-1967), además de las teorías sobre el procesamiento de la información. Para esta versión del constructivismo son de gran valía las interacciones sociales entre los que aprenden. Finalmente, se denomina constructivismo radical (Ernst von Glaserfeld, 1917-2010) a una corriente que rechaza la idea según la cual lo que se construye en la mente del que aprende es un reflejo de algo existente fuera de su pensamiento.

A un lado la referencia a las orientaciones aludidas en el aula, el profesor interviene en el proceso pedagógico logrando siempre avances que de ningún modo ocurrirían en otro ámbito. Esto es así porque para conseguir sus objetivos, la escuela realiza — vía diferentes agentesactividades como la lectura de textos sobre un mismo tema que representan distintos puntos de vista, promueve la libre expresión de las ideas, debates, trabajos en grupo, diálogos sobre problemas de actualidad y la participación activa en todo momento del alumnado. El presente trabajo importa llevar a cabo diversas actividades individuales y colectivas en escuelas secundarias estatales del Distrito de Junín con sustento en el prisma del constructivismo piagetiano, mediante la participación de diferentes agentes educativos.

\subsection{El valor de la educación}

Teniendo en cuenta lo expresado en relación a las teorías educativas surge la pregunta de cómo es actualmente la oferta en educación, a tenor de las características de sus destinatarios y de las circunstancias existentes en torno a ellos. Dentro del aspecto exterior a la educación debe tenerse muy en cuenta el posible influjo de la televisión en el conocimiento y en la conducta de un número no siempre definitivamente precisado de seres humanos. Al respecto existen diversos trabajos de investigación realizados en diferentes países. ${ }^{35}$ Para Fernando

35. En cierta medida y haciendo una lectura directa de los resultados se podría afirmar que los adolescentes se encuentran en un proceso de maduración y transición que genera inestabilidad y se 
Savater (1947-) "la televisión ofrece modelos de vida, ejemplos y contraejemplos, viola todos los recatos y promociona esa urgencia de elegir inscripta en la abundancia de noticias a menudo contradictorias". ${ }^{36}$ Hoy día la televisión trasluce una realidad que inquieta a todos los universos de producción cultural: la contradicción entre las condiciones económicas y sociales en las cuales se produce un tipo de obras (esas llamadas "puras"; es decir, autónomas de las imposiciones comerciales) y las condiciones de transmisión de los productos obtenidos en tales circunstancias. Por lo demás, la pequeña pantalla siempre promueve debates -la mayoría de ellos más apasionados que racionales- donde muchas veces están en juego (aunque no se lo manifieste expresamente) la libertad de expresión y la libertad de empresa. Nadie duda que, entre otros efectos, la televisión induce pautas de vida al reflejar — si bien de una manera sesgada - los hechos que acontecen en las diferentes sociedades.

A todo esto, Pierre Bourdieu asevera que "uno de los mayores problemas que plantea la televisión es el de las relaciones entre el pensamiento y la velocidad. ¿Se puede pensar atenazado por la velocidad?", se pregunta. ${ }^{37}$ Por tal razón, interesa saber si una televisión de mayor calidad que la actual es posible. En relación a esta problemática, pareciera que la escuela tiene algo significativo que decir al respecto. Va de suyo que es transmisora de mensajes al igual que la televisión, por lo que su función es absolutamente relevante. Pero además ella debe enseñar a todos los alumnos a servirse de la computadora y de las diferentes herramientas multimedia ${ }^{38}$ para alcanzar una mayor y mejor producción intelectual.

observa una ausencia significativa de una programación específica para ellos. Este hecho, generalizable a otros grupos (infantil y tercera edad) explica que los adolescentes señalen entre sus preferencias programas televisivos destinados a adultos. Airbe Barandiaran, Ana, Medrano Samaniego, Concepción, y Palacios Navarro, Santiago, "El perfil de consumo televisivo en adolescentes, jóvenes y adultos: implicaciones para la educación" en Revista de Educación, 352. Universidad del País Vasco. Facultad de Filosofía y Ciencias de la Educación. Departamento de Psicología Evolutiva y de la Educación. Mayo-Agosto 2010.

Entre los principales resultados de la encuesta puede leerse 4 de cada 10 niños y adolescentes han visto televisión desde otras plataformas, siendo Youtube y los sitios de los canales por Internet las más comunes. [...] La demanda programática declarada se da especialmente después de las 22:00 horas, siendo la telerrealidad (realities) y la comedia los géneros más requeridos. [...] Existe una crítica respecto a la imagen erotizada de las jóvenes que la televisión abierta muestra. 8 de cada 10 encuestados opinan que ellas siempre andan vestidas de manera sexy y la mitad afirma que sólo les preocupa conquistar a los hombres. En Consejo Nacional de Televisión (CNTV), Encuesta Niños, Adolescentes y Televisión, Departamentos Estudios, Chile, septiembre de 2012.

36. Savater, Fernando, op. cit., páginas 37 y 38.

37. Bourdieu, Pierre, "La urgencia y el fast thinking", en Sobre la televisión. Barcelona, Editorial Anagrama S.A., traducción de Thomas Kauf, 1997, página 42.

38. Confederación de Trabajadores de la Educación de la República Argentina (CTERA). Capítulo IV "Trabajo docente y reforma educativa (La Argentina de los años '90). Informe de 
Argentina tiene deudas significativas en materia de acceso a las nuevas tecnologías en la escuela. Un estudio comparado de la UNESCO realizado en 2008 señala que en 2007 el 48 por ciento de los alumnos en el país no tenía acceso a la computadora, mientras esa cifra disminuía al 2,7 por ciento en Chile. En provincias con extendida pobreza como Catamarca, Formosa y Santiago del Estero apenas el 2 por ciento de las escuelas tenía conexión a Internet en 2007. En cambio, en la Ciudad Autónoma de Buenos Aires, en Chubut y en Tierra del Fuego, más de la mitad de las escuelas tenía acceso a Internet. La posibilidad de proveer una computadora portátil a los alumnos y/o a los docentes, la conformación de gabinetes o la incorporación de computadoras en las propias aulas se suman a nuevos dispositivos como el libro electrónico o los pizarrones interactivos. ${ }^{39}$ Algunos de estos avances empezaron a mostrar visos de concreción en escuelas estatales de nivel medio del Distrito de Junín a partir de 2010. Empero, esa realidad aún no se observa en los colegios que reciben jóvenes socialmente desfavorecidos.

Respecto de tal cuestión, en el Distrito de Junín aún hoy existen escuelas secundarias a las que no han llegado las netbooks y en aquéllas donde ello sí se produjo, no todos los educadores ni todos los alumnos las recibieron. Por lo demás, una observación —en el marco de esta investigación - en diferentes cursos de egresados de nivel medio permitió comprobar que pocos profesores las utilizaban durante las clases y cuando sí lo hacían se trataba de un uso personal, no referido a algún tema de su materia. Asimismo, durante los recreos muchos estudiantes permanecían en el aula entretenidos con juegos en sus computadoras. "Fijate que lindo... Un silencio absoluto. Esto es lo máximo que se ha creado para tener a los alumnos tranquilos, sin que se pongan molestos" (tal el comentario de un profesor de nivel medio).

En otra línea de análisis de la problemática educativa, la justificación de la desigualdad social a partir de los resultados de investigaciones genéticas es uno de los principales ejes acerca del papel que — según algunos autores - tendrá el conocimiento en la estructura social futura. Así, para el científico social Francis Fukuyama (1952-) fenómenos como el alcoholismo, la separación, la criminalidad, el divorcio, la drogadicción, la promiscuidad y otras "conductas desviadas", se explicarían por factores genéticos (hereditarios) y serían difícilmente modificables por medio de políticas sociales. Disponer de información genética pareciera que disminuirá la posibilidad de continuar administrando justicia según el principio del "velo de ignorancia" (presentado por John Rawls, 1921-2002, en su Teoría de la Justicia), ignorancia que contribuye positivamente a la cohesión y a la socialización de toda la comunidad. Por otro lado, como respuesta a las ideologías neoconservadoras existentes se

Argentina”, en Las reformas educativas en los países del Cono Sur. Ensayos \& Investigaciones del Laboratorio de Políticas Públicas - Buenos Aires, No 11, CLACSO, 2005, páginas 166 y 167.

39. Rivas, Axel, Capítulo 3. "Cartografias", en Radiografía de la educación argentina. Buenos Aires, Fundación CIPPEC, Fundación Arcor, Fundación Roberto Noble, 2010, página 98. 
estaría gestando en 2012 un nuevo pensamiento democrático basado en la idea según la cual eliminar la desigualdad no es contradictorio con el respeto a la diversidad. La justicia y la solidaridad son principios básicos que garantizan el desarrollo social, pero no pueden ser aplicados de la misma forma que en el pasado. Este nuevo enfoque de la justicia social está asociado al fortalecimiento de la dimensión política de la sociedad y de la democracia. ${ }^{40} \mathrm{Y}$ para lograr todo esto se espera un aporte significativo proveniente de la educación, especialmente a favor de los egresados adolescentes y adultos de nivel medio pertenecientes a sectores desfavorecidos.

No debe olvidarse que existen tres dimensiones transversales que están presentes en todos los niveles de la organización y del funcionamiento del sistema educativo. La primera es la relativa al para qué de la educación escolar, a sus finalidades y funciones. Es la dimensión básica por el hecho de que la educación escolar se ve compelida actualmente a la tarea de garantizar la transmisión de un patrimonio a las nuevas generaciones y de prepararlas para el futuro en un contexto de incertidumbre, de carencia de perspectivas a largo plazo y de ausencia de referencias claras sobre hacia dónde se quiere ir.

La segunda es la relativa al qué de la educación escolar. Constituye una concreción de la anterior en términos de intenciones educativas, de decisiones sobre cuál es el capital cultural que la educación escolar debe transmitir a las nuevas generaciones y cuáles son los conocimientos y las competencias que se han de enseñar en las escuelas secundarias y en los institutos terciarios. Y la tercera es la dimensión relativa al cómo de la educación escolar, que se concreta de forma diferente en los distintos niveles de organización y funcionamiento del sistema educativo. Así, mientras que el nivel de la estructura y del ordenamiento del sistema se concreta en temas relacionados con la gestión (descentralización, distribución de recursos, gestión de equipamiento e infraestructura, rendición de cuentas y evaluación y programas de apoyo), en el nivel del aula lo hace en temas relacionados con la planificación y el despliegue de actividades de enseñanza y de aprendizaje; es decir, en temas metodológicos y de práctica docente. $^{41}$

40. Fukuyama, Francis y Rawls, John cit. por Tedesco, Juan Carlos, "La educación en el marco del nuevo capitalismo", en Memorias del II Congreso Nacional de Educación Superior a Distancia. Medellín, Educación en la Globalización, 2000, páginas 28, 29 y 30.

41. Coll, César; Marchesi, Álvaro y Tedesco, Juan Carlos (coordinadores), Calidad, equidad y reformas en la enseñanza, en Gobierno y dirección de los sistemas educativos en América Latina. 1. ${ }^{\mathrm{a}}$ reunión del grupo de expertos de la OEI sobre "Reformas educativas". Documento de trabajo interno. Ciudad de México, mayo 2007, páginas 102, 103 y 105. 
Ahora bien, en América Latina las teorías educativas pasan hoy por un momento crítico. Se caracterizan por el eclecticismo ${ }^{42}$ que las fundamenta o - lo que resulta preocupante- por la marcha errática de las ideas en materia educativa, carentes de un sistema filosófico que les dé coherencia. No obstante, se observa una intención integradora entre el paradigma cuantitativo y el cualitativo de la investigación científica, lo que resulta positivo. Hay, además, una revalorización de la educación popular en los últimos cinco años pero que aún no se concreta en una mejor calidad educativa para todos, sin discriminación alguna. No ha de olvidarse que la región necesita unirse tanto en lo material como en lo espiritual y nada más apropiado que hacerlo a través de la educación, por la importancia que ésta tiene en el desarrollo de las capacidades humanas y - por ende- de los pueblos.

\section{La educación desde una perspectiva jurídica}

\subsection{El marco de la Constitución Nacional}

En su Parte Primera, el texto supremo aprobado el 1 de mayo de 1853 reconoce - entre otros derechos civiles - el de la educación, consagrado en el artículo 14 in fine para todos los habitantes de la Nación como derecho de "enseñar y aprender". ${ }^{43}$ Esta separación tajante que efectúa el constituyente entre un sujeto que posee el saber (el docente) y otro que va en busca del mismo (el alumno) origina desde un análisis sesgado una mirada estática - por ende, dogmatizada - del proceso de transmisión y adquisición del conocimiento. Por otro lado, la interacción entre ambos actores acontece enmarcada en un proceso de enseñanza y de aprendizaje. Así identificado, el proceso responde inequívocamente a la dicotomía antes señalada. Asimismo, su direccionalidad siempre le pertenece al docente, quien planifica las clases sin perder de vista tal ecuación. Por lo demás, es plausible que a veces se hable de la enseñanza como de una intención. Esto es así porque al tratarse de una relación entre personas no es posible asegurar que aquello que se debe o quiere comunicar sea efectivamente transmitido y adquirido. Para decirlo en un lenguaje más usual: el hecho de que el docente enseñe no significa que el alumno aprenda (mucho o poco) lo que se pretende enseñarle. En tal sentido, los docentes partícipes en esta investigación aseguraban - en el transcurso de una jornada de perfeccionamiento realizada el viernes 7 de septiembre de 2012 en la escuela Aque "nunca todos los educandos aprenden de igual manera un tema dado". Variadas son las causas personales y/o familiares —así como las del ámbito escolar mismo- que coadyuvan

42. En esta investigación se entiende por eclecticismo la mezcla de distintos y - a menudoopuestos puntos de vista, criterios filosóficos, premisas teóricas y valoraciones políticas.

43. Bidart Campos, Germán José, Tratado elemental de derecho constitucional argentino: La reforma constitucional de 1994. Tomo II. Buenos Aires, Ediar, 1995, página 36. 
con mayor o menor intensidad a ello. Determinar el cuántum aprendido por cada egresado en un aula donde hay veinte o treinta de ellos —en los primeros años del nivel medio la cifra llega a veces a cincuenta - al finalizar una clase de cuarenta o de ciento veinte minutos, aparece como una tarea ciclópea cuando no imposible. Sin embargo, no hay que desesperar por esta afirmación. Si el alumno no aprendiera nunca algo cercano o parecido a lo que se le intenta transmitir, la enseñanza sería una actividad sin sentido y las instituciones educativas estarían de más. Silvina Gvirtz y Mariano Palamidessi resumen la idea cuando afirman que "se pretende poner en marcha un proceso de diálogo entre el aprendiz y la realidad, apoyado en la búsqueda compartida con los compañeros y con los mayores, siempre y cuando dichos apoyos sean provisionales y desaparezcan progresivamente, permitiendo que el adolescente asuma el control de su actividad". ${ }^{4}$

Esta visión del proceso donde existen un emisor y quienes receptan el conocimiento produjo la existencia de clases conocidas como magistrales, que han tenido lugar en diferentes espacios geográficos, el Distrito de Junín incluido. El investigador apreció que las clases magistrales continúan vigentes al presenciar durante 2010 las de varios profesores del último año del nivel medio (adolescentes y adultos) en escuelas seleccionadas para esta investigación.

Ahora bien, un análisis realizado desde una óptica diferente permitiría distinguir que en una clase se genera siempre un proceso dinámico (nunca estático de compartimentos estancos), con intercambios de informaciones, conocimientos y experiencias entre los agentes, suscitándose momentos donde la producción de ideas y la transmisión de valores pueden generar modificaciones en sus estructuras mentales. Cuando las influencias ejercidas pueden sobreponerse a las posturas omnipotentes surgen nuevos conocimientos, habilidades y actitudes como resultados más destacados de la actividad áulica. Por lo demás, esos cambios se producen en cada agente (el educador y los educandos) de un modo personal.

El derecho de enseñar implica la facultad de toda persona (que posea título habilitante) de transmitir sus conocimientos y sus experiencias. La libertad de enseñar implica libertad de cátedra (pluralismo ideológico). Para Germán José Bidart Campos (1995)

la denominada libertad de cátedra se desglosa en varios aspectos: a) para quien imparte la enseñanza implica poder transmitir los conocimientos de acuerdo con una valoración, criterio y orientación propios; b) para la asociación o persona propietarias de un establecimiento educacional significa poder imprimir a la enseñanza la orientación ideológica o espiritual adoptadas en el mismo y c) para quien recibe la

44. Gvirtz, Silvina y Palamidessi, Mariano. Capítulo 5. "Enseñanza y filosofías de la enseñanza", en El ABC de la tarea docente: Currículum y enseñanza. Ciudad Autónoma de Buenos Aires, Aique, Tercera edición, mayo de 2011, páginas 134 y 137. 
enseñanza comporta la necesaria libertad de crítica y de juicio propios para exponer razonadamente su punto de vista. ${ }^{45}$

Gregorio Badeni (2006) asevera que la libertad de enseñar y aprender "consiste en la potestad reconocida a toda persona para acceder, mediante su capacitación intelectual, al conocimiento de la labor científica en todas sus áreas y niveles y para transmitir esos conocimientos a los demás en un marco de pluralismo y libertad de opinión". ${ }^{46}$

Nadie será obligado a recibir una enseñanza determinada. Por libertad de aprender se comprende, asimismo, la opción por un tipo de educación, por su orientación espiritual o ideológica, por un establecimiento determinado, todo lo cual conlleva el reconocimiento del Estado nacional. Asimismo, existe la tutela constitucional a la objeción de conciencia. Aplicada a docentes y a estudiantes, no les es exigible participar en actos o ceremonias que su conciencia religiosa o moral repruebe, ni prestar juramentos de igual naturaleza ni exteriorizar conductas o sentimientos que no comparten. ${ }^{47}$

El derecho a la educación (denominación receptada por el Derecho Internacional de los Derechos Humanos) también se observa en varios instrumentos internacionales sobre derechos humanos con jerarquía suprema, incluidos en el artículo 75, inciso 22, párrafo $2^{\circ}$, por la reforma de 1994. De dicha normativa, a continuación se explicarán los contenidos educativos de algunos instrumentos. Así, la Declaración Americana de los Derechos y Deberes del Hombre afirma que el derecho a la educación debe basarse en los principios de libertad, moralidad y solidaridad. Su ejercicio ha de propender a la capacitación de las personas para que logren una existencia digna, mejoren su nivel de vida y puedan ser útiles a la sociedad. Por tal declaración se impone a toda persona la obligación de completar - a lo menos- la instrucción primaria. Por lo demás, a nadie escapa que hoy la gratuidad debería extenderse a todos los niveles de la educación pública. Sobre el nivel educativo alcanzado personalmente se han de efectuar preguntas - vía cuestionario- a padres $u$ otros responsables y a abuelos de los egresados participantes en esta investigación. También se ha

45. Bidart Campos, Germán José, op. cit., página 36.

46. Badeni, Gregorio en Tratado de Derecho Constitucional. $2^{\circ}$ Edición actualizada y ampliada. La Ley, 2006, Tomo I, página 187.

47. En el caso "Barros, Juan C. c/Consejo Nacional de Educación", del 6 de marzo de 1979, la Corte Suprema de Justicia de la Nación hizo lugar a un amparo contra la medida que separó de un establecimiento escolar a dos menores que cursaban primero y segundo grados, por haberse negado a reverenciar los símbolos patrios a causa de la confesión religiosa (Testigos de Jehová) de sus padres. La Corte consideró prevalente el derecho de aprender, asumiendo igual postura en los casos "Ascencio" de 1982 — por idéntica causal- y "Santa Cruz" de 1981, por no aceptar la distinción de actuar como escolta. En todos los casos ordenó la reincorporación de los estudiantes a los respectivos establecimientos. 
de interrogar a los directores, secretarios y profesores respecto del nivel educativo logrado por sus padres u otros responsables.

La Declaración Universal de Derechos Humanos establece los caracteres obligatorio y gratuito de la instrucción elemental y el principio de igualdad para el acceso a los estudios superiores. Pero la realidad muestra que siempre han existido $-\mathrm{y}$ persisten actualmente en diversos países, particularmente los pobres - sectores sociales que no sólo tienen vedados los estudios superiores, también el nivel secundario e incluso el primario. Asimismo, esta declaración prescribe que la educación debe fomentar la comprensión, la tolerancia y la amistad entre las naciones y entre los grupos raciales, étnicos o religiosos. No admite duda que la propensión a la amistad entre los países es algo muy valioso, pero no debe perderse de vista que en política internacional existe el enfoque o teoría realista, la cual sostiene que las relaciones internacionales se basan en el poder (concebido como la relación de mando y obediencia, incluso cuando tiene lugar contra toda forma de resistencia). Además, ese poder - legal y eficientemente ejercido - tendrá como finalidad la defensa de los intereses nacionales. Desde esta perspectiva poco es el margen para lograr la comprensión, la tolerancia y la amistad en tanto puedan obstaculizar los intereses de la nación, especialmente si es desarrollada (o — como otros autores denominan - del Primer Mundo). Asimismo, la educación también ha de apuntar al reconocimiento del derecho de los padres (u otros responsables) a elegir el tipo de educación que se les brindará a quien tienen a su cargo. En esta investigación se alude a la última problemática en el cuestionario que se aplicará a los responsables de los egresados de nivel medio del Distrito de Junín.

En el Pacto Internacional de Derechos Económicos, Sociales y Culturales fueron incluidas características de la libertad de enseñar a las cuales deben adecuarse las leyes de los Estados partes. Se prevén la participación en la vida cultural y en el progreso científico, así como la libertad para investigar, la actividad creadora y los derechos de autor. Se establece que la educación debe orientarse hacia la actualización continua de las potencialidades humanas. Al respecto oportuno es recordar que, un desarrollo equilibrado de la personalidad sólo es posible si son respetados los derechos y las libertades del ser humano. De lo contrario resultará obstruido (alterado) el conjunto de los sistemas responsables de su conducta, originándose consecuencias negativas para él y los demás seres con quienes interactúa. Asimismo, el desarrollo normal de la personalidad constituye la expresión más fehaciente de la dignidad humana. Por lo demás, este Pacto obliga a los Estados partes a respetar la libertad de los padres de elegir para sus hijos escuelas distintas de las creadas por las autoridades públicas, a fin de que reciban la educación religiosa o moral que sea acorde con sus convicciones.

La Convención sobre la Eliminación de todas las Formas de Discriminación contra la Mujer prevé la igualdad de derechos con el varón y la educación de la mujer rural. En un mundo predominantemente urbano, la educación rural queda muchas veces invisibilizada o 
relegada. La escasez de recursos en los contextos rurales es un desafío, tanto por la necesidad de revertir condiciones sociales adversas como por los costos extras que implican las distancias y la menor densidad de alumnos por docente en dichos ámbitos. ${ }^{48}$ Mirta Zaida Lobato (2000) menciona a los maestros rurales que jugaron un papel importante en la organización de la protesta que tuvo lugar en el territorio nacional de La Pampa en la década de 1910. Los colonos demandaban —-desde hacía tiempo- la eliminación o la disminución de los gravámenes fiscales que pesaban sobre la producción y la comercialización de sus productos. $^{49}$ En esta investigación se tomará en cuenta al sector rural (sus escuelas) del Distrito de Junín. Allí se llevarán a cabo actividades con agentes educativos del nivel medio.

Otros instrumentos significativos - pese a no integrar el denominado bloque de constitucionalidad - son la Convención de los Derechos de las Personas con Discapacidad (CDPD), en la cual se reconoce el derecho a la educación para dichas personas ${ }^{50}$ y la Declaración Universal sobre la Diversidad Cultural (DUDC), donde aparece tal derecho reconocido a las minorías étnicas y a los pueblos originarios. ${ }^{51}$ También debe mencionarse a la Convención contra la Discriminación en Educación, de la UNESCO de 1960, donde aparece una definición de discriminación. ${ }^{52}$ El tema de los pueblos originarios pertenecientes al Distrito de Junín ha de ser considerado en esta investigación, poniéndose énfasis en lo educativo.

En ningún momento - y en ningún lugar- han de desconocerse los caracteres propios y la pluralidad cultural que aluden al derecho a la identidad y a la diferencia. Se abarca así toda índole de manifestaciones, como las que surgen de asociaciones, regiones, minorías, provincias y grupos con expresiones peculiares. En tal sentido, "los pueblos indígenas tienen derecho a mantener, controlar, proteger y desarrollar su patrimonio cultural, sus conocimientos tradicionales, sus expresiones culturales tradicionales y las manifestaciones de sus ciencias, tecnologías y culturas, comprendidos los recursos humanos y genéticos, las

48. Rivas, Axel, Capítulo 4. "Cuestiones”, op. cit., página 142.

49. Lobato, Mirta Zaida, "Los trabajadores en la era del progreso", Nueva Historia Argentina. Buenos Aires, Sudamericana, 2000, Tomo V, página 482.

50. Artículo 24 de la CDPD.

51. Artículo 4 de la DUDC.

52. Para dicha Convención la discriminación es cualquier preferencia, exclusión, distinción o limitación basada en la raza, lengua, religión, sexo, motivos políticos u otros tipos de opinión, origen social, económico o país de origen, que tiene como propósito o efecto: i) limitar el acceso de determinadas personas o grupos a cualquier tipo y nivel educativo; ii) proporcionar a determinadas personas o grupos una educación con estándares inferiores de calidad; iii) establecer o mantener sistemas educativos separados o instituciones para personas o grupos y iv) infligir a determinadas personas o grupos un trato incompatible con la dignidad humana. 
semillas, las medicinas, el conocimiento de las propiedades de la fauna y la flora, las tradiciones orales, las literaturas, los diseños, los deportes y juegos tradicionales, y las artes visuales e interpretativas". 53

Expresamente en el inciso 17 del artículo 75 del texto supremo - a tenor de la reforma '94- se particularizan derechos de los "pueblos indígenas argentinos", a quienes se garantiza el respeto a su identidad y a una educación bilingüe e intercultural. "Plexo de derechos de incidencia colectiva [...] pero de matices muy especiales. [...]. Sus titulares son las comunidades, tribus, etnias "naciones" o "pueblos indígenas" [...], sin que ello implique desconocer la dimensión individual de los derechos de sus integrantes", afirman algunos constitucionalistas. ${ }^{54} \mathrm{Su}$ estructura comprende dos párrafos: el primero -en su brevedadconduce a reflexionar sobre el valor de tal reconocimiento, habida cuenta de todos los perjuicios que sufrió el originario ${ }^{55}$ de América a manos del europeo. Lo reconocido hoy no pasaría de ello; unas cuantas palabras, verbalizadas por doquier o expresadas en dicho texto, empero que no superan el formalismo. En realidad, es muy poco lo que muchos argentinos saben acerca de los pueblos originarios, especialmente en relación al ejercicio de sus derechos fundamentales o qué obligaciones deben cumplir. El segundo párrafo —-más extenso- refiere a un conjunto de derechos que intenta satisfacer diferentes necesidades. De innegable valor resulta lo atinente a la "educación bilingüe e intercultural" por lo que representa en atención a preservar su identidad. Tal intencionalidad muestra un ejemplo que no es nuevo — ni deja de ser lamentable - en la historia de la humanidad. Primeramente se somete al enemigo por la fuerza (en este caso, al pueblo originario) y transcurrido un tiempo determinado se reconocen expresamente sus derechos. En la lógica del victorioso pareciera que todo vale: la destrucción del otro y -en un momento posterior- su reivindicación (sea por alguna conveniencia o necesidad, igual da). ${ }^{56}$

53. Artículo 31.1 de la Declaración de las Naciones Unidas sobre los derechos de los pueblos indígenas. Publicado por las Naciones Unidas. Marzo de 2008, página 12.

54. Quiroga Lavié, Humberto, Benedetti, Miguel Ángel y Cenicacelaya, María de las Nieves, op. cit., páginas 323 y 324 .

55. Se utiliza esta denominación $-\mathrm{y}$ no aborigen o indígena- por respeto a los que consideran que la misma es la que mejor se adecua a la realidad de esos pueblos. Así lo expresó públicamente el dirigente político Oscar Farías —nieto de mapuches_ radicado en la ciudad de Junín.

56. El último informe - de 2003 - emanado de la Dirección de Estadísticas de Formosa muestra algunos datos de la realidad provincial: la mortalidad infantil es del 17,8 por ciento (la más alta del país); cuatro de cada diez mayores de cinco años nunca fueron a la escuela y ocho de cada diez mayores de cinco años no terminaron la primaria. Asimismo, el 74 por ciento de los hogares formoseños no tiene computadora. Por otro lado, en la localidad cuyo nombre es Ramón Lista el 90 por ciento de sus pobladores son originarios (la mayoría wichís). El 90 por ciento de ellos no tiene agua y el 56 por ciento no tiene baño en sus viviendas. En el programa "Periodismo para todos", 
La ley de Asuntos Indígenas establece que es prioritaria la educación y la cultura en las áreas de asentamiento de las comunidades indígenas. Los planes que se implementen deberán resguardar y revalorizar la identidad histórico-cultural de cada comunidad aborigen, asegurando al mismo tiempo su integración igualitaria en la sociedad nacional. ${ }^{57}$ Además, en el nivel primario se adoptará una modalidad consistente en dividirlo en dos ciclos: en los tres primeros años la enseñanza se impartirá en la lengua indígena materna correspondiente y se desarrollará como materia especial el idioma nacional. En los restantes años la enseñanza será bilingüe. $^{58}$

El Convenio sobre pueblos indígenas y tribales establece que se adoptarán medidas para garantizar a los miembros de los pueblos originarios la posibilidad de adquirir una educación a todos los niveles, en pie de igualdad con la restante comunidad nacional. ${ }^{59}$ Asimismo, los programas de educación se desarrollarán en cooperación con ellos a fin de responder a sus necesidades y deberán abarcar su historia, sus conocimientos y técnicas, sus sistemas de valores y todas sus demás aspiraciones sociales, económicas y culturales. ${ }^{60}$

La Resolución 107 de 1999 estableció que en Argentina residen pueblos de diversa complejidad sociocultural y sociolingüística. Son numerosas las etnias que conviven; entre otras, mapuche, chiriguano chané, tapieté, diaguita-calchaquí, tehuelche, wichí, pilagá, coya, toba, mocoví, chorote, chulupi, huarpe y guaraní. Asimismo, es difícil dar cuenta del número de estos argentinos existentes en nuestro país porque no hay datos uniformes al respeto. El único censo nacional realizado en 1968 dio cuenta de 75.837. El Instituto Nacional de Asuntos Indígenas (INAI) informó que el total alcanza a 452.800. Por otro lado, la formación y el perfeccionamiento de los docentes que enseñan en estos ámbitos debería revisar y profundizar disciplinas como Ciencias Naturales, Ciencias Sociales y Lengua y Literatura por ser espacios curriculares que posibilitan el tratamiento adecuado de la diversidad procurando el estudio de situaciones concretas del país. ${ }^{61}$ Por otro lado, la provincia de Buenos Aires

conducido por el periodista Jorge Lanata, emitido el domingo 19 de agosto de 2012 a las 22 horas por el canal 13 de televisión.

57. Artículo 14 de la Ley Nacional No 23.302 de 1985 de Asuntos Indígenas.

58. Artículo 16 de la Ley Nacional No 23.302 de 1985 de Asuntos Indígenas.

59. Artículo 26 de la ley $\mathrm{N}^{\mathrm{o}} 24.071$ de aprobación del Convenio 169 de la Organización Internacional del Trabajo sobre Pueblos Indígenas y Tribales en Países Independientes sancionada en 1992.

60. Artículo 27 de la ley $\mathrm{N}^{\mathrm{o}} 24.071$ de aprobación del Convenio 169 de la Organización Internacional del Trabajo sobre Pueblos Indígenas y Tribales en Países Independientes sancionada en 1992.

61. Resolución 107/99 Consejo Federal de Cultura y Educación. Ministerio de Educación de la Nación. 
—entre otras - también reivindicó la existencia de dichos pueblos, garantizando el respeto a sus identidades étnicas, el desarrollo de sus culturas y la posesión de las tierras que ocupan. ${ }^{62}$

$\mathrm{Al}$ hacerse referencia a los pueblos originarios de América, cabe aclarar que al margen del sometimiento por parte del europeo ${ }^{63}$, ora español ora portugués. Muchos de ellos lo fueron antes por otros originarios más poderosos. Las etnias sojuzgadas por los aztecas ${ }^{64}$ son un ejemplo de ello. Asimismo, no todos los triunfadores destruían a sus vencidos. Por caso, los incas ${ }^{65}$ en su fase imperial buscaron incorporar a su propio gobierno a los dirigentes más destacados de las etnias sojuzgadas. A todo esto, más allá de lo preceptuado en la Ley Fundamental no existen en Argentina hombres o mujeres que ostenten - a nivel nacional, provincial o municipal (Junín incluido) - posiciones de elevado poder político, económico, militar, social o cultural. En las escuelas estatales de nivel medio del Distrito de Junín esta problemática - al margen de su tratamiento en las aulas en alguna fecha especial- no tiene prácticamente desarrollo. Consultados que fueron, muchos egresados (tanto adolescentes como adultos) expresaron al investigador no tener conocimiento alguno sobre aspectos fundamentales de la vida de los pueblos originarios y que no estaban tampoco preocupados por ello.

Por lo demás, la ignorancia manifestada por muchos habitantes del Distrito citado sobre la realidad de los pueblos mencionados, a poco de investigarse surge - entre otras- la presencia de mapuches. En un campo denominado La Cruz - a diez kilómetros del centro de la ciudad de Junín - se asienta una comunidad mapuche. Allí viven treinta y dos familias, que padecen deficiencias de infraestructura y la falta de apoyo -afirman algunos de sus integrantes- del Estado municipal. Las viviendas son muy humildes, con falencias de todo tipo ya que no hay agua potable y el tendido eléctrico es tan precario como peligroso. "Encima hay familias que están pagando facturas de quinientos pesos por la luz", afirmó Miguel Huechuqueo, vocero del pueblo mapuche por la provincia de Buenos Aires (elegido en parlamento) y delegado suplente en el Consejo de Participación Indígena (CPI).

62. Artículo 36, inciso 9, de la Constitución de la provincia de Buenos Aires.

63. La conquista y colonización de América se refiere al proceso histórico por el cual diversas potencias europeas conquistaron y establecieron sistemas de dominación colonial en el continente americano, desde finales del siglo XV hasta el siglo XIX. La ocupación efectiva de tierras en América en dicho lapso de tiempo estuvo a cargo de: España, Portugal, Gran Bretaña, Francia y Holanda (de mayor a menor extensión territorial).

64. El imperio azteca fue una entidad de control territorial, político y económico que existió en la zona central de Mesoamérica, durante el posclásico tardío (que comprendió los siglos VIII a XV), antes de la conquista española.

65. La civilización incaica o quechua fue la última de las grandes civilizaciones precolombinas que conservó su estado independiente (imperio incaico) durante la conquista de América, hasta la conquista del Perú (1532-1533). 
Continuando con el aspecto descriptivo varios metros antes de llegar al campo ya se percibe el olor que emana de los hornos de ladrillos, la principal actividad de sus pobladores. Las viviendas están distribuidas en ciento seis hectáreas que no presentan desniveles. La tierra de este lugar es una de las más fértiles del país para realizar actividades agropecuarias (cultivo de cereales y cría de ganado vacuno, especialmente). De los servicios públicos básicos sólo tienen electricidad, aunque no todos se sirven de ella. Dos hermanos expresaron lo siguiente: "necesidades hay muchas; uno porque se acostumbró a vivir así. Acá en nuestro rancho no tenemos luz, nos alumbramos con una vela y nos calentamos con una estufa a leña". Asimismo, en esta zona se halla ubicada la Escuela $N^{\circ} 26$ donde cursan sus estudios primarios niños del paraje y los de barrios aledaños. Sólo una joven entre todos los mapuches que viven en este campo es actualmente estudiante universitaria. ${ }^{66}$

En otro orden de ideas, no obstante los instrumentos internacionales que reconocen el derecho a la educación, la comunidad internacional ${ }^{67}$ admite sin cortapisas la enorme deuda que aún hoy existe con la educación, primordialmente en los países denominados — por los centros del poder económico- emergentes, en vías de desarrollo o del Tercer Mundo. ${ }^{68}$ Argentina es una nación donde las políticas educativas se suceden —como así los ministros del área - y el déficit no desaparece. Como ejemplo vaya el de la villa 1.11.14 — la más grande de la ciudad de Buenos Aires - ubicada en la zona sur del barrio de Flores frente al estadio de fútbol del club San Lorenzo de Almagro. Son catorce hectáreas en las que conviven familias argentinas, paraguayas, peruanas, chilenas, bolivianas (que representan casi la mitad de todas ellas) y coreanas. ${ }^{69}$ Dentro de este centro urbano el poder se reparte entre dos grupos

66. Véase la nota 133 ubicada al pie de la página 71.

67. La expresión comunidad internacional designa — de manera imprecisa - al conjunto de actores influyentes en materia internacional. Según el contexto en que se aplique, el término puede referirse a: 1) los actores del sistema internacional, 2) la Sociedad Internacional, 3) la comunidad internacional regulada por las normas y tratados internacionales, 4) todos los países representados en la Organización de las Naciones Unidas y 5) toda población constituida ad hoc por habitantes de diversos orígenes.

68. También existe otra clasificación elaborada por la Organización de las Naciones Unidas, la cual reconoce la existencia de tres categorías de países: los desarrollados (PD), los en desarrollo (PED) y los menos adelantados (PMA). Dicha Organización no define en qué consisten tales categorías. Argentina está incluida entre los países en desarrollo.

69. Entre las principales razones por las que sus habitantes decidieron vivir allí se encuentran motivos familiares, laborales, de salud y económicos. El porcentaje de dueños de viviendas en la villa es del 68 por ciento, mientras que el de inquilinos es del 32 por ciento. La desocupación llega al 36,4 por ciento. Si se considera al grupo económicamente activo el porcentaje baja al 27,1 por ciento. En cuanto a los empleos, la construcción (23,6 por ciento), la costura (19,7 por ciento), el comercio (10,8 por ciento), la limpieza ( 8,3 por ciento) y las changas $(8,3$ por ciento) son los más frecuentes. Tales ocupaciones suelen implicar condiciones laborales inestables y precarias, la mayor parte de las veces 
minoritarios: los peruanos y los coreanos. Ambos pugnan por el control de los negocios de la droga, la prostitución y el contrabando. Estas actividades ilegales - llevadas a cabo ante la pasividad de los funcionarios públicos- permiten a pocas personas obtener mucho dinero. Surge imperiosa, por lo señalado, una educación de calidad para todos en esta villa, ${ }^{70}$ algo que "resultará imposible mientras sigan habiendo funcionarios inidóneos que sólo apuntan a cobrar un sueldo y muy elevado en algunos casos" (así expresaban su preocupación vecinos de la misma en un diálogo mantenido con el investigador el 24 de abril de 2012 en dicha villa).

La Constitución Nacional histórica asignó al Congreso la competencia de dictar planes de instrucción general y universitaria, cláusula progresista (inspiración de Juan Bautista Alberdi) del ex artículo 67 inciso 16. La misma subsiste hoy sin modificación en el artículo 75 inciso 18. Pero el inciso 19 ha ampliado tal previsión en su párrafo $3^{\circ}$, siendo menester correlacionar ambas normas. El Estado federal, está habilitado para dictar una ley-marco (o varias, ya que el inciso 19 se refiere a leyes). Por lo demás, el artículo $5^{71}$ establece que las provincias dictarán una Constitución que asegure "la educación primaria". Al final del artículo 125 se establece que "Las provincias y la ciudad de Buenos Aires pueden [...] y promover [...] la educación, la ciencia, el conocimiento y la cultura”. En esta investigación se abonan tales ideas, razón por la que se trabajará en escuelas medias ubicadas en diferentes ámbitos (urbano, suburbano y rural) del Distrito de Junín, con la finalidad de obtener datos que posibiliten cotejar la realidad áulica con lo prescripto por la normativa vigente.

En el artículo 75, inciso 19, párrafo $3^{\circ}$ se establecen -en torno a la educacióndiferentes objetivos y garantías. Entre los primeros, consolidar "la unidad nacional respetando las particularidades provinciales y locales"; esto es, la ley nacional debe dejar a las leyes provinciales completar el diseño general para asegurar la pluralidad dentro de la unidad. El segundo es asegurar "la responsabilidad indelegable del Estado", consagrando a la educación como obligación del Estado nacional. Implica su sostenimiento económico para lograr un servicio educativo eficiente. El tercero es "la participación de la familia y la sociedad", lo cual

poco remuneradas, sin opción de obra social ni cobertura ante los riesgos del trabajo y con jornadas de alrededor de 12 horas.

70. Un caso típico es el que sigue: Carlos (cartonero) vive con su familia integrada por su esposa y tres hijos (dos de ellos asisten en diferentes turnos a una escuela alejada del hogar). Realizan por tal motivo cuatro viajes diarios en colectivo que representan $\$ 40$. Cuando llueve Carlos no trabaja y por eso no percibe su ganancia diaria que es $\$ 60$. Como consecuencia, Pedro y Joaquín ese día no van a la escuela: "Cuando no tenemos dinero - confiesa - sólo comen los niños; mi esposa y yo tomamos té". Carlos fue entrevistado por una periodista en el programa "70-20-13", conducido por Samuel Gelblung, emitido el sábado 11 de agosto de 2012, a las 22 horas, por el canal 13 de televisión.

71. Respecto de este artículo, la enseñanza primaria se organizó — desde el punto de vista normativo- en función de un modelo político federal. 
significa que todos los agentes involucrados en el proceso educativo deben cumplir su rol eficazmente. El último es promover "los valores democráticos y la igualdad de oportunidades y posibilidades sin discriminación alguna" para que el servicio educativo coadyuve a una mejor calidad de vida para todos los habitantes. En atención a los referidos objetivos, en esta investigación se registrarán datos referidos a los responsables de los egresados (adolescentes y adultos) que asisten a escuelas estatales de nivel medio del Distrito de Junín.

En otro orden de ideas, la respuesta a la pregunta sobre qué se considera básico para ser enseñado en la escuela no es sencilla ni puede hallarse sólo a partir de argumentos filosóficos, psicológicos o pedagógicos. Silvina Gvirtz y Mariano Palamidessi informan que en el diccionario se lee que el término "contenido" puede ser un adjetivo: es la propiedad o situación de estar encerrado adentro de otra cosa. Sin embargo, en su acepción educacional refiere a un sustantivo: lo que se contiene dentro de una cosa. Si se analizan dichas acepciones, se entenderá que la palabra "contenido" tiene un vínculo muy estrecho con las acciones de limitar, ocupar, controlar, conservar. El contenido educativo permite llenar el tiempo, conservar una información y demarcar un tema. ${ }^{72}$

Por otro lado, lo difícil es llegar a acordar contenidos obligatorios cuando toda opción es parcial y puede ocasionar exclusiones sociales y culturales. Pareciera existir de algún modo un mecanismo de imposición poco compatible con una sociedad pluricultural. Investigadores de la educación argentina se han preguntado si no sería conveniente dejar librada la resolución de esta problemática a los cuerpos directivos, a los docentes y a los responsables de los educandos. Incluso, en más de una ocasión — de esto hace ya al menos una década- en algunos círculos académicos se impulsó la idea de incorporar también a los educandos en la toma de decisiones respecto de los contenidos a enseñarse. Una cosa está clara: resulta harto complejo decidir contenidos que puedan ser útiles a alumnos tan diferentes, en una sociedad - como la argentina - donde las culturas son tan diversas y complejas. ${ }^{73}$

La disposición del párrafo $3^{\circ}$ del inciso 19 permitiría afirmar que las provincias han de adoptar criterios similares a los del Estado federal. No obstante, un interrogante podría surgir de la circunstancia de hallarse estas pautas en la norma sobre competencias del Congreso, lo que serviría de argumento para afirmar que la misma no obliga a las provincias. Sin embargo, cuando se consiente aquí el lineamiento de las leyes de organización y la base de la educación - y que dictarlas es atribución federal- pareciera que la educación provincial no ha de incurrir en contradicciones ni apartamientos. Tampoco hay que olvidar que el derecho de

72. Gvirtz, Silvina y Palamidessi, Mariano. Capítulo 1. "La construcción social del contenido a enseñar", op. cit., página 18.

73. Gvirtz, Silvina y Palamidessi, Mariano. Capítulo 1. "La construcción social del contenido a enseñar", op. cit., páginas 40 y 41. 
enseñar y aprender del artículo 14 guarda estrecho nexo con el diseño que la constitución implanta en la parte orgánica. ${ }^{74}$

Como se expusiera, las leyes de organización y de base que ha de dictar al Congreso Nacional garantizarán "los principios de gratuidad y equidad de la educación pública estatal". ${ }^{75}$ Gratuidad y equidad implican no sólo no pagar por el servicio educativo sino - en determinadas circunstancias - recibir ayuda del Estado (nacional, provincial o municipal) para costear los gastos del aprendizaje. Aquélla podrá consistir en un sistema de becas o subsidios. En tal orden de ideas, en el Distrito de Junín se comprobó (en diálogos del investigador con docentes y egresados del establecimiento) que en la escuela $\mathrm{O}_{2}$ - de nivel medio, para adultos- la mayoría de ellos asistía a clase en 2011 en motocicletas $0 \mathrm{~km}$ regaladas por sus padres o adquiridas con dinero obtenido de sus trabajos. A todo esto, mensualmente recibían cuatrocientos cincuenta pesos del gobierno nacional, para lo cual al comenzar —en marzo - el ciclo lectivo debieron completar un formulario donde únicamente se exigía la inscripción como alumno regular. Si ese dinero que se otorgaba $-\mathrm{y}$ se 10 continuó haciendo durante 2012- se justificaba por las dificultades económicas de los estudiantes, éstos en realidad no las padecían. Y si la finalidad -coetánea con lo económico- era ayudar a aquéllos que tenían deseos de progresar, sólo dos del total de once educandos asistían regularmente a clase (los demás faltaban asiduamente sin causa que lo justificare) y la mayoría de ellos adeudó al final del ciclo lectivo dos o más materias. No obstante, aquella suma de dinero nunca dejaron de percibirla. "En pocas palabras, un dispendio del gobierno nacional", calificó a ese accionar un profesor de tales egresados. Por su lado, los jóvenes afirmaban "no nos interesa la ideología, ni ser de un partido o de otro. Venga el dinero y a otra cosa".

Por otra parte, la gratuidad en educación es un principio relacionado con el derecho de acceso a la misma. Invariablemente se asocia gratuidad con la educación pública y suele vinculársela con la obligatoriedad. Esto no significa dejar de reconocer a la educación privada, ampliamente aceptada en el mundo. En Argentina, una pequeña proporción de la educación privada también es gratuita, al igual que la ofrecida por instituciones de beneficencia y ciertas congregaciones religiosas. Por lo demás, la gratuidad de la educación primaria, secundaria y universitaria está garantizada también en otros países -Uruguay y Finlandia, por casos - pero en Chile existen todavía importantes limitaciones. En este último país, desde 2011 a la fecha varias han sido las multitudinarias manifestaciones en reclamo de una educación pública gratuita. La última — donde hubieron decenas de heridos y detenidos-

74. Bidart Campos, Germán José, op. cit., página 45.

75. Artículo 75, inciso 19, párrafo $3^{\circ}$, de la Constitución Nacional. 
se llevó a cabo el martes 9 de abril de 2013, partiendo — tal la costumbre- desde plaza Italia, en la capital chilena. ${ }^{76}$

Además de lo señalado, esas leyes deberán garantizar "la autonomía y autarquía ${ }^{77}$ de las universidades nacionales". La cláusula asegura tales caracteres sólo a esas entidades de educación superior; no hace alusión ni a las públicas provinciales ni a las universidades privadas. Germán José Bidart Campos (1995) sostiene que la autonomía de las universidades nacionales permite reconocerlas como personas jurídicas de derecho público no estatales. Esto, entre otras consecuencias, las coloca al margen de toda intervención y subordinación respecto del Estado, salvo los recursos que el mismo prevé a través del presupuesto. ${ }^{78}$ Jorge Vanossi afirma que la autonomía debe concebirse como un medio y no como un fin en sí misma. Debe ser una herramienta apta para el mejor servicio que la universidad debe prestar. ${ }^{79}$ Y Humberto Quiroga Lavié (1987), refiriéndose a la autonomía universitaria escribió que como toda autonomía, ella se ejerce en un contexto normativo superior que le pone límites a su ejercicio. Así, en el caso de la autonomía universitaria el límite está dado por las bases legales que establezca el Congreso Nacional. ${ }^{80}$

Asimismo, coexisten la educación estatal y la privada y el Estado ejerce su función de contralor de toda la enseñanza. En tal sentido, Germán Bidart Campos asegura que el Estado asume responsabilidad por la enseñanza en sus establecimientos y también por la educación privada. Tal responsabilidad no sólo implica un razonable control sobre los establecimientos

76. La Constitución Política de la República de Chile establece el principio de gratuidad de la educación básica y media (artículo 10), mientras que la Ley General de Educación $\mathrm{N}^{\mathrm{o}} 20.370$, de 2009, sienta la obligación del Estado de proveer una educación gratuita a los establecimientos educacionales de su propiedad (artículo 4). No obstante, en contradicción con lo que prescribe dicha ley general, el sistema de educación media subvencionado no es gratuito. El artículo 16 Decreto con Fuerza de Ley $\mathrm{N}^{\mathrm{o}} 2$ establece que "Los establecimientos subvencionados de educación media podrán cobrar por concepto de derechos de matrícula, por una sola vez al año, la cantidad que anualmente fije el Ministerio de Educación...". Además, los centros educativos subvencionados bajo la modalidad "establecimientos educacionales de financiamiento compartido" pueden realizar cobros mensuales a los educandos, según indica el artículo 24 de dicho decreto.

77. En el derecho administrativo la autarquía es la forma de descentralización administrativa que permite gobernarse por sí mismo en lo administrativo, tener personalidad jurídica y patrimonio propio y -además - una finalidad pública en sus funciones. Tal es la característica del ente autárquico. Según el derecho constitucional es la capacidad de autoadministrarse o autogobernarse conforme a estatutos orgánicos provenientes de un poder superior. Los conceptos de autonomía y de autarquía, para adquirir precisión, deben estar referidos a un sistema jurídico-político determinado puesto que existen diferencias de matices.

78. Bidart Campos, Germán José, op. cit., página 37.

79 Vanossi, Jorge Reinaldo, Universidad y Facultad de Derecho: sus problemas. Buenos Aires, Editorial Universitaria de Buenos Aires, 1989, página 91.

80. Quiroga Lavié, Humberto, La Autonomía Universitaria. La Ley, Tomo B, 1987, página 724. 
educativos a cargo de particulares, sino que apareja la obligación de ayuda, estímulo, cooperación y fomento. ${ }^{81}$ En el Distrito de Junín desarrollan actividades las escuelas medias estatales (entre ellas las incluidas en esta investigación) y las privadas. La ubicación de los establecimientos privados es más próxima al centro de la ciudad y ediliciamente tienen un estado general superior respecto de los públicos. Los educandos pertenecientes a colegios privados asisten a clase con una vestimenta que los identifica, al tiempo que en las escuelas estatales la ropa del alumnado es informal.

La última reforma constitucional incorpora los derechos de incidencia colectiva o derechos públicos subjetivos. El artículo 41, párrafo $2^{\circ}$, prescribe que "Las autoridades proveerán [...] y a la información y educación ambientales”. Humberto Quiroga Lavié, Miguel Ángel Benedetti y María de las Nieves Cenicacelaya (2001) aseveran que la información ambiental alude al derecho a estar informado, lo cual es un instrumento de participación para la toma de decisiones que puedan influir en los habitantes. Las empresas, en tanto, tienen el deber de preservar el ambiente prevaleciendo sobre su derecho patrimonial de ejercer industria lícita (reconocido en el artículo 14 de la Ley Fundamental). Los mismos autores expresan que la instauración del Estado Ecológico de Derecho requiere de la sociedad en su conjunto la adhesión a sus contenidos. Para lograrlo será menester incluir en la currícula $^{82}$ de todos los niveles el aprendizaje de la cuestión ambiental. ${ }^{83}$

En el texto incorporado se observa la distinción que efectúa el constituyente entre información y educación referidas al ambiente. Aquélla se materializa a través de los medios de comunicación social (especialmente la televisión). A ellos deben agregarse los artículos publicados en revistas especializadas e Internet. En tanto, la educación ambiental está a cargo - principalmente- de las autoridades de todo nivel en el ámbito geográfico donde actúen. En el Distrito de Junín la misma se canaliza a través de los directivos de los colegios, los profesores, los responsables (padres, tutores u otros) de los estudiantes y los propios alumnos.

\section{Bidart Campos, Germán José, op. cit., página 39.}

82. De acuerdo con el significado más difundido, el currículum provee un modelo al cual deben ajustarse las prácticas escolares. Esta concepción supone una distinción importante entre lo que es el currículum y lo que son los procesos de enseñanza que sirven para su desarrollo. Por un lado está el diseño y, por el otro, la práctica; lo que se hace o se debe hacer en la escuela es analizado a través del cristal de una definición única y externa. Se piensa el currículum como un modelo a desarrollar que puede tomar diversas formas, cada una de las cuales expresa diferentes proyectos acerca de la naturaleza y organización del contenido y de los diversos modos de influir sobre los sujetos de la enseñanza y del aprendizaje. En Gvirtz, Silvina y Palamidessi, Mariano. Capítulo 2. "La escuela siempre enseña. Nuevas y viejas concepciones sobre el currículum", op. cit., página 55.

83. Quiroga Lavié, Humberto, Benedetti, Miguel Ángel y Cenicacelaya, María de las Nieves, op. cit., páginas 304-306. 
En relación a esta problemática, casi a diario las noticias y los comentarios que aparecen en diferentes medios dan cuenta de cuán poco interesa en muchos países —en Argentina particularmente- ese ambiente que se dice respetar y preservar. Parecería que a pocos interesa saber cuánto se daña hoy a la naturaleza en nombre de una producción de mercancías que sólo beneficia a los menos, degradando los ecosistemas en perjuicio de los seres vivos. "Es el poder del dinero que no respeta límites legales, ni morales, ni religiosos" aseguraron dos profesoras del último año (I y II División) del nivel medio, a cargo de la asignatura "Recursos Naturales" en la escuela C (de adolescentes) del Distrito de Junín. Además, para muchos docentes del Distrito, desde la escuela ha de seguirse esta realidad con atención y en sus dependencias han de efectuarse las acciones pertinentes para evitar todo tipo de daños, haciendo cesar los que se estén produciendo. Mediante actividades variadas (charlas, paneles y debates, con la presencia de expertos) y disponiendo de un actualizado instrumental — que será utilizado convenientemente- podrá lograrse una mayor conciencia sobre el ambiente y su importancia - especialmente- para la vida de los seres humanos. Es dable señalar que tal conciencia social está aún lejos de haberse alcanzado en Argentina ${ }^{84}$ (incluido el Distrito de Junín, a estar por las observaciones a cargo del investigador).

El artículo 42, párrafo $2^{\circ}$ de la Constitución Nacional establece la obligación de las "autoridades" públicas de todos los poderes y niveles de proteger los derechos de los "usuarios y consumidores" de bienes y servicios. En tal orden de ideas, Germán Bidart Campos asevera que en lugar de interpretarse como proclive al consumismo, la norma significa que - dentro del mercado y de la competencia - hay que favorecer los hábitos de selección y defensa de los intereses referidos al consumo y al uso de los diferentes bienes y servicios. ${ }^{85}$ Por lo demás, el Estado nacional realiza una síntesis entre el capital clásico y la

84. Como ejemplo de lo señalado vaya lo siguiente: el río Matanza-Riachuelo, llamado Riachuelo en su desembocadura y Matanza en la mayor parte de su recorrido, es un curso de agua al Este de Argentina. Nace en la provincia de Buenos Aires, constituye el límite sur de la Ciudad Autónoma de Buenos Aires y desemboca en el Río de la Plata. Tiene una longitud de $80 \mathrm{~km}$, una dirección general sudoeste-noreste y un ancho medio de $35 \mathrm{~m}$, cubriendo una superficie de $2200 \mathrm{~km}^{2}$ hasta la desembocadura en dicho río. En esta región habitan cinco millones de personas que representan el 12,5 por ciento del total del país. Dicha cuenca es parte del área metropolitana de Buenos Aires, el sitio más poblado del territorio argentino. En general su infraestructura urbana es deficiente: los servicios de agua potable sólo alcanzan al 65 por ciento de los habitantes y apenas el 45 por ciento de las viviendas tiene acceso al servicio de cloacas. A lo expresado debe agregarse que el Riachuelo posee niveles de mercurio, zinc, cromo y plomo cincuenta veces por encima de los valores legalmente admitidos. Existen más de cien basurales a cielo abierto y dos rellenos sanitarios, uno de ellos clausurado. Los asentamientos precarios están en situación de altísimo riesgo sanitario. En el caso de "Villa Inflamable" el plomo en sangre de los niños es cinco veces superior a los niveles por debajo de los cuales se supone que no hay efectos visibles sobre la salud, según la Agencia de Cooperación Internacional del Japón (JICA). Téngase presente que el plomo es un metal sumamente tóxico.

85. Bidart Campos, Germán José, op. cit., página 37. 
idea de justicia social, lo cual posibilita una organización económica donde no sólo interesa la producción sino también - y especialmente- la protección de los usuarios y consumidores, puesto que todos lo son a tenor de las circunstancias. Recíprocamente origina el deber de indemnizar para el oferente, lo cual es una aplicación específica del genérico alterum non laedere (no dañarás).

Ligada con el derecho a una información adecuada y veraz y con la cláusula ambiental del artículo 41, la "educación para el consumo" ha de interpretarse como educación para un consumo racional y sustentable. En tal sentido, el Estado y las asociaciones respectivas han de ejercer un rol fundamental como motores del cambio de los patrones de consumo. ${ }^{86}$

\subsection{Normas infraconstitucionales}

\subsubsection{El comportamiento docente en el marco de la ética pública}

Todos los integrantes de las comunidades educativas estatales están comprendidos —entre otros funcionarios y empleados públicos- en la Ley de Ética de la Función Pública ${ }^{87}$ $\mathrm{N}^{\mathrm{o}} 25.188$ de 1999. Por ella están obligados a cumplir determinadas pautas de comportamiento ético, como "honestidad, probidad, rectitud, buena fe y austeridad republicana". 88

No es la primera vez que funcionarios públicos ocupan espacios en los medios de comunicación social por la presunta comisión de delitos y que, pasado el tiempo, casi nunca se los juzga ni —menos aún- son condenados. Lo que interesa sobremanera aquí es la posible reacción de un adolescente al enterarse de que tres argentinos cuyas conductas influyen sobremanera en los demás pudieron haber cometido delitos. Su psiquis procesará un efecto devastador - o no- respecto de la confianza en los gobernantes y - por ende- en el mundo adulto. Cuáles serán sus pasos futuros, habida cuenta del abismo que podría surgir entre lo que él creía de esas personas (y/o de sus investiduras) y lo que ahora conoce, es algo incierto. Escuchará voces a favor y en contra de los encartados que quizás lo confundan

86. Quiroga Lavié, Humberto, Benedetti, Miguel Ángel y Cenicacelaya, María de las Nieves, op. cit., página 319 .

87. En esta investigación se considera función pública a toda actividad realizada por una persona en nombre o al servicio del Estado o de sus entidades. En tal calidad le está prohibido recibir beneficios personales indebidos vinculados al ejercicio de su función. La historia argentina ofrece casos de estos beneficios - muchos de ellos denunciados, pero casi nunca probados- recibidos por funcionarios de todos los niveles. Considerando los últimos treinta y seis años - aunque el flagelo se inició en el siglo XIX- fueron sindicados como corruptos funcionarios pertenecientes tanto a la última dictadura militar como a los gobiernos civiles desde 1983 a la fecha.

88. Artículo 2.b de la Ley de Ética de la Función Pública. 
sobremanera. Las opiniones sobre el tema que surjan en su familia y lo que oportunamente algún docente $-u$ otro adulto referente- puedan comunicarle, tal vez ayuden al adolescente en la encrucijada. En tal sentido, las palabras de los padres (u otros responsables) y/o las de docentes (todos como modelos de identificación) serán de valor para reivindicar a dos instituciones que vienen sufriendo los embates de una sociedad que —en estos inicios del siglo XXI- debe resolver en forma integrada viejos y nuevos problemas de política educativa. Ellas son la familia y la escuela. Pero también existen quienes piensan diferente: "no tenemos con quién identificarnos; los profesores, los que gobiernan, no queremos ser como ellos", expresaban cuatro egresados (dos varones y dos mujeres) del nivel medio de la escuela C, pertenecientes al Distrito de Junín. Ahora bien, tras cambios que se habrían producido en las últimas décadas, la adolescencia tiende hoy a continuar en el tiempo y no se la vive como una etapa "incómoda" o "de paso". Ya a fines de los '60 investigadores de la psicología de la conducta llamaban la atención sobre la prolongación de la misma.

En el ámbito educativo también suceden comportamientos ilícitos. Así, fue criticada por sus pares la actitud que tuvieron en 2011 algunos profesores de nivel medio del Distrito citado, quienes produjeron datos inexactos en sus declaraciones juradas para obtener un beneficio personal. ${ }^{89}$ Hicieron constar menos horas/cátedra de las que realmente trabajaban, con la finalidad de acceder — vía actos públicos - a más horas/cátedra, perjudicando así a otros profesores. La falta de control y el silencio de algunos docentes a pesar de que tuvieron conocimiento de dichas actitudes- explican la impunidad frente a lo sucedido. ${ }^{90}$

En otro orden de ideas, un tema al que periódicamente se hace referencia (por ejemplo en la sala de profesores) es la manera en que se guía a los educandos hacia comportamientos positivos. Es conocido por todos los agentes educativos que los docentes de los primeros años del nivel medio realizan una tarea de la que seguramente aprovecharán sus frutos los educadores de los últimos años (particularmente los profesores de quienes egresan). Es decir, una realidad es la que viven diariamente con un educando de trece años y otra diferente es la interacción profesor-alumno cuando transcurre el último año del nivel. La "obra" de aquéllos

89. Tenía vigencia por entonces una normativa provincial a tenor de la cual se otorgaban horas/cátedra de cualquier asignatura — según el puntaje de cada docente registrado en el listado oficial- a aquel profesor que, al momento del acto público, tuviera acreditadas hasta diez horas/cátedra como máximo, independientemente de su situación de revista (titular, provincial o suplente). Si superaba ese número debía abstenerse de intervenir en el acto público.

90. Estas informaciones se obtuvieron en diálogo con docentes de nivel medio del referido Distrito, al finalizar los actos públicos - llevados a cabo en el organismo estatal pertinente- el 4 de abril y el 6 de mayo de 2011. En dichos actos se efectuó el otorgamiento de horas/cátedra a docentes teniendo en cuenta su puntaje en los listados confeccionados anualmente según las diferentes ramas y áreas. La ilicitud - cometida por tres docentes - se producía falseando los datos en sus declaraciones juradas, con los que —ulteriormente- se constituían los referidos listados. 
se observa con nitidez en el desempeño escolar de los egresados. Por tal razón, algunos docentes sostienen que la formación profesional debería incluir algunas diferencias y caracteres propios, tratándose del Ciclo Básico o del Ciclo Superior. Por otro lado, en torno al comportamiento ético del profesor, éste debe conducir a un grupo de alumnos con un irrestricto respeto por los derechos humanos de todos ellos. Debería descartarse siempre una conducta opuesta, aunque un suceso como el denominado "Jardín del horror"91 mostró qué cosas pueden acontecer. Por otro lado, los docentes imparten sus enseñanzas en un ámbito donde el diálogo es el instrumento idóneo para aunar criterios y liberar tensiones. Éstas nunca debieran alcanzar una intensidad tal que conduzca al conflicto, pero si el mismo acontece deberá aceptárselo. Ello significará afrontar la realidad. En tales circunstancias, los docentes rescatarán el valor de la tolerancia para aprender a partir de las diferencias. En esta investigación se consultará a educadores de egresados adolescentes y adultos del Distrito de Junín en orden al reencauzamiento de conductas inadaptadas de los mismos (en el aula y en otros ámbitos escolares).

\subsubsection{EI neoliberalismo y la educación nacional}

Emilio Tenti Fanfani (2007) asevera que en la década de 1990 en América Latina se registró un aumento de la inversión en la educación pública. Según la CEPAL (2003) esta inversión varió del 2,9 por ciento del PBI en 1990-1991 al 4,2 por ciento en 2000-2001, pero en muchos países ese incremento no fue proporcional al aumento de las matrículas. Por ende, hubo que atender a más alumnos - por lo general pobres - con menos recursos. Esta desproporción obligó en no pocos casos a ofrecer un servicio de menor calidad a niños y a adolescentes que necesitaban más y mejor educación para compensar sus carencias familiares y sociales.

91. Todo comenzó el martes 29 de enero de 2013 cuando un matrimonio de San Isidro veía "poco estimulada" a su hija que asistía al Jardín Tribilín. Lo cierto es que en el mismo los niños sufrían maltratos por parte de algunos docentes. Fuentes de la Dirección General de Cultura y Educación de la provincia de Buenos Aires aseguraron a La Nación que el instituto "no contaba con una autorización para que funcione como una entidad educativa", ya que desde 1996 ese establecimiento figura con un "cierre técnico pedagógico". Además, el local del jardín de infantes estaba inscripto como una "casa de fiesta" y durante el verano funcionaba como una "colonia de vacaciones". Algo debían hacer - pensaron sus padres - y en ese momento fue cuando decidieron mandar a su hija una vez más al cuestionado jardín de infantes. Pero esta vez iría con un iPod escondido en su mochila para grabar todo lo que pasaba en el aula. El resultado fue cuatro horas y media de grabación en las que se oyen gritos de una de las maestras, llantos de los niños y hasta ciertos golpes. "Callate Catalina, callate, guay que vayas a decir cualquier huevada en tu casa" y "№ me hagas enojar porque vas a terminar mal, abrí la boca!", son algunos de los gritos de la grabación a la que accedió La Nación (argentina). 
Por otro lado, en países donde la escolarización de los adolescentes alcanzó las tasas más altas, como Argentina, Chile y Panamá, todavía en 1999 existían problemas de alumnos que desertaban durante el ciclo primario o al finalizarlo. Éstos alcanzaban aproximadamente el 10,7 por ciento en el caso de las zonas urbanas de los tres países. En las rurales de Brasil, Perú y Colombia ese porcentaje de deserción era del 33,3 por ciento, mientras que en las áreas rurales de México, Perú y Honduras la deserción afectaba al 49,2 por ciento de los alumnos. Estos datos evidencian que aún en un contexto de escolarización masiva existían grandes dificultades para incluir a los adolescentes de zonas rurales de las naciones más pobladas de América Latina. ${ }^{92}$

Ahora bien, en Argentina la Ley de Educación Nacional No 26.206 (de 2006) fue precedida por la Ley Federal de Educación No 24.195 - de 1993- que sucedió al postergado debate en el marco del Congreso Pedagógico Nacional (1984-1988). Dicho Congreso había generado expectativas de participación y de cambios democráticos, pero resultó cooptado por grupos de poder fuertemente instalados en la novel democracia, frustrando tales aspiraciones. Al mismo tiempo que aquél transcurría, en la provincia de Buenos Aires tenía lugar la experiencia de los Consejos de Escuela que, si bien tuvieron un alcance limitado, evidenciaron las inquietudes de algunos sectores identificados con posturas asumidas en el mencionado Congreso.

La ley 24195 inauguró la transformación educativa sustentada en una importante cantidad de regulaciones en el marco del Consejo Federal de Educación. Fue sancionada cuando prevalecía una política denominada neoliberal responsable de la mercantilización de la economía, de la sociedad y de la cultura, según alguna doctrina. Por su lado, Axel Rivas (2010) asevera que

la educación estatal, al menos en el período 1995-2000, pareció estar atada a otras lógicas a más del ciclo económico. En primer lugar, la aplicación de la Ley Federal de Educación impulsó un acceso masivo a la escuela estatal de sectores que antes abandonaban al terminar la primaria. El declive posterior, que no muestra una recuperación concordante con el crecimiento de la economía desde 2003, se debería a que la reforma educativa no generó condiciones de sustentabilidad en la inclusión de los estudiantes de sectores populares que ingresaron al nivel medio. A su vez, el crecimiento del empleo junto con la mejora de la economía pueden haber impulsado a los jóvenes a dejar la escuela para incorporarse tempranamente al mercado de trabajo o bien los paros docentes podrían haber originado un pasaje al sector privado. ${ }^{93}$

A todo esto, la provincia de Buenos Aires se pronunció a través de la Ley de Educación $\mathrm{N}^{\mathrm{o}}$ 11.612, sancionada en 1994. La misma consagró los principios de la Ley Federal de

92. Tenti Fanfani, Emilio, La escuela y la cuestión social. Ensayos de sociología de la educación. Buenos Aires, Siglo XIX, 2007, páginas 70 y 71.

93. Rivas, Axel, Capítulo 4. “Cuestiones”, op. cit., página 156. 
Educación y aumentó la obligatoriedad escolar a diez años, incluyendo con tal carácter el último año del Jardín de Infantes y la Educación General Básica. Ésta, de nueve años de duración, fue entendida como una unidad pedagógica integral y se organizó en ciclos.

Al realizar un balance entre los aspectos positivos y los negativos de la Ley Federal, la comunidad educativa del Distrito de Junín coincide en que avanzó en el reconocimiento de la obligatoriedad y en la manifestación de problemáticas político-pedagógicas de importancia, pero su implementación profundizó la fragmentación y la desarticulación del sistema. Estas objeciones las sostienen también en 2013 muchas personas vinculadas al tema educativo - políticos principalmente- que por aquellos años de vigencia de tal doctrina nada objetaron públicamente o sus palabras no tuvieron una difusión masiva. Por lo demás, la crítica al neoliberalismo de los '90 no debería culminar — como pretenden algunos - en la postura que adjudica las mejores intenciones a los partidarios y las peores a los adversarios. El modelo político y social aplicado por aquel entonces es el que se pretende revertir — no sin dificultades - en el presente a nivel nacional. Así, en la provincia de Buenos Aires, por ejemplo, desde 2007 se concibe a la educación y al conocimiento como bienes públicos y como derechos personales y sociales, mientras que el Estado es garante de aquéllos. ${ }^{94}$ Desde la normativa jurídica se intenta encontrar las formas de inclusión que ayudarán a resolver algunas de las injusticias actuales y pergeñar mecanismos e instituciones que eviten cristalizarlas permanentemente. Resultará pertinente imaginar a una sociedad argentina más abierta y móvil, con una vida democrática basada en la diversidad y con iguales derechos para todos. $^{95}$

Para Emilio Tenti Fanfani (2007), la exclusión social en Argentina es un espacio construido alrededor de dos polos. Por una parte están aquellos que se integran a los campos más dinámicos: empresas de servicios y de alta producción multinacional, intensivas en capital y en tecnología, que distribuyen ingresos altos. Por la otra están los que literalmente "se quedan afuera"; es decir, los desempleados crónicos y los "inempleables". Entre ellos se hallan los que ni siquiera poseen el capital mínimo requerido para lograr una inserción -aunque sea precaria- en la economía monetaria. En el medio están los que tienen una inserción defectuosa en el mercado de trabajo puesto que, por la falta de estímulos, desistieron de ingresar en él o porque tienen una inserción marginal en términos de tiempo o porque

94. Artículo 2 de la Ley de Educación de la provincia de Buenos Aires $N^{\circ} 13.688$, sancionada el 5 de julio de 2007.

95. Dussel, Inés, "Notas finales: confrontando la pérdida de confianza en la escolaridad en la posmodernidad latinoamericana", en La producción de la exclusión en el aula, Ponencia presentada en la X Jornada LOGSE, "La escuela y sus agentes ante la exclusión social". Granada (España), 2000, página 19. 
forman parte del trabajo informal y de baja productividad. ${ }^{96}$ En esta investigación, en el Distrito de Junín se han de cotejar características de los hogares de donde provienen los egresados (adolescentes y adultos) de escuelas estatales de nivel medio, para determinar la posible existencia de desigualdades en la transmisión y en la generación de instrumentos teóricos y de valores.

Otras leyes nacionales también efectúan aportes para la configuración de la política educativa en Argentina: la No 26.058 de Educación Técnico Profesional del 7 de septiembre de 2005, la N 26.061 de Protección Integral de los Derechos de las Niñas, Niños y Adolescentes del 28 de septiembre de $2005,{ }^{97}$ la $\mathrm{N}^{\mathrm{o}} 26.075$ de Financiamiento de la Educación del 21 de diciembre de $2005^{98}$ y la No 26.206 de Educación Nacional del 14 de diciembre de 2006. Esta última prescribe la garantía del Estado respecto de la educación y del conocimiento. ${ }^{99}$

Ahora bien, a nadie escapa que información y conocimiento no significan lo mismo. El acceso a una gran cantidad de información - por cualquier fuente- no asegura su transformación en conocimiento. Éste no viaja por Internet y construirlo ("puesto que de una construcción gradual se trata", tal como lo reconocen muchos de los docentes del nivel medio del Distrito de Junín, partícipes en esta investigación), es una tarea compleja para la cual no basta crear condiciones de acceso al mismo. Para obtener información útil del océano de datos en Internet se requiere un conocimiento básico del tema que se investiga y estrategias que permitan identificar cuáles fuentes son confiables. Asimismo, para transformar la información en conocimiento es menester —más que cualquier otra cosa- un pensamiento lógico y juicio

96. Tenti Fanfani, Emilio, La escuela y la cuestión social. Ensayos de sociología de la educación. Buenos Aires, Siglo XIX, 2007, página 151.

97. Esta ley fue precedida, en la provincia de Buenos Aires, por la No 13.298 de Promoción y Protección Integral de los Derechos de los Niños, sancionada el 29 de diciembre de 2004.

98. La creación del Fondo Compensatorio Salarial (FCS) a partir de dicha ley apuntó a dos estrategias: mejorar los salarios y privilegiar a las provincias más débiles. Se trató de un gran avance en términos de la equidad salarial interprovincial. Sin embargo, en el FCS persisten tres problemas: primero, no fue reglamentado y - por lo tanto - no existe una fórmula objetiva para distribuir los recursos entre las provincias lo cual potencia la discrecionalidad. Segundo, su rigidez en tanto su asignación se define 'a todo o nada', de modo que no existen niveles intermedios de aportes salariales según indicadores provinciales. Tercero (y principal) la ausencia de criterios objetivos de distribución hace que no necesariamente las provincias que realizan un mayor esfuerzo para financiar la educación sean beneficiadas por el FCS (otras que realizan un bajo esfuerzo financiero en tal sentido igual reciben el fondo compensatorio). En Rivas, Axel, Capítulo 4. "Cuestiones", op. cit., página 136.

99. Artículo 2 de la Ley de Educación Nacional. 
crítico. ${ }^{100}$ La escuela, en esta problemática, ha cumplido y sigue ejerciendo un rol destacado. En este trabajo se indagará —-mediante la aplicación de cuestionarios- cómo adquieren la información y el conocimiento los diversos agentes de las comunidades educativas de nivel medio del Distrito de referencia.

En otro orden de ideas, debería ponerse énfasis en reconocer las necesidades y los derechos de otras personas en un pie de igualdad con los propios (integrantes todos, al cabo, de una misma nación). Esto significa respeto por los rasgos identitarios de cualquier habitante. También equivale a entender la diversidad entre las personas, sin aplicarles a priori escalas valorativas determinadas. Por último, expresa el rechazo a las desigualdades injustas y a todas las formas de discriminación. ${ }^{101}$ Éstas se hallan en muchas legislaciones nacionales prohibidas - lo mismo acontece en diversos instrumentos internacionales de derechos humanos - pero muchas veces la realidad es muy diferente. Así, se verbalizan palabras que tienen un innegable sesgo discriminatorio: "negro", "peruano", "discapacitado", "boliviano", "gordo", "pobre", "mujer" y "judío" son los términos más utilizados en Argentina para discriminar al que es diferente. ${ }^{102}$ Por lo demás, es sabido que hay un discurso retrógrado en la sociedad - el Distrito de Junín no es ajeno al mismo- que promueve el aislamiento. Cuando se discrimina se invisibiliza al otro, se lo transforma en peligroso. "Quien más sufre es el pobre y si, al mismo tiempo, es mujer y discapacitada los padecimientos se multiplican. Ante esta realidad, la escuela tiene mucho para decir y hacer a fin de prevenir conductas discriminatorias que dañan particularmente a los grupos minoritarios". Tal es lo que aseveraba la psicopedagoga Muriel Salvato, que desempeña sus tareas en el gabinete psicopedagógico de la escuela E del mencionado Distrito.

Ahora bien, la obligatoriedad de la educación secundaria - establecida en la Ley de Educación Nacional $\mathrm{N}^{\mathrm{0}} 26.206$ - deviene una condición necesaria pero no suficiente para garantizar el derecho a la educación. Para que éste sea realmente ejercido es preciso asegurar la gratuidad. Pero acontece que ésta es una asignatura pendiente en América Latina pese a estar consagrada en los marcos normativos de los países. La siguiente expresión de las

100. Gutiérrez Martínez, Jorge, Capítulo III. "Las nuevas tecnologías y el desafío de la educación", en Brunner, José Joaquín y Tedesco, Juan Carlos (editores), Las nuevas tecnologías y el futuro de la educación. Buenos Aires, Grupo Editor Septiembre, 2003, página 68.

101. Rodino, Ana María, Educación para la vida en democracia: contenidos y orientaciones metodológicas, en Cuadernos Pedagógicos. Instituto Interamericano de Derechos Humanos (IIDH), 2002, página 8 .

102. Estas fueron las adjetivaciones — propias de las diferentes formas de discriminaciónpronunciadas como ejemplos por los integrantes de un panel, durante el programa "Argentina para armar" conducido por la periodista María Laura Santillán, emitido el domingo 15 de enero de 2012 a las 22 horas, por el canal TN de televisión. 
Directoras de las escuelas estatales secundarias B y C del Distrito de Junín evidencia tal realidad: "dado el rol fundamental de las escuelas públicas para asegurar la igualdad de oportunidades, a fin de ejercer el derecho a la educación, resulta preocupante su debilitamiento y la ampliación de la brecha con las escuelas privadas". ${ }^{103}$ Asimismo, en el orden axiológico los docentes formarán a los educandos en valores de naturaleza universal que sustenten la dignidad y los derechos de las personas. También les han de transmitir actitudes coherentes con esos valores, que devenguen conductas responsables las cuales han de coadyuvar a la realización de una sociedad más justa.

Por lo demás, conduce a un arduo debate el aporte que puede realizar la tecnología en pos de una mejor educación para todos. ${ }^{104}$ Introducir en una clase productos multimedia, servirse de la computadora o de Internet, no es en sí una garantía de eficacia pedagógica, menos aún de innovación. A lo más, en ciertos casos se trata de un barniz modernista, ya que las tecnologías que han nacido y se han desarrollado afuera de la escuela no tienen en sí mismas virtudes pedagógicas. ${ }^{105}$ Muchos docentes del Distrito aludido, participantes en este trabajo, expresaron que -en principio - los más favorecidos podrían ser aquellos educandos de los sectores más desaventajados, contribuyendo la tecnología a equiparar situaciones frente al desigual punto de partida (hogares en los que nacen los estudiantes). Sin embargo, la desorganizada implementación del uso de las computadoras en clase, en algunas escuelas de adolescentes del Distrito mencionado, ha impedido hasta ahora alcanzar los resultados deseados. Por ejemplo, en las escuelas $\mathrm{H}$ y la $\mathrm{J}$ la mayoría de los egresados se entretenía con videojuegos que en nada se relacionaban con el tema desarrollado en ese momento por el docente. A esta conclusión puede arribarse luego de diálogos mantenidos —durante varios días de 2011 y de 2012 - con profesores y preceptores intervinientes en esta investigación en las que ya existen computadoras. Por lo demás, en los colegios secundarios de adultos las netbooks no llegaron para los educandos ni para los docentes comenzado ya el ciclo lectivo 2013.

\subsubsection{La responsabilidad del Estado en materia educativa provincial}

Identificados como trabajadores, los docentes integran diferentes entidades que - cada una desde su lugar - realizan una variada actividad cuya finalidad es lograr el irrestricto

103. "El derecho a una educación de calidad para todos en América Latina y el Caribe". 1 "El contexto: los principales desafíos para los sistemas educativos de la región", en REICE. Vol. $5 \mathrm{~N}^{\circ} 3$. Santiago, OREALC/UNESCO, 2007.

104. Artículo 100 de la Ley de Educación Nacional.

105. Carrier, Jean-Pierre, 2. "Los retos de los multimedia para la escuela", en Escuela y multimedia. Traducción de Tatiana Sule Fernández, Siglo XXI Editores, 2002, página 82. 
cumplimiento de los derechos de los integrantes del sector. Así, la Confederación de Trabajadores de la Educación de la República Argentina (CTERA), fundada en 1973, es una entidad gremial de segundo grado (federación) que afilia a sindicatos docentes de todas las jurisdicciones educativas del país: veintitrés provincias y la ciudad capital. En la lista de sindicatos docentes provinciales que integran CTERA se encuentra el Sindicato Unificado de Trabajadores de la Educación de la Provincia de Buenos Aires (SUTEBA) - de cuya fundación se cumplen en 2013 veintisiete años- que enfrentó en la década de 1990 la transformación estructural del sistema educativo bonaerense junto con la flexibilización laboral del sector que representaba. Asimismo, la Unión Docentes de la Provincia de Buenos Aires (UDOCBA) es una entidad gremial de primer grado con ámbito de actuación en todo el territorio provincial que incluye a los docentes de gestión estatal de todos los niveles, modalidades y especialidades. A partir de su nacimiento, a fines de 1996, realizó una activa participación en la vida educativa provincial, impulsando la sanción de normas legales que propendieron al mejoramiento de la situación laboral docente. Por otro lado, la Federación de Educadores Bonaerenses "Domingo Faustino Sarmiento" (FEB) se fundó el 4 de abril de 1959 a partir de la iniciativa de las diecinueve delegaciones que conformaban el Movimiento Pro Dignificación del Magisterio "Domingo Faustino Sarmiento", antecedente histórico de la FEB. Desde entonces, esta entidad gremial de segundo grado viene defendiendo los intereses de los docentes, la calidad educativa y la profesionalización docente. En el plano nacional, desde 2012, integra Docentes Argentinos Confederados (DAC). En 2013, el Frente Gremial Docente Bonaerense (FGDB), integrado por los sindicatos Asociación del Magisterio de Enseñanza Técnica (AMET), FEB, Sindicato Argentino de Docentes Privados (SADOP), SUTEBA y Unión Docentes Argentinos (UDA) lleva a cabo periódicamente reuniones donde se analiza la actualidad docente, especialmente la temática salarial.

Sabido es que el trabajo desapareció como herramienta para encarar la construcción del propio destino. La falta del mismo o la subocupación lanzó a una parte de la población a la vulnerabilidad y a la exclusión. El "otro" en tanto pobre puede ser un significante más en el discurso educativo. Sin embargo, la materialidad de la pobreza y de la exclusión en el territorio bonaerense movilizaron a los docentes y los ubicaron en una posición dilemática: dar de comer o leer un cuento, repartir zapatillas o enseñar el teorema de Pitágoras, distribuir guardapolvos sólo para algunos o resistir el clientelismo. Deconstruir tal discurso representó —quizás - una de las principales tareas para los espacios de capacitación de educadores que enseñaban realidades económicas, sociales y culturales complejas.

Las condiciones de vida de los excluidos, al igual que las de muchos formalmente "incluidos", amenazan la integración social. Hasta llegan a poner en duda la existencia misma de ese referente empírico designado con el sustantivo "sociedad" como espacio social común de un conjunto de individuos en situación de interdependencia subjetiva y objetiva. Más que de "la sociedad argentina" habría que pensar en distintos espacios sociales de vida cuyas 
relaciones de interdependencia son más objetivas que subjetivas (mediadas por la conciencia colectiva de pertenencia a una totalidad que trasciende a los individuos en cuanto tales). Más aún, desde cierta lógica economicista, pareciera ser que algunos grupos no son "necesarios" (no aportan nada al conjunto) en la medida en que nadie depende de ellos. Ésta es quizá la forma más extrema de exclusión, el hecho de que muchos seres humanos — pese a la nacionalidad y la ciudadanía jurídica y formal - se han desprendido del sistema de relaciones de interdependencia que constituye la base del "formar parte" (de la sociedad, del país, de la nación y de la patria). ${ }^{106}$

A todo esto, el artículo 198 — según la reforma de 1994- sustituyó al 189 de la Constitución de la provincia de Buenos Aires de 1934. Tal artículo define a la cultura y a la educación como derechos humanos fundamentales. Asimismo, la provincia reconoce a la familia como agente educador y socializador primario, si bien la educación es responsabilidad indelegable del Estado que asegurará el acceso, la permanencia y el egreso de la educación en igualdad de oportunidades y posibilidades. Como puede apreciarse, se mantiene a la familia como primer núcleo de normas y de afectos que coadyuvan a la formación de una personalidad sana. Cuando en aquélla existe una conflictividad extrema, todos sus integrantes podrán verse afectados y tal realidad tendrá - muy probablemente- un efecto negativo en el estudiante, tornándose ello visible especialmente en su rendimiento escolar.

La constitución provincial expresa, además, que "la educación tendrá por objeto la formación integral de la persona con dimensión trascendente y el respeto de los derechos humanos y libertades fundamentales". También hace referencia a la formación "de los niños en el culto de las instituciones patrias, en el respeto a los símbolos nacionales y en los principios de la moral cristiana, respetando la libertad de conciencia". ${ }^{107}$ Una realidad —a la que todos van acostumbrándose de a poco- es que en los actos oficiales, el Himno Nacional Argentino y otras canciones patrias casi no se cantan, o se lo hace imperceptiblemente, por los alumnos (así lo manifestaron muchos egresados y sus docentes del Distrito cuando se les consultó al respecto). Esto también pudo ser comprobado por el investigador durante varios actos patrios y clases observadas - todo ello en 2011 y en 2012- en diferentes escuelas estatales de nivel secundario del Distrito de Junín, participantes en este trabajo.

Asimismo, dicho cuerpo legal establece que la normativa de base del sistema educativo se ajustará a los siguientes principios: la educación pública es gratuita en todos los niveles y obligatoria en el nivel general básico; la educación podrá ser impartida por otros sujetos —privados o públicos no estatales - bajo control estatal y la calidad educativa será

106. Tenti Fanfani, Emilio, La escuela y la cuestión social. Ensayos de sociología de la educación. Buenos Aires, Siglo XIX, 2007, página 152.

107. Artículo 199 de la Constitución de la provincia de Buenos Aires. 
equitativa, con énfasis en el acervo cultural y en la protección, así como la preservación del medio ambiente. Los términos calidad, gratuidad, equidad y obligatoriedad educativas reconocidos en el texto adquieren una connotación provincial, fundamental para la construcción de una sociedad con mayores dosis de justicia. "Algo difícil de alcanzar pero a lo que nunca se debe renunciar", expresaron varios Directores de escuelas estatales de nivel medio del Distrito de Junín, dialogando sobre el tema con el investigador.

La provincia de Buenos Aires presenta - en la faz educativa- una característica particular cual es la de no poseer un ministerio de la rama. De acuerdo con la Constitución provincial de 1994, el gobierno y la administración del sistema educativo estarán a cargo de la Dirección General de Cultura y Educación —entidad autárquica- cuyo titular es el Director General. ${ }^{108}$ Dicho funcionario es designado por el Poder Ejecutivo con acuerdo del Senado, dura cuatro años en su mandato y puede ser reelecto. Respecto de su gestión podría suceder lo siguiente: si integra el partido político que gobierna la provincia, su proyecto iría encadenado al plan educativo nacional en tanto el partido que ganó la elección provincial haya triunfado también en la nacional. Si no pertenece a partido político alguno, cuando deba evaluar el funcionamiento de los colegios provinciales podría tener en cuenta la idea "cada escuela, un proyecto" la que, devenida en propuesta, es alentada por especialistas en educación. ${ }^{109}$

También fue creado el Consejo de Cultura y Educación por mandato de la Constitución de la provincia de Buenos Aires de 1873 que cumple funciones de asesoramiento y de consulta. El Director General de Cultura y Educación ejerce su presidencia y lo integran además diez Consejeros Generales que representan a los docentes, a los movimientos sociales y a los partidos políticos. En su conformación están presentes las diversas realidades del conurbano bonaerense y de los distritos del interior provincial. Como órgano asesor acompaña la gestión del presidente aportando información y conocimiento. Asimismo, los Consejeros Generales reunidos semanalmente en comisiones ordinarias, elaboran conclusiones y proyectos que han de ser analizados en las sesiones plenarias del cuerpo.

Es obligatoria la consulta al Consejo en temas como planes y programas de estudio; diseños curriculares de todos los niveles, modalidades y establecimientos experimentales; proyectos de leyes, estatutos y reglamentos relacionados con el ordenamiento educativo, la administración escolar y la carrera docente y cuestiones de interpretación de la normativa educativa a casos no previstos. Asimismo, brindará asesoramiento en lo que atañe a - por

108. Artículo 201 de la Constitución de la provincia de Buenos Aires.

109. Entre otros, tal propuesta es sostenida por el Licenciado en Educación Gustavo Iaies, Director General de Políticas Públicas, quien la desarrolló durante una entrevista en el programa "Factor futuro", conducido por el periodista Pablo Duggan, emitido el domingo 30 de octubre de 2011 a las 13:30 horas por el canal Metro de televisión (por cable). 
ejemplo- material didáctico y libros de texto a utilizarse en escuelas públicas y privadas; categorías a otorgar a los servicios educativos; acciones de apoyo social y pedagógico destinadas a la eliminación de la deserción, el ausentismo y el analfabetismo y programación de congresos, encuentros y seminarios a nivel provincial, nacional e internacional a los fines de promover el intercambio de experiencias. ${ }^{110}$

Dicho Consejo emerge - por lo aseverado supra - como una institución clave para el desarrollo de la educación provincial. Empero, su función de asesoramiento - por la verticalidad del sistema educativo argentino- pareciera no alcanzar en los hechos la efectividad esperada. Los docentes que participan en esta investigación aducen que no existe la correlación que es posible esperar entre el Consejo y quienes cumplen a diario su labor en la escuela. "Y ello es así —afirman — porque las actividades administrativas que se realizan son tantas y tan complejas - consecuencia todas ellas de un fárrago de disposiciones- que muchas veces se tornan prácticamente incumplibles por lo incongruentes y oscuras". En otras oportunidades son los directivos de los colegios medios los disconformes, puesto que las disposiciones de los organismos superiores no son comunicadas oportunamente o bien son modificadas periódicamente, sin que exista tiempo suficiente para comprobar su eficacia en la realidad. Por lo demás, el Consejo debería tener conocimiento de que en algunos colegios secundarios (de adolescentes y de adultos) de distritos como el de Junín no hay libros de texto (tampoco en algunos de ellos existen espacios destinados a las bibliotecas). Tales falencias se experimentan -en algunos casos- desde la creación misma de la escuela. Asimismo, respecto de los congresos, encuentros y seminarios a realizarse, tales inquietudes no admiten discusión (así lo aseveran educadores consultados en esta investigación), pero también es cierto que asistir a dichos eventos es complicado, habida cuenta que la mayoría de ellos no dispone de tiempo y - a veces tampoco - del dinero suficiente. Existen casos en que, además de impartir una o más asignaturas, el educador ocupa un cargo en una o en más escuelas, con el objetivo de lograr un ingreso mensual digno o porque tiene una mentalidad de progreso. Por ende, casi toda o toda la semana laboral lo encuentra inmerso en sus actividades habituales y con pocas expectativas - a veces con escasas fuerzas - para intentar una mayor capacitación. Un comentario generalizado entre los propios docentes respecto del bajo nivel - a priori- que le asignan a un evento, termina a veces convenciéndolos de su inviabilidad.

\subsubsection{Escuelas plurales para sociedades más inclusivas}

La ley 13.688/07 de Educación bonaerense actual expresa las ideas-fuerza que basamentan la política educativa. Como lo esencial de una política de inclusión es enfrentar la

110. Artículo 103 de la Ley de Educación de la provincia de Buenos Aires. 
segmentación y la exclusión social, una de sus principales expresiones son las escuelas plurales, punto de iniciación para arribar a sociedades con más incluidos. Según Emilio Tenti Fanfani, en muchos casos la tarea asistencial a cargo de la escuela afronta el riesgo de desnaturalizar su función y —al mismo tiempo- de afectar la identidad profesional de los docentes. De acuerdo con ello, durante los próximos años las políticas educativas deberán resolver cómo articular mejor sus compromisos pedagógicos y sociales, a través de una oferta enriquecida (en tiempo escolar, en recursos) o mediante una fluida vinculación con otras políticas sociales y recursos comunitarios específicos. ${ }^{111}$ Esto significa propender al desarrollo de la escuela pública ya que ésta tiene como función esencial posibilitar el acceso a la educación de niños y adolescentes de los ambientes más desfavorecidos, integrando la diversidad. ${ }^{112}$ Asimismo, existe consenso en reconocer el fuerte condicionamiento que el entorno social ejerce sobre las características de las instituciones y sus posibilidades para la obtención de diferentes recursos. En tal orden de ideas, las escuelas participan en muy buena medida de los rasgos del contexto en que aparecen enclavadas. ${ }^{113}$ A propósito, en esta investigación se analizará el posible vínculo entre los lugares de ubicación de los colegios estatales de nivel medio en el Distrito de Junín y la formación de sus recursos humanos y materiales.

La ley citada prescribe que los niveles del sistema educativo provincial son la Educación Inicial, constituida por los Jardines Maternales (para niños de cuarenta y cinco días a dos años) y los Jardines de Infantes (para niños de tres a cinco años, siendo los dos últimos obligatorios); la Educación Primaria —obligatoria— de seis años de duración (para niños a partir de los seis años); la Educación Secundaria —obligatoria- que se extiende seis años (para quienes hubieren cumplido la Educación Primaria) y la Educación Superior (para los que hubiesen finalizado la Educación Secundaria). El nivel Terciario se lleva a cabo en Institutos Superiores, en la Universidad Pedagógica, en la Universidad Provincial del Sudoeste, en la Universidad Provincial de Ezeiza (creada por Ley Provincial No 14.006 y promulgada mediante Decreto 1022/09) y en las universidades que se creen a tal efecto. ${ }^{114}$ Así torna visible la decisión tomada por la provincia en relación al artículo 134 de la ley de

111. Tenti Fanfani, Emilio, La escuela y la cuestión social. Ensayos de sociología de la educación. Buenos Aires, Siglo XIX, 2007, página 71.

112. "El derecho a una educación de calidad para todos en América Latina y el Caribe". 1 "El contexto: los principales desafíos para los sistemas educativos de la región", en REICE. Vol. $5 \mathrm{~N}^{\circ} 3$. Santiago, OREALC/UNESCO, 2007.

113. Belossi, Mariana y Palacios de Caprio, María Alicia, Capítulo 2. "Una mirada hacia el interior de la escuela", La escuela media y los jóvenes socialmente desfavorecidos. Buenos Aires, Lugar Editorial, 2004, página 41.

114. Artículo 24 de la Ley de Educación de la provincia de Buenos Aires. 
Educación nacional. Dicho artículo establece que cada jurisdicción decidirá entre dos opciones de estructura para los niveles primario y secundario. Buenos Aires eligió la que prevé seis años y seis años (explicitada en el párrafo anterior), lo cual da lugar a la pregunta sobre si la obligatoriedad no sería conveniente o necesaria también en el nivel superior. Podrá argüirse aquí lo que muchas veces se ha escuchado: "No puede ser; si todos estudian ¿quién va a trabajar?". Tal argumentación puede refutarse afirmando que los profesionales también están trabajando cuando transmiten conocimientos o aplican lo que han aprendido. Por otro lado, un repaso de la historia argentina — de cincuenta años a hoy- vuelve a hacer visible para todos que muchas personas de sectores urbanos y rurales humildes no realizaron el preprimario; otras no iniciaron o no concluyeron el nivel primario, aquellas que nunca empezaron o no finalizaron la escuela secundaria y también están los que nunca comenzaron o no pusieron fin al nivel terciario (universitario o profesorado). ${ }^{115}$ "Hoy día la obligatoriedad es algo fundamental especialmente para los más humildes. "La expectativa general se centra en que en un mañana también esté vigente en el nivel superior", comentaba un docente a otros que lo escuchaban atentamente, todos profesores del nivel terciario en el Distrito de Junín. A un lado lo aseverado, es de conocimiento público que las sociedades van cambiando y que las exigencias en la formación de los recursos humanos -especialmente en los países desarrollados- van en aumento día a día. Y también se incrementan en naciones en desarrollo, como Argentina, donde muchas veces es difícil hallar a personas capacitadas para llevar a cabo tal o cual oficio o ejercer una determinada profesión. Aunque es difícil que lo admitan públicamente, están aquéllos para quienes algunas personas (por su origen) han de estudiar y otras (también por su origen) serán la mano de obra necesaria para cumplir los deseos de los más poderosos. Tal razonamiento encubre la falacia de que el "destino" de cada uno está fijado desde su nacimiento (tal como acontecía en las sociedades de castas ${ }^{116}$ ). Para quienes así piensan de poco valdrá el esfuerzo personal que realicen muchos (los más desfavorecidos) para cambiar un final preanunciado. A esta manera -que podría denominarse "estática" - de explicar el status de las personas cabría oponérsele otra idea

115. Tales afirmaciones fueron vertidas por el político José Antonio Romero Feris, conductor del programa "Corrientes de pensamiento" emitido el martes 14 de julio de 2012 a las 22 horas por el canal Metro de televisión (por cable). En dicho programa, el político José Luis Brown aseguró que "hoy día, de cien adolescentes que empiezan el nivel medio sólo treinta y ocho lo finalizan".

116. Se tiene en cuenta aquí - a modo de ejemplo- que las castas coloniales hacen referencia a un sistema de estratificación social que tuvo su aparición en las colonias de España en América y Filipinas, a partir del siglo XVIII. Un sistema de castas es una forma particular de estratificación caracterizada por rasgos estructurales específicos (rigidez del sistema, pertenencia a una casta por nacimiento, imposibilidad de cambiar de casta, endogamia, jerarquía absoluta en todos los campos, particularmente en el sistema de valores). Tuvo su origen en el temor de los grupos privilegiados de la dicotomía entre españoles e indios, por la progresiva adquisición de derechos y poder político o económico por parte de un número cada vez mayor de mestizos. 
según la cual ha de existir para todos "la igualdad de oportunidades y posibilidades sin discriminación alguna". 117

En otro orden de ideas, la institución educativa es la unidad pedagógica del sistema, responsable de los procesos de enseñanza y de aprendizaje para lo cual articula la participación de las personas que constituyen la comunidad educativa. ${ }^{118}$ Como es dable observar, para la normativa provincial las escuelas cumplen un rol de suma importancia en la vida de la sociedad, cualquiera sea su ubicación. Ello es así no obstante que algunas de ellas como, por caso la D, situadas muy próximas al centro de la ciudad de Junín tengan objetivamente mejor "fama" por diferentes razones que otras - la J por ejemplo- que funcionan muy próximas a los límites urbano-suburbano. Consultados varios padres de egresados de estas últimas, se manifestaron "conformes con la institución y muy agradecidos a los profesores por la contención que les dan a nuestros hijos". Asimismo, muchas de ellas tienen un elevado prestigio en el seno de sus comunidades y son vistas y sentidas por la gente (principalmente, los responsables de los egresados) como organizaciones comunitarias más que como instituciones públicas. ${ }^{119}$ En ellas los docentes no son visualizados como funcionarios públicos sino como maestros y —en virtud de tales - no sufren el descrédito generalizado de los primeros. Silvia Mariela Grinberg subraya que esto es importante porque salva a la escuela - al menos por ahora - de la crítica despiadada y de la desconfianza que sufren otras instituciones. Sus directivos están llamados a considerarse hoy líderes organizacionales; no pueden ser sólo buenos pedagogos. Su lugar social está resignificado y lo estará muy probablemente aún más en los próximos años. ${ }^{120}$

Respecto de la labor en el aula, más importante que la teoría y los recursos es la cultura del maestro. Ella es la que determina el uso mecánico o creativo de las teorías y los métodos. El buen maestro está permanentemente con una actitud abierta frente a lo nuevo, siempre dispuesto a incorporar nuevas técnicas y procedimientos a su bagaje instrumental. Pero la herramienta sola no da solución a ningún problema. Se puede aprender el uso de una técnica. Otra cosa es aprender a usarla; es decir, saber cuándo, en qué caso y hasta qué punto usarla y cómo combinarla con otras herramientas. Debido a la abundancia de "soluciones pedagógicas" que tienden a ser presentadas como dotadas de validez universal y excluyente,

117. Artículo 75, inciso 19 , párrafo $3^{\circ}$, de la Constitución Nacional.

118. Artículo 63 de la Ley de Educación de la provincia de Buenos Aires.

119. Así sucede, por ejemplo, con tres de las escuelas de adolescentes (A, C y E) y de adultos $\left(\mathrm{H}_{1}\right.$ y M), del Distrito de Junín, intervinientes en el presente trabajo.

120. Grinberg, Silvia Mariela, Capítulo III. "La comunidad, nuevo locus de gobierno", en Educación y poder en el siglo XXI: gubernamentalidad y pedagogía en las sociedades de gerenciamiento. Madrid - Buenos Aires, Miño y Dávila Editores, 2008, página 162. 
es menester desarrollar una actitud abierta pero crítica. En otras palabras, el docente ha de reservarse siempre el derecho a determinar las condiciones de su utilización. Sin esta aptitud básica, todo el esfuerzo del perfeccionamiento docente puede terminar en una simple actualización del lenguaje (antes decía "disciplina", ahora "convivencia"; antes se dedicaba a enseñar, ahora construye conocimientos) que no afecta en casi nada el modo de hacer las cosas en la escuela. ${ }^{121}$

A propósito, en muchas escuelas estatales del Distrito de Junín el docente de nivel medio además de enseñar contenidos integra valores, fomenta el respeto y la solidaridad entre todos los integrantes de la escuela, pregona pautas de convivencia y -en muchas ocasionesaparece como un agente contenedor ante situaciones individuales y grupales conflictivas. El investigador pudo comprobar tales afirmaciones en las escuelas A, E, I y J (de adolescentes) y en $\mathrm{A}_{1}, \mathrm{H}_{1}$, L y M (de adultos) mediante diferentes actividades realizadas en 2011 y 2012.

\section{El estado de la cuestión}

\subsection{La educación en tiempos de globalización}

Según el sociólogo Alain Touraine (1925-), la globalización es un proceso nefasto mediante el cual los países cedieron el poder de sus economías a fuerzas globales antidemocráticas, tales como los mercados y las agencias de calificación de la deuda externa. $^{122}$

El uso del vocablo pueblo para hacer referencia a este tema resulta cuanto menos confuso. No han sido precisamente los pueblos — como sujetos colectivos- quienes cedieron el poder de sus economías. En todo caso fueron sus representantes, desoyendo la propia voz de aquéllos, con la intención de satisfacer sus espúreos intereses personales. De manera que en un escenario donde las políticas nacionales son menos trascendentes y eficaces, uno de los efectos de la globalización ha sido sustraer capacidad de decisión al ciudadano de a pie, debido fundamentalmente a que las políticas internacionales han adquirido mayor trascendencia en la política interna de los Estados. No obstante las mentadas relaciones interestatales que tendrían lugar entre los países, las mismas no se darían en un pie de igualdad. En tal sentido, ha logrado consenso la distinción realizada por el investigador Carlos Escudé, quien afirma:

121. Tenti Fanfani, Emilio, La escuela y la cuestión social. Ensayos de sociología de la educación. Buenos Aires, Siglo XIX, 2007, páginas 245 y 246.

122. Touraine, Alain, Un nuevo paradigma para comprender el mundo de hoy, Volumen 135 de Paidós Estado y sociedad, Editorial Paidós, 2005, páginas 114 y 115. 
Mal que nos pese, existen tres tipos de Estados: los que contribuyen a establecer las reglas de juego (o sea las grandes potencias); los que aceptan esas reglas (que son la gran mayoría) y los que se rebelan contra esas reglas (que son los llamados Estados paria). Esta es la estructura, incipientemente jerárquica, del orden interestatal. ${ }^{123}$

Por su parte, el psicolingüista Noam Chomsky (1928-) advierte que en los últimos treinta años la longevidad en los países más pobres ha pasado de 46 a 63 años, la alfabetización del 20 al 60 por ciento, en tanto otras estadísticas - desde una perspectiva macroeconómica - también resultan positivas. ${ }^{124}$ Sin embargo, según datos de 2010 pertenecientes a la Organización de las Naciones Unidas (ONU), un 25 por ciento de la población mundial acapara el 80 por ciento de la riqueza mientras que el 75 por ciento restante sólo tiene acceso al 20 por ciento de lo producido mundialmente. Además, sesenta mil personas mueren al día a causa de enfermedades curables relacionadas con la pobreza. Las cifras son alarmantes y no permiten ser optimistas ni alabar las bondades del proceso de globalización ya que en los últimos treinta años la tendencia no ha sido disminuir la brecha entre ricos y pobres sino - por el contrario - ampliarla. Asimismo, en la mayoría de los países más pobres de cualquier continente, la combinación de escasos recursos e ingresos mínimos con gobiernos incompetentes y corruptos ha llevado a situaciones extremas no exentas de violencia. De los cincuenta países con renta más baja en 1990, veintitrés de ellos permanecen hoy en el mismo nivel de renta que tenían en dicho año y de los veintisiete restantes que lograron algún progreso, el aumento anual sólo fue —en promedio- del 2,7 por ciento. $^{125}$

Ahora bien, teniendo en mira a los Estados miembros de la ONU se observa que ciento cuarenta de ellos — con constituciones posteriores a 1945- hacen referencia expresa al derecho fundamental a la educación. Pero ninguno de esos textos supremos, excepto el de China en su artículo $164,{ }^{126}$ cuantifica el esfuerzo material dirigido al acceso efectivo de este

123. Escudé, Carlos, "La transformación de las ecuaciones del realismo periférico en el siglo XXI", en Revista POSTData No 12, Agosto 2007, página 224.

124. Chomsky, Noam, Neoliberalismo y globalización, Ediciones Universidad de la Frontera, 2009, páginas 55-57.

125. González Ibáñez, Joaquín, Tratados Internacionales de Derechos Humanos y Principio de Legalidad. La quiebra de las obligaciones de los tratados internacionales en el ámbito del derecho a la educación, en Derechos humanos, relaciones internacionales y globalización. Bogotá, Grupo Editorial Ibáñez, 2006, página 282.

126. El citado artículo de la Constitución de la República de China prescribe lo siguiente: "Los gastos para los programas educativos, estudios científicos y servicios culturales no deben ser menores del 15 por ciento del presupuesto nacional total del Gobierno Central; no menores del 25 por ciento del presupuesto total de la provincia y no menores del 35 por ciento de los presupuestos totales de las ciudades o del hsien. Las fundaciones educacionales y culturales establecidas de acuerdo con la ley, así como sus propiedades, deben ser protegidas". 
derecho para todos. Nada puede agregarse a una manifestación tan evidente de la responsabilidad con que dicho país aborda la temática educativa. Se dirá que no sólo con recursos materiales se alcanza una educación de alta calidad, lo cual es cierto. Pero de allí se empieza para lograr a futuro cuerpos de profesionales idóneos que —en muchas naciones de Latinoamérica, por casos- no abundan. Si dentro de la región se considerara la situación en Argentina, ésta no escaparía a tal realidad. Tal afirmación surge habida cuenta de los resultados obtenidos por alumnos argentinos de nivel medio en pruebas internacionales de hace pocos años. ${ }^{127}$ Este fracaso lleva a inquirir por el qué y el cómo de la enseñanza. El acento está puesto aquí en el docente, pero no debe olvidarse al otro integrante del par educativo: el estudiante, que al igual que aquél vive inmerso en una realidad histórica determinada y dista mucho, en ocasiones, de tener actitudes positivas hacia el aprendizaje. En esta investigación se explora este aspecto sustancial de la educación media que tiene lugar en escuelas estatales (para adolescentes y adultos) del Distrito de Junín.

Ahora bien, más allá de cuestiones técnico-legales y de diversas problemáticas, lo trascendente es reflexionar sobre los motivos que llevan a los gobiernos a no promover los derechos en materia educativa reconocidos en los textos constitucionales, inclusive en acuerdos internacionales. Las causas que subyacen, más allá de las limitaciones económicas que muchos Estados soportan, se centralizan en la ausencia de voluntad política para lograr -en sus respectivas comunidades - un ejercicio pleno del derecho a la educación. Gabriel Zaid (1934-) afirma en El progreso improductivo: "Nadie va a parar el progreso: tiene miles, millones de años. Ni la ciega voluntad de progreso, que tiene apenas unos siglos. [...] somos ejecutantes de esa voluntad que se extiende por el planeta. Sólo podemos exigirle autocrítica: volverla nuestra de una manera menos ciega; hacerla progresar". ${ }^{128}$ No se trata, pues, de mayor velocidad, cantidad o diversidad geográfica. Lo esencial es impregnar a la actual globalización de una naturaleza más ética, social y solidaria. En ese contexto, la educación devenida en ciudadanía activa y participativa representa una construcción de la vida política y de la ética que tienen presente la desigualdad que proyecta el siglo XXI. Torna imprescindible - por tanto- una educación que permita a los seres humanos convertirse en auténticos ciudadanos y — con ello- intervenir en la construcción de su futura comunidad.

\subsection{Principales problemas educativos en América Latina}

Se visualizan dos problemas serios en relación a la educación implementada en América Latina (especialmente en el caso chileno donde se creó el sistema privado subvencionado pero

127. Véase Introducción, página 6.

128. Zaid, Gabriel, El progreso improductivo. Océano, 1999, página 14. 
se mantiene también la escuela pública). Por un lado existe un riesgo de segregación educativa por subsistema que se suma a la segregación de base territorial. Si anteriormente la segregación se producía por razones de residencia y por la capacidad de los sectores altos de salir de lo público al contratar un sistema privado, ahora se agrega la posibilidad de salida del sistema público para sectores medios y medios bajos que no podían pagar el colegio privado; aparece la figura del privado subvencionado. Ello implicó que colegios del sistema público se vaciaran no sólo de elites sino también de clases medias.

Por otro lado, debe tenerse presente que los mercados distribuyen bienes y servicios en forma desigual, social y espacialmente. Mercados ineficientes y con fuertes rigideces agudizan dicha inequidad. En América Latina este problema adquiere dimensiones alarmantes cuando se observan las diferencias de desarrollo regional y las que existen en los ámbitos rurales y urbanos.

El caso chileno durante el gobierno del dictador Augusto Pinochet Ugarte (1915-2006) es un buen ejemplo de lo aseverado. La ausencia de mecanismos participativos reales a nivel comunitario y la no transferencia de recursos significativos desde el gobierno central a las nuevas unidades administrativas llevó a una agudización de la estratificación regional. Este experimento fue tildado de desconcentración regional y alcaldización de los municipios (el alcalde no era electo sino nombrado por Pinochet) y no de descentralización. Con el regreso de la democracia a dicho país (el presidente constitucional Patricio Aylwin asumió el poder el 11 de marzo de 1990) se implementaron dos reformas que permitieron enfrentar - al menos parcialmente - el problema. Por un lado, se aplicaron mecanismos participativos y electivos para la selección de las autoridades locales y por el otro se creó un fondo de solidaridad basado en rentas generales y en ingresos fiscales de las autonomías y municipios más ricos, lo que permitió cubrir las deficiencias fiscales de las unidades más pobres.

En otro orden de ideas, en materia de resultados educativos las políticas descentralizadoras implementadas en América Latina enfrentan el riesgo de la segmentación de la calidad educativa, como consecuencia de la lógica del mercado. Asimismo, esta segmentación de la calidad de la oferta puede generar la segregación social a partir de la división en compartimentos estancos. Esta lógica estima posible la movilidad social ascendente pero es necesario preguntarse por los sectores sociales menos favorecidos y sus posibilidades reales de ser admitidos en un sistema de libre juego sin correctivos estatales. Con mayor razón debe hacerse esta pregunta en relación a sociedades desiguales o previamente segmentadas como son las latinoamericanas. En ellas, si los adolescentes con mayor capacidad de aprendizaje abandonan sus escuelas de origen hacia colegios de mejor calidad, pero otra cantidad de éstos se ve imposibilitada de hacerlo, se tendrían dos posibles consecuencias. Por un lado, estos sectores movilizados serían favorecidos por el efecto pares de los adolescentes ubicados en mejores escuelas, lo que mejoraría su capacidad de aprendizaje y la calidad del mismo, generando para ellos mayor equidad respecto de la 
sociedad en que viven. La otra consecuencia sería que aquellos educandos atrapados en las peores escuelas también experimentarían el efecto pares, pero en una situación de empobrecimiento intelectual que los potenciaría negativamente. La calidad de su educación se vería amenazada por el empobrecimiento del grupo social al que pertenecen y del que no lograrían movilizarse ascendentemente. La problemática descripta desafía a las más lúcidas personalidades en materia educativa para buscar una solución que coadyuve a una sociedad latinoamericana más justa.

Con la mirada puesta en los estudiantes que provienen de hogares humildes, los diferentes Estados elaboraron políticas educativas tendientes a equilibrar las desigualdades de origen. Así, el aumento en la cobertura del nivel medio (de casi 15 puntos entre 1990 y 2003) se produjo - especialmente- en los sectores pobres de la región, aunque también benefició a los sectores altos que casi universalizaron su participación en el mismo. Cifras publicadas en 2010 pertenecientes al Sistema de Información de Tendencias Educativas en América Latina (SITEAL), señalan que los jóvenes de entre 13 y 17 años incluidos en el 30 por ciento más pobre de la sociedad pasaron del 53,1 por ciento de asistencia a la escuela secundaria al 74,4 por ciento entre 1990 y 2003. Es decir, estos sectores aumentaron su asistencia escolar en un 40,1 por ciento mientras que el 40 por ciento más rico creció menos aceleradamente $(14,6$ por ciento basado en el salto del 81,3 por ciento en 1990 al 93,2 por ciento en 2003). Empero, las tasas de escolarización en ambos sectores continuaron siendo en 2003 muy disímiles, con casi 20 puntos de diferencia entre el 40 por ciento más alto y el 30 por ciento más bajo. ${ }^{129} \mathrm{Al}$ respecto de lo expresado, véase el siguiente cuadro:

Tasa neta de escolarización secundaria (porcentajes)

\begin{tabular}{|c||c||c||c|c|}
\hline Grupo de edad & $\begin{array}{c}\text { Nivel de ingresos } \\
\text { per cápita familiar }\end{array}$ & 1990 & 2003 & $\begin{array}{c}\text { Diferencia } \\
\text { porcentual }\end{array}$ \\
\hline \multirow{3}{*}{13 a 17 años } & $30 \%$ más bajo & $53,1 \%$ & $74,4 \%$ & $40,1 \%$ \\
\cline { 2 - 5 } & $30 \%$ medio & $71,3 \%$ & $84,5 \%$ & $18,5 \%$ \\
\cline { 2 - 5 } & $40 \%$ más alto & $81,3 \%$ & $93,2 \%$ & $14,6 \%$ \\
\hline \hline \multicolumn{2}{|c|}{ Promedio } & $68,5 \%$ & $85,0 \%$ & $24,4 \%$ \\
\hline
\end{tabular}

Fuente: SITEAL (Sistema de Información de Tendencias Educativas en América Latina), base de datos disponible en www.siteal.iipe-oei.org.

129 Dussel, Inés, La escuela media argentina y los desafios de las metas 2021. Presentación V: Foro Latinoamericano de Educación Metas educativas 2021. Buenos Aires, Propuestas iberoamericanas y análisis nacional, Fundación Santillana-OEI, 2009, página 3. 
Las cifras del cuadro anterior son elocuentes. Y que esta realidad acontezca en el siglo XXI debería escandalizar, no sorprender. Máxime si se tienen en cuenta los tratados internacionales sobre derechos humanos surgidos luego de la segunda guerra mundial y la continua prédica de los gobiernos democráticos, dejado atrás el horror de las últimas dictaduras latinoamericanas. Va de suyo el reconocimiento internacional -en sus aspectos formales- del derecho a la educación sin distinción alguna. Pero el ejercicio del mismo para los sectores pobres dista mucho de ser el deseado. Más allá de las plausibles intenciones de quienes están unas cuantas horas diarias pensando - y tratando de llevar a la práctica- una política educativa que posibilite una mejor calidad de vida para todos, sería valioso saber qué opinan los integrantes de los sectores pobres respecto de la educación y si la consideran un sendero viable para dejar atrás la pobreza. En el presente trabajo se abordan estos aspectos mediante cuestionarios suministrados a los egresados (adolescentes y adultos) de escuelas estaduales del Distrito de Junín, ubicadas en los ámbitos urbano y rural.

Los urgentes desafíos que debe afrontar América Latina para alcanzar un crecimiento económico sostenible y concretar los Objetivos de Desarrollo del Milenio (ODM) ${ }^{130}$ tienen que ver con el incremento de la producción para combatir la pobreza, superar las desigualdades y la fragmentación sociocultural ${ }^{131}$ y fortalecer las instituciones democráticas. Asimismo, a pesar que en muchos de sus países la pobreza ha disminuido, la desigualdad en la distribución del ingreso continúa siendo una gran preocupación: todavía el 10 por ciento más rico supera en 20 veces o más el ingreso del 40 por ciento más pobre. Entre las causas de esta desigualdad se señalan la inequitativa distribución del patrimonio (que es aún más marcada), la composición demográfica de los hogares (las familias de menores recursos tienen más hijos que las de mayores recursos), la educación (los pobres aún no alcanzan un umbral educativo que les permita salir de la pobreza), el empleo (los hogares pobres son más

130. Los Objetivos de Desarrollo del Milenio es una iniciativa de carácter global que se creó en 2000 a partir de la Declaración del Milenio en las Naciones Unidas, firmada por 189 países. La Declaración del Milenio identifica preocupaciones, valores y principios relacionados con el desarrollo. Sobre la base de esta Declaración se estableció un conjunto de objetivos y metas cuantificables a alcanzarse en 2015, con los correspondientes indicadores numéricos internacionalmente convenidos a partir de los cuales se puede evaluar el progreso general. Tales objetivos son erradicar el hambre, lograr la enseñanza primaria universal, promover la igualdad entre los géneros y la autonomía de la mujer, reducir la mortalidad infantil, mejorar la salud materna, combatir el VIH/SIDA, el paludismo y otras enfermedades, garantizar el sustento del medio ambiente y fomentar una asociación mundial para el desarrollo.

131. En esta investigación con el concepto de fragmentación social se pretende dar cuenta de una configuración de la sociedad que resulta de los modos segregados de las prácticas sociales. Cuando se habla de fragmentación se alude a un modo de segregación que constituye una distancia social específica entre quienes habitan los distintos fragmentos. Aquí se sigue a Tiramonti, Guillermina y Ziegler, Sandra, "Introducción. La dinámica de selección de los sectores de privilegio", La educación de las elites. Aspiraciones, estrategias y oportunidades. Buenos Aires, Paidós, 2008, página 28. 
numerosos pero tienen menos miembros que reciben ingresos fijos y son pocos los que están registrados tal como exige la ley) y finalmente el gasto social cuando es regresivo y no progresivo. Aunque los fondos en salud, educación y seguridad social hayan aumentado en el período 1990-2000, los recursos no se distribuyeron en tales ítems en forma equitativa por lo que el gasto social no se ha convertido en una eficaz herramienta de redistribución. ${ }^{132}$ Las políticas de focalización resultan positivas pero no son suficientes para construir sociedades más equitativas en forma estable. Tienen un impacto beneficioso a corto plazo pero si se prolongan mucho tiempo pueden establecer un régimen segmentado en la calidad de las prestaciones (educación para pobres y para el resto, salud para pobres y para el resto). Ello reforzaría las desigualdades de origen, de trayectorias y de resultados, aunque se busque a través de las mismas igualar oportunidades de acceso.

Sabido es que las políticas económicas constituyen la variable más importante, tanto del aumento o disminución de la pobreza como de la mayor o menor equidad en la distribución de los ingresos. El resultado de la aplicación de las mismas en los últimos cuarenta años en América Latina (treinta y seis en Argentina) ha sido una mayor concentración de la riqueza y aumentos de la exclusión social, la desocupación, la informalidad y la precariedad del empleo. Los habitantes de los diferentes países de la región se preguntan quiénes, si no los diferentes gobiernos, han sido o son los responsables de tal estado de cosas. Afirman - coincidentemente- que todos ellos anunciaron al momento de empezar a ejercer el poder políticas para eliminar estos males, pero ello nunca aconteció. Las clases dirigentes contribuyeron también al engaño, formulando promesas que casi nunca cumplieron.

Además de crecer más y superar las desigualdades, los latinoamericanos deben encarar con mayor decisión el tema de la marginalidad política, social y cultural de gran parte de su población, particularmente la indígena y la afrodescendiente. Muchas personas que viven en espacios cercanos tienen diferencias muy marcadas en sus formas de vida. En Argentina esto también sucede. Vayan como ejemplos las realidades de los sectores aledaños a la terminal de ómnibus de Retiro —en la Ciudad Autónoma de Buenos Aires- y a la autopista Buenos Aires-La Plata. En ambos casos se observan "dos Argentinas" diferentes: una es la pujante, la desarrollada y otra es la atrasada, la olvidada. Respecto de la terminal mencionada, a un lado se erige el hotel Sheraton (de cinco estrellas) y al otro las villas 31 y 31 bis (con una población total que ya está próxima a las veinte mil personas). Y lo mismo sucede a un costado y al otro de la citada autopista: el progreso y el oprobio (barrios de viviendas humildes, cuyos habitantes viven en condiciones paupérrimas). Cabe agregar en los últimos

132. Datos obtenidos de la Organización Panamericana de la Salud (OPS). Situación de la Salud en las Américas: Indicadores Básicos. Washington, OPS cit. en "El derecho a una educación de calidad para todos en América Latina y el Caribe", en REICE. Vol. 5, № 3, Santiago, OREALC/UNESCO, 2007. 
cinco años la irrupción de los movimientos indígenas en el escenario político y social, cuyo efecto ha sido dar mayor visibilidad a una discriminación estructural en todo el país sobre estos argentinos expresada en marginalidad, exclusión y pobreza. Lo señalado también se advierte en algunos sectores del Distrito de Junín, pudiéndose citar como ejemplo lo que acontece con los mapuches. Evangelina Soledad Ponce, de diecinueve años, es mapuche y está en segundo año de la carrera de Abogacía, en la Universidad Nacional del Noroeste de la provincia de Buenos Aires (UNNOBA). La suya es una historia de sacrificio, esfuerzo y perseverancia. ${ }^{133}$

La sociedad latinoamericana polarizada hace evidente - de manera sin precedentes - la brecha entre ricos y pobres, indígenas y no indígenas, afrodescendientes y blancos, convirtiéndose en una causa del incremento de la inseguridad y de la violencia. Entre los varones la tasa de mortalidad por homicidio en la región era en 2000 de 17,8 por ciento por cada cien mil habitantes. Pero al desagregar los datos por subregiones se eleva a 25,1 por ciento, ${ }^{134}$ convirtiéndose en una de las más altas del mundo. Si bien la desigualdad social no puede ser considerada la única causa del aumento de la violencia -ella también se asocia a las expectativas que resultan de las diferencias entre el consumo simbólico y el consumo material, entre nivel educativo y acceso a empleos productivos, entre el deseo de autonomía y la imposibilidad de materializarla - su aumento ha sido tal que los costos para combatirla se han estimado en cifras que oscilan entre el 7 y el 12 por ciento del Producto Bruto Interno (PBI) de la región. ${ }^{135}$

En este contexto, el entramado social se ha vuelto más frágil, se ha resquebrajado el concepto de comunidad y ya no se espera una solidaridad vertebrada desde el Estado (lo cual es, desde cualquier análisis, tan sorprendente como inadmisible). Los ciudadanos difícilmente

133. Dicha alumna para solventar sus estudios trabaja seis horas en la Cooperativa de Trabajo Talleres Junín Limitada (COTTAJ) y en la cocina de una pizzería los fines de semana. Además, ayuda a su familia y cuida a sus hermanos. "Se necesitan abogados especializados en derecho originario; hay muchas leyes", se entusiasma Evangelina. "A nosotros nos trajeron a Junín para quedarse con nuestras tierras, para colonizar lo que quedaba y ahora, después de tantos años, todavía seguimos ahí, en la toldería", agrega. "Quiero recibirme y defender a mi comunidad", señaló, visiblemente emocionada, al final de la entrevista. En Democracia, Sección Recorriendo los barrios, Junín, sábado 5 de mayo de 2012, página 8 .

134. Datos obtenidos de la Organización Panamericana de la Salud (OPS). Situación de la Salud en las Américas: Indicadores Básicos. Washington, OPS cit. en "El derecho a una educación de calidad para todos en América Latina y el Caribe", en REICE. Vol. 5, № 3, Santiago, OREALC/UNESCO, 2007.

135. Ganuza, Enrique cit. en "El derecho a una educación de calidad para todos en América Latina y el Caribe", en REICE. Vol. 5, No 3, Santiago, OREALC/UNESCO, 2007. 
se ven a sí mismos formando parte de un sujeto colectivo, de un "nosotros", lo cual afecta a "nuestras maneras de vivir juntos", tal como la UNESCO ha definido a la cultura. ${ }^{136}$

Como hecho positivo deben mencionarse los gobiernos democráticos que llegaron al poder en América Latina. Éstos, de a poco y con diferentes ideologías, han tomado conciencia —aún no definitivamente- de lo esencial que resulta la capacitación de sus recursos humanos para alcanzar el desarrollo económico. Y para ello han puesto énfasis en la educación, aumentando el porcentaje del PBI destinado a la misma, si bien aún no en la forma que deberían. También es sabido que todo ser humano necesita adquirir conocimientos para desarrollar plenamente sus potencialidades. Desde este punto de vista su finalidad es cultivarse, por lo que la educación tiene un valor en sí misma y no sólo como herramienta para el crecimiento económico o el desarrollo social, como suele concebírsela desde visiones más utilitaristas. ${ }^{137}$ Ahora bien, este derecho no sólo ha merecido su reconocimiento por parte de los Estados sino que diferentes instrumentos internacionales también lo hicieron -en el marco de Naciones Unidas - con el fin de asegurar la igualdad de oportunidades.

Si bien es cierto que América Latina —en cuanto a sus logros y metas - no se encuentra en la misma delicada situación que los países de África Subsahariana, los Estados Árabes y Asia Meridional y Occidental, no menos cierto es que los avances aún no son significativos y los informes de organismos internacionales llevan a concluir que está en entredicho el real cumplimiento de las promesas formuladas. Se requiere que la familia, la sociedad y el Estado le garanticen a pobres y a ricos, a niños y a niñas, a jóvenes y a adultos, a los grupos mayoritarios y a los minoritarios, su acceso sin cortapisas a los niveles preescolar, primario, secundario y superior. Para alcanzar tal finalidad se necesita un marco jurídico que vincule (haga responsables) a la totalidad de los países, para que todas las personas puedan acceder plenamente a este derecho. Sin educación no hay participación política y sin participación política no puede afirmarse que existe una verdadera democracia, arguyen destacados políticos latinoamericanos. También manifiestan que con el paso de los años las deudas en tal sentido se tornan cada vez más difíciles de saldar. El deseo generalizado es que se terminen los discursos oportunistas y se pase a actuar de inmediato, para que no haya en el futuro más generaciones frustradas. "Los dirigentes - especialmente políticos - debemos pergeñar y llevar a cabo una educación que permita a todos los latinoamericanos una vida en paz y

136. "El derecho a una educación de calidad para todos en América Latina y el Caribe", en REICE. Vol. 5, No 3, Santiago, OREALC/UNESCO, 2007.

137. Savater, Fernando, op. cit., página 25. 
prosperidad mediante la más completa exteriorización de sus capacidades", señaló Daniel Filmus (1955-) en un reportaje radial. ${ }^{138}$

\subsubsection{La sociedad del conocimiento y los agentes socializadores}

El material bibliográfico sobre las nuevas formas organizativas del capitalismo es aleccionador y se ha visto enriquecido en los últimos diez años por aportes críticos significativos. Desde el punto de vista productivo existe consenso entre científicos sociales y economistas en reconocer que la globalización, así como la profunda transformación tecnológica y la competencia exacerbada por conquistar mercados, están modificando los patrones de organización y de producción del trabajo. Se estaría pasando lentamente de una organización del trabajo basada en jerarquías piramidales y destinada a la producción masiva a una organización en redes y orientada al consumo diversificado, donde se otorgan amplios poderes de decisión a las unidades locales. Se trata de un modelo que supera las formas del taylorismo y del fordismo basadas en la producción en serie para mercados masivos. La innovación permanente, la flexibilidad interna y la ruptura de las categorías fijas, al tiempo que elimina las jerarquías tradicionales evidencia un potencial destructivo muy importante. Estos cambios provocarían un aumento significativo de la desigualdad social: los datos sobre la distribución del ingreso y de la riqueza — suministrados por diferentes organismos económicos internacionales- indican que se ha producido un fuerte proceso de concentración. Esta tendencia se percibe en todos los países, aunque su rapidez y su intensidad sean diferentes. ${ }^{139}$

Este aumento de la desigualdad va acompañado de un incremento igualmente significativo de las teorías que tienden a justificarlo. Mientras en el capitalismo tradicional la pobreza o la condición asalariada podían percibirse como consecuencias de un orden social injusto, en el nuevo capitalismo tienden a ser asociadas a la naturaleza de las cosas y -en última instancia - a la responsabilidad personal. No es casual el resurgimiento de ideas que tienden a explicar determinados patrones de conducta, los niveles de desarrollo cognitivo personal y la ubicación en la estructura social, a través de factores genéticos. Una de las versiones más difundidas de este neodarwinismo social es el libro de Richard Herrnstein (1930-1994) y de Charles Murray (1943-), The Bell Curve: Intelligence and Class Structure

138. Así se expresó el político Daniel Filmus del Frente Para la Victoria (FPV) en un diálogo con la periodista Magdalena Ruiz Guiñazú, durante el programa "Magdalena Tempranísimo" emitido por Radio Continental el martes 11 de diciembre de 2012, a las 6 horas.

139. Fukuyama, Francis y Rawls, John cit. por Tedesco, Juan Carlos, "La educación en el marco del nuevo capitalismo", en Memorias del II Congreso Nacional de Educación Superior a Distancia. Medellín, Educación en la Globalización, 2000, páginas 33 y 34. 
in American Life, basado en el supuesto de que la habilidad cognitiva es la variable decisiva en la estructura social del nuevo siglo y que dicha habilidad es fundamentalmente hereditaria. El problema que enfrentarían las clases bajas en este aspecto es su inteligencia siempre o cada vez más baja y no tanto sus desventajas raciales y sociales. ${ }^{140}$

En esta tesis se centra la atención en las diversas circunstancias históricas en que el niño nace: será en un país desarrollado o subdesarrollado (no tienen marcos idénticos nacer en Estados Unidos o Japón que en Burundi o en Haití), en democracia o en dictadura (es diferente si alguien nace en Francia o bajo alguna dictadura del continente africano), perteneciente a la clase social alta, media o baja (no espera, en algunos aspectos, un mismo futuro al nacido en el seno de la familia de la Reina $X$ que al que nació en la familia de un pequeño empresario o al que proviene de una madre asalariada cuyo trabajo es no especializado). A un lado dichas circunstancias —donde se generan las diferencias básicas que luego se advertirán en la escuela- el único tiempo donde todos los seres humanos son iguales (en realidad, sólo lo son en derechos, como - por ejemplo- a vivir) es durante la gestación en el vientre materno. Desde el parto todo empieza a ser distinto pues se hacen presentes inmediatamente aquellas circunstancias a que se aludiera supra y que - poco a poco- empiezan a provocar disparidades. De modo que la habilidad cognitiva - como la denominan Hernstein y Murray- poco o nada tiene que ver con lo genético, desde esta mirada.

Asimismo, las explicaciones dadas por los economistas a este fenómeno coinciden en reconocer la complejidad de las variables que actúan y advierten que una fundamental es - como ya quedó dicho- la transformación en la organización del trabajo. Al respecto, numerosos estudios de economistas han comprobado que si bien las nuevas tecnologías aumentan la productividad, suprimen numerosos empleos. La mayor parte de los nuevos puestos de trabajo no se crea en los sectores tecnológicamente más avanzados sino en los servicios, donde el costo del trabajo representa una proporción importante del precio del producto.

Es por todos sabido que los cambios actuales en lo económico, político, social y cultural responden a diversos factores, entre los cuales se halla el papel cada vez más relevante del conocimiento. La denominación de la actual como "sociedad del conocimiento" o "sociedad de la información" ha ganado muchos adeptos entre los autores que se dedican a los análisis prospectivos. Anthony Giddens (1938-) en Consecuencias de la modernidad conceptualizó el papel del conocimiento a través de la categoría reflexividad que — según sus análisis- es el rasgo central de la sociedad actual. La información y el conocimiento estarían reemplazando a

140. Herrnstein, Richard y Murray, Charles. The Bell Curve: Intelligence and Class Structure in American Life. Simon and Schuster, 1995, páginas 48 y 60. 
los recursos naturales, a la fuerza y/o al dinero, como variables claves de la generación y distribución del poder en la sociedad. Si bien el conocimiento siempre ha sido una fuente de poder ahora sería su fuente principal lo que genera efectos importantes sobre la dinámica interna de la sociedad. ${ }^{141}$ A partir de lo aseverado, la educación ha pasado a tener mayor significación. De ello han tomado debida nota muchos países desarrollados y en menor medida los emergentes, que son aquéllos que más la necesitarían para convertirse en sociedades con futuro. Para algunos de éstos la educación no sería prioritaria, al menos para que sus efectos lo sean en beneficio de los más desaventajados. En esta investigación se analizará dicha problemática a través de la participación de los agentes educativos de nivel medio del Distrito de Junín.

De lo siguiente pareciera no haber duda: la información y el conocimiento integran la esfera de poder de toda persona. Ese poder ha de ser ejercido en beneficio propio y del grupo al que se pertenece, cuando la necesidad o la conveniencia así lo requieran. Va de suyo que si no se orientan las conductas en un sentido ético (pensando que el otro es un ser humano que tiene idénticos derechos y obligaciones) el resultado final de ese "todos contra todos" es una sociedad cada vez más desigual (por ende, más injusta). Lo mismo da se trate de personas que habiten en Estados Unidos, en Malasia, en Egipto o en Argentina; la desigualdad siempre existirá.

Ahora bien, los primeros estudios acerca de la información y del conocimiento como variables centrales del poder fueron significativamente optimistas respecto de sus potencialidades democratizadoras. Alvin Toffler (1928-) ${ }^{142}$ fue - sin duda- el representante más importante de esta corriente. Sus análisis se basaron en el carácter supuestamente democrático que tienen la producción y la distribución de las informaciones y de los conocimientos. Según dicho autor el conocimiento es infinitamente ampliable; su uso no lo desgasta sino que - al contrario - puede producir aún más conocimientos. Su producción requiere además un ambiente de libertad — que favorece a la creatividad- opuesto a toda tentativa autoritaria o burocrática de control del poder. Desde este punto de vista, la utilización intensiva de conocimientos produciría la disolución de las formas burocráticas de gestión porque obliga a adoptar permanentemente decisiones en función de la acumulación y del intercambio de los mismos. A todo esto, la distribución de conocimientos es más democrática que la de cualquier otro factor de poder, ya que el débil y el pobre pueden adquirirlos. Esto último conduce a hipotetizar que quienes ocupan la base de la pirámide

141. Giddens, Anthony. cit. por Tedesco, Juan Carlos, "Los pilares de la educación del futuro", en Debates de educación. Barcelona, Ponencia en línea, Fundación Jaume Bofill, 2003. $<$ http://www.uoc.edu/dt/20367/index.html $>$. Fecha de consulta: 5 de octubre de 2011. 228.

142. Toffler, Alvin, La tercera ola. Edición Décima, Madrid, Plaza y Janés, 1995, páginas 226- 
social tienen el mismo acceso al conocimiento que los demás, lo cual parece de una ingenuidad supina (o de una hipocresía extrema), máxime si se tiene en cuenta que se vive en sociedades de clases o diferenciadas económica y socialmente. En ellas el acceso a los bienes materiales y culturales nunca es igual para todos. Incluso existe un agravante: los sectores de menos recursos no suelen tener internalizados los valores intelectuales (pasan, por ejemplo, más horas delante del televisor y/o de la computadora con la finalidad de distracción que leyendo libros; optan más por trabajar que por estudiar). Todo esto se observa en la formación de los responsables que tienen a su cargo niños y adolescentes. También las diferencias pueden observarse en éstos cuando están en edad escolar. Tales realidades impulsaron a analizar la problemática en este trabajo.

Se vive, devenida de lo expresado, en una sociedad mundial dinámica en la que el concepto tradicional de ciudadanía (como el de patria) ha comenzado a perder significado. En su reemplazo aparece la adhesión a entidades supranacionales y un repliegue sobre el comunitarismo local, definiéndose la integración fundamentalmente como cultural y no como política. La aparición de lo local y de lo supranacional —como nuevos espacios de participación social - está asociada a la ruptura de la acción política tal como se la concebía hasta ahora. Así, la construcción de un concepto de ciudadanía mundial, de ciudadanía planetaria, exige un concepto de solidaridad vinculado al género humano y no a alguna de sus formas particulares. Esta construcción - empero- enfrenta dificultades, la mayoría de las cuales se vincula a las formas a través de las cuales se realiza el proceso de globalización. Desde el punto de vista económico, globalización no sólo significa que los capitales pueden moverse rápida y libremente por todo el planeta. Lo socialmente más importante es que, como las empresas pueden instalarse en cualquier parte del mundo y conectarse a través de redes de información, tienden a radicarse allí donde los costos son menores. ${ }^{143}$ De manera que son ellas las que deciden - y no los países donde se instalan- en qué ámbitos físicos van a realizar sus producciones. Valga señalar que esta realidad puede observarse en diferentes países, particularmente aquéllos que integran América Latina, los cuales vivieron procesos similares durante el neoliberalismo triunfante en los noventa.

Ahora bien, en este contexto - modificable prácticamente de continuo- habrá que darle sumo valor a una institución que es fundamental en cualquier sociedad: la familia. Ésta mantiene su gravitación, pero ya no es la familia estable de antes. La trayectoria familiar de una persona puede atravesar circunstancias diferentes, como pareja estable, familia monoparental y unión libre. Los parientes se transforman en una combinación de lazos electivos y de sangre. Precisamente, fueron estas características las que llevaron a incluir en

143. Tedesco, Juan Carlos, "Los pilares de la educación del futuro", en Debates de educación. Barcelona, Ponencia en línea, Fundación Jaume Bofill, 2003. 
esta investigación a los responsables (padres, madres, tutores u otros) de los egresados adolescentes y adultos de nivel medio del Distrito de Junín.

En el orden de ideas descripto, es preciso abrir la escuela a los requerimientos de la sociedad actual y redefinir sus pactos con los otros agentes socializadores, particularmente la familia y los medios tecnológicos. Surge así la pregunta referida a cuál debería ser el papel específico de la escuela. Pareciera necesario enfatizar la idea de que ella debe asumir una parte significativa de la formación en los aspectos "duros" de la socialización. Esto no significa reivindicar la rigidez, la memoria y la autoridad, sino aceptar que su tarea es llevar a cabo - en forma consciente y sistemática- la construcción de las bases de la personalidad de las nuevas generaciones. En un mundo donde las informaciones y los conocimientos se desplazan a través de tecnologías cada vez más sofisticadas y poderosas, el papel de la escuela debe ser definido por su capacidad de preparar al alumnado para el uso consciente, crítico y activo, de los aparatos que acumulan la información y el conocimiento. Así como el diseño institucional tradicional no debiera ser mantenido en las actuales circunstancias históricas, es preciso advertir que un diseño basado sólo en la autonomía de las escuelas puede aumentar los riesgos de atomización y de fragmentación social y cultural. Desde este punto de vista, la autonomía debe ser un estímulo para la vinculación y no para el aislamiento. Así, la idea de red constituye una forma útil para estimular conexiones entre las instituciones escolares que superen el formalismo tradicional y permitan intercambios reales, tanto a nivel local como nacional e internacional. ${ }^{144}$ Argentina no ha de quedar rezagada ante el desafío actual. En tal sentido, las diversas instituciones educativas (es decir, los agentes que las integran) deberán meditar concienzudamente en pos de arribar a decisiones que involucrarán a las generaciones que vendrán. No hay posibilidad alguna para el pensamiento único dadas la complejidad e importancia de la problemática. Todos los partícipes de la educación están llamados a manifestarse puesto que las diferentes voces enriquecerán el panorama. Vayan como ejemplo las palabras del licenciado en Ciencias de la Educación Gustavo Iaies:

Proponemos un modelo en el que se establezcan grandes bases de datos con actividades e información localizadas en los servidores de cada una de las escuelas. Estas bases deberían ser dinámicas, con contenidos provistos centralmente y otros producidos, seleccionados y actualizados por los docentes. ${ }^{145}$

144. Tedesco, Juan Carlos, La educación en el marco del nuevo capitalismo, en Memorias del II Congreso Nacional de Educación Superior a Distancia. Medellín, Educación en la Globalización, 2000, páginas 7 y 8 .

145. Iaies, Gustavo, Capítulo VI. "Introducción de nuevas tecnologías: el caso Argentina", en Las nuevas tecnologías y el futuro de la educación. Buenos Aires, Septiembre Grupo Editor, 2003, página 136. 


\subsubsection{Democracia y valores: creatividad, solidaridad y eficiencia}

Existe consenso entre los politólogos en reconocer que las democracias de hoy (particularmente las latinoamericanas) sólo serán sustentables (es decir, implicarán calidad de vida para todos) si se apoyan en niveles razonables de equidad y en una ciudadanía capaz de participar reflexiva y activamente en los procesos políticos. Competitividad, equidad y ciudadanía son los componentes fundamentales de las estrategias desarrollistas y la única política que actúa simultáneamente sobre todos ellos es la educativa. La educación no debería ser considerada una política social más y su prioridad no puede quedar circunscripta al reconocimiento retórico de su importancia, sin las decisiones fundamentales en materia de compromisos financieros y políticos. ${ }^{146}$ Las ideas de este párrafo trasuntan el pensamiento de Juan Carlos Tedesco (1944-). Negarlas sería desconocer cómo se pergeña y lleva a cabo la política educativa de un país. Pero llevarlas a la práctica suele traducir sólo los deseos de quien tiene una quimera. Especialmente si el escenario son algunas naciones de Latinoamérica, África y Asia.

A tenor de lo expresado surgen algunos interrogantes como por qué razón una democracia sustentable debe basarse en razonables niveles de equidad y no sea ella misma la que los origine. Y también por qué se requieren ciudadanos activos en lo político en lugar de ser la democracia misma la que los convierta en tales. Por otro lado, los compromisos políticos (que incluyen los financieros) se vienen celebrando desde hace ya tiempo y seguramente habrá otros en el futuro. Pero nunca se sabe exactamente a quiénes benefician. Suele escucharse la siguiente expresión: "no se sabe adónde va a parar el dinero" (por ejemplo, el de un préstamo concedido por un organismo multilateral de crédito a algún país). Se sabe, en cambio, que no han sido los sectores más necesitados y — a veces- ni siquiera los sectores medios los favorecidos con el mismo. Asimismo, más allá de la ayuda que suelen otorgar los gobiernos nacionales (de Argentina, Brasil y Uruguay, por ejemplos) a los más desaventajados, no se registran casos de personas que nacieran en un barrio humilde (menos aún si provienen de una "villa", "favela" o "cantegril") y pasaron a ocupar - varios años después - posiciones de poder en alguna empresa privada (mediana o grande) u organismo de gobierno (nacional, provincial o municipal). A ellos les estarían "reservados" determinados oficios (mínimamente remunerados), para los que - a veces - no existen siquiera escuelas $\mathrm{u}$ otras instituciones donde formarse. Algunas de esas actividades - como las correspondientes a una pequeña empresa alimenticia - no requieren capacitación teórica alguna ya que se aprende a realizarlas con la práctica misma. Estas dificultades para acceder a la información y

146. Tedesco, Juan Carlos, "La educación como clave para el desarrollo nacional". La Nación, (Sección Educación), 25 de mayo de 2003, página 22. 
al conocimiento por parte de grupos desfavorecidos son objeto de análisis en esta investigación.

El sistema educativo de cualquier país tiene ante sí dos grandes responsabilidades: por un lado, producir información y conocimiento y por el otro, distribuirlos democráticamente. La educación se convierte en un factor de desarrollo en la medida en que la sociedad sea capaz de producir endógenamente conocimientos y que éstos se distribuyan sin diferencia alguna en toda la población. La formación de una persona democrática en cualquier región, particularmente en América Latina, es una de las metas fundamentales de la educación. Para ello la escuela no sólo ejerce su influjo a través de la producción y la distribución de aquéllos sino - fundamentalmente- por los métodos y las prácticas que rigen a los sistemas educativos. Asimismo, es menester reflexionar sobre tres órdenes de valores. En primer lugar la creatividad, que tanto a nivel de la tecnología como de las ciencias sociales, de las artes y de las letras, debería ser uno de los valores fundamentales que orienten las prácticas pedagógicas. El segundo es la solidaridad. América Latina ha vivido no hace mucho un desmembramiento, una ruptura del tejido social y un acentuado proceso de polarización social. En el futuro, ningún orden democrático sería posible si las sociedades no asumen conductas que expresen los elementos básicos de la solidaridad social. El tercer orden de valores se refiere a la eficiencia. El sistema educativo y las demás prácticas sociales han de ser eficientes; es decir, deben responder adecuadamente a las demandas sociales. Torna necesario romper las contradicciones existentes entre la eficiencia y la democracia como así entre la eficiencia y la creatividad y la solidaridad. Si no se logra esto será muy difícil sostener un proceso de crecimiento y de satisfacción de necesidades sociales (especialmente las de aquellos sectores más pobres), única vía para romper el proceso de decadencia que algunos países de la región han vivido en los últimos treinta años. ${ }^{147}$ Este retroceso inquieta a todos. Más que ello, se diría que preocupa a tal punto que el interrogante se refiere a cómo es posible (o cómo justificar) que con gobiernos democráticos llegados al poder después de las dictaduras en el último tercio del siglo XX, existan hoy problemas tan graves sin solucionar. Nadie pone en duda lo que se ha avanzado en los últimos veinte años en materia de reconocimiento de los derechos humanos fundamentales, pero acontece que muchos de ellos (trabajo, salud, educación, seguridad y vivienda, entre otros) no pueden aún ser ejercidos plenamente por vastos sectores de la población.

Por lo demás, es conteste en las sociedades latinoamericanas la opinión de que el retorno de la democracia originó (algunos sostienen que continuó) un fenómeno de corrupción estatal, evidenciado en gobiernos que ejercen el poder sin contralor alguno. Por otro lado, no existe (o

147. Tedesco, Juan Carlos, La educación como clave para el desarrollo nacional. La Nación, (Sección Educación), 25 de mayo de 2003, página 23. 
pareciera no haber) ningún "iluminado" (o "iluminados") de sector alguno con intenciones de solucionar este problema en forma violenta (sean civiles o militares). Las democracias actuales, con sus virtudes a más de todo lo que necesitan mejorar, se han constituido en un valor firmemente internalizado en los habitantes. En relación con ello, los nuevos escenarios demandan una educación de igual calidad (y muy buena) para todos, constituyendo un tema prioritario en la agenda de los gobiernos (el de Argentina incluida). Se requiere una formación profesional de excelencia y continua en todos los agentes que cumplen funciones en las comunidades educativas. Esta exigencia se extiende a todos aquellos docentes que se desempeñan en escuelas estatales de nivel medio del Distrito de Junín. El ejercicio de sus roles - teniendo en cuenta los cargos que ocupan- será objeto de análisis en esta investigación.

\subsubsection{Una educación de calidad para todos}

Sobre la base de considerar a la educación como derecho humano fundamental, la Organización de las Naciones Unidas para la Educación, la Ciencia y la Cultura (UNESCO) incorporó —en alusión a la calidad de la educación - cinco dimensiones relacionadas entre sí, al punto que la ausencia de una de ellas motivaría una concepción errónea de lo que debe entenderse por calidad educativa. Estas dimensiones son equidad, relevancia, pertinencia, eficacia y eficiencia.

A continuación se analizan todas ellas, habida cuenta la posible confusión que podrían generar tales términos. Así, desde una postura que algunos denominarían liberal se sostiene que no es posible lograr un nivel de excelencia en el aula con todos los estudiantes. Se correría el riesgo de bajar los parámetros de calidad, ofreciendo una educación peor a la totalidad. Como mecanismos para promover una mayor calidad se utiliza la competitividad entre las escuelas, la libertad de elección del colegio y la información acerca de los resultados que se dan en los mismos. En cambio, desde la perspectiva de la UNESCO la calidad y la equidad no sólo no son incompatibles sino que son indisociables. Una educación es de calidad si ofrece recursos y ayudas necesarios para que todos los estudiantes — de acuerdo con sus capacidades - alcancen los máximos niveles de aprendizaje posibles. Es decir, cuando todos los educandos y no sólo quienes pertenecen a la clase dominante alcanzan a desarrollar las competencias necesarias para ejercer la ciudadanía, insertarse en la sociedad del conocimiento y acceder a una profesión o empleo dignos. ${ }^{148}$

148. Marchesi, Álvaro y Martín, Elena, Calidad de la enseñanza en tiempos de cambio. Madrid, Alianza, 1998, página 242. 
Ahora bien, equidad no es lo mismo que igualdad aunque ambos vocablos están estrechamente relacionados. La equidad comprende los principios de igualdad y de diferenciación, ya que sólo una educación adaptada a las necesidades de cada uno asegurará que todos tengan las mismas oportunidades de hacer efectivos sus derechos. Se podría hablar aquí de tres niveles vinculados entre sí: en primer lugar, equidad de acceso. Las oportunidades de acceder a los diferentes niveles educativos son las mismas para todos. El segundo nivel está dado por la equidad en los recursos y en los procesos educativos. Aquí cabe exigir un trato diferenciado de los recursos materiales, pedagógicos, tecnológicos y financieros según las necesidades de las personas o grupos y finalmente equidad en los resultados del aprendizaje: se aspira a que todos los alumnos, sea cual fuere su origen social y cultural o la zona geográfica que habiten, alcancen aprendizajes equiparables.

Junto con la equidad, la relevancia y la pertinencia responden a las preguntas de educación para qué y educación para quién, respectivamente. ${ }^{149}$ En tal sentido, es opinión compartida entre docentes de nivel medio del Distrito de Junín que las deficiencias observadas en muchos egresados de 2010 provienen de aprendizajes defectuosos del año anterior. Los profesores dijeron "hacemos lo que podemos" para el mejoramiento del nivel de esos alumnos. Como es dable advertir, la labor de los educadores es muy rudimentaria, casi no profesional. Hacer lo que se pueda es la expresión inequívoca de una realidad incontrastable y - no por ello- menos desesperanzadora, porque si los docentes no pueden no se sabe quiénes podrían en su lugar. Consecuentemente, los educandos de los sectores desaventajados son los más perjudicados porque casi siempre (por diferentes causas) están más atrasados en sus aprendizajes. En esta investigación se prestará atención a los resultados que se obtengan de los cuestionarios aplicados a egresados de sectores desfavorecidos y también se analizará qué relación existe con los que correspondan a los demás egresados. Asimismo, la pertinencia de la educación remite a la necesidad de que ella sea significativa para personas de distintos estratos sociales y con diferentes capacidades e intereses, de manera que puedan incorporar los contenidos de la cultura mundial y local y "construirse" como sujetos, desarrollando su autonomía, autogobierno, libertad e identidad. ${ }^{150}$

Todos los conceptos explicitados supra son irrefutables, pero la realidad — visualizada por numerosos especialistas en materia educativa a través de sus obras y comprobada a diario por los educadores en las aulas- dista muchas veces en grado sumo de tales conceptos teóricos. Bastó presenciar — como sucedió periódicamente en 2010 - clases de egresados del nivel medio (adolescentes y adultos) en escuelas del Distrito de Junín. En relación a lo

149. "El derecho a una educación de calidad para todos en América Latina y el Caribe", en REICE. Vol. 5, No 3. Santiago, OREALC/UNESCO, 2007.

150. Marchesi, Álvaro y Martín, Elena, op. cit., página 246. 
observado podría aseverarse que la educación nunca llegó a ser personalizada, tal como se exige desde la normativa y desde los libros educativos. Menos aún cuando se trató de cursos que tienen entre veinte y cincuenta estudiantes. No debe olvidarse que muchos de esos educandos se ven compelidos a asistir a clase por sus responsables, por lo que muestran a su hora una actitud negativa hacia el conocimiento, la cual determina que se vean impedidos de aprender. Frente a estas situaciones poco se podrá lograr no obstante el esfuerzo del docente y en tanto éste utilice —oportuna y adecuadamente- todos los medios que tiene a su alcance.

Además de los señalados, la eficacia y la eficiencia son los restantes atributos básicos de una educación de calidad para todos. La eficacia se pregunta por la medida en que se logran los objetivos de la educación. Por ejemplos: en qué proporción los niños logran acceder a la escuela o se atienden las necesidades educativas de los adultos o las personas alcanzan los aprendizajes que corresponden en cada etapa educativa. Bajo esta dimensión no sólo se deben tener en cuenta los aprendizajes de las materias del currículo - Lenguaje y Matemática principalmente- sino también la eficacia de la gestión en su sentido más amplio (comprensivo de todas las actividades administrativas). Por su parte, la eficiencia se pregunta por el costo con que dichos objetivos son alcanzados. Ella es definida en base al financiamiento destinado a la educación, la responsabilidad en el uso de los recursos y los modelos de gestión institucional. ${ }^{151}$

En Argentina, desde la puesta en marcha del Operativo Nacional de Evaluación (ONE) en 1993, hubo diversas modificaciones en las pruebas y no se ha establecido un mecanismo de empalme técnico para comparar los resultados a través del tiempo. Un primer aspecto a señalar es que en 1995 las provincias más pobladas lideraban el ránking de la calidad educativa: la Ciudad Autónoma de Buenos Aires, la provincia de Buenos Aires, Mendoza y Santa Fe, en ese orden. En cambio, en 2005 se observó el crecimiento de las provincias patagónicas, menos pobladas y con mayor financiamiento por alumno. Según Axel Rivas, en Radiografía de la educación argentina: "las cuatro provincias con mejor posición en las evaluaciones de la calidad educativa en 2005 estaban entre las seis provincias con mayor inversión por alumno estatal del país". 152

Por lo antes mencionado surge el interrogante de cómo ha de ser la gestión - a todo nivel- para que se materialice una educación de calidad para todos. Tal problemática se abordará en esta investigación vía cuestionarios aplicados a directores y secretarios de escuelas secundarias estatales — de adolescentes y de adultos— del Distrito de Junín.

151. "El derecho a una educación de calidad para todos en América Latina y el Caribe", en REICE. Vol. 5, № 3, Santiago, OREALC/UNESCO, 2007.

152. Rivas, Axel, Capítulo 3. "Cartografías”, op. cit., página 100. 


\subsection{Características del nivel medio del sistema educativo argentino}

En todos los países el sistema educativo — con sus niveles inicial, primario, secundario y universitario- se estructuró progresiva y tardíamente desde arriba hacia abajo. Primeramente se organizaron las universidades a partir de los siglos XII y XIII. En el mundo occidental la universidad más antigua (que continúa en funciones) y que fue la primera en usar tal denominación, es la de Bolonia (en Italia) que comenzó sus actividades en 1088 como una agrupación de estudiantes. Luego surgieron los colegios que hoy se denominan de enseñanza media (en los siglos XVI y XVII), posteriormente las escuelas primarias en la segunda mitad del siglo XIX y por último (en la segunda mitad del siglo XX) se institucionalizó la educación llamada en algunos países pre-escolar (en Argentina se denomina inicial, en atención al artículo 18 de la Ley de Educación Nacional Nº 26.206 sancionada en 2006).

Las instituciones de enseñanza pasaron a ocupar gradualmente lugares que antes le correspondían a la familia, la cual se vio desplazada por la creciente complejización de la sociedad. Preceptores, institutrices y niñeras cedieron sus puestos a colegios, escuelas y jardines, respectivamente. Así, muchos que no accedían a contratar a un preceptor o a una institutriz para educar a sus hijos en el seno familiar, pudieron enviarlos a un establecimiento educativo. Ahora bien, durante el siglo XIX, progresivamente se producirían cambios que -en gran medida - fueron el resultado de una presión cada vez mayor de los nuevos sectores sociales para acceder a la escuela secundaria. Este nivel paulatinamente se fue integrando a sistemas nacionales que se desarrollaron a partir de Napoleón Bonaparte (1769-1821) y desde allí se planteó como estatal y gratuito en muchos casos. Hacia fines de siglo comenzó a extenderse a las mujeres.

A partir de 1900 se constituyó una escuela secundaria más unitaria en rasgos tales como continuar a la primaria y tener un reconocimiento oficial, con modalidades diferentes y segmentaciones que habilitan al estudiante para futuros sociales disímiles. En la segunda mitad del siglo la escuela media, inicialmente concebida desde la universidad como una preparación para ésta, pasó a ser pensada como una prolongación de la primaria. La coexistencia -más o menos inarmónica- de estos propósitos u objetivos está en la base de la crisis en que se encuentra hoy en casi todo el mundo, dicho nivel, Argentina incluida.

Centrando la mira en dicho país, es dable observar que su sistema educativo nunca fue uno solo sino que estuvo dividido en dos niveles que constituyeron culturas educativas muy distintas: el primario y el secundario. Una Argentina moderna vio nacer la escuela media en 1863 con la recreación — por Bartolomé Mitre - del Colegio Nacional de Buenos Aires y la fundación de colegios nacionales en las principales capitales de provincia en las décadas siguientes. Como dato negativo se señala que el nivel medio careció de una norma que definiera sus objetivos, modalidades y contenidos. Su organización se debió, según afirman Guillermo Obiols (1950-2002) y Silvia Di Segni Obiols, a las iniciativas de los ministros de 
turno que propusieron - y en algunos casos lograron llevar a cabo- distintos proyectos de reforma. Todo ello finalmente no prosperó y como prueba vaya este dato: en los últimos cien años Argentina cambió un ministro de educación nacional cada once meses. ${ }^{153}$

La Ley de Educación Común No 1.420 (sancionada el 8 de julio de 1884) es considerada la piedra basal del sistema educativo nacional. Dicha ley estableció la educación primaria obligatoria, gratuita y gradual. Se observó allí la temprana masificación del sistema educativo con el objetivo de la homogeneización cultural ante el contingente de inmigrantes europeos y la diversidad provincial. La educación secundaria, en cambio, se erigió sobre un principio opuesto: la selección social. Mientras aquélla siguió el modelo sarmientino del docente vocacional - como funcionario del Estado que persigue el ideal civilizatorio- el colegio secundario se basó en el modelo mitrista enciclopédico de selección de la clase gobernante.

Las estadísticas expresan fehacientemente ambos modelos: en 1900 asistían cuatrocientos cincuenta mil alumnos a la escuela primaria y sólo seis mil setecientos a la secundaria. Por entonces existía una escuela media por provincia como cabeceras del modelo. Mientras la creación de escuelas primarias era una atribución provincial (establecida en la Constitución Nacional de 1853), los colegios secundarios fueron una iniciativa de la Nación.

En cuanto a sus trayectorias, a diferencia de la expansión continua de la primaria la secundaria mostró grandes saltos. El primero de ellos se dio durante los dos primeros gobiernos peronistas (que ocuparon el período 1946-1955) con la multiplicación de escuelas y el reconocimiento del derecho a la educación de los sectores populares. Si bien en los primeros treinta años del siglo XX se sumaron apenas ochenta mil alumnos al nivel medio, entre 1930 y 1960 surgieron cuatrocientos ochenta mil nuevos estudiantes. El segundo gran salto en la escolarización media se inició en 1983 (con la recuperación democrática) como señal de una etapa que comenzó a definir - por primera vez- el derecho social a la educación secundaria. Este derecho incluye, entre otras modificaciones, la eliminación de los exámenes de ingreso que fueran implementados por la última dictadura militar (1976-1983).

Sabido es que la autonomía escolar es uno de los importantes ejes de debate en la política educativa de cualquier país. Una encuesta realizada entre directivos escolares argentinos por la Organización de las Naciones Unidas para la Educación, la Ciencia y la Cultura (UNESCO) permite arribar a interesantes conclusiones. Una primera es que las escuelas en Argentina - las medias entre ellas - tienen pocas atribuciones en la gestión de los diferentes recursos y muchas de ellas en lo referido a las definiciones pedagógicas. Así, las escuelas estatales no pueden seleccionar a sus educadores (el 25 por ciento que sí puede hacerlo es el

153. Obiols, Guillermo y Di Segni Obiols, Silvia, Capítulo III "La crisis de la escuela secundaria", en Adolescentes, posmodernidad y escuela, Buenos Aires, Ediciones Noveduc Libros, agosto 2008, páginas 140 y 141. 
universo de las escuelas privadas). Tampoco les es dado establecer los salarios de los docentes (ni siquiera en la mayoría de las escuelas privadas, que pagan los mismos sueldos que las estatales) o manejar un presupuesto propio. En cambio, los directores destacan el alto nivel de autonomía respecto de las políticas referidas a la disciplina y a la evaluación de los alumnos, a la selección de los libros de texto y —en buena medida también- en la definición de los contenidos curriculares. Incluso tienen una alta autonomía para seleccionar a los educandos, lo cual podría ser interpretado como una ventana abierta a la discrecionalidad. Cabría aquí, entonces, la pregunta sobre cuál es el criterio utilizado por esas escuelas para elegir a sus estudiantes. En el Distrito de Junín pudieron observarse durante 2010, 2011 y 2012, en los colegios medios estatales D, E y F, algunas prácticas que podrían calificarse como discrecionales - cuando no discriminatorias- por diversas razones (económica por ejemplo). ${ }^{154}$

Actualmente en Argentina hay escuelas medias de jurisdicción nacional y provincial, públicas y privadas, algunas con abundantes y otras escasos recursos humanos y materiales, algunas que cubren espacios físicos amplios y otras reducidos, con distintas modalidades, para sectores sociales altos, medios y bajos y para adolescentes y para adultos. Para Axel Rivas "se observa que las escuelas estatales con educandos de mayor nivel socioeconómico tienen una oferta levemente mayor de computadoras y de edad de los directivos, así como amplias ventajas en la calidad edilicia". ${ }^{155}$ Por ende, resulta muy difícil hacer una referencia idónea de la escuela secundaria en su conjunto. Empero, más allá de esas variedades hay un modelo de escuela que está dirigido a los sectores medios. Ahora bien, en esta escuela "promedio" se ha erigido una cultura - verdaderos patrones cristalizados de comportamiento- muy difícil de modificar en el corto plazo y en la que poco inciden las resoluciones ministeriales referidas al proceso educativo. A propósito de lo aseverado, en esta investigación se centralizan las actividades individuales y colectivas en diecinueve escuelas estatales de nivel medio del Distrito de Junín, que contaban en 2010 con egresados de diferentes sectores sociales, si bien —según la opinión de muchos de ellos- no tenían certeza a cuál de esos sectores pertenecían exactamente.

154. En las escuelas D, E y F los estudiantes abonan mensualmente un monto de dinero, en concepto de cuota para satisfacer las necesidades materiales de la asociación cooperadora (lo recaudado se destina a arreglar deficiencias edilicias). El pago de dicha cuota es voluntario. Hay casos en que uno o más alumnos no pagan durante varios meses y esa situación se normaliza a fin del ciclo lectivo, exigiéndose el pago de lo atrasado contra entrega del boletín de calificaciones. También las tres escuelas citadas priorizan - para admitir a un educando que empieza el nivel- que tenga o haya tenido años atrás un/a hermano/a que estudie o haya estudiado en ese mismo colegio.

155. Rivas, Axel, Capítulo 4. “Cuestiones”, op. cit., página 152. 
En otro orden de ideas, desde una añeja práctica organizacional se suponía que es mejor separar a los alumnos según sus niveles de aprendizaje con el fin de constituir grupos homogéneos en las aulas. En Argentina, diversas políticas educativas abrazaron durante décadas esta creencia pedagógica. Por ejemplo, el Reglamento General de Escuelas de la provincia de Buenos Aires - de 1958 - creaba los Grados A para los alumnos con dificultades de conducta o de aprendizaje, una norma que ya no se aplica pero que tuvo su auge hasta la última dictadura militar.

Estas prácticas fueron modificándose, especialmente a partir del retorno de la democracia en 1983 y comenzaron a afianzarse modelos de integración con todos los alumnos en las mismas aulas. No sólo se buscó eliminar estereotipos que los discriminaban, sino también fomentar la enseñanza en contextos de diversidad, con una apertura al aprendizaje desde las diferencias. Sin embargo, muchos docentes de diferentes escuelas (estatales y privadas) siguieron -y continúan hoy- defendiendo el supuesto pedagógico de los grupos homogéneos. Su práctica no está en absoluto desterrada, pese a los grandes avances de la teoría pedagógica en pos de la integración. Las pruebas del Programa Internacional para la Evaluación de Estudiantes (PISA) muestran que el 22,4\% de las escuelas secundarias argentinas todavía agrupa a los alumnos según sus capacidades (dentro de las aulas o entre ellas). Esto mismo ocurre en otros países de la región (especialmente Brasil y Colombia) y -en menor medida - en los naciones de la Organización para la Cooperación y el Desarrollo Económicos (OCDE).

Cuando se comparan los resultados de los aprendizajes de los educandos, eliminando el sesgo del nivel socioeconómico y considerando sólo el "efecto escuela”, se observa que en los colegios que trabajan con grupos heterogéneos se obtienen mejores resultados en un 5,4 por ciento que en aquéllos que clasifican según los diferentes niveles. Estos datos sustentan el postulado ético y democrático de la integración a partir de la evidencia pedagógica concreta. Asimismo, en ningún país se ha observado una diferencia estadísticamente significativa a favor de los aprendizajes alcanzados en las escuelas que agrupan homogéneamente a los alumnos según sus aptitudes. ${ }^{156}$

Si se analiza la educación en las provincias pueden advertirse situaciones muy dispares. En el siguiente cuadro se comparan niveles de pobreza, tasas de escolarización secundaria y porcentajes de analfabetismo (nótese que hay una relación cercana entre peores indicadores sociales y peores indicadores educativos):

156. Rivas, Axel, Capítulo 4. “Cuestiones”, op. cit., página 164. 
Nivel de pobreza, tasa neta de escolarización secundaria y porcentaje de analfabetismo, 2004. Por provincia

\begin{tabular}{|l|c|c|c|}
\hline & Nivel de pobreza & $\begin{array}{c}\text { Tasa neta de escolarización } \\
\text { secundaria } 2004\end{array}$ & $\begin{array}{c}\text { Porcentaje de } \\
\text { analfabetismo 2004 }\end{array}$ \\
\hline Buenos Aires ${ }^{*}$ & $19 \%$ & $77 \%$ & $2 \%$ \\
Catamarca & $32 \%$ & $68 \%$ & $3 \%$ \\
Chaco & $46 \%$ & $53 \%$ & $9 \%$ \\
Chubut & $10 \%$ & $73 \%$ & $4 \%$ \\
Ciudad Autón. de Bs. As. & $12 \%$ & $84 \%$ & $1 \%$ \\
Córdoba & $19 \%$ & $66 \%$ & $2 \%$ \\
Corrientes & $40 \%$ & $55 \%$ & $7 \%$ \\
Entre Ríos & $28 \%$ & $65 \%$ & $3 \%$ \\
Formosa & $40 \%$ & $58 \%$ & $7 \%$ \\
Jujuy & $40 \%$ & $70 \%$ & $5 \%$ \\
La Pampa & $17 \%$ & $72 \%$ & $3 \%$ \\
La Rioja & $28 \%$ & $66 \%$ & $3 \%$ \\
Mendoza & $18 \%$ & $69 \%$ & $4 \%$ \\
Misiones & $37 \%$ & $51 \%$ & $7 \%$ \\
Neuquén & $21 \%$ & $67 \%$ & $4 \%$ \\
Río Negro & $22 \%$ & $65 \%$ & $4 \%$ \\
Salta & $35 \%$ & $67 \%$ & $5 \%$ \\
San Juan & $30 \%$ & $66 \%$ & $3 \%$ \\
San Luis & $25 \%$ & $64 \%$ & $3 \%$ \\
Santa Cruz & $3 \%$ & $72 \%$ & $2 \%$ \\
Santa Fe & $19 \%$ & $72 \%$ & $3 \%$ \\
Santiago del Estero & $43 \%$ & $49 \%$ & $7 \%$ \\
Tierra del Fuego & $6 \%$ & $58 \%$ & $5 \%$ \\
Tucumán & $35 \%$ & & $5 \%$ \\
\hline
\end{tabular}

* Destácase a la provincia de Buenos Aires donde se ubica el Distrito de Junín en el noroeste de la misma.

Fuente: CIPPEC (Centro de Implementación de Políticas Públicas para la Equidad y el Crecimiento), Proyecto de Monitoreo de la Ley de Financiamiento Educativo.

El federalismo argentino expresa desigualdades entre las provincias que agregan un elemento adicional a las desigualdades sociales de su población. Así, en el análisis comparado de la inversión por alumno entre 1996 y 2006 la enorme desigualdad entre las provincias no 
sólo se mantuvo sino que aumentó levemente. En 2006 las seis provincias con menos recursos invertían dos veces y media menos que las seis provincias con más recursos. ${ }^{157}$

El análisis del financiamiento educativo entre las provincias requiere comparar -al menos- dos indicadores complementarios: la inversión anual por alumno y el gasto educativo como porcentaje del gasto total. Sólo mirando ambos datos al mismo tiempo se puede comprender la desigualdad del financiamiento educativo por provincia y del esfuerzo que realiza cada una de ellas para financiar al sistema educativo. Tierra del Fuego en 2006 invirtió \$ 7.171 por alumno del sector estatal, al tiempo que Salta apenas alcanzó los \$1.497, es decir casi cinco veces menos. La causa central de esta disparidad debe hallársela en desigualdades fiscales de las provincias. Las patagónicas son muy beneficiadas por la coparticipación federal de impuestos y/o por recursos propios, mientras que varias del norte argentino y las más pobladas del país son las que tienen los Estados más pobres.

Buena parte del esfuerzo de cada una destinado a la educación está condicionado por las capacidades fiscales: si tienen menos recursos deben realizar un mayor esfuerzo para financiar la educación. Por ello no resulta extraño que Buenos Aires sea la que tiene menos recursos estatales por habitante y realice el mayor esfuerzo presupuestario en educación. ${ }^{158}$ Asimismo, comparando los alumnos que ingresaron a $1^{\circ}$ Año en 2000 y el número de ellos que en 2004 accedió a $5^{\circ}$ Año, se observa que sólo un 51 por ciento pudo finalizar sus estudios en el tiempo considerado ideal (sin repitencias ni abandonos ${ }^{159}$ ). Préstese atención al siguiente cuadro para tener un panorama detallado de esta realidad:

Porcentaje de retención en el nivel medio según región geográfica entre 2000 y 2004

\begin{tabular}{|l|c|c|c|}
\hline Regiones & Alumnos en $1^{\circ}$ Año en 2000 & Alumnos en 5 ${ }^{\circ}$ Año en 2004 & \% retención \\
\hline \hline Centro & 447.326 & 231.231 & 51,7 \\
Cuyo & 60.093 & 28.999 & 48,3 \\
Noreste & 193.673 & 97.489 & 50,3 \\
Noroeste & 84.728 & 45.477 & 53,7 \\
Sur & 39.935 & 18.929 & 47,4 \\
Total país & 825.755 & 422.139 & 51 \\
\hline
\end{tabular}

Fuente: Dussel, Montes y Legarralde, 2006, basado en Relevamientos Estadísticos anuales 2000 y 2004. Ministerio de Educación, Ciencia y Tecnología (MECyT).

157. Rivas, Axel, Capítulo 4. "Cuestiones”, op. cit., página 134.

158. Rivas, Axel, Capítulo 3. "Cartografías", op. cit., página 108.

159. Rivas, Axel, Capítulo 3. "Cartografías", op. cit., página 84. 
Nota: En las regiones Centro y Noroeste aparecen las mayores cantidades de educandos que ingresaron a $1^{\circ}$ Año en 2000 y que lograron llegar a $5^{\circ}$ Año en 2004.

La cifra final de retención del 51 por ciento es muy preocupante. Significa que muy poco más de uno de cada dos estudiantes que iniciaron el nivel medio logró finalizarlo. Saber dónde están hoy esos ex alumnos que representan el 49 por ciento que no concluyó el nivel generaría otra investigación.

Como se señaló, Argentina en el período 2000-2004 dejó de capacitar recursos humanos, siendo éste uno de los elementos esenciales considerados por todos los economistas para el desarrollo económico de un país. Surge la pregunta, entonces, acerca de si esta realidad podrá ser revertida en el futuro. Si para responderla se pone la mira en los países desarrollados se verifica cuán importante es en ellos la materia educativa. De manera que, al no resolver problemáticas como la planteada, Argentina se aleja cada vez más de la calidad de vida de que gozan aquéllos. Existen también datos de la misma fuente anterior y de idéntico período (2000-2004) que muestran la deuda respecto de la educación adulta: en las provincias del norte -especialmente- alrededor del 25 por ciento de su población adulta carece de instrucción o sólo posee la primaria incompleta. Esta deficiencia educativa ocasiona al país perjuicios en lo económico, político, social y cultural. El efecto más grave lo sufrirán ellos mismos: serán casi seguramente mano de obra no calificada, con la desventaja que ello acarrea en la vida personal (poca o nula posibilidad de decidir por sí mismos su futuro) y social (ocupar bajos status, escasamente reconocidos).

A todo esto, la información oficial por ciudades argentinas muestra diferencias más profundas: mientras que en Buenos Aires la retención interanual es del 65 por ciento, en Misiones es del 46 por ciento. La brecha entre ambas es del 19 por ciento. En otro orden, Argentina no presenta actualmente desigualdades en el acceso a la educación según el género, pero aún es fuerte la segmentación por ámbito urbano o rural. En cuanto a la tasa de repitencia anual, véase el cuadro siguiente donde se consideran las diferencias entre el sector estatal y el privado y entre escuelas ubicadas en zonas urbanas y rurales: 
Tasa de repitencia por sector y ámbito (porcentajes)

\begin{tabular}{|l|c|c|c||c|c|c|c|}
\hline \multirow{2}{*}{$\begin{array}{c}\text { Tasa de repitencia en } \\
2007\end{array}$} & \multirow{2}{*}{$\begin{array}{c}\text { Total } \\
\text { seis años de } \\
\text { estudio) }\end{array}$} & \multicolumn{7}{|c|}{ Año de estudio } \\
\cline { 6 - 9 } & & $7^{\circ}$ & $8^{\circ}$ & $9^{\circ}$ & $10^{\circ}$ & $11^{\circ}$ & $12^{\circ}$ \\
\hline \hline Estatal & $11,9 \%$ & $11,7 \%$ & $18,3 \%$ & $14,2 \%$ & $14,7 \%$ & $10,4 \%$ & $1,8 \%$ \\
\hline \hline Privado & $4,3 \%$ & $3,6 \%$ & $6,5 \%$ & $4,9 \%$ & $6,0 \%$ & $3,8 \%$ & $0,5 \%$ \\
\hline \hline & $10,2 \%$ & $10,2 \%$ & $15,9 \%$ & $12,2 \%$ & $12,5 \%$ & $8,5 \%$ & $1,5 \%$ \\
\hline \hline Urbano & $8,2 \%$ & $7,6 \%$ & $13,1 \%$ & $9,4 \%$ & $11,3 \%$ & $6,5 \%$ & $0,9 \%$ \\
\hline \hline Rural
\end{tabular}

Fuente: Documento Preliminar para la discusión sobre la educación secundaria en Argentina, Ministerio de Educación de la Nación, octubre de 2008.

Los peores indicadores de repitencia se encuentran en la educación estatal (en total, 7,6 por ciento más respecto de la enseñanza privada durante 2007) y en todos los años de la escolaridad (obsérvese desde $7^{\circ}$ al $12^{\circ}$ años). Por otra parte, en los establecimientos rurales pueden observarse mejores desempeños. Ello podría deberse a que reciben menos alumnos y ofrecen condiciones de cursada particulares (muchas veces, semi internados), que permiten un mayor seguimiento de los estudiantes. ${ }^{160}$ La cobertura escolar en estas zonas es menor porque ya operó una elección previa que dejó ingresar al sistema educativo a quienes están en mejores condiciones para aprender. ${ }^{161}$ Se hace evidente esta injusticia del sistema que, en base a una selección previa, permite el ingreso de aquéllos que están en una mejor situación (básicamente económica). Con apoyo en lo expresado podría conjeturarse lo siguiente: resulta baladí lo establecido en el texto supremo argentino respecto de "la promoción de los valores democráticos y la igualdad de oportunidades y posibilidades sin discriminación alguna". ${ }^{162} \mathrm{La}$ falta y/o la igualdad de oportunidades y de posibilidades en los ámbitos rural y urbano se aprecia todos los días, independientemente de los discursos — de políticos y de dirigentes educativos - en contrario.

160. Al respecto, se han constituido sistemas de pago extra a los docentes por la situación de desfavorabilidad o ruralidad. Esta política — que varía según las provincias- es vital para compensar los costos extras de las distancias y el desarraigo de muchos docentes rurales, así como para incentivar que educadores con alto puntaje elijan trabajar en este tipo de escuelas. Ahora bien, mientras el $22 \%$ de los alumnos del Noroeste Argentino (NOA) asiste a escuelas rurales, esta proporción apenas representa el 5\% en la región central. Rivas, Axel, Capítulo 4. "Cuestiones", op. cit., página 142.

161. Dussel, Inés, Montes, Nancy y Legarralde, Martín, Informe sobre Educación y Desarrollo para el proyecto Gestión XXI, PNUD 97/025, Ministerio de Economía de la Nación, agosto de 2006, página 48.

162. Artículo 75, inciso 19, párrafo $3^{\circ}$, de la Constitución Nacional. 
Otro dato interesante de la realidad argentina es que en las escuelas públicas se advierte la incorporación de nuevos sectores sociales en mucha mayor medida que en las privadas. Por otro lado, la incidencia de las desigualdades socioeconómicas en la educación se trasunta en que la deserción en las escuelas públicas quintuplica a la de las privadas. Esto sucede en el nivel medio pero el problema empieza en el Jardín. La psicoanalista Adriana Gladsztein asevera que en la escuela secundaria “aparecen pautas más rígidas, objetos novedosos (cuaderno, cartuchera), nuevas reglas que cumplir. En muchos casos los niños no pueden llegar a incorporar esos estímulos. Es decir, no a todos esa experiencia les resulta de igual modo". ${ }^{163}$ En atención a esto, obsérvese el cuadro siguiente:

\section{$\underline{\text { Las diferencias comienzan en el jardín de infantes (porcentajes) }}$}

\section{Niños que asisten según la edad}

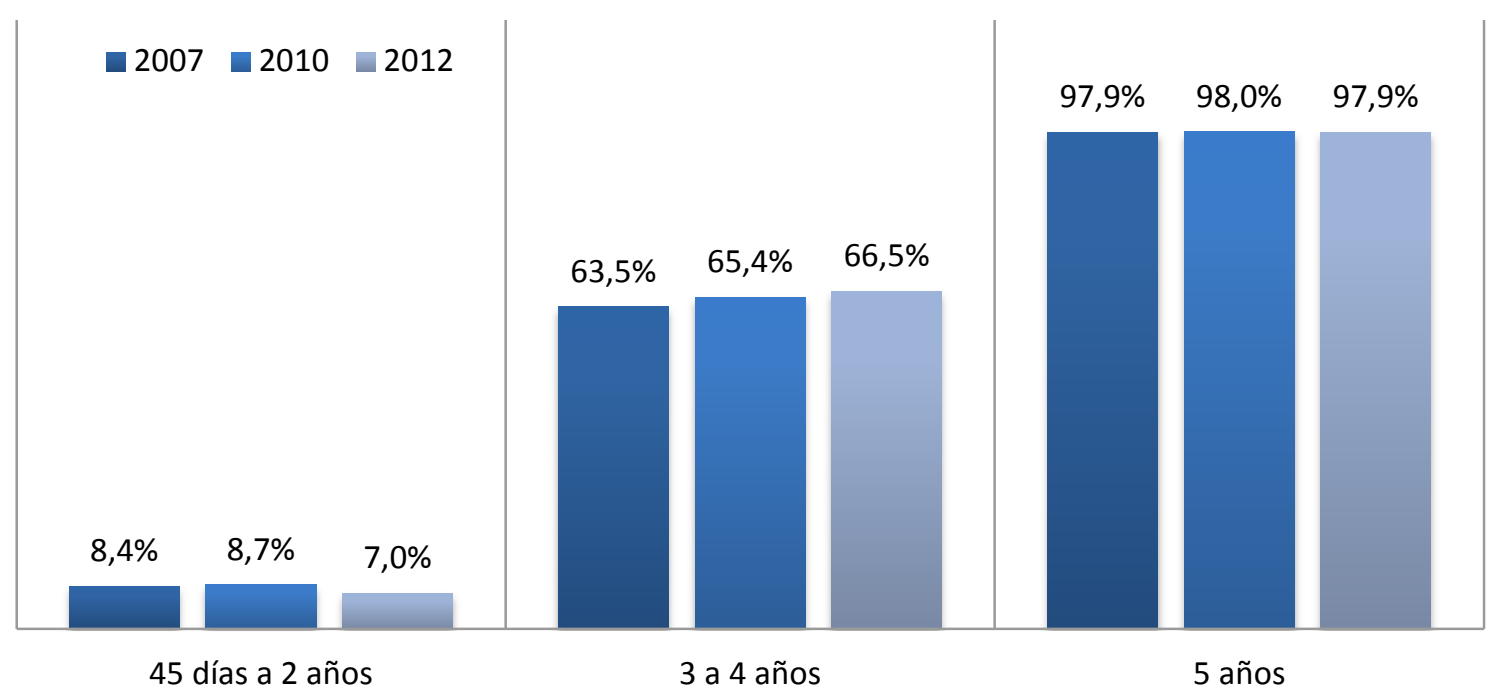

45 días a 2 años

3 a 4 años

5 años

163. Gladsztein, Adriana (psicoanalista especialista en niños y adolescentes), "La deserción en las públicas quintuplica a la de las privadas", Clarín, Sección Educación, 26 de junio de 2012, página 20. 


\section{Niños que asisten por estrato social}

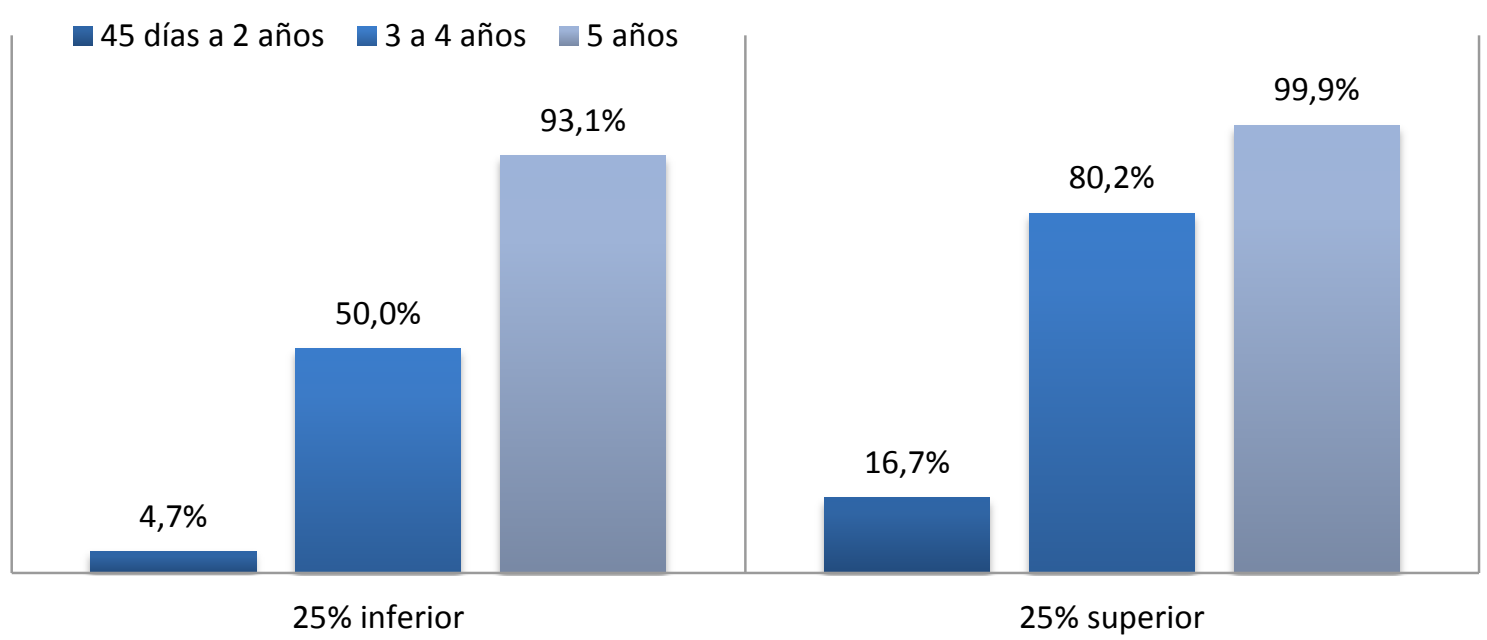

En otro orden de ideas, es en el tercer ciclo de la educación general básica (o primer ciclo de la escuela secundaria) donde se ponen de relieve el problema de articulación con la primaria y las dificultades para atender a las demandas de los nuevos alumnos con instituciones poco flexibles y mal preparadas para hacerlo. ${ }^{164}$

Ahora bien, al mismo tiempo que se están dando transformaciones en la cobertura y en las respuestas que las instituciones educativas elaboran para atender las necesidades de los estudiantes, existen cambios en la gobernabilidad y en la integración del sistema que configuran nuevas formas de diferenciación. Conviven dentro del nivel medio instituciones muy diferentes. Parecen organizarse de forma diversa a como lo hacían antes, cuando las modalidades bachiller, comercial y técnica remitían a sectores sociales diferentes y el colegio del centro frente al colegio del barrio referían a jerarquías y lugares claramente identificables. Incluso, la diferenciación entre establecimientos religiosos y no religiosos aparece hoy menos clara, al tiempo que las instituciones privadas reconocen nuevos perfiles que no son los que se relacionaban término a término con afiliaciones religiosas. ${ }^{165}$

Por lo demás, existen algunos elementos que le otorgan otra dimensión a la integración del sistema educativo. Tienen que ver con la reestructuración de la autoridad política del Estado y con la crisis de gobernabilidad de las instituciones. Un ejemplo es la disparidad de

164. Clarín, Sección Educación, martes 26 de junio de 2012, página 5.

165. Del Cueto, Carla Muriel, cit. por Dussel, Inés, La escuela media argentina y los desafíos de las metas 2021. Presentación V: Foro Latinoamericano de Educación Metas educativas 2021. Buenos Aires, Propuestas iberoamericanas y análisis nacional, Fundación Santillana-OEI, 2009, páginas 6 y 7. 
estructuras curriculares que existe en el nivel medio, no sólo entre las provincias sino también dentro de ellas. Obsérvese, al respecto, el cuadro siguiente:

Estructuras curriculares de la educación secundaria en las provincias argentinas

\begin{tabular}{|l|l|l||l|l|}
\hline \hline \multicolumn{3}{|c|}{ Estructura única } & \multicolumn{2}{c|}{ Estructura múltiple } \\
\hline \hline \multicolumn{1}{|c||}{7 y 5 años } & 9 y 3 años & 6 y 6 años & $7-5 / 9-3 / 6-6$ años & 6-6/9-3 años \\
\hline Río Negro & La Pampa & Córdoba & Salta & Chubut \\
Jujuy & Catamarca & Corrientes & Santa Fe & La Rioja \\
Mendoza & Santa Cruz & Entre Ríos & Chaco & Misiones \\
Neuquén & & Buenos Aires & Formosa & San Juan \\
Ciudad de Buenos Aires & & Tierra del Fuego & Santiago del Estero & San Luis \\
& & & & Tucumán \\
\hline \hline
\end{tabular}

Fuente: Documento Preliminar para la discusión sobre la educación secundaria en Argentina, Ministerio de Educación de la Nación, octubre de 2008.

No obstante estos cambios, aún se mantienen algunas características del núcleo "duro" de la escuela secundaria: una estructura graduada (con grados o años de escolaridad uniformes), un currículo organizado por asignaturas, la formación y designación de profesores asociada a una especialidad (Matemática, Historia, Geografía y Literatura, por citar algunos ejemplos) y - muchas veces - un horario muy fragmentado con un currículo enciclopédico que dificulta la interacción entre los campos del conocimiento.

Las características del nivel medio señaladas en el anterior párrafo han sido motivo de preocupación, teniendo en mira una mejor educación para todos a fin de alcanzar una sociedad más justa. En esta investigación se trabajará el denominado núcleo "duro" a través de diecinueve colegios estatales (diez de adolescentes y nueve de adultos) a los efectos de comprobar cuán duro es el mentado núcleo de la escuela en el Distrito de Junín. En otro orden, las características de los docentes pueden ser estudiadas a partir de una muy amplia base estadística nacional (censos docentes de 1994 y de 2004) y de distintos trabajos complementarios. Se destaca la prevalencia de las mujeres, especialmente en los niveles inicial y primario, donde apenas el 5,6 por ciento y el 12 por ciento - respectivamente- de los docentes son hombres. En el nivel secundario la proporción de hombres continúa siendo minoritaria pero representa ya el 34,7 por ciento. Asimismo, la antigüedad de los educadores es un dato relevante ya que se trata de un factor indicativo de su experiencia pedagógica. En los tres niveles de la educación básica la antigüedad promedio en Argentina es similar: 10,5 años en inicial, 11,8 en primaria y 11,5 en secundaria. Este dato indica el denominado cargo "testigo" utilizado para analizar el salario docente promedio, que incluye el pago por antigüedad en cada provincia. Otro dato de interés es la cantidad de escuelas en las que 
trabajan los profesores de nivel medio: el 29 por ciento lo hace en tres o más. En la comparación provincial se destaca el caso de Buenos Aires donde el 41 por ciento de los profesores desarrolla sus actividades en tres o más de ellas. Ello implica indubitablemente una relación débil (por ende, bajo compromiso) con las instituciones escolares debido al escaso conocimiento que adquiere de los estudiantes que están a su cargo. ${ }^{166}$

Un docente en Argentina tiene distinta calidad de vida según el lugar donde le toque desempeñarse. En términos reales (es decir, considerando la inflación), el salario docente aumentó en promedio un 23,7 por ciento entre diciembre de 2001 e igual mes de 2008. En ese promedio están las disparidades: La Pampa aumentó 83 por ciento en términos reales el salario docente y La Rioja lo disminuyó un 12 por ciento. Así, entre esos años La Pampa pasó de la posición 11 en el ranking salarial a la 3, mientras que La Rioja pasó del puesto 8 al 21. Por otro lado, entre 1991 y 2001 hubo una escasa movilidad salarial fruto del Plan de Convertibilidad (que estableció una pauta de inflación cercana a cero) y del escaso aumento salarial. En cambio, desde 2002 los aumentos vinculados con la inflación y la mayor capacidad de demanda de los sindicatos hicieron que el orden salarial de las provincias varíe profundamente. ${ }^{167}$

En otro orden de ideas, no parece haber duda que en las últimas décadas la matrícula de la educación secundaria se expandió a un ritmo sostenido. De acuerdo con la información proporcionada por el Censo 2001, 71 de cada 100 adolescentes que tenían entre 13 y 18 años asistían a un establecimiento de ese nivel. La participación de los jóvenes en las escuelas medias aumentó (ya lo venía haciendo desde 1990) un 12,2 por ciento en el período 1991-2001 (pasó del 59,3 por ciento al 71,5 por ciento). Los niveles inicial, primario y superior también experimentaron incrementos durante los períodos 1980-1991 y 1991-2001. Sin embargo, aún queda pendiente - a nivel país - la escolarización ${ }^{168}$ de un importante número de adolescentes que llegan aproximadamente a los seiscientos mil, de los cuales el 44 por ciento son mujeres. Asimismo, existen grandes diferencias entre la población urbana y la rural (especialmente en el último tramo de la escolarización, 15 a 17 años): mientras que sólo el 56 por ciento de los jóvenes que viven en zonas rurales concurren a escuelas medias, en el sector urbano lo hace el 82 por ciento. En el cuadro siguiente obsérvense las tasas de escolarización por año según el nivel educativo:

166. Terigi, Flavio, cit. por Dussel, Inés, La escuela media argentina y los desafios de las metas 2021. Presentación V: Foro Latinoamericano de Educación Metas educativas 2021. Buenos Aires, Propuestas iberoamericanas y análisis nacional, Fundación Santillana-OEI, 2009, página 8.

167. Rivas, Axel, Capítulo 3. "Cartografías”, op. cit., página 110.

168. Rivas, Axel, Capítulo 3. "Cartografías”, op. cit., página 78. 
Tasas netas de escolarización por año

según nivel de enseñanza de 1980, 1991 y 2001 (porcentajes)

\begin{tabular}{|l|c|c|c|}
\hline \multicolumn{1}{|c|}{ Nivel de enseñanza } & 1980 & 1991 & $2001^{*}$ \\
\hline Inicial & $57,5 \%$ & $72,6 \%$ & $78,8 \%$ \\
Primario & $90,5 \%$ & $95,7 \%$ & $99,7 \%$ \\
Medio & $38,8 \%$ & $59,3 \%$ & $71,5 \%$ \\
Superior & $7,5 \%$ & $14,4 \%$ & $18,3 \%$ \\
\hline
\end{tabular}

* La información se organizó con la estructura del sistema educativo anterior a la Ley Federal de Educación $\mathrm{N}^{\circ} 24.195 / 93$ para permitir la comparación entre censos.

Fuente: Nancy Montes, 2006, basado en censos de población, INDEC.

En la expansión producida entre 1980 y 2001 confluyeron varios factores: la recuperación de la vida democrática, el trabajo que — aún para puestos de baja calificación en el sector servicios - requiere el nivel medio completo (cuyo equivalente hace tres décadas era el ciclo básico aprobado), las reformas educativas implementadas durante la década de 1990 (uno de cuyos ejes consistió en aumentar la cobertura de los niveles básicos de enseñanza) y -más recientemente - la implementación de políticas que promueven la inclusión educativa de todos los niños y adolescentes, en especial de aquéllos más castigados por la desigualdad económica y social. ${ }^{169}$

En 2007 Argentina invirtió casi cuarenta y cuatro mil millones de pesos en su sistema educativo, lo que representó el 14,8 por ciento del gasto público consolidado nacional y provincial. A partir de ese financiamiento se garantizó el derecho a la educación de alrededor de diez millones de alumnos en todo el país. Esos recursos se repartieron entre la Nación y las provincias, las que - a partir de la transferencia de los servicios educativos nacionales en 1991 - tienen a su cargo la mayor carga fiscal, dado que todas las escuelas son provinciales. En total, las provincias representaban en 2007 el 69,59 por ciento del gasto público en educación y la Nación el restante 30,41 por ciento. El origen de tales recursos es el esquema tributario. Para apreciar los datos en relación a lo expresado, véanse los gráficos siguientes:

169. Filmus, Daniel, cit. por Abrile de Vollmer, María Inés, "Estrategias para superar las desigualdades y la fragmentación en el sistema educativo", en Tedesco, Juan Carlos (comp.), ¿Cómo superar la desigualdad y la fragmentación del sistema educativo argentino? Ministerio de Educación, Ciencia y Tecnología, Presidencia de la Nación, 2005, página 315. 


\section{$\underline{\text { Recaudación tributaria y gasto en educación del gobierno nacional y de las provincias }}$}

\section{Recaudación tributaria en 2007 (en millones de \$)}

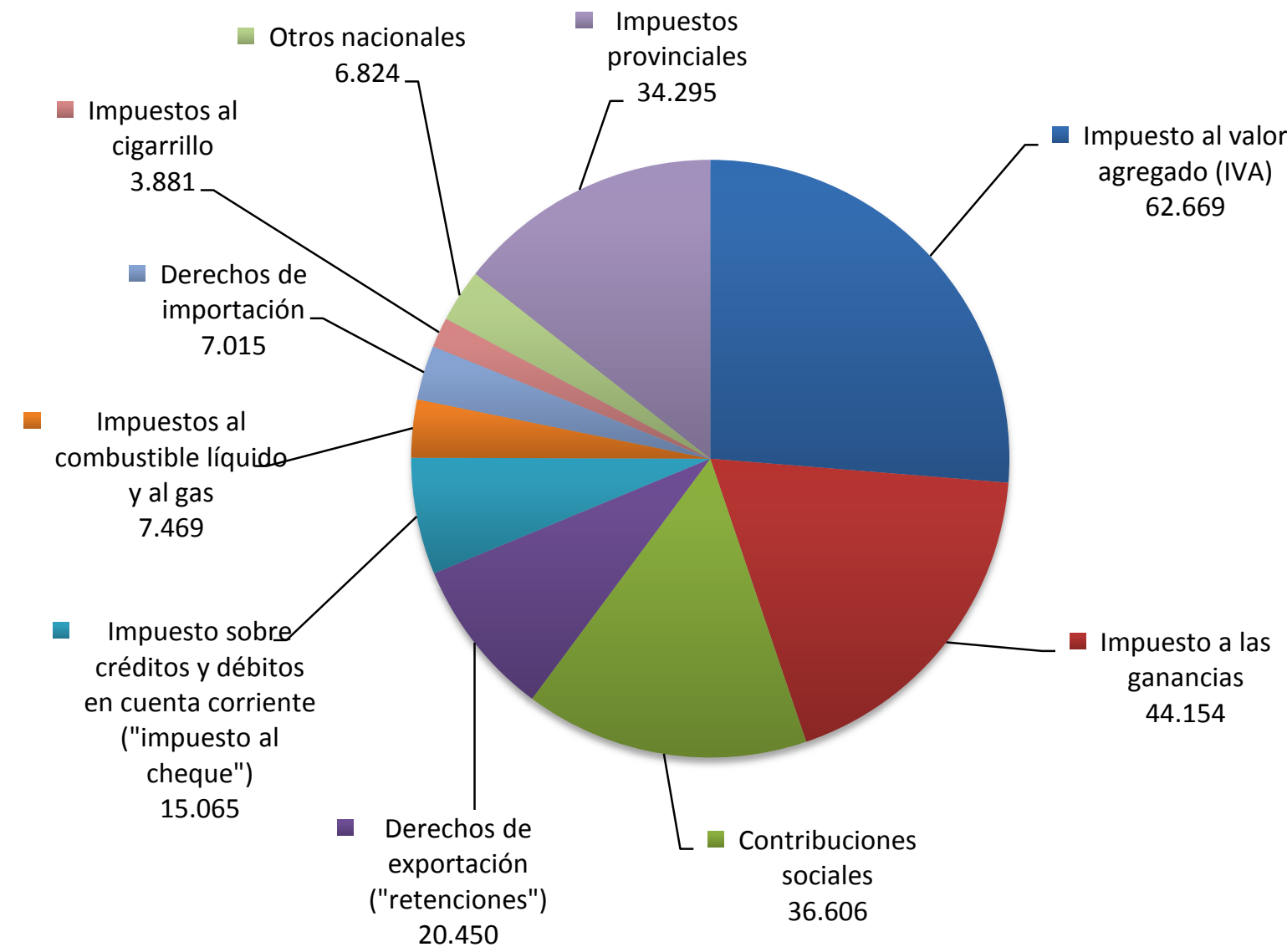

\section{Recaudación bruta total: $\mathbf{2 3 8 . 4 2 8}$}

\section{Gasto en educación en 2007 (en millones de \$)}

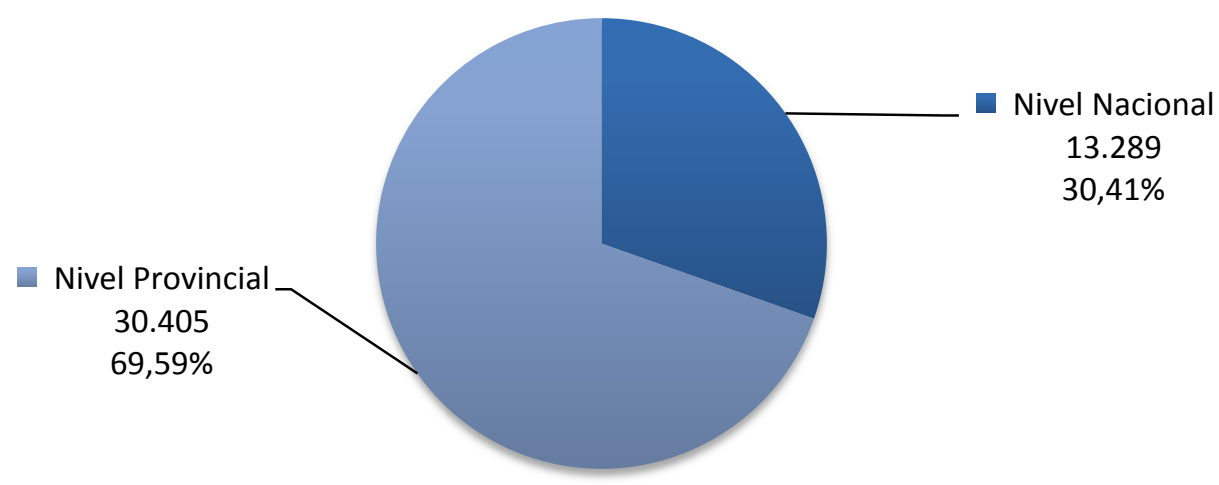

Gasto en educación consolidado: 43.694

Nota: Se considera el gasto en Educación, Ciencia y Tecnología. 
Fuente: Elaboración de CIPPEC sobre la base de información obtenida de la Coordinación General de Estudio de Costos del Sistema Educativo (CGECSE), Ministerio de Educación, la Ejecución Presupuestaria Nacional 2007, la Dirección Nacional de Investigaciones y Análisis Fiscal y la Dirección Nacional de Coordinación Fiscal con las Provincias, Ministerio de Economía y Producción.

Por lo demás, la rotación de los ministros de Educación es un interesante indicador de la política educativa provincial, dado que la continuidad es central para planificar e implementar actividades. En promedio, entre 1991 y 2009 los ministros de Educación provinciales duraron un año y once meses, aunque con muchas disparidades. Jujuy con diecisiete ministros y Santiago del Estero con quince en dieciocho años son los casos más extremos en cuanto a discontinuidad política. Esto es propio de provincias que han vivido recurrentes crisis de gobernabilidad, con intervenciones nacionales, juicios políticos a los gobernadores y alta conflictividad social. Así ocurrió - en distintos momentos- en Tierra del Fuego, Corrientes y Tucumán, por casos. Por otro lado se destacan Catamarca, La Pampa y Misiones con apenas cuatro o cinco ministros con un promedio de duración de casi cinco años. En La Pampa esta continuidad se tradujo en significativos logros en materia de organización y formación de los agentes de la educación. ${ }^{170}$ Asimismo, obsérvese quiénes eran las fuerzas políticas que ejercían el poder en 2009 en las veintitrés provincias (más la Ciudad Autónoma de Buenos Aires):

Fuerza política gobernante en 2009

\begin{tabular}{|ll||ll||}
\hline Buenos Aires & PJ & Mendoza & PJ \\
CABA & PRO & Misiones \\
Catamarca & UCR & Feuquén & MPN \\
Chaco & PJ & Río Negro & UCR \\
Chubut & PJ & Salta & PJ \\
Córdoba & PJ & San Juan & PJ \\
Corrientes & UCR & San Luis & PJ \\
Entre Ríos & PJ & Santa Cruz & PJ \\
Formosa & PJ & Santa Fe & PS \\
Jujuy & PJ & Santiago del Estero & UCR \\
La Pampa & PJ & Tierra del Fuego & ARI \\
La Rioja & PJ & Tucumán & PJ \\
\hline
\end{tabular}

ARI: Afirmación para una República Igualitaria; FR: Frente Renovador de la Concordia; MPN: Movimiento Popular Neuquino; PJ: Partido Justicialista; PRO: Propuesta Republicana; PS: Partido Socialista; UCR: Unión Cívica Radical.

170. Rivas, Axel, Capítulo 3. ”Cartografías”, op. cit., páginas 104 y 105. 
Luego de lo expresado supra surgen varias preguntas como la referida al grado de autonomía relativa que tiene el sistema educativo en relación con los procesos socioeconómicos. También, si es posible que la educación desempeñe una función integradora en el marco de un modelo social marginador. Asimismo, si aparece como una utopía el logro de una educación de calidad que ofrezca iguales oportunidades y posibilidades para todos. La política educativa argentina enfrenta hoy escenarios de empobrecimiento y de exclusión, crisis de integración social, debilitamiento de la cohesión social y desestructuración de los mecanismos de contención social. A ello se agregan desajustes en la distribución de responsabilidades entre las instituciones (escuela, familia y organismos públicos). Torna imprescindible, pues, un abordaje integral del fracaso escolar que trascienda las funciones del área y se articule con otras políticas sectoriales para encontrar soluciones. La educación es básica para la formación de sujetos autónomos cuya participación propenda al logro de una sociedad más equitativa. ${ }^{171}$

Logros se han producido. Pero, como es dable observar a través de lo expresado hasta aquí, todavía existen deudas, principalmente con los grupos que no tienen como hacer oír sus demandas. Los discursos de políticos de primera línea han sido hasta el presente altisonantes, pero no existen —más allá de datos proporcionados por los gobiernos desde 1990 a la fecha susceptibles de contrastación - soluciones concretas para mejorar la calidad educativa en los diferentes niveles, especialmente el medio. Los últimos datos del Censo Nacional de Población, Hogares y Viviendas 2010, dados a conocer por el INDEC a principios de julio de 2012, expresan que el 18,4 por ciento de los jóvenes de entre 15 y 17 años sigue sin ir al colegio. Y que el leve aumento de la matrícula en esa franja -2,1 por ciento con respecto a 2001- sólo alcanzó a equiparar el crecimiento poblacional. ${ }^{172}$ La realidad que muestran los números (y la que subyace a ellos) es desconocida por muchos funcionarios de escritorio que -al margen de buenas intenciones- evidencian un parcial o absoluto desconocimiento de las características que hacen al funcionamiento de una comunidad educativa. Esta época democrática es propicia para dialogar (y podría quedar en la historia de la educación argentina por la riqueza de las posturas a debatirse). Todo ello, con la finalidad de establecer políticas educativas que intenten obtener resultados positivos; esto es: una educación que permita la

171. Tedesco, Juan Carlos, cit. por Abrile de Vollmer, María Inés, "Estrategias para superar las desigualdades y la fragmentación en el sistema educativo", en Tedesco, Juan Carlos (comp.), ¿Cómo superar la desigualdad y la fragmentación del sistema educativo argentino? Ministerio de Educación, Ciencia y Tecnología, Presidencia de la Nación, 2005, página 316.

172. "Diagnóstico 2001-2010. Abandono y poca inclusión, la peor cara de la Secundaria", en Clarín, Sección Sociedad, 3 de julio de 2012, página 26. 
inclusión ${ }^{173}$ sin discriminaciones de ningún tipo y de igual calidad para todos en cuanto a los aprendizajes. Presupuestos que resultan ineludibles para alcanzar una Argentina más justa, dentro de la cual debería hallarse un Distrito de Junín más justo. Al respecto, obsérvese el siguiente gráfico que comprende a una franja de la población argentina en su evolución durante ochenta años:

\section{Evolución de la población de 3 a 17 años en la Argentina (Período 1950-2030)}

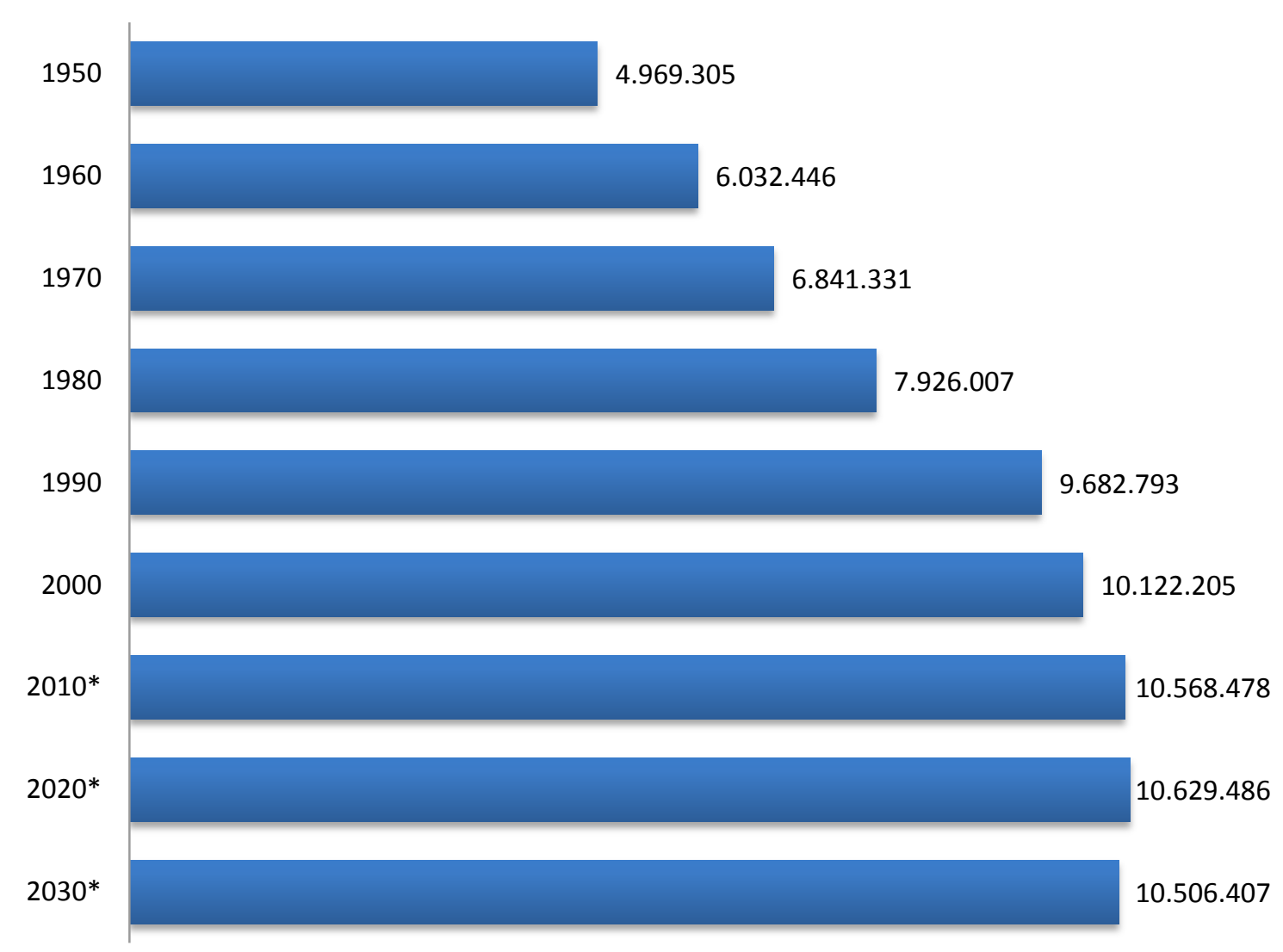

* Valores proyectados

Fuente: Elaboración de CIPPEC sobre la base de información obtenida del Boletín demográfico $\mathrm{N}^{\circ} 66$ de julio de 2000, División de Población, Comisión Económica para América Latina y el Caribe/Centro Latinoamericano de Desarrollo (CEPAL/CELADE).

173 La inclusión constituye un movimiento cuya principal aspiración es asegurar para toda la población el derecho a una educación de calidad. La misma está relacionada con el acceso, la participación y los logros de todos los educandos, con especial énfasis en aquéllos que están en riesgo de ser excluidos o marginados. 


\subsubsection{El valor de la escuela para la formación del adolescente y del adulto}

Si por un lado aparece problematizada la realidad del adolescente debido a su edad cronológica (factor interno) y a circunstancias familiares y sociales (factor externo), por el otro la escuela como institución formal no ha tenido, a criterio de muchos especialistas en educación, los cimientos firmes. En relación a este tema varios autores han mostrado - desde ópticas diferentes - un modelo de adolescente moderno. En esta investigación se pone énfasis en algunas ideas (considerando el tipo ideal, al que se aspira) de quien — por sus aportes a la educación de niños y de adolescentes- es motivo de consulta permanente en los ámbitos académicos: Jean Piaget. Para éste el adolescente es un creador de teorías - un metafísico por excelencia- al tiempo que el adulto debiera ser capaz de poner la habilidad de aquél en conjunción con la realidad. "La etapa de las utopías resulta imprescindible como pasaje para la madurez de la inteligencia y el mecanismo fundamental para estructurar la propia personalidad es la identificación", expresa el psicólogo suizo en una de sus obras más destacadas. ${ }^{174} \mathrm{~A}$ sus palabras cabría agregar que en la actualidad los adolescentes no encuentran fácilmente figuras adultas con las cuales identificarse y que tanto los padres como los docentes han perdido en buena medida ese lugar, no obstante que de ellos siempre se espera un comportamiento ejemplar. Asimismo, la independencia económica era un logro (hoy ya no lo es tanto) que distinguía al adulto del adolescente: significaba haber llegado, alcanzar un nivel profesional o laboral estable. Debe recordarse también que legalmente otrora la mayor edad se alcanzaba a los 22 años, a partir de 1968 se era mayor de edad a los 21 años y desde $2009^{175}$ la mayoría de edad (en varones y en mujeres) tiene lugar a los 18 años.

En la hora actual muchos jóvenes aspiran a mantenerse; es decir, luchan para no volver a fojas cero. Casi ninguno está seguro y — por otra parte- el camino de formación es muy largo (se necesita cada vez menos manos de obra y mucho más capacitada). Para un buen número de ellos es difícil mantenerse económicamente y más aún lo es independizarse de los padres. Esta realidad acontece en países latinoamericanos (Argentina es un ejemplo) y también sucede en Europa, donde faltan empleos y los que existen requieren una sofisticada calificación. Estas dificultades aún son mayores cuando el que trata de educarse es un adulto. Responsabilidades ineludibles (muchas veces la familia y/o el trabajo) hacen que en no pocas ocasiones abandonen el secundario o ni siquiera lo comiencen. En esta investigación se analiza tal problemática en escuelas medias estatales (con egresados adolescentes y adultos) del Distrito de Junín.

174. Piaget, Jean, Seis estudios de psicología. Volumen 2 de Colección Labor. Nueva Serie. Labor, Tercera Edición, 1994, páginas 28 y 64.

175. Ley Nacional No 26.579 sancionada el 2 de diciembre de 2009. 
En otro orden de ideas, la importancia de la escuela no fue siempre reconocida únicamente en todas partes. En Argentina, desde la intelectualidad nativa y la foránea se han exacerbado —en alguna época- las críticas, especialmente como institución formadora de jóvenes proyectados hacia una adultez responsable. No obstante, ciertas voces oportunas se ocuparon de reafirmar lo insustituible de sus funciones. Entre ellas, la del profesor Antonio Salonia quien señalara: “A fines de la década de 1970 estuvo de moda cierto movimiento tremendista y negativo respecto de la institución escuela, [...]. En nuestro país algunas figuras prominentes de la educación adhirieron al snobismo de proclamar la agonía o la muerte de la escuela en el corto plazo". ${ }^{176}$ Esa actitud ácrata e irresponsable acerca de la decadencia de la escuela se superó con la madurez y el compromiso que supieron poner de manifiesto muchos educadores. Ello ratificó la convicción de muchos respecto de la vigencia de las instituciones formales de la educación. En esa línea de pensamiento, Hilario Fernández Long afirma: "Para educar a las personas no serán suficientes los nuevos medios, ni las organizaciones intermedias. En todas las épocas y en todos los lugares del mundo los niños y los adolescentes de los pueblos civilizados se han reunido alrededor de un maestro". ${ }^{177}$ A estas ideas podría agregarse que una relación fluida docentes-estudiantes es primordial (especialmente para los últimos), cualquiera sea el nivel socioeconómico de los responsables de los educandos. Y esa fluidez ha de tener mayor importancia aún en aquellos alumnos de sectores desfavorecidos donde las necesidades son siempre mayores. Entre otras, de sus demandas, está la de recibir mensajes veraces y oportunos sobre cuestiones que hacen a la formación de la persona para la vida misma. Ello resulta primordial, pues sabido es que en familias pertenecientes a dichos sectores (aunque no son las únicas) la comunicación necesaria puede faltar o llevarse a cabo aisladamente o de manera autoritaria, desvirtuándose - por ende- su esencia, con el consiguiente perjuicio final para todos sus interlocutores.

A su turno, Héctor Delbosco reconoce:

La primera responsabilidad educativa siempre le corresponderá a la familia [...] la familia - lamentablemente - va perdiendo fuerza; entonces parece que cada vez se hace más necesaria una institución que, sin reemplazarla - lo que sería a la vez imposible e indeseable - cubra aquello que la familia no alcanza a hacer en forma total. ${ }^{178}$

176. Salonia, Antonio cit. por López Espinosa, Gustavo y van Gelderen, Alfredo Manuel en $L a$ escuela argentina en transformación: ocho cuestiones y veintidós protagonistas. Buenos Aires, Aula XXI, Ediciones Santillana S.A., 1996, página 32.

177. Fernández Long, Hilario cit. por López Espinosa, Gustavo y van Gelderen, Alfredo Manuel, op. cit., página 33 .

178. Delbosco, Héctor cit. por López Espinosa, Gustavo y van Gelderen, Alfredo Manuel, op. cit., página 34 . 
Algunos estudios de investigadores en educación confirman que las familias de clase alta no han perdido fuerza; al contrario, inician y continúan su etapa educativa teniendo muy definido el posible futuro de sus hijos. ${ }^{179}$ Familia y escuela devienen pilares insustituibles - hoy por hoy - en la formación ya no sólo del ciudadano sino de todos los habitantes, cualquiera sea su condición social. Empero, muchas veces ambas instituciones - de la que tanto y tan profundamente se escribe- no crean vínculos entre sí. Familias que prácticamente ignoran las características que tienen las escuelas a que asisten sus hijos y colegios donde casi el único dato de interés que disponen de las familias de los estudiantes son las firmas de sus responsables en un libro especial (actividad que se cumple todos los años al comenzar el ciclo lectivo). En la presente investigación se realizará el abordaje de esta problemática mediante la aplicación de cuestionarios a los responsables de los egresados del nivel medio de escuelas estatales del Distrito de Junín.

Cecilia Braslavsky (1952-2005) funda la necesidad de la escuela en la relevancia de la alfabetización - postura que se comparte en esta tesis- y recogiendo testimonios históricos afirma:

Siempre que desaparecieron las escuelas las sociedades se transformaron en ágrafas y el ejemplo más claro es la caída del Imperio Romano de Occidente. [...]. Aquí no hay que hacerse ilusiones: ni la computadora, ni la TV, ni la familia pueden enseñar a leer y a escribir, ni pueden formar las habilidades intelectuales superiores. ${ }^{180}$

Podría colegirse que tales afirmaciones reflejan —a lo más - una expresión de deseos. En apoyo de esta reflexión sobre las palabras de Braslavsky vaya lo siguiente: los especialistas en educación del siglo XIX no anunciaron el uso de la tecnología en la escuela. La computadora llegó y está empezando a tener — si bien aún a los remezones - una participación activa en el desarrollo de las clases. Surge la pregunta de si podría ser utilizada por los niños para aprender a leer y a escribir, sin la presencia del maestro. Hay -asimismo - otra realidad incontrastable: que alude a la responsabilidad que tienen la familia y la escuela respecto de muchos egresados que leen y escriben con suma dificultad. Por lo demás, se discute si el lenguaje de los jóvenes es un producto de la televisión o el resultado de lo que se enseña en las aulas (o de lo que sucede en ambas a la vez). Existen padres que, a sabiendas de algunas deficiencias de la educación actual, enseñan ellos mismos - a veces con éxito- a leer y escribir a sus hijos. Otros inquieren qué sucedería con las escuelas si se aplicase extensivamente la idea de contratar a personas que enseñen en los

179. Tiramonti, Guillermina y Ziegler, Sandra, op. cit., páginas 34-36.

180. Braslavsky, Cecilia cit. por López Espinosa, Gustavo y van Gelderen, Alfredo Manuel, op. cit., páginas 36 y 37. 
hogares a los hijos de los responsables que habitan en ellos, a similitud de lo que acontecía en la Antigüedad.

Ahora bien, sin encuadrarse entre las propuestas de la antiescolaridad han surgido algunas líneas de pensamiento que indican una crisis profunda de los sistemas escolares, inclusive reciclados o actualizados. Alberto Taquini (h) (1935-) describe el estado de la cuestión así: "El sistema educativo formal, como lo conocemos hoy y está vigente en las sociedades desde la organización de los Estados, tiene menos de ciento cincuenta años y se basa en la sistematización de la transmisión de los conocimientos y en la tecnología del libro". ${ }^{181}$ Sobre este sistema tradicional la explosión demográfica tuvo un efecto impensado: desde el origen del hombre hasta el 1800 de la era actual, se llegó a mil millones de habitantes; en 1930 se arribó a dos mil millones y hoy suman somos cinco mil millones. Se produjo así una expansión extraordinaria de los alumnos dentro del sistema, caracterizada por la necesidad de una educación permanente. Por consiguiente, no sólo existen cinco mil millones de personas sino que también se trata de cinco mil millones de habitantes aprendiendo todos los días.

A todo lo dicho podría agregarse lo siguiente: nacen ochenta millones de niños por año, de los cuales el 90 por ciento pertenece a los países pobres. Por lo tanto, el aumento de la cantidad de docentes y el de la infraestructura que se conoce como escuela o colegio, todo eso es fundamental en el momento de evaluar a un sistema educativo. Empero, debe tenerse presente que no existe capacidad económica suficiente para mantener dicho sistema en funcionamiento y aunque se lo lograse no habría calidad, sostienen algunos especialistas. Una idea que difiere de lo antes expuesto es aquélla que sostiene que una mayor extensión de la educación -especialmente la que incluye a los sectores desaventajados- no necesariamente debería ir en desmedro de la calidad educativa. En tal sentido, el 17 de febrero de 2012 la ministra de gobierno bonaerense Cristina Álvarez Rodríguez sostuvo que el gobierno nacional destinó el 6,6 por ciento del Producto Bruto Interno a la educación y que en la provincia de Buenos Aires el gobernador Daniel Scioli (1957-) tomó la decisión de disponer para esa área la mayor porción del presupuesto, que alcanza al 30 por ciento, convirtiéndola en la provincia que más invierte en educación. ${ }^{182}$

181. Taquini, Alberto (h), cit. por López Espinosa, Gustavo y van Gelderen, Alfredo Manuel, op. cit., página 38 .

182. Tales conceptos fueron vertidos por dicha funcionaria al presidir el acto inaugural del nuevo edificio de la Escuela Secundaria $\mathrm{N}^{\mathrm{o}} 3$ de General Pirán, provincia de Buenos Aires, Argentina. Clarín, Sección Educación, 18 de febrero de 2012, página 23. 


\subsubsection{La nueva secundaria en la provincia de Buenos Aires}

En las últimas cuatro décadas la escuela media dejó de ser —en casi todo el mundouna opción de minorías para constituir una escuela multitudinaria a la que ingresan sectores sociales más bajos que aquéllos considerados tradicionales hasta la Segunda Guerra Mundial. Burocratizada, rutinaria e ignorante de las transformaciones sociales que se llevaban a cabo a su alrededor, dicha escuela no ha sabido delinear - hasta 2012 - una política capaz de dar asidero a la nueva cultura juvenil.

La distribución de la población argentina en diferentes escuelas responde a una multiplicidad de factores. En el caso de la educación primaria es muy marcado el sesgo territorial en el reclutamiento del alumnado. Lo es menos en el ciclo medio. En sociedades con altos niveles de desigualdad (como la de Argentina) existen dos fuentes que generan riesgos de segregación educativa ${ }^{183}$ : la base territorial de reclutamiento y la existencia de una oferta segmentada en materia de calidad y costos. En tal sentido, el libro que es resultado de una investigación llevada a cabo por las profesores Mariana Belossi y María Palacios de Caprio en seis escuelas medias de la provincia de Buenos Aires, en el marco de la Transformación Educativa a cargo de la Dirección de Escuelas Medias Técnicas y Agrarias (DEMTyA), constituye un aporte para comprender la relación entre educación y escuelas que reciben a jóvenes socialmente desfavorecidos. ${ }^{184}$ En contraste con la abundante producción sobre los sectores pobrecidos o marginados de la sociedad, existe menos literatura que aborda a aquéllos que fueron promovidos a las posiciones más altas de la sociedad. ${ }^{185}$

En el contexto señalado, la Escuela Secundaria Básica (ESB) bonaerense fue creada en 2005 con vista a superar algunas dificultades generadas por la implementación del tercer ciclo de la Educación General Básica (EGB). Se trata de un nuevo esquema de enseñanza que apunta a secundarizar ese tercer ciclo vigente durante años en gran parte del territorio nacional. La propuesta transformó al $7^{\circ}, 8^{\circ}$ y $9^{\circ}$ años en una institución independiente, con atención específica a los estudiantes que culminan su formación básica. Si bien la ESB formó

183. Por segregación educativa debe entenderse - a criterio de quien lleva a cabo esta investigación - la situación en la cual la experiencia áulica de la persona tiende a desarrollarse principalmente con otras de su misma extracción social. La segregación va en menoscabo no sólo de la formación integral de la población sino también de sus logros educativos. Valga recordar que en la profusa literatura especializada están documentado los efectos que la segregación educativa tiene sobre la asistencia, la deserción y la repetición escolares.

184. Belossi, Mariana y Palacios de Caprio, María Alicia. Prólogo y Presentación. La escuela media y los jóvenes socialmente desfavorecidos. Buenos Aires, Lugar, 2004, páginas 10 y 11.

185. Es pertinente señalar aquí los trabajos del equipo de Economía y Tecnología de la FLACSOArgentina, que han proporcionado una importante bibliografía sobre la composición de la cúpula empresarial a lo largo del tiempo y su variación en relación con los cambios en el modelo de acumulación. 
parte de un proyecto político a cargo de la Dirección General de Cultura y Educación (DGCyE) de la provincia de Buenos Aires durante 2005 (Resolución 1045 de ese año), en 2007 las reformas se integraron a los cambios promulgados por la Ley Nacional de Educación $\mathrm{N}^{\mathrm{o}} 26.206$ (de 2006) reflejada en la Ley Provincial No 13.688 (de 2007).

Esta nueva secundaria representa el trayecto inicial con su complemento en otra estructura, la Escuela Secundaria Superior (ESS), que surge en reemplazo del Polimodal. ${ }^{186}$ La reestructuración llevada a cabo otorga a la escuela primaria y a la secundaria autoridades independientes y una propuesta académica diferente para cada nivel. Si bien desde mayo de 2005 la ESB funcionó como experiencia piloto, en el ciclo lectivo 2007 se pusieron en marcha los cambios curriculares y pedagógicos en todos los primeros años de las escuelas medias bonaerenses. Las modificaciones tuvieron lugar año a año ininterrumpidamente hasta 2012 inclusive.

A nivel curricular el nuevo régimen implica cambios en las asignaturas propuestas. Previó el retorno de las materias tradicionales (cuya importancia - coinciden los docentes del Distrito de Junín partícipes en esta investigación - nunca debió ser dejada de lado), quedando atrás los contenidos por área, excepto para el primer año que conserva la estructura curricular del antiguo tercer ciclo. La propuesta correspondiente a los años $2^{\circ}$ y $3^{\circ}$ incluye diez materias, una de ellas en respuesta al interés de los adolescentes cuya denominación es Construcción de Ciudadanía. Esta materia también integra el $1^{\circ}$ año de la ESB. Respecto de lo aseverado, véase la tabla siguiente:

186. Los educandos (adolescentes y adultos) participantes en esta investigación cursaron en 2010 el último año $-3^{\circ}-$ del nivel Polimodal, el cual dejó de estar vigente definitivamente al inicio del ciclo lectivo 2012. 
Tabla de materias de la Escuela Secundaria Básica

\begin{tabular}{|c|l|l|l||}
\hline Materias & \multicolumn{1}{|c|}{$1^{\circ}$ Año } & \multicolumn{1}{c||}{$2^{\circ}$ Año } & \multicolumn{1}{c||}{$3^{\circ}$ Año } \\
\hline \hline 1 & Prácticas del Lenguaje & Prácticas del Lenguaje & Prácticas del Lenguaje \\
\hline \hline 2 & Matemática & Matemática & Matemática \\
\hline \hline 3 & Inglés & Inglés & Inglés \\
\hline \hline 4 & Educación Física & Educación Física & Educación Física \\
\hline \hline 5 & Educación Artística & Educación Artística & Educación Artística \\
\hline \hline 7 & Construcción de Ciudadanía & Construcción de Ciudadanía & Construcción de Ciudadanía \\
\hline \hline 8 & Ciencias Naturales & Biología & Biología \\
\hline \hline 9 & Ciencias Sociales & Físico-Química & Físico-Química \\
\hline \hline 10 & & Historia & Historia \\
\hline \hline
\end{tabular}

Nota: los espacios en blanco correspondientes a los lugares 9 y 10 de Primer año se deben a la inexistencia de materias.

El régimen de cursada y de aprobación de las asignaturas no presenta modificaciones con respecto al tradicional esquema de la escuela media. Es una estructura gradual y anualizada en la cual la promoción de cada año requiere acreditar - por lo menos- ocho de las diez materias cursadas, con una nota promedio de siete puntos o más. Esto significa que pueden quedar pendientes de aprobación - al inicio del ciclo lectivo siguiente - no más de dos asignaturas; en caso contrario el alumno habrá repetido y deberá cursar nuevamente el año escolar. Para no repetir la normativa establece que si una vez concluido el turno febrero adeudase tres materias, puede solicitar se constituya una mesa de examen de la asignatura que él elija (entre las tres que quedasen pendientes) para rendirla en los primeros días de marzo. Tendrá esta última posibilidad, siempre que hubiese sido evaluado en esas materias en diciembre y en febrero, obteniendo sendos aplazos. Así, en marzo de 2011 un no precisado número de estudiantes de todo el país intentó — según informaron básicamente los medios de comunicación social - aprobar materias para no repetir el año que habían cursado en $2010 .{ }^{187}$ Más allá de los resultados obtenidos — diferentes, según las escuelas y/o los cursos- muchos profesores del Distrito de Junín criticaron la realización de esta última posibilidad. Afirmaron que la misma puede conducir a los educandos a presentarse a rendir no habiendo estudiado la materia (o no habiéndolo hecho suficientemente) y "ver si, en una de esas, zafo" (como señaló

187. En esta investigación pudo observarse en el Distrito de Junín —en todas las escuelas medias partícipes- cómo se llevó a la práctica tal normativa en febrero de 2011. 
Carla Piumato, alumna de $2^{\circ}$ Año del Polimodal de la escuela A del Distrito de Junín). Si un educando no logró aprobar en diciembre ni en febrero, al menos se presentó a rendir en los dos turnos y eso tiene valor cuando sea necesario utilizar la última chance fijada para marzo. Es decir, con tal normativa jurídica ha quedado definitivamente sepultada (olvidada o no aprendida) para los adolescentes de hoy aquella expresión que era típica de la axiología reinante en el pasado: "El alumno debe presentarse a rendir conociendo perfectamente la materia y debe hacerlo así por respeto a sí mismo, a su condición de estudiante y a los profesores de la mesa examinadora".

En cuanto a la asistencia y a la puntualidad se establecieron los requisitos para la condición de regular. En caso de exceder las inasistencias permitidas (veintiocho a lo largo del ciclo lectivo), el educando deberá acreditar todas las asignaturas ante una comisión de evaluación en diciembre o en febrero, aunque la calificación alcanzada al finalizar el ciclo lectivo fuera de siete o más puntos. En relación a esta disposición, directivos de varias escuelas estatales participantes en esta investigación aseguraron que rendir todas las materias muy pocas veces se da en la realidad. Pudo tomarse conocimiento que muchos preceptores de diferentes colegios no registran como debieran todas las inasistencias de los educandos, siendo muy pocos — por ende- los que exceden el máximo permitido. Justificarían sus procederes diciendo que lo hacen por una cuestión de humanidad.

Un componente de importancia de la ESB es que intenta conformar una oferta especializada en un tramo sensible como es el pasaje de la escolaridad primaria a la media. En cuanto a la generación de una unidad académica específica, podría hipotetizarse que la concreción de unidades más pequeñas (con menor matrícula) debiera generar mejores condiciones de gestión. Desde la percepción de los directivos y demás docentes pertenecientes a colegios medios de diferentes regiones argentinas la propuesta tiene cierta continuidad con el proyecto curricular anterior y recupera aspectos de la estructura tradicional de la escuela secundaria. ${ }^{188}$

Interesa seguidamente analizar la creación de la asignatura Construcción de Ciudadanía, uno de los puntos novedosos del actual régimen, tanto por su temática como -especialmente - por su implementación. El objetivo principal es el aprendizaje teórico para construir una ciudadanía que valorice la participación de los jóvenes en todos los aspectos de la vida social. El diseño curricular propone el desarrollo de proyectos organizados entre docentes y educandos, tomando en cuenta los intereses, saberes y prácticas de los alumnos y vinculándolos a uno o a varios problemas del conocimiento. El proyecto de estudio podrá ser encuadrado en distintos ámbitos de problemas como: Ambiente; Arte, Comunicación y

188. Indagados directivos y otros docentes de las escuelas medias estatales del Distrito de Junín, incluidos en la presente investigación, se manifestaron cautelosos respecto de tal recuperación. 
Tecnología; Juego y Deporte; Identidades; Política y Democracia; Salud y Alimentación o Trabajo. $^{189}$

Asimismo, las autoridades educativas de cada escuela pueden ubicar Construcción de Ciudadanía en cualquier lugar de la grilla horaria, si bien se sugiere no sea a contraturno (si se dictase a contraturno las inasistencias se computarán como media falta). Tal asignatura es no promocional pero se realiza un control de la asistencia ya que no se trata de un taller optativo sino de una materia obligatoria. ${ }^{190} \mathrm{Al}$ no ser promocional, al docente se le podrían originar dificultades para la enseñanza y la evaluación del alumnado. Asimismo, la media inasistencia colocada por cada ausencia a clase lejos de beneficiar su implementación podría generar un mayor desinterés en el estudiantado. Habría que tomar en consideración - habida cuenta de su posible influencia- la opinión de las familias respecto de las características de tal materia. No debe olvidarse que entre los agentes educativos está en primer lugar la familia, que hace posible (o no) el acceso de los alumnos a los variados recursos y diferentes oportunidades. ${ }^{191}$ Valga recordar que intentos similares al descripto, llevados a cabo a nivel nacional hace veinte años, alcanzaron —no obstante los múltiples esfuerzos realizadosresultados muy pobres. Entre otros, alumnos con pocas asistencias a clase, casi nunca motivados y materias que, finalizada la experiencia piloto, dejaron muchas veces de impartirse sin que adquirieran estado público las conclusiones obtenidas de tal experiencia (si es que aquéllas se alcanzaron en algún momento).

En definitiva, el propósito de esta nueva organización del nivel medio conduce a que los adolescentes, al finalizar la ESB (denominada por algunos educadores Ciclo Básico), posean los conocimientos, habilidades y actitudes necesarios para desenvolverse y participar comprometidamente en una sociedad democrática. Al propio tiempo, la finalidad de la ESS

189. En el Distrito de Junín se pudo conocer, al actuar el investigador como observador no participante, el contenido de algunas conversaciones entre docentes durante los recreos (en los turnos mañana, tarde y noche) en las escuelas de adolescentes y de adultos. Fue motivo de comentarios entre profesores - con expresiones que variaron entre la incredulidad y el enojo- conocer que la asignatura Construcción de Ciudadanía podía ser impartida por profesores de Educación Física. Vale señalar que tal materia puede encuadrarse en uno de los ámbitos de problemas - en este caso Juego y Deporteautorizados por la normativa. Por ende, "los profesores de esa especialidad están habilitados para dictarla y nada puede objetárseles al respecto”, señaló la directora de la escuela D.

190. Se desconocen - a nivel país- los efectos que tiene esta disposición en la diaria realidad áulica. Las experiencias narradas por directores y secretarios de las escuelas del Distrito de Junín indican que - en general - los estudiantes no otorgan a dicha materia la importancia que ella tiene (ello lo observan, por ejemplo, dado el elevado número de inasistencias).

191. Montes, Nancy, cit. por Tiramonti, Guillermina (comp.) Capítulo 2. "Adolescentes y jóvenes en contexto. El marco cercano: la familia y el marco amplio: los otros" en La trama de la desigualdad educativa: mutaciones recientes en la escuela media. Buenos Aires, FLACSO. Biblioteca del docente. Ediciones Manantial, 2004, página 47. 
(que algunos educadores llaman Ciclo Orientado), apunta a que los jóvenes al concluirla hayan adquirido los conocimientos, habilidades y actitudes para poder comunicarse, trabajar y participar activamente en una sociedad democrática, decidiendo responsablemente su futuro educacional y/o laboral. Por lo demás, cuando la educación secundaria se articula con la formación técnica y profesional apunta a desarrollar competencias generales y específicas de iniciación en un campo ocupacional, evitando así una formación centrada en un puesto laboral. Esto es altamente valioso para los estudiantes debido a las características cambiantes del mercado de trabajo.

La decisión del egresado relacionada con el estudio, respecto de las carreras que pueden cursarse en la Universidad Nacional del Noroeste de la Provincia de Buenos Aires (UNNOBA) - ubicada en las ciudades de Junín y de Pergamino, ambas sedes- el mayor porcentaje de ingresantes se da en carreras tradicionales como Abogacía, Contador Público y Agronomía en línea con la tendencia de otras universidades nacionales. ${ }^{192}$ En tal sentido, obsérvese el cuadro siguiente:

\section{Porcentajes de estudiantes según las carreras}

\begin{tabular}{|l|c|c|c||}
\hline \multirow{2}{*}{ Carrera } & \multicolumn{3}{|c||}{ Año } \\
\cline { 2 - 4 } & $\mathbf{2 0 0 9}$ & $\mathbf{2 0 1 0}$ & $\mathbf{2 0 1 1}$ \\
\hline \hline Abogacía & $12 \%$ & $13 \%$ & $11 \%$ \\
\hline \hline Contador Público & $17 \%$ & $16 \%$ & $20 \%$ \\
\hline \hline Ingeniería Agronómica & $11 \%$ & $10 \%$ & $9 \%$ \\
\hline \hline Ingeniería en Informática & $2 \%$ & $2 \%$ & $1 \%$ \\
\hline Ingeniería Industrial & $2 \%$ & $4 \%$ & $3 \%$ \\
\hline Ingeniería Mecánica & $2 \%$ & $1 \%$ & $2 \%$ \\
\hline \hline Licenciatura en Administración & $2 \%$ & $2 \%$ & $2 \%$ \\
\hline \hline Licenciatura en Ciencias de los Alimentos & $7 \%$ & $6 \%$ & $9 \%$ \\
\hline \hline Licenciatura en Diseño de Indumentaria y Textil & $1 \%$ & $1 \%$ & $1 \%$ \\
\hline \hline Licenciatura en Diseño Gráfico & $3 \%$ & $3 \%$ & $4 \%$ \\
\hline
\end{tabular}

192. "Pese a múltiples ofertas, la mayoría de los estudiantes elige las carreras tradicionales", Democracia, Sección Locales, Junín, 10 de noviembre de 2011, página 2. 


\begin{tabular}{|l|c|c||c||}
\hline Licenciatura en Diseño Industrial & No existía & $1 \%$ & $1 \%$ \\
\hline \hline Licenciatura en Enfermería & $4 \%$ & $5 \%$ & $4 \%$ \\
\hline \hline Licenciatura en Genética & $4 \%$ & $4 \%$ & $4 \%$ \\
\hline \hline Licenciatura en Sistemas & $9 \%$ & $8 \%$ & $5 \%$ \\
\hline Tecnicatura en Alimentos & $1 \%$ & $1 \%$ & $3 \%$ \\
\hline \hline Tecnicatura en Informática Agropecuaria & $1 \%$ & $1 \%$ & $1 \%$ \\
\hline \hline Tecnicatura en Mantenimiento Industrial & $1 \%$ & $1 \%$ & $2 \%$ \\
\hline \hline Tecnicatura Universitaria en Desarrollo de Sistemas & $2 \%$ & $2 \%$ & $2 \%$ \\
\hline \hline Tecnicatura Universitaria en Gestión de PyMEs & $5 \%$ & $7 \%$ & $6 \%$ \\
\hline \hline Tecnicatura Universitaria en Producción Agropecuaria & $5 \%$ & $5 \%$ & $5 \%$ \\
\hline \hline Tecnicatura Universitaria en Gestión Pública & $3 \%$ & $5 \%$ & $4 \%$ \\
\hline \hline
\end{tabular}

Fuente: Secretaría Académica de la UNNOBA. 10 de noviembre de 2011.

Para abordar las cuestiones referidas a estudios superiores, en esta investigación, se formularán preguntas — vía cuestionarios autoadministrados - a egresados adolescentes y adultos de diversas escuelas estatales de nivel medio pertenecientes al Distrito de Junín. 


\section{Capítulo II EL PROCESO DE INVESTIGACIÓN}

\section{El enfoque mixto o multimodal}

\subsection{Su esencia}

En esta investigación se decidió llevar a cabo un proceso mixto. A través de él se recolectaron, analizaron y vincularon datos cuantitativos y cualitativos. Lo pretendido así fue ofrecer una perspectiva más completa del fenómeno, lo cual implicó desde el planteamiento del problema considerar la lógica inductiva y la deductiva. ${ }^{193}$

\subsection{Definiciones fundamentales que llevaron a su elección}

Se establecieron las siguientes:

1) racionalización del diseño mixto: se aspiraba a explicar con más detalle hallazgos cuantitativos y cualitativos;

2) establecimiento de relaciones entre los datos cuantitativos y cualitativos: se otorgó a cada tipo de datos el mismo peso conceptual e interpretativo. La calidad en la obtención de los mismos y la sistematización en el análisis fueron iguales para ambas partes;

3) secuencia en la recolección y análisis de los datos: resultó concurrente (es decir, al mismo tiempo). Esta secuencia dependió del fenómeno en estudio, del planteamiento del problema y de las circunstancias que rodearon al trabajo. La estimación tentativa de los tiempos de ejecución de ambos procesos fue la siguiente: recolección de datos, septiembre a diciembre de 2010 y análisis de los mismos, abril a septiembre de 2011;

4) forma de asociar y/o combinar tipos de datos distintos: el proceso cuantitativo (cuestionarios, documentos e indicadores o estadísticas) generó datos para el análisis llamados puntuaciones o valores numéricos. Del proceso cualitativo (observaciones,

193. Hernández Sampieri, Roberto, Fernández Collado, Carlos y Baptista Lucio, Pilar, Capítulo 17 "Los procesos mixtos o multimodales", op. cit., página 755. 
grupos de enfoque y documentos) emergieron datos para el análisis denominados textos transcriptos y anotaciones y

5) forma de presentar los resultados inherentes a cada enfoque: se hará de manera independiente. ${ }^{194}$

\subsection{Diseño en paralelo}

Se realizaron a un mismo tiempo dos estudios: uno cuantitativo y uno cualitativo. De los resultados de ambos se efectuarán las interpretaciones sobre el problema investigado. No se combinarán los datos cuantitativos con los cualitativos, los análisis se llevarán a cabo por separado y —en el final- habrá conclusiones, limitaciones y sugerencias generales.

El reto es que las bases de datos sean comparables. Asimismo, entre otras posibilidades de análisis e interpretación se elige la comparación de resultados: los cuantitativos serán directamente contrastados con los cualitativos. El propósito de este diseño es convergencia y resultados complementarios. ${ }^{195}$

\subsection{El instrumento de medición}

Seleccionados el diseño de investigación y las muestras probabilísticas pertinentes, de acuerdo con el problema de estudio y la hipótesis general (a más, las subhipótesis), la siguiente etapa consistió en recolectar los datos sobre los participantes. Para ello se utilizaron diferentes instrumentos o técnicas de medición. A efectos de seleccionar los mismos se tuvieron en cuenta los siguientes aspectos: a) demostraciones de mayor confiabilidad, validez y objetividad, ${ }^{196}$ b) más aplicaciones al planteamiento y propósito de recolección de los datos, c) mejor adecuación a las muestras y contextos y d) ajuste en mayor medida con las aptitudes del investigador.

194. Hernández Sampieri, Roberto, Fernández Collado, Carlos y Baptista Lucio, Pilar, Capítulo 17 "Los procesos mixtos o multimodales", op. cit., página 792.

195. Hernández Sampieri, Roberto, Fernández Collado, Carlos y Baptista Lucio, Pilar, Capítulo 17 "Los procesos mixtos o multimodales", op. cit., página 777 y 778.

196. La confiabilidad alude al grado en que un instrumento produce resultados consistentes y coherentes. La validez, en términos generales, es el grado en que un instrumento realmente mide la variable que pretende medir. Y la objetividad - concepto difícil de lograr, particularmente en las Ciencias Sociales - se refiere al grado en que el instrumento es permeable a la influencia de los sesgos y tendencias del investigador que lo administra, califica e interpreta. En Hernández Sampieri, Roberto, Fernández Collado, Carlos y Baptista Lucio, Pilar, Capítulo 9 "Recolección de los datos cuantitativos", op. cit., páginas 274, 277 y 287. 
El cuestionario para aplicar a los egresados, sus responsables, sus profesores, directores y secretarios, fue elaborado teniendo en mira que su tamaño no fuese muy corto (para evitar la pérdida de información) ni resultase largo (para no ser tedioso). El tamaño dependió, según el agente educativo de que se tratase, del número de variables y dimensiones a medir y la manera como se administraría. Su duración fue de veinticinco minutos para los egresados y de veinte para el resto, tiempo que resultó suficiente para todos los participantes, salvo muy pocas excepciones. En algunos casos resultó conveniente iniciar el cuestionario con preguntas fáciles de contestar para que el sujeto se adentrase en la situación. Todos comenzaron con preguntas demográficas o de ubicación (consideradas obligatorias por algunos autores) ante el supuesto de que los participantes no se sentirían comprometidos si los respondían.

En ocasiones bastó una pregunta para recolectar la información necesaria sobre la variable a medir (ejemplo: variable 1, pregunta 1 del cuestionario para egresados). En otras se elaboraron varias para verificar la consistencia de las respuestas (ejemplo: variables 2, preguntas 2 a 10 del mismo cuestionario). Obedeciendo a necesidades y al problema de investigación, en los cuestionarios de egresados, sus responsables y sus profesores se usaron preguntas cerradas. En los de directores y secretarios fue conveniente utilizar preguntas cerradas y abiertas. Respecto de las cerradas, para superar su principal desventaja se colocó —como última respuesta válida — la opción "Otro/s (especificar)". Se pensó en ella para que los encuestados no tuviesen que escribir o verbalizar pensamientos, sino únicamente seleccionar la o las alternativas que sintetizaran mejor su/s respuesta/s. Las preguntas abiertas proporcionaron una información más amplia en situaciones donde se deseaba profundizar una opinión, a sabiendas que los directores y los secretarios responderían con precisión, sin generar confusión en sus respuestas.

Hubieron preguntas cerradas que contenían dos posibilidades de respuesta (denominadas dicotómicas) previamente delimitadas. En ellas el participante debía elegir la opción que describiera más adecuadamente su respuesta (por ejemplo: variable 2, pregunta 3, del cuestionario para responsables). Y preguntas cerradas donde el sujeto podía seleccionar más de una opción o categoría de respuesta (ejemplo: variable 1, pregunta 4, profesores). Precisamente, con respecto a tales preguntas cerradas, donde se podía elegir más de una opción, se observó que en todos los casos — trátese de egresados, sus responsables, sus profesores, directores y secretarios- el número total de categorías de respuesta elegidas fue superior al número de participantes. Ejemplo respecto de los egresados: en la pregunta 1 ¿Por/para qué cursás el secundario?, los 330 adolescentes eligieron en total 1158 opciones (lo cual evidencia que hubieron alumnos que seleccionaron más de una opción). Los porcentajes que figuran en los cuadros respectivos (y sus gráficos correspondientes) están en relación directa con la cantidad total de participantes en la encuesta. Asimismo, a título de ejemplos, en las preguntas 1 (egresados), 5.a (responsables), 8 (profesores) y 1 (directores y secretarios), se confeccionó una última columna —en la parte derecha del cuadro- donde están los 
porcentajes obtenidos en base al total de opciones de respuesta elegidas (que es coincidente con el total de participantes). Cuando las preguntas cerradas contenían dos o más posibilidades de respuesta y el participante debía elegir una, los porcentajes se lograron en forma idéntica a la anteriormente señalada. Asimismo, las preguntas abiertas se codificaron una vez conocidas todas las respuestas de los directores y secretarios a los cuales se aplicaron. Con la codificación se obtuvieron ciertas categorías que representan los resultados finales. El procedimiento consistió en encontrar y darles nombre a los patrones generales de respuesta (respuestas similares o comunes). Algo similar aconteció con los secretarios.

\section{Enfoque Cuantitativo}

A lo largo de la historia de la ciencia han surgido corrientes de pensamiento tales como el materialismo dialéctico, el empirismo, el estructuralismo, la fenomenología y el positivismo. Asimismo, pueden citarse diversos marcos interpretativos como la etnografía y el constructivismo, que han originado diferentes rutas en la búsqueda del conocimiento. Sin embargo, desde la segunda mitad del siglo XX dichas corrientes se han polarizado en dos enfoques principales: el enfoque cuantitativo y el enfoque cualitativo de la investigación. A continuación se desarrollará el primero de los mencionados: 


\subsection{Egresados de escuelas estatales de nivel medio del Distrito de Junín}

Total de egresados adolescentes que fueron encuestados

Total de egresados adultos que fueron encuestados

Total de egresados (adolescentes y adultos) que fueron encuestados

Total de egresados (adolescentes y adultos) que no fueron encuestados por estar ausentes el día de la recolección de datos

Total de egresados (adolescentes y adultos) no encuestados porque sus escuelas no integraron la muestra

Total de egresados (adolescentes y adultos) del ciclo lectivo 2010

Prueba piloto: se efectuó en julio de 2010 con 40 egresados.

Instrumento de recolección de datos: cuestionario autoadministrado individual (no precodificado) que incluye preguntas cerradas con varias opciones de respuesta no mutuamente excluyentes (1 a 10 y 18 a 23). Y preguntas cerradas con varias posibilidades de respuesta de las que debe elegir una (11 a 14). Las preguntas 15, 16 y 17 presentan algunas características propias. En total, 23 preguntas. 


\subsubsection{Presentación de los participantes}

A continuación se hará referencia a seis escuelas de nivel medio: A, D, F y J (para adolescentes), $\mathrm{L}_{4}$ y M (para adultos). La D y la $\mathrm{F}$ (urbanas) fueron elegidas por tener ambas cinco cursos con diferentes modalidades. La escuela A (rural) y la J (urbana) lo fueron por albergar un curso cada una con sus modalidades. También se tuvo en cuenta a la escuela $\mathrm{M}$ (dos cursos, dos modalidades) y a la $\mathrm{L}_{4}$ (un curso con su modalidad), ambas para adultos, mixtas - al igual que todas las demás - y urbanas. Ahora bien, de todos los colegios citados se conocerán los datos demográficos o de ubicación correspondientes a los egresados, a sus responsables y a sus profesores. Asimismo, se darán a conocer los datos demográficos de los directores y secretarios de las escuelas A, B, C, D, E, F, G, H, I y J (de adolescentes) y $\mathrm{H}_{1}$, L y M (de adultos). Se empezará con los datos relativos a los egresados, tomando en consideración a los colegios $\mathrm{D}, \mathrm{F}, \mathrm{A}, \mathrm{J}, \mathrm{M}$ y L 4 (en ese orden): 


\begin{tabular}{|c|c|}
\hline \multicolumn{2}{|r|}{ Escuela D } \\
\hline Total de egresados & 129. \\
\hline $\begin{array}{l}\text { Total de egresados } \\
\text { encuestados }\end{array}$ & 93. \\
\hline Nacionalidad & $\begin{array}{l}\text { Dos alumnos no contestaron la pregunta. Otro contestó "Junín" (incorrecto, } \\
\text { por ende no se contabiliza) y los demás, argentina. }\end{array}$ \\
\hline Sexo & 31 varones y 62 mujeres. \\
\hline Edad promedio & 17 años y 7 meses. \\
\hline Estado civil & $\begin{array}{l}\text { La mayoría expresó ser soltero/a. Una alumna respondió "de novia", otras dos } \\
\text { contestaron "en una relación", tres varones escribieron "de novio" (quedan } \\
\text { anuladas las seis respuestas). }\end{array}$ \\
\hline $\begin{array}{l}\text { Nivel } \\
\text { socioeconómico }\end{array}$ & $\begin{array}{l}\text { La mayoría señaló que su nivel socioeconómico es medio. Otros cuatro } \\
\text { afirmaron pertenecer a un nivel socioeconómico bajo. Seis no respondieron. }\end{array}$ \\
\hline $\begin{array}{l}\text { Barrio o zona } \\
\text { donde viven }\end{array}$ & $\begin{array}{l}\text { Los egresados pertenecen a barrios ubicados entre diez y treinta cuadras del } \\
\text { establecimiento. "El Picaflor", "Las Morochas", "Belgrano" y "Pueblo } \\
\text { Nuevo" son los que incluyen al mayor número. La mayoría vive en ellos desde } \\
\text { que nació. }\end{array}$ \\
\hline Repitencia & Diecinueve educandos repitieron una vez. El resto, ninguna. \\
\hline $\begin{array}{l}\text { Actividad laboral } \\
\text { que realizan }\end{array}$ & $\begin{array}{l}\text { De los egresados, setenta y ocho no trabajan. Los demás llevan a cabo } \\
\text { diferentes actividades, como empleada en una fábrica de bordados, repositora, } \\
\text { secretaria, técnico en armado y reparaciones de PC, vendedora de cosméticos } \\
\text { y profesora de danzas. }\end{array}$ \\
\hline Actividad física & $\begin{array}{l}\text { Mayoritariamente practican fútbol o básquetbol o van a caminar, a correr o a } \\
\text { un gimnasio. Y treinta y nueve de ellos no realizan actividad física alguna. }\end{array}$ \\
\hline
\end{tabular}




\begin{tabular}{|c|c|}
\hline \multicolumn{2}{|r|}{ Escuela F } \\
\hline Total de egresados & 130. \\
\hline $\begin{array}{l}\text { Total de egresados } \\
\text { encuestados }\end{array}$ & 110. \\
\hline Nacionalidad & $\begin{array}{l}\text { Todos, argentina menos una alumna que contestó "Junín" (incorrecto por ello } \\
\text { no se contabiliza). }\end{array}$ \\
\hline Sexo & 42 varones y 68 mujeres. \\
\hline Edad promedio & 17 años y 8 meses. \\
\hline Estado civil & $\begin{array}{l}\text { Dos egresadas contestaron "de novia" y "comprometida" (estas respuestas no } \\
\text { se contabilizan). Los demás son solteros/as. }\end{array}$ \\
\hline $\begin{array}{l}\text { Nivel } \\
\text { socioeconómico }\end{array}$ & $\begin{array}{l}\text { La mayoría contestó nivel socioeconómico medio. Dos, nivel bajo; dos nivel } \\
\text { medio alto y once no respondieron. }\end{array}$ \\
\hline $\begin{array}{l}\text { Barrio o zona } \\
\text { donde viven }\end{array}$ & $\begin{array}{l}\text { Estos egresados viven en barrios que se hallan entre diez y treinta cuadras de } \\
\text { la escuela. La mayor cantidad reside en los denominados "Prado Español", "9 } \\
\text { de Julio", "Nuestra Señora de Fátima" y "La Loba". Casi todos ellos están en } \\
\text { los mismos desde que nacieron. }\end{array}$ \\
\hline Repitencia & $\begin{array}{l}\text { La mayoría de los egresados no repitió. Trece repitieron una vez. Ocho } \\
\text { repitieron dos veces. Otro dato: en un curso de quince encuestados sólo tres no } \\
\text { repitieron. }\end{array}$ \\
\hline $\begin{array}{l}\text { Actividad laboral } \\
\text { que realizan }\end{array}$ & $\begin{array}{l}\text { La gran mayoría no trabaja. Pocos lo hacen en relación de dependencia } \\
\text { (algunos, sólo una o dos veces por semana). Cuatro estudiantes no contestaron } \\
\text { la pregunta. }\end{array}$ \\
\hline Actividad física & $\begin{array}{l}\text { Sólo treinta y tres no realizan actividad física alguna. La mayoría practica } \\
\text { fútbol o básquetbol o hockey o van a un gimnasio al menos una vez por } \\
\text { semana. }\end{array}$ \\
\hline
\end{tabular}




\begin{tabular}{|c|c|}
\hline \multicolumn{2}{|r|}{ Escuela A } \\
\hline Total de egresados & 13. \\
\hline $\begin{array}{l}\text { Total de egresados } \\
\text { encuestados }\end{array}$ & 12. \\
\hline Nacionalidad & Once, argentina. Una alumna no contestó. \\
\hline Sexo & 6 varones y 6 mujeres. \\
\hline Edad promedio & 17 años y 5 meses. \\
\hline Estado civil & Todos solteros/as. \\
\hline $\begin{array}{l}\text { Nivel } \\
\text { socioeconómico }\end{array}$ & Diez nivel medio; dos no contestaron. \\
\hline $\begin{array}{l}\text { Barrio o zona } \\
\text { donde viven }\end{array}$ & $\begin{array}{l}\text { Nueve egresados viven en la localidad (distante } 20 \mathrm{~km} \text { de la ciudad de Junín) } \\
\text { donde está ubicada la escuela. Uno vive en el Cuartel II (campo), uno en el } \\
\text { Cuartel X (campo) y al restante en la zona Noroeste. Todos residen en sus } \\
\text { actuales hogares desde que nacieron. }\end{array}$ \\
\hline Repitencia & Diez egresados no repitieron nunca. Los dos restantes repitieron una vez. \\
\hline $\begin{array}{l}\text { Actividad laboral } \\
\text { que realizan }\end{array}$ & $\begin{array}{l}\text { Siete trabajan (la mayoría de ellos colabora con sus padres en el campo); uno } \\
\text { realiza changas y cuatro no trabajan. }\end{array}$ \\
\hline Actividad física & $\begin{array}{l}\text { Ocho egresados practican deportes, mayoritariamente fútbol. Los otros cuatro } \\
\text { no realizan ninguna actividad física. }\end{array}$ \\
\hline
\end{tabular}




\begin{tabular}{|l|l|||}
\hline \multicolumn{2}{|l||}{ Escuela J } \\
\hline Total de egresados & 16. \\
\hline $\begin{array}{l}\text { Total de egresados } \\
\text { encuestados }\end{array}$ & 10. \\
\hline Nacionalidad & Todos, argentina. \\
\hline Sexo & 3 varones y 7 mujeres. \\
\hline Edad promedio & 18 años y 2 meses. \\
\hline \hline Estado civil & Todos solteros/as. \\
\hline $\begin{array}{l}\text { Nivel } \\
\text { socioeconómico }\end{array}$ & Cuatro, nivel bajo, tres medio y tres no contestaron. \\
\hline \hline $\begin{array}{l}\text { Barrio o zona } \\
\text { donde viven }\end{array}$ & $\begin{array}{l}\text { La mayoría vive en sectores ubicados a una distancia que media entre cinco y } \\
\text { diez cuadras, respecto de la escuela. La minoría vive en barrios municipales } \\
\text { aledaños a la misma. Casi todos residen en los ámbitos mencionados desde } \\
\text { que nacieron. }\end{array}$ \\
\hline \hline Repitencia & $\begin{array}{l}\text { Tres alumnos no repitieron nunca; un educando dejó un año y luego retomó. } \\
\text { Cinco estudiantes repitieron una vez y uno repitió dos veces. }\end{array}$ \\
\hline $\begin{array}{l}\text { Actividad laboral } \\
\text { que realizan }\end{array}$ & $\begin{array}{l}\text { Todos trabajan. La mayoría lo hace en relación de dependencia y la minoría } \\
\text { como ama de casa. }\end{array}$ \\
\hline \hline $\begin{array}{l}\text { Practican algún deporte nueve alumnos, predominantemente fútbol. Un } \\
\text { educando no contestó. }\end{array}$ \\
\hline Actica
\end{tabular}




\begin{tabular}{|c|c|}
\hline \multicolumn{2}{|r|}{ Escuela M } \\
\hline Total de egresados & 33. \\
\hline $\begin{array}{l}\text { Total de egresados } \\
\text { encuestados }\end{array}$ & 14. \\
\hline Nacionalidad & Todos, argentina. \\
\hline Sexo & 10 varones y 4 mujeres. \\
\hline Edad promedio & 19 años y 7 meses. \\
\hline Estado civil & Trece solteros/as y uno casado. \\
\hline $\begin{array}{l}\text { Nivel } \\
\text { socioeconómico }\end{array}$ & Todos, nivel medio. \\
\hline $\begin{array}{l}\text { Barrio o zona } \\
\text { donde viven }\end{array}$ & $\begin{array}{l}\text { Los hogares están ubicados en diversos sectores a aproximadamente — todos } \\
\text { ellos- veinte cuadras de la escuela. La minoría en la zona céntrica, muy } \\
\text { próximos al colegio. Todos viven en tales hogares desde que nacieron. }\end{array}$ \\
\hline Repitencia & $\begin{array}{l}\text { Tres egresados no repitieron nunca. Cuatro repitieron una vez y seis repitieron } \\
\text { dos veces. Un alumno abandonó un tiempo y luego retomó. }\end{array}$ \\
\hline $\begin{array}{l}\text { Actividad laboral } \\
\text { que realizan }\end{array}$ & $\begin{array}{l}\text { Ocho egresados no llevan a cabo ninguna. Seis lo hacen en relación de } \\
\text { dependencia. }\end{array}$ \\
\hline Actividad física & Siete egresados realizan diferentes actividades físicas. Siete, ninguna. \\
\hline
\end{tabular}




\begin{tabular}{|c|c|}
\hline \multicolumn{2}{|r|}{ Escuela $\mathbf{L}_{4}$} \\
\hline Total de egresados & 13. \\
\hline $\begin{array}{l}\text { Total de egresados } \\
\text { encuestados }\end{array}$ & 11. \\
\hline Nacionalidad & Todos argentina. \\
\hline Sexo & 5 varones y 6 mujeres. \\
\hline Edad promedio & 22 años. \\
\hline Estado civil & $\begin{array}{l}\text { Todos solteros/as, salvo una alumna que respondió "de novia" (respuesta que } \\
\text { no se contabiliza). }\end{array}$ \\
\hline $\begin{array}{l}\text { Nivel } \\
\text { socioeconómico }\end{array}$ & La mayoría expresó nivel medio. Una egresada, nivel bajo y otra no contestó. \\
\hline $\begin{array}{l}\text { Barrio o zona } \\
\text { donde viven }\end{array}$ & $\begin{array}{l}\text { Estos egresados viven en barrios distantes entre diez y veinte cuadras del } \\
\text { colegio. La mayoría de las viviendas fue construida por la Nación o la } \\
\text { Provincia de Buenos Aires. Mayoritariamente residen en los mismos desde } \\
\text { hace entre cinco y diez años. La minoría, desde hace menos de un año. }\end{array}$ \\
\hline Repitencia & $\begin{array}{l}\text { Diez egresados repitieron. Cuatro sólo una vez y seis de ellos dos veces } \\
\text { (varios de éstos repitieron Octavo y Noveno Año de la EGB). Un varón } \\
\text { abandonó dos veces Primer Año. }\end{array}$ \\
\hline $\begin{array}{l}\text { Actividad laboral } \\
\text { que realizan }\end{array}$ & $\begin{array}{l}\text { Ocho trabajan. De ellos, seis lo hacen en relación de dependencia, desde hace } \\
\text { entre uno y dos años. Tres de los egresados no trabajan. }\end{array}$ \\
\hline Actividad física & $\begin{array}{l}\text { Nueve no realizan actividad física alguna. Del resto, una mujer camina } \\
\text { periódicamente y un varón juega de vez en cuando al fútbol con amigos. }\end{array}$ \\
\hline
\end{tabular}

\subsubsection{Conceptos preliminares al trabajo de campo}

\subsubsection{Estrategia metodológica y diseño muestral}

Se impulsó en 2010 la realización de una investigación que permitiera obtener datos acerca del universo de estudiantes adolescentes y adultos del último año del nivel medio, en los establecimientos de gestión estatal del Distrito de Junín, perteneciente a la Región XIV de la Dirección General de Cultura y Educación de la provincia de Buenos Aires. A tal efecto se tramitaron las pertinentes autorizaciones para llevar a cabo la misma, obteniéndose los permisos correspondientes. En esta investigación se plantea una hipótesis general y varias subhipótesis para indagar las conexiones entre características sociales, rendimiento educativo y aspectos personales, con las orientaciones de futuro de los egresados. Se decidió utilizar 
como instrumento el cuestionario porque se lo considera un instrumento adecuado para atender a los dos propósitos del conocimiento: las asociaciones entre distintos aspectos sociales y psicosociales y sus tendencias más frecuentes.

Para predicar sobre el universo estudiantil se diseñó una muestra ${ }^{197}$ probabilística estratificada a partir de los establecimientos educativos, tomando como unidad de muestreo a la escuela-etapa evolutiva-modalidad-turno. Para armar los estratos se clasificó a las escuelas según la etapa evolutiva de los educandos que asisten a ellas: de adolescentes y de adultos. También se lo hizo por modalidad: Arte, Diseño y Comunicación (ADICO), Automotores, Ciencias Agrarias, Ciencias Naturales, Economía y Gestión de las Organizaciones (EGEOR), Electromecánica, Electrónica, Humanidades y Ciencias Sociales (HUSOC) y Producción de Bienes y Servicios (Informática), todas ellas (nueve en total) referidas a los adolescentes. Y Ciencias Naturales, Ciencias Sociales, Defensa Civil, EGEOR, Hotelería y Restaurantes, Maestro Mayor de Obras, Organización y Administración de Empresas, Periodismo, Producción de Bienes y Servicios (BIES), Salud, Bachillerato para Adultos con Orientación Tecnológica (BAOT) y Bachillerato para Adultos con Orientación en Artesanías Regionales (BAO Art. Reg.), todas referidas a los adultos (doce modalidades en total). Además, fueron clasificadas por turno: diurno, vespertino y nocturno y por zona donde se encuentran ubicadas: urbana, en el límite urbano-suburbano y rural. De la combinación de todos los aspectos mencionados se constituyeron estratos, tal como se puede observar en los Cuadros 1.a, 1.b, 2.a y 2.b.

Cuadro 1.a

\begin{tabular}{|c|c|c|c|c|c|c|c|c|c|c|}
\hline \multirow{3}{*}{ Turno } & \multicolumn{10}{|c|}{ Adolescentes Encuestados } \\
\hline & \multicolumn{9}{|c|}{ Modalidad } & \multirow{2}{*}{ Total } \\
\hline & EGEOR & Cs.Nat. & HUSOC & $\mathrm{ADICO}$ & BIES & Electrom. & Electrón. & Cs. Agrarias & Autom. & \\
\hline Diurno & 38 & 81 & 49 & 46 & \multirow{2}{*}{$9^{(*)}$} & \multirow{2}{*}{$8^{(*)}$} & \multirow{2}{*}{$2^{(*)}$} & \multirow{2}{*}{$5^{(*)}$} & \multirow{2}{*}{$3^{(*)}$} & 241 \\
\hline Vespertino & 48 & 17 & 9 & 15 & & & & & & 89 \\
\hline Total & 86 & 98 & 58 & 61 & 9 & 8 & 2 & 5 & 3 & 330 \\
\hline
\end{tabular}

Nota: Total de modalidades: 9.

${ }^{(*)}$ Escuelas de doble turno: diurno y vespertino

Fuente: Encuesta propia a egresados 2010.

197. La muestra es un subconjunto de la población y para elegirla existen varios métodos: al azar, estratificada (como en esta tesis), por racimos y de conjuntos o grupos de elementos, entre otros. Asimismo, pueden ser no probabilísticas y probabilísticas (como en esta investigación). En las muestras probabilísticas todos los elementos de la población tienen la misma probabilidad de ser seleccionados. Para la muestra probabilística de esta investigación (tal el caso de los cuestionarios) hubo que determinar su tamaño a través del cálculo. 
Cuadro 1.b

\begin{tabular}{|c|c|c|c|c|c|c|c|c|c|c|}
\hline \multirow{3}{*}{ Turno } & \multicolumn{10}{|c|}{ Adultos Encuestados } \\
\hline & \multicolumn{9}{|c|}{ Modalidad } & \multirow[b]{2}{*}{ Total } \\
\hline & $\begin{array}{c}\text { BAO } \\
\text { Art Reg. }\end{array}$ & Def.Civil & EGEOR & Period. & Cs.Soc. & Cs.Nat. & $\begin{array}{l}\text { Hotel. } \\
\text { y Rest. }\end{array}$ & $\begin{array}{c}\text { Org. y Adm. } \\
\text { de } \\
\text { Empresas }\end{array}$ & Salud & \\
\hline $\begin{array}{c}\text { Nocturno } \\
\text { Total }\end{array}$ & 2 & 4 & 21 & 3 & 18 & 3 & 11 & 6 & 9 & 77 \\
\hline
\end{tabular}

Notas: 1. Total de modalidades: 9.

2. No fueron encuestados adultos de las modalidades BAOT, BIES y Maestro Mayor de Obras.

Fuente: Encuesta propia a egresados 2010.

\section{Cuadro 2.a}

\begin{tabular}{|l||c|c|c|c||}
\hline \multirow{2}{*}{\multicolumn{1}{|c||}{ Modalidad }} & \multicolumn{2}{c|}{ Adolescentes (N) } & \multicolumn{2}{c||}{ Adolescentes Encuestados } \\
\cline { 2 - 5 } & Cantidad & Porcentaje & Cantidad & Porcentaje \\
\hline \hline ADICO & 74 & $12,63 \%$ & 61 & $18,48 \%$ \\
\hline Automotores & 9 & $1,55 \%$ & 2 & $0,9 \%$ \\
\hline \hline BIES & 33 & $5,64 \%$ & 9 & $2,73 \%$ \\
\hline Ciencias Agrarias & 7 & $1,19 \%$ & 3 & $1,52 \%$ \\
\hline Ciencias Naturales & 181 & $30,89 \%$ & 98 & $29,70 \%$ \\
\hline EGEOR & 152 & $25,92 \%$ & 86 & $26,06 \%$ \\
\hline \hline Electromecánica & 22 & $3,75 \%$ & 8 & $2,42 \%$ \\
\hline \hline Electrónica & 9 & $1,54 \%$ & 5 & $0,61 \%$ \\
\hline \hline HUSOC & 99 & $16,89 \%$ & 58 & $17,58 \%$ \\
\hline TOTAL & 586 & $100 \%$ & 330 & $100 \%$ \\
\hline
\end{tabular}

$\mathrm{N}$ = población o universo

Notas: 1. De una población de 586 egresados adolescentes fueron encuestados 330; es decir, el 56,31\%.

2. No fueron encuestados por estar ausentes el día de la recolección de datos: 143 adolescentes.

3. No fueron encuestados porque sus escuelas no integraron la muestra: 113 adolescentes.

4. Total de modalidades: 9.

Fuente: Encuesta propia a egresados 2010. 
Cuadro 2.b

\begin{tabular}{|l|c|c|c|c|}
\hline \multirow{2}{*}{\multicolumn{1}{|c|}{ Modalidad }} & \multicolumn{2}{c|}{ Adultos (N) } & \multicolumn{2}{c|}{ Adultos Encuestados } \\
\cline { 2 - 5 } & Cantidad & Porcentaje & Cantidad & Porcentaje \\
\hline \hline BAO Artesanías Regionales & 2 & $0,82 \%$ & 2 & $2,60 \%$ \\
\hline \hline BAOT & 25 & $10,20 \%$ & 0 & $0 \%$ \\
\hline BIES & 13 & $5,30 \%$ & 0 & $0 \%$ \\
\hline Ciencias Naturales & 19 & $7,76 \%$ & 3 & $3,90 \%$ \\
\hline \hline Ciencias Sociales & 73 & $29,80 \%$ & 18 & $23,38 \%$ \\
\hline Defensa Civil & 7 & $2,86 \%$ & 4 & $5,18 \%$ \\
\hline \hline EGEOR & 59 & $24,08 \%$ & 21 & $27,27 \%$ \\
\hline Hotelería y Restaurantes & 13 & $5,31 \%$ & 11 & $14,29 \%$ \\
\hline Maestro Mayor de Obras & 11 & $4,48 \%$ & 0 & $0 \%$ \\
\hline Periodismo & 6 & $2,45 \%$ & 3 & $3,90 \%$ \\
\hline Organización y & 8 & $3,27 \%$ & 6 & $7,79 \%$ \\
\hline Administración de Empresas & 9 & $3,67 \%$ & 9 & $11,69 \%$ \\
\hline Salud & 245 & $100 \%$ & 77 & $100 \%$ \\
\hline TOTAL & & & & \\
\hline
\end{tabular}

$\mathrm{N}=$ población o universo

Notas: 1. De una población de 245 egresados adultos fueron encuestados 77; es decir, el 31,43\%.

2. No fueron encuestados por estar ausentes el día de la recolección de datos: 85 adultos.

3. No fueron encuestados porque sus escuelas no integran la muestra: 83 adultos.

4. Total de modalidades: 12 .

Fuente: Encuesta propia a egresados 2010.

Dada la amplia cobertura geográfica de la investigación (por el diseño muestral probabilístico elaborado), se decidió aplicar un cuestionario autoadministrado con preguntas cerradas $^{198}$ (algunas de ellas con una opción de respuesta correcta y otras con varias opciones de respuesta válidas no mutuamente excluyentes). Siendo la muestra de cuatrocientos siete egresados, la prueba piloto se llevó a cabo con cuarenta de ellos. Dicha prueba (realizada en julio de 2010) se efectuó en cuatro escuelas identificadas con las letras A, B y D (de adolescentes) y $\mathrm{M}$ (de adultos), con un instrumento que contenía varias preguntas abiertas las

198. El cuestionario se adjunta en los Anexos. 
cuales posibilitaron la ulterior construcción de preguntas con opciones de respuesta prefijadas. El cuestionario definitivo (23 preguntas en total) incluyó tres grandes bloques organizados en función de los siguientes temas: 1) atributos sociodemográficos; 2) sentidos atribuidos a la escuela media; 3) planes de futuro. En el ordenamiento de las preguntas se tuvo en cuenta tanto la hilación lógica como la psicológica que pudieran existir entre unas y otras. El tiempo razonable para responder al mismo fue estimado en veinticinco minutos.

La presencia del investigador durante la aplicación del cuestionario permitió clarificar dudas in situ y generar el interés de los estudiantes para responder en forma completa y a conciencia. Merced a la colaboración de todos los profesores, las actividades se llevaron a cabo al comienzo o antes del final de las clases respectivas. A veces se utilizaron las denominadas "horas libres" (en las que, por alguna causa, no se imparten conocimientos). Pese a que uno de los inconvenientes de esta técnica es el riesgo de niveles significativos de no respuesta, sólo fueron tres (entre cuatrocientos siete interrogados) los educandos — dos adolescentes y una adulta- que devolvieron el cuestionario sin responder a pregunta alguna.

\subsubsection{La construcción del instrumento de medición}

Indagar esta problemática a través de un cuestionario autoadministrado individual exigió unificar interrogantes y respuestas posibles. Para confeccionar las preguntas y opciones del cuestionario definitivo se tuvieron en cuenta los aportes de la información precedente sobre la problemática y los resultados de la prueba piloto.

En atención a los sentidos atribuidos a la escuela media, el cuestionario destaca razones de tipo instrumental ligadas a la obtención de credenciales para la prosecución de estudios superiores y para el mercado de trabajo.

Ampliando lo anterior, se identifican tres líneas argumentativas entre los objetivos privilegiados por los alumnos para concurrir a la escuela. Una de ellas remite a gratificaciones diferidas: la asistencia se funda en la posibilidad futura de proseguir estudios superiores, "ser alguien en la vida" o conseguir un buen trabajo. Otra línea se expresa en gratificaciones en tiempo presente, que remiten a los aprendizajes adquiridos "para desenvolverme mejor en esta sociedad" o "para ampliar mis conocimientos" o a la convivencia social con sus pares. La tercera alude a la idea de adquirir conocimientos útiles para el trabajo actual o de una asistencia obligada por efecto del mandato familiar o por autoimposición.

Los aportes de la escuela para su futuro se indagaron a partir de interrogar a los alumnos si consideraban que la orientación cursada en el nivel medio les brindó elementos para seguir estudios superiores y/o para trabajar. Además, se investigó qué espacios o actividades organizados por la institución fueron visualizados como aportes a futuro. Qué capacidades desarrolladas en la escuela podían vincularse con estudios superiores y/o con la inserción 
laboral y si las actividades escolares de orientación vocacional y/u ocupacional - si hubieron- contribuyeron a la elección de estudios de nivel superior y/o de un trabajo.

Las Tablas 1 y 2, que se presentarán a continuación, expresan el proceso de operacionalización de estas variables; desde el establecimiento de dimensiones, subdimensiones e indicadores, hasta la formulación de las preguntas e ítems del cuestionario aplicado a los egresados. 
Tabla 1. Operacionalización de "Razones de asistencia a la escuela"

\begin{tabular}{|c|c|c|c|}
\hline Dimensiones & Subdimensiones & Indicadores & Preguntas del cuestionario \\
\hline $\begin{array}{l}\text { A. Asistencia por } \\
\text { mandato familiar }\end{array}$ & & Exigencia familiar para asistir & $\begin{array}{l}\text { Pregunta 1: ¿Por/para qué cursás el secundario? } \\
\text { Opción: Porque en mi casa me dijeron: “o estudiás o } \\
\text { trabajás” }\end{array}$ \\
\hline \multirow[t]{3}{*}{$\begin{array}{l}\text { B. Asistencia por } \\
\text { motivaciones } \\
\text { personales }\end{array}$} & $\begin{array}{l}\text { Futuro profesional } \\
\text { (estudio y/o trabajo) }\end{array}$ & $\begin{array}{l}\text { Acreditación para la continuidad educativa } \\
\text { Aprendizaje de saberes útiles para el trabajo } \\
\text { Acreditación para la inserción en el mercado laboral }\end{array}$ & $\begin{array}{l}\text { Pregunta 1: ¿Por/para qué cursás el secundario? } \\
\text { Opción: Porque necesito aprobar este nivel para seguir } \\
\text { estudios superiores } \\
\text { Opción: Para adquirir conocimientos que me sean útiles para } \\
\text { el trabajo que estoy realizando } \\
\text { Opción: Porque el título secundario me permitirá conseguir } \\
\text { trabajo y así tener una vida digna y respetable }\end{array}$ \\
\hline & Desarrollo personal & $\begin{array}{l}\text { Ampliación de conocimientos y aprendizajes } \\
\text { Capacidades para el desempeño social } \\
\text { Atribución de identidad social }\end{array}$ & $\begin{array}{l}\text { Pregunta 1: ¿Por/para qué cursás el secundario? } \\
\text { Opción: Para ampliar mis conocimientos, para aprender más } \\
\text { Opción: Porque adquirir conocimientos me permitirá } \\
\text { desenvolverme mejor en esta sociedad } \\
\text { Opción: Para ser "alguien” en la vida }\end{array}$ \\
\hline & $\begin{array}{l}\text { Sociabilidad e inclusión } \\
\text { social }\end{array}$ & $\begin{array}{l}\text { Valoración de la vida cotidiana en la escuela } \\
\text { Estrategia frente a la exclusión }\end{array}$ & $\begin{array}{l}\text { Pregunta 1: ¿Por/para qué cursás el secundario? } \\
\text { Opción: Porque en la escuela la paso bien (tengo } \\
\text { compañeros/amigos) } \\
\text { Opción: Para no estar en la calle }\end{array}$ \\
\hline
\end{tabular}


Tabla 2. Operacionalización de "Percepción de aportes de la formación escolar"

\begin{tabular}{|c|c|c|}
\hline Dimensiones & Indicadores & Preguntas del cuestionario \\
\hline \multirow[t]{3}{*}{$\begin{array}{l}\text { A. Percepción del aporte de } \\
\text { aprendizajes relativos a } \\
\text { conocimientos, habilidades } \\
\text { y actitudes vinculados al } \\
\text { trabajo y al estudio }\end{array}$} & $\begin{array}{l}\text { Conocimientos: } \\
\text { - Aprehender la realidad y sus cambios } \\
\text { - Creatividad } \\
\text { - Fundamentar opiniones en una discusión } \\
\text { - Investigación/búsqueda de información }\end{array}$ & $\begin{array}{l}\text { Pregunta 5: ¿Cuál/cuáles son los temas que frecuentemente aparecen en las } \\
\text { conversaciones de los egresados? } \\
\text { Pregunta } 8: \text { ¿De qué fuente te valés para adquirir la información y el } \\
\text { conocimiento? } \\
\text { Pregunta 9: ¿De quién/es es la responsabilidad de impartir la educación para } \\
\text { todos los habitantes enArgentina? } \\
\text { Pregunta 10: ¿Dónde está reconocido el derecho a la educación? } \\
\text { Preguntas } 11 \text { a } 17 .\end{array}$ \\
\hline & $\begin{array}{l}\text { Habilidades: } \\
\text { - Ajuste de la tarea a tiempos pautados } \\
\text { - Organización del tiempo para estudiar } \\
\text { - Planificación } \\
\text { - Presentación escrita u oral de un tema } \\
\text { - Trabajar individualmente y/o en equipo } \\
\text { - Uso de tecnologías informáticas }\end{array}$ & $\begin{array}{l}\text { Pregunta 2: ¿Cuántas horas diarias en promedio estudiás? } \\
\text { Pregunta 3: ¿Cuál/cuáles de los siguientes servicios que presta la biblioteca } \\
\text { utilizaste durante } 2010 ?\end{array}$ \\
\hline & $\begin{array}{l}\text { Actitudes: } \\
\text { - Resolver conflictos con otras personas a través del } \\
\text { diálogo } \\
\text { - Respetar las opiniones propias y las de los demás } \\
\text { - Responsabilidad en el ejercicio de los derechos y en } \\
\text { el cumplimiento de las obligaciones }\end{array}$ & Pregunta 4: ¿Qué opinás del Acuerdo Institucional de Convivencia? \\
\hline $\begin{array}{l}\text { B. Contribución de las } \\
\text { actividades o espacios } \\
\text { organizados por la escuela } \\
\text { para la elección educacional } \\
\text { y/u ocupacional. }\end{array}$ & & $\begin{array}{l}\text { Pregunta 6: ¿En qué actividades o espacios organizados por la escuela } \\
\text { participaste con la finalidad de adoptar una decisión respecto de tu futuro } \\
\text { (estudio y/o trabajo)? } \\
\text { Pregunta 7: ¿A qué se debió, finalmente, tu decisión? }\end{array}$ \\
\hline
\end{tabular}


Retomando lo expresado supra acerca del futuro de los egresados 2010 del Distrito de Junín, el proyecto de vida vislumbrado podría constituirse en motor de decisiones sobre ese futuro. Las imágenes y proyectos que los jóvenes construyen tienen un peso fundamental en lo que luego puedan concretar, teniendo en cuenta - además- que las opciones que evalúen estarán condicionadas por las restricciones de su contexto familiar y escolar, en alguna medida.

Según las ideas básicas de la psicología cognitiva y de la teoría de la acción, las orientaciones de futuro se describen en tres procesos: motivación, planificación y evaluación. La motivación refiere a qué intereses futuros tienen las personas. La actividad de planificación, a cómo se prevé la realización de esos intereses en un contexto futuro. Y la evaluación se refiere al grado en que se espera se concreten dichos intereses. La planificación de las orientaciones de futuro no fue parte de la presente investigación porque aproximarse a ese aspecto exige identificar los medios y las acciones necesarios para lograr las metas, lo cual excedía las posibilidades de la misma.

En esta investigación se exploró la atribución de metas por los alumnos próximos a egresar en cinco ámbitos: 1) educación, 2) trabajo, 3) familia y relaciones de pareja, 4) adquisición de bienes materiales, 5) tiempo libre. No se indagó el plazo en el que cada educando espera concretar sus metas en el plano laboral y/o educativo. La evaluación del futuro supone el estudio de las atribuciones causales y de las emociones involucradas en los objetivos que los sujetos proponen. Ambas subdimensiones se trabajaron para los objetivos laborales y educativos. Las atribuciones causales se exploraron a partir de la identificación de posibles circunstancias obstaculizadoras para la realización de sus metas, lo cual permite observar el grado en que los egresados reconocen la incidencia personal como factor capaz de intervenir en los cursos de acción ideados. Las emociones asociadas al pensamiento sobre el futuro se indagaron a través del establecimiento de niveles de optimismo. La Tabla 3 presentada seguidamente resume el proceso de operacionalización descripto. 
Tabla 3. Operacionalización del concepto de orientaciones de futuro

\begin{tabular}{|c|c|c|c|}
\hline Dimensiones & Subdimensiones & Indicadores & Preguntas del cuestionario \\
\hline Motivación & Contenido & $\begin{array}{l}\text { - Objetivos laborales propuestos } \\
\text { - Objetivos educativos propuestos }\end{array}$ & $\begin{array}{l}\text { Pregunta 18: ¿Qué harías una vez finalizado el nivel medio? } \\
\text { Pregunta 19: ¿Dónde trabajarías? } \\
\text { Pregunta 21: ¿Qué estudio superior estarías dispuesto a seguir? } \\
\text { Pregunta 22: ¿Dónde estudiarías? }\end{array}$ \\
\hline \multirow[t]{2}{*}{ Evaluación } & Condicionamientos & $\begin{array}{l}\text { - Circunstancias obstaculizadoras para el } \\
\text { objetivo laboral/educativo elegido }\end{array}$ & \multirow{2}{*}{$\begin{array}{l}\text { Pregunta 20: ¿Qué obstáculo/s deberías sortear para que se } \\
\text { cumpla tu meta laboral? } \\
\text { Pregunta 23: ¿Qué obstáculo/s deberías superar para el logro de } \\
\text { tu meta educativa? }\end{array}$} \\
\hline & Emociones & $\begin{array}{l}\text { - Nivel de optimismo para la consecución } \\
\text { del objetivo laboral/educativo elegido }\end{array}$ & \\
\hline
\end{tabular}




\subsubsection{Datos obtenidos al operacionalizar las variables}

\subsubsection{La importancia de educarse}

Ante la pregunta 1 ¿Por/para qué cursás el secundario?, el 72,24\% del alumnado de las diecinueve escuelas partícipes en esta investigación eligió la opción "Porque necesito aprobar este nivel para seguir estudios superiores". Si se tiene en cuenta sólo a los adolescentes la cifra se eleva al $75,45 \%$. Y si se consideran solamente a los adultos, baja al 58,44\%. Podría darse una explicación de este último porcentaje (sensiblemente inferior respecto de lo observado en los adolescentes) acudiendo a la pregunta 23 del cuestionario: ¿Qué obstáculo/s deberías superar para el logro de tu meta educativa? La opción "Poco tiempo para estudiar" fue elegida por 26 egresados adultos (el 33,77\%). Y también téngase en cuenta la opción "Otras responsabilidades u obligaciones familiares" (elegida por el 27,27\% de dichos estudiantes). La suma de estas dos últimas cifras $(61,04 \%)$ evidenciaría la importancia de las dificultades mencionadas por estos educandos.

Continuando con las razones de asistencia a la escuela, la opción "Porque el título secundario me permitirá conseguir trabajo y así tener una vida digna y respetable" fue elegida por el $48,48 \%$ de los adolescentes, el $45,45 \%$ de los adultos y el $47,91 \%$ si se toma en cuenta a unos y a otros. Aquéllos que consideran al secundario importante "Para adquirir conocimientos que me sean útiles para el trabajo que estoy realizando", representan el 11,21\% de los adolescentes, el 10,39\% de los adultos y el 11,06\% sumando a unos con otros. Como puede observarse, a través de los guarismos vertidos desde el comienzo, la dimensión que remitiría a una gratificación diferida (la obtención de credenciales para el estudio y/o trabajo futuros) gana terreno a la valoración de aprendizajes habilitantes para el mundo laboral actual. Por otro lado, los adolescentes consideran también que realizan el secundario por alguna de las siguientes razones vinculadas al desarrollo personal: "Porque adquirir conocimientos me permitirá desenvolverme mejor en la sociedad" (66,67\%), "Para ser 'alguien' en la vida" (53,64\%) o "Para ampliar mis conocimientos, para saber más" (39,70\%). Es decir, a más de la visión enraizada en supuestas exigencias sociales de ciertos umbrales educativos mínimos, los adolescentes rescatan aspectos que remiten a lo que pueden aprender en el colegio para sí mismos y para la vida en sociedad.

Por otro lado, más allá de las prevalecientes razones vinculadas con el futuro profesional y el desarrollo personal, surgen otras que remiten a la sociabilidad ("Porque en la escuela la paso bien (tengo compañeros/amigos)" y "Para no estar en la calle"). Sumando los porcentajes de ambas opciones, en adultos se obtuvo el 9,09\% respecto del 43,94\% en adolescentes y el $37,35 \%$ en adolescentes más adultos. Ello mostraría que para los adultos esos aspectos referidos a la sociabilidad tendrían (considerados solos o vinculados entre sí) una importancia significativamente menor que en los adolescentes. 
Por último, el 3,90\% de los adultos que eligieron "Porque en mi casa me dijeron 'o estudiás o trabajás", indicaría que el mandato familiar tiene una influencia algo más débil entre ellos respecto del $10 \%$ obtenido de los adolescentes. Pareciera que existe en este tiempo una cada vez mayor conciencia de que la educación es un derecho de todos y que el ejercicio del mismo connota interesantes posibilidades para mejorar la calidad de vida individual y social.

Respecto de todo lo desarrollado supra, véanse el Cuadro 3 y los Gráfico 1.a y 1.b correspondientes al mismo. Asimismo, elegidas al azar como fueron tres escuelas de adolescentes y tres de adultos; pueden observarse más datos en torno a la sociabilidad referida a adolescentes y a adultos en los Gráficos 2 y 3. 
Pregunta 1: ¿Por/para qué cursás el secundario?

\begin{tabular}{|c|c|c|c|c|c|c|c|}
\hline Opciones & \multicolumn{2}{|c|}{ Adolescentes } & \multicolumn{2}{|c|}{ Adultos } & \multicolumn{3}{|c|}{ TOTALES } \\
\hline $\begin{array}{l}\text { Porque necesito aprobar este nivel para seguir } \\
\text { estudios superiores }\end{array}$ & 249 & 75,45 & 45 & 58,44 & 294 & $72,24 \%$ & $21,84 \%$ \\
\hline $\begin{array}{l}\text { Para adquirir conocimientos que me sean útiles para } \\
\text { el trabajo que estoy realizando }\end{array}$ & 37 & 11,21 & 8 & 10,39 & 45 & $11,06 \%$ & $3,34 \%$ \\
\hline $\begin{array}{l}\text { Porque el título secundario me permitirá conseguir } \\
\text { trabajo y así tener una vida digna y respetable }\end{array}$ & 160 & 48,48 & 35 & 45,45 & 195 & $47,91 \%$ & $14,49 \%$ \\
\hline Para ampliar mis conocimientos, para saber más & 131 & 39,70 & 24 & 31,17 & 155 & $38,08 \%$ & $11,52 \%$ \\
\hline $\begin{array}{l}\text { Porque adquirir conocimientos me permitirá } \\
\text { desenvolverme mejor en esta sociedad }\end{array}$ & 220 & 66,67 & 23 & 29,87 & 243 & $59,71 \%$ & $18,05 \%$ \\
\hline Para no estar en la calle & 25 & 7,58 & 3 & 3,90 & 28 & $6,88 \%$ & $2,08 \%$ \\
\hline Porque en mi casa me dijeron "o estudiás o trabajás" & 33 & 10 & 3 & 3,90 & 36 & $8,85 \%$ & $2,67 \%$ \\
\hline Otra/s (especificar) & 6 & 1,82 & 2 & 2,60 & 8 & $1,97 \%$ & $0,59 \%$ \\
\hline
\end{tabular}




\section{Gráfico 1.a: Porcentajes en base al total de participantes}

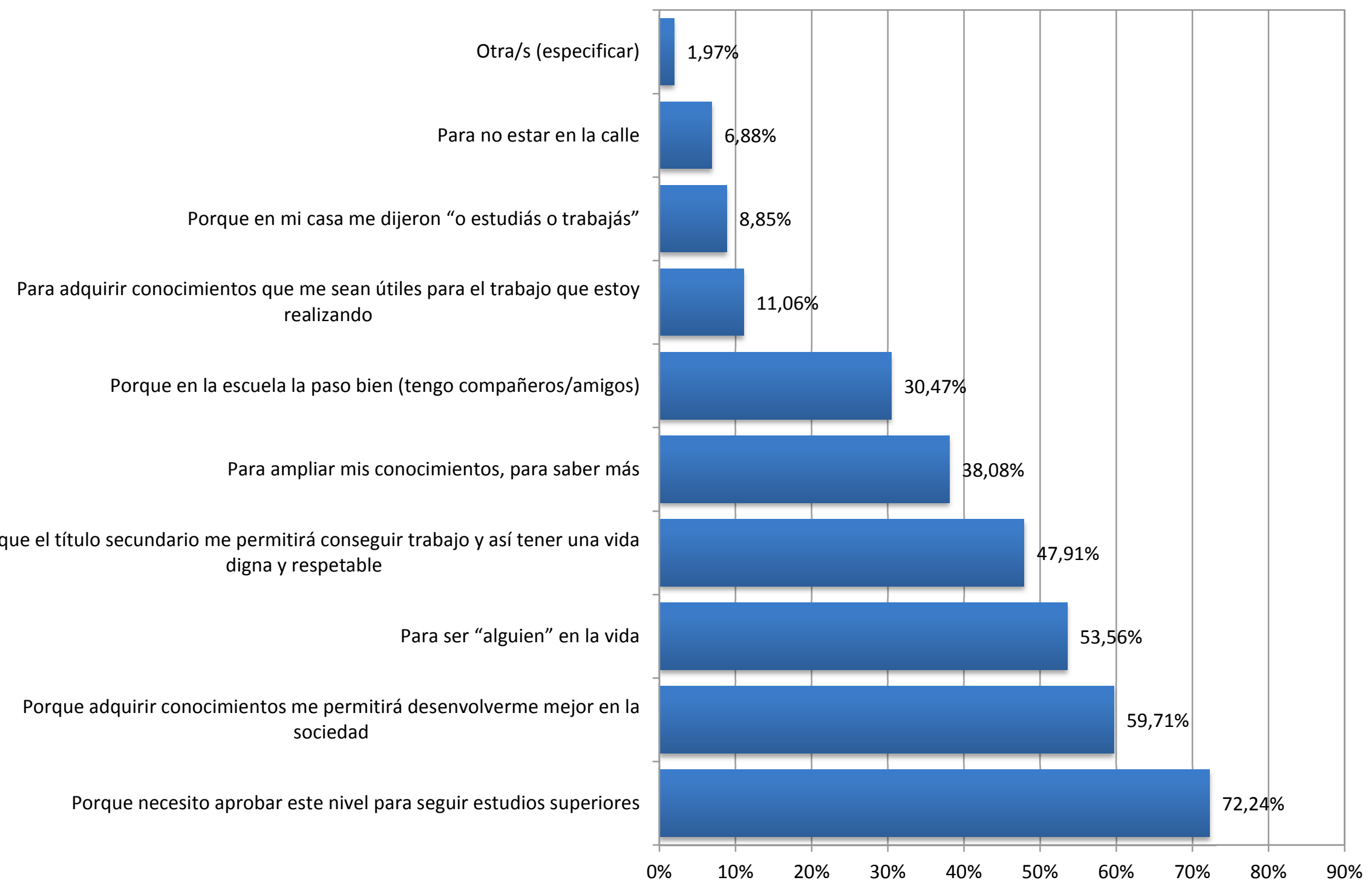




\section{Gráfico 1.b: Porcentajes en base al total de respuestas dadas}

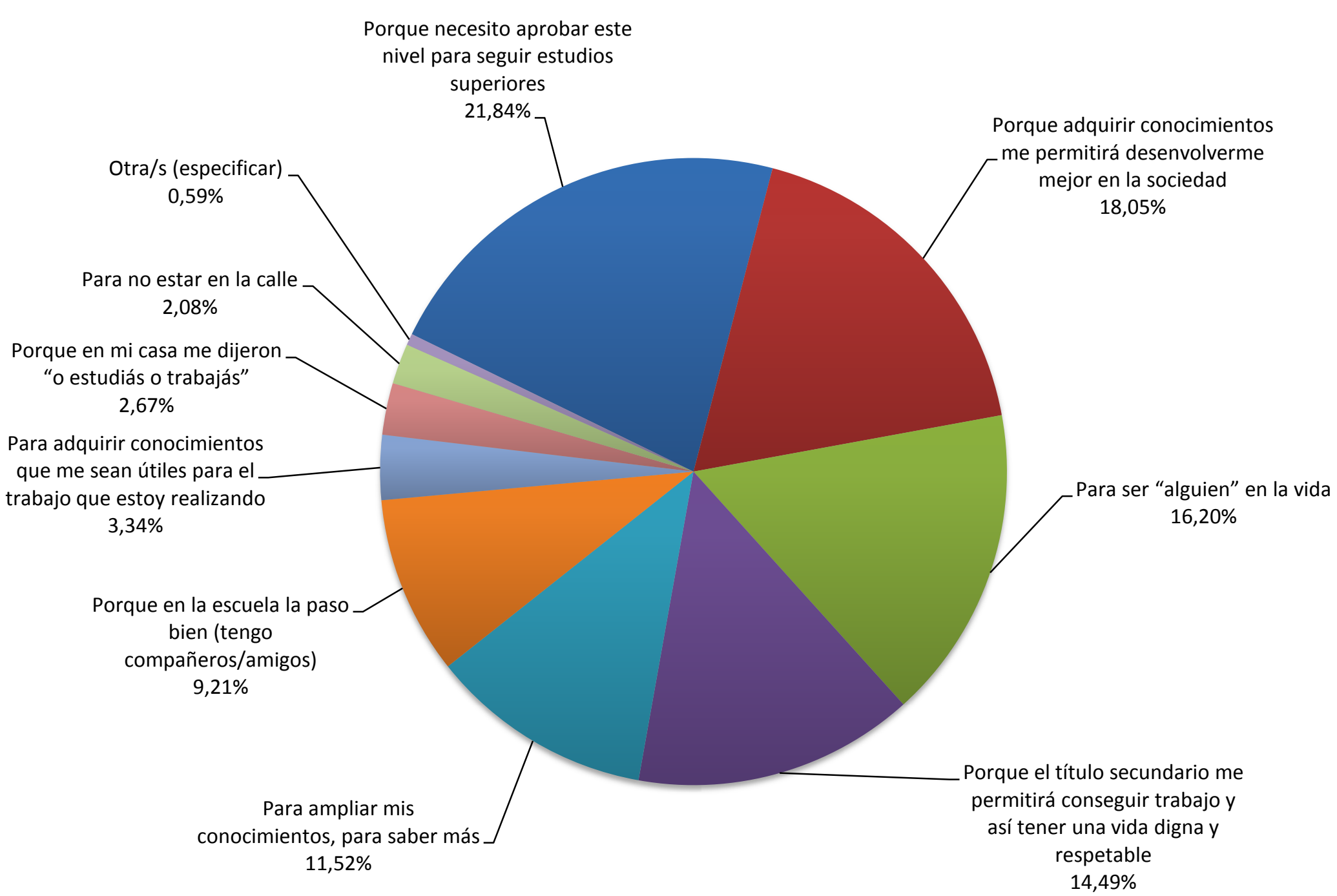




\section{Gráfico 2: Sociabilidad (Porcentajes Totales)}

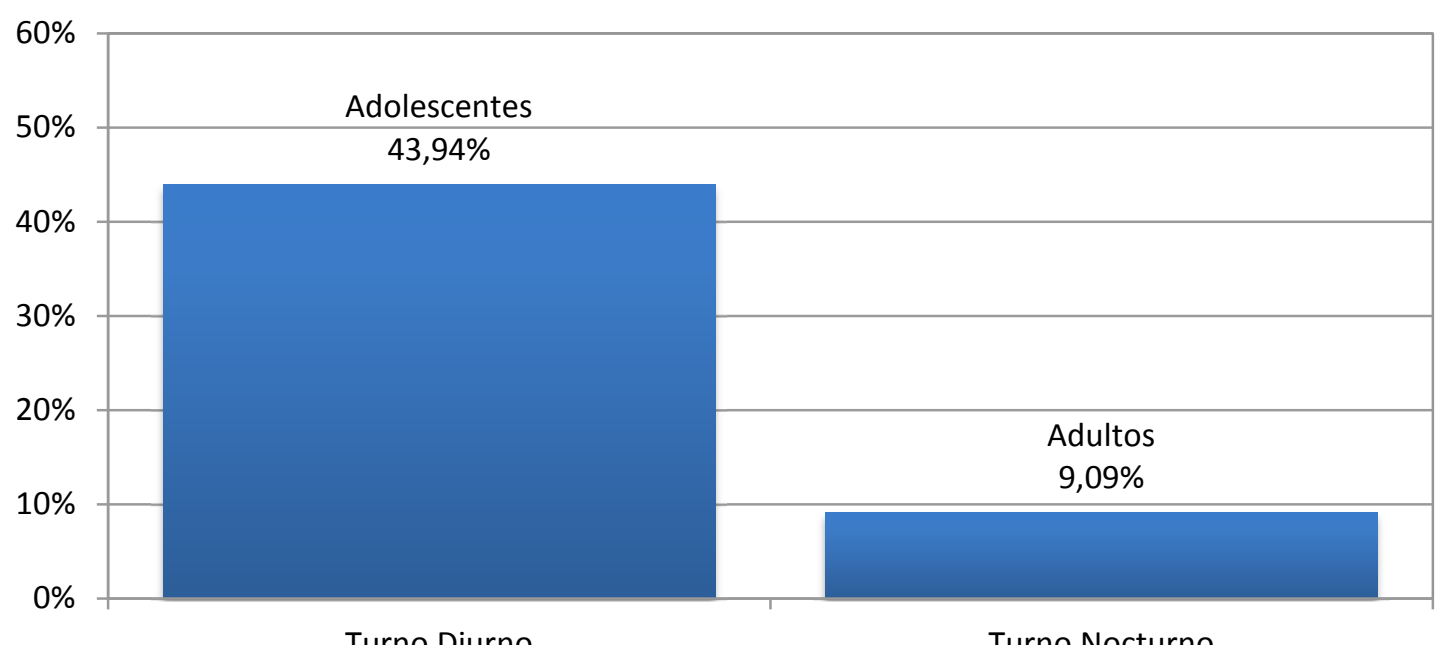

Gráfico 3: Sociabilidad (Porcentajes de algunas escuelas)

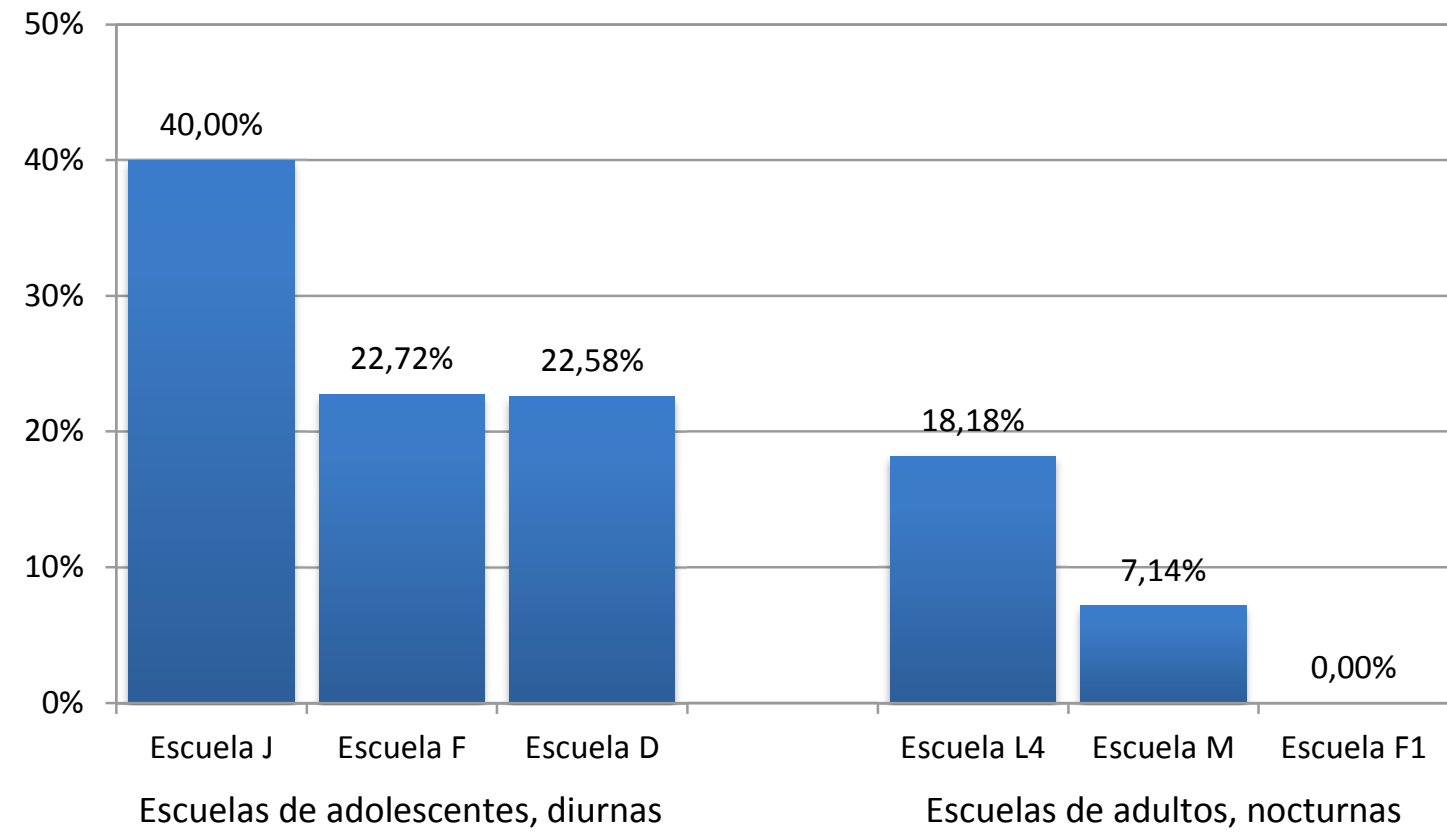

Ante la pregunta 2 ¿Cuántas horas diarias estudiás?, la gran mayoría de los egresados adolescentes y adultos eligió la opción "Cuando hay examen todo lo necesario". La opción que siguió en orden decreciente (también entre todos ellos) fue "Me basta con atender las explicaciones del profesor en clase". Las demás lograron porcentajes más bajos en ambos casos. En relación a la pregunta 3 ¿Cuál/cuáles de los siguientes servicios que presta la biblioteca utilizaste durante 2010? la mayoría de los egresados adolescentes y adultos eligió la opción "Entré a consultar algún libro". Aquí los más altos porcentajes de la misma estuvieron en las escuelas D, F, M y $\mathrm{H}_{1}$. También se observaron casos extremos: la totalidad de los egresados de la escuela $\mathrm{H}$ eligió aquella opción y ninguno lo hizo en las escuelas $\mathrm{J}_{\text {y L }}$. Téngase presente que en estos 
dos últimos colegios no existen bibliotecas como tales, sólo espacios físicos destinados al efecto (con bibliografía escasa y desactualizada). Asimismo, "Entré a utilizar la computadora" se ubicó en segundo lugar entre las opciones elegidas, tanto por adolescentes como por adultos. Poco elegida por unos y otros fue la opción "Entré a estudiar".

Respecto del Acuerdo Institucional de Convivencia (pregunta 4), la mayoría del estudiantado adolescente y adulto opinó que es "Bueno". Un bajo porcentaje eligió las opciones "No lo conozco" y "No me interesa". Nadie se inclinó por la opción "Malo" o "Muy malo". En lo que atañe a la pregunta 5 ¿Cuál/cuáles son los temas que frecuentemente aparecen en las conversaciones de los egresados?, las opciones "Vida social" y "Deportes" fueron elegidas por la gran mayoría de adolescentes y adultos. En escuelas alejadas del centro de la ciudad de Junín (como G, J, $\mathrm{H}_{1}$ y L4), "Pobreza", "Inseguridad" y "Drogadicción" —en ese orden- alcanzaron porcentajes en adolescentes y adultos muy cercanos a los de las dos opciones mencionadas anteriormente. "Corrupción", "Desempleo" y "Política" se ubicaron después en el orden decreciente de elecciones. "Inflación", "Prostitución” y "Religión” no fueron elegidas por ningún egresado de las escuelas D y F.

En otro orden de ideas, en la pregunta 8 ¿De qué fuente te valés para adquirir la información y el conocimiento?, el mayor número de adolescentes eligió la opción "Internet", mientras que en adultos resultaron preeminentes las opciones "La escuela" y "Libros, periódicos, revistas" y muy cercana a esos porcentajes estuvo "La familia". Asimismo, los más bajos se alcanzaron, para adolescentes y adultos, respecto de la opción "El cine, el teatro".

En otro orden de ideas, la propuesta pedagógica de las instituciones escolares puede contribuir a lograr una mayor disposición de los educandos hacia los estudios superiores. En tal sentido puede favorecer a una mejor orientación para la elección definitiva entre las ofertas educativas existentes. Es decir, resulta válido para el estudiante preguntarse qué aporta la formación escolar.

Interesaba conocer si los adolescentes que egresaban habían participado en actividades o espacios de orientación, organizados por la escuela, con la finalidad de ayudarlos en la toma de decisión (pregunta 6). Así, el 37,58\% eligió la opción "Búsqueda en Internet", seguida por el "Taller de orientación vocacional y/u ocupacional" (30,61\%) y las "Charlas informativas a cargo de especialistas" (30\%). Los "Intercambios informativos con uno o más profesores" $(21,21 \%)$ y la "Visita a instituciones educativas terciarias (Profesorado o Universidad)" (14,85\%) continúan entre las opciones preferidas. Los guarismos correspondientes a las restantes muestran porcentajes menores. Por lo demás, el 13,63\% del alumnado adolescente señaló que no intervino debido a que "No se realizaron en 2010 actividades o espacios referidos a orientación vocacional y/u ocupacional”. 
También se indagó si los que habían asistido a una o más de dichas actividades/espacios las valoraban como instancias de acompañamiento para la adopción de decisiones sobre su futuro estudio y/o trabajo (pregunta 7). Las opiniones respecto de la contribución de las mismas no fueron unívocas. Sólo el 10,61\% afirmó que se decidió en base a las actividades/espacios que organizó la escuela. El 89,39\% restante que no basó en ellos su decisión podría deberse a un déficit en las actividades o espacios dentro del ámbito escolar y/o a que lo organizado por las diferentes instituciones se caracterizó —en general- por lo esporádico (nótese que la vivencia de situaciones como la "Realización de una pasantía" o el "Trabajo en talleres o laboratorios", tuvieron una elección muy baja: 3,33\% y 6,97\%, respectivamente). Este escaso reconocimiento podría vincularse, con el hecho de que las elecciones de los egresados respecto del futuro estaban ligadas a otras esferas: los "Gustos o preferencias propias" (76,36\%), "Las sugerencias del grupo familiar" (16,06\%) y "Las conversaciones con el grupo de compañeros/amigos" (11,21\%). Ese 76,36\% (en adultos, tal opción logró el 71,43\%) mostraría claramente el carácter absolutamente personal que tiene este tipo de decisiones, en tanto todo lo contemplado en las demás opciones contribuiría en diferente medida a ello.

El 32,47\% de los adultos sostuvo que "No se realizaron en 2010 actividades o espacios referidos a orientación vocacional y/u ocupacional". Este porcentaje, mucho más del doble respecto del obtenido en los adolescentes, dejaría al descubierto una mayor preocupación y realización, en este aspecto, de las escuelas a las que asisten los adolescentes. Los demás resultados en adultos son inferiores al 32,47\% citado. Respecto de todo lo desarrollado supra en relación a la propuesta pedagógica de las escuelas, véanse los Cuadros 4 y 5 y sus Gráficos 4 y 5 correspondientes. 
Pregunta 6: ¿En qué actividades o espacios organizados por la escuela participaste con la finalidad de adoptar una decisión respecto de tu futuro (estudio y/o trabajo)?

\begin{tabular}{|c|c|c|c|c|c|c|}
\hline \multirow{2}{*}{ Opciones } & \multicolumn{2}{|c|}{ Adolescentes } & \multicolumn{2}{|c|}{ Adultos } & \multicolumn{2}{|c|}{ TOTALES } \\
\hline & Cantidad & $\%$ & Cantidad & $\%$ & Cantidad & $\%$ \\
\hline Taller de orientación vocacional y/u ocupacional & 101 & 30,61 & 11 & 14,29 & 112 & 27,52 \\
\hline Charlas informativas a cargo de especialistas & 99 & 30,00 & 12 & 15,58 & 111 & 27,27 \\
\hline Visita a instituciones educativas terciarias (Profesorado o Universidad) & 49 & 14,85 & 2 & 2,60 & 51 & 12,53 \\
\hline Intercambios informativos con uno o más profesores & 70 & 21,21 & 9 & 11,69 & 79 & 19,41 \\
\hline Búsqueda en Internet & 124 & 37,58 & 16 & 20,78 & 140 & 34,40 \\
\hline Consulta en la Guía del Estudiante & 27 & 8,18 & 1 & 1,30 & 28 & 6,88 \\
\hline Realización de una pasantía & 11 & 3,33 & 0 & 0 & 11 & 2,70 \\
\hline Trabajo en talleres o laboratorios & 23 & 6,97 & 4 & 5,19 & 27 & 6,63 \\
\hline $\begin{array}{l}\text { Existe una asignatura que se denomina "Orientación Vocacional y/u } \\
\text { Ocupacional" }\end{array}$ & 15 & 4,55 & 2 & 2,60 & 17 & 4,18 \\
\hline $\begin{array}{l}\text { No se realizaron en } 2010 \text { actividades o espacios referidos a orientación } \\
\text { vocacional y/u ocupacional }\end{array}$ & 45 & 13,64 & 25 & 32,47 & 70 & 17,20 \\
\hline Otra/s (especificar) & 26 & 7,88 & 4 & 5,19 & 30 & 7,37 \\
\hline
\end{tabular}




\section{Gráfico 4: Porcentajes Totales}

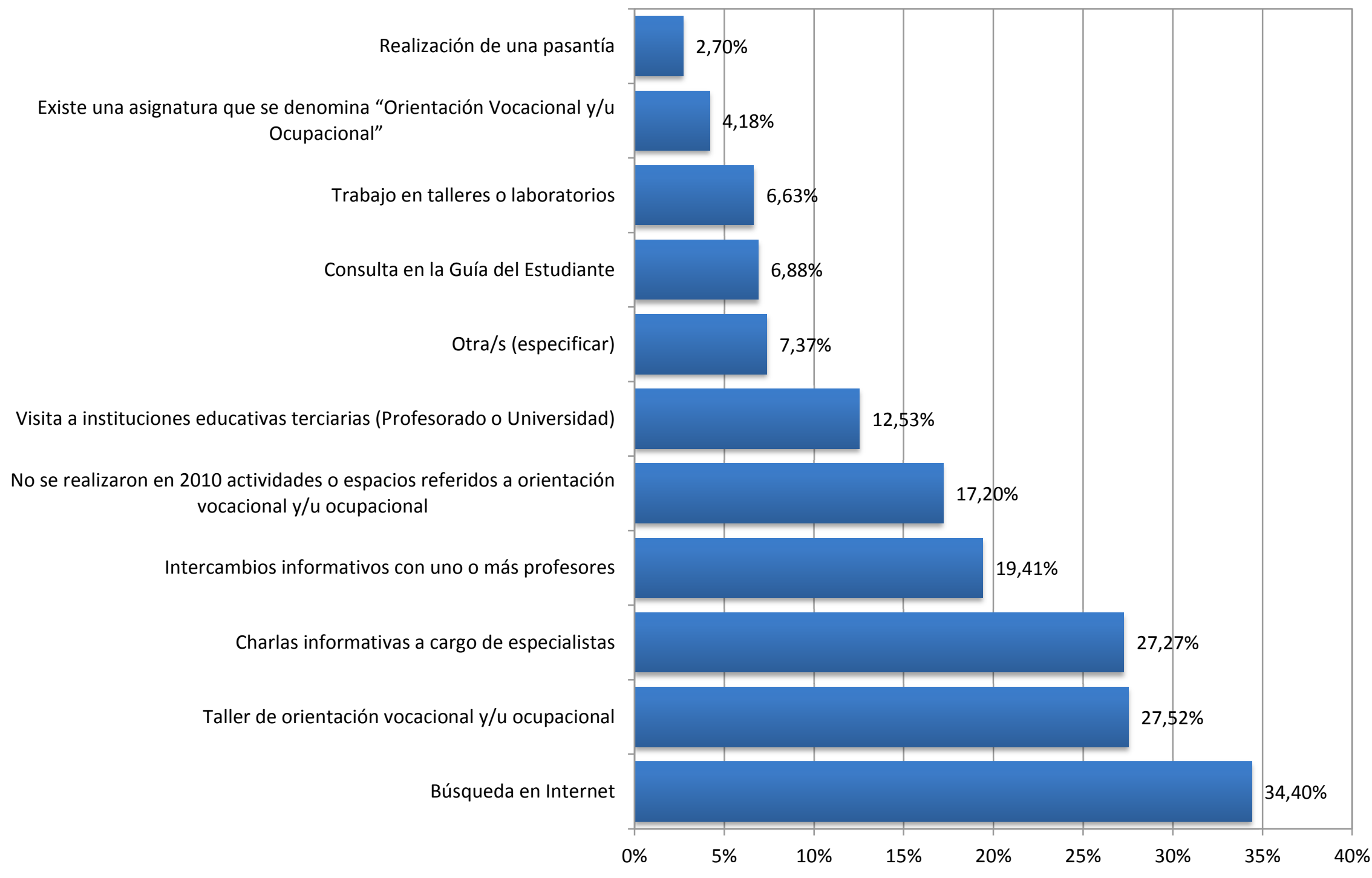


Pregunta 7: ¿A qué se debió, finalmente, tu decisión?

\begin{tabular}{|c|c|c|c|c|c|c|}
\hline \multirow{2}{*}{ Opciones } & \multicolumn{2}{|c|}{ Adolescentes } & \multicolumn{2}{|c|}{ Adultos } & \multicolumn{2}{|c|}{ TOTALES } \\
\hline & Cantidad & $\%$ & Cantidad & $\%$ & Cantidad & $\%$ \\
\hline A las actividades o espacios que organizó la escuela & 35 & 10,61 & 1 & 1,30 & 36 & 8,85 \\
\hline A las conversaciones con el grupo de compañeros/amigos & 37 & 11,21 & 10 & 12,99 & 47 & 11,55 \\
\hline A gustos o preferencias propias & 252 & 76,36 & 55 & 71,43 & 307 & 75,43 \\
\hline
\end{tabular}

\section{Gráfico 5: Porcentajes Totales}

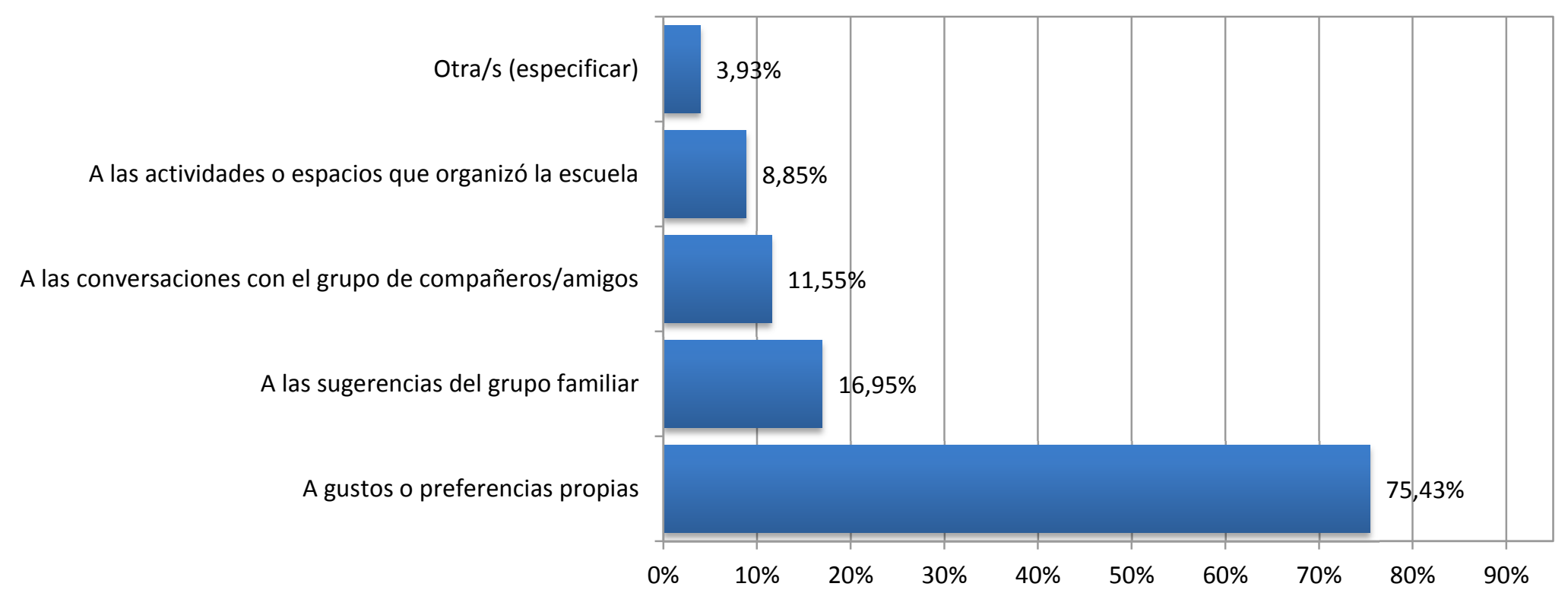


A renglón seguido podrá observarse lo relativo a la trascendencia de la educación en la vida de los egresados. La finalidad de las preguntas 9 ¿De quién/es es la responsabilidad de impartir la educación para todos los habitantes en Argentina? y 10 ¿Dónde está reconocido el derecho a la educación? fue obtener datos respecto de la información que poseen los alumnos acerca de la educación. La primera de ellas permitió obtener un elevadísimo porcentaje de aciertos de los educandos que eligieron la opción "Del Estado Nacional" (tanto en adolescentes como en adultos). Las demás obtuvieron muy bajos porcentajes de aciertos, lo que permitiría señalar el desconocimiento de los egresados sobre la temática educativa analizada desde el prisma jurídico. En la pregunta 10 ¿Dónde está reconocido el derecho a la educación?, la opción "En la Constitución Nacional" fue elegida por el $70 \%$ de los adolescentes, el $68,83 \%$ de los adultos y el $69,78 \%$ considerando a unos y a otros. Los aciertos disminuyen drásticamente cuando de las restantes opciones se trata, lo cual mostraría el conocimiento que tienen de la Ley Fundamental pero no así respecto de las demás normas jurídicas. En torno a lo aseverado en este párrafo, véanse los Cuadros 6 y 7.

\section{Cuadro 6}

Pregunta 9: ¿De quién/es es la responsabilidad de impartir la educación para todos los habitantes en Argentina?

\begin{tabular}{|l||c||c|c||}
\hline \hline Opciones & Adolescentes & Adultos & TOTALES \\
\hline Del Estado Nacional & $313(94,85 \%)$ & $73(94,81 \%)$ & $386(94,84 \%)$ \\
\hline \hline De las escuelas privadas & $5(1,52 \%)$ & $1(1,30 \%)$ & $6(1,47 \%)$ \\
\hline De las provincias & $32(9,70 \%)$ & $6(7,79 \%)$ & $38(9,34 \%)$ \\
\hline \hline De las municipalidades & $19(5,76 \%)$ & $4(5,19 \%)$ & $23(5,65 \%)$ \\
\hline \hline De los gremios & $13(3,94 \%)$ & $1(1,30 \%)$ & $14(3,44 \%)$ \\
\hline $\begin{array}{l}\text { De las organizaciones no } \\
\text { gubernamentales }\end{array}$ & $1(0,30 \%)$ & $1(1,30 \%)$ & $2(0,49 \%)$ \\
\hline \hline De las sociedades de fomento & $1(0,30 \%)$ & $1(1,30 \%)$ & $2(0,49 \%)$ \\
\hline \hline Otro/s (especificar) & $4(1,21 \%)$ & $1(1,30 \%)$ & $5(1,23 \%)$ \\
\hline
\end{tabular}


Cuadro 7

Pregunta 10: ¿Dónde está reconocido el derecho a la educación?

\begin{tabular}{|l||c|c|c||}
\hline Opciones & Adolescentes & Adultos & TOTALES \\
\hline \hline En la Constitución Nacional & $231(70 \%)$ & $53(68,83 \%)$ & $284(69,78 \%)$ \\
\hline $\begin{array}{l}\text { En uno o más Tratados Internacionales de } \\
\text { Derechos Humanos con jerarquía } \\
\text { constitucional }\end{array}$ & $101(30,61 \%)$ & $20(25,97 \%)$ & $121(29,73 \%)$ \\
\hline \hline En una Ley Nacional & $56(16,97 \%)$ & $15(19,48 \%)$ & $71(17,44 \%)$ \\
\hline $\begin{array}{l}\text { En la Constitución de la Provincia de } \\
\text { Buenos Aires }\end{array}$ & $14(4,24 \%)$ & $4(5,19 \%)$ & $18(4,42 \%)$ \\
\hline $\begin{array}{l}\text { En una Ley de la Provincia de Buenos } \\
\text { Aires }\end{array}$ & $6(1,82 \%)$ & $6(7,79 \%)$ & $12(2,95 \%)$ \\
\hline $\begin{array}{l}\text { En una Ordenanza Municipal del Partido } \\
\text { de Junín }\end{array}$ & $1(0,30 \%)$ & $3(3,90 \%)$ & $4(0,98 \%)$ \\
\hline \hline Otro/s (especificar) & $3(0,91 \%)$ & $4(5,19 \%)$ & $7(1,72 \%)$ \\
\hline
\end{tabular}

Seguidamente, se transcribirán los resultados alcanzados cuando los egresados respondieron a las preguntas 11 a 17 del cuestionario. Se tomará como referencia el texto $L a$ tragedia educativa, de Guillermo Jaim Etcheverry y se cotejarán los datos en él vertidos con los obtenidos — respecto de idénticas actividades - en la presente investigación. ${ }^{199}$ Así, en el texto de Etcheverry se lee: "En el sexto grado de la educación primaria, sólo 5 de cada 10 estudiantes (cuyas edades oscilan entre 10 y 11 años) identifican la siguiente forma de expresión correcta: "El aula y el patio están vacíos"'. En este trabajo, en la pregunta 11 respondió correctamente (es decir, eligió la opción "El aula y el patio están vacíos") el $85,76 \%$ de los adolescentes, el $72,73 \%$ de los adultos y el $77,40 \%$ si se toma en cuenta al total del alumnado.

Continuando con el texto de Etcheverry, puede leerse: "Algo menos de 5 de cada 10 alumnos que cursan el $2^{\circ}$ Año del colegio secundario responden correctamente al problema planteado: '22,50 metros de cinta'”. En la pregunta 12 de esta investigación respondió acertadamente (eligió la opción " 22,50 metros de cinta") el 70,91\% de los adolescentes, el $45,45 \%$ de los adultos y el $60,20 \%$ del total de los educandos.

199. Para el conocimiento de todas las opciones de respuesta en relación a ésta y a las demás preguntas formuladas, puede leerse el Instrumento de Recolección de Datos para egresados que consta en los Anexos. 
Prosiguiendo con la obra de Etcheverry, otro ejercicio fue el siguiente: "Al concluir la escuela secundaria, sólo 5 de cada 10 estudiantes son capaces de responder correctamente: “\$510”. En la pregunta 13 de este trabajo acertó (eligiendo la opción “\$510”) el 49,39\% de los adolescentes, el $32,47 \%$ de los adultos y el $46,19 \%$ del total del estudiantado. Como se observa, menos de la mitad de los adolescentes, de los adultos y del total de egresados acertó aquí.

En La tragedia educativa, el último ejercicio es el que sigue: "Al concluir el secundario, sólo 4 de cada 10 alumnos son capaces de calcular un porcentaje simple, cuya respuesta es 7/22". En la pregunta 14 de esta investigación acertó (al elegir la opción “7/22”) el 42,42\% de adolescentes, el $29,87 \%$ de adultos y el $40,05 \%$ del total de alumnos. Nuevamente prevalecieron los adolescentes sobre los adultos y sobre el total del alumnado. Asimismo, la disminución de los aciertos continúa acentuándose aquí respecto de las preguntas anteriores.

Ahora bien, si se tienen en cuenta a todos los que acertaron en la pregunta 14 (adolescentes más adultos: 163 educandos) el porcentaje es prácticamente igual al de los ejemplos que están en la página 24 del libro de Etcheverry. Una coincidencia reveladora de la persistencia de dificultades en los educandos, más allá de las diferentes políticas educativas implementadas desde 1993 a la fecha (los datos de Etcheverry son, precisamente, de aquel año). En el mismo libro aparece también el siguiente comentario suyo "si bien se podría abundar en ejemplos bastan los citados para comprender que las deficiencias se registran a propósito de conocimientos elementales, que no representan grandes proezas intelectuales sino operativas y conceptos imprescindibles para el desempeño normal de la vida cotidiana". Huelga agregar aquí reflexión alguna.

Si se presta atención a los diferentes cuadros realizados, en los porcentajes referidos al total de alumnos se observa una marcada disminución de los aciertos desde la pregunta 11 hasta la 14. Algo idéntico sucede en relación a los adolescentes y a los adultos en las mismas preguntas. Respecto de los resultados alcanzados, consultados por el investigador de esta tesis varios profesores de las materias Lengua Nacional y Matemática, sus opiniones fueron coincidentes: "ninguna de las preguntas, desde la 11 hasta la 17, debería presentar dificultad alguna puesto que son educandos que finalizan (en 2010) el nivel secundario".

La pregunta 15 incursiona en el espacio curricular Historia. Aquí se debe tener presente que la respuesta correcta es sólo una: el siglo que corresponde al acontecimiento mencionado. Éstos son los guarismos obtenidos respecto de "Revolución de Mayo": acertó el 43,00\% de todos los educandos desglosados de este modo: el 43,94\% adolescentes y el 38,96\% adultos. El 43,94\% señalado corresponde a 145 adolescentes que acertaron el siglo: XIX, lo cual indica que teniendo en cuenta a los egresados encuestados en esta investigación (330 en total), más de la mitad no sabe cuándo se produjo la Revolución de Mayo. Este dato es muy preocupante, máxime que se trata de jóvenes que ya tienen 12 años de educación formal. Los 
otros 9 acontecimientos incluidos en la pregunta tuvieron porcentajes de aciertos inferiores o muy inferiores a los de "Revolución de Mayo".

Las preguntas 16 y 17 se adentran (al igual que la 11) en Lengua Nacional. En la primera de aquéllas las opciones correctas eran "Agarrar", "Apresar", "Asir” y "Capturar". Lograron los mayores porcentajes: 58,79\%, 58,79\% y 63,33\%, las opciones "Agarrar", "Apresar" y "Capturar" - - respectivamente- entre los adolescentes. En la pregunta 17 las opciones correctas ("Buscar", "Escrutar", "Examinar" y "Observar") obtuvieron entre los adultos los mayores porcentajes: $83,12 \%, 10,39 \%, 79,22 \%$ y $67,53 \%$, respectivamente. Los demás guarismos obtenidos en las preguntas 16 y 17 son inferiores -en casi todos los casos- a los señalados. Respecto de la pregunta 17, existe una visible diferencia entre los aciertos correspondientes a las opciones "Buscar", "Examinar" y "Observar" (en ese orden, todos bastantes próximos, en adolescentes, en adultos y en la suma de todos ellos) y los registrados en relación a la opción "Escrutar".

Respecto de todo lo desarrollado en este punto, véanse los Cuadros 8, 9, 10 y 11 y sus Gráficos 6, 7, 8 y 9. Por lo mismo, obsérvense los Cuadros 12, 13 y 14.

\section{Cuadro 8}

Pregunta 11: Indicar cuál de las siguientes frases no tiene error de ortografía

\begin{tabular}{||l||c||c||c||}
\hline Opciones & Adolescentes & Adultos & TOTALES \\
\hline \hline El aula y el patio está vacío & $17(5,15 \%)$ & $9(11,69 \%)$ & $26(6,39 \%)$ \\
\hline El aula y el patio están vacías & $25(7,58 \%)$ & $8(10,39 \%)$ & $33(8,11 \%)$ \\
\hline El aula y el patio están vacíos & $283(85,76 \%)$ & $56(72,73 \%)$ & $339(83,29 \%)$ \\
\hline \hline El aula y el patio está vacía & $3(0,91 \%)$ & $2(2,60 \%)$ & $5(1,23 \%)$ \\
\hline No sabe/No contesta & $2(0,61 \%)$ & $2(2,60 \%)$ & $4(0,98 \%)$ \\
\hline \hline TOTAL & $330(100 \%)$ & $77(100,00 \%)$ & $407(100,00 \%)$ \\
\hline
\end{tabular}

Nota: en sombreado figura la opción correcta.

\section{Gráfico 6}

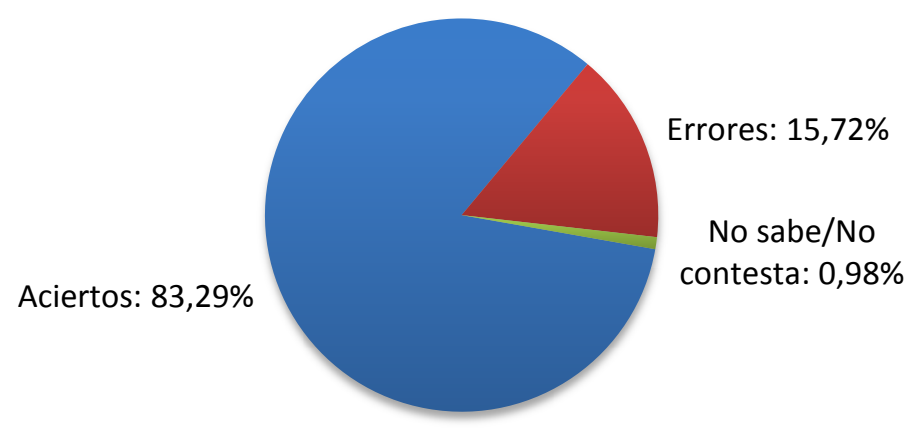


Cuadro 9 Pregunta 12: Sabiendo que una cassette de 60 minutos de duración tiene 90 metros de cinta, ¿cuántos metros de cinta serán utilizados para una grabación de un cuarto de hora?

\begin{tabular}{|l||c|c|c||}
\hline Opciones & Adolescentes & Adultos & TOTALES \\
\hline \hline 0,375 metros & $23(6,97 \%)$ & $7(9,09 \%)$ & $30(7,37 \%)$ \\
\hline 6 metros & $22(6,67 \%)$ & $14(18,18 \%)$ & $36(8,85 \%)$ \\
\hline \hline 22,50 metros & $234(70,91 \%)$ & $35(45,45 \%)$ & $269(66,09 \%)$ \\
\hline 360 metros & $30(9,09 \%)$ & $10(12,99 \%)$ & $40(9,83 \%)$ \\
\hline No sabe/No contesta & $21(6,36 \%)$ & $11(14,29 \%)$ & $32(7,86 \%)$ \\
\hline \hline TOTAL & $330(100 \%)$ & $77(100,00 \%)$ & $407(100,00 \%)$ \\
\hline
\end{tabular}

Nota: en sombreado figura la opción correcta.

\section{Gráfico 7}

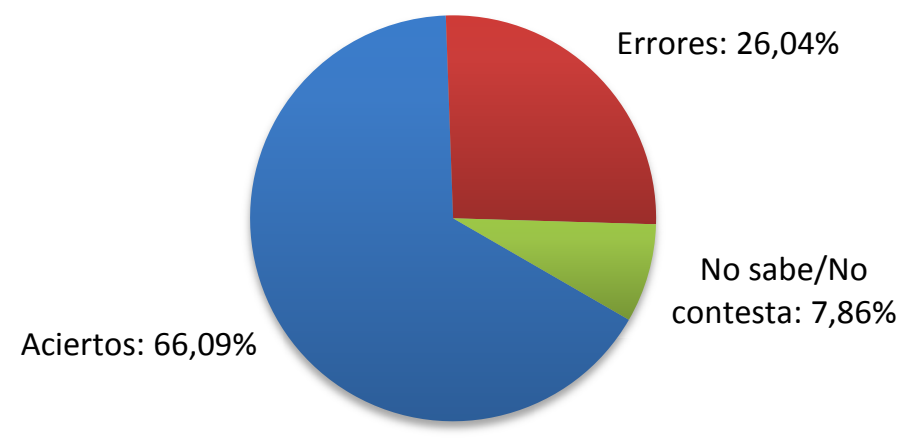

Cuadro 10

Pregunta 13: Juan y Rodrigo decidieron ahorrar para comprar una guitarra eléctrica. Si Juan reunió el triple de dinero que Rodrigo y entre los dos juntaron \$ 2.040, ¿cuál es el aporte de Rodrigo?

\begin{tabular}{|l||c||c||c||}
\hline Opciones & Adolescentes & Adultos & TOTALES \\
\hline \hline$\$ 1.530$ & $36(10,91 \%)$ & $11(14,29 \%)$ & $47(11,55 \%)$ \\
\hline \hline$\$ 1.020$ & $29(8,79 \%)$ & $5(6,49 \%)$ & $34(8,35 \%)$ \\
\hline \hline$\$ 680$ & $75(22,73 \%)$ & $25(32,47 \%)$ & $100(24,57 \%)$ \\
\hline$\$ 510$ & $163(49,39 \%)$ & $25(32,47 \%)$ & $188(46,19 \%)$ \\
\hline \hline No sabe/No contesta & $27(8,18 \%)$ & $11(14,29 \%)$ & $38(9,34 \%)$ \\
\hline \hline TOTAL & $330(100 \%)$ & $77(100,00 \%)$ & $407(100,00 \%)$ \\
\hline \hline
\end{tabular}

Nota: en sombreado figura la opción correcta. 
Gráfico 8

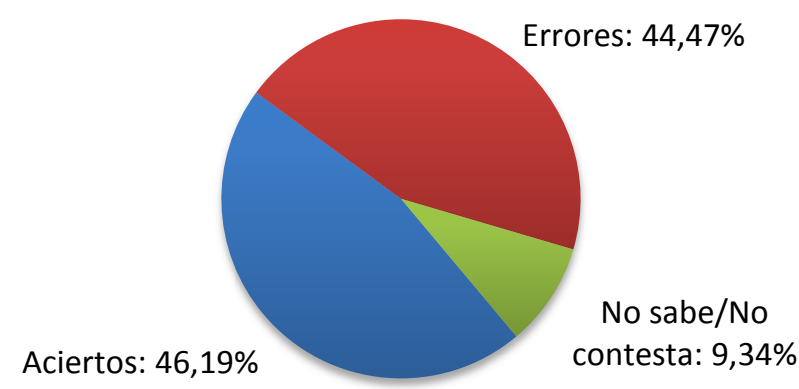

Cuadro 11 Pregunta 14: En un saco hay 15 bolillas blancas y 7 bolillas negras. Si se extrae una al azar, ¿cuál es la probabilidad de extraer una bolilla negra?

\begin{tabular}{|l||c||c|c||}
\hline Opciones & Adolescentes & Adultos & TOTALES \\
\hline \hline $7 / 15$ & $106(32,12 \%)$ & $18(23,38 \%)$ & $124(30,47 \%)$ \\
\hline \hline $7 / 22$ & $140(42,42 \%)$ & $23(29,87 \%)$ & $163(40,05 \%)$ \\
\hline \hline $22 / 7$ & $23(6,97 \%)$ & $3(3,90 \%)$ & $26(6,38 \%)$ \\
\hline \hline $1 / 22$ & $42(12,73 \%)$ & $22(28,57 \%)$ & $64(15,73 \%)$ \\
\hline No sabe/No contesta & $19(5,76 \%)$ & $11(14,29 \%)$ & $30(7,37 \%)$ \\
\hline TOTAL & $330(100 \%)$ & $77(100,00 \%)$ & $407(100,00 \%)$ \\
\hline
\end{tabular}

Nota: en sombreado figura la opción correcta.

Gráfico 9

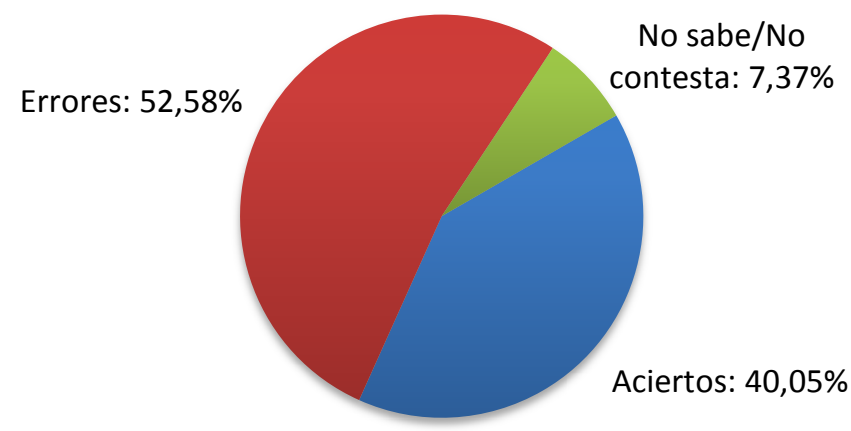


Cuadro 12

Pregunta 15: Indicá el siglo en el que se produjeron los siguientes acontecimientos

\begin{tabular}{|l||c||c|c||}
\hline Opciones & Adolescentes & Adultos & TOTALES \\
\hline \hline Caída del Imperio Romano de Occidente & $36(10,91 \%)$ & $3(3,90 \%)$ & $39(9,58 \%)$ \\
\hline \hline Descubrimiento de América & $113(34,24 \%)$ & $19(24,68 \%)$ & $132(32,43 \%)$ \\
\hline \hline Revolución Francesa & $85(25,76 \%)$ & $16(20,78 \%)$ & $101(24,82 \%)$ \\
\hline \hline Independencia de Estados Unidos & $60(18,18 \%)$ & $13(16,88 \%)$ & $73(17,94 \%)$ \\
\hline Revolución de Mayo & $145(43,94 \%)$ & $30(38,96 \%)$ & $175(43,00 \%)$ \\
\hline \hline Batalla de Caseros & $82(24,85 \%)$ & $18(23,38 \%)$ & $100(24,57 \%)$ \\
\hline \hline Primera y Segunda Guerras Mundiales & $110(33,33 \%)$ & $23(29,87 \%)$ & $133(32,68 \%)$ \\
\hline \hline Invención de la Computadora & $122(36,97 \%)$ & $24(31,17 \%)$ & $146(35,87 \%)$ \\
\hline \hline Llegada del hombre a la Luna & $134(40,61 \%)$ & $23(29,87 \%)$ & $157(38,57 \%)$ \\
\hline \hline Caída del Muro de Berlín & $96(29,09 \%)$ & $21(27,27 \%)$ & $117(28,75 \%)$ \\
\hline \hline $\begin{array}{l}\text { Total de aciertos de los alumnos } \\
\text { lncuestados }\end{array}$ & $983(29,78 \%)$ & $190(24,67 \%)$ & $1173(28,82 \%)$ \\
\hline $\begin{array}{l}\text { Total ideal de aciertos de los alumnos } \\
\text { encuestados }\end{array}$ & $3300(100 \%)$ & $770(100 \%)$ & $4070(100 \%)$ \\
\hline \hline
\end{tabular}


Cuadro 13

Pregunta 16: ¿Cuál/es son sinónimos de la palabra "aprehender"?

\begin{tabular}{|l|c|c||c||}
\hline Opciones & Adolescentes & Adultos & TOTALES \\
\hline \hline Agarrar & $194(58,79 \%)$ & $44(57,14 \%)$ & $238(58,48 \%)$ \\
\hline \hline Apresar & $194(58,79 \%)$ & $44(57,14 \%)$ & $238(58,48 \%)$ \\
\hline \hline Asir & $12(3,64 \%)$ & $15(19,48 \%)$ & $27(6,63 \%)$ \\
\hline \hline Calificar & $14(4,24 \%)$ & $10(12,99 \%)$ & $24(5,90 \%)$ \\
\hline Capturar & $209(63,33 \%)$ & $43(55,84 \%)$ & $252(61,92 \%)$ \\
\hline Enamorar & $2(0,61 \%)$ & $1(1,30 \%)$ & $3(0,74 \%)$ \\
\hline \hline Estacionar & $9(2,73 \%)$ & $1(1,30 \%)$ & $10(2,46 \%)$ \\
\hline \hline Sesionar & $23(6,97 \%)$ & $5(6,49 \%)$ & $28(6,88 \%)$ \\
\hline \hline Soldar & $8(2,42 \%)$ & $1(1,30 \%)$ & $9(2,21 \%)$ \\
\hline \hline Verificar & $24(7,27 \%)$ & $10(12,99 \%)$ & $34(8,35 \%)$ \\
\hline
\end{tabular}

Nota: en sombreado figuran las opciones correctas.

Cuadro 14

Pregunta 17: ¿Cuál/es son sinónimos de la palabra "investigar”?

\begin{tabular}{|l|c|c||c||}
\hline Opciones & Adolescentes & Adultos & TOTALES \\
\hline \hline Buscar & $272(82,42 \%)$ & $64(83,12 \%)$ & $336(82,56 \%)$ \\
\hline \hline Coleccionar & $19(5,76 \%)$ & $3(3,90 \%)$ & $22(5,41 \%)$ \\
\hline \hline Dominar & $11(3,33 \%)$ & $2(2,60 \%)$ & $13(3,19 \%)$ \\
\hline \hline Encuadernar & $21(6,36 \%)$ & $5(6,49 \%)$ & $26(6,39 \%)$ \\
\hline \hline Escrutar & $16(4,85 \%)$ & $8(10,39 \%)$ & $24(5,90 \%)$ \\
\hline \hline Examinar & $260(78,79 \%)$ & $61(79,22 \%)$ & $321(78,87 \%)$ \\
\hline \hline Observar & $200(60,61 \%)$ & $52(67,53 \%)$ & $252(61,92 \%)$ \\
\hline \hline Proteger & $3(0,91 \%)$ & $3(3,90 \%)$ & $6(1,47 \%)$ \\
\hline \hline Sojuzgar & $9(2,73 \%)$ & $1(1,30 \%)$ & $10(2,46 \%)$ \\
\hline \hline Transitar & $8(2,42 \%)$ & $2(2,60 \%)$ & $10(2,46 \%)$ \\
\hline
\end{tabular}

Nota: en sombreado figuran las opciones correctas. 


\subsubsection{Ideas respecto del futuro}

Pensar el futuro es una actividad habitual en los estudiantes del último año del nivel medio. Sólo el 1,72\% de ellos (adolescentes más adultos) no lo ha hecho. Al respecto véase el Gráfico 10.

\section{Gráfico 10: Porcentaje de estudiantes y el futuro}

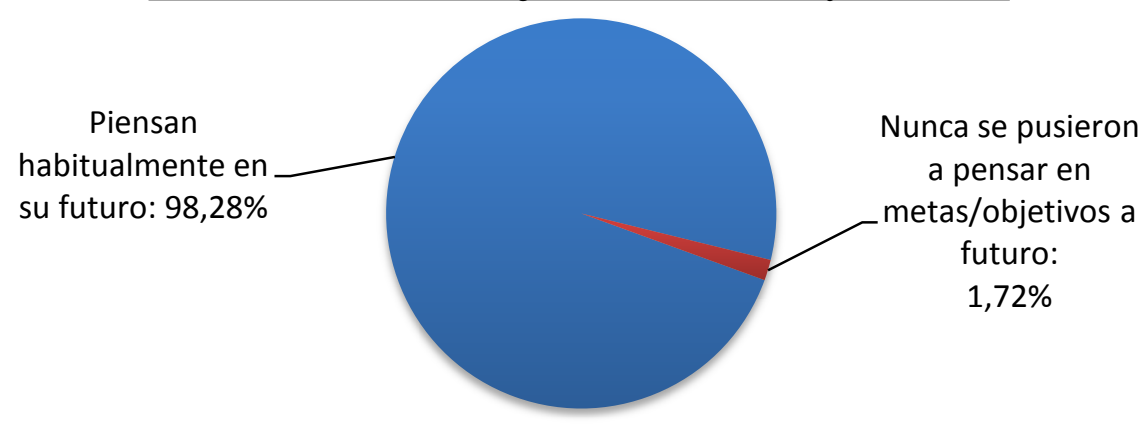

A la indagación acerca de los planes futuros (pregunta 18), el 48,18\% de los adolescentes se imagina estudiando y trabajando simultáneamente; el $48,79 \%$ piensa un futuro caracterizado exclusivamente por el estudio y sólo el 3,33\% piensa dedicarse a trabajar. Estos resultados parecieran contraponerse a algunas visiones del sentido común, las cuales sostienen que la apatía y la escasa reflexión sobre el futuro son aspectos característicos del pensamiento juvenil. Entre los adultos los guarismos fueron: 67,53\%, 19,48\% y 9,09\% para los que -en ese orden- decidieron estudiar y trabajar conjuntamente, estudiar solamente o trabajar exclusivamente. Si se tuviese en cuenta a todo el alumnado las cifras son, respectivamente, $51,84 \%, 43,24 \%$ y 4,42\%. Como se observa a tenor de estas últimas cifras, es poco menos del $10 \%$ la diferencia entre quienes estudiarán y trabajarán simultáneamente respecto de los que han de estudiar solamente. Otro dato de interés es el siguiente: el 3,33\% (adolescentes) se eleva al 9,09\% (adultos) cuando de trabajar solamente se trata.

No se advierten diferencias - en general- en las decisiones respecto del futuro, según las modalidades de los establecimientos educativos. Sólo podría destacarse lo siguiente: en la escuela $\mathrm{F}$, tres de los cinco cursos (con diferentes modalidades) muestran un mayor porcentaje de alumnos que estudiarán solamente respecto de aquellos que simultáneamente trabajarán; en otro curso hay paridad entre los que únicamente estudiarán y los que al mismo tiempo trabajarán y en el restante son más los que piensan estudiar y trabajar que los que decidieron estudiar exclusivamente. Asimismo, ninguno de los encuestados del colegio F (130 en total) piensa trabajar solamente. En cambio, de los diez egresados de la escuela J, seis piensan estudiar y trabajar, estudiar únicamente ninguno y 4 decidieron trabajar solamente. Esto último evidenciaría que la educación sistemática para ellos termina aquí, al menos por ahora. Por lo demás, dos de ellos sostuvieron no haberse planteado nunca metas u objetivos a futuro (tal actitud no se repitió nunca entre los demás egresados y adultos encuestados de las diecinueve escuelas) y cuatro optaron por "Hacer uso del tiempo libre". 
Las dos dimensiones centrales de las orientaciones de futuro consideradas en esta investigación -la motivación y la evaluación - se indagaron en profundidad para los planes referidos al estudio y/o al trabajo. También se incluyeron otros intereses de los estudiantes: metas referidas a "Constituir una familia" (5,15\% adolescentes; 9,09\% adultos y 5,90\% considerados ambos); "Adquirir algunos bienes materiales" (7,58\% adolescentes; 2,60\% adultos y 6,63\% ambos); "Establecer relaciones de pareja" (4,85\% adolescentes; 2,60\% adultos y 4,42\% ambos); "Hacer uso del tiempo libre" (8,79\% adolescentes, $5,19 \%$ adultos y $8,11 \%$ ambos) y "Otros planes de la vida" (2,12\% adolescentes y ninguna elección por parte de los adultos). "Nunca pensé en metas u objetivos a futuro" el 1,52\% de los adolescentes; el $2,60 \%$ de los adultos y el $1,72 \%$ de ambos. Ningún adulto pensó otras metas u objetivos que no fueran los señalados en las diferentes opciones. Se observan aquí nítidas diferencias a favor de los porcentajes referidos al estudio y al trabajo con relación a los obtenidos en otras opciones de respuesta planteadas en la pregunta 18. Al respecto véanse el Cuadro 15 y su Gráfico 11 correspondiente. 
Pregunta 18: ¿Qué harías una vez finalizado el nivel medio?

\begin{tabular}{|c|c|c|c|c|c|c|}
\hline Opciones & \multicolumn{2}{|c|}{ Adolescentes } & \multicolumn{2}{|c|}{ Adultos } & \multicolumn{2}{|c|}{ TOTALES } \\
\hline Estudiar y trabajar & 159 & 48,18 & 52 & 67,53 & 211 & 51,84 \\
\hline Estudiar solamente & 161 & 48,79 & 15 & 19,48 & 176 & 43,24 \\
\hline Trabajar solamente & 11 & 3,33 & 7 & 9,09 & 18 & 4,42 \\
\hline Constituir una familia & 17 & 5,15 & 7 & 9,09 & 24 & 5,90 \\
\hline Hacer uso del tiempo libre & 29 & 8,79 & 4 & 5,19 & 33 & 8,11 \\
\hline Adquirir algunos bienes materiales & 25 & 7,58 & 2 & 2,60 & 27 & 6,63 \\
\hline Nunca pensé en metas u objetivos a futuro & 5 & 1,52 & 2 & 2,60 & 7 & 1,72 \\
\hline Otro/s (especificar) & 7 & 2,12 & 0 & 0 & 7 & 1,72 \\
\hline
\end{tabular}




\section{Gráfico 11: Porcentajes Totales}

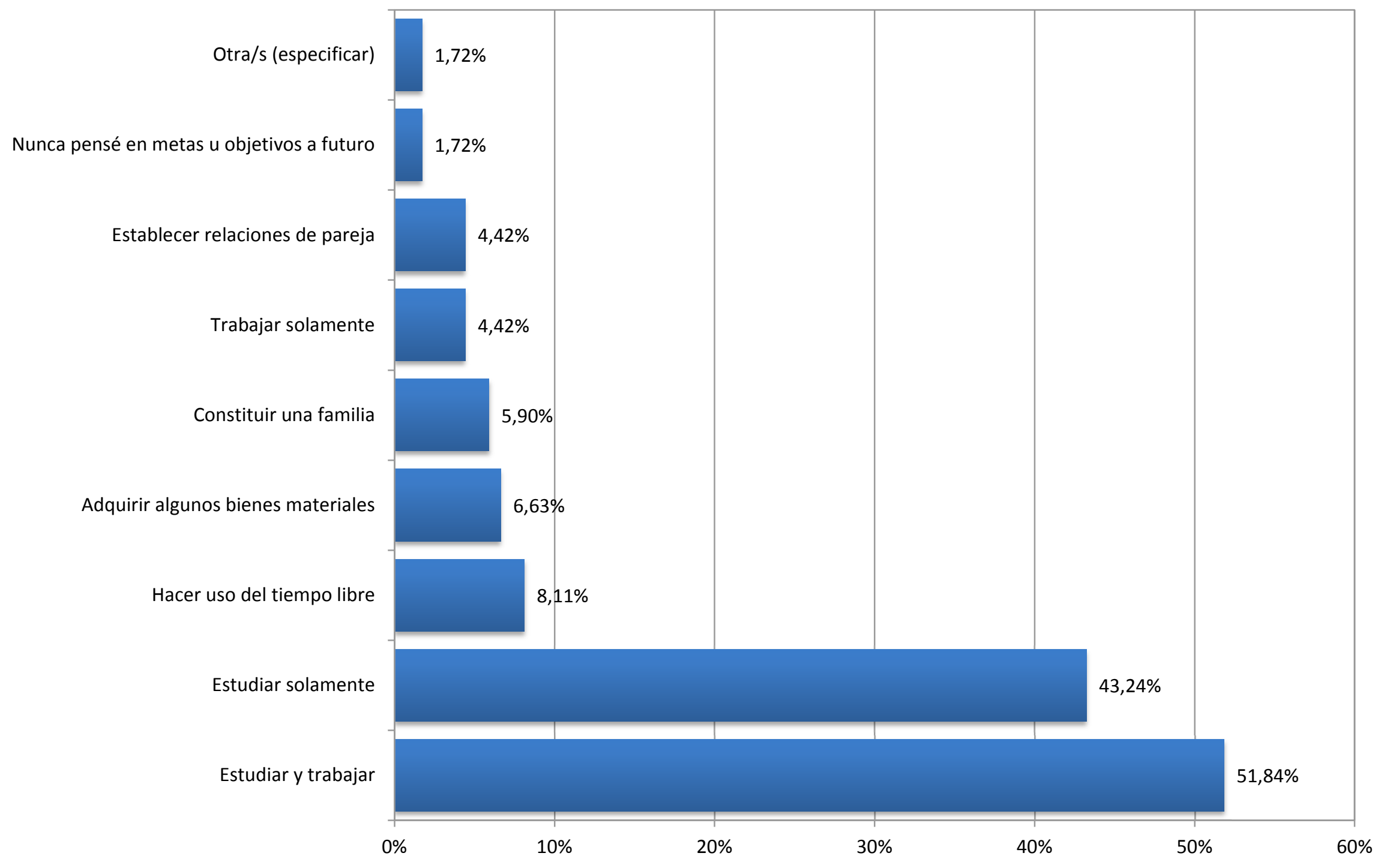


Con relación al futuro laboral (pregunta 19), de 330 adolescentes encuestados surgieron estas elecciones: 189 (el 57,27\%) trabajarían "Por cuenta propia", 146 (el 44,24\%) lo harían en una "Empresa privada" y 67 (el 20,30\%) en un organismo de "Gobierno". De los 77 adultos participantes, 40 (el 51,95\%) trabajarían en forma "Independiente", 31 (el 40,26\%) lo harían en una "Empresa privada" y 13 (el 16,88\%) preferiría hacerlo en una dependencia de "Gobierno". Tanto adolescentes como adultos mayoritariamente trabajarían de manera "Independiente", un porcentaje inferior lo haría en una "empresa privada" y un porcentaje aún menor lo haría en algún ámbito de "Gobierno". Como se advierte, la mayoría de ellos pareciera inclinarse por actividades laborales mediante las cuales afirmar su yo a través del ejercicio del poder en la toma de decisiones, con responsabilidades personales definidas en tiempo y espacio. Al respecto de todo lo señalado véanse el Cuadro 16 y el Gráfico 12 correspondiente al mismo.

Atendiendo a los obstáculos a sortear para el logro de sus metas laborales (pregunta 20), los adolescentes señalaron "Mucha competencia" (el 30,61\%), "Falta de oportunidades" (el $22,42 \%$ ) y "Falta de confianza en mí mismo" (el 19,39\%). En adultos fueron elegidas las mismas opciones, representando el $27,27 \%$, el $18,18 \%$ y el $22,08 \%$, respectivamente. Al considerar a todos los egresados encuestados, nuevamente las tres opciones mencionadas fueron las que recibieron más adhesiones. Por lo demás, tanto en adolescentes como en adultos, los guarismos correspondientes a las demás opciones resultaron inferiores.

El reconocimiento de estos valladares para lograr el trabajo futuro pondría de manifiesto una percepción del mercado laboral donde el aumento de la competencia por los puestos, el azar y las relaciones informales son percibidos como factores cruciales para el acceso al mismo. Otro obstáculo mencionado es la "Falta de capacitación suficiente" (el 16,36\% en adolescentes y el $18,18 \%$ en adultos). Este condicionamiento podría ser entendido como la percepción de un déficit en los conocimientos y habilidades con que se debería contar para desempeñarse laboralmente, como reflejaría una sobreestimación de los alumnos respecto de los conocimientos y capacidades que se requieren para una inserción exitosa en el mercado laboral que -en muchos casos- podría vincularse con su falta de experiencia y de conocimiento directo del mundo del trabajo. Al respecto de lo señalado, véanse el Cuadro 17 y su Gráfico 13 correspondiente. 


\begin{tabular}{|c|c|c|c|c|c|c|}
\hline \multirow{2}{*}{ Opciones } & \multicolumn{2}{|c|}{ Adolescentes } & \multicolumn{2}{|c|}{ Adultos } & \multicolumn{2}{|c|}{ TOTALES } \\
\hline & Cantidad & $\%$ & Cantidad & $\%$ & Cantidad & $\%$ \\
\hline Empresa privada & 146 & 44,24 & 31 & 40,26 & 177 & 43,49 \\
\hline Por cuenta propia (independiente) & 189 & 57,27 & 40 & 51,95 & 229 & 56,27 \\
\hline
\end{tabular}

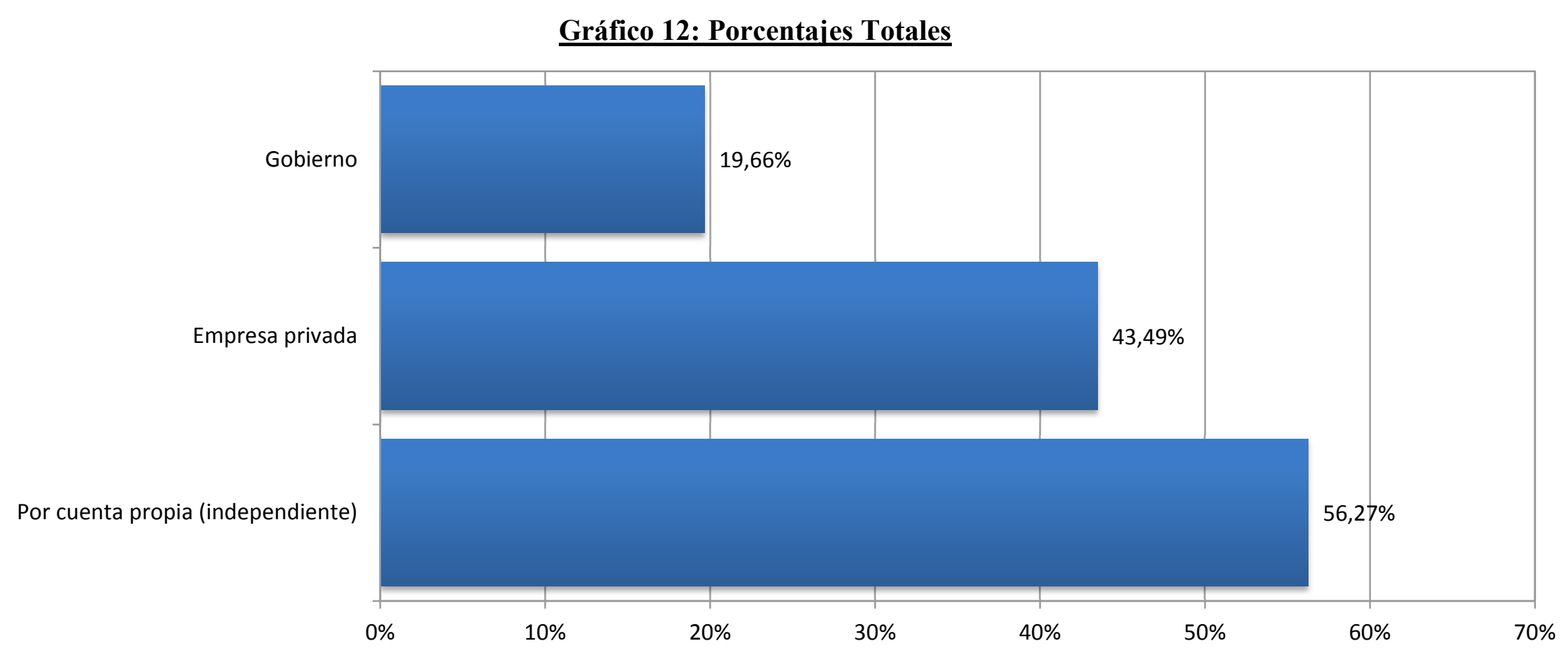




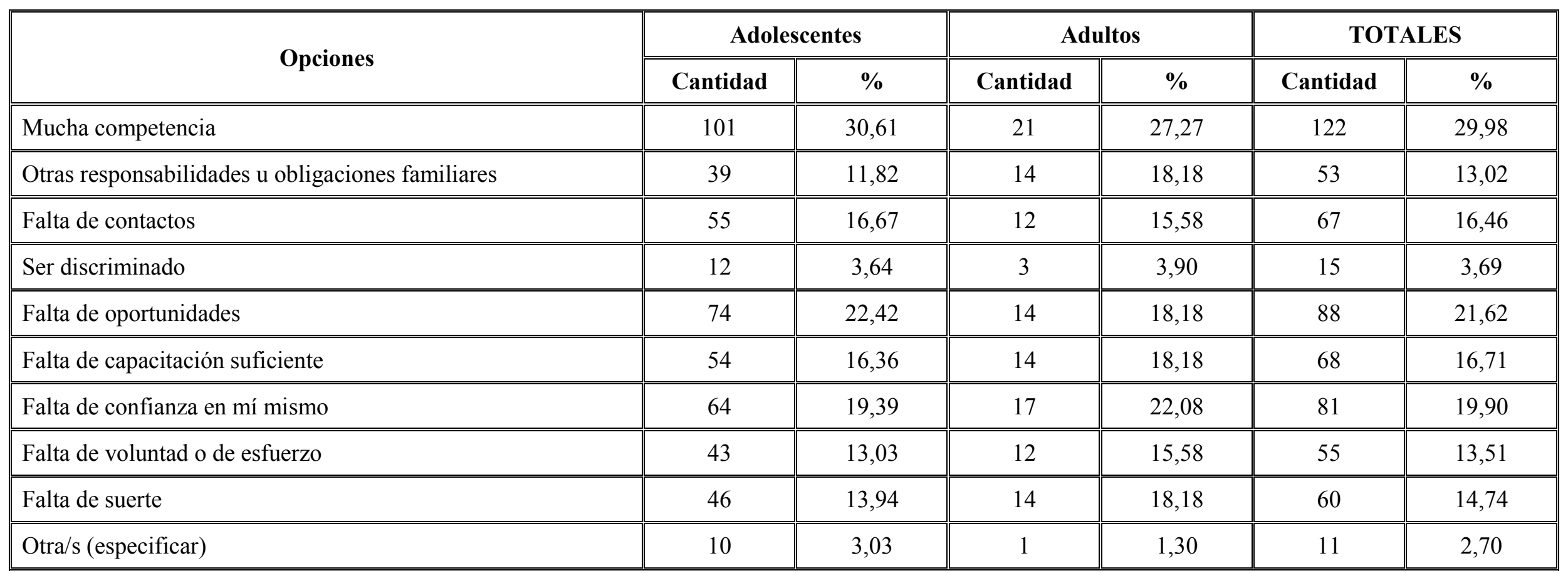




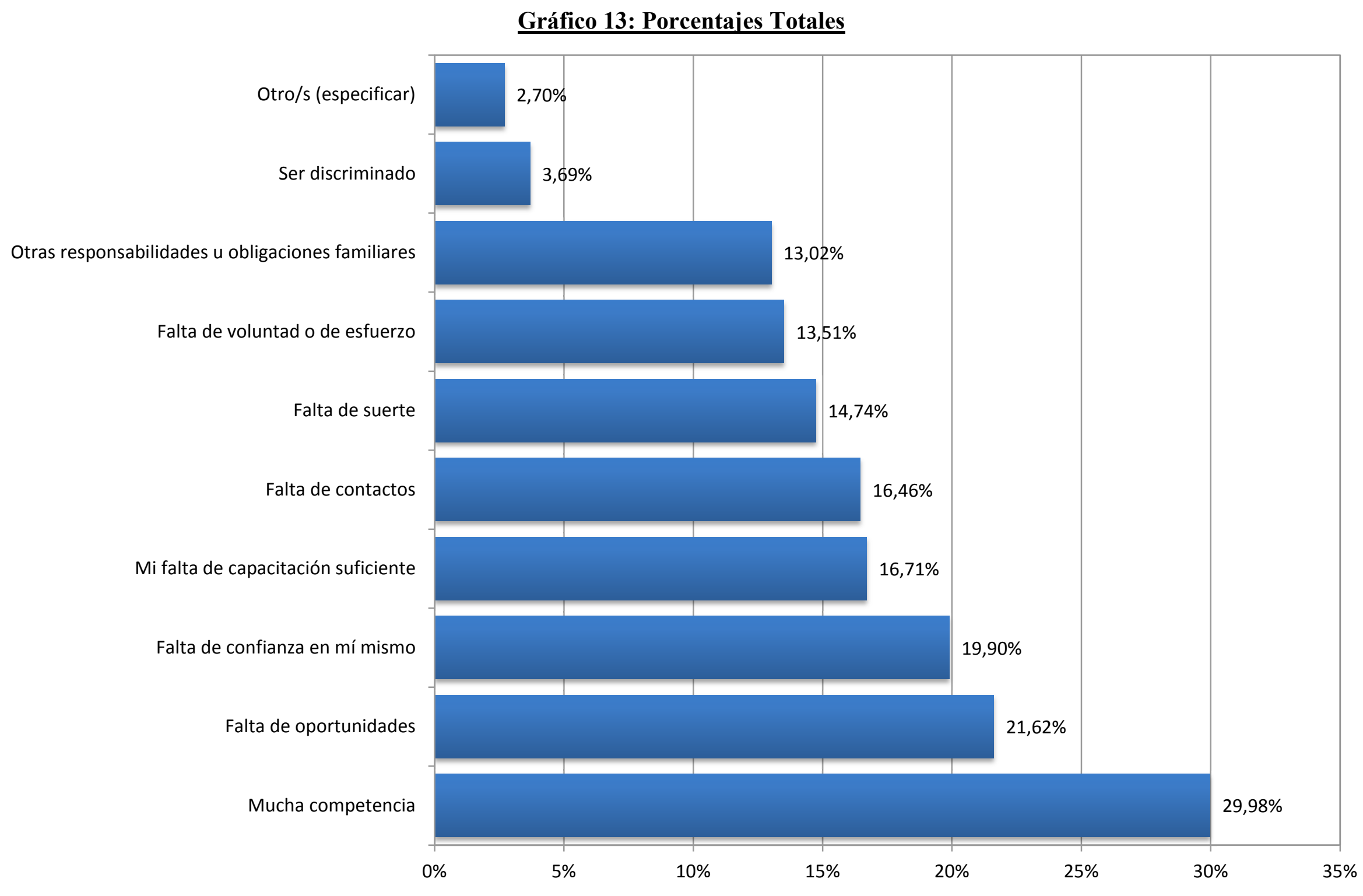


Seguidamente se hará mención a las orientaciones de futuro (pregunta 21) de los egresados 2010. Considerando a los 407 encuestados (330 adolescentes y 77 adultos), 93 de ellos $(22,85 \%)$ seguirán un "Profesorado". Esta cifra se reparte entre 75 adolescentes $(22,73 \%)$ y 18 adultos (23,38\%). Estos porcentajes similares muestran intereses comunes de esos egresados hacia los estudios terciarios no universitarios. Asimismo, carreras como "Administración de Empresas, Contador Público, Economía”, fueron elegidas por el 14,55\% de los adolescentes (48) y el 12,99\% de los adultos (10). Las demás opciones tuvieron, en adolescentes y en adultos, porcentajes inferiores. Al respecto, véanse el Cuadro 18 y su Gráfico 14 correspondiente. 


\begin{tabular}{|c|c|c|c|c|c|c|}
\hline \multirow{2}{*}{ Opciones } & \multicolumn{2}{|c|}{ Adolescentes } & \multicolumn{2}{|c|}{ Adultos } & \multicolumn{2}{|c|}{ TOTALES } \\
\hline & Cantidad & $\%$ & Cantidad & $\%$ & Cantidad & $\%$ \\
\hline Abogacía & 33 & 10,00 & 8 & 10,39 & 41 & 10,07 \\
\hline Administración de Empresas; Contador Público; Economía & 48 & 14,55 & 10 & 12,99 & 58 & 14,25 \\
\hline Arquitectura & 24 & 7,27 & 3 & 3,90 & 27 & 6,63 \\
\hline Artes & 31 & 9,39 & 4 & 5,19 & 35 & 8,60 \\
\hline Carreras vinculadas con la Computación & 30 & 9,09 & 4 & 5,19 & 34 & 8,35 \\
\hline Comunicación Social; Publicidad; Periodismo & 29 & 8,79 & 3 & 3,90 & 32 & 7,86 \\
\hline Despachante de Aduana & 3 & 0,91 & 1 & 1,30 & 4 & 0,98 \\
\hline Diseño(Gráfico, Imagen y Sonido, Indumentaria, Industrial) & 45 & 13,64 & 12 & 15,58 & 57 & 14,00 \\
\hline Enfermería & 15 & 4,55 & 8 & 10,39 & 23 & 5,65 \\
\hline Gastronomía & 19 & 5,76 & 6 & 7,79 & 25 & 6,14 \\
\hline Hotelería; Turismo & 14 & 4,24 & 5 & 6,49 & 19 & 4,67 \\
\hline Ingeniería (Agronómica, Civil, Industrial, Mecánica, en Sistemas) & 45 & 13,64 & 6 & 7,79 & 51 & 12,53 \\
\hline Medicina & 44 & 13,33 & 4 & 5,19 & 48 & 11,79 \\
\hline Psicología; Psicología social & 40 & 12,12 & 3 & 3,90 & 43 & 10,57 \\
\hline Sociología; Relaciones del Trabajo & 8 & 2,42 & 1 & 1,30 & 9 & 2,21 \\
\hline Fuerzas de Seguridad (Militar, Policía, otra) & 22 & 6,67 & 11 & 14,29 & 33 & 8,11 \\
\hline Otra carrera de Grado (especificar) & 30 & 9,09 & 7 & 9,09 & 37 & 9,09 \\
\hline Profesorado (especificar) & 75 & 22,73 & 18 & 23,38 & 93 & 22,85 \\
\hline Otro (especificar) & 5 & 1,52 & 2 & 2,60 & 7 & 1,72 \\
\hline
\end{tabular}




\section{Gráfico 14: Porcentajes Totales}

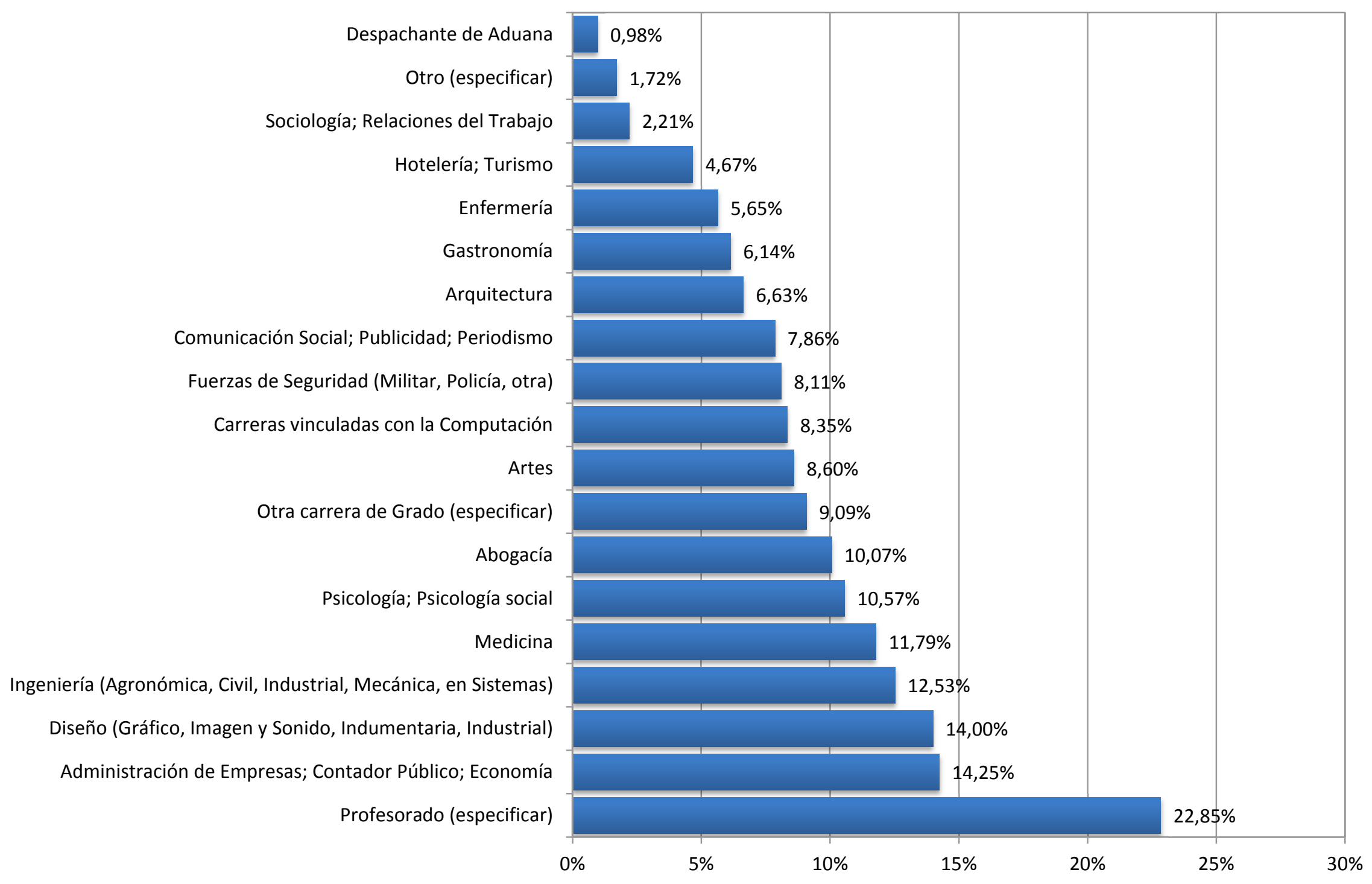


En relación a la pregunta 22 ¿Dónde estudiarías?, la gran mayoría de todos los egresados seguiría estudiando en "Junín”. Los menos — que están presentes en algunas escuelas de adolescentes y de adultos - se trasladarían a ciudades como "Buenos Aires, La Plata o Rosario". La elección de estas últimas ciudades se registró - mayoritariamente- en las escuelas D, E y F (de adolescentes) y en la M (de adultos). Ningún egresado de los colegios $\mathrm{G}, \mathrm{J}$ y $\mathrm{H}$ de adolescentes y de $\mathrm{M} \mathrm{y} \mathrm{L}_{4}$ de adultos estudiaría fuera de Junín.

En otro orden de ideas, la principal preocupación adolescente y adulta en relación al logro de sus metas educativas (pregunta 23) deriva de la convivencia entre estudio y trabajo. Así, "Poco tiempo para estudiar" fue la opción elegida por 103 adolescentes (el 31,21\%) y 26 adultos (el 33,77\%). La opción "Dificultades económicas" (el 22,42\% en adolescentes y $20,78 \%$ en adultos) refleja la preocupación por sustentar económicamente los estudios en base a sus condiciones de vida y/o a las de sus familias. En los adolescentes también aparecen condicionantes en el plano personal: entre ellos, la "Falta de voluntad o de esfuerzo" (el 21,82\%) y la "Falta de confianza en mí mismo" (el 20,30\%). Esta autopercepción -luego de haber recibido 12 años de educación formal- invita a reflexionar acerca de las características que asume la experiencia escolar en los adolescentes. En los adultos se obtuvieron, asimismo, estos resultados: el 27,27\% señaló "Otras responsabilidades u obligaciones familiares" y el 23,38\% indicó "Falta de confianza en mí mismo". Al respecto de lo aseverado, véanse el Cuadro 19 y el Gráfico 15 correspondiente al mismo. 


\begin{tabular}{|c|c|c|c|c|c|c|}
\hline Opciones & \multicolumn{2}{|c|}{ Adolescentes } & \multicolumn{2}{|c|}{ Adultos } & \multicolumn{2}{|c|}{ TOTALES } \\
\hline Poco tiempo para estudiar & 103 & 31,21 & 26 & 33,77 & 129 & 31,70 \\
\hline Dificultades económicas & 74 & 22,42 & 16 & 20,78 & 90 & 22,11 \\
\hline Mucha distancia desde mi residencia al lugar de cursada & 32 & 9,70 & 5 & 6,49 & 37 & 9,09 \\
\hline Otras responsabilidades u obligaciones familiares & 56 & 16,97 & 21 & 27,27 & 77 & 18,92 \\
\hline Mucha dificultad para aprender los contenidos & 56 & 16,97 & 7 & 9,09 & 63 & 15,48 \\
\hline Falta de confianza en mí mismo & 67 & 20,30 & 18 & 23,38 & 85 & 20,88 \\
\hline Falta de voluntad o de esfuerzo & 72 & 21,82 & 10 & 12,99 & 82 & 20,15 \\
\hline Otro/s (especificar) & 13 & 3,94 & 9 & 11,69 & 22 & 5,41 \\
\hline
\end{tabular}




\section{Gráfico 15: Porcentajes Totales}

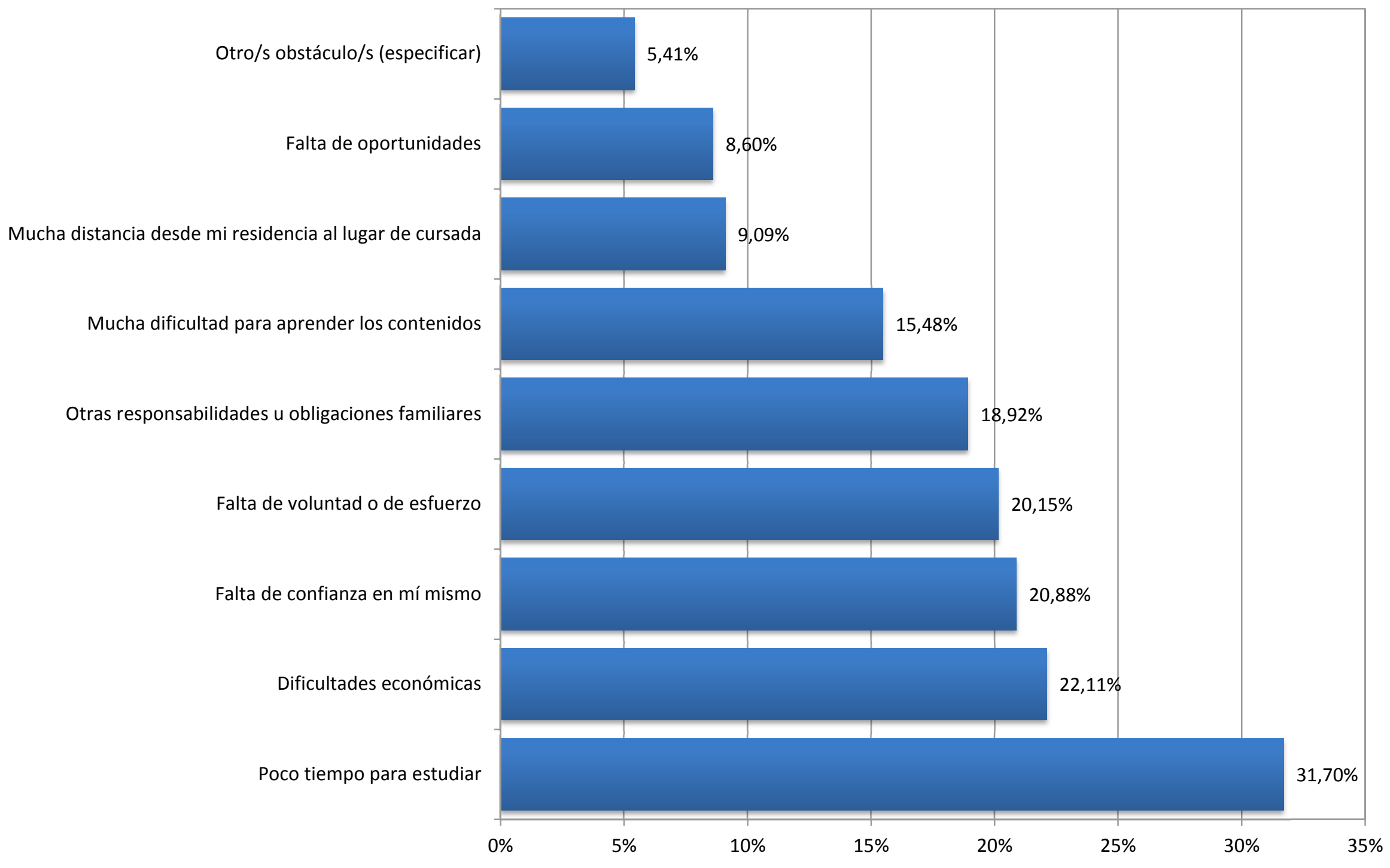


En otro orden de ideas, cabe suponer que la elección de la educación superior (universitaria o no) estaría influida por la modalidad que los estudiantes cursaron en la escuela media, en el sentido de favorecer la elección de estudios superiores afines a las disciplinas que prevalecían en la modalidad. Los datos obtenidos teniendo en cuenta a la totalidad de los encuestados (407) entre adolescentes (330) y adultos (77) permiten señalar —a modo de ejemplos - lo siguiente: la modalidad Ciencias Naturales estaba en 6 escuelas de adolescentes (D, E, F, G, H y J) en 8 cursos (porque en 2 de ellas se impartía en 2 divisiones) y en 1 escuela de adultos $\left(\mathrm{H}_{1}\right)$ en 1 curso. Y la modalidad EGEOR aparecía en 6 escuelas de adolescentes (A, C, E, F, G y H) en 7 cursos (porque en una de ellas existían 2 divisiones) y en 3 de adultos $\left(A_{1}, G_{1} \text { y } M\right)^{200}$ en 3 cursos.

De los 101 alumnos encuestados que pertenecían a Ciencias Naturales, 22 de ellos (el 22,77\%) estudiarían "Medicina", 11 (el 10,89\%) "Enfermería", 8 (el 7,92\%) lo harían en las denominadas "Fuerzas de Seguridad (Militar, Policía, otra)" y 7 (el 6,93\%) seguirían "Ingeniería".

Respecto de la modalidad HUSOC se observó lo siguiente: de los 76 educandos partícipes en esta investigación, 16 (el 21,05\%) seguirían un "Profesorado", estando divididas las preferencias por Maestra (con diferentes especialidades) o "Profesores" (en diversas áreas del saber). Otros 12 (el 14,47\%) preferiría seguir "Comunicación Social; Publicidad; Periodismo". Asimismo, 11 educandos (el 13,15\%) estudiarían "Abogacía”. Otros estudios terciarios lograron en las elecciones porcentajes menores.

Los educandos de establecimientos técnicos (con modalidades específicas, salvo excepciones) suman 22. Ellos optarían por alguna de las especialidades de la carrera de "Ingeniería" (el 56\%). Le sigue "Diseño" (con sus especialidades) que reúne a un grupo menor de educandos (32\%), "Computación" (28\%) y "Arquitectura" (16\%).

De los 107 encuestados que cursaron la modalidad EGEOR, 41 de ellos (el 38,31\%) estudiarían "Administración de Empresas; Contador Público; Economía” y 18 (el 16,82\%) seguirían un "Profesorado". Otras carreras elegidas fueron "Diseño" (7,47\%) y "Arquitectura" $(3,73 \%)$. Ahora bien, en relación a las modalidades Ciencias Naturales y EGEOR, las carreras de Medicina y de Administración de Empresas; Contador Público y Economía - respectivamente- concentran las preferencias del estudiantado observándose el vínculo entre ellas y la modalidad de los estudios secundarios cursados. En las preferencias, detrás de Medicina sigue Enfermería cuya relación con aquélla vuelve aún más nítido dicho vínculo.

200. Más datos respecto de los egresados de veinticinco escuelas estatales del Distrito de Junín -en el ámbito de las respectivas modalidades - pueden hallarse en el Capítulo II, en el cuadro de la página 315 . 
En cuanto a la modalidad ADICO se observa que fueron 61 los encuestados, teniendo en cuenta 2 escuelas y 3 cursos. Los resultados obtenidos fueron los siguientes: el 36,06\% seguiría un "Profesorado" (en alguna de sus variadas áreas), el 34,42\% alguna de las especialidades referidas a "Diseño" y el 19,67\% proseguiría estudios superiores en "Artes". Al respecto de todo lo señalado véase el Gráfico 16.

\section{Gráfico 16: Porcentajes más relevantes}

\section{Modalidad: Ciencias Naturales}

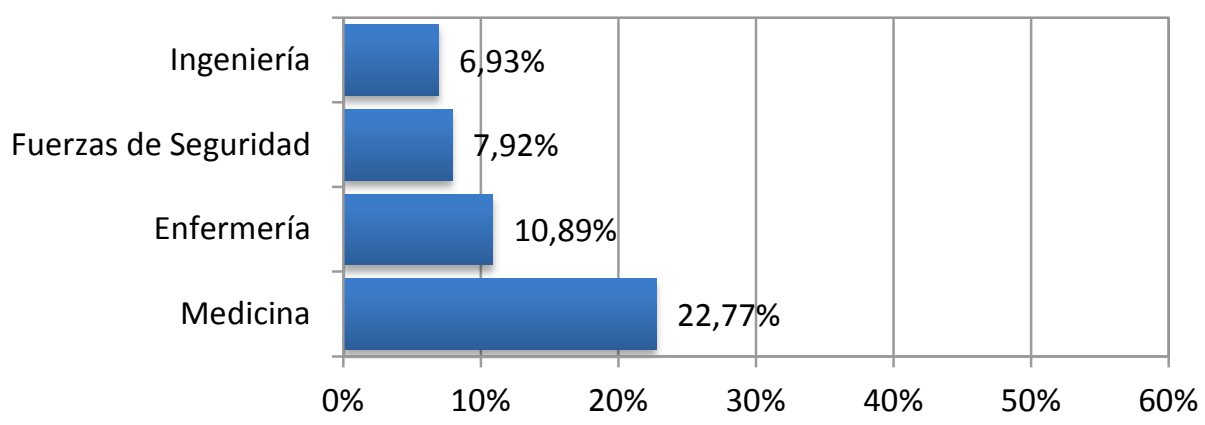

Modalidad: HUSOC

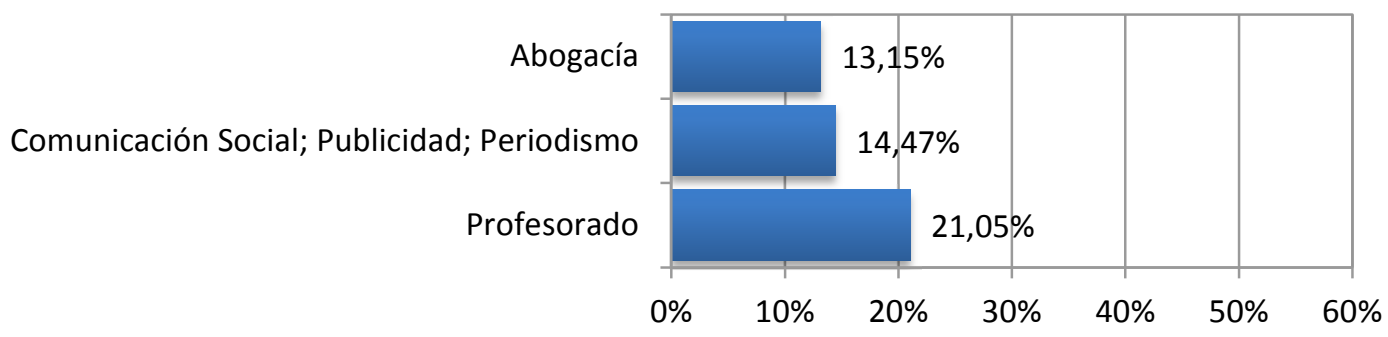

Modalidad: Técnicas

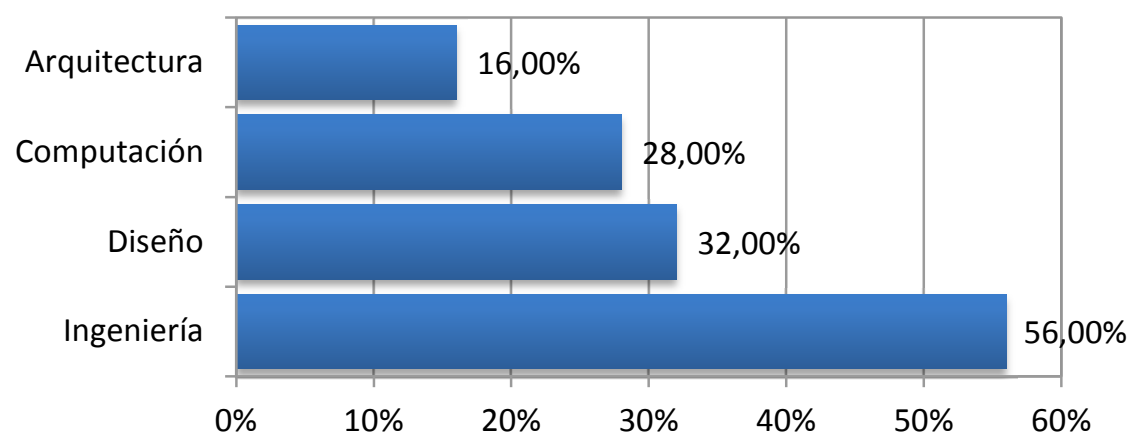




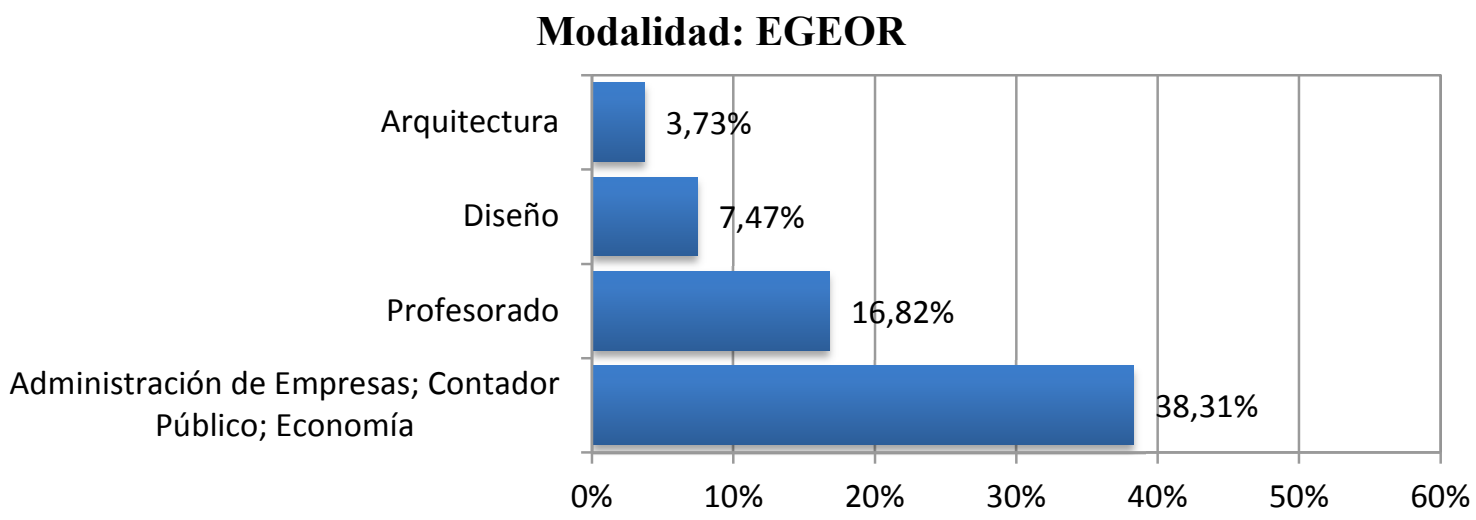

Modalidad: ADICO

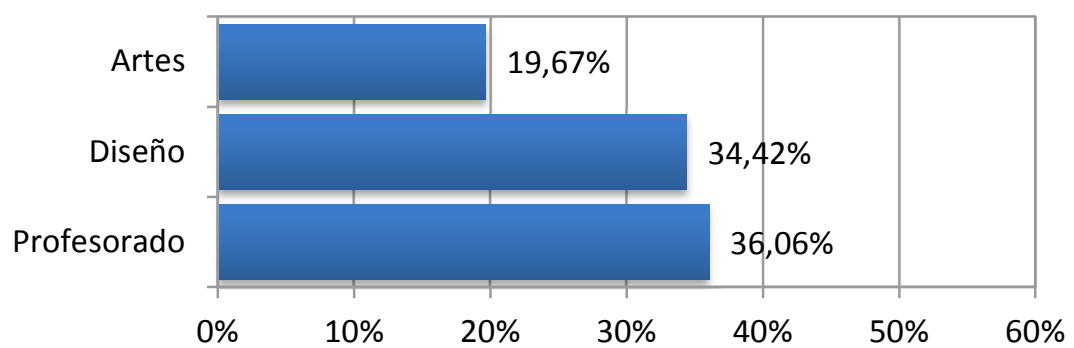

A continuación serán tomados en cuenta datos atinentes a los sexos en su acceso a la educación superior. Históricamente, la comparación entre mujeres y varones ha permitido observar algunas diferencias en los estudios superiores de los adolescentes. Una investigación sobre la incorporación de mujeres a la universidad mostró —con datos censales de la Universidad de Buenos Aires para el período 1958/1988 - que las primeras que ingresaron tendían a hacerlo en Ciencias Sociales, en Psicología y - particularmente- en carreras docentes de la Facultad de Filosofía y Letras, como opción para insertarse en el mundo profesional. En 1971 el 43\% de las mujeres universitarias se proyectaba en la actividad docente o académica. Otro estudio, con datos de 2003 de varias universidades argentinas, mostró que su inserción en las mismas (de gestión estatal) sigue siendo mayoritaria en Psicología, Educación, Ciencias Sociales y Ciencias Auxiliares de la Medicina (representan el $70 \%$ o más del estudiantado de esas carreras) y que se mantienen barreras de acceso a las áreas tecnológicas y a las ciencias básicas, consideradas como típicamente masculinas.

En este trabajo, en la modalidad EGEOR se obtuvieron los siguientes resultados: de 107 encuestados (67 mujeres y 40 varones), 41 de ellos estudiarían "Administración de Empresas; Contador Público; Economía", siendo 26 mujeres (el 63,42\%) y 15 varones (el 36,58\%). Seguirían un "Profesorado" 18 alumnos. Otros 8 estudiarían "Diseño" en alguna de sus especialidades, siendo 6 mujeres (el 75\%) y 2 varones (el 25\%). Respecto de 
"Arquitectura", 4 alumnos: 2 mujeres (el 50\%) y 2 varones (el 50\%) seguirían dicha carrera. Los demás educandos continuarían otros estudios superiores.

En la modalidad Ciencias Naturales, de 101 encuestados (41 varones y 60 mujeres), 23 seguirían "Medicina": 12 mujeres (el 52,18\%) y 11 varones (el 47,82\%). Asimismo, estudiarían "Enfermería" 11 alumnos: 7 mujeres (el 63,64\%) y 4 varones (el 36,36\%). Los demás proseguirán otros estudios superiores, obteniéndose porcentajes inferiores.

En HUSOC se observó lo siguiente: de los 76 encuestados (45 mujeres y 31 varones), 16 seguirán un "Profesorado", siendo 11 mujeres (el 68,75\%) y 5 varones (el 31,25\%). "Comunicación Social; Publicidad; Periodismo" serían estudiadas por 12 educandos: 9 mujeres (el 75\%) y 3 varones (el 25\%). Y “Abogacía” la estudiarían 11 alumnos: 9 mujeres (el $81,82 \%$ ) y 2 varones (el 18,18\%). Los restantes continuarían otros estudios superiores, en porcentajes menores.

Respecto de ADICO, de 61 encuestados (45 mujeres y 16 varones), 22 de ellos (el 36,06\%) seguirían un "Profesorado"; 21 (el 34,42\%) alguna de las especialidades de "Diseño" y 12 (el 19,67\%) estudiarían “Artes”. Los restantes seguirían otros estudios superiores, con porcentajes menores.

En la presente investigación, el análisis de la elección de estudios superiores muestra las preferencias de los y las estudiantes del último año de nivel medio en el Distrito de Junín. Las especialidades de Ingeniería fueron las carreras elegidas por 14 de los 22 alumnos pertenecientes a los dos establecimientos técnicos. De allí, el 68,57\% de los varones seguiría Ingeniería, respecto del $11,43 \%$ de mujeres que estudiaría la misma carrera. Los restantes educandos optaron por llevar a cabo otros estudios superiores.

Al respecto de todo lo expresado véanse los Cuadros 20, 21 y 22: 
Estudios superiores según escuela, modalidad y sexo (algunos ejemplos):

Cuadro 20

\begin{tabular}{|c|c|c|c|c|c|c|c|}
\hline \multirow{3}{*}{\multicolumn{2}{|c|}{ Escuelas }} & \multicolumn{6}{|c|}{ EGEOR (107 encuestados) } \\
\hline & & \multicolumn{2}{|c|}{$\begin{array}{l}\text { Administración de Empresas; } \\
\text { Contador Público; Economía }\end{array}$} & \multicolumn{2}{|c|}{ Diseño } & \multicolumn{2}{|c|}{ Arquitectura } \\
\hline & & Varones & Mujeres & Varones & Mujeres & Varones & Mujeres \\
\hline \multirow{5}{*}{ 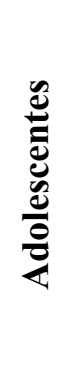 } & $\mathbf{A}$ & 2 & 3 & 0 & 3 & 0 & 0 \\
\hline & $\mathbf{C}$ & 0 & 3 & 0 & 0 & 0 & 1 \\
\hline & $\mathbf{E}$ & 3 & 6 & 0 & 0 & 1 & 0 \\
\hline & $\mathbf{F}$ & 5 & 9 & 1 & 1 & 0 & 0 \\
\hline & $\mathbf{H}$ & 1 & 2 & 0 & 0 & 0 & 0 \\
\hline \multirow{3}{*}{$\frac{\stackrel{\mathscr{\varrho}}{E}}{\frac{E}{z}}$} & $\mathbf{F}_{1}$ & 1 & 0 & 1 & 0 & 1 & 1 \\
\hline & $\mathbf{L}_{1}$ & 1 & 2 & 0 & 2 & 0 & 0 \\
\hline & $\mathbf{M}$ & 2 & 1 & 0 & 0 & 0 & 0 \\
\hline \multirow{2}{*}{\multicolumn{2}{|c|}{ TOTAL }} & 15 & 26 & 2 & 6 & 2 & 2 \\
\hline & & \multicolumn{2}{|c|}{41 alumnos } & \multicolumn{2}{|c|}{8 alumnos } & \multicolumn{2}{|c|}{4 alumnos } \\
\hline
\end{tabular}

Cuadro 21

\begin{tabular}{|c|c|c|c|c|c|}
\hline \multirow{3}{*}{\multicolumn{2}{|c|}{ Escuelas }} & \multicolumn{4}{|c|}{ CIENCIAS NATURALES (101 encuestados) } \\
\hline & & \multicolumn{2}{|c|}{ Medicina } & \multicolumn{2}{|c|}{ Enfermería } \\
\hline & & Varones & Mujeres & Varones & Mujeres \\
\hline \multirow{6}{*}{ 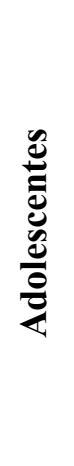 } & D & 3 & 5 & 0 & 0 \\
\hline & $\mathbf{E}$ & 3 & 0 & 1 & 0 \\
\hline & $\mathbf{F}$ & 2 & 4 & 0 & 0 \\
\hline & G & 1 & 2 & 1 & 1 \\
\hline & H & 1 & 0 & 0 & 1 \\
\hline & $\mathbf{J}$ & 1 & 1 & 0 & 3 \\
\hline \multirow{2}{*}{$\frac{\stackrel{\varrho}{E}}{\frac{E}{E}}$} & $\mathbf{H}_{1}$ & 0 & 0 & 1 & 0 \\
\hline & $\mathbf{L}_{2}$ & 0 & 0 & 1 & 2 \\
\hline \multirow{2}{*}{\multicolumn{2}{|c|}{ TOTAL }} & 11 & 12 & 4 & 7 \\
\hline & & \multicolumn{2}{|c|}{23 alumnos } & \multicolumn{2}{|c|}{11 alumnos } \\
\hline
\end{tabular}


Cuadro 22

\begin{tabular}{|c|c|c|c|c|c|c|c|}
\hline \multirow{3}{*}{\multicolumn{2}{|c|}{ Escuelas }} & \multicolumn{6}{|c|}{ HUSOC (76 encuestados) } \\
\hline & & \multicolumn{2}{|c|}{ Profesorado } & \multicolumn{2}{|c|}{$\begin{array}{l}\text { Comunicación Social; } \\
\text { Publicidad; Periodismo }\end{array}$} & \multicolumn{2}{|c|}{ Abogacía } \\
\hline & & Varones & Mujeres & Varones & Mujeres & Varones & Mujeres \\
\hline \multirow{3}{*}{ 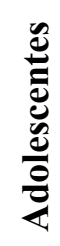 } & $\mathbf{D}$ & 3 & 5 & 2 & 9 & 0 & 6 \\
\hline & $\mathbf{E}$ & 0 & 3 & 1 & 0 & 2 & 3 \\
\hline & $\mathbf{G}$ & 0 & 1 & 0 & 0 & 0 & 0 \\
\hline \multirow{2}{*}{$\frac{\mathscr{E}}{\stackrel{E}{E}}$} & $\mathbf{F}_{1}$ & 2 & 2 & 0 & 0 & 0 & 0 \\
\hline & $\mathbf{M}$ & 0 & 0 & 0 & 0 & 0 & 0 \\
\hline \multirow{2}{*}{\multicolumn{2}{|c|}{ TOTAL }} & 5 & 11 & 3 & 9 & 2 & 9 \\
\hline & & \multicolumn{2}{|c|}{16 alumnos } & \multicolumn{2}{|c|}{12 alumnos } & \multicolumn{2}{|c|}{11 alumnos } \\
\hline
\end{tabular}

\subsubsection{Análisis descriptivo}

Estudiar los sentidos de la escuela media y las orientaciones hacia el futuro de los egresados, importa romper nociones existentes sobre estos campos problemáticos. El sistema escolar genera el capital cultural institucionalizado que acredita un cúmulo de conocimientos por medio de la obtención del diploma o título de egresado. Así, frente a posturas que subrayan el desinterés del estudiantado en la educación o una asistencia a clase fundada sólo en la exigencia familiar, los egresados de las escuelas estatales del Distrito de Junín manifestaron que asistían porque consideraban que la concurrencia los beneficiaría en el futuro (opinión prevaleciente) y/o porque la estiman positiva para su presente (así se expresaron tanto adolescentes como adultos).

En el tipo de gratificaciones a futuro, la mayoría del alumnado destacó que la obtención del título secundario - en tanto credencial educativa - le servirá para continuar estudios superiores y/o para acceder a una ocupación, prevaleciendo éstas sobre razones atinentes al logro de aprendizajes útiles para el desempeño laboral presente. Así, la educación es valorada como una inversión y como requisito que permitirá alcanzar mejores resultados a futuro.

Entre las razones de concurrencia al colegio vinculadas con una gratificación inmediata se desprenden afirmaciones relativas al aporte escolar para el desarrollo personal. Así, articulan una mirada de la escuela como instrumento para desenvolverse mejor en la sociedad y como fin en sí misma, "para saber más". Esto último indica una valoración positiva de la escuela por el estudiantado. Asimismo, en línea con una gratificación inmediata aparece la asistencia por la sociabilidad, aunque en menor medida que las dos razones anteriores. Por lo 
demás, la experiencia de "estar con otros" o "estar con amigos" en la escuela también es valorada por los estudiantes, aunque estos nuevos sentidos son más débiles que otros más tradicionales, como la asistencia en pos del futuro y por los aprendizajes que en ella tienen asidero. A todo esto, la asistencia por obligación apareció muy débilmente en las respuestas de los egresados.

Como esta investigación se realiza con educandos que llegaron al final del nivel, caben dos consideraciones: en primer lugar, la asistencia puede ser resultado del papel jugado por la institución escolar en términos de construcción de otros sentidos que superan la obligatoriedad legal y el mandato familiar. Pero debe advertirse que se desconocen las causas atinentes a alumnos que no lograron llegar a $3^{\circ}$ Año. Incluso, se ignoran los motivos de quienes abandonaron el colegio cuando estaban cursando el último año.

Otro tema de análisis es la percepción del alumnado de los aportes escolares para la adquisición de conocimientos, habilidades y actitudes y acerca del futuro educativo y/o laboral, cuyos resultados muestran diferencias entre grupos de estudiantes de una misma y de diferentes escuelas. Los porcentajes referidos a los conocimientos logrados en tres asignaturas -Historia, Lengua Nacional y Matemática- muestran que los guarismos más bajos se dan en las que reciben a los alumnos más desfavorecidos (tanto adolescentes como adultos). Los resultados obtenidos en este aspecto - deficitarios según lo que sería dable esperar en un egresado- son similares a los que pueden observarse en una investigación realizada en Argentina por Guillermo Jaim Etcheverry. ${ }^{201}$

Al trabajar las orientaciones de futuro, nuevos hallazgos permiten un distanciamiento con los discursos más pesimistas acerca del futuro estudiantil. Los encuestados mostraron que la reflexión sobre su futuro es una actividad habitual para la inmensa mayoría de ellos. La relación entre trabajo y estudio sería una constante que emerge del análisis de sus orientaciones de futuro. El trabajo coexistente con estudios superiores pareciera ser una estrategia para sustentar económicamente la educación después del nivel medio. Asimismo, las elevadas aspiraciones educativas de la mayoría sugieren que tienen claro que la escuela media no alcanza para garantizar una buena inserción laboral y que los títulos de ese nivel se hallan devaluados. Visualizan que necesitarán más educación para ampliar sus posibilidades de inserción o distinción social. Otro dato relevante es que en pos de la meta educativa, el "poco tiempo para estudiar" es el mayor obstáculo para todos los educandos, si bien la mayoría admitió que sólo cuando hay examen estudia todo lo necesario. En cuanto a los límites para llevar adelante sus planes laborales, destacan en forma mayoritaria obstáculos que remiten a condicionamientos de difícil intervención personal, como la competencia y la falta

201. Léase al respecto la página 144 de esta tesis. 
oportunidades. En el plano educativo también aparecen valladares de tipo objetivo que expresarían una mirada realista sobre el futuro: muchos temen (más los adolescentes que los adultos) no poder sustentar económicamente sus estudios. Por lo demás, en lo educativo como en lo laboral la falta de confianza en sí mismo y la falta de voluntad o de esfuerzo se mostraron con porcentajes significativos, tanto en unos como en otros.

No se hallaron diferencias significativas en las elecciones de estudios futuros entre los adolescentes y los adultos. Estuvieron orientadas, básicamente, por las modalidades que hubieren cursado. Para la inmensa mayoría de los egresados, estudiar y trabajar o estudiar solamente constituyen una decisión relevante en vista del futuro. En esta decisión, las actividades o espacios de orientación organizados por las escuelas no parecieran haber cumplido un papel central ya que no lograron constituir en aportes decisivos para gran parte del alumnado, menos aún entre los adultos. Sus respuestas mostraron, además, que esas actividades o espacios — cuando se produjeron— fueron puntuales y transitorios.

En otro orden de ideas, los egresados usan la computadora: en la biblioteca para la realización de trabajos solicitados por los profesores y - asimismo- buscar información a los fines de decidir su futuro. Sólo unas pocas escuelas de adultos aún no cuentan con aquéllas. El uso de computadoras y de otras Tecnologías de la Información y de la Comunicación (TIC) permitirían imaginar nuevos modos de enseñar y de aprender.

Se ha abordado la contribución de la escuela media en las orientaciones de futuro de los egresados. Los resultados obtenidos sugerirían que esta temática tiene un camino a recorrer. Va de suyo que el acompañamiento de la escuela al alumno no puede reducirse a una actividad puntual ni al momento inmediatamente anterior a su egreso. 


\subsection{Responsables de los egresados de escuelas estatales de nivel medio del Distrito de Junín}

Total de responsables de los egresados adolescentes que fueron encuestados

Total de responsables de los egresados adultos que fueron encuestados

Total de responsables de los egresados adolescentes y adultos que fueron encuestados

Total de responsables de los egresados (adolescentes y adultos) no encuestados porque las escuelas a que asistían los egresados no integraron la muestra

Total de responsables de los egresados (adolescentes y adultos) respecto de los cuales se desconoce qué sucedió con el cuestionario elaborado para ellos

Total de responsables de los egresados adolescentes y adultos del ciclo lectivo 2010 .

Prueba piloto: se efectúo en julio de 2010 con 20 responsables.

Instrumento de recolección de datos: cuestionario autoadministrado individual (no precodificado) que incluye preguntas cerradas con varias opciones de respuesta no mutuamente excluyentes (3.b, 3.d y 4 a 13). Y preguntas cerradas con 2 o más posibilidades de respuesta, de las que debe elegir una (1, 2, 3.a y 3.c). En total, 13 preguntas. 


\subsubsection{Presentación de los participantes}

A continuación podrán leerse datos demográficos correspondientes a responsables de los egresados, teniendo en cuenta las mismas escuelas -en idéntico orden- que las seleccionadas respecto de aquéllos:

\section{Escuela D}

\begin{tabular}{|l|l||}
\hline \hline Total de responsables encuestados & 45. \\
\hline Nacionalidad & Todos, argentina salvo 3 que no contestaron. \\
\hline Sexo & 17 varones y 28 mujeres. \\
\hline \hline Edad promedio & 41 años. \\
\hline \hline Estado civil & $\begin{array}{l}\text { Varones: } 11 \text { casados, } 3 \text { divorciados, } 1 \text { viudo y } 2 \text { solteros. } \\
\text { Mujeres: } 18 \text { casadas, } 4 \text { divorciadas, } 4 \text { separadas, } 1 \text { en } \\
\text { concubinato y } 1 \text { viuda. }\end{array}$ \\
\hline \hline Nivel socioeconómico & $\begin{array}{l}\text { Todos, nivel medio salvo } 3 \text { (2 madres y } 1 \text { padre) que } \\
\text { respondieron: bajo. }\end{array}$ \\
\hline
\end{tabular}

\begin{tabular}{|l||l||}
\hline \multicolumn{2}{|c||}{ Escuela F } \\
\hline \hline Total de responsables encuestados & 48. \\
\hline \hline Nacionalidad & Todos, argentina. \\
\hline Sexo & 22 varones y 26 mujeres. \\
\hline Edad promedio & 46 años y 5 meses. \\
\hline \hline Estado civil & $\begin{array}{l}\text { Trece padres están casados. Uno divorciado, uno separado y } \\
\text { los demás no contestaron. Veinte madres están casadas, una } \\
\text { divorciada, una separada y las demás no contestaron. }\end{array}$ \\
\hline Nivel socioeconómico & $\begin{array}{l}\text { La gran mayoría, nivel medio. Un padre y una madre } \\
\text { manifestaron nivel bajo y cuatro no contestaron. }\end{array}$ \\
\hline \hline
\end{tabular}




\begin{tabular}{|l||l||}
\hline \multicolumn{2}{|c||}{ Escuela A } \\
\hline \hline Total de responsables encuestados & 9. \\
\hline Nacionalidad & Todos, argentina. \\
\hline Sexo & 4 varones y 5 mujeres. \\
\hline \hline Edad promedio & 48 años. \\
\hline \hline Estado civil & Todos casados, salvo una madre que es viuda. \\
\hline \hline Nivel socioeconómico & Todos, nivel medio. \\
\hline \hline
\end{tabular}

\begin{tabular}{|l||l||}
\hline \multicolumn{2}{|c||}{ Escuela $\mathbf{J}$} \\
\hline \hline Total de responsables encuestados & 4. \\
\hline \hline Nacionalidad & Todos, argentina. \\
\hline Sexo & 1 varón y 3 mujeres. \\
\hline Edad promedio & 40 años. \\
\hline Estado civil & $\begin{array}{l}\text { El padre está casado. Dos de las madres están casadas y la } \\
\text { restante es soltera. }\end{array}$ \\
\hline \hline Nivel socioeconómico & Todos, nivel bajo salvo una madre que manifestó medio. \\
\hline
\end{tabular}

\begin{tabular}{|l|l||}
\hline \multicolumn{2}{|c||}{ Escuela M } \\
\hline \hline Total de responsables encuestados & 10. \\
\hline \hline Nacionalidad & Ocho, argentina y dos no contestaron. \\
\hline \hline Sexo & 5 varones y 5 mujeres. \\
\hline \hline Edad promedio & 50 años. \\
\hline \hline Estado civil & $\begin{array}{l}\text { Tres padres están casados, uno es divorciado y uno es soltero. } \\
\text { Dos madres están casadas, una es divorciada, una es separada } \\
\text { y una es soltera. }\end{array}$ \\
\hline \hline Nivel socioeconómico & $\begin{array}{l}\text { Todos, nivel medio salvo la tutora que expresó nivel } \\
\text { socioeconómico bajo. }\end{array}$ \\
\hline
\end{tabular}




\begin{tabular}{|l|l||}
\hline \multicolumn{2}{|c||}{ Escuela $\mathbf{L}_{\mathbf{4}}$} \\
\hline \hline Total de responsables encuestados & 2. \\
\hline \hline Nacionalidad & Ambas, argentina. \\
\hline \hline Sexo & Ambas, mujeres. \\
\hline \hline Edad promedio & 41 años. \\
\hline \hline Estado civil & Una madre está casada y la otra divorciada. \\
\hline \hline Nivel socioeconómico & Ambas, nivel socioeconómico medio. \\
\hline \hline
\end{tabular}

\subsubsection{Conceptos preliminares al trabajo de campo}

\subsubsection{Los responsables y el instrumento de medición}

Los papás, mamás, tutores u otros responsables partícipes en esta investigación nacieron entre 1955 y 1970. Tenían entre 6 y 21 años al inicio de la última dictadura militar. ${ }^{202}$ Durante el período en que gobernó la misma (1976/83) transcurrió la segunda infancia (tal como se denomina psicológicamente) para algunos de esos responsables y su adolescencia y entrada en la adultez, para otros. Ellos tenían en 2010 entre 40 y 55 años y sus hijos -entre 17 y 27 años - culminaban el nivel medio. La diferencia entre lo vivido en aquella época y la realidad de la democracia actual ofrece aristas relevantes, las cuales podrían considerar - por ejemplo- aspectos esenciales de la educación en tiempos de inconstitucionalidad y caracteres propios de la misma durante el imperio de la ley. No es del caso analizar en esta tesis la mentada diferencia.

La prueba piloto se llevó a cabo con 20 responsables de los egresados: 10 padres, 9 madres y 1 tutor. Con sus resultados, el instrumento de medición preliminar se modificó, ajustó y mejoró (se quitaron y agregaron ítems y se cambiaron palabras). Se logró de esa manera la versión final del cuestionario para ser administrado.

202. La gestión del gobierno autoritario del autodenominado Proceso de Reorganización Nacional (PRN) empezó el 24 de marzo de 1976. Bajo la pretensión legitimadora de la simbiosis ideológica orden y progreso/modernización/satisfacción, generaron el cauce y los operativos por el que discurrieron las gestiones ministeriales en la re-organización del sistema educativo. En la provincia de Buenos Aires se intentó regular el trabajo de enseñar mediante la supresión de algunas asignaturas y la prohibición (y autorización o recomendación) de textos escolares. 
En esta investigación fueron encuestados 192 responsables. Hay padres (73), madres (112) y tutores (7). De ellos, 149 son responsables de estudiantes adolescentes y 43 tienen ese vínculo con los educandos adultos.

Se utilizaron cuestionarios autoadministrados individuales con 13 preguntas en total; algunas de ellas con opciones de respuesta válida no mutuamente excluyentes y otras de opción única. Dada la imposibilidad de aplicar el instrumento en la propia escuela (en ninguna de ellas estaban previstas reuniones con padres de los egresados en el período septiembre-noviembre de 2010), fueron sus hijos (los egresados encuestados) quienes lo llevaron a sus hogares, junto con una carta introductoria en la que se explicaban las razones de su aplicación, agradeciéndose la colaboración prestada.

\subsubsection{Datos obtenidos al operacionalizar las variables}

\subsubsection{Nivel educativo alcanzado}

Respecto del máximo nivel educativo alcanzado por los responsables de los egresados (pregunta 1), de los 57 padres de adolescentes que fueron encuestados, 1 tiene un posgrado finalizado, 9 son universitarios y 6 aún no culminaron dicho estudio superior. Otros 4 concluyeron el nivel terciario (no universitario) y 2 aún no. De las 86 madres, sólo 2 son licenciadas, 7 poseen un título universitario y cinco aún no culminaron dicho estudio. Entre los 6 tutores, 1 posee título universitario, 1 tiene título terciario (no universitario) y otro no culminó el terciario (no universitario). O sea, de los 149 responsables de egresados adolescentes, 25 (el 16,77\%) culminaron estudios superiores.

Respecto de los adultos, de 16 padres sólo 1 tiene el nivel terciario (no universitario) finalizado. Entre las 26 madres, 1 tiene título universitario, 2 alcanzaron el nivel terciario (no universitario) y otras 2 todavía no. El único tutor finalizó el secundario. Es decir, de 43 responsables de egresados adultos, 4 (el 9,30\%) finalizaron estudios superiores. Existe una diferencia del $7,47 \%$ a favor de los responsables de adolescentes, respecto de los de adultos en cuanto a logros académicos superiores. La misma indagación, pero referida a los abuelos de los egresados (pregunta 2), mostró que en atención a los adolescentes, 2 abuelos paternos y una abuela paterna son universitarios. Otro abuelo y otra abuela paternos terminaron el nivel terciario (no universitario). Entre los abuelos maternos, 4 finalizaron el nivel terciario (no universitario). Entre las abuelas maternas, una alcanzó el posgrado, una es universitaria, 4 culminaron el nivel terciario (no universitario) y 2 aún no. Entre los padres y/o madres de tutores, 1 alcanzó la licenciatura, 2 son universitarios, 3 culminaron el nivel terciario (no universitario) y 2 aún no finalizaron ese nivel.

En relación a los egresados adultos, un abuelo paterno y una abuela paterna tienen un estudio universitario no finalizado. Lo mismo acontece con un abuelo materno y una abuela 
materna. Entre los padres y/o madres de los tutores, 2 mostraron un estudio universitario no culminado. Quizás por las experiencias de fracasos generacionales o por la ausencia de otros modos de organización social, el progreso es reemplazado hoy por el acento en la realización personal, por lo cual la deuda social se transfiere al sujeto mismo como elección para la búsqueda de su destino. Las formas en que construye su vida convertirían al relato en eje de la propia experiencia que transcurre con otros.

Respecto de lo desarrollado en este punto, véanse los Cuadros 1.a, 1.b, 2.a y 2.b: 
ADOLESCENTES

Cuadro 1.a

Pregunta 1: ¿Cuál es el máximo nivel educativo alcanzado por usted?

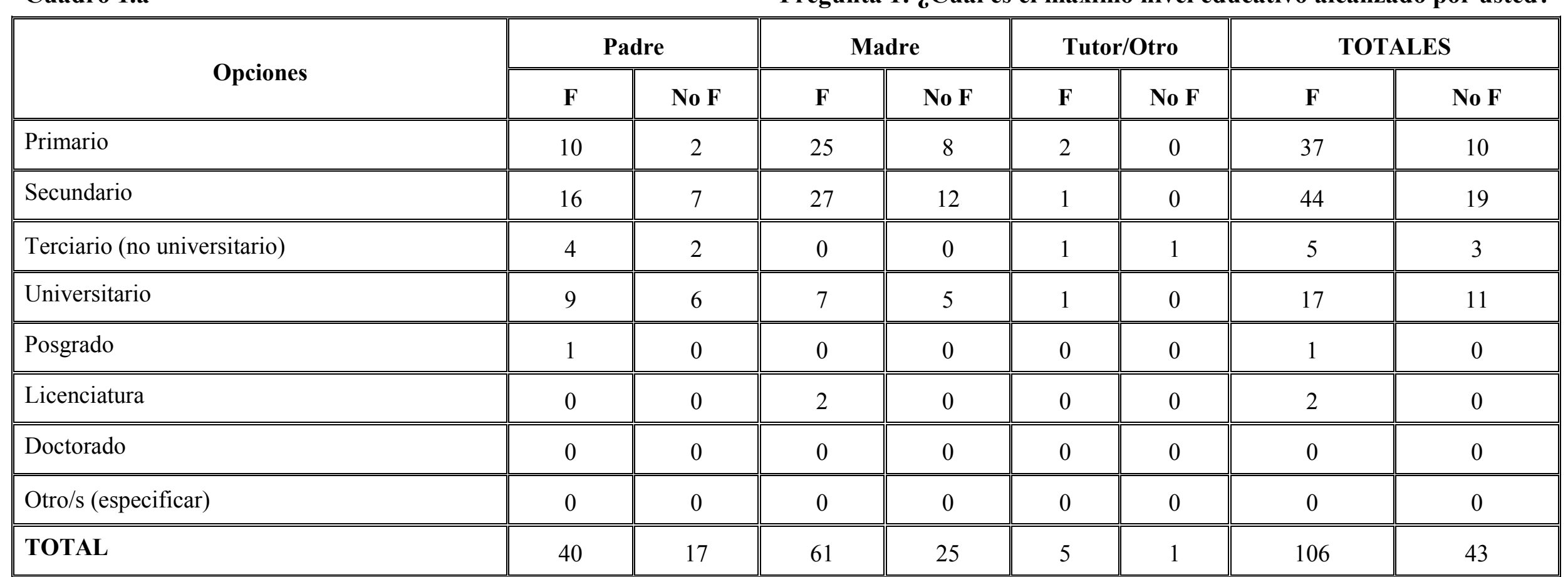

Nota: "F": Finalizado; "No F": No Finalizado 


\section{ADULTOS}

Cuadro 1.b

Pregunta 1: ¿Cuál es el máximo nivel educativo alcanzado por usted?

\begin{tabular}{|c|c|c|c|c|c|c|c|c|}
\hline Opciones & \multicolumn{2}{|c|}{ Padre } & \multicolumn{2}{|c|}{ Madre } & \multicolumn{2}{|c|}{ Tutor/Otro } & \multicolumn{2}{|c|}{ TOTALES } \\
\hline Primario & 4 & 2 & 9 & 3 & 0 & 0 & 13 & 5 \\
\hline Secundario & 4 & 5 & 6 & 3 & 1 & 0 & 11 & 8 \\
\hline Terciario (no universitario) & 1 & 0 & 2 & 2 & 0 & 0 & 3 & 2 \\
\hline Posgrado & 0 & 0 & 0 & 0 & 0 & 0 & 0 & 0 \\
\hline Licenciatura & 0 & 0 & 0 & 0 & 0 & 0 & 0 & 0 \\
\hline Doctorado & 0 & 0 & 0 & 0 & 0 & 0 & 0 & 0 \\
\hline Otro/s (especificar) & 0 & 0 & 0 & 0 & 0 & 0 & 0 & 0 \\
\hline
\end{tabular}

Nota: "F": Finalizado; "No F": No Finalizado 
ADOLESCENTES

Pregunta 2: ¿Cuál es el máximo nivel educativo alcanzado por su padre y/o madre o tutor/otro, es decir, los abuelos del egresado/a?

\begin{tabular}{|c|c|c|c|c|c|c|c|c|c|c|c|c|}
\hline \multirow{2}{*}{ Opciones } & \multicolumn{2}{|c|}{ Abo Pat } & \multicolumn{2}{|c|}{ Aba Pat } & \multicolumn{2}{|c|}{ Abo Mat } & \multicolumn{2}{|c|}{ Aba Mat } & \multicolumn{2}{|c|}{ P/M/Tutor/O } & \multicolumn{2}{|c|}{ TOTALES } \\
\hline & $\mathbf{F}$ & $\mathbf{N F}$ & $\mathbf{F}$ & NF & $\mathbf{F}$ & NF & $\mathbf{F}$ & NF & $\mathbf{F}$ & NF & $\mathbf{F}$ & NF \\
\hline Primario & 32 & 18 & 25 & 19 & 32 & 14 & 34 & 13 & 11 & 1 & 134 & 65 \\
\hline Secundario & 10 & 5 & 7 & 8 & 12 & 8 & 6 & 6 & 9 & 3 & 44 & 30 \\
\hline Terciario (no universitario) & 1 & 0 & 1 & 0 & 4 & 0 & 4 & 2 & 3 & 2 & 13 & 4 \\
\hline Universitario & 2 & 0 & 1 & 0 & 0 & 0 & 1 & 0 & 2 & 0 & 6 & 0 \\
\hline Posgrado & 0 & 0 & 0 & 0 & 0 & 0 & 1 & 0 & 0 & 0 & 1 & 0 \\
\hline Licenciatura & 0 & 0 & 0 & 0 & 0 & 0 & 0 & 0 & 1 & 0 & 1 & 0 \\
\hline Doctorado & 0 & 0 & 0 & 0 & 0 & 0 & 0 & 0 & 0 & 0 & 0 & 0 \\
\hline Otro/s (especificar) & 0 & 0 & 0 & 0 & 0 & 0 & 0 & 0 & 0 & 0 & 0 & 0 \\
\hline TOTAL & 45 & 23 & 34 & 27 & 48 & 22 & 46 & 21 & 26 & 6 & 199 & 99 \\
\hline
\end{tabular}

Nota: “Abo Pat”: Abuelo Paterno; “Aba Pat”: Abuela Paterna; “Abo Mat”: Abuelo Materno;“Aba Mat”: Abuela Materna;

"P/M/Tutor/O": Padre o Madre o Tutor u Otro; "F": Finalizado; "NF": No Finalizado 
ADULTOS

Pregunta 2: ¿Cuál es el máximo nivel educativo alcanzado por su padre y/o madre o tutor/otro, es decir, los abuelos del egresado/a?

\begin{tabular}{|c|c|c|c|c|c|c|c|c|c|c|c|c|}
\hline \multirow{2}{*}{ Opciones } & \multicolumn{2}{|c|}{ Abo Pat } & \multicolumn{2}{|c|}{ Aba Pat } & \multicolumn{2}{|c|}{ Abo Mat } & \multicolumn{2}{|c|}{ Aba Mat } & \multicolumn{2}{|c|}{ P/M Tutor/O } & \multicolumn{2}{|c|}{ TOTALES } \\
\hline & $\mathbf{F}$ & NF & $\mathbf{F}$ & $\mathbf{N F}$ & $\mathbf{F}$ & $\mathbf{N F}$ & $\mathbf{F}$ & NF & $\mathbf{F}$ & NF & $\mathbf{F}$ & NF \\
\hline Primario & 13 & 3 & 12 & 6 & 12 & 4 & 11 & 7 & 1 & 1 & 49 & 21 \\
\hline Secundario & 3 & 2 & 0 & 0 & 1 & 1 & 0 & 0 & 1 & 0 & 5 & 3 \\
\hline Terciario (no universitario) & 0 & 0 & 0 & 1 & 0 & 0 & 0 & 1 & 0 & 0 & 0 & 2 \\
\hline Universitario & 0 & 1 & 0 & 1 & 0 & 1 & 0 & 1 & 0 & 2 & 0 & 6 \\
\hline Posgrado & 0 & 0 & 0 & 0 & 0 & 0 & 0 & 0 & 0 & 0 & 0 & 0 \\
\hline Licenciatura & 0 & 0 & 0 & 0 & 0 & 0 & 0 & 0 & 0 & 0 & 0 & 0 \\
\hline Doctorado & 0 & 0 & 0 & 0 & 0 & 0 & 0 & 0 & 0 & 0 & 0 & 0 \\
\hline Otro/s (especificar) & 0 & 0 & 0 & 0 & 0 & 0 & 0 & 0 & 0 & 0 & 0 & 0 \\
\hline TOTAL & 16 & 6 & 12 & 8 & 13 & 6 & 11 & 9 & 2 & 3 & 54 & 32 \\
\hline
\end{tabular}

Nota: “Abo Pat”: Abuelo Paterno; “Aba Pat”: Abuela Paterna; “Abo Mat”: Abuelo Materno; “Aba Mat”: Abuela Materna;

"P/M Tutor/O": Padre o Madre o Tutor u Otro; "F": Finalizado;"NF”: No Finalizado 


\subsubsection{Experiencia laboral}

Ante las preguntas 3.a ¿Trabajó alguna vez? y 3.b ¿Dónde trabajo?, los siguientes datos atañen a responsables de los egresados adolescentes. De un total de 149, 145 (el 97,32\%) afirmaron que trabajaron alguna vez y 4 (el 2,68\%) sostuvieron "No" que nunca lo hicieron. Entre los que trabajaron, 67 (el 44,97\%) lo hicieron "Por cuenta propia", 61 (el 40,94\%) laboraron en una "Empresa privada" y 33 (el 22,14\%) en la esfera del "Gobierno". Consultados si trabajan actualmente (pregunta 3.c), 115 (el 77,18\%) respondieron "Sí" mientras que 34 (el 22,82\%) sostuvieron "No". De los trabajadores actuales, 61 (el 40,93\%) lo hacen "Por cuenta propia", 38 (el 25,50\%) se desempeñan en la "Empresa privada" y 21 (el $14,09 \%$ ) en una organismo de "Gobierno" (opciones de respuesta ante la pregunta 3.d)

Seguidamente, datos relativos a responsables de egresados adultos. De un total de 43, 42 (el 97,67\%) han afirmado que trabajaron alguna vez. Una madre afirmó que no lo hizo nunca. De los que trabajaron, 25 (el 58,14\%) señalaron haberlo hecho "Por cuenta propia", 15 (el 34,88\%) en una "Empresa privada" y 10 (el 23,25\%) en una dependencia de "Gobierno". Al consultárseles si trabajan actualmente, 28 (el 65,12\%) respondieron afirmativamente y 15 (el $34,88 \%$ ) contestaron "No". De los trabajadores actuales, 13 (el 30,23\%) lo realizan "Por cuenta propia", 12 (el 27,91\%) en una "Empresa privada" y 3 (el 6,98\%) en el "Gobierno".

Respecto de lo desarrollado supra, véanse los Cuadros 3.a, 3.b, 4.a, 4.b, 5.a, 5.b, 6.a, 6.b y los Gráficos del 1 al 8 correspondientes.

\section{ADOLESCENTES}

Cuadro 3.a

Pregunta 3.a: ¿Trabajó alguna vez?

\begin{tabular}{||c||c|c|c||c||}
\hline \multicolumn{1}{|c||}{ Opciones } & Padre & Madre & Tutor/Otro & TOTALES \\
\hline Sí & 56 & 83 & 6 & $145(97,32 \%)$ \\
\hline No & 1 & 3 & 0 & $4(2,68 \%)$ \\
\hline
\end{tabular}

\section{Gráfico 1}

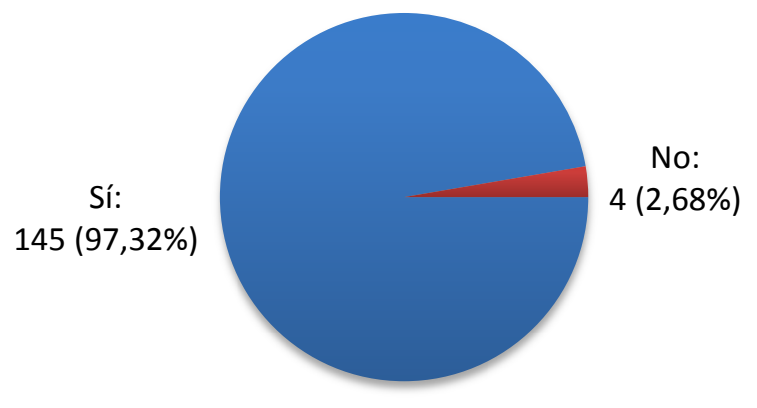


ADULTOS

Cuadro 3.b

Pregunta 3.a: ¿Trabajó alguna vez?

\begin{tabular}{||c|c|c|c|c||}
\hline \multicolumn{1}{|c|}{ Opciones } & Padre & Madre & Tutor/Otro & TOTALES \\
\hline \hline Sí & 16 & 25 & 1 & $42(97,67 \%)$ \\
\hline \hline No & 0 & 1 & 0 & $1(2,33 \%)$ \\
\hline
\end{tabular}

Gráfico 2

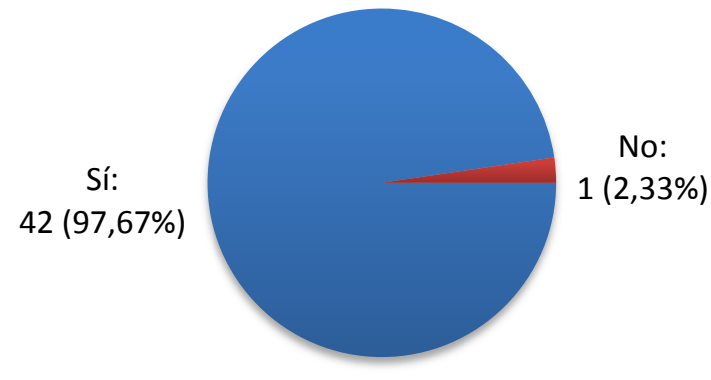

ADOLESCENTES

Cuadro 4.a

Pregunta 3.b: ¿Dónde trabajó?

\begin{tabular}{|l||c|c||c||c||}
\hline \multicolumn{1}{|c||}{ Opciones } & Padre & Madre & Tutor/Otro & Padre+Madre+Tutor/Otro \\
\hline Empresa privada & 28 & 32 & 1 & $61(40,94 \%)$ \\
\hline \hline Gobierno & 15 & 16 & 2 & $33(22,14 \%)$ \\
\hline \hline Por cuenta propia (independiente) & 29 & 35 & 3 & $67(44,97 \%)$ \\
\hline
\end{tabular}

Gráfico 3: Porcentajes Totales

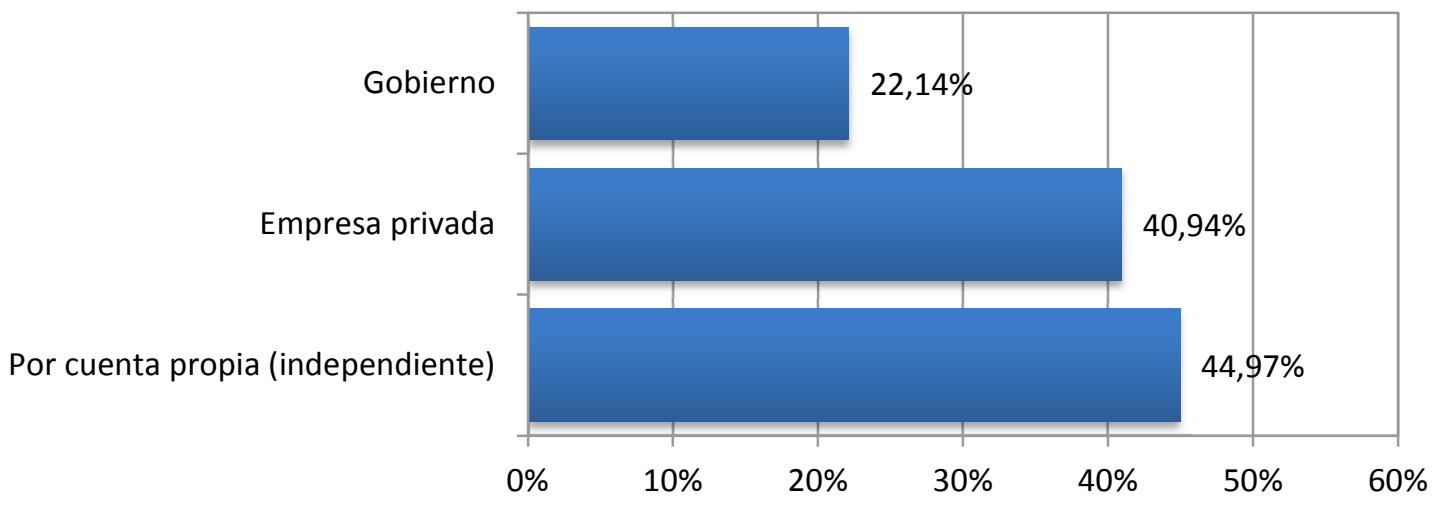


ADULTOS

Cuadro 4.b

Pregunta 3.b: ¿Dónde trabajó?

\begin{tabular}{|l|c|c|c|c||}
\hline \multicolumn{1}{|c||}{ Opciones } & Padre & Madre & Tutor/Otro & Padre+Madre+Tutor/Otro \\
\hline \hline Empresa privada & 5 & 10 & 0 & $15(34,88 \%)$ \\
\hline \hline Gobierno & 4 & 5 & 1 & $10(23,25 \%)$ \\
\hline \hline Por cuenta propia (independiente) & 10 & 15 & 0 & $25(58,14 \%)$ \\
\hline
\end{tabular}

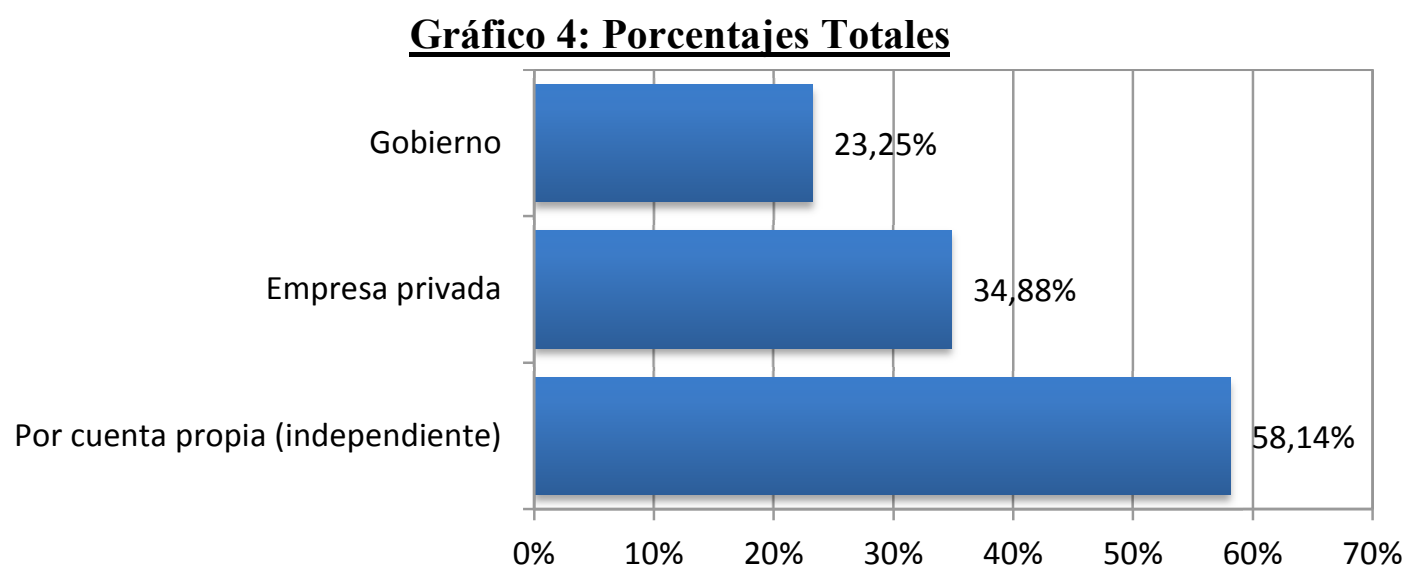

Cuadro 5.a

ADOLESCENTES

\begin{tabular}{|c|c|c|c|c|}
\hline Opciones & Padre & Madre & Tutor/Otro & Padre + Madre + Tutor/Otro \\
\hline Sí & 50 & 60 & 5 & $115(77,18 \%)$ \\
\hline No & 7 & 26 & 1 & $34(22,82 \%)$ \\
\hline
\end{tabular}

\section{Gráfico 5}

Sí:

$115(77,18 \%)$ 
ADULTOS

Cuadro 5.b

Pregunta 3.c: ¿Actualmente trabaja?

\begin{tabular}{||c|c||c||c|c||}
\hline \multicolumn{1}{|c|}{ Opciones } & Padre & Madre & Tutor/Otro & Padre+Madre+Tutor/Otro \\
\hline \hline Sí & 13 & 14 & 1 & $28(65,12 \%)$ \\
\hline \hline No & 3 & 12 & 0 & $15(34,88 \%)$ \\
\hline
\end{tabular}

\section{Gráfico 6}

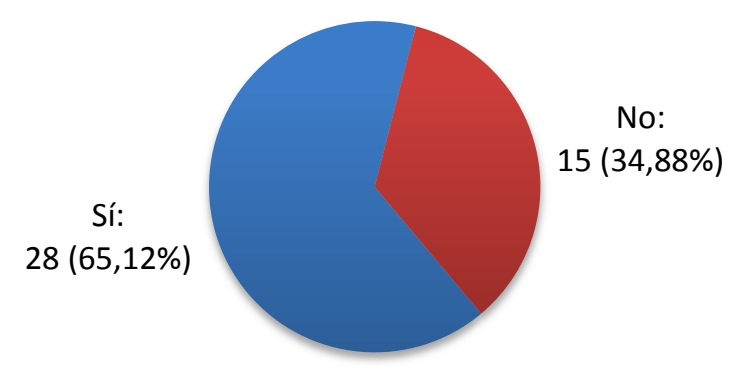

ADOLESCENTES

Cuadro 6.a

Pregunta 3.d: ¿Dónde trabaja?

\begin{tabular}{||l||c|c||c||c||}
\hline \multicolumn{1}{|c||}{ Opciones } & Padre & Madre & Tutor/Otro & Padre+Madre+Tutor/Otro \\
\hline \hline Empresa privada & 19 & 19 & 0 & $38(25,50 \%)$ \\
\hline \hline Gobierno & 8 & 13 & 0 & $21(14,09 \%)$ \\
\hline Por cuenta propia (independiente) & 28 & 28 & 5 & $61(40,93 \%)$ \\
\hline
\end{tabular}

Gráfico 7: Porcentajes Totales

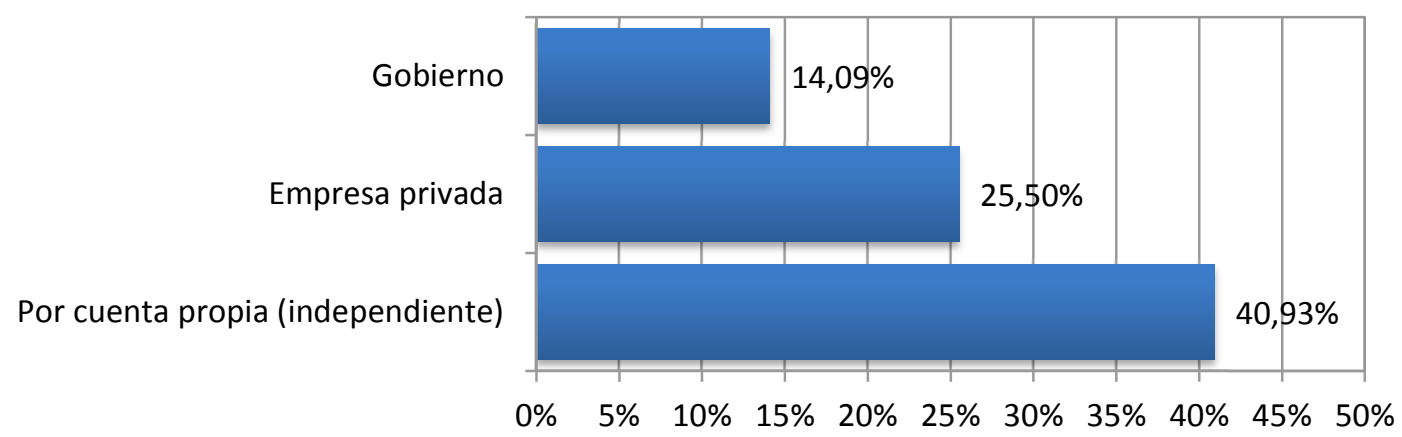


Cuadro 6.b

ADULTOS

\begin{tabular}{|l|c||c||c|c||}
\hline \multicolumn{1}{|c|}{ Opciones } & Padre & Madre & Tutor/Otro & Padre+Madre+Tutor/Otro \\
\hline \hline Empresa privada & 5 & 6 & 1 & $12(27,91 \%)$ \\
\hline \hline Gobierno & 2 & 1 & 0 & $3(6,98 \%)$ \\
\hline Por cuenta propia (independiente) & 6 & 7 & 0 & $13(30,23 \%)$ \\
\hline
\end{tabular}

Gráfico 8: Porcentajes Totales

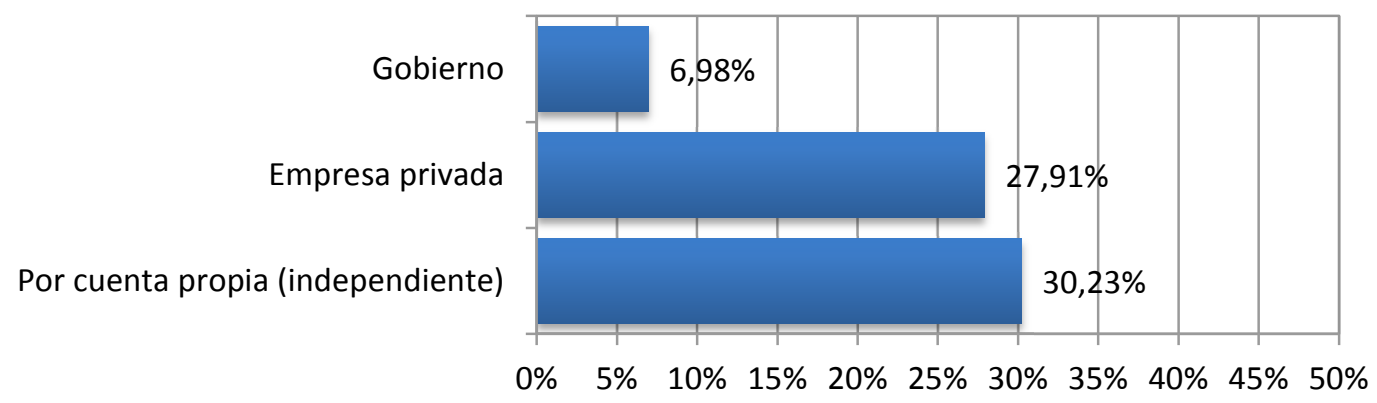

\subsubsection{Conocimiento de la realidad social}

Ante la pregunta 4 ¿De qué fuente se vale para adquirir la información y el conocimiento?, los responsables de los egresados adolescentes contestaron "Internet" (el 61,74\%) y "Libros, periódicos, revistas" (el 58,39\%), siendo las opciones más elegidas. Entre responsables de los egresados adultos la opción más elegida fue "La familia" (el 58,13\%). Luego, "La escuela" (el 55,81\%) y "La radio, la televisión" (el 44,19\%). "Libros, periódicos, revistas" logró el 39,53\% e "Internet” aparece después con el 25,58\% de adhesiones.

La pregunta 5.a ¿A qué atribuye fenómenos como el alcoholismo, la delincuencia, la drogadicción y la prostitución en el Distrito de Junín? originó como respuesta "La falta de límites que se observa en los jóvenes" en el 59,06\% y "La actual crisis de valores" en el $58,39 \%$, ambos de los responsables de los egresados adolescentes. Los de los egresados adultos los atribuyen a "Factores familiares" (el 67,44\%). Tanto aquéllos como éstos afirman que se puede cambiar esta realidad "A través de una mejor calidad educativa" (el 56,38\% y el $65,12 \%$ respectivamente). Sólo el 4,03\% de los responsables de egresados adolescentes y el $13,95 \%$ de los de adultos niegan que esta realidad pueda cambiar ya que "Estos flagelos existieron siempre y siempre existirán".

Respecto de la pregunta 6 ¿De quién/es es la responsabilidad de impartir la educación para todos los habitantes en Argentina?, entre responsables de adolescentes y de adultos, el "Estado Nacional" fue la opción elegida con el 85,23\% entre los primeros y el 95,35\% entre 
los adultos. Las restantes opciones originaron porcentajes de adhesión muy inferiores en ambos casos.

En cuanto a la pregunta 7 ¿Dónde está reconocido el derecho a la educación?, las opciones "En la Constitución Nacional" (el 65,10\%) y "En uno o más Tratados Internacionales de Derechos Humanos con jerarquía constitucional" (el 22,82\%) fueron elegidas por los responsables de egresados adolescentes. Entre los de egresados adultos, "En la Constitución Nacional" fue elegida por el 69,77\% y "En una Ley Nacional” logró el 27,91\%. Las demás opciones lograron porcentajes menores de adhesión.

Ante la pregunta 8 ¿Cómo evalúa la calidad educativa desde el retorno de la democracia (1983) hasta hoy?, el 33,55\% de los responsables de adolescentes eligió la opción "Buena" y el 30,20\% la opción "Regular". Entre responsables de adultos las elecciones fueron 39,53\% para "Buena" y 18,60\% para "Regular". En ambos casos, las demás opciones alcanzaron porcentajes significativamente inferiores.

Respecto de todo lo expresado supra, véanse los Cuadros 7.a, 7.b, 8.a, 8.b, 9.a, 9.b, 10.a, 10.b, 11.a, 11.b, 12.a, 12.b y sus Gráficos 9, 10, 11.a, 11.b, 12.a, 12.b, 13, 14, 15, 16, 17, 18, 19 y 20 correspondientes: 
Cuadro 7.a

ADOLESCENTES

\begin{tabular}{|c|c|c|c|c|}
\hline Opciones & \multicolumn{4}{|c|}{ lé fuente se vale para adquirir la información y el conocimiento? } \\
\hline La familia & 24 & 37 & 5 & $66(44,29 \%)$ \\
\hline Los amigos & 8 & 11 & 2 & $21(14,09 \%)$ \\
\hline Internet & 34 & 54 & 4 & $92(61,74 \%)$ \\
\hline La radio, la televisión & 28 & 36 & 0 & $64(42,95 \%)$ \\
\hline El cine, el teatro & 2 & 6 & 0 & $8(5,37 \%)$ \\
\hline Otra/s (especificar) & 0 & 2 & 0 & $2(1,34 \%)$ \\
\hline
\end{tabular}

Gráfico 9: Porcentajes Totales

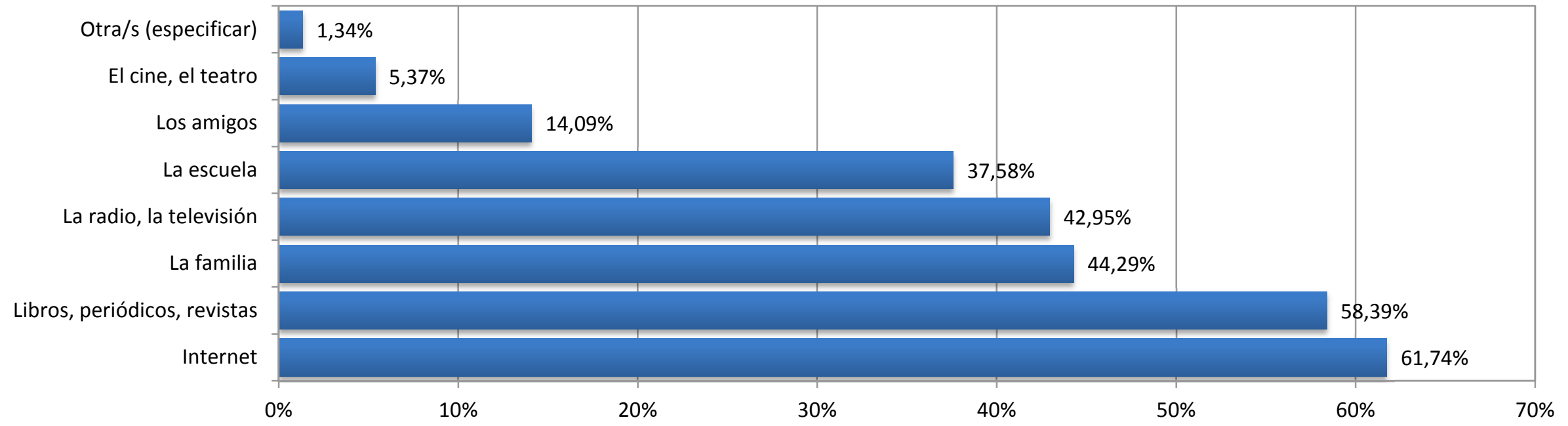




\begin{tabular}{|c|c|c|c|c|}
\hline Cuadro 7.b & \multicolumn{2}{|c|}{ ADULTOS } & ra adquirir la & n y el conocimiento? \\
\hline La familia & 9 & 15 & 1 & $25(58,13 \%)$ \\
\hline La escuela & 10 & 13 & 1 & $24(55,81 \%)$ \\
\hline Los amigos & 3 & 4 & 0 & $7(16,28 \%)$ \\
\hline Libros, periódicos, revistas & 5 & 12 & 0 & $17(39,53 \%)$ \\
\hline La radio, la televisión & 5 & 14 & 0 & $19(44,19 \%)$ \\
\hline El cine, el teatro & 0 & 0 & 0 & $0(0 \%)$ \\
\hline Otra/s (especificar) & 0 & 0 & 0 & $0(0 \%)$ \\
\hline
\end{tabular}

\section{Gráfico 10: Porcentajes Totales}

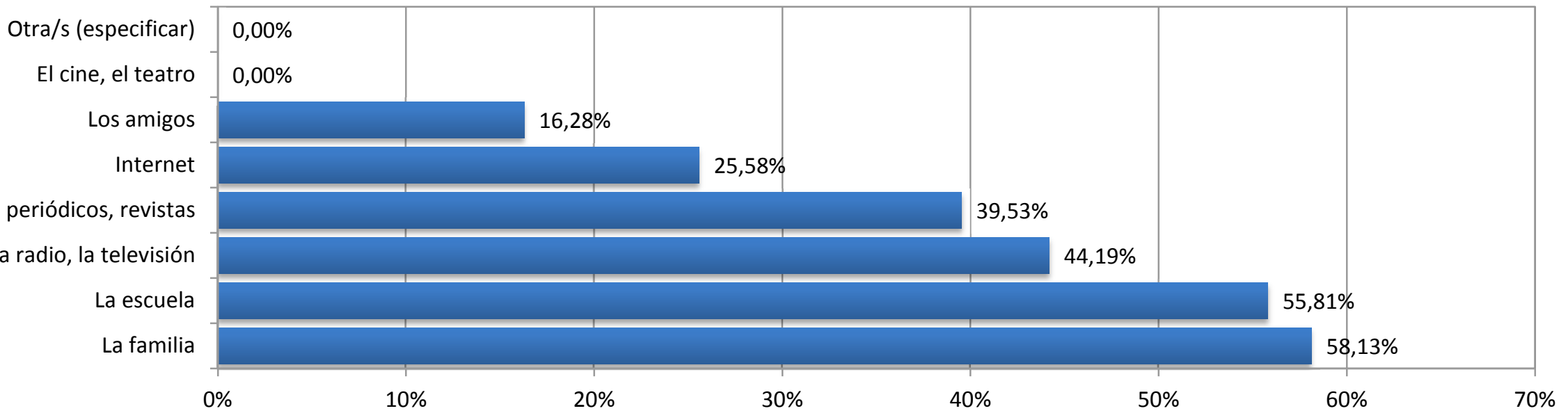




\section{ADOLESCENTES}

Cuadro 8.a Pregunta 5.a: ¿A qué atribuye fenómenos como el alcoholismo, la delincuencia, la drogadicción y la prostitución en el Distrito de Junín?

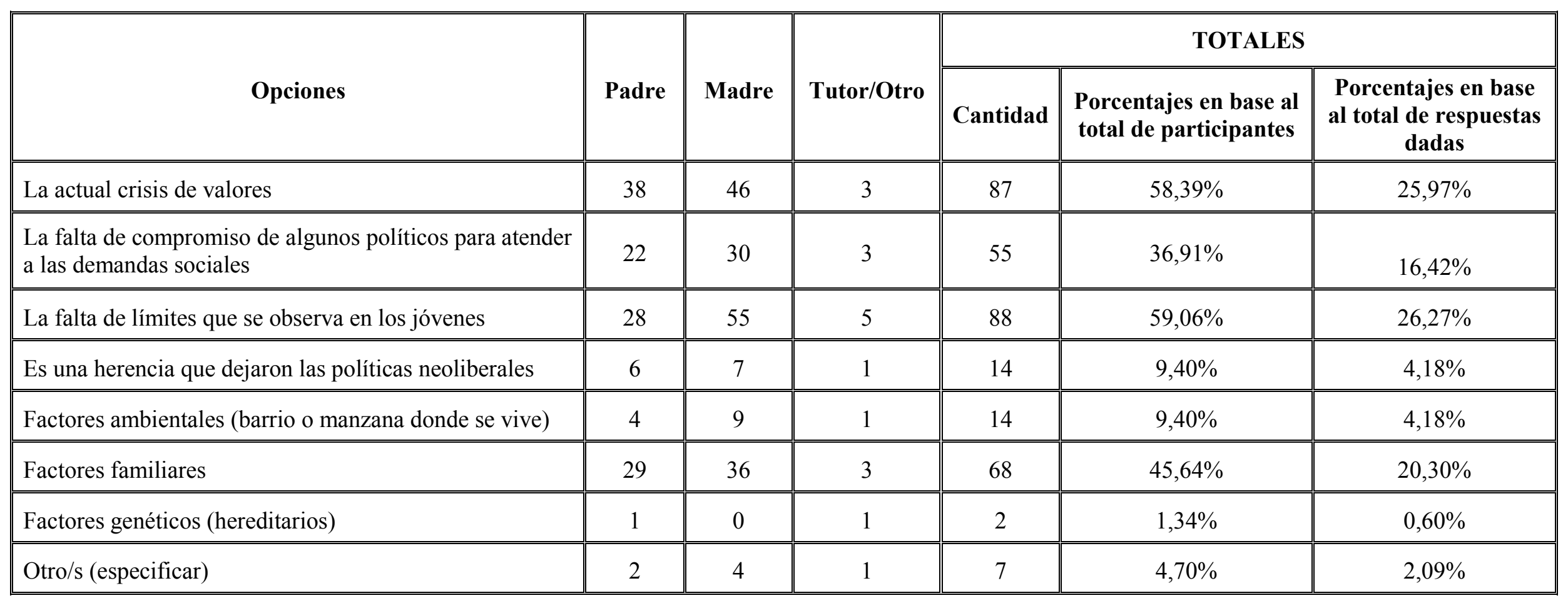




\section{Gráfico 11.a: Porcentajes en base al total de participantes}

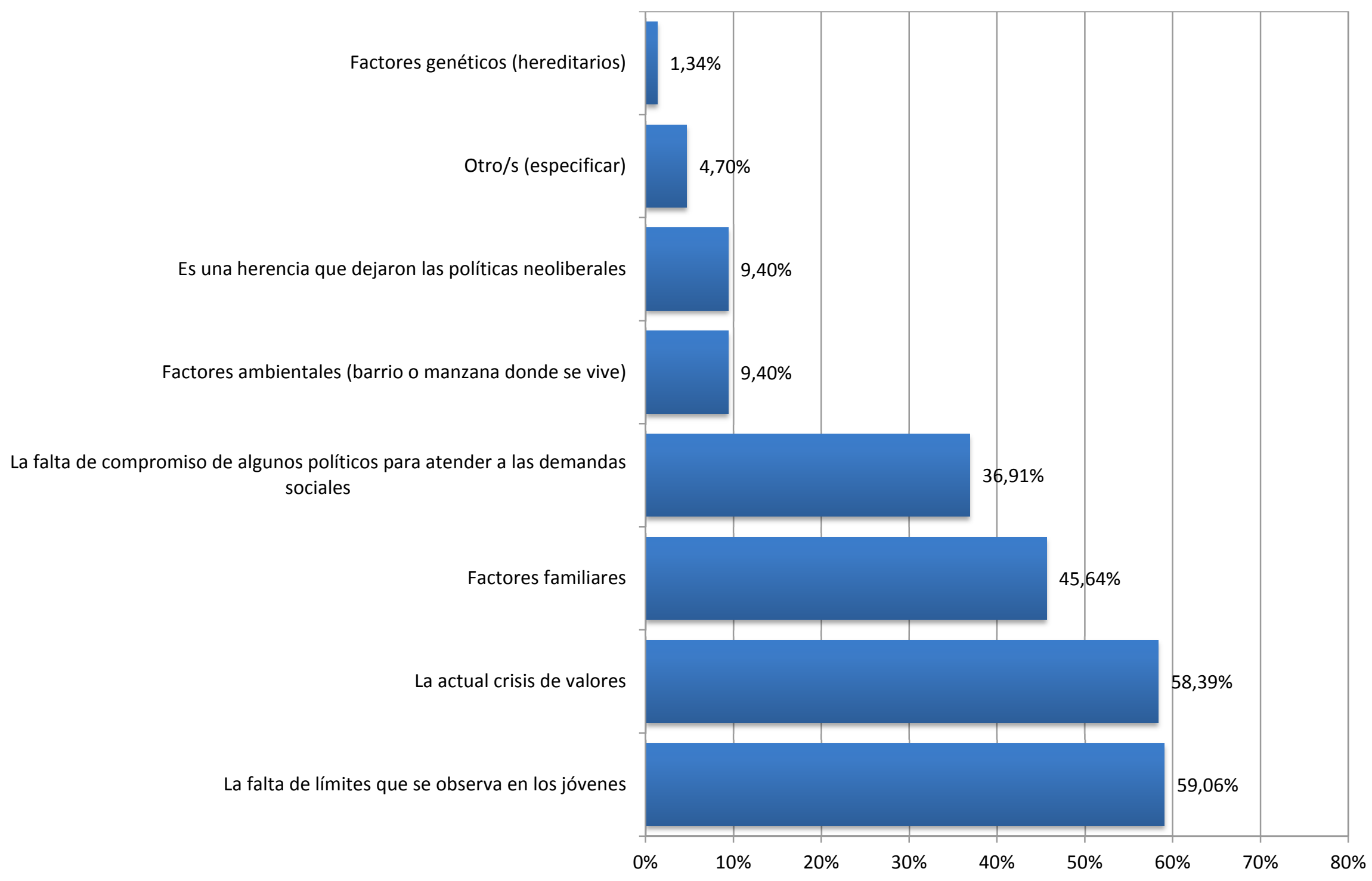




\section{Gráfico 11.b: Porcentajes en base al total de respuestas dadas}

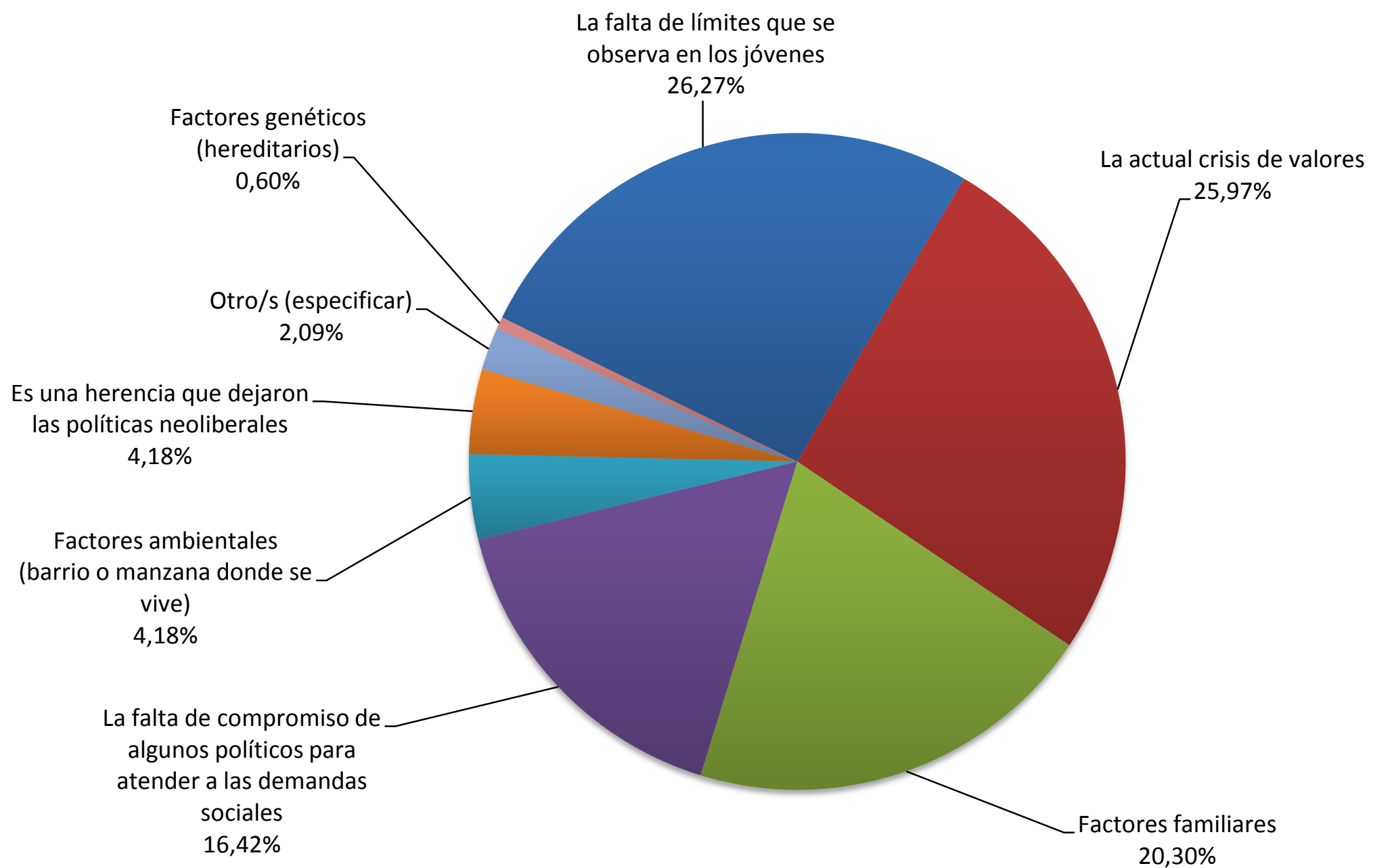




\section{ADULTOS}

Cuadro 8.b Pregunta 5.a: ¿A qué atribuye fenómenos como el alcoholismo, la delincuencia, la drogadicción y la prostitución en el Distrito de Junín?

\begin{tabular}{|c|c|c|c|c|c|c|}
\hline \multirow[b]{2}{*}{ Opciones } & \multirow[b]{2}{*}{ Padre } & \multirow[b]{2}{*}{ Madre } & \multirow[b]{2}{*}{ Tutor/Otro } & \multicolumn{3}{|c|}{ TOTALES } \\
\hline & & & & Cantidad & $\begin{array}{c}\text { Porcentajes en base } \\
\text { al total de } \\
\text { participantes }\end{array}$ & $\begin{array}{l}\text { Porcentajes en base } \\
\text { al total de respuestas } \\
\text { dadas }\end{array}$ \\
\hline La actual crisis de valores & 5 & 11 & 1 & 17 & $39,53 \%$ & $19,10 \%$ \\
\hline $\begin{array}{l}\text { La falta de compromiso de algunos políticos para atender } \\
\text { a las demandas sociales }\end{array}$ & 2 & 5 & 0 & 7 & $16,28 \%$ & $7,87 \%$ \\
\hline La falta de límites que se observa en los jóvenes & 9 & 17 & 0 & 26 & $60,47 \%$ & $29,21 \%$ \\
\hline Es una herencia que dejaron las políticas neoliberales & 1 & 2 & 0 & 3 & $6,98 \%$ & $3,37 \%$ \\
\hline Factores ambientales (barrio o manzana donde se vive) & 2 & 5 & 0 & 7 & $16,28 \%$ & $7,87 \%$ \\
\hline Factores familiares & 10 & 18 & 1 & 29 & $67,44 \%$ & $32,58 \%$ \\
\hline
\end{tabular}




\section{Gráfico 12.a: Porcentajes en base al total de participantes}

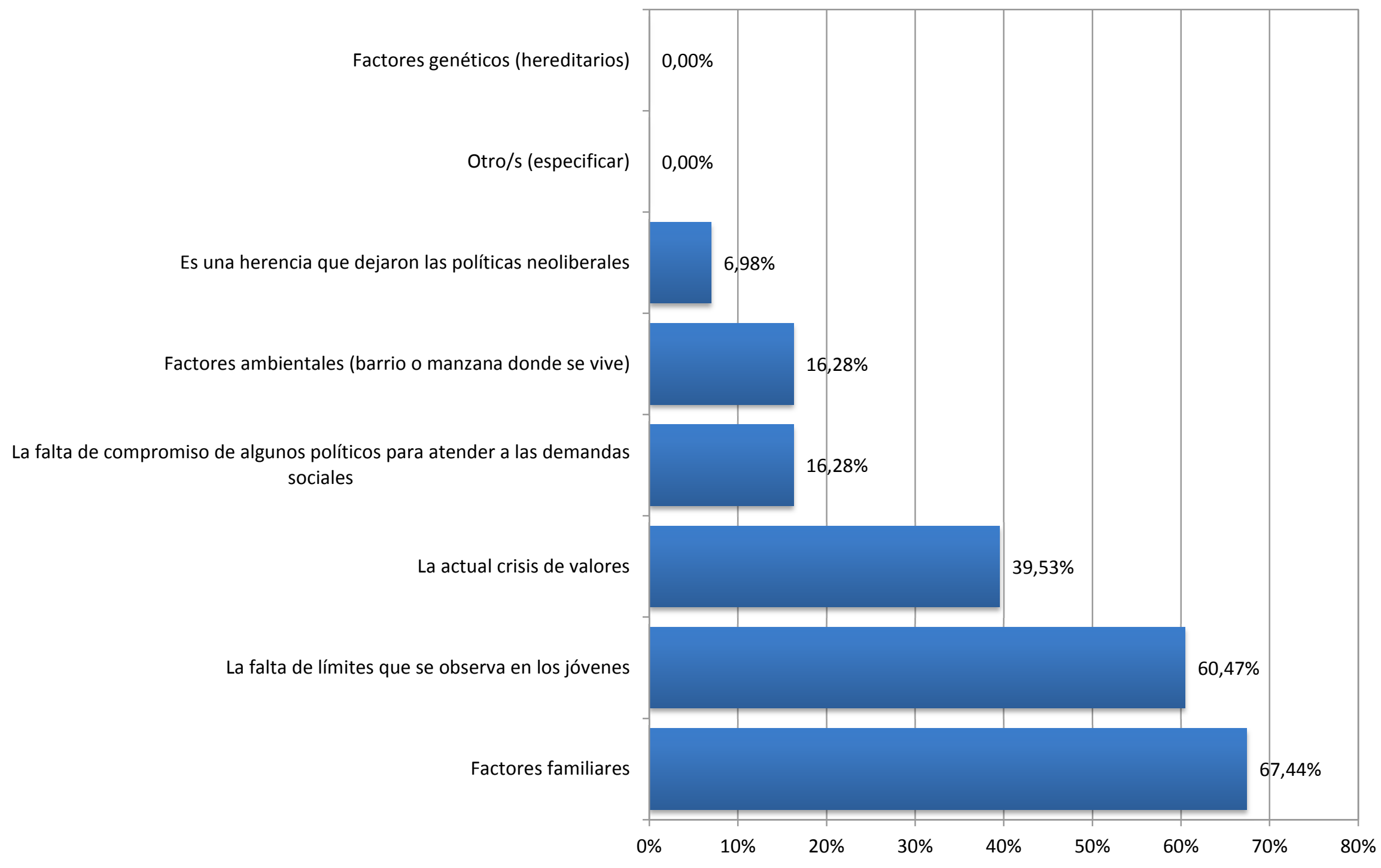




\section{Gráfico 12.b: Porcentajes en base al total de respuestas dadas}

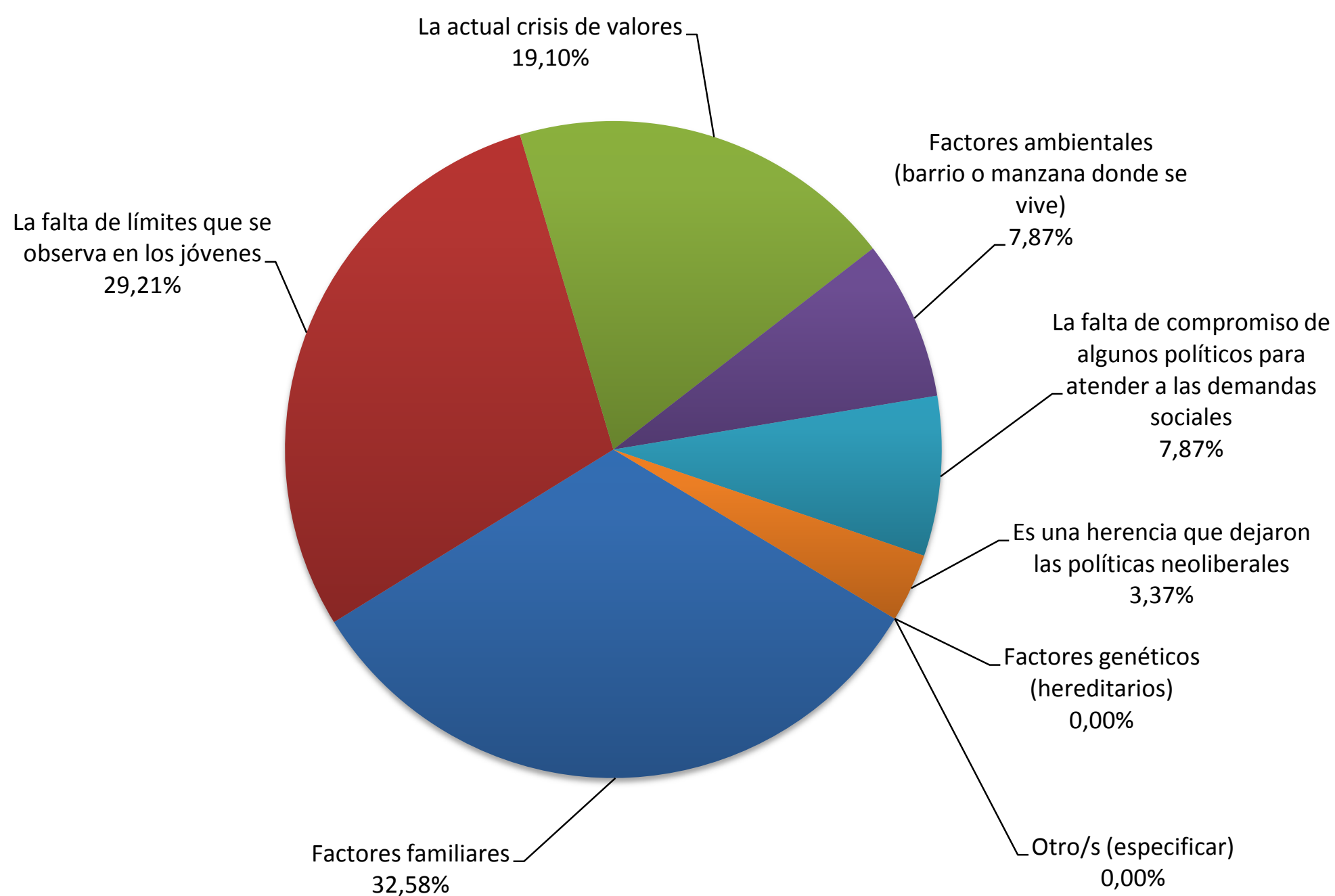




\section{ADOLESCENTES}

\section{Cuadro 9.a}

\begin{tabular}{|c|c|c|c|c|}
\hline Opciones & Padre & Madre & Tutor/Otro & TOTALES \\
\hline Sí. A través de una mejor calidad educativa & 31 & 48 & 5 & $84(56,38 \%)$ \\
\hline Sí. A través de un mejor servicio policial & 19 & 22 & 3 & $44(29,53 \%)$ \\
\hline Sí. A través de un mejor servicio de justicia & 27 & 38 & 4 & $69(46,31 \%)$ \\
\hline Sí. Desarrollando todos nosotros la capacidad de vivir juntos & 10 & 28 & 0 & $38(25,50 \%)$ \\
\hline No. Estos flagelos existieron siempre y siempre existirán & 2 & 3 & 1 & $6(4,03 \%)$ \\
\hline Otro/s (especificar) & 1 & 2 & 0 & $3(2,01 \%)$ \\
\hline
\end{tabular}

Pregunta 5.b: ¿Se puede cambiar esta realidad? 


\section{Gráfico 13: Porcentajes Totales}

No. Estos flagelos existieron siempre y siempre existirá

Sí. Desarrollando todos nosotros la capacidad de vivir juntos

Sí. A través de un mejor servicio policial

Sí. Cuando algunos políticos piensen más en los problemas de la gente

Sí. A través de políticas sociales de prevención

Sí. A través de un mejor servicio de justicia

Sí. A través de una mejor calidad educativa

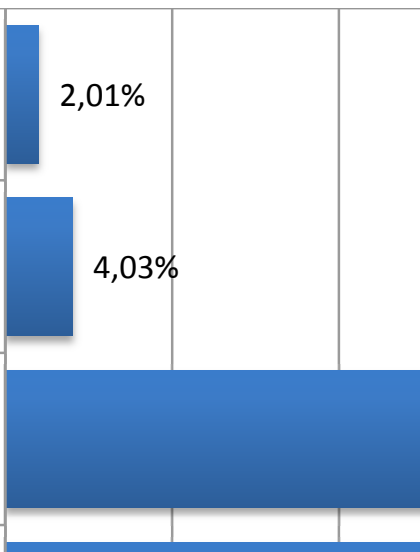

$25,50 \%$

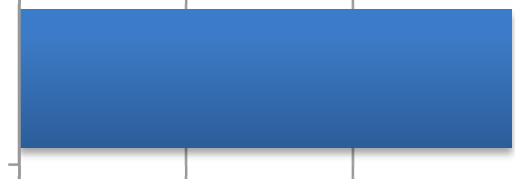

$29,53 \%$
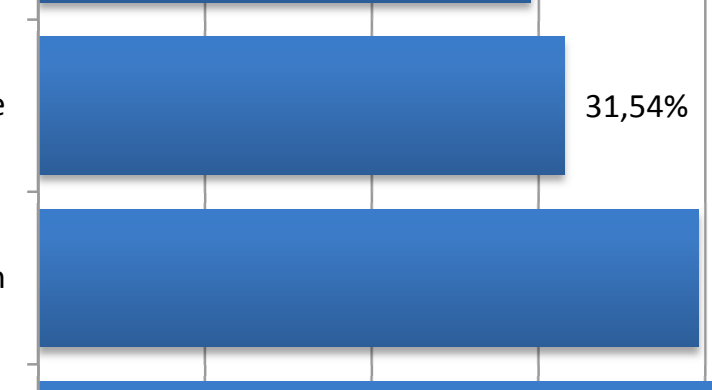

$39,60 \%$

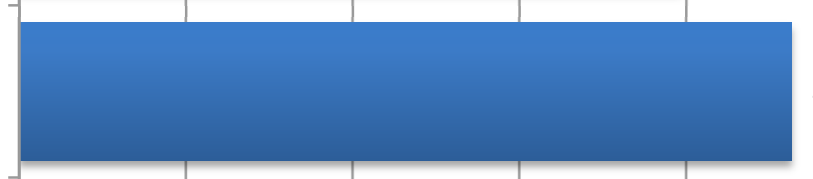

$46,31 \%$

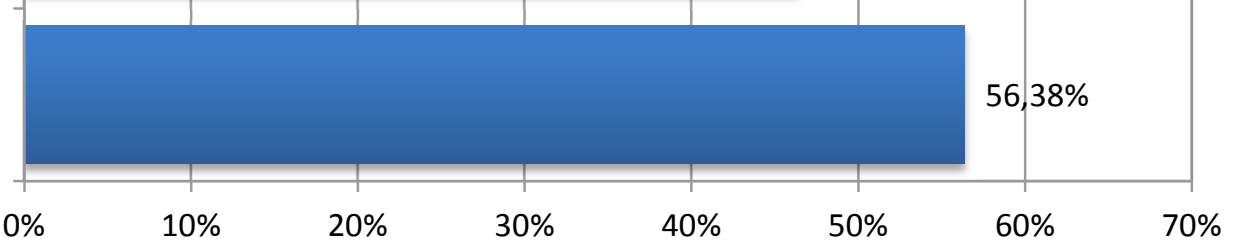




\section{ADULTOS}

\section{Cuadro 9.b}

\begin{tabular}{|c|c|c|c|c|}
\hline Opciones & Padre & Madre & Tutor/Otro & TOTALES \\
\hline Sí. A través de una mejor calidad educativa & 10 & 17 & 1 & $28(65,12 \%)$ \\
\hline Sí. A través de un mejor servicio policial & 3 & 7 & 0 & $10(23,26 \%)$ \\
\hline Sí. A través de un mejor servicio de justicia & 7 & 11 & 0 & $18(41,86 \%)$ \\
\hline Sí. Desarrollando todos nosotros la capacidad de vivir juntos & 0 & 5 & 0 & $5(11,63 \%)$ \\
\hline No. Estos flagelos existieron siempre y siempre existirán & 2 & 4 & 0 & $6(13,95 \%)$ \\
\hline Otro/s (especificar) & 0 & 0 & 0 & $0(0 \%)$ \\
\hline
\end{tabular}

Pregunta 5.b: ¿Se puede cambiar esta realidad? 


\section{Gráfico 14: Porcentajes Totales}

Sí. Desarrollando todos nosotros la capacidad de vivir juntos

No. Estos flagelos existieron siempre y siempre existirán

Sí. A través de un mejor servicio policial

Sí. Cuando algunos políticos piensen más en los problemas de la gente
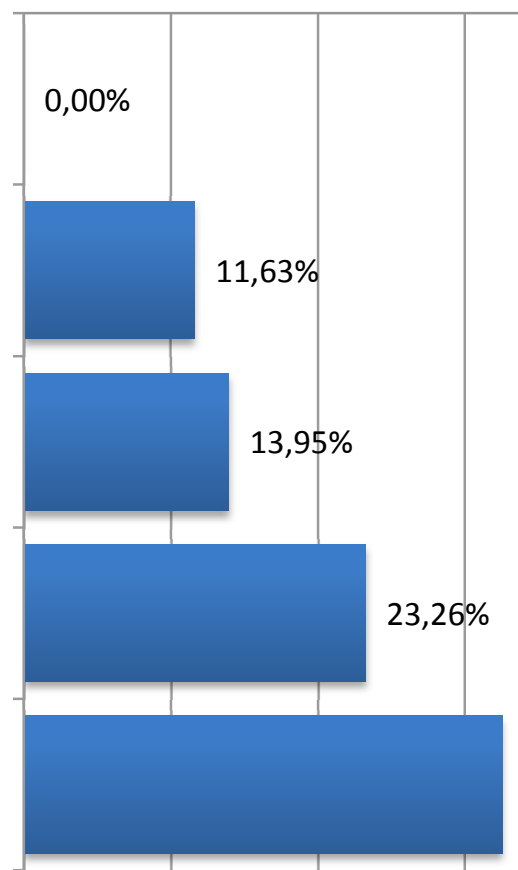

$32,56 \%$

Sí. A través de un mejor servicio de justicia

Sí. A través de políticas sociales de prevención

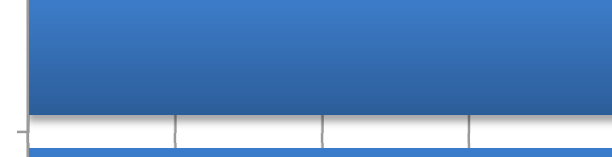

$41,86 \%$
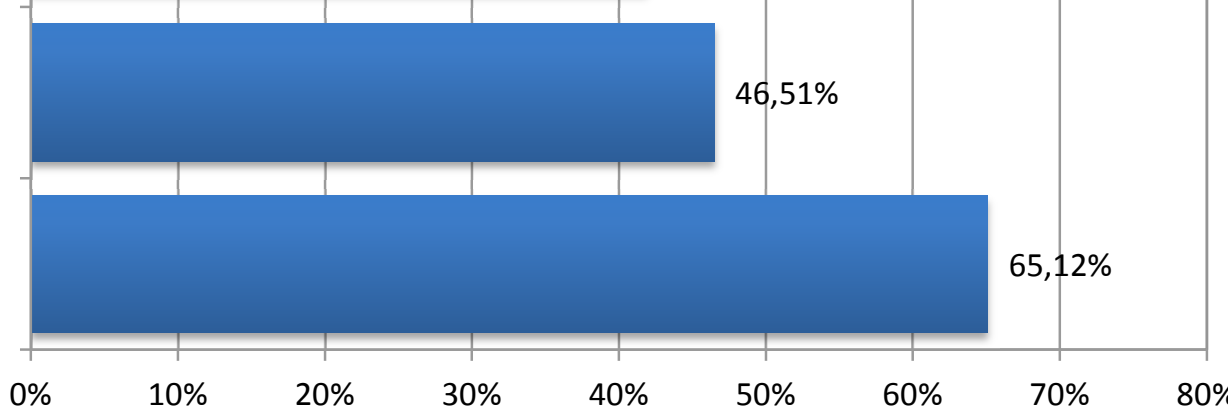
ADOLESCENTES

Cuadro 10.a

Pregunta 6: ¿De quién/es es la responsabilidad de impartir la educación para todos los habitantes en Argentina?

\begin{tabular}{|c|c|c|c|c|}
\hline Opciones & Padre & Madre & Tutor/Otro & TOTALES \\
\hline Del Estado Nacional & 47 & 77 & 3 & $127(85,23 \%)$ \\
\hline De las escuelas privadas & 0 & 0 & 0 & $0(0 \%)$ \\
\hline De las provincias & 8 & 10 & 2 & $20(13,42 \%)$ \\
\hline De las municipalidades & 2 & 7 & 1 & $10(6,71 \%)$ \\
\hline De los gremios & 1 & 4 & 1 & $6(4,03 \%)$ \\
\hline De las organizaciones no gubernamentales & 1 & 2 & 0 & $3(2,01 \%)$ \\
\hline De las sociedades de fomento & 0 & 1 & 0 & $1(0,67 \%)$ \\
\hline Otro/s (especificar) & 2 & 3 & 0 & $5(3,36 \%)$ \\
\hline
\end{tabular}

\section{Gráfico 15: Porcentajes Totales}

De las sociedades de fomento

De las organizaciones no gubernamentales

Otro/s (especificar)

De los gremios

De las municipalidade

De las provincias

Del Estado Nacional

\begin{tabular}{|c}
\hline $0,00 \%$ \\
$0,67 \%$ \\
$2,01 \%$ \\
$3,36 \%$ \\
$4,03 \%$ \\
\hline
\end{tabular}

\section{(1)}

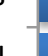


ADULTOS

Pregunta 6: ¿De quién/es es la responsabilidad de impartir la educación para todos los habitantes en Argentina?

\begin{tabular}{|c|c|c|c|c|}
\hline Opciones & Padre & Madre & Tutor/Otro & TOTALES \\
\hline Del Estado Nacional & 15 & 25 & 1 & $41(95,35 \%)$ \\
\hline De las escuelas privadas & 1 & 2 & 0 & $3(6,98 \%)$ \\
\hline De las provincias & 2 & 4 & 0 & $6(13,95 \%)$ \\
\hline De las municipalidades & 2 & 2 & 0 & $4(9,30 \%)$ \\
\hline De los gremios & 0 & 0 & 0 & $0(0 \%)$ \\
\hline De las organizaciones no gubernamentales & 0 & 0 & 0 & $0(0 \%)$ \\
\hline De las sociedades de fomento & 1 & 1 & 0 & $2(4,65 \%)$ \\
\hline Otro/s (especificar) & 1 & 1 & 0 & $2(4,65 \%)$ \\
\hline
\end{tabular}

Gráfico 16: Porcentajes Totales

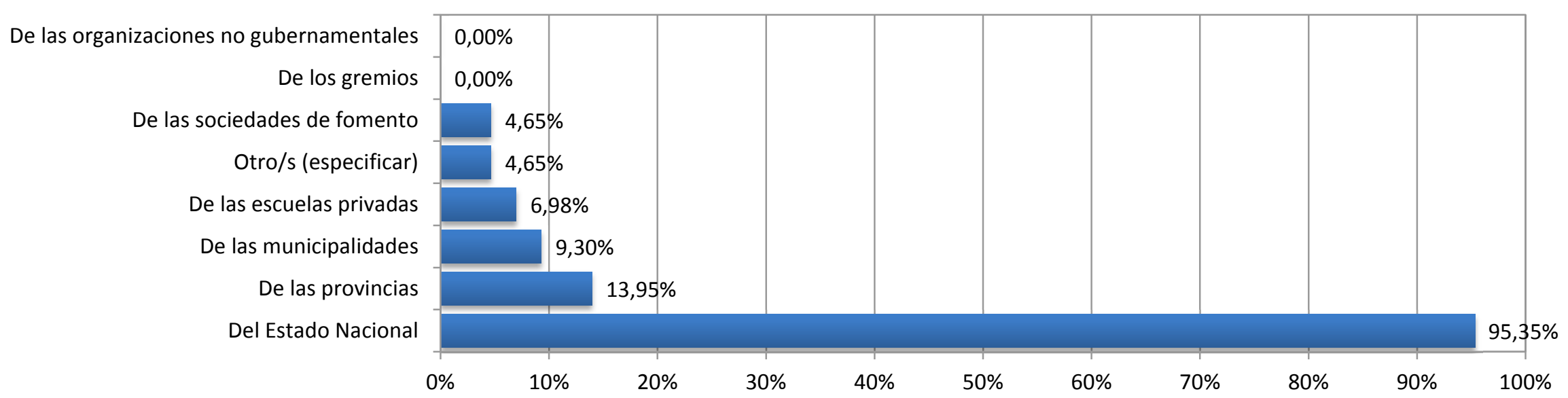


ADOLESCENTES

\section{Cuadro 11.a}

\begin{tabular}{|c|c|c|c|c|}
\hline Opciones & Padre & Madre & Tutor/Otro & TOTALES \\
\hline En la Constitución Nacional & 43 & 51 & 3 & $97(65,10 \%)$ \\
\hline $\begin{array}{l}\text { En uno o más Tratados Internacionales de Derechos Humanos con jerarquía } \\
\text { constitucional }\end{array}$ & 11 & 22 & 1 & $34(22,82 \%)$ \\
\hline En una Ley Nacional & 6 & 5 & 0 & $11(7,38 \%)$ \\
\hline En la Constitución de la Provincia de Buenos Aires & 10 & 17 & 1 & $28(18,79 \%)$ \\
\hline En una Ley de la Provincia de Buenos Aires & 2 & 8 & 0 & $10(6,71 \%)$ \\
\hline En una Ordenanza Municipal del Partido de Junín & 1 & 1 & 0 & $2(1,34 \%)$ \\
\hline En todo lo anteriormente dicho & 2 & 4 & 0 & $6(4,03 \%)$ \\
\hline En nada de lo anteriormente dicho & 0 & 0 & 1 & $1(0,67 \%)$ \\
\hline Otro/s (especificar) & 1 & 3 & 0 & $4(2,68 \%)$ \\
\hline
\end{tabular}




\section{Gráfico 17: Porcentajes Totales}

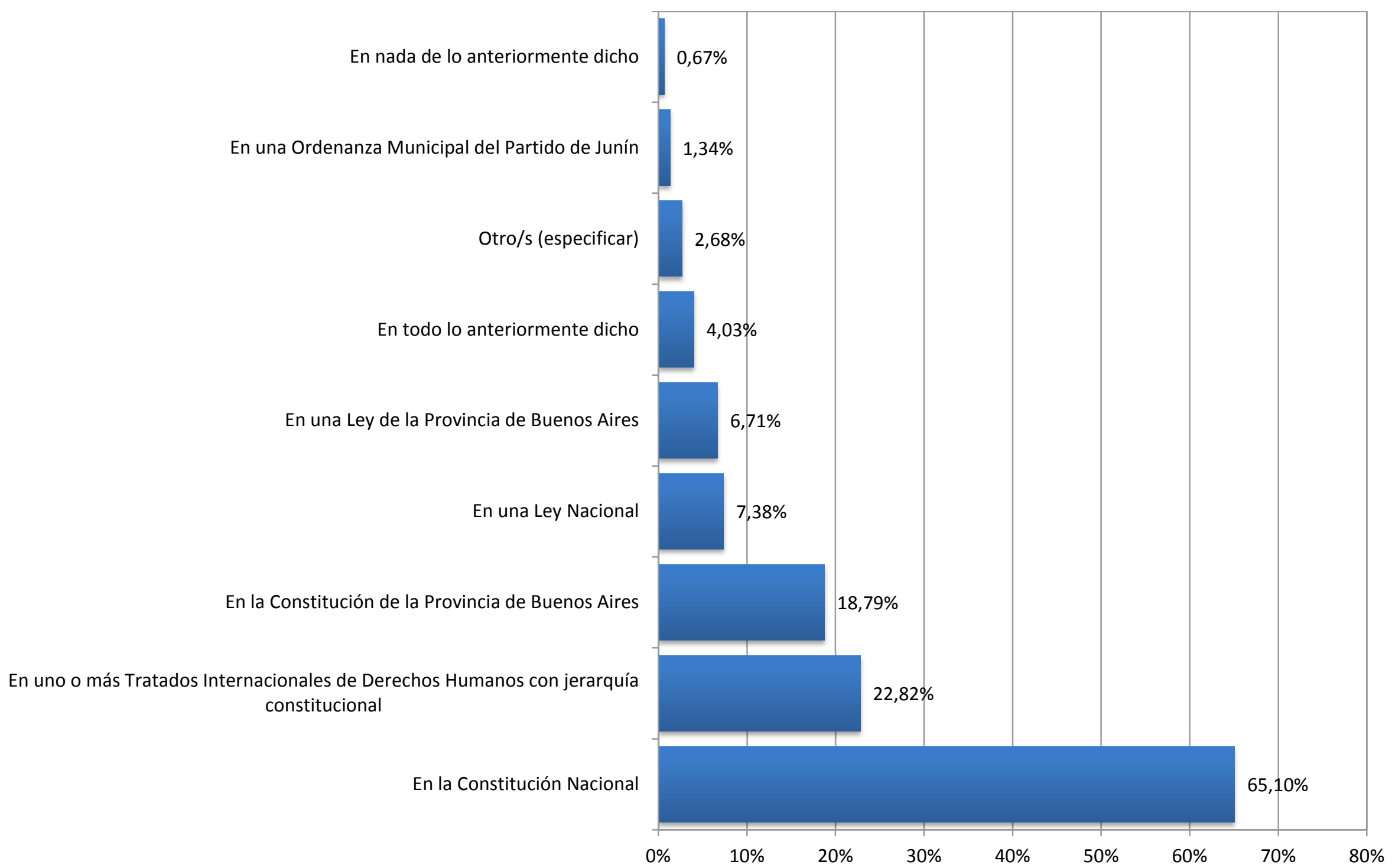




\section{ADULTOS}

\section{Cuadro 11.b}

\begin{tabular}{|c|c|c|c|c|}
\hline Opciones & Padre & Madre & Tutor/Otro & TOTALES \\
\hline En la Constitución Nacional & 13 & 16 & 1 & $30(69,77 \%)$ \\
\hline $\begin{array}{l}\text { En uno o más Tratados Internacionales de Derechos Humanos con jerarquía } \\
\text { constitucional }\end{array}$ & 3 & 6 & 0 & $9(20,93 \%)$ \\
\hline En una Ley Nacional & 3 & 9 & 0 & $12(27,91 \%)$ \\
\hline En la Constitución de la Provincia de Buenos Aires & 2 & 7 & 0 & $9(20,93 \%)$ \\
\hline En una Ley de la Provincia de Buenos Aires & 1 & 4 & 0 & $5(11,63 \%)$ \\
\hline En una Ordenanza Municipal del Partido de Junín & 0 & 1 & 0 & $1(2,33 \%)$ \\
\hline En todo lo anteriormente dicho & 3 & 5 & 0 & $8(18,60 \%)$ \\
\hline En nada de lo anteriormente dicho & 0 & 0 & 0 & $0(0 \%)$ \\
\hline Otro/s (especificar) & 0 & 1 & 0 & $1(2,33 \%)$ \\
\hline
\end{tabular}




\section{Gráfico 18: Porcentajes Totales}

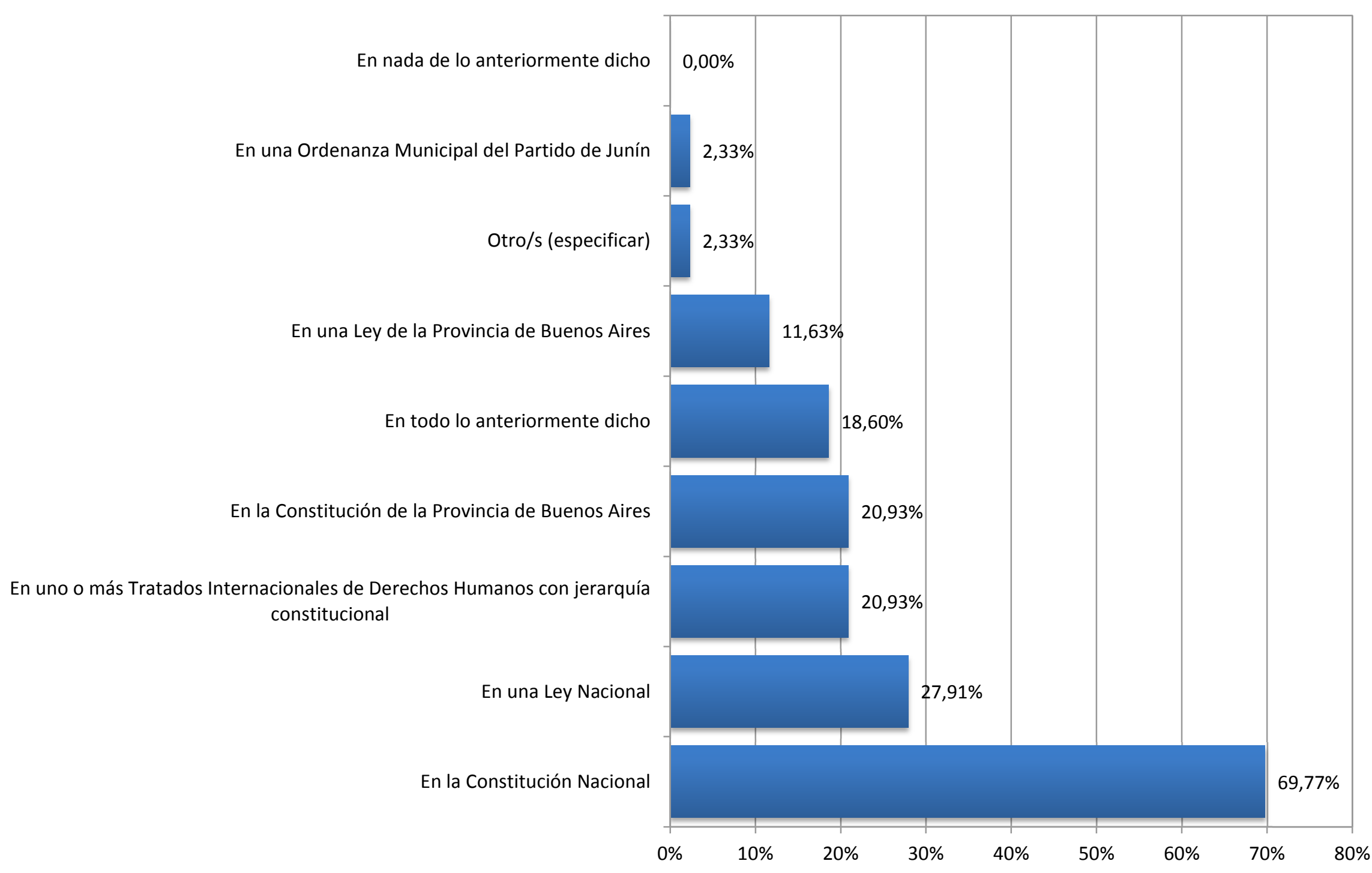


ADOLESCENTES

Cuadro 12.a

Pregunta 8: ¿Cómo evalúa la calidad educativa desde el retorno de la democracia (1983) hasta hoy?

\begin{tabular}{|c|c|c|c|c|}
\hline Opciones & Padre & Madre & Tutor/Otro & TOTALES \\
\hline Excelente & 0 & 0 & 0 & $0(0 \%)$ \\
\hline Muy buena & 5 & 15 & 0 & $20(13,42 \%)$ \\
\hline Buena & 20 & 29 & 1 & $50(33,55 \%)$ \\
\hline Indeciso/a & 2 & 7 & 1 & $10(6,71 \%)$ \\
\hline Mala & 6 & 8 & 0 & $14(9,40 \%)$ \\
\hline Muy mala & 2 & 2 & 0 & $4(2,68 \%)$ \\
\hline Otra/s (especificar) & 3 & 4 & 0 & $7(4,70 \%)$ \\
\hline
\end{tabular}


Gráfico 19: Porcentajes Totales

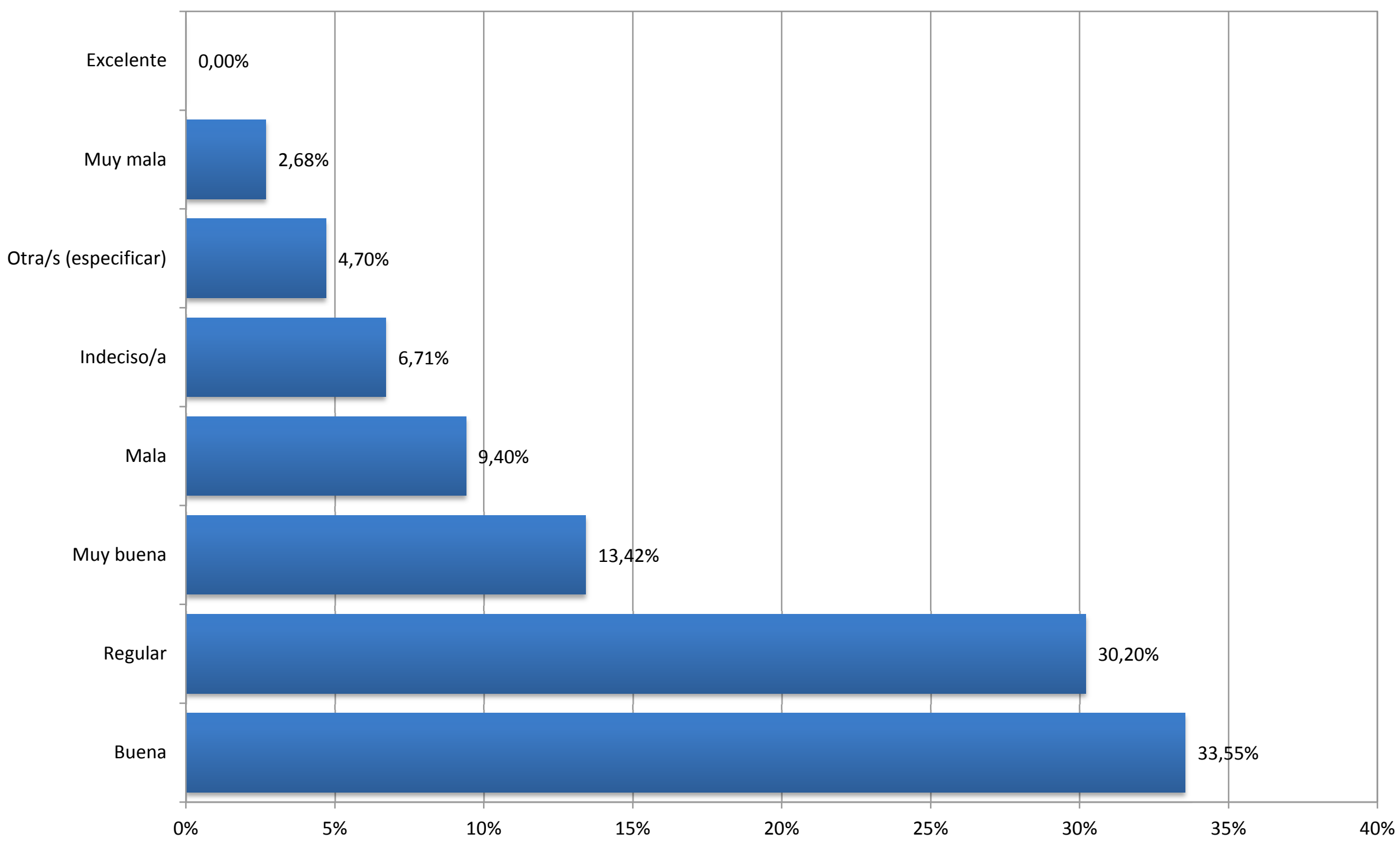


ADULTOS

Cuadro 12.b

Pregunta 8: ¿Cómo evalúa la calidad educativa desde el retorno de la democracia (1983) hasta hoy?

\begin{tabular}{|c|c|c|c|c|}
\hline Opciones & Padre & Madre & Tutor/Otro & TOTALES \\
\hline Muy buena & 1 & 2 & 0 & $3(6,98 \%)$ \\
\hline Buena & 7 & 10 & 0 & $17(39,53 \%)$ \\
\hline Indeciso/a & 3 & 4 & 0 & $7(16,28 \%)$ \\
\hline Mala & 0 & 2 & 0 & $2(4,65 \%)$ \\
\hline Muy mala & 0 & 1 & 1 & $2(4,65 \%)$ \\
\hline Otra/s (especificar) & 0 & 0 & 0 & $0(0 \%)$ \\
\hline
\end{tabular}




\section{Gráfico 20: Porcentajes Totales}

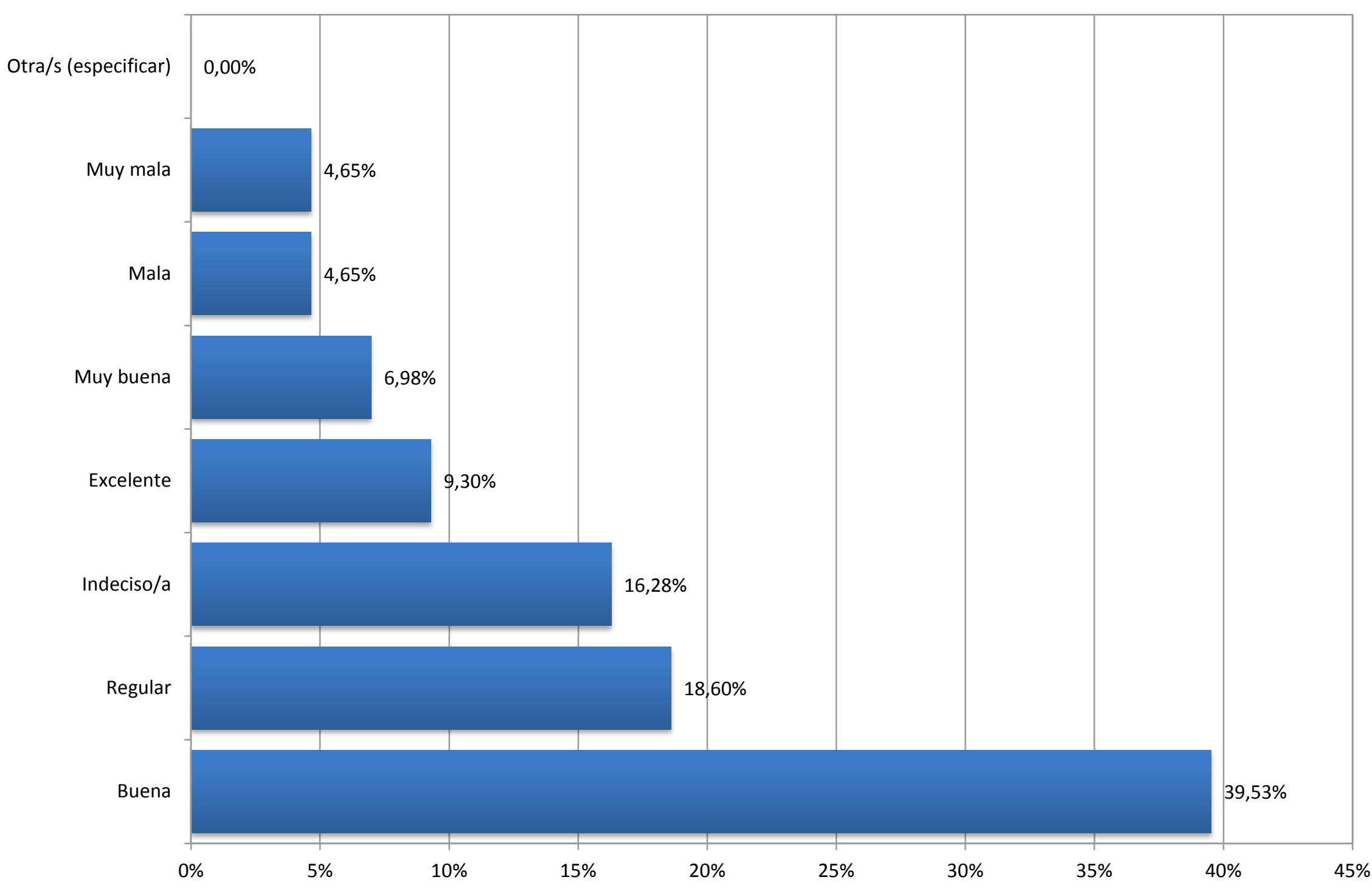




\subsubsection{Determinantes del status}

La pregunta 9 referida al tema de la comunicación entre padres e hijos observó estos resultados: en responsables de adolescentes, el 52,35\% eligió la opción "A veces fácil, a veces difícil”. Entre los responsables de adultos la misma opción tuvo el 53,49\%. Las demás fueron elegidas minoritariamente, tanto en unos como en otros. Téngase presente que la edad promedio de los adolescentes es 17 años y 5 meses, mientras que en los adultos es 22 años y 7 meses, en ambos casos en referencia a los egresados 2010 del nivel medio de escuelas estatales del Distrito de Junín.

En relación a quién eligió la escuela a la que asiste el/la egresado/a (pregunta 10.a), estos fueron los resultados: en adolescentes, las madres (con el 40,26\%) eligieron las escuelas a que asisten sus hijos. En porcentajes significativamente inferiores están las elecciones realizadas por los hijos y por los padres, en ese orden. En adultos, los egresados que eligieron la escuela en la que estudian representaron el 58,13\%. Las madres y los padres continúan, respectivamente, en el orden descendente de elecciones.

Ante la pregunta $10 . \mathrm{b}$ referida al motivo por el cual se eligió tal escuela, el 35,57\% de los responsables de adolescentes eligió la opción "Está ubicada cerca de mi/nuestra casa". Siguen en orden decreciente las opciones "Nos comentaron que es muy buena escuela" con el 23,49\% y "Porque estamos de acuerdo con el perfil institucional" con el 21,48\%. Entre los responsables de adultos, el 41,86\% eligió la opción "Está ubicada cerca de mi/nuestra casa"; el 27,91\% la opción "Nos comentaron que es muy buena escuela", al tiempo que las opciones "Porque estamos de acuerdo con el perfil institucional" y "Porque egresan capacitados para trabajar" concitaron la adhesión —en ambos casos- del 23,26\%. Las demás opciones —en adolescentes como en adultos- obtuvieron porcentajes inferiores.

La pregunta 11 ¿Qué desea para su hijo/a en el futuro? originó estos guarismos: en adolescentes la opción "Que sea feliz" fue la más elegida (por el 71,81\% de los responsables) y la opción "Que sea una buena persona" tuvo el 64,43\% de las elecciones. "Que sea un buen profesional" y "Que constituya una familia" lograron el 49,66\%. En adultos ese orden no se repitió: la opción "Que sea una buena persona” tuvo el 88,37\%, "Que sea feliz" logró el 79,07\% y "Que constituya una familia” alcanzó el 51,16\%. Entre todos los responsables considerados, las restantes opciones obtuvieron porcentajes menores. Así, la opción "Que gane mucho dinero" fue, entre todos ellos, la menos elegida: $15,44 \%$ y $18,60 \%$, respectivamente.

Con relación a la pregunta 12 referida a la opinión que les merecen los profesores de $3^{\circ}$ Año de su hijo/a, los responsables - tanto de egresados adolescentes como de adultoseligieron la opción "Todos buena" el 23,48\% de aquéllos y el 37,21\% de éstos. En orden decreciente, entre los responsables de adolescentes el 18,79\% eligió la opción "Muchos buena y algunos mala" y el 13,95\% en adultos se inclinó por "Algunos buena y muchos mala". Las 
demás fueron minoritariamente elegidas, en adolescentes como en adultos. Esta realidad podría indicar que se estaría frente a condiciones diferentes de las de hace unas décadas. Son otros sujetos, otros conflictos y otras demandas las que se enfrentan hoy.

Ante la pregunta 13 ¿De qué manera hace conocer a las autoridades de la escuela sus inquietudes/opiniones sobre la marcha de la educación de su hijo/a?, los responsables de adolescentes opinaron "Yendo por mi/nuestra propia decisión a la escuela" (el 38,26\%) y "Cuando soy/somos citado/s desde la escuela por algún motivo" (el 34,22\%). En adultos, el $39,53 \%$ eligió "En las reuniones de padres con los profesores" y el 34,88\% la opción "Yendo por mi/nuestra propia decisión a la escuela". Estos datos permitirían afirmar que las actitudes respecto de la escuela, de la cultura escolar y del futuro ofrecido por los estudios serían, en gran parte, la expresión del sistema de valores - implícitos o explícitos- de la comunidad en la que se vive.

Respecto de todo lo aseverado en este punto, véanse los Cuadros 13.a, 13.b, 14.a, 14.b, 15.a, 15.b, 16.a, 16.b, 17.a, 17.b, 18.a, 18.b y sus Gráficos 21, 22, 23, 24, 25, 26, 27, 28, 29 , 30,31 y 32 correspondientes. 


\begin{tabular}{|c|c|c|c|c|}
\hline Cuadro 13.a & \multicolumn{4}{|c|}{$\begin{array}{l}\text { LESCENTES } \\
\text { Pregunta 9: ¿Cómo es actualmente la comunicación entre padres e hijos? }\end{array}$} \\
\hline Opciones & Padre & Madre & Tutor/Otro & TOTALES \\
\hline Fácil & 13 & 19 & 1 & $33(22,15 \%)$ \\
\hline A veces fácil, a veces difícil & 31 & 46 & 1 & $78(52,35 \%)$ \\
\hline Muy difícil & 1 & 0 & 1 & $2(1,34 \%)$ \\
\hline Otra/s (especificar) & 0 & 8 & 1 & $9(6,04 \%)$ \\
\hline
\end{tabular}

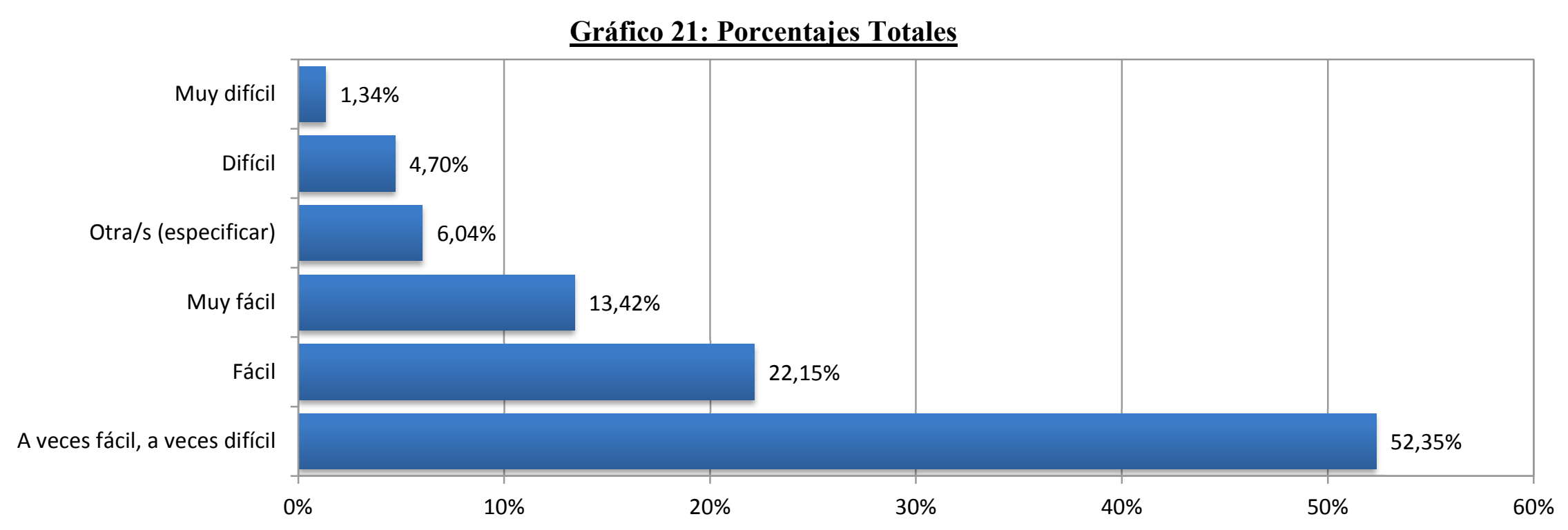


ADULTOS

\begin{tabular}{|c|c|c|c|c|}
\hline Opciones & Padre & Madre & Tutor/Otro & TOTALES \\
\hline Fácil & 0 & 5 & 0 & $5(11,63 \%)$ \\
\hline A veces fácil, a veces difícil & 9 & 14 & 0 & $23(53,49 \%)$ \\
\hline Difícil & 1 & 1 & 1 & $3(6,98 \%)$ \\
\hline Otra/s (especificar) & 0 & 0 & 0 & $0(0 \%)$ \\
\hline
\end{tabular}

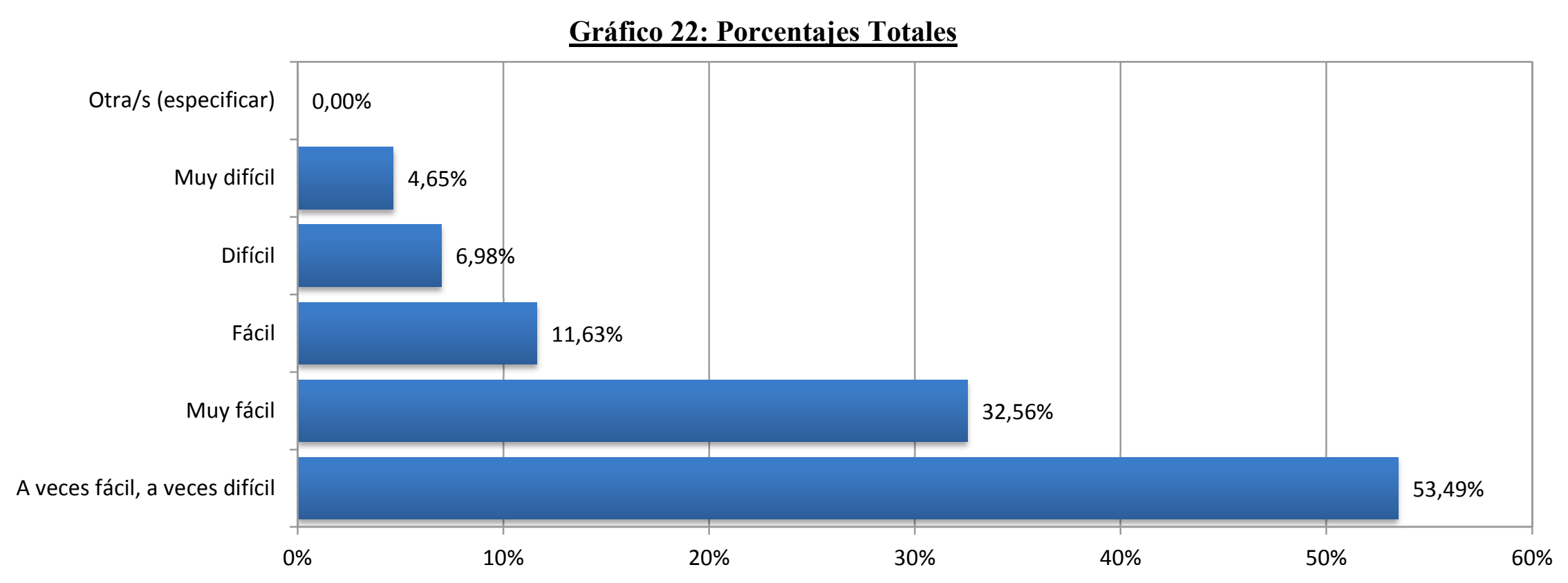


ADOLESCENTES

Cuadro 14.a Pregunta 10.a: ¿Quién eligió la escuela a la que asiste su hijo/a?

\begin{tabular}{|l|c|}
\hline \multicolumn{1}{|c|}{ Opciones } & TOTALES \\
\hline \hline Padre & $40(26,84 \%)$ \\
\hline Madre & $60(40,26 \%)$ \\
\hline Hijo/a & $50(33,55 \%)$ \\
\hline \hline Tutor/Otro & $6(4,02 \%)$ \\
\hline
\end{tabular}

Gráfico 23: Porcentajes Totales

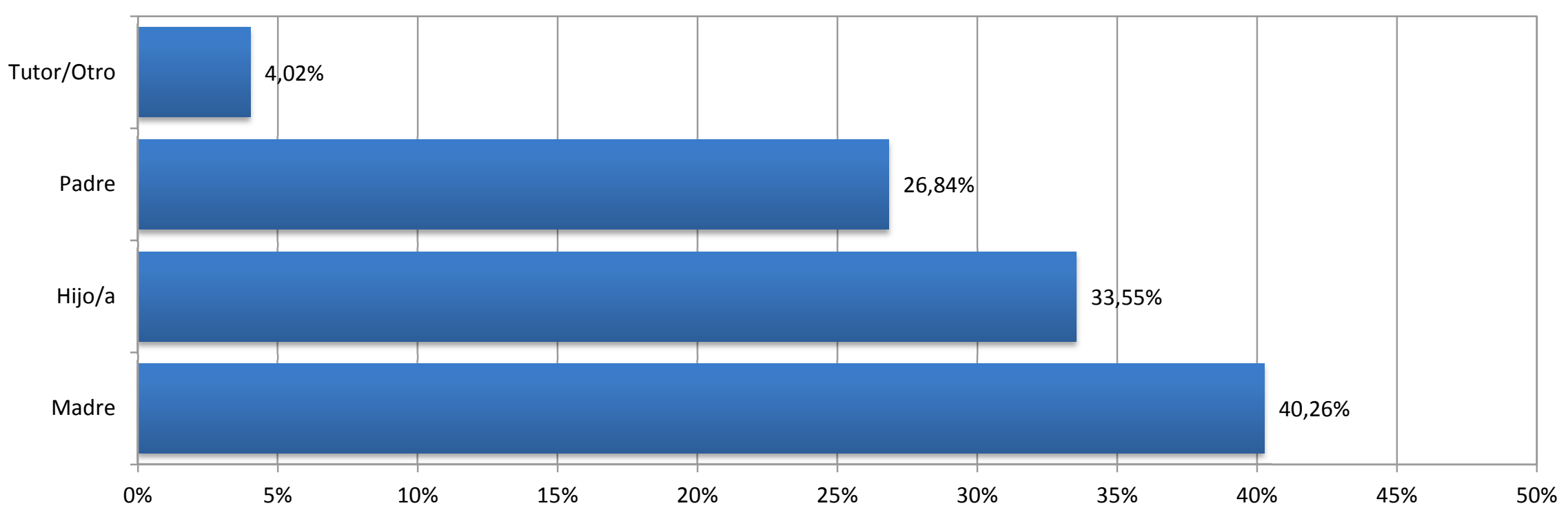




Pregunta 10.a: iQuién eligió la escuela a la que asiste su hijo/a?
\begin{tabular}{|l|c|}
\hline \multicolumn{1}{|c|}{ Opciones } & TOTALES \\
\hline \hline Padre & $5(11,63 \%)$ \\
\hline Madre & $15(34,88 \%)$ \\
\hline Hijo/a & $25(58,13 \%)$ \\
\hline Tutor/Otro & $1(2,33 \%)$ \\
\hline
\end{tabular}

Gráfico 24: Porcentajes Totales

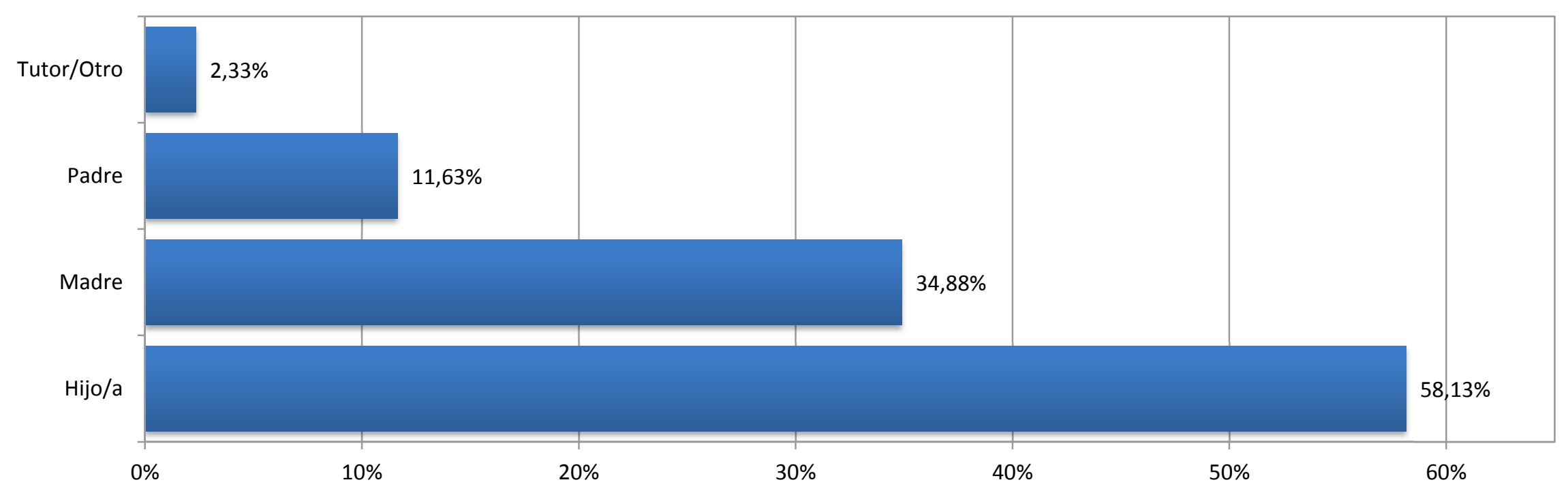


ADOLESCENTES

Cuadro 15.a

Pregunta 10.b: ¿Por qué motivo?

\begin{tabular}{|c|c|c|c|c|c|}
\hline Opciones & Padre & Madre & Hijo/a & Tutor/Otro & TOTALES \\
\hline Nos comentaron que es muy buena escuela & 12 & 21 & 1 & 1 & $35(23,49 \%)$ \\
\hline Porque estamos de acuerdo con el perfil institucional & 13 & 19 & 0 & 0 & $32(21,48 \%)$ \\
\hline Yo estudié en ella & 4 & 12 & 1 & 0 & $17(11,41 \%)$ \\
\hline Otro hijo/a también estudió en ella & 11 & 15 & 1 & 1 & $28(18,79 \%)$ \\
\hline Está ubicada cerca de mi/nuestra casa & 18 & 33 & 1 & 1 & $53(35,57 \%)$ \\
\hline
\end{tabular}




\section{Gráfico 25: Porcentajes Totales}

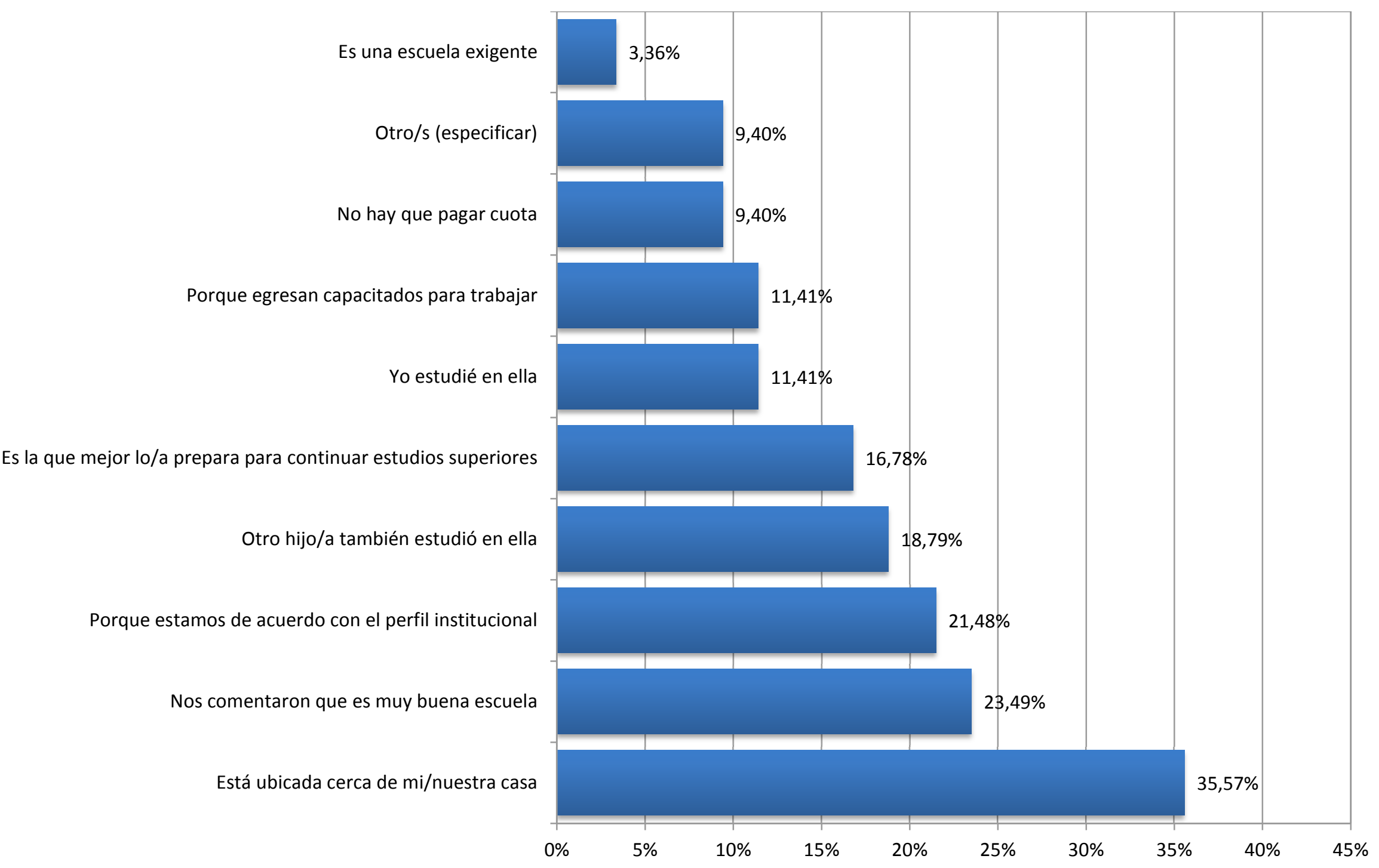




\section{ADULTOS}

\section{Cuadro 15.b}

Pregunta 10.b: ¿Por qué motivo?

\begin{tabular}{|l|c|c|c|c||c||}
\hline \multicolumn{1}{|c|}{ Opciones } & Padre & Madre & Hijo/a & Tutor/Otro & TOTALES \\
\hline $\begin{array}{l}\text { Es la que mejor lo/a prepara para continuar estudios } \\
\text { superiores }\end{array}$ & 1 & 4 & 1 & 1 & $7(16,28 \%)$ \\
\hline \hline Es una escuela exigente & 3 & 2 & 0 & 0 & $5(11,63 \%)$ \\
\hline \hline Nos comentaron que es muy buena escuela & 3 & 9 & 0 & 0 & $12(27,91 \%)$ \\
\hline \hline Porque estamos de acuerdo con el perfil institucional & 2 & 7 & 1 & 0 & $10(23,26 \%)$ \\
\hline Porque egresan capacitados para trabajar & 4 & 5 & 1 & 0 & $10(23,26 \%)$ \\
\hline Yo estudié en ella & 2 & 2 & 0 & 0 & $4(9,30 \%)$ \\
\hline \hline Otro hijo/a también estudió en ella & 2 & 4 & 0 & 0 & $6(13,95 \%)$ \\
\hline \hline Está ubicada cerca de mi/nuestra casa & 5 & 11 & 2 & 0 & $18(41,86 \%)$ \\
\hline No hay que pagar cuota & 0 & 1 & 0 & 0 & $1(2,33 \%)$ \\
\hline Otro/s (especificar) & 3 & 2 & 0 & 0 & $5(11,63 \%)$ \\
\hline
\end{tabular}




\section{Gráfico 26: Porcentajes Totales}

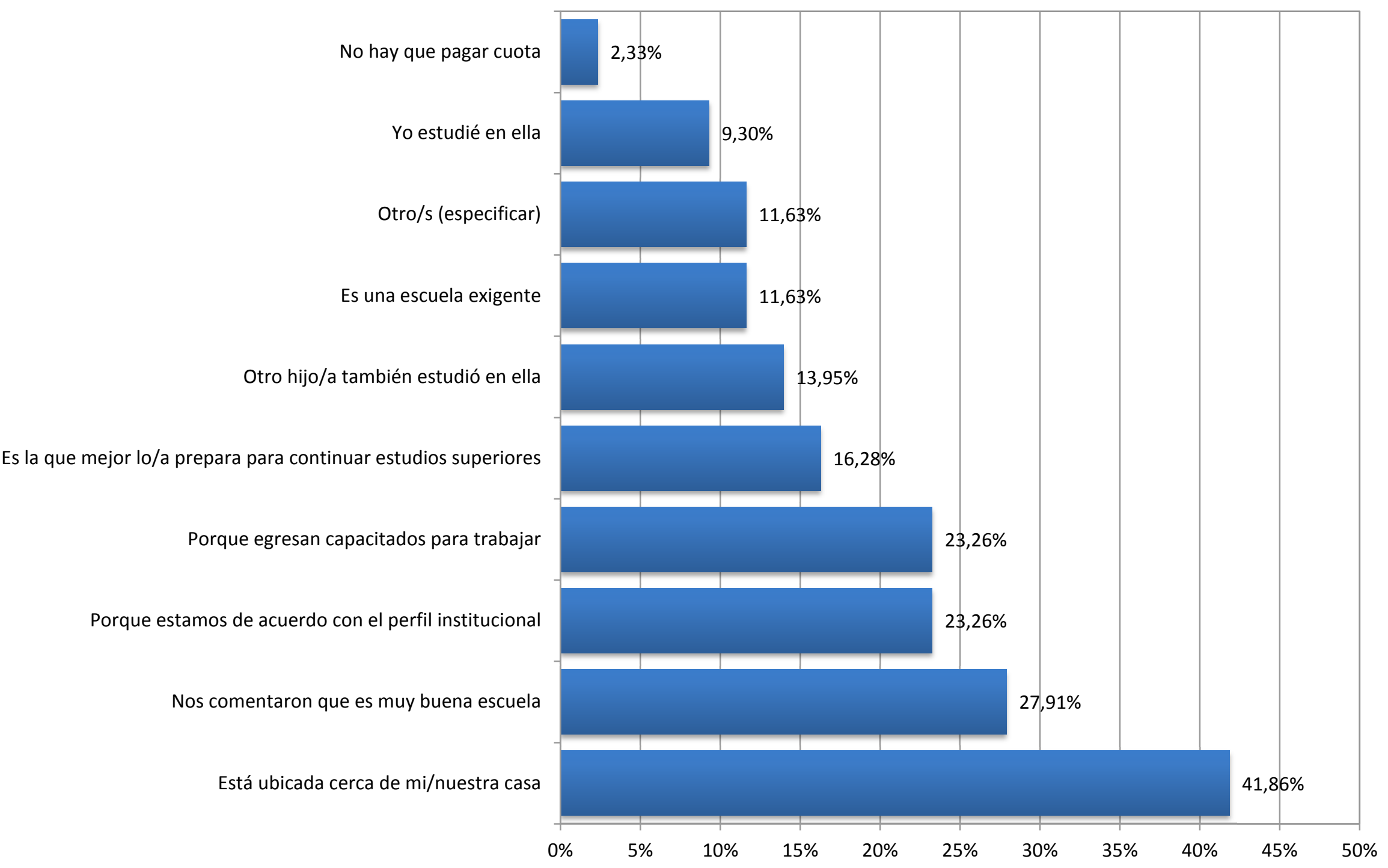


ADOLESCENTES

Cuadro 16.a

Pregunta 11: ¿Qué desea para su hijo/a en el futuro?

\begin{tabular}{|c|c|c|c|c|}
\hline Opciones & Padre & Madre & Tutor/Otro & TOTALES \\
\hline Que sea un buen profesional & 28 & 45 & 1 & $74(49,66 \%)$ \\
\hline Que sea un buen trabajador & 23 & 35 & 2 & $60(40,27 \%)$ \\
\hline Que sea una buena persona & 32 & 62 & 2 & $96(64,43 \%)$ \\
\hline Que constituya una familia & 26 & 46 & 2 & $74(49,66 \%)$ \\
\hline Que sea feliz & 40 & 65 & 2 & $107(71,81 \%)$ \\
\hline Que gane mucho dinero & 9 & 14 & 0 & $23(15,44 \%)$ \\
\hline Otro/s (especificar) & 0 & 0 & 0 & $0(0 \%)$ \\
\hline
\end{tabular}

\section{Gráfico 27: Porcentajes Totales}

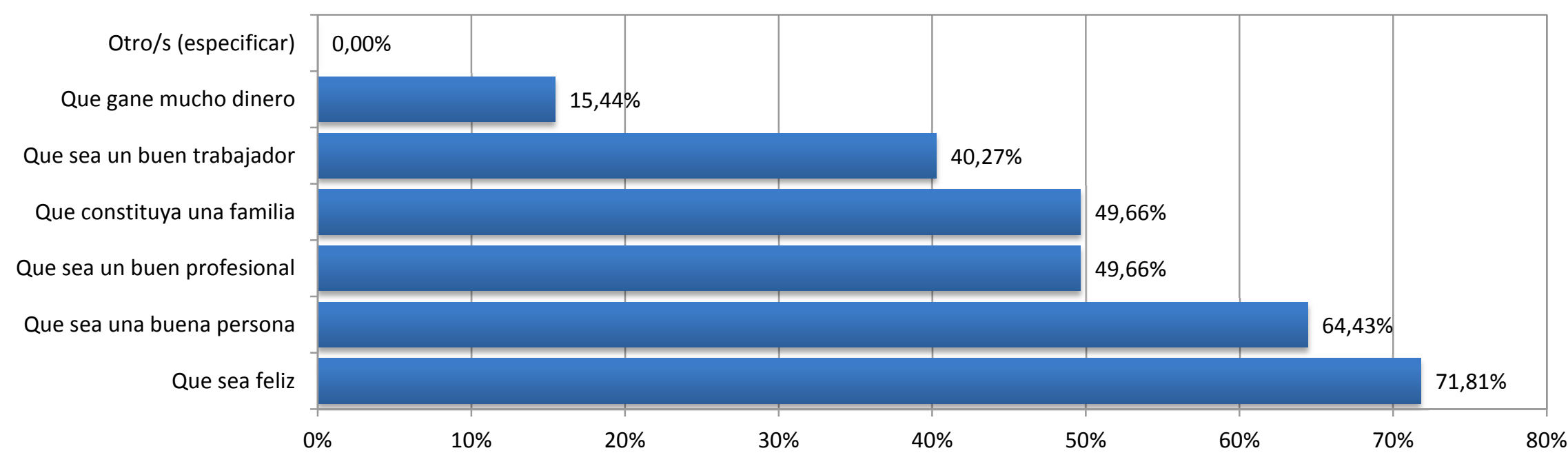


Cuadro 16.b

ADULTOS

\begin{tabular}{|c|c|c|c|c|}
\hline Que sea un buen profesional & 8 & 11 & 1 & $20(46,51 \%)$ \\
\hline Que sea una buena persona & 13 & 24 & 1 & $38(88,37 \%)$ \\
\hline Que constituya una familia & 7 & 14 & 1 & $22(51,16 \%)$ \\
\hline Que gane mucho dinero & 2 & 6 & 0 & $8(18,60 \%)$ \\
\hline Otro/s (especificar) & 0 & 0 & 0 & $0(0 \%)$ \\
\hline
\end{tabular}

Pregunta 11: ¿Qué desea para su hijo/a en el futuro?

Gráfico 28: Porcentajes Totales

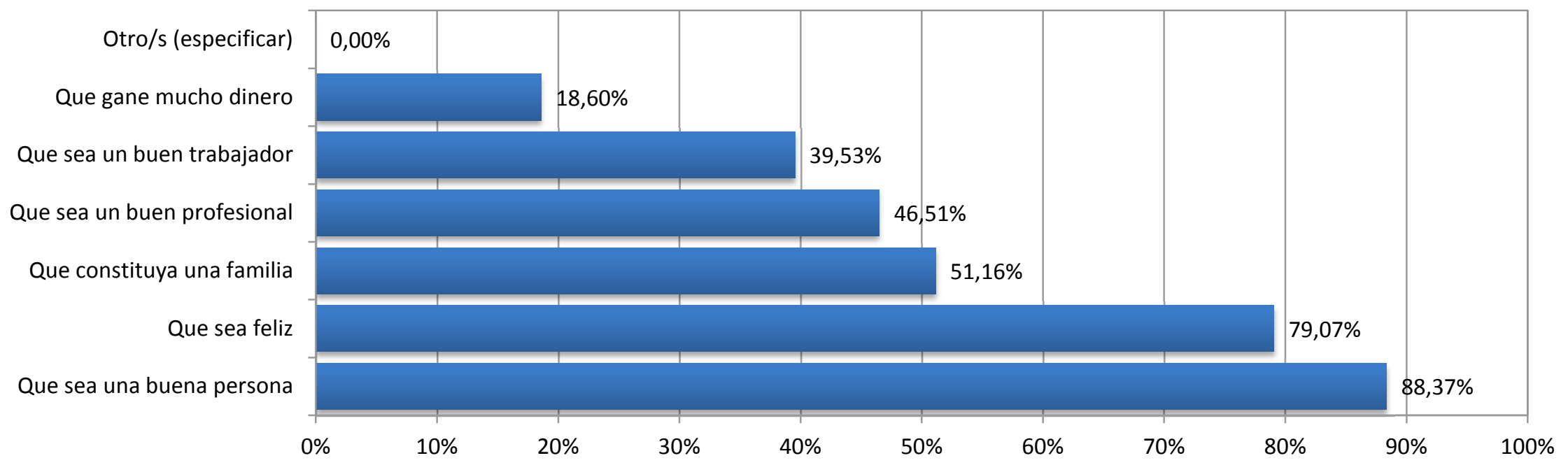




\section{ADOLESCENTES}

\section{Cuadro 17.a}

Pregunta 12: ¿Qué opinión le merecen los profesores de $3^{\circ}$ año de su hijo/a?

\begin{tabular}{|c|c|c|c|c|}
\hline Opciones & Padre & Madre & Tutor/Otro & TOTALES \\
\hline Todos excelente & 3 & 8 & 0 & $11(7,38 \%)$ \\
\hline Muchos excelente y algunos buena & 8 & 14 & 0 & $22(14,76 \%)$ \\
\hline Algunos excelente y muchos buena & 9 & 11 & 0 & $20(13,42 \%)$ \\
\hline Todos buena & 14 & 20 & 1 & $35(23,48 \%)$ \\
\hline Algunos buena y muchos mala & 7 & 9 & 3 & $19(12,75 \%)$ \\
\hline Todos regular & 0 & 1 & 0 & $1(0,67 \%)$ \\
\hline Otra/s (especificar) & 4 & 8 & 1 & $13(8,72 \%)$ \\
\hline
\end{tabular}




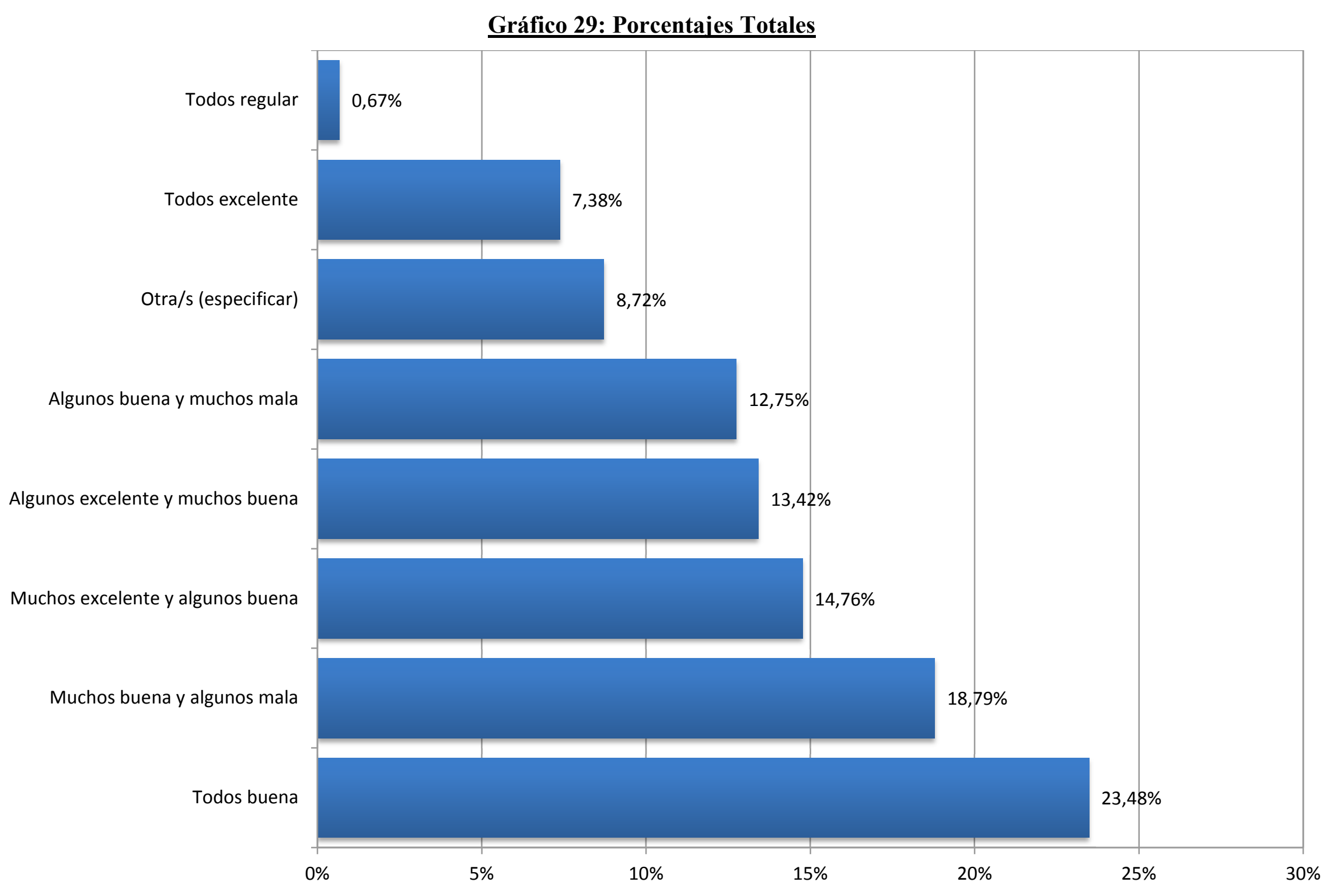




\section{Cuadro 17.b}

\begin{tabular}{|c|c|c|c|c|}
\hline Opciones & Padre & Madre & Tutor/Otro & TOTALES \\
\hline Muchos excelente y algunos buena & 1 & 2 & 0 & $3(6,98 \%)$ \\
\hline Algunos excelente y muchos buena & 2 & 3 & 0 & $5(11,63 \%)$ \\
\hline Todos buena & 6 & 10 & 0 & $16(37,21 \%)$ \\
\hline Algunos buena y muchos mala & 3 & 3 & 0 & $6(13,95 \%)$ \\
\hline Todos regular & 2 & 1 & 1 & $4(9,30 \%)$ \\
\hline Otra/s (especificar) & 0 & 1 & 0 & $1(2,33 \%)$ \\
\hline
\end{tabular}




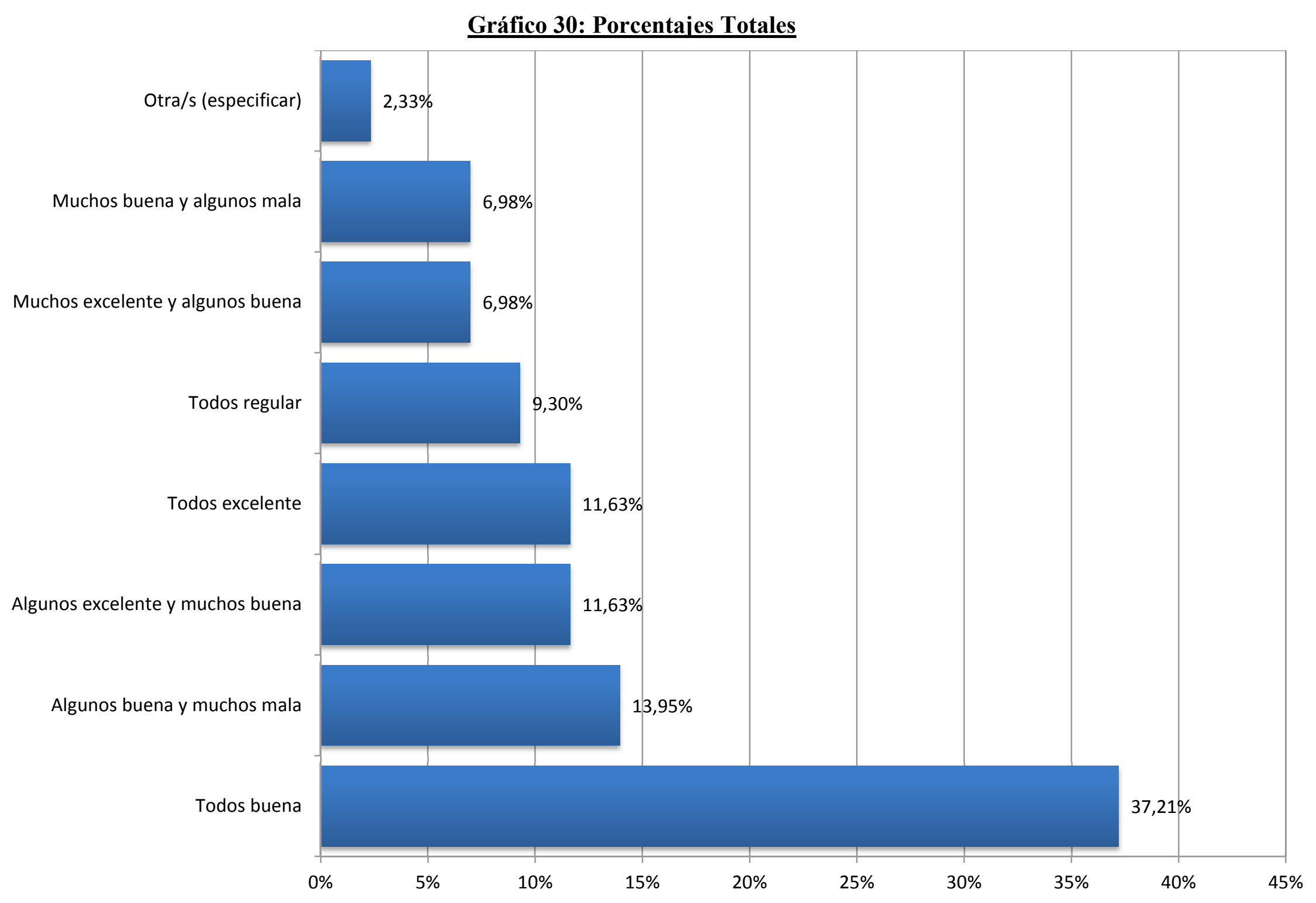




\section{Cuadro 18.a}

ADOLESCENTES

Pregunta 13: ¿De qué manera hace conocer a las autoridades de la escuela sus inquietudes/opiniones sobre la marcha de la educación de su hijo/a?

\begin{tabular}{|c|c|c|c|c|}
\hline Opciones & Padre & Madre & Tutor/Otro & TOTALES \\
\hline Cuando soy/somos citado/s desde la escuela por algún motivo & 20 & 27 & 4 & $51(34,22 \%)$ \\
\hline En las reuniones de padres con los directivos & 18 & 24 & 0 & $42(28,19 \%)$ \\
\hline En las reuniones de padres con los profesores & 12 & 18 & 1 & $31(20,81 \%)$ \\
\hline Yendo por mí/nuestra propia decisión a la escuela & 17 & 39 & 1 & $57(38,26 \%)$ \\
\hline De ninguna manera & 4 & 5 & 0 & $9(6,04 \%)$ \\
\hline Otra/s (especificar) & 2 & 4 & 0 & $6(4,03 \%)$ \\
\hline
\end{tabular}

\section{Gráfico 31: Porcentajes Totales}

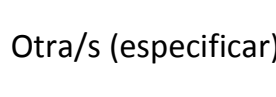

De ninguna manera

En las reuniones de padres con los profesores

En las reuniones de padres con los directivos

Cuando soy/somos citado/s desde la escuela por algún motivo Yendo por mi/nuestra propia decisión a la escuela

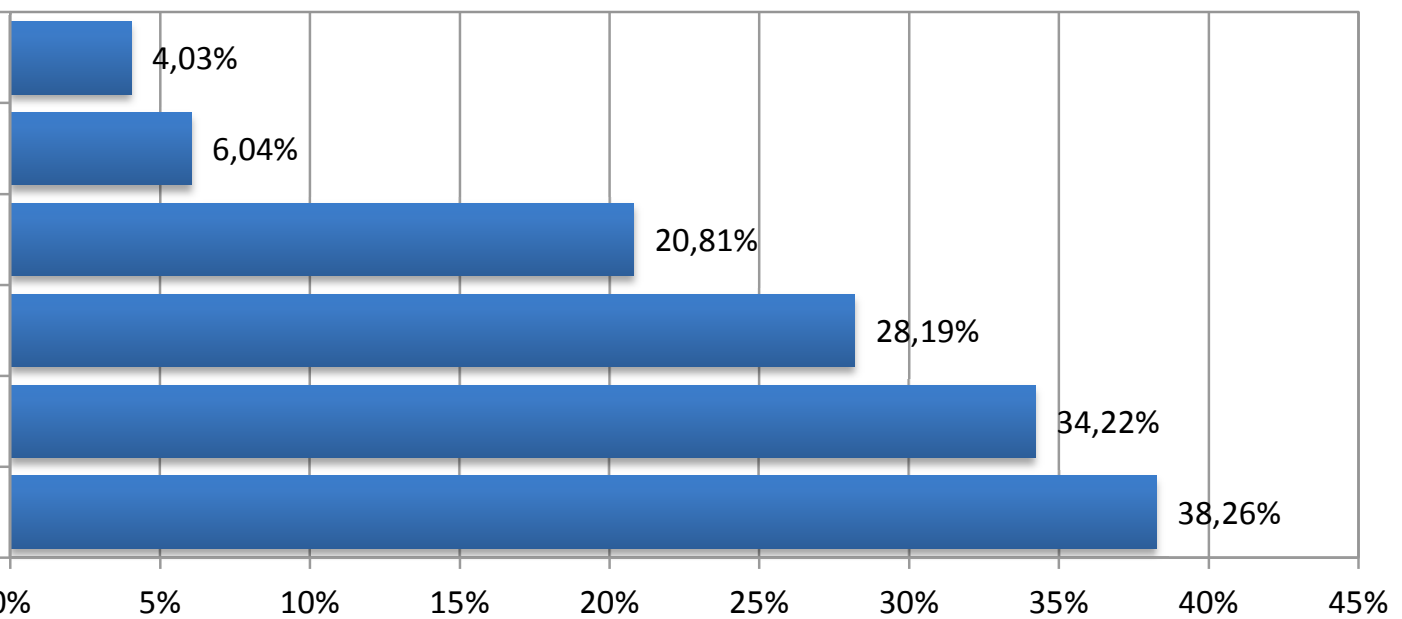




\section{ADULTOS}

Cuadro 18.b

Pregunta 13: ¿De qué manera hace conocer a las autoridades de la escuela sus inquietudes/opiniones sobre la marcha de la educación de su hijo/a?

\begin{tabular}{|c|c|c|c|c|}
\hline Opciones & Padre & Madre & Tutor/Otro & TOTALES \\
\hline Cuando soy/somos citado/s desde la escuela por algún motivo & 1 & 2 & 0 & $3(6,98 \%)$ \\
\hline En las reuniones de padres con los directivos & 5 & 5 & 0 & $10(23,26 \%)$ \\
\hline En las reuniones de padres con los profesores & 7 & 10 & 0 & $17(39,53 \%)$ \\
\hline Yendo por mí/nuestra propia decisión a la escuela & 4 & 10 & 1 & $15(34,88 \%)$ \\
\hline De ninguna manera & 0 & 2 & 0 & $2(4,65 \%)$ \\
\hline Otra/s (especificar) & 1 & 1 & 0 & $2(4,65 \%)$ \\
\hline
\end{tabular}

\section{Gráfico 32: Porcentajes Totales}

\section{Otra/s (especificar)}

De ninguna manera

Cuando soy/somos citado/s desde la escuela por algún motivo

En las reuniones de padres con los directivos

Yendo por mi/nuestra propia decisión a la escuela

En las reuniones de padres con los profesores

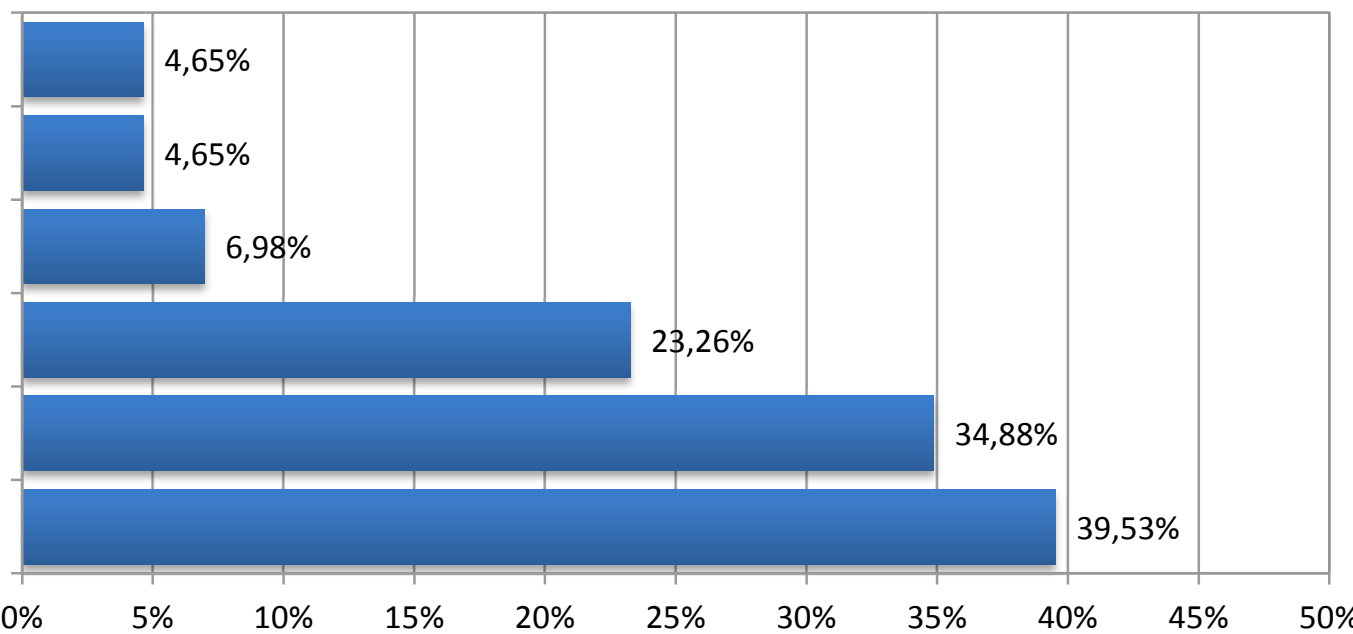




\subsubsection{Análisis descriptivo}

Aquí se prestará debida atención a los datos surgidos de los responsables de los egresados de las escuelas urbanas $\mathrm{J}$ y $\mathrm{G}$, elegidas por las particularidades que será posible observar en ellas. Ningún responsable de los egresados 2010 de ambos colegios finalizó el nivel medio y tampoco concluyeron el primario los abuelos de dichos alumnos.

En la escuela $J$ el cuestionario autoadministrado fue para diez adolescentes (seis estuvieron ausentes el día de la recolección de datos). De veinte responsables de esos egresados figuran sólo doce en el libro escolar donde se registran sus firmas. Según informaron al investigador las autoridades del colegio, son varias las causas por las cuales no se hallan todos. De esos doce sólo cuatro (un padre y tres madres) devolvieron el cuestionario respondido, observándose lo siguiente: 41 años tiene el padre y 40 años promedio es la edad de las madres. Son los más jóvenes de todos los encuestados teniendo en cuenta los diferentes colegios partícipes en esta investigación. La escuela $\mathrm{J}$ pertenece a una zona de familias de trabajadores, mayoritariamente en relación de dependencia. De los cuatro progenitores, tres (el padre y dos madres) actualmente trabajan. La restante madre, no. A la pregunta de si trabajaron alguna vez, las tres madres respondieron que lo hicieron por cuenta propia (independientes). El padre que trabaja lo hace en una empresa privada y las dos madres lo hacen por cuenta propia. El papá egresó de la actividad independiente y está ahora como dependiente, quizás buscando una mayor continuidad (relativa) laboral y se ignora si su actual ocupación encaja con sus aspiraciones y capacidades laborales. En cuanto a las madres, debido a las actividades que deben cumplir en sus casas, posiblemente el trabajo por cuenta propia represente un ingreso no desechable que les permita una mejor organización de su tiempo y planificar sus roles como proveedoras. Consultados todos respecto de qué desean para su hijo/a en el futuro, la opción "Que sea un buen trabajador" fue la más elegida (por el papá y dos de las madres). También, dos progenitores (el padre y una madre) eligieron la opción "Que sea un buen profesional". Dos mamás opinaron "Que sea una buena persona" y ningún progenitor eligió las opciones "Que constituya una familia" y "Que gane mucho dinero", metas que ameritarían una investigación futura para analizar la posible relación entre familias de trabajadores no especializados y la movilidad social ascendente.

La escuela $\mathrm{G}$ mostró tres progenitores de los adolescentes (un padre y dos madres), observándose lo que sigue: 63 años tiene el padre y 56 es el promedio de edad de las madres. Son los responsables de más edad de todos los encuestados de los diferentes colegios. La escuela está ubicada en una zona de familias de trabajadores (mayoritariamente en relación de dependencia), muy distante de la escuela $\mathrm{J}$ y del centro de la ciudad de Junín. Los datos de ambos establecimientos educativos ( $\mathrm{J}$ y $\mathrm{G}$ ) aparecen como extremos de mínima y máxima referidos a las edades de los responsables de los egresados de las once escuelas a las que se acudió para realizar este trabajo. 
Todos los padres de esta escuela trabajaron alguna vez y lo hacen actualmente. Antes, todos por cuenta propia y hoy continúan siendo trabajadores independientes. La permanencia laboral exhibida podría interpretarse como una actitud conformista frente a la realidad que tienen ante sí o como asimilación a un tipo de vida que provee a ambos sexos elementos suficientes para la satisfacción de sus necesidades, al menos las básicas. Respecto de los deseos para su hijo/a en el futuro, "Que constituya una familia" y "Que sea feliz" fueron las opciones más elegidas (ambas, por los tres padres). Las restantes opciones merecieron dos elecciones (siempre, el padre y la madre). Sólo una mamá eligió la opción "Que gane mucho dinero". De esto último podría deducirse que en los demás padres faltarían aspiraciones en tal sentido (congruente con una escala axiológica personal determinada) o que avizoran la imposibilidad de alcanzar esa meta por sus descendientes, dadas las circunstancias de la realidad que les toca vivir.

A más de las realidades descriptas, los datos -a través de porcentajescorrespondientes al nivel educativo alcanzado (a partir de la página 177), el conocimiento de la realidad (desde la 187) y los determinantes del status (cuyo inicio es la 211), permitirán visualizar otros aspectos en torno a los responsables de los egresados. Con ellos se completa el panorama abarcativo de las restante diecisiete escuelas (ocho de adolescentes y nueve de adultos) intervinientes en esta tesis.

En otro orden de ideas e incluyendo a todos los responsables de los egresados (adolescentes y adultos), la transmutación de la herencia social en herencia escolar en las clases media, media baja y baja que habitan el Distrito de Junín se observaría en la elección del establecimiento escolar. Un análisis del proceso de selección implicaría la posibilidad de empezar a comprender la relación entre la posición social de las familias, el perfil institucional de la escuela, la formación de los educandos y los diferentes campos posibles de actuación para los egresados. En tal sentido, la escuela sería una institución "civilizatoria" porque formaría las subjetividades en un determinado patrón cultural y normativo que regula las relaciones entre las personas. De allí que se trataría de una institución del orden destinada a generar una comprensión compartida de la realidad. 


\subsection{Profesores de los egresados de escuelas estatales de nivel medio del Distrito de Junín}

Total de profesores (de los egresados adolescentes) que fueron encuestados

Total de profesores (de los egresados adultos) que fueron encuestados

Total de profesores (de los egresados adolescentes y adultos) que fueron encuestados

Total de profesores (de los egresados adolescentes y adultos) no encuestados porque las escuelas donde trabajan no integraron la muestra

Prueba piloto: se realizó en julio de 2010 con 12 profesores.

Instrumento de medición: cuestionario autoadministrado individual (no precodificado) que incluye preguntas cerradas con varias opciones de respuesta no mutuamente excluyentes ( 1 a 5 y 8 a 13). Y preguntas cerradas con varias posibilidades de respuesta de las que debe elegir una (6 y 7). Total de preguntas: 13 . 


\subsubsection{Presentación de los participantes}

Seguidamente podrán leerse los datos demográficos o de ubicación pertenecientes a los profesores de los egresados 2010, teniendo en mira las mismas escuelas - y en idéntico orden- que las seleccionadas para los egresados y para sus responsables:

\begin{tabular}{|l||l||}
\hline \multicolumn{2}{|l||}{ Escuela D } \\
\hline Total de profesores encuestados & 7. \\
\hline \hline Nacionalidad & Todos, argentina. \\
\hline \hline Sexo & 2 varones y 5 mujeres. \\
\hline \hline Edad promedio & 40 años. \\
\hline \hline $\begin{array}{l}\text { Antigüedad promedio en la } \\
\text { docencia }\end{array}$ & 13 años y 4 meses. \\
\hline \hline Estado civil & $\begin{array}{l}\text { Ambos profesores están casados. De las profesoras, } 1 \text { está } \\
\text { casada, 1 divorciada, 1 viuda, 1 es soltera y 1 no contestó. }\end{array}$ \\
\hline \hline Nivel socioeconómico & Todos, nivel medio salvo 1 profesora que respondió medio bajo. \\
\hline \hline Barrio o zona donde viven & $\begin{array}{l}\text { Los profesores en el barrio "Belgrano". 2 profesoras residen } \\
\text { camino al Balneario Municipal (muy alejadas de esta escuela). } \\
\text { Las demás, cerca de la zona céntrica. Mayoritariamente ocupan } \\
\text { los actuales domicilios desde hace más de 10 años. }\end{array}$ \\
\hline \hline Actividad física & $\begin{array}{l}\text { Salvo } 2 \text { profesoras que no realizan actividad alguna, los demás } \\
\text { hacen caminatas y/o pilates y/o natación. }\end{array}$ \\
\hline
\end{tabular}




\begin{tabular}{|l||l||}
\hline \multicolumn{2}{|c||}{ Escuela F } \\
\hline \hline Total de profesores encuestados & 7. \\
\hline \hline Nacionalidad & Todas, argentina. \\
\hline \hline Sexo & 7 mujeres. \\
\hline \hline Edad promedio & 37 años. \\
\hline \hline Antigüedad promedio en la \\
docencia & 12 años y 8 meses. \\
\hline \hline Estado civil & 2 profesoras son casadas, 1 está separada y 4 son solteras. \\
\hline Nivel socioeconómico & Todas, nivel medio. \\
\hline \hline Barrio o zona donde viven & $\begin{array}{l}\text { 2 viven en el barrio "Belgrano" y las demás en otros alejados de } \\
\text { la escuela. La mayoría reside en ellos desde hace más de 10 años. }\end{array}$ \\
\hline \hline Actividad física & $\begin{array}{l}\text { Mayoritariamente practican yoga y pilates. Las demás, baile y } \\
\text { natación. }\end{array}$ \\
\hline \hline
\end{tabular}

\begin{tabular}{|c|c|}
\hline \multicolumn{2}{|r|}{ Escuela A } \\
\hline Total de profesores encuestados & 6. \\
\hline Nacionalidad & Todas, argentina. \\
\hline Sexo & 6 mujeres. \\
\hline Edad promedio & 35 años y 7 meses. \\
\hline $\begin{array}{l}\text { Antigüedad promedio en la } \\
\text { docencia }\end{array}$ & 13 años y 5 meses. \\
\hline Estado civil & 3 son casadas, 2 son solteras y la restante no contestó. \\
\hline Nivel socioeconómico & Todas, nivel medio. \\
\hline Barrio o zona donde viven & $\begin{array}{l}\text { Todas viven en barrios diferentes ubicados entre } 10 \text { y } 20 \text { cuadras } \\
\text { del centro de la ciudad. Mayoritariamente residen en ellos desde } \\
\text { hace } 10 \text { y más años. }\end{array}$ \\
\hline Actividad física & 4 realizan caminatas y pilates. 2 no contestaron. \\
\hline
\end{tabular}




\begin{tabular}{|l||l||}
\hline \multicolumn{2}{|c||}{ Escuela J } \\
\hline Total de profesores encuestados & 6. \\
\hline Nacionalidad & Todas, argentina. \\
\hline Sexo & 6 mujeres. \\
\hline Edad promedio & 35 años. \\
\hline Antigüedad promedio en la \\
docencia & 8 años y 7 meses. \\
\hline \hline Estado civil & 5 están casadas y 1 soltera. \\
\hline Nivel socioeconómico & Todas, nivel medio. \\
\hline Barrio o zona donde viven & $\begin{array}{l}\text { Mayoritariamente, en el barrio “Eusebio Marcilla". El resto vive } \\
\text { en otros. Sólo } 2 \text { de estas profesoras residen en sus actuales } \\
\text { hogares desde hace más de 10 años. }\end{array}$ \\
\hline \hline Actividad física & 3 hacen caminatas y 2 pilates. 1 no realiza actividad física alguna. \\
\hline \hline
\end{tabular}

\begin{tabular}{|c|c|}
\hline \multicolumn{2}{|r|}{ Escuela M } \\
\hline Total de profesores encuestados & 5. \\
\hline Nacionalidad & Todos, argentina. \\
\hline Sexo & 1 varón y 4 mujeres. \\
\hline Edad promedio & 50 años. \\
\hline $\begin{array}{l}\text { Antigüedad promedio en la } \\
\text { docencia }\end{array}$ & 19 años. \\
\hline Estado civil & Todos son casados. \\
\hline Nivel socioeconómico & 4, nivel socioeconómico medio. 1 no contestó. \\
\hline Barrio o zona donde viven & $\begin{array}{l}2 \text { residen en la zona céntrica. Los demás en barrios alejados de } \\
\text { dicha zona. Todos viven en los hogares actuales desde hace más } \\
\text { de } 10 \text { años, salvo } 1 \text { profesora que lo habita desde hace } 3 \text { años. }\end{array}$ \\
\hline Actividad física & 4 de ellos realizan caminatas. 1 no contestó. \\
\hline
\end{tabular}




\begin{tabular}{|l||l||}
\hline \multicolumn{2}{|c||}{ Escuela $\mathbf{L}_{4}$} \\
\hline Total de profesores encuestados & 1. \\
\hline Nacionalidad & Argentina. \\
\hline Sexo & 1 mujer. \\
\hline \hline Edad promedio & 40 años. \\
\hline \hline $\begin{array}{l}\text { Antigüedad promedio en la } \\
\text { docencia }\end{array}$ & 14 años y 6 meses. \\
\hline \hline Estado civil & Casada. \\
\hline \hline Nivel socioeconómico & Medio. \\
\hline \hline Barrio o zona donde viven & Vive en un barrio próximo a la escuela desde que nació. \\
\hline \hline Actividad física & Ciclismo. \\
\hline
\end{tabular}




\subsubsection{Datos obtenidos al operacionalizar las variables}

\subsubsection{Conocimiento de la normativa}

Frente a la pregunta 1 ¿A quién/es se le/s reconoce el derecho a la educación?, el 88,24\% de los profesores opinó que a "Todos" se les reconoce el derecho a la educación. Sólo un educador de egresados adolescentes afirmó que tal derecho no se le reconoce a "Nadie". Existe consenso en que no existiría ningún ser humano si no se hallase implicado — de cierta manera- en alguna práctica educativa. Durante toda su vida las personas jamás dejan de educarse. En una democracia todos tienen ese derecho a cualquier edad y —en razón del mismo- a ser respetados en la diferencia. En La educación de las elites (2008) de Guillermina Tiramonti y Sandra Ziegler, en la página 82 puede leerse: "En cuanto a los sectores medios, la generación de los abuelos no alcanzó a completar estudios básicos". Esos abuelos serían, en este caso, los padres de los profesores de egresados adolescentes y adultos que más que completar estudios básicos, varios de ellos finalizaron un estudio superior. Dicho todo esto aceptando que se hace referencia a la clase media ${ }^{203}$ de la sociedad argentina y en este caso de la del Distrito de Junín. La interpretación —en términos científicos- de los diferentes ítems que hacen a lo que debe entenderse por tales sectores no corresponde a esta investigación.

Respecto de la pregunta 2 ¿Dónde está reconocido el derecho a la educación?, el 77,45\% de todos los educadores opinó "En la Constitución Nacional". El 35,29\% de ellos sostuvo que lo está "En una Ley Nacional" y el 34,31\% afirmó que este derecho se halla reconocido "En uno o más Tratados Internacionales de Derechos Humanos con jerarquía constitucional". Así, un elevado número de los 102 profesores encuestados tiene presente a la Ley Fundamental la cual contiene una serie de normas dedicadas expresamente a la educación, aún más a partir de su última reforma en 1994. Las demás opciones que incluye la pregunta citada han dado lugar a porcentajes sensiblemente menores lo que permitiría deducir que algunos educadores, fuera del marco constitucional no saben en qué otra normativa tal derecho aparece reconocido y qué se prescribe al respecto. Conocer la o las causas de tal realidad es ajeno a esta investigación. No obstante, en el marco caracterizado por el estallido de las categorías con que se piensa el mundo debe inscribirse la crisis de la educación. En este ámbito puede constatarse de qué modo los cambios en la sociedad afectan al mundo escolar, particularmente a los docentes que -al desconocer, como en este caso, las prescripciones legales- no podrán cumplir plenamente la importante y compleja función que tienen a su cargo.

203. A un lado las definiciones de Karl Marx y de Max Weber referidas, en esta tesis se considera clase media al grado o estamento de la estratificación de clase social que se aplica a las personas con un nivel socioeconómico medio que se sitúa entre la clase obrera y la clase alta. 
En la respuesta a la pregunta 3 ¿Cómo evalúa la calidad educativa desde el retorno de la democracia (1983) hasta hoy? el 43,14\% de todos los educadores la evaluó como "Regular". El 29,41\% de ellos afirmó que es "Buena". El 7,84\% opinó que es "Muy buena" (7 docentes de egresados adolescentes y 1 de adultos). En contraste, el 8,82\% estimó que es "Mala" (5 profesores de adolescentes y 4 de adultos). Este regular en la evaluación de la calidad educativa aparece como lejano de las aspiraciones de lograr una educación de muy buena calidad para todos. Disposiciones de políticas educativas nacional y provinciales han habido desde hace años y existen hoy en pos — precisamente— de la calidad anhelada.

Ante la pregunta 4 ¿A qué atribuye fenómenos como el alcoholismo, la delincuencia, la drogadicción y la prostitución en el Distrito de Junín?, el 79,41\% de todos los profesores los atribuyó a "La actual crisis de valores". E1 57,84\% de ellos opinó que se deben a "Factores familiares". El 55,88\% de los docentes los atribuyó a "La falta de límites que se observa en los jóvenes”. Tomando en consideración estos dos últimos porcentajes, podría colegirse que para estos profesores la familia cumple un rol significativo en la formación de la personalidad de quienes en 2010 fueron sus alumnos.

Respecto de todo lo desarrollado en este punto, véanse los Cuadros 1, 2, 3 y 4 y sus Gráficos 1, 2, 3 y 4 correspondientes. 
Cuadro 1

\begin{tabular}{|c|c|c|c|}
\hline Opciones & Adolescentes & Adultos & TOTALES \\
\hline Consumidores & 1 & 2 & $3(2,94 \%)$ \\
\hline Mujeres & 7 & 6 & $13(12,75 \%)$ \\
\hline Niños & 13 & 9 & $22(21,57 \%)$ \\
\hline Usuarios & 1 & 2 & $3(2,94 \%)$ \\
\hline Todos & 67 & 23 & $90(88,24 \%)$ \\
\hline Nadie & 1 & 0 & $1(0,98 \%)$ \\
\hline Otro/s (especificar) & 1 & 1 & $2(1,96 \%)$ \\
\hline
\end{tabular}




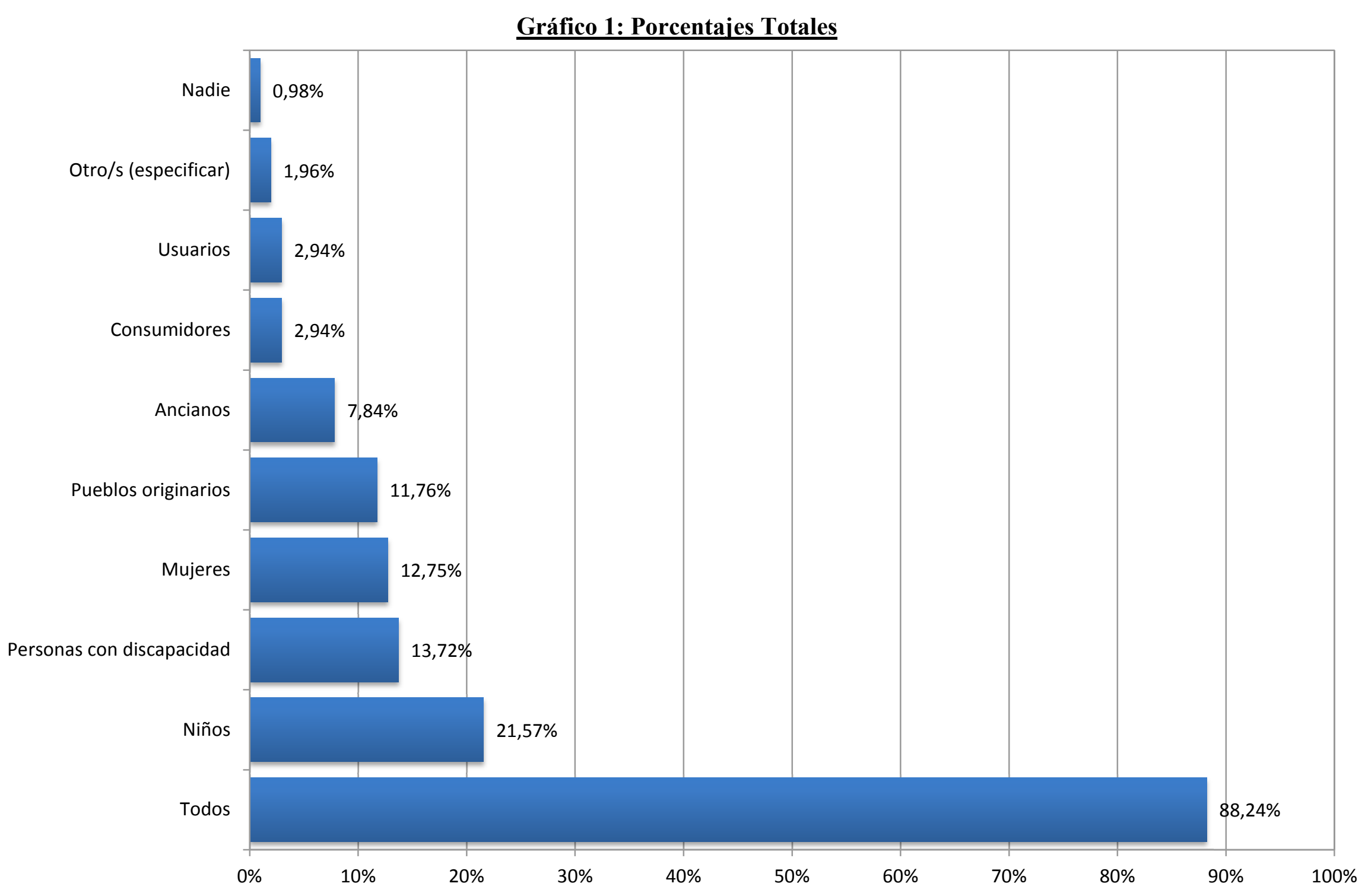


Pregunta 2: ¿Dónde está reconocido el derecho a la educación?

\begin{tabular}{|c|c|c|c|}
\hline Opciones & Adolescentes & Adultos & TOTALES \\
\hline En uno o más Tratados Internacionales de Derechos Humanos con jerarquía constitucional & 25 & 10 & $35(34,31 \%)$ \\
\hline En una Ley Nacional & 24 & 12 & $36(35,29 \%)$ \\
\hline En la Constitución de la Provincia de Buenos Aires & 23 & 7 & $30(29,41 \%)$ \\
\hline En una Ordenanza Municipal del Partido de Junín & 2 & 0 & $2(1,96 \%)$ \\
\hline En todo lo anteriormente dicho & 14 & 7 & $21(20,59 \%)$ \\
\hline En nada de lo anteriormente dicho & 0 & 0 & $0(0,00 \%)$ \\
\hline Otro/s (especificar) & 3 & 0 & $3(2,94 \%)$ \\
\hline
\end{tabular}




\section{Gráfico 2: Porcentajes Totales}

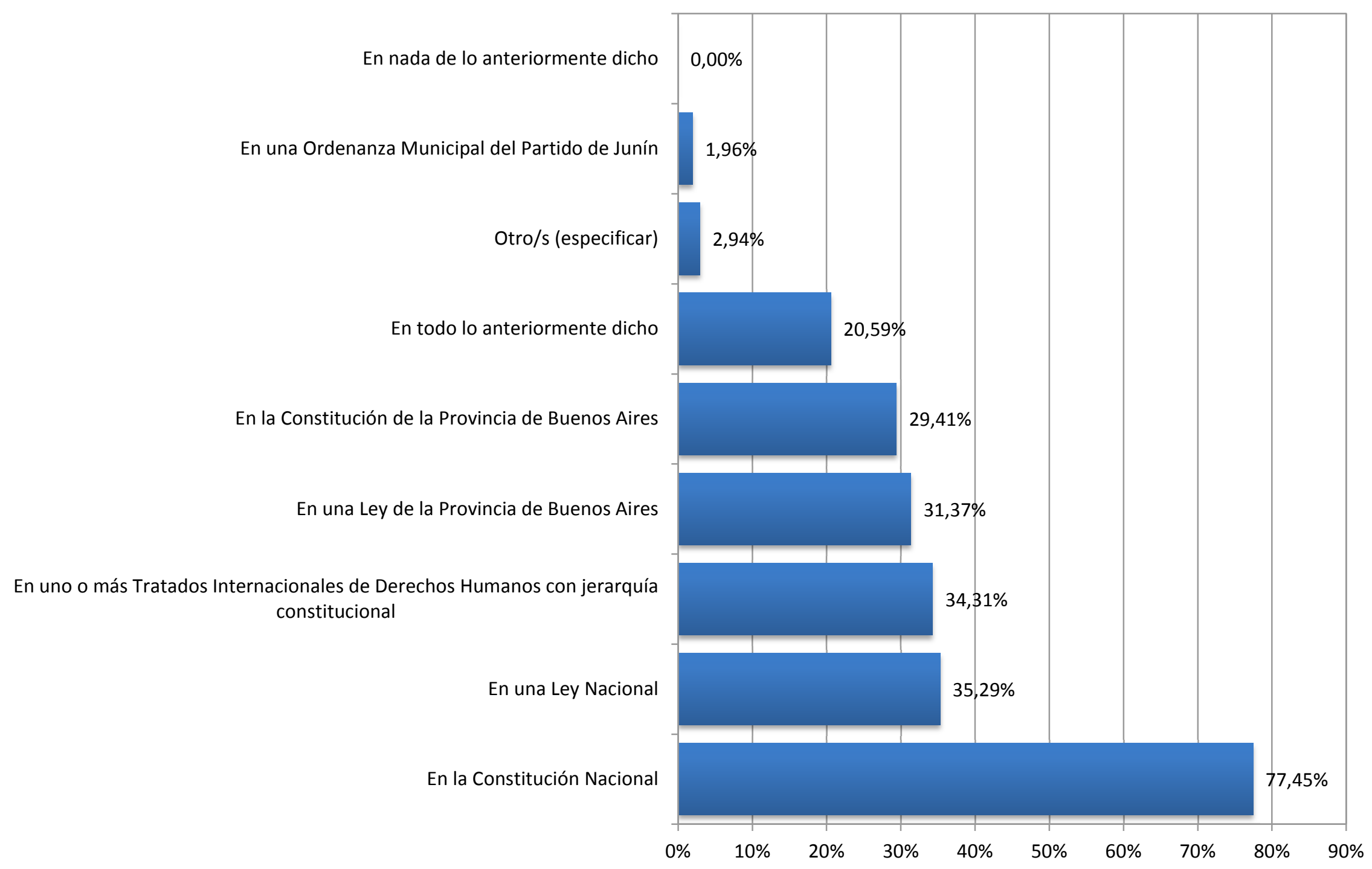


Cuadro 3

\begin{tabular}{|l|c|c|c||}
\hline \multicolumn{1}{|c|}{ Opciones } & Adolescentes & Adultos & 0 \\
\hline Excelente & 0 & 1 & $0(0,00 \%)$ \\
\hline Muy buena & 7 & 8 & $8(7,84 \%)$ \\
\hline Buena & 22 & 3 & $30(29,41 \%)$ \\
\hline Indeciso/a & 10 & 12 & $13(12,75 \%)$ \\
\hline Regular & 32 & 4 & $4(43,14 \%)$ \\
\hline Mala & 5 & 1 & $9(8,82 \%)$ \\
\hline Muy mala & 1 & 1 & $8(1,96 \%)$ \\
\hline \hline Otra/s (especificar) & 7 & $8(7,84 \%)$ \\
\hline
\end{tabular}




\section{Gráfico 3: Porcentajes Totales}

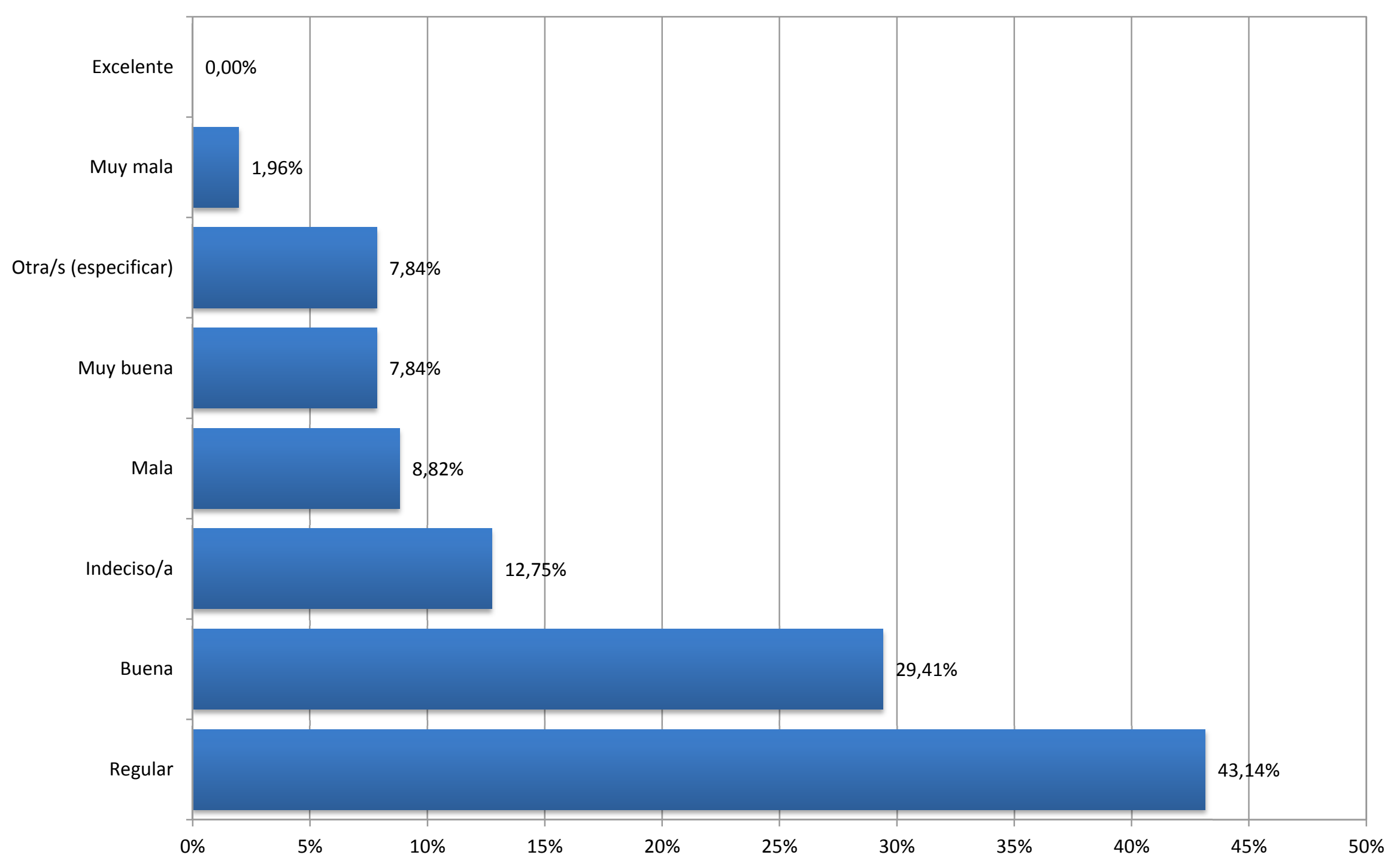


Pregunta 4: ¿A qué atribuye fenómenos como el alcoholismo, la delincuencia, la drogadicción y la prostitución en el Distrito de Junín?

\begin{tabular}{|c|c|c|c|}
\hline Opciones & Adolescentes & Adultos & TOTALES \\
\hline La actual crisis de valores & 56 & 25 & $81(79,41 \%)$ \\
\hline La falta de compromiso de algunos políticos para atender a las demandas sociales & 34 & 12 & $46(45,10 \%)$ \\
\hline La falta de límites que se observa en los jóvenes & 40 & 17 & $57(55,88 \%)$ \\
\hline Es una herencia que dejaron las políticas neoliberales & 17 & 5 & $22(21,57 \%)$ \\
\hline Factores ambientales (barrio o manzana donde se vive) & 11 & 1 & $12(11,76 \%)$ \\
\hline Factores familiares & 41 & 18 & $59(57,84 \%)$ \\
\hline Factores genéticos (hereditarios) & 2 & 0 & $2(1,96 \%)$ \\
\hline Otro/s (especificar) & 13 & 1 & $14(13,73 \%)$ \\
\hline
\end{tabular}




\section{Gráfico 4: Porcentajes Totales}

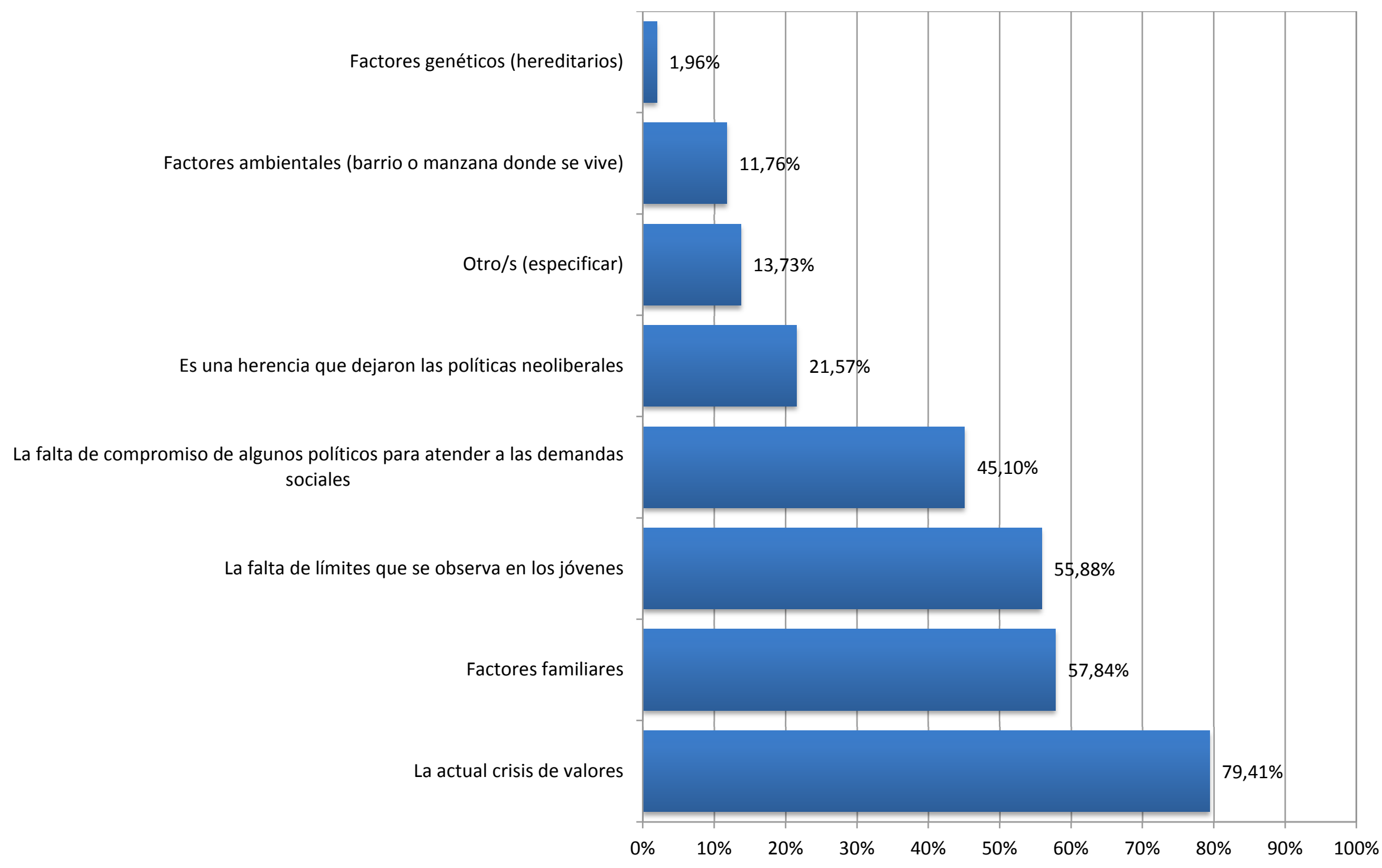




\subsubsection{El ejercicio del rol docente}

Ante la pregunta 5 ¿Trabaja usted en alguna otra institución educativa?, el 57,84\% de los profesores de todos los educandos afirmó "Sí. Preceptor en otra/s escuela/s". El 31,37\% indicó "Sí. Profesor en otra/s escuela/s". El 11,76\% eligió la opción "Sí. Profesor en un Profesorado (en Junín y/o en la zona)" y el 10,78\% de todos los educadores afirmó que no trabaja en otra institución educativa Las demás opciones recibieron porcentajes de adhesión inferiores.

También se formuló la pregunta 6 ¿Qué tan de acuerdo se encuentra con lo dispuesto sobre la educación secundaria, según las leyes 26.206 (nacional) y 13.688 (de la provincia de Buenos Aires)? De todos los profesores encuestados, el 34,31\% eligió la opción "De acuerdo" en referencia a ambas leyes. "No estoy debidamente informado/a" fue reconocido por el $24,51 \%$ de los docentes, tanto de egresados adolescentes como de adultos.

Producto de la variada normativa vigente, al trabajo cotidiano de los docentes se han agregado nuevas actividades, responsabilidades y exigencias (autoevaluación, capacitación, integración interdisciplinaria). Todo esto en un contexto de crisis en las familias y en los estudiantes, ante los cuales los profesores - acorde con sus posibilidades - deben atender. En definitiva, deben hacerse cargo de un marco regulatorio actualizado para operar sobre una realidad compleja.

Entre los padres de los educadores de egresados adolescentes y adultos (la pregunta 7 alude al máximo nivel educativo alcanzado) hay 5 que concluyeron diferentes estudios superiores y 3 que no los finalizaron. Entre las madres de todos ellos, 16 culminaron un estudio superior y 5 no lo terminaron. Asimismo, un tutor concluyó el terciario (no universitario). Es decir, 22 (el 21,56\%) de todos los educadores encuestados (102 profesores) finalizaron un estudio superior.

Frente a la pregunta 8 ¿Qué teoría/recurso educativa/o aplica en el desarrollo de las clases?, el 59,80\% del total de profesores afirmó que una teoría educativa "Distinta, según las características del grupo de egresados". El 49,02\% de ellos sostuvo que utiliza una "Distinta, según los diferentes temas de la asignatura" y el 46,08\% aplica "Una combinación de diferentes teorías". Estos porcentajes — que son los mayoritarios- muestran la complejidad de la actividad áulica, con docentes que — dentro del momento histórico que les toca vivirintentan lo más conveniente - eso se espera de ellos- para que los alumnos construyan por sí el conocimiento. "Las asignaturas comprendidas en las diferentes modalidades incluyen contenidos que motivan en el educador un casi permanente replanteo de su accionar". Tales fueron los conceptos vertidos por Karen, profesora de Historia en la escuela B, al investigador.

A la pregunta 9 ¿Por qué causa/s eligió ser docente?, el 59,80\% de los encuestados respondió "Por vocación". El 22,55\% asumió lo siguiente: "Nunca pensé ser docente pero un 
día cambié de opinión". Asimismo, el 17,65\% de ellos sostuvo "Desde mi infancia pensé ser docente". "No sería posible imaginar una recuperación de lo social sin pensar en la escuela", aseveró Judith, profesora de Matemática en el colegio H, al investigador.

Ante la pregunta 10 ¿De qué fuente se vale para adquirir la información y el conocimiento?, el $91,18 \%$ de todos los encuestados respondió que se vale de "Libros, periódicos, revistas". El 88,24\% de ellos afirmó que se sirve de "Internet". El 46,08\% sostuvo que lo hace a través de "La radio, la televisión". Las demás opciones permiten observar porcentajes de elección menores, sensiblemente en algunos casos. En este orden de ideas, los cambios económicos, políticos, sociales y culturales que están sucediendo a escala mundial responden a diversos factores, entre los que se destaca el papel cada vez más relevante del conocimiento. Existe consenso en reconocer la rápida y profunda transformación tecnológica. En estas condiciones la educación ya no estaría dirigida solamente a la transmisión de conocimientos y de informaciones sino a desarrollar en los estudiantes la capacidad de producirlos y de utilizarlos.

Respecto de todo lo señalado supra, véanse los Cuadros 5, 6, 7, 8, 9 y 10 y sus Gráficos 5, 6, 7.a, 7.b, 8 y 9 correspondientes: 
Pregunta 5: ¿Trabaja usted en alguna otra institución educativa?

\begin{tabular}{|c|c|c|c|}
\hline Opciones & Adolescentes & Adultos & TOTALES \\
\hline Sí. Profesor en otra/s escuela/s & 4 & 28 & $32(31,37 \%)$ \\
\hline Sí. Profesor en un Profesorado (en Junín y/o en la zona) & 10 & 2 & $12(11,76 \%)$ \\
\hline Sí. Profesor en la Universidad (UNNOBA u otra) & 3 & 2 & $5(4,90 \%)$ \\
\hline Otra/s (especificar) & 5 & 3 & $8(7,84 \%)$ \\
\hline
\end{tabular}

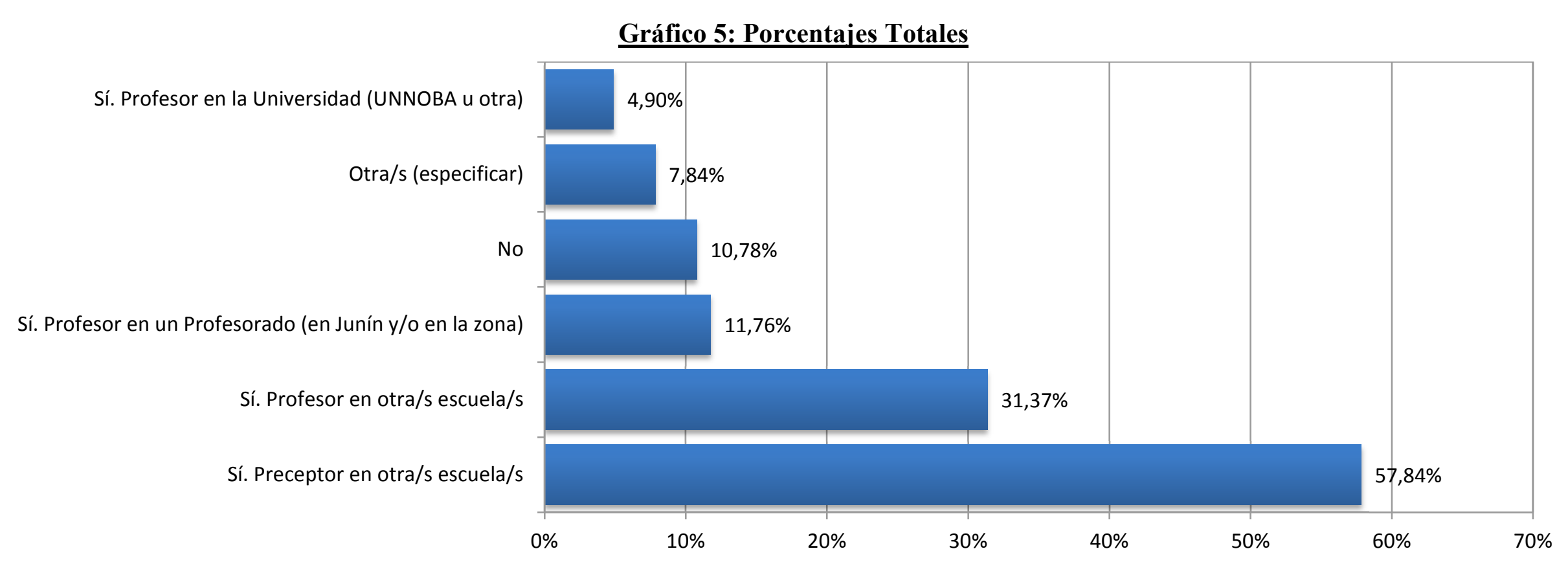


Pregunta 6: ¿Qué tan de acuerdo se encuentra con lo dispuesto sobre la educación secundaria en las siguientes leyes?

\begin{tabular}{|c|c|c|c|c|c|c|}
\hline \multirow{2}{*}{ Opciones } & \multicolumn{3}{|c|}{ Ley de Educación Nacional No 26.206/06 } & \multicolumn{3}{|c|}{ Ley de Educación Provincial No 13.688/07 } \\
\hline & Adolescentes & Adultos & TOTALES & Adolescentes & Adultos & TOTALES \\
\hline Muy de acuerdo & 3 & 2 & $5(4,90 \%)$ & 5 & 0 & $5(4,90 \%)$ \\
\hline Ni de acuerdo ni en desacuerdo & 15 & 4 & $19(18,63 \%)$ & 15 & 4 & $19(18,63 \%)$ \\
\hline En desacuerdo & 4 & 6 & $10(9,80 \%)$ & 4 & 6 & $10(9,80 \%)$ \\
\hline $\begin{array}{l}\text { No estoy debidamente } \\
\text { informado/a }\end{array}$ & 18 & 7 & $25(24,51 \%)$ & 18 & 7 & $25(24,51 \%)$ \\
\hline Otro/s (especificar) & 5 & 0 & $5(4,90 \%)$ & 4 & 1 & $5(4,90 \%)$ \\
\hline
\end{tabular}




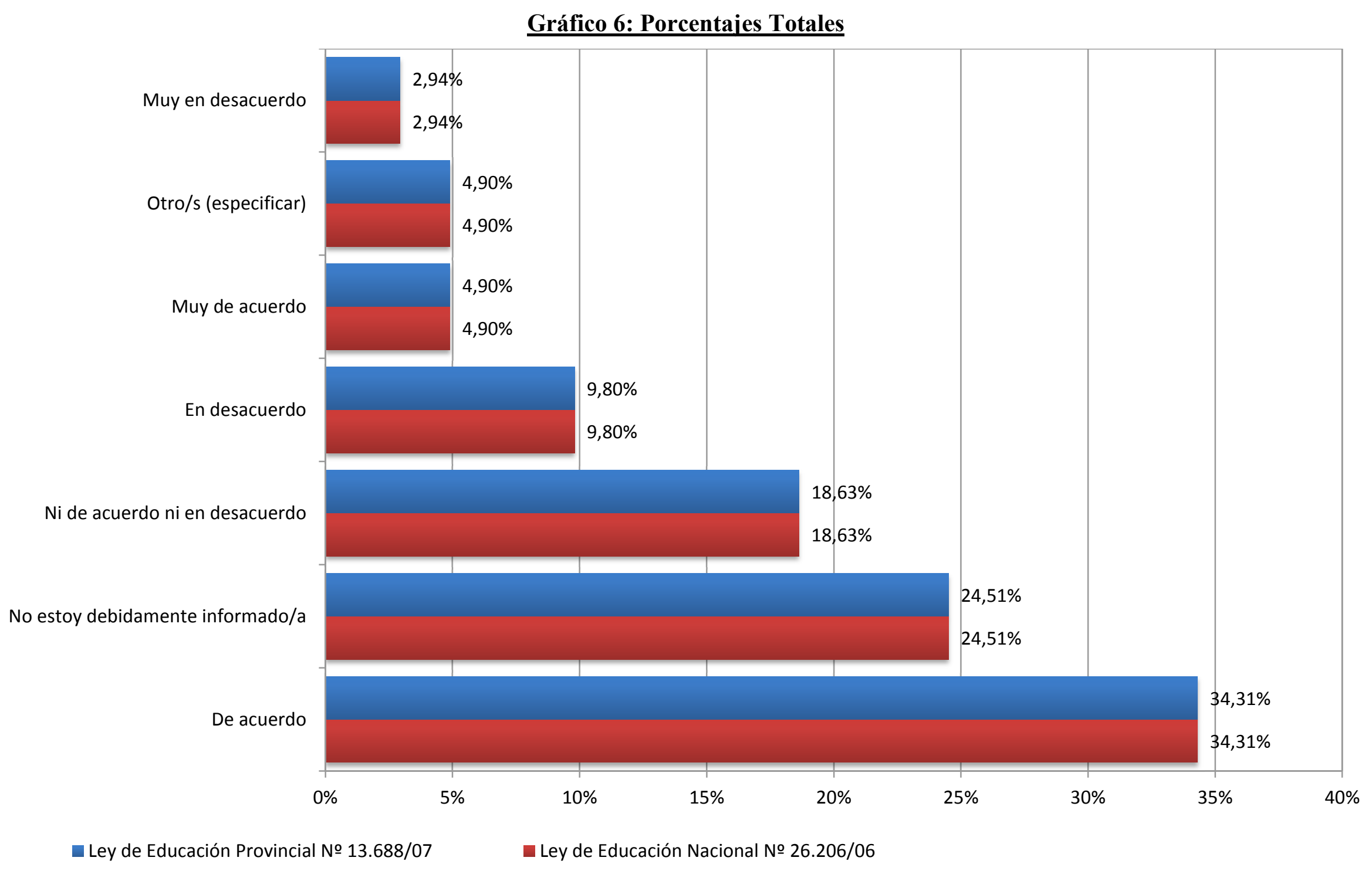


Pregunta 7: ¿Cuál es el máximo nivel educativo alcanzado por su...?

\begin{tabular}{|c|c|c|c|c|c|c|c|c|c|c|c|c|c|c|}
\hline \multirow{3}{*}{ Opciones } & \multicolumn{6}{|c|}{ Adolescentes } & \multicolumn{6}{|c|}{ Adultos } & \multirow{2}{*}{\multicolumn{2}{|c|}{ TOTALES }} \\
\hline & \multicolumn{2}{|c|}{ Padre } & \multicolumn{2}{|c|}{ Madre } & \multicolumn{2}{|c|}{ Tutor/Otro } & \multicolumn{2}{|c|}{ Padre } & \multicolumn{2}{|c|}{ Madre } & \multicolumn{2}{|c|}{ Tutor/Otro } & & \\
\hline & $\mathbf{F}$ & No $F$ & $\mathbf{F}$ & No $F$ & $\mathbf{F}$ & No $F$ & $\mathbf{F}$ & No $F$ & $\mathbf{F}$ & No $F$ & $\mathbf{F}$ & No $F$ & $\mathbf{F}$ & No $F$ \\
\hline Primario & 35 & 6 & 35 & 3 & 1 & 0 & 12 & 4 & 11 & 4 & 0 & 0 & 94 & 17 \\
\hline Secundario & 17 & 7 & 16 & 5 & 0 & 0 & 8 & 3 & 6 & 1 & 0 & 0 & 47 & 16 \\
\hline Universitario & 2 & 1 & 2 & 2 & 0 & 0 & 1 & 1 & 1 & 0 & 0 & 0 & 6 & 4 \\
\hline Posgrado & 1 & 0 & 0 & 0 & 0 & 0 & 0 & 0 & 0 & 0 & 0 & 0 & 1 & 0 \\
\hline Licenciatura & 1 & 0 & 0 & 0 & 0 & 0 & 0 & 0 & 0 & 0 & 0 & 0 & 1 & 0 \\
\hline
\end{tabular}

Nota: "F": Finalizado; "No F": No Finalizado 
Pregunta 8: ¿Qué teoría/recurso educativa/o aplica en el desarrollo de las clases?

\begin{tabular}{|c|c|c|c|c|c|}
\hline Opciones & Adolescentes & Adultos & \multicolumn{3}{|c|}{ TOTALES } \\
\hline Distinta, según las características del grupo de egresados & 47 & 14 & 61 & $59,80 \%$ & $34,66 \%$ \\
\hline Distinta, según los diferentes temas de la asignatura & 35 & 15 & 50 & $49,02 \%$ & $28,41 \%$ \\
\hline La epistemología genética & 3 & 0 & 3 & $4,90 \%$ & $1,70 \%$ \\
\hline La teoría del procesamiento de información & 2 & 0 & 2 & $1,96 \%$ & $1,14 \%$ \\
\hline Una combinación de diferentes teorías & 30 & 17 & 47 & $46,08 \%$ & $26,70 \%$ \\
\hline
\end{tabular}




\section{Gráfico 7.a: Porcentajes en base al total de participantes}

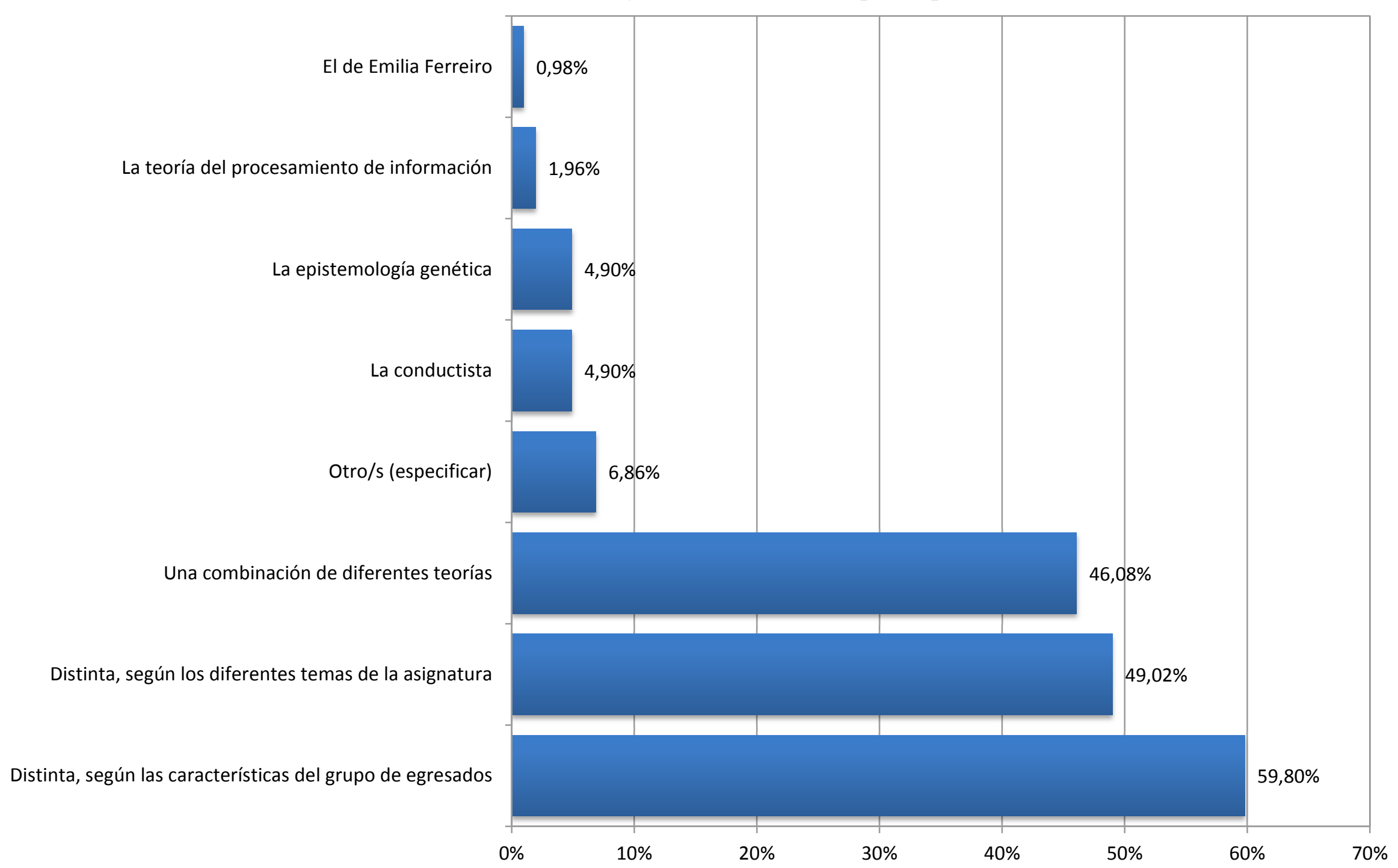




\section{Gráfico 7.b: Porcentajes en base al total de respuestas dadas}

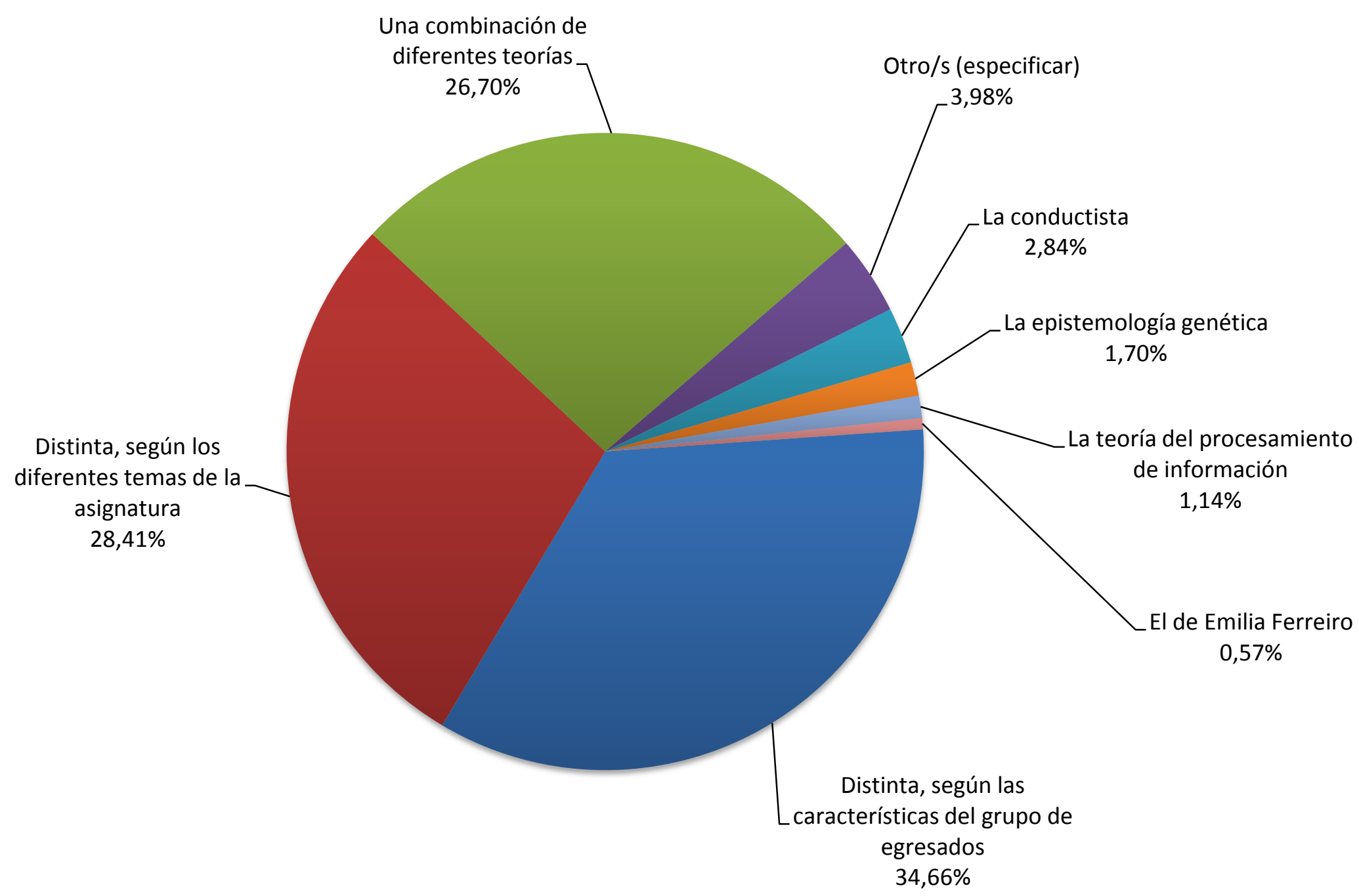


Pregunta 9: ¿Por qué causa/s eligió ser docente?

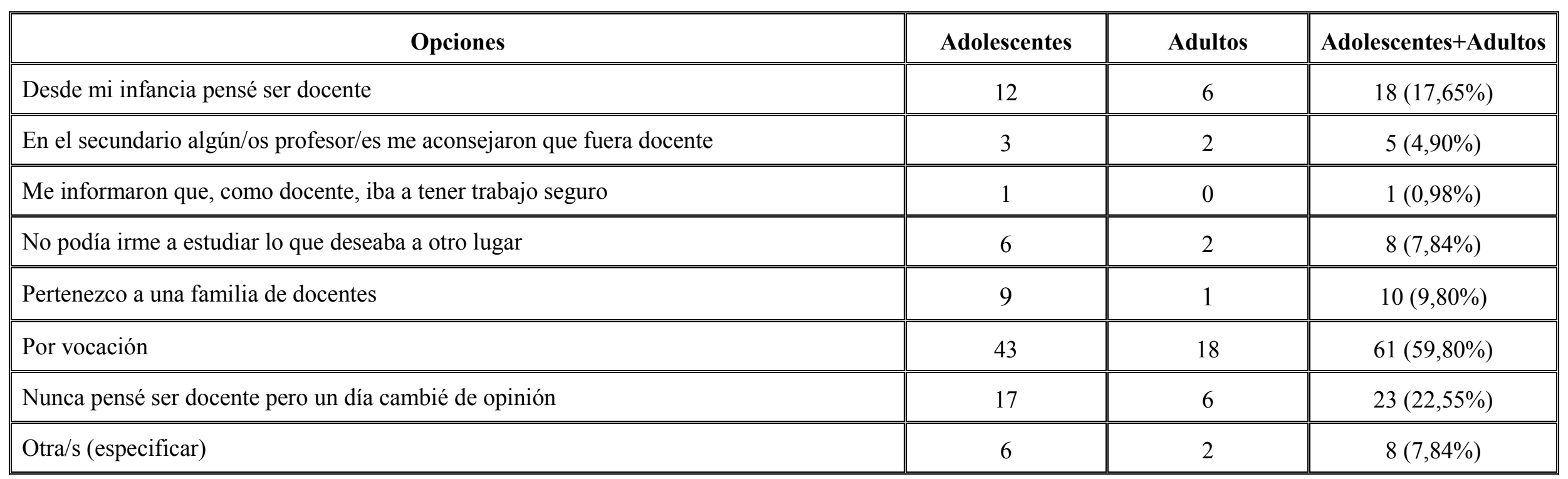




\section{Gráfico 8: Porcentajes Totales}

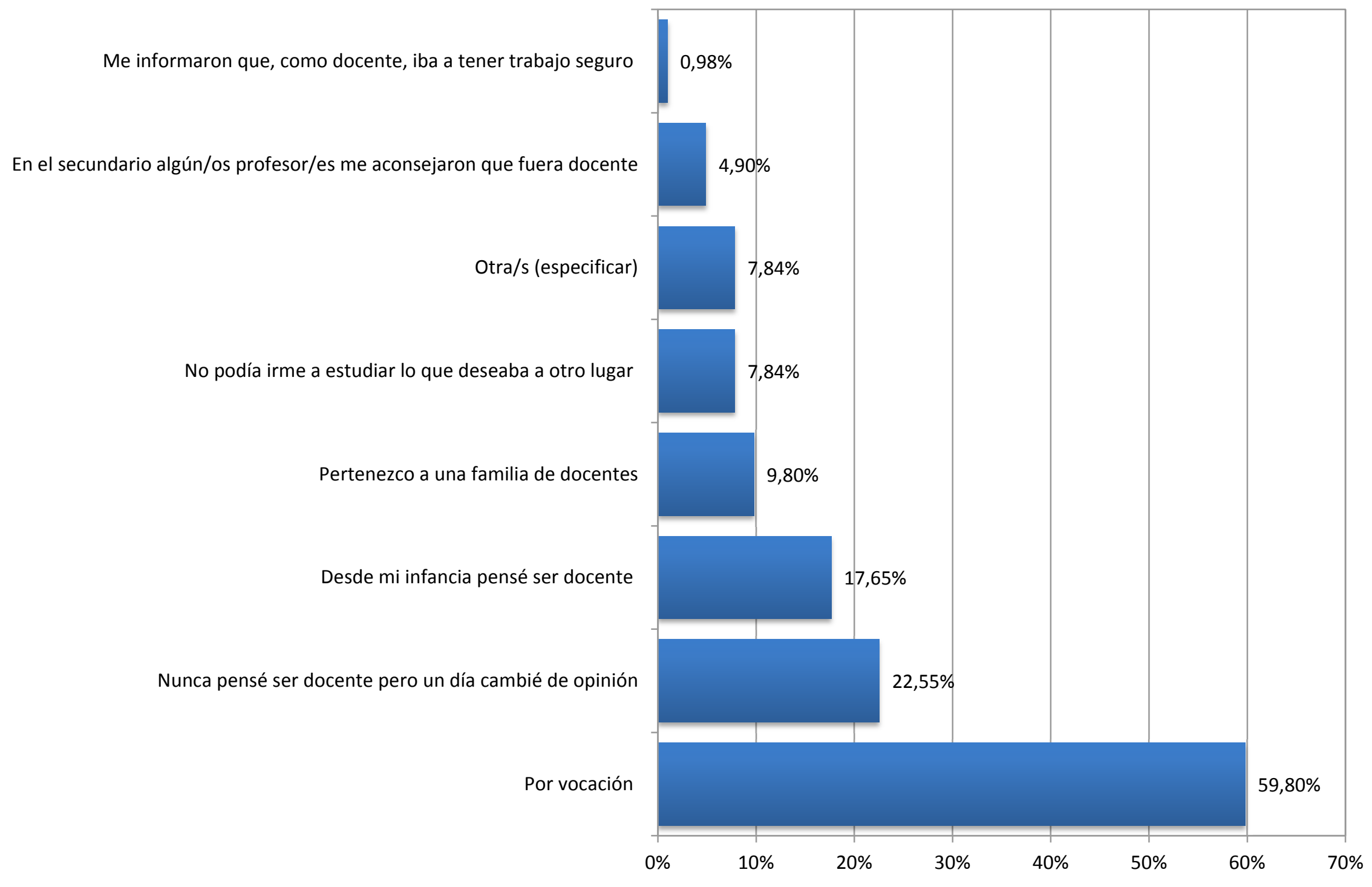


Pregunta 10: ¿De qué fuente se vale para adquirir la información y el conocimiento?

\begin{tabular}{|l|c|c|c||}
\hline \multicolumn{1}{|c|}{ Opciones } & Adolescentes & Adultos & \multicolumn{1}{|c||}{ TOTALES } \\
\hline La familia & 17 & $22(21,57 \%)$ & $37(36,27 \%)$ \\
\hline La escuela & 27 & 2 & $11(10,78 \%)$ \\
\hline Los amigos & 9 & 26 & $90(88,24 \%)$ \\
\hline Internet & 64 & 26 & $93(91,18 \%)$ \\
\hline Libros, periódicos, revistas & 67 & 12 & $47(46,08 \%)$ \\
\hline La radio, la televisión & 35 & 4 & $26(25,49 \%)$ \\
\hline \hline El cine, el teatro & 22 & 6 & $16(15,69 \%)$ \\
\hline \hline Otra/s (especificar) & 10 & 2 \\
\hline
\end{tabular}




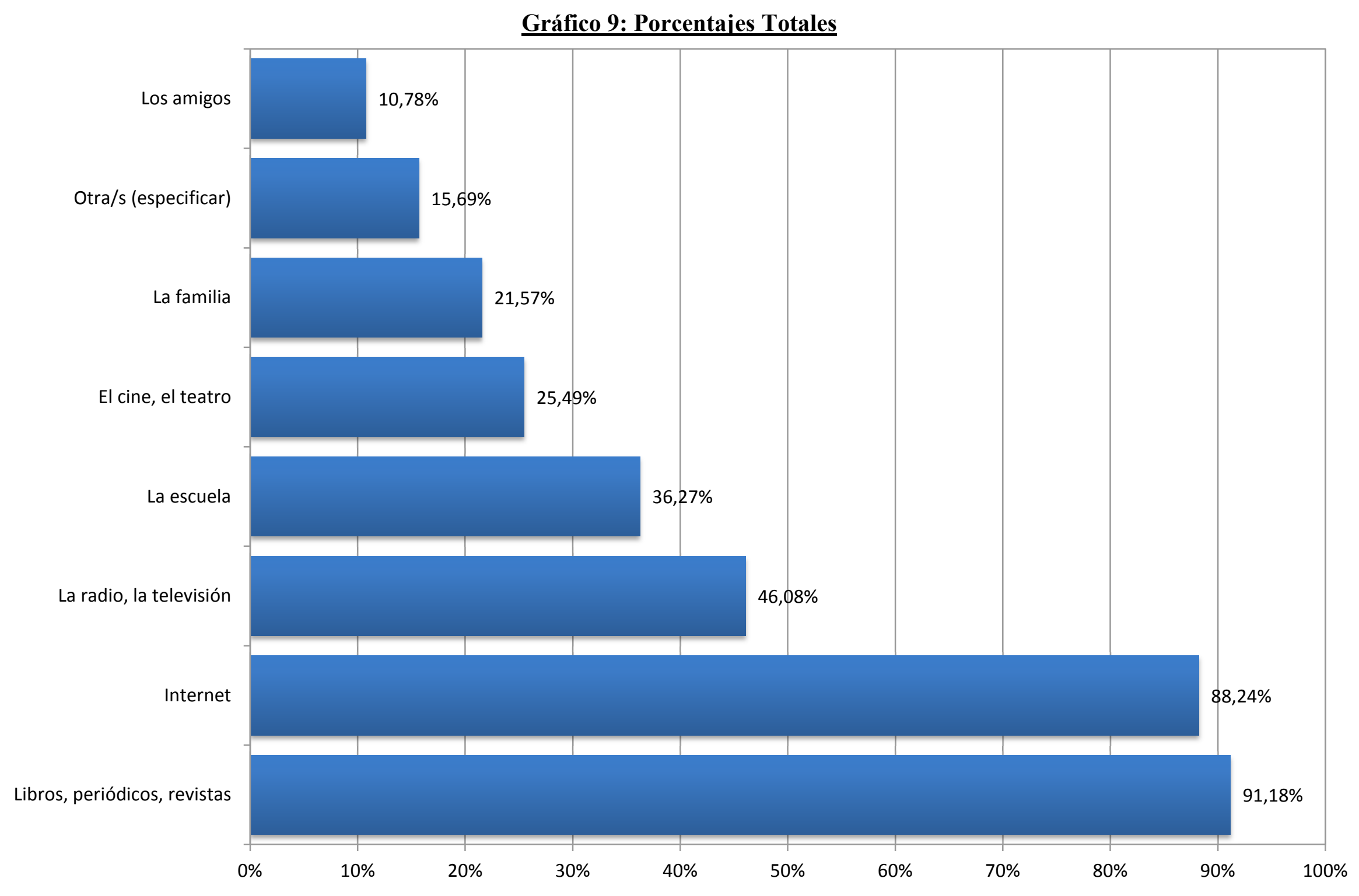




\subsubsection{Trayectorias educativas}

Al responder a la pregunta 11 ¿Cómo considera que son como estudiantes los egresados de esta escuela?, los profesores de adolescentes y de adultos afirmaron que son "Muy buenos" (el 41,57\% y el 46,45\%, respectivamente). Son "Excelentes", el 8,40\% entre los primeros y el $6,20 \%$ entre los educadores de adultos. Por lo demás, si se agregaran a los "Buenos", según sostuvieron el $11,25 \%$ y el $30,61 \%$ de los educadores de adolescentes y de adultos, respectivamente, se llegaría al $61,22 \%$ en los de egresados adolescentes y al $83,26 \%$ en los de egresados adultos. "No debería olvidarse que —en última instancia - la calidad de la educación dependería del nivel de los docentes y de la actitud de apertura hacia el aprendizaje por parte del alumnado". Tal lo manifestado por Jorgelina, profesora de Inglés en la escuela $\mathrm{E}$, al investigador.

En la pregunta 12 ¿Cuáles son las conductas inadecuadas del alumnado en clase?, el $62,75 \%$ de los profesores de egresados adolescentes y adultos eligió "Hablar con algún compañero cuando el profesor explica". E1 54,90\% de todos los educadores señaló la "Ofensa verbal entre ellos". Asimismo, el 18,63\% de ellos afirmó que el alumnado no incurre en ninguna conducta inadecuada. Respecto de la pregunta 13 ¿Cómo encauza/pone fin a dichas conductas?, el 66,67\% de todos los educadores sostuvo que "Si son perturbadoras corrijo al o a los responsables". Los demás porcentajes que atañen a las restantes opciones son significativamente inferiores. Téngase presente que, tradicionalmente, la escuela fue entendida como uno de los principales agentes de socialización, tanto para la producción del orden social como para la conformación de subjetividades capaces de habitarlo. Hoy día se denuncian la pérdida de eficacia de la misma en la función de socialización así como en la transmisión de conocimientos. Respecto de lo señalado supra, léanse los Cuadros 11.a, 11.b, 12 y 13 y sus Gráficos 10 y 11 correspondientes: 
Pregunta 11: ¿Cómo considera que son como estudiantes los egresados de esta escuela? (Indique en porcentaje)

\begin{tabular}{|c|c|c|c|c|c|c|c|c|c|c|c|}
\hline \multirow{2}{*}{ Opciones } & \multicolumn{10}{|c|}{ Escuelas de Adolescentes (por abecedario) } & \multirow{2}{*}{ Promedio } \\
\hline & $\mathbf{A}$ & B & $\mathbf{C}$ & D & $\mathbf{E}$ & $\mathbf{F}$ & G & $\mathbf{H}$ & I & $\mathbf{J}$ & \\
\hline Excelentes & $5 \%$ & $10 \%$ & $10 \%$ & $6,25 \%$ & $9,40 \%$ & $12,14 \%$ & $8 \%$ & $0 \%$ & $15,71 \%$ & $7,50 \%$ & $8,40 \%$ \\
\hline Muy buenos & $52,50 \%$ & $40 \%$ & $10 \%$ & $63,75 \%$ & $49 \%$ & $41,42 \%$ & $54 \%$ & $40 \%$ & $45 \%$ & $20 \%$ & $41,57 \%$ \\
\hline Buenos & $25 \%$ & $0 \%$ & $60 \%$ & $17,50 \%$ & $0 \%$ & $0 \%$ & $0 \%$ & $0 \%$ & $10 \%$ & $0 \%$ & $11,25 \%$ \\
\hline Regulares & $17,50 \%$ & $40 \%$ & $20 \%$ & $12,50 \%$ & $31,60 \%$ & $37,14 \%$ & $36 \%$ & $60 \%$ & $22,14 \%$ & $50,75 \%$ & $32,76 \%$ \\
\hline Malos & $0 \%$ & $10 \%$ & $0 \%$ & $0 \%$ & $10 \%$ & $9,30 \%$ & $2 \%$ & $0 \%$ & $7,15 \%$ & $21,75 \%$ & $6,02 \%$ \\
\hline
\end{tabular}

Total: 10 escuelas.

\section{Cuadro 11.b}

\begin{tabular}{|c|c|c|c|c|c|c|c|c|c|}
\hline Opciones & \multicolumn{8}{|c|}{ Escuelas de Adultos (por abecedario) } & Promedio \\
\hline Excelentes & $5 \%$ & $2,50 \%$ & $0 \%$ & $8 \%$ & $31,66 \%$ & $0 \%$ & $0 \%$ & $2,50 \%$ & $6,20 \%$ \\
\hline Muy buenos & $80 \%$ & $77,50 \%$ & $100 \%$ & $12,50 \%$ & $61,66 \%$ & $10 \%$ & $0 \%$ & $30 \%$ & $46,45 \%$ \\
\hline Buenos & $10 \%$ & $7,50 \%$ & $0 \%$ & $38,25 \%$ & $6,68 \%$ & $50 \%$ & $100 \%$ & $32,50 \%$ & $30,61 \%$ \\
\hline Malos & $0 \%$ & $0 \%$ & $0 \%$ & $1,25 \%$ & $0 \%$ & $10 \%$ & $0 \%$ & $5 \%$ & $2,03 \%$ \\
\hline
\end{tabular}

Total: 8 escuelas. 
Pregunta 12: ¿Cuáles son las conductas inadecuadas del alumnado en clase?

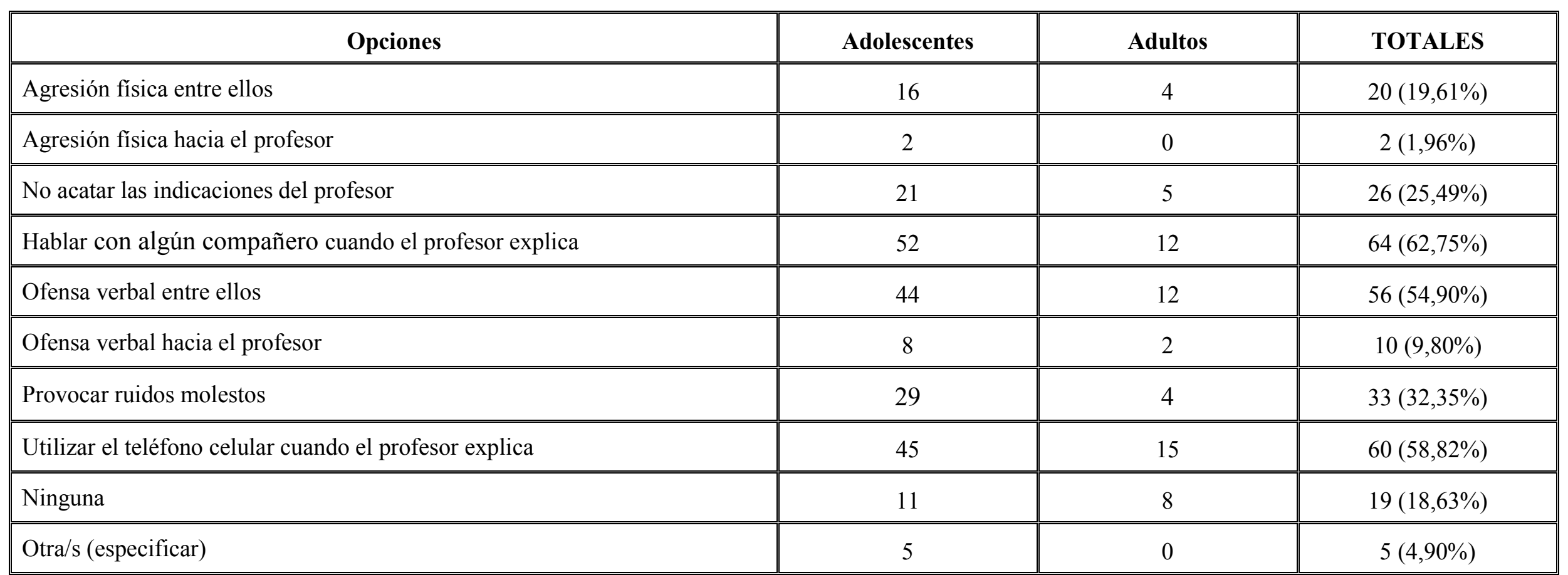




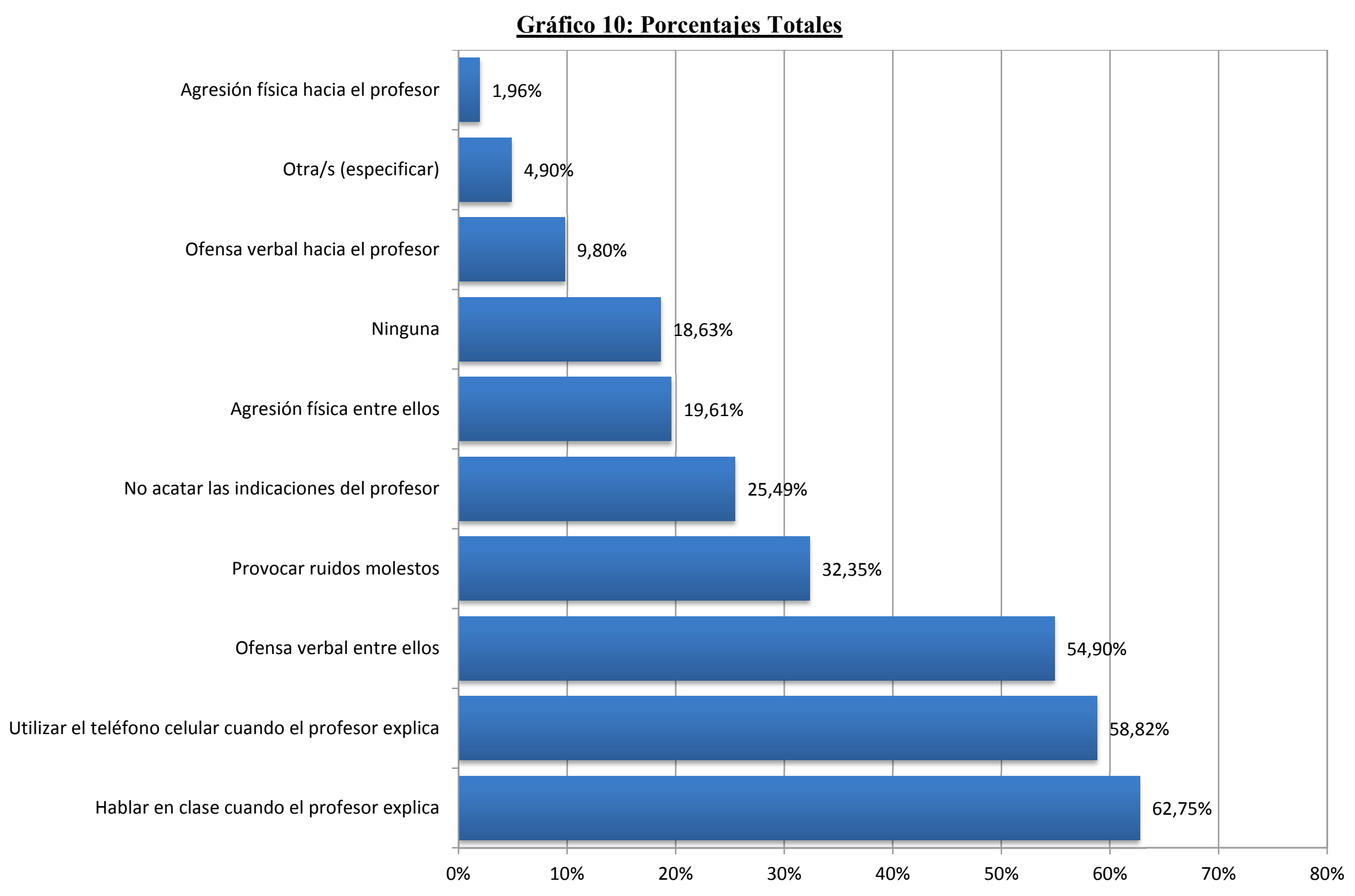




\begin{tabular}{|c|c|c|c|}
\hline Opciones & Adolescentes & Adultos & TOTALES \\
\hline Hago venir al director al aula y le comento lo sucedido & 3 & 0 & $3(2,94 \%)$ \\
\hline Si no son muy perturbadoras, no intervengo & 11 & 5 & $16(15,68 \%)$ \\
\hline Si son perturbadoras corrijo al o a los responsables & 54 & 14 & $68(66,67 \%)$ \\
\hline Suspendo la clase y empezamos todos a dialogar sobre aspectos del Acuerdo de Convivencia & 26 & 6 & $32(31,37 \%)$ \\
\hline Suspendo la clase, pienso qué hacer y luego actúo & 2 & 2 & $4(3,92 \%)$ \\
\hline Otra/s (especificar) & 6 & 1 & $7(6,86 \%)$ \\
\hline
\end{tabular}




\section{Gráfico 11: Porcentajes Totales}

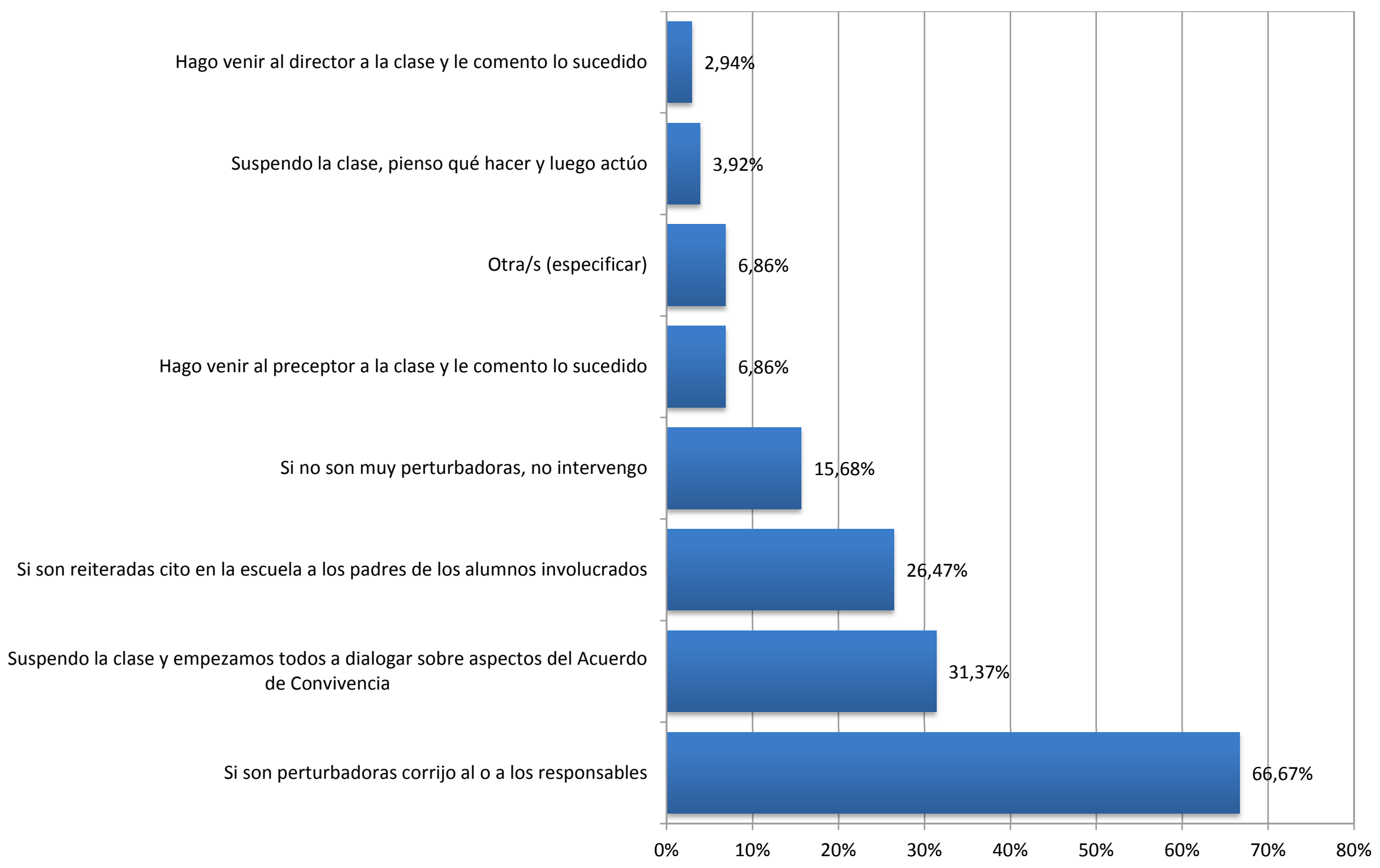




\subsubsection{Análisis descriptivo}

Teniendo en cuenta que los egresados "Excelentes", "Muy buenos" y "Buenos" representan el $61,22 \%$ entre los adolescentes y el $83,26 \%$ entre los adultos y que, entre todos los profesores, el 43,14\% afirmó que la calidad educativa desde 1983 hasta hoy es "Regular", en tanto el 8,82\% la consideró "Mala", surgiría una posible línea de investigación futura. La misma consistiría en relacionar esos elevados porcentajes de alumnos "Excelentes", "Muy buenos" y "Buenos" con los porcentajes referidos a la educación considerada "Regular" y "Mala" que, sumados, alcanzan el 51,96\%. En otras palabras, muchos alumnos destacados en el contexto de una educación de regular o baja calidad.

Asimismo, sabido es que a los adolescentes se les exige adquirir más conocimientos —al menos, esta afirmación es unánime entre los profesores- que a los adultos. No obstante, los datos mostraron que hay un 22,04\% más entre los mejores educandos adultos al compararlos con los adolescentes. Este dato es relevante habida cuenta que aquéllos tienen menos tiempo para estudiar por otras responsabilidades que han asumido (por ejemplo: familiares y laborales). Indagar sobre esta realidad y su vinculación con el rendimiento escolar no es actividad de esta investigación.

En otro orden de ideas, a la opinión que les merecieron a los educadores las actuales leyes educativas nacional y de la provincia de Buenos Aires. De los resultados obtenidos surge que casi la mitad de todos los profesores ante la normativa vigente evidencia entre desconocimiento y lo que podría denominarse indiferencia. La posible causa (o causas) de esta postura exceden el marco del presente trabajo, pero sus consecuencias directas muy posiblemente incidan negativamente en la calidad educativa (especialmente en el aprendizaje de los estudiantes desaventajados). Por lo demás, casi el $60 \%$ de todos los profesores se desempeña como preceptor en otra/s escuela/s y poco más del $30 \%$ es educador en más de un establecimiento. Éstos son índices evidentes de la ubicación de los educadores en el mercado de trabajo y de su situación de vida como asalariados. Podría debatirse si deben ser considerados profesionales por la actividad que cumplen, mas no su rol de trabajadores al tiempo de percibir la contraprestación por el servicio que brindan. Los efectos en el ejercicio del rol que de todo esto emanan ameritarían un debate amplio.

Otro dato relevante es que más de la mitad de todos los educadores lo es "Por vocación". E1 22,55\% afirmó "Nunca pensé ser docente pero un día cambié de opinión". Ambas actitudes podrían indicar — ab initio - "mentalidades" diferentes frente al objeto educación, mas nada de ello define en última instancia la calidad del profesor al momento de estar en clase.

En cuanto a las teorías o recursos educativos aplicados en clase, los tres porcentajes más elevados permitirían conjeturar que habría algo así como dos posturas extremas y una tercera, ecléctica, que actuaría como síntesis de las anteriores. La aplicación de diferentes teorías pone de manifiesto a los docentes que pueden hallarse en los colegios. La inquietud podría referirse 
a cómo recepcionan los alumnos aquellos mensajes transmitidos por diez educadores en un mismo curso, a través de las diferentes teorías aplicadas durante todo el año. Consultados que fueron por el investigador, estudiantes de diferentes escuelas y modalidades no supieron distinguir con precisión qué teoría educativa aplicaban los profesores en sus clases. Con este agregado: el carácter monolítico de las propuestas curriculares centradas en la transmisión y la acumulación de conocimientos retrocedió —en los últimos años - ante el avance de una concepción educacional asociada a las visiones cognitivista y constructivista del aprendizaje. Estas últimas atribuyen un nuevo papel al educando al valorar su creatividad y un nuevo rol al docente, visto como un facilitador de aprendizajes y no meramente como un transmisor de saberes. Esta concepción educacional, fundada en el cognitivismo y en el constructivismo, fue elegida como respuesta por un porcentaje ínfimo de todos los profesores encuestados.

A propósito de las teorías o recursos, su influjo sería visible — desde un punto de vistaen la irrupción de conductas inadecuadas por parte del alumnado. Cualquiera de ellos implicaría una metodología pertinente y de esta realización podrían sobrevenir diferentes actitudes en los estudiantes, de modo que no siempre "Hablar en clase" obstaculizaría el proceso enseñanza-aprendizaje ni "estar en silencio" siempre implicaría atención respecto del tema que está desarrollando el profesor. 


\subsection{Directores de escuelas estatales de nivel medio del Distrito de Junín}

Total de directores (de egresados adolescentes) que fueron encuestados

Total de directores (de egresados adultos) que fueron encuestados

Total de directores (de egresados adolescentes y adultos) que fueron encuestados

Total de directores (de egresados adolescentes y adultos) no encuestados porque sus escuelas no integraron la muestra

Total de directores (de egresados adolescentes y adultos) del ciclo lectivo 2010

Prueba piloto: se efectuó en julio de 2010 con una directora.

Instrumento de recolección de datos: cuestionario autoadministrado individual (no precodificado) que incluye preguntas cerradas con varias opciones de respuesta no mutuamente excluyentes (1, 2 y 4). Otras preguntas cerradas con varias posibilidades de respuesta de las que debe elegir una (3 y 5). Y preguntas abiertas (6 a 17). En total, 17 preguntas. 


\subsubsection{Presentación de los participantes}

\begin{tabular}{|c|c|c|c|c|c|}
\hline \multicolumn{6}{|c|}{ Directores de Escuelas de Adolescentes } \\
\hline Escuela & Sexo & Edad & Estado Civil & $\begin{array}{l}\text { Antigüedad en la } \\
\text { docencia }\end{array}$ & $\begin{array}{l}\text { Antigüedad } \\
\text { en el cargo }\end{array}$ \\
\hline $\mathbf{A}$ & $\mathrm{F}$ & 55 años & Soltera & 28 años & 8 años \\
\hline B & M & 53 años & Casado & 34 años & 14 años \\
\hline $\mathbf{C}$ & M & 47 años & Casado & 26 años & 4 años \\
\hline D & M & 45 años & Casado & 24 años & 1 año \\
\hline $\mathbf{E}$ & M & 47 años & Unido de hecho & 22 años & 1 año \\
\hline $\mathbf{F}$ & $\mathrm{F}$ & 65 años & Casada & 42 años & 20 años \\
\hline G & $\mathrm{F}$ & 49 años & Soltera & 25 años & 5 años \\
\hline $\mathbf{H}$ & $\mathrm{F}$ & 53 años & Casada & 24 años & 5 años \\
\hline $\mathbf{I}$ & $\mathrm{F}$ & 45 años & Casada & 22 años & 5 años \\
\hline $\mathbf{J}$ & M & 48 años & Casado & 19 años & 8 años \\
\hline \multicolumn{4}{|c|}{ PROMEDIO 50 años y 8 meses } & 26 años y 7 meses & 7 años y 1 me \\
\hline
\end{tabular}

\begin{tabular}{|c|c|c|c|c|c|}
\hline \multicolumn{6}{|c|}{ Directores de Escuelas de Adultos } \\
\hline Escuela & Sexo & Edad & Estado Civil & $\begin{array}{c}\text { Antigüedad en la } \\
\text { docencia }\end{array}$ & $\begin{array}{l}\text { Antigüedad } \\
\text { en el cargo }\end{array}$ \\
\hline $\mathbf{H}_{1}$ & $\mathrm{~F}$ & 56 años & Casada & 27 años & 8 años \\
\hline $\mathbf{L}$ & $\mathrm{F}$ & 43 años & Soltera & 23 años & 2 años \\
\hline $\mathbf{M}$ & $\mathrm{F}$ & 52 años & Casada & 29 años & 1 año \\
\hline \multicolumn{2}{|c|}{ PROMEDIO } & 50 años y $4 \mathrm{~m}$ & & 26 años y 4 meses & 3 años y 8 meses \\
\hline
\end{tabular}

$\begin{array}{ll}\text { PROMEDIO } & 50 \text { años y } 7 \text { meses } \\ \text { FINAL } & 26 \text { años y } 6 \text { meses } \quad 6 \text { años y } 4 \text { meses }\end{array}$

Total de Directores participantes: 13

\subsubsection{Datos obtenidos al operacionalizar las variables}




\begin{tabular}{|c|c|c|c|}
\hline Opciones & \multicolumn{3}{|c|}{ TOTALES } \\
\hline El coordinador natural de la institución educativa & 7 & $53,85 \%$ & $29,17 \%$ \\
\hline El encargado de resguardar la estructura orgánica de la institución & 7 & $53,85 \%$ & $29,17 \%$ \\
\hline Nada de lo anteriormente dicho & 0 & $0.00 \%$ & $0,00 \%$ \\
\hline Otra/s (especificar) & 2 & $15,38 \%$ & $8,33 \%$ \\
\hline
\end{tabular}




\section{Gráfico 1.a: Porcentajes en base al total de participantes}

Nada de lo anteriormente dicho

Otra/s (especificar)

Todo lo anteriormente dicho

La autoridad con funciones y competencias indeclinables

El encargado de resguardar la estructura orgánica de la institución

El coordinador natural de la institución educativa

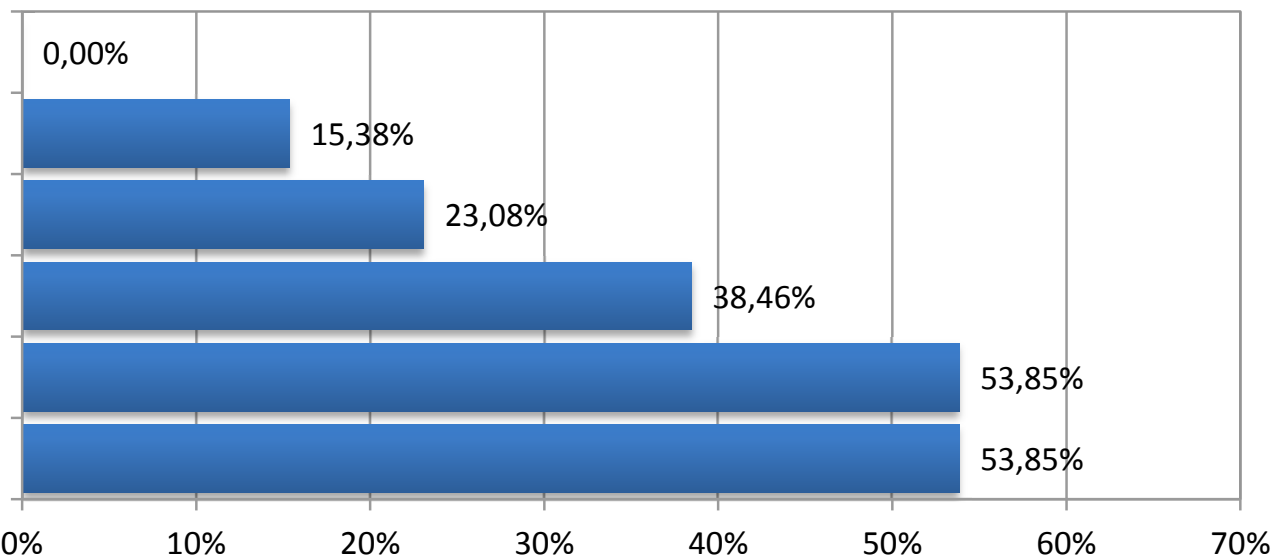

\section{Gráfico 1.b: Porcentajes en base al total de respuestas dadas}

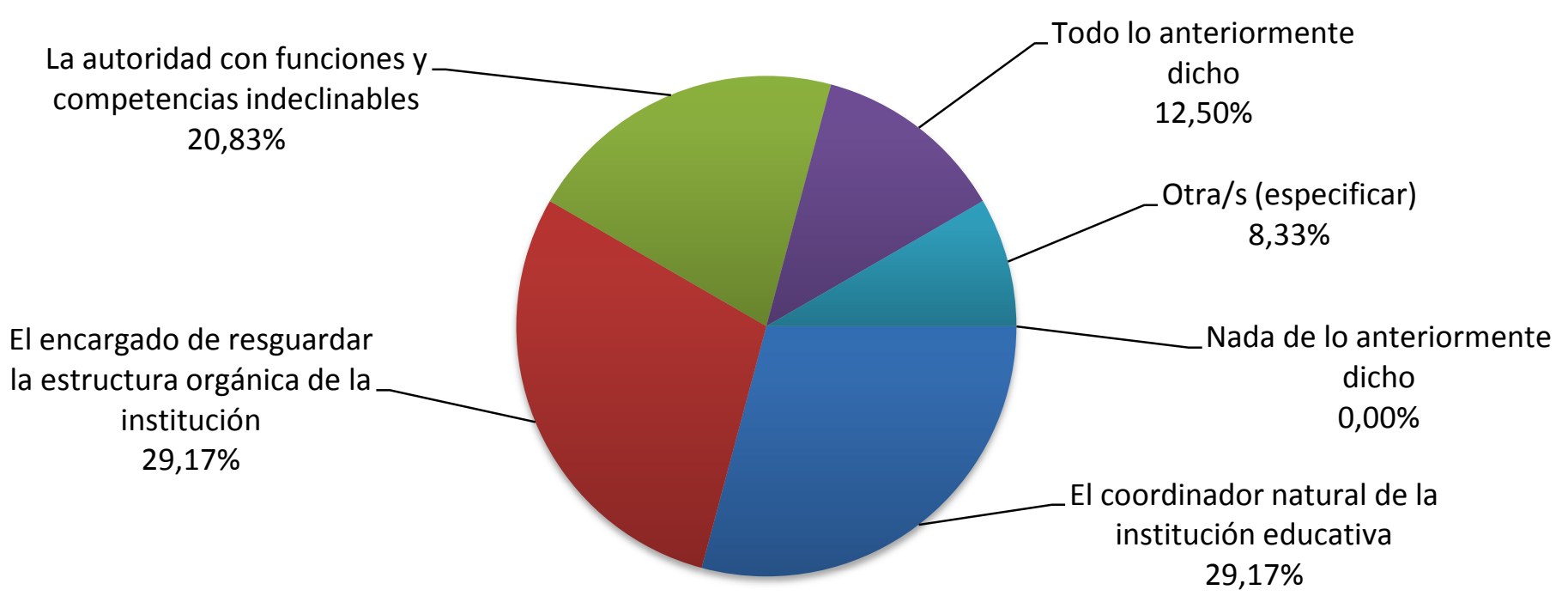




\begin{tabular}{|l|c|}
\hline \multicolumn{1}{|c|}{ Opciones } & TOTALES \\
\hline En la Constitución Nacional & $10(76,92 \%)$ \\
\hline En uno o más Tratados Internacionales de Derechos Humanos con jerarquía constitucional & $9(69,23 \%)$ \\
\hline En una Ley Nacional & $10(76,92 \%)$ \\
\hline En la Constitución de la Provincia de Buenos Aires & $8(61,54 \%)$ \\
\hline En una Ley de la Provincia de Buenos Aires & $10(76,92 \%)$ \\
\hline En una Ordenanza Municipal del Partido de Junín & $0(0,00 \%)$ \\
\hline En todo lo anteriormente dicho & $0(0,00 \%)$ \\
\hline \hline En nada de lo anteriormente dicho & $0(0,00 \%)$ \\
\hline Otro/s (especificar) & $0(0,00 \%)$ \\
\hline
\end{tabular}




\section{Gráfico 2: Porcentajes Totales}

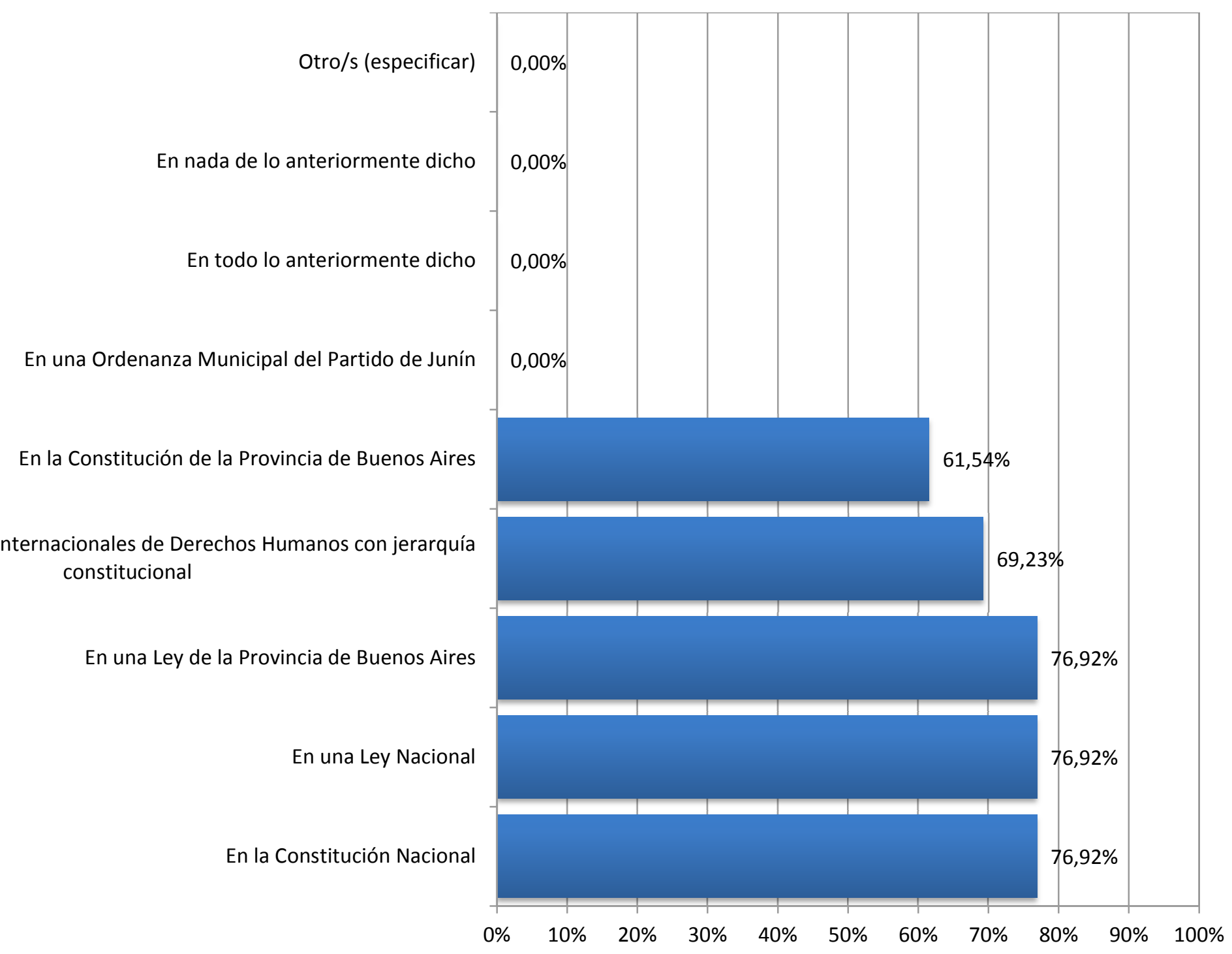


Pregunta 3: ¿Qué tan de acuerdo se encuentra con lo dispuesto sobre la educación secundaria en las siguientes leyes?

\begin{tabular}{|l|c|c||}
\hline \multicolumn{1}{|c||}{ Opciones } & $\begin{array}{c}\text { Ley de Educación Nacional No 26.206/06 } \\
\text { TOTALES }\end{array}$ & $\begin{array}{c}\text { Ley de Educación Provincial No 13.688/07 } \\
\text { TOTALES }\end{array}$ \\
\hline \hline Muy de acuerdo & $7(53,85 \%)$ & $7(53,85 \%)$ \\
\hline \hline De acuerdo & $6(46,15 \%)$ & $6(46,15 \%)$ \\
\hline \hline Ni de acuerdo ni en desacuerdo & $0(0,00 \%)$ & $0(0,00 \%)$ \\
\hline En desacuerdo & $0(0,00 \%)$ & $0(0,00 \%)$ \\
\hline Muy en desacuerdo & $0(0,00 \%)$ & $0(0,00 \%)$ \\
\hline No estoy debidamente informado/a & $0(0,00 \%)$ & $0(0,00 \%)$ \\
\hline \hline Otra/s (especificar) & $0(0,00 \%)$ & $0(0,00 \%)$ \\
\hline
\end{tabular}

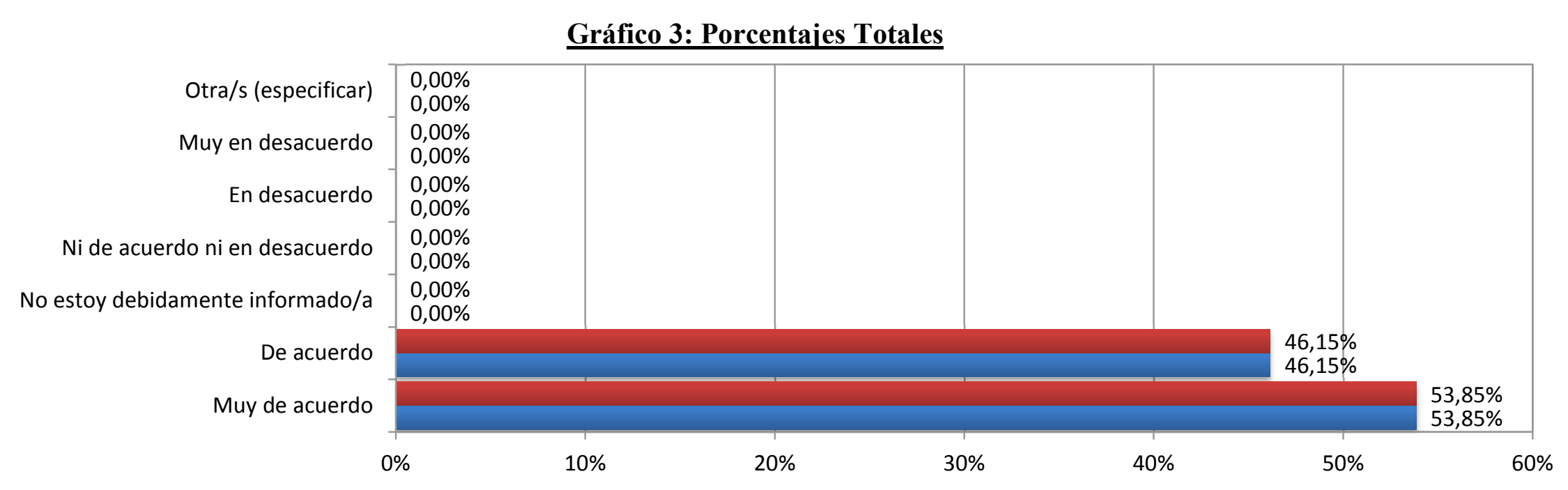

—ey de Educación Provincial №13.688/07

- Ley de Educación Nacional №26.206/06 


\begin{tabular}{|l||c||}
\hline \multicolumn{1}{|c||c||}{ Opciones } & TOTALES \\
\hline Excelente & $0(0,00 \%)$ \\
\hline Muy buena & $0(0,00 \%)$ \\
\hline Buena & $7(53,85 \%)$ \\
\hline Indeciso/a & $0(0,00 \%)$ \\
\hline Regular & $6(46,15 \%)$ \\
\hline Mala & $0(0,00 \%)$ \\
\hline Muy mala & $0(0,00 \%)$ \\
\hline \hline Otra/s (especificar) & $0(0,00 \%)$ \\
\hline
\end{tabular}

\section{Gráfico 4: Porcentajes Totales}

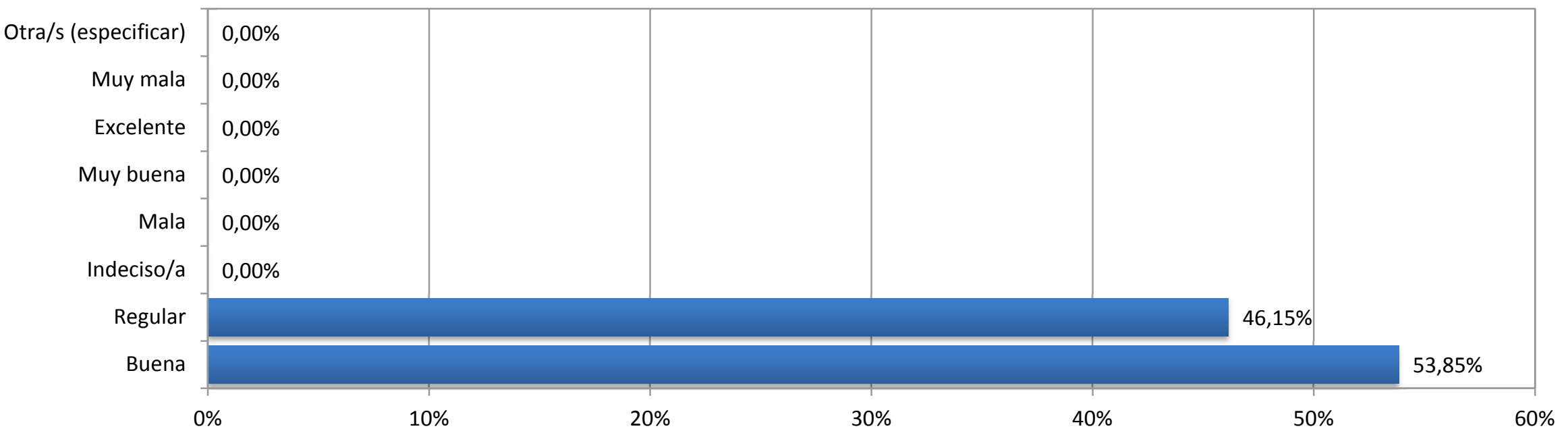


Cuadro 5

\begin{tabular}{|c|c|c|c|c|c|c|}
\hline \multirow{3}{*}{ Opciones } & \multicolumn{6}{|c|}{ TOTALES } \\
\hline & \multicolumn{2}{|c|}{ Padre } & \multicolumn{2}{|c|}{ Madre } & \multicolumn{2}{|c|}{ Tutor/Otro } \\
\hline & $\mathbf{F}$ & No $F$ & $\mathbf{F}$ & No $F$ & $\mathbf{F}$ & No $F$ \\
\hline Primario & 6 & 2 & 7 & 2 & 0 & 0 \\
\hline Secundario & 2 & 1 & 2 & 1 & 0 & 0 \\
\hline Universitario & 0 & 0 & 0 & 0 & 0 & 0 \\
\hline Posgrado & 0 & 0 & 0 & 0 & 0 & 0 \\
\hline Licenciatura & 0 & 0 & 0 & 0 & 0 & 0 \\
\hline Doctorado & 0 & 0 & 0 & 0 & 0 & 0 \\
\hline
\end{tabular}

Nota: "F" = Finalizado; "No F" = No Finalizado

Pregunta 5: ¿Cuál es el máximo nivel educativo alcanzado por su...? 
Pregunta 6: ¿Cómo se relaciona esta institución educativa con los responsables de los egresados 2010?

\begin{tabular}{||l|c||}
\hline \multicolumn{1}{|c||}{ Opinión de los Directores } & $\begin{array}{c}\text { Cantidad de Directores que } \\
\text { respondieron de esta manera }\end{array}$ \\
\hline $\begin{array}{l}\text { Mediante citaciones personales y cuadernos de comunicaciones } \\
\text { para facilitar los mensajes de interés educativo. }\end{array}$ & 9 \\
\hline \hline $\begin{array}{l}\text { Actitud receptiva del personal ante la formulación de inquietudes } \\
\text { escolares provenientes de los responsables del alumno. }\end{array}$ & 4 \\
\hline
\end{tabular}

Pregunta 7: ¿Cómo se llegó a confeccionar el Acuerdo Institucional de Convivencia?

\begin{tabular}{|l|c|}
\hline \multicolumn{1}{|c|}{ Opinión de los Directores } & $\begin{array}{c}\text { Cantidad de Directores que } \\
\text { respondieron de esta manera }\end{array}$ \\
\hline $\begin{array}{l}\text { Por la participación activa de todos los miembros de la comunidad } \\
\text { educativa. }\end{array}$ & 10 \\
\hline \hline Participaron activamente algunos sectores y otros no tanto. & 3 \\
\hline
\end{tabular}

Pregunta 8: ¿Cuáles son las prioridades de esta escuela?

\begin{tabular}{|l|c||}
\hline \multicolumn{1}{|c|}{ Opinión de los Directores } & $\begin{array}{c}\text { Cantidad de Directores que } \\
\text { respondieron de esta manera }\end{array}$ \\
\hline Lograr la valoración de la actividad educativa, inclusión mediante. & 6 \\
\hline Vivir una educación fundada en valores y para la libertad. & 3 \\
\hline Fortalecer su identidad en la comunidad. & 2 \\
\hline Alcanzar un clima institucional adecuado. & 1 \\
\hline \hline Tener edificio propio y mejoras edilicias. & 1 \\
\hline
\end{tabular}


Pregunta 9: ¿Qué tareas hay que realizar en la escuela referidas a su organización?

\begin{tabular}{|l|c||}
\hline \multicolumn{1}{|c|}{ Opinión de los Directores } & $\begin{array}{c}\text { Cantidad de Directores que } \\
\text { respondieron de esta manera }\end{array}$ \\
\hline \hline $\begin{array}{l}\text { Realizar de las gestiones administrativa, pedagógica y } \\
\text { político-social. }\end{array}$ & 5 \\
\hline Asignar de espacios de responsabilidades y formar de grupos. & 3 \\
\hline Distribuir de tareas considerando varias dimensiones. & 2 \\
\hline \hline Cumplir lo planificado y resolver las situaciones imprevistas. & 1 \\
\hline Llevar a cabo políticas socio-educativas. & 1 \\
\hline Lograr que se comprometan todos los agentes educativos. & 1 \\
\hline
\end{tabular}

Pregunta 10: ¿Quién/quiénes la/s lleva/n a cabo?

\begin{tabular}{||l|c|}
\hline \multicolumn{1}{|c|}{ Opinión de los Directores } & $\begin{array}{c}\text { Cantidad de Directores que } \\
\text { respondieron de esta manera }\end{array}$ \\
\hline \hline El equipo directivo y otros agentes por derivación. & 8 \\
\hline \hline El equipo intermedio; entre otros, los jefes de departamento. & 3 \\
\hline \hline Padres y docentes. & 2 \\
\hline
\end{tabular}

Pregunta 11: ¿Cómo se puede contribuir a ellas?

\begin{tabular}{|l|c||}
\hline \multicolumn{1}{|c|}{ Opinión de los Directores } & $\begin{array}{c}\text { Cantidad de Directores que } \\
\text { respondieron de esta manera }\end{array}$ \\
\hline Generando proyectos democráticos con participación responsable. & 6 \\
\hline \hline Trabajando en equipos. & 4 \\
\hline \hline Trabajando en libertad, con clima agradable, valorizando a todos. & 2 \\
\hline \hline $\begin{array}{l}\text { Trabajando con sentido de "pertenencia", evitando superposiciones } \\
\text { y ambigüedades. }\end{array}$ & 1 \\
\hline
\end{tabular}


Pregunta 12: ¿Quién decide los pasos a seguir?

\begin{tabular}{|l|c||}
\hline \multicolumn{1}{|c|}{ Opinión de los Directores } & $\begin{array}{c}\text { Cantidad de Directores que } \\
\text { respondieron de esta manera }\end{array}$ \\
\hline \hline $\begin{array}{l}\text { El equipo de gestión (directivos, jefes de departamento, jefe de } \\
\text { preceptores, integrantes de los centros de estudiantes). }\end{array}$ & 8 \\
\hline \hline $\begin{array}{l}\text { El director consulta a su equipo para llevar a la práctica el PEI } \\
\text { (Proyecto Educativo Institucional). }\end{array}$ & 5 \\
\hline
\end{tabular}

Pregunta 13: ¿Qué se decide? ¿Cuándo se decide?

\begin{tabular}{|l|c||}
\hline \multicolumn{1}{|c||}{ Opinión de los Directores } & $\begin{array}{c}\text { Cantidad de Directores que } \\
\text { respondieron de esta manera }\end{array}$ \\
\hline \hline Todo. Cuando se presente el evento, salvo que se pueda prever. & 6 \\
\hline $\begin{array}{l}\text { El plan de acción a desarrollar durante el año escolar. Al comenzar } \\
\text { el ciclo lectivo }\end{array}$ & 5 \\
\hline \hline Se deben valorar los tiempos cronológicos preestablecidos. & 2 \\
\hline
\end{tabular}

Pregunta 14: ¿Quién informa a los demás?

\begin{tabular}{|l|c|}
\hline \multicolumn{1}{|c|}{ Opinión de los Directores } & $\begin{array}{c}\text { Cantidad de Directores que } \\
\text { respondieron de esta manera }\end{array}$ \\
\hline $\begin{array}{l}\text { Existe una verticalidad manifiesta en la transmisión de las } \\
\text { informaciones. }\end{array}$ & 8 \\
\hline \hline La persona designada a tal fin. & 4 \\
\hline \hline Secretaría. & 1 \\
\hline
\end{tabular}

Pregunta 15: ¿A quién/es se informa? ¿Para qué se informa?

\begin{tabular}{|l|c||}
\hline \multicolumn{1}{|c||}{ Opinión de los Directores } & $\begin{array}{c}\text { Cantidad de Directores que } \\
\text { respondieron de esta manera }\end{array}$ \\
\hline $\begin{array}{l}\text { A quien corresponda para efectuar la tarea, para la toma de } \\
\text { decisiones. }\end{array}$ & 8 \\
\hline $\begin{array}{l}\text { A todas las autoridades del sistema educativo, a la comunidad toda. } \\
\text { Para dar a conocer lo que se hace. }\end{array}$ & 5 \\
\hline
\end{tabular}


Pregunta 16: ¿Quién ayuda a quién?

\begin{tabular}{|l|c||}
\hline \multicolumn{1}{|c|}{ Opinión de los Directores } & $\begin{array}{c}\text { Cantidad de Directores que } \\
\text { respondieron de esta manera }\end{array}$ \\
\hline \hline $\begin{array}{l}\text { Existe colaboración entre todos los agentes en vista del educando y } \\
\text { su aprendizaje. }\end{array}$ & 13 \\
\hline
\end{tabular}

Pregunta 17: ¿Cómo afecta el trabajo de uno a la tarea del otro?

\begin{tabular}{|l|c||}
\hline \multicolumn{1}{|c|}{ Opinión de los Directores } & $\begin{array}{c}\text { Cantidad de Directores que } \\
\text { respondieron de esta manera }\end{array}$ \\
\hline $\begin{array}{l}\text { Trabajar coordinadamente, juntos con un mismo objetivo, cada uno } \\
\text { desde su lugar para bien de todos. }\end{array}$ & 8 \\
\hline Debe haber respeto entre todos y cumplimiento de las reglas. & 4 \\
\hline $\begin{array}{l}\text { Concientización de los perjuicios que ocasionan la superposición de } \\
\text { labores y los diferentes discursos. }\end{array}$ & 1 \\
\hline
\end{tabular}




\subsection{Secretarios de escuelas estatales de nivel medio del Distrito de Junín}

Total de secretarios (de egresados adolescentes) que fueron encuestados

Total de secretarios (de egresados adultos) que fueron encuestados

Total de secretarios (de egresados adolescentes y adultos) que fueron encuestados

Total de secretarios (de egresados adolescentes y adultos) no encuestados porque sus escuelas no integraron la

muestra

Total de secretarios (de egresados adolescentes y adultos) del ciclo lectivo 2010

Prueba piloto: se llevó a cabo en julio de 2010 con una secretaria.

Instrumento de recolección de datos: cuestionario autoadministrado individual (no precodificado) que incluye preguntas cerradas con varias opciones de respuesta no mutuamente excluyentes (1, 2 y 4). Otras preguntas cerradas con varias posibilidades de respuesta de las que debe elegir una (3 y 5). Y preguntas abiertas (6 a 11). En total, 11 preguntas. 
2.5.1. Presentación de los participantes

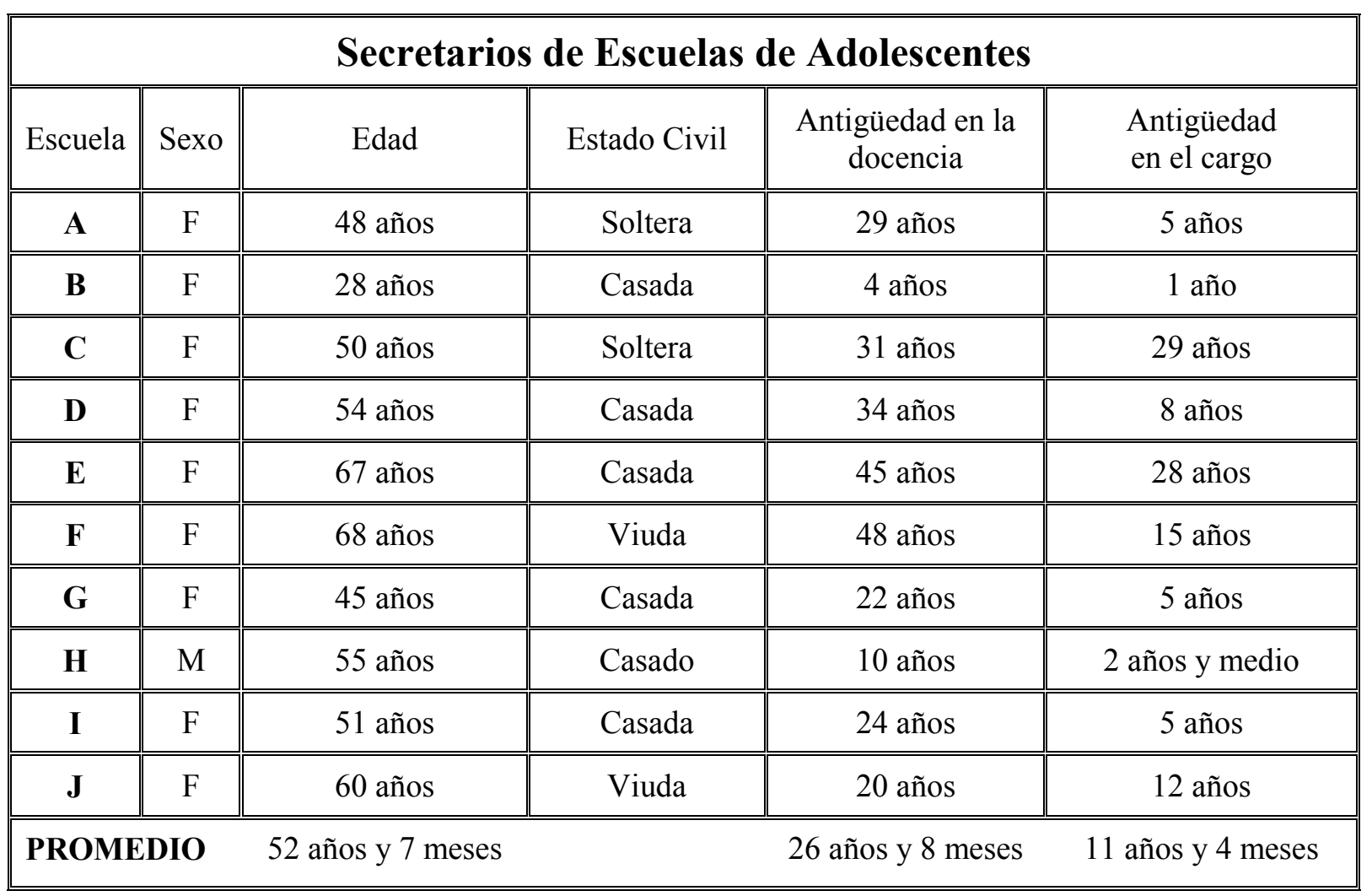

\begin{tabular}{|c|c|c|c|c|c|}
\hline \multicolumn{6}{|c|}{ Secretarios de Escuelas de Adultos } \\
\hline Escuela & Sexo & Edad & Estado Civil & $\begin{array}{c}\text { Antigüedad en la } \\
\text { docencia }\end{array}$ & $\begin{array}{l}\text { Antigüedad } \\
\text { en el cargo }\end{array}$ \\
\hline $\mathbf{H}_{1}$ & M & 56 años & Casado & 11 años & 3 años \\
\hline $\mathbf{L}$ & $\mathrm{F}$ & 67 años & Casada & 45 años & 28 años \\
\hline $\mathbf{M}$ & $\mathrm{F}$ & 47 años & Soltera & 24 años & 5 años \\
\hline \multicolumn{2}{|c|}{ PROMEDIO } & 56 años y $8 \mathrm{~m}$ & & 26 años y 8 meses & 12 años \\
\hline
\end{tabular}

\begin{tabular}{|l}
$\begin{array}{l}\text { PROMEDIO } \\
\text { TOTAL }\end{array}$ \\
53 años y 6 meses
\end{tabular}$\quad 26$ años y 8 meses $\quad 11$ años y 6 meses

Total de Secretarios participantes: 13

2.5.2. Datos obtenidos al operacionalizar las variables 


\begin{tabular}{|c|c|c|c|}
\hline Opciones & \multicolumn{3}{|c|}{ TOTALES } \\
\hline $\begin{array}{l}\text { Comprender la problemática del medio en que actúa y operar en razón de sus } \\
\text { demandas y necesidades }\end{array}$ & 5 & $38,46 \%$ & $11,90 \%$ \\
\hline Intervenir en la elaboración y el control del proyecto educativo institucional & 5 & $38,46 \%$ & $11,90 \%$ \\
\hline $\begin{array}{l}\text { Observar y describir el trabajo, con el fin de proponer mecanismos para la } \\
\text { mejor coordinación }\end{array}$ & 5 & $38,46 \%$ & $11,90 \%$ \\
\hline Participar de la organización institucional & 7 & $53,85 \%$ & $16,67 \%$ \\
\hline Nada de lo anteriormente dicho & 0 & $0,00 \%$ & $0,00 \%$ \\
\hline Otro/s (especificar) & 1 & $7,69 \%$ & $2,38 \%$ \\
\hline
\end{tabular}




\section{Gráfico 1.a: Porcentajes en base al total de participantes}

Nada de lo anteriormente dicho

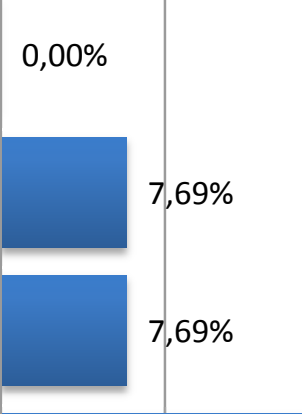

Observar y describir el trabajo, con el fin de proponer mecanismos para la mejor coordinación

Intervenir en la elaboración y el control del proyecto educativo institucional

Dar cuenta de los recursos humanos, materiales y financieros existentes

Comprender la problemática del medio en que actúa y operar en razón de sus demandas y necesidades

Asegurar canales de comunicación entre todos los actores de la institución y con los organismos con quienes se relacionan

Tomar decisiones en el marco de su competencia y en el ejercicio legítimo de su autoridad

Participar de la organización institucional
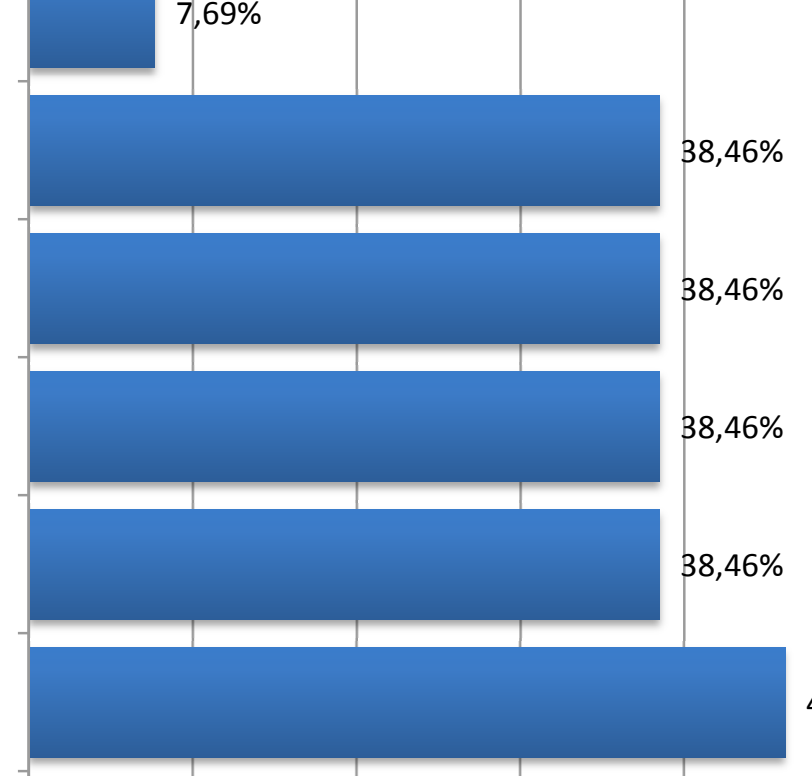

$46,15 \%$

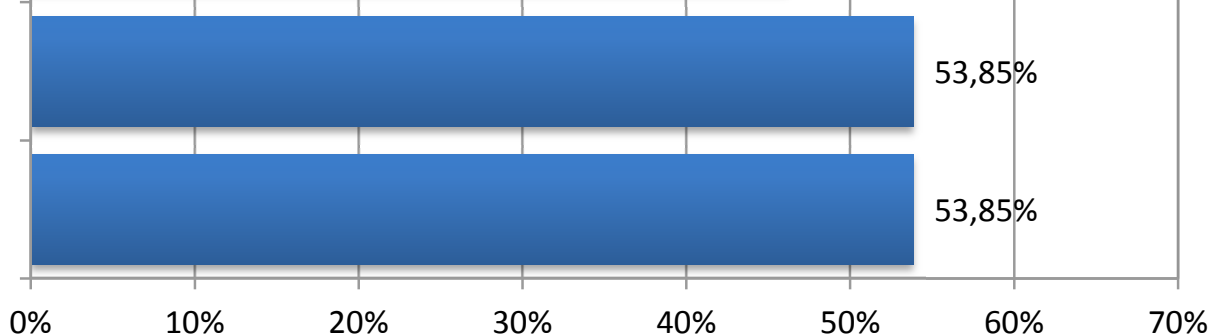




\section{Gráfico 1.b: Porcentajes en base al total de respuestas dadas}

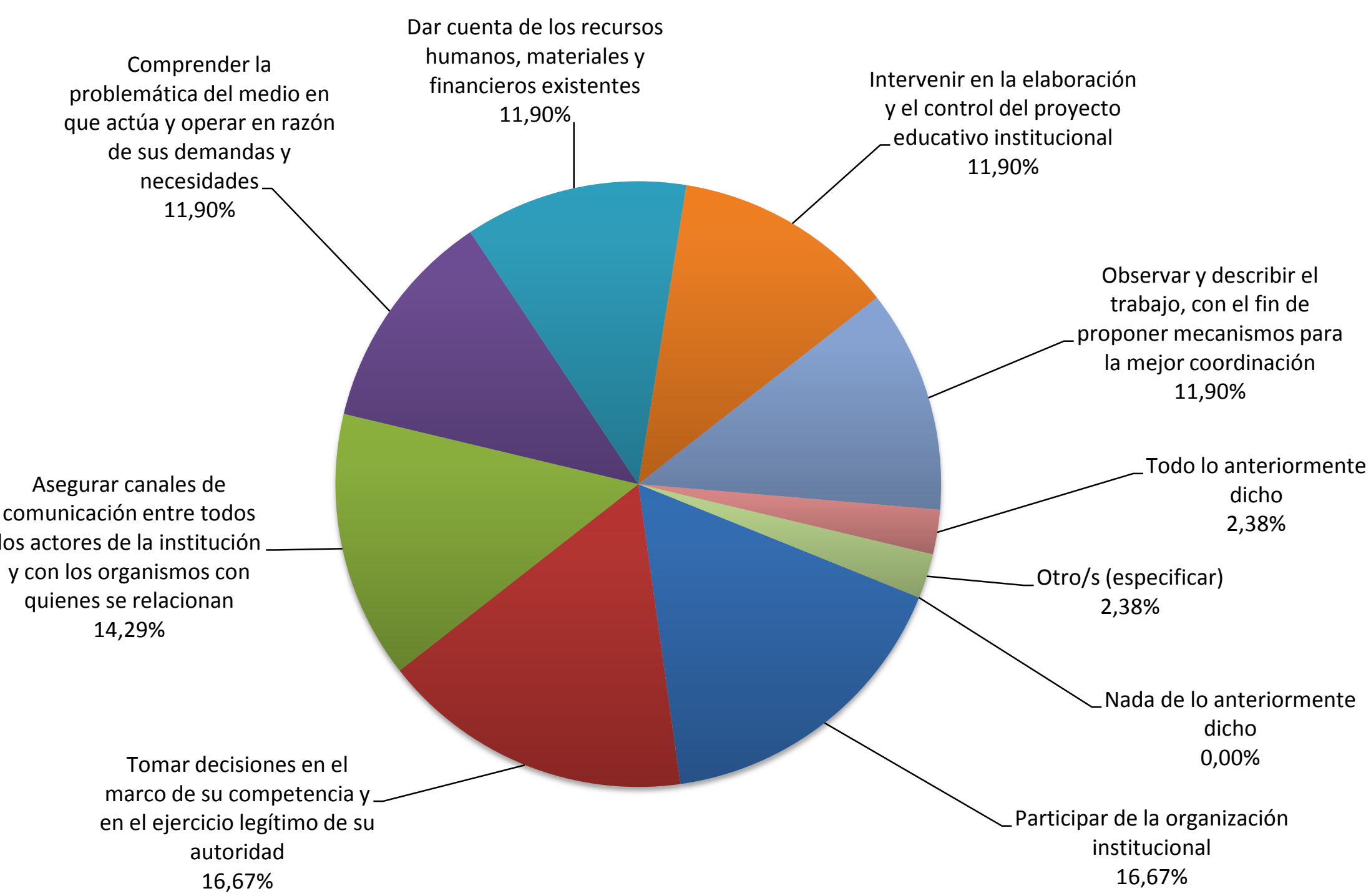




\section{Cuadro 2}

\begin{tabular}{||l||c||}
\hline \multicolumn{1}{|c||}{ Opciones } & TOTALES \\
\hline \hline En la Constitución Nacional & $7(53,85 \%)$ \\
\hline En uno o más Tratados Internacionales de Derechos Humanos con jerarquía constitucional & $7(53,85 \%)$ \\
\hline En una Ley Nacional & $7(53,85 \%)$ \\
\hline \hline En la Constitución de la Provincia de Buenos Aires & $6(46,15 \%)$ \\
\hline \hline En una Ley de la Provincia de Buenos Aires & $6(46,15 \%)$ \\
\hline En una Ordenanza Municipal del Partido de Junín & $2(15,38 \%)$ \\
\hline \hline En todo lo anteriormente dicho & $1(7,69 \%)$ \\
\hline \hline En nada de lo anteriormente dicho & $0(0,00 \%)$ \\
\hline \hline Otro/s (especificar) & $0(0,00 \%)$ \\
\hline
\end{tabular}

Pregunta 2: ¿Dónde está reconocido el derecho a la educación? 


\section{Gráfico 2: Porcentajes Totales}

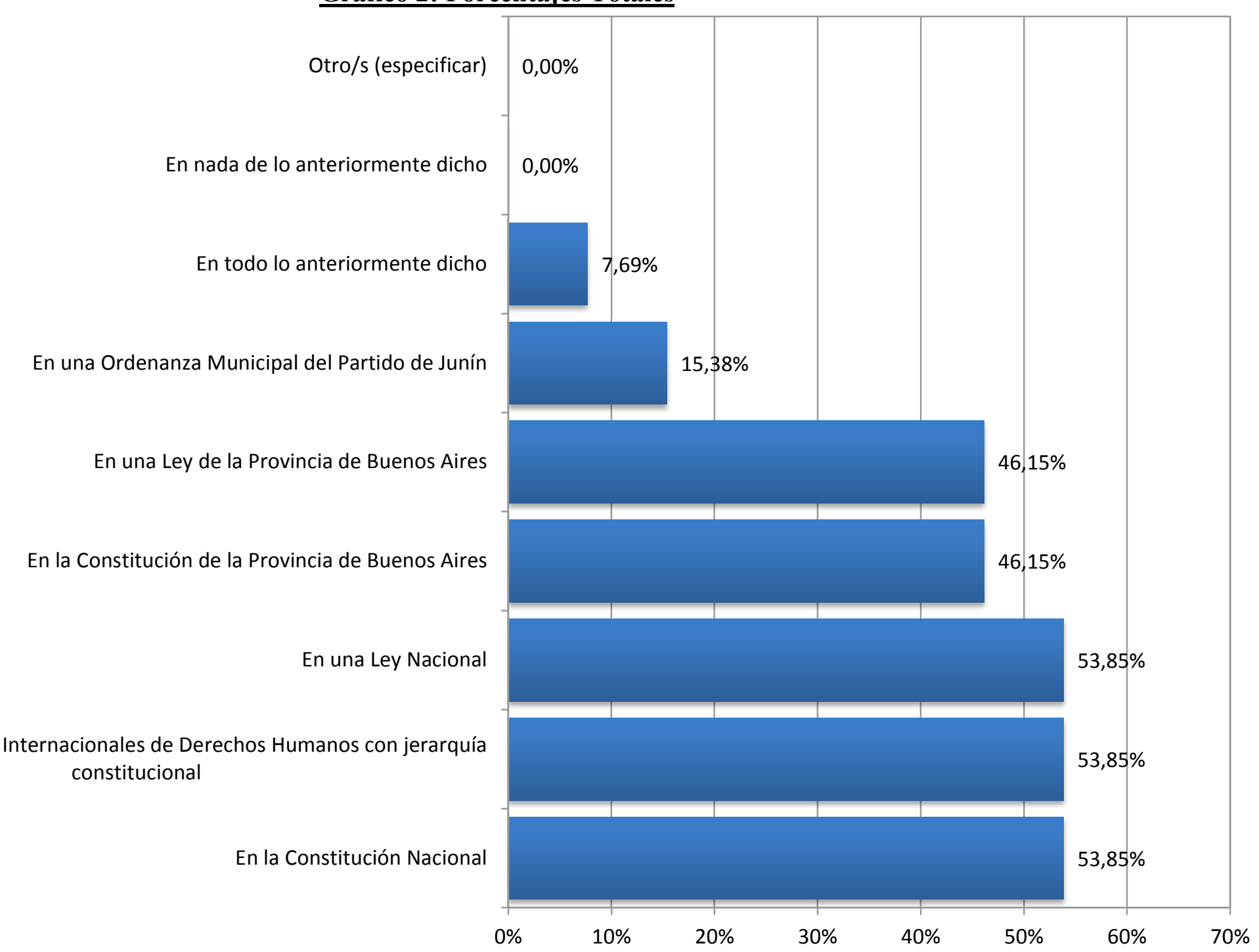




\begin{tabular}{|l|c|c||}
\hline Opciones & $\begin{array}{c}\text { Ley de Educación Nacional No 26.206/06 } \\
\text { TOTALES }\end{array}$ & $\begin{array}{c}\text { Ley de Educación Provincial No 13.688/07 } \\
\text { TOTALES }\end{array}$ \\
\hline \hline Muy de acuerdo & $0(0,00 \%)$ & $0(0,00 \%)$ \\
\hline \hline De acuerdo & $5(38,46 \%)$ & $6(46,15 \%)$ \\
\hline \hline Ni de acuerdo ni en desacuerdo & $3(23,08 \%)$ & $3(23,08 \%)$ \\
\hline En desacuerdo & $3(23,08 \%)$ & $3(23,08 \%)$ \\
\hline Muy en desacuerdo & $0(0,00 \%)$ & $0(0,00 \%)$ \\
\hline No estoy debidamente informado/a & $0(0,00 \%)$ & $1(7,69 \%)$ \\
\hline \hline Otro (especificar) & $1(7,69 \%)$ & $1(7,69 \%)$ \\
\hline
\end{tabular}

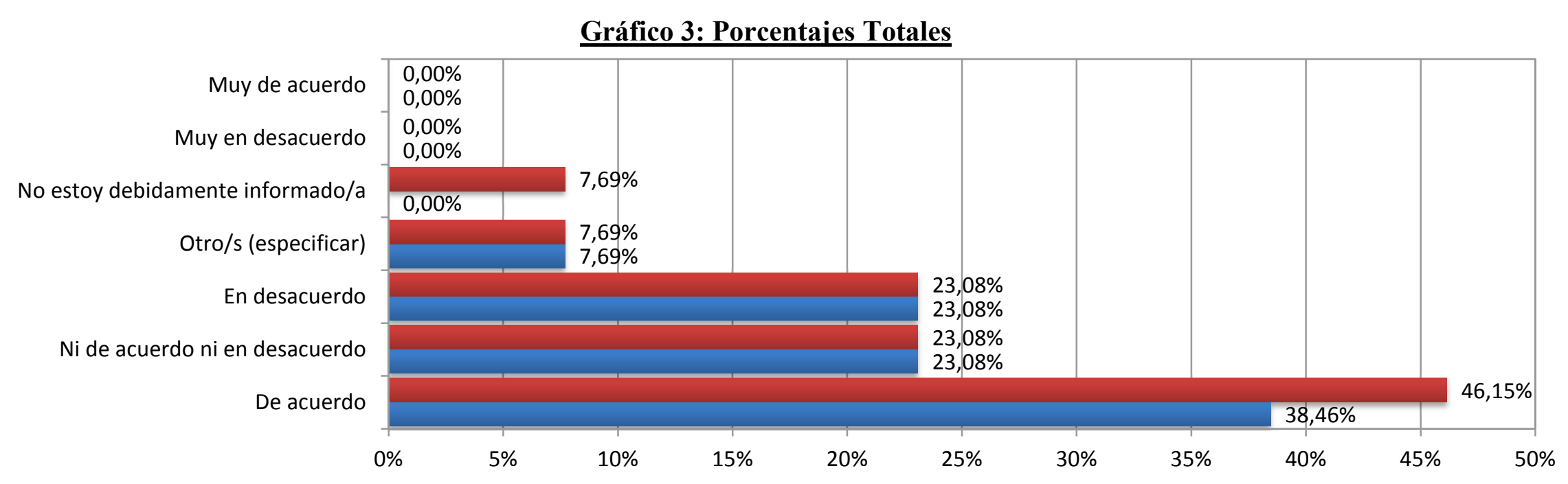

—ey de Educación Provincial №13.688/07

— Ley de Educación Nacional №26.206/06 


\begin{tabular}{|l||c|}
\hline \multicolumn{1}{|c||}{ Opciones } & TOTALES \\
\hline Excelente & $0(0,00 \%)$ \\
\hline Muy buena & $0(0,00 \%)$ \\
\hline Buena & $5(38,46 \%)$ \\
\hline Indeciso/a & $3(23,08 \%)$ \\
\hline Regular & $4(30,77 \%)$ \\
\hline Mala & $0(0,00 \%)$ \\
\hline Muy mala & $0(0,00 \%)$ \\
\hline \hline Otra/s (especificar) & $1(7,69 \%)$ \\
\hline
\end{tabular}

Gráfico 4: Porcentajes Totales

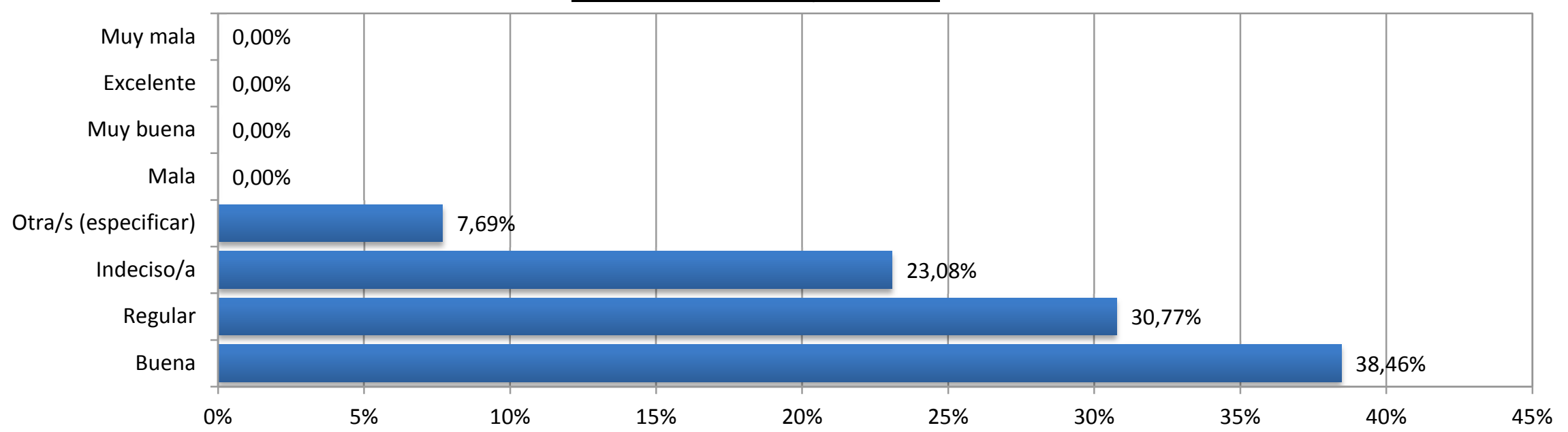


Cuadro 5

\begin{tabular}{|c|c|c|c|c|c|c|}
\hline \multirow{3}{*}{ Opciones } & \multicolumn{6}{|c|}{ TOTALES } \\
\hline & \multicolumn{2}{|c|}{ Padre } & \multicolumn{2}{|c|}{ Madre } & \multicolumn{2}{|c|}{ Tutor/Otro } \\
\hline & Finalizado & No Finalizado & Finalizado & No Finalizado & Finalizado & No Finalizado \\
\hline Primario & 5 & 2 & 4 & 2 & 0 & 0 \\
\hline Secundario & 3 & 1 & 3 & 2 & 0 & 0 \\
\hline Universitario & 0 & 0 & 0 & 0 & 0 & 0 \\
\hline Posgrado & 0 & 0 & 0 & 0 & 0 & 0 \\
\hline Licenciatura & 0 & 0 & 0 & 0 & 0 & 0 \\
\hline Doctorado & 0 & 0 & 0 & 0 & 0 & 0 \\
\hline
\end{tabular}


Pregunta 6: ¿Qué relación se da entre la escuela y el medio?

\begin{tabular}{|l|c||}
\hline \multicolumn{1}{|c|}{ Opinión de los Secretarios } & $\begin{array}{c}\text { Cantidad de Secretarios que } \\
\text { respondieron de esta manera }\end{array}$ \\
\hline \hline De cooperación y de colaboración mutuas & 8 \\
\hline \hline $\begin{array}{l}\text { Escasa participación de la familia pero no así de instituciones } \\
\text { barriales, circundantes al establecimiento }\end{array}$ & 3 \\
\hline Muy buena, a través de la implementación de la radio & 1 \\
\hline \hline Sólo a través del alumnado, si bien todas ellas son muy interesantes & 1 \\
\hline
\end{tabular}

Pregunta 7: ¿Cuáles son las reacciones esperadas ante probables cambios?

\begin{tabular}{|l|c|}
\hline \multicolumn{1}{|c|}{ Opinión de los Secretarios } & $\begin{array}{c}\text { Cantidad de Secretarios que } \\
\text { respondieron de esta manera }\end{array}$ \\
\hline $\begin{array}{l}\text { Actitud positiva hacia los cambios internos y externos respecto de } \\
\text { la escuela }\end{array}$ & 9 \\
\hline \hline Son aceptados, aunque al principio generen oposición & 4 \\
\hline
\end{tabular}

Pregunta 8: ¿Hay división del trabajo?

\begin{tabular}{|l|c|}
\hline \multicolumn{1}{|c|}{ Opinión de los Secretarios } & $\begin{array}{c}\text { Cantidad de Secretarios que } \\
\text { respondieron de esta manera }\end{array}$ \\
\hline $\begin{array}{l}\text { Sí, existe un apoyo efectivo al desempeño de los diferentes agentes } \\
\text { educativos }\end{array}$ & 9 \\
\hline \hline Por lo general sí; a veces hay que actuar en soledad & 4 \\
\hline
\end{tabular}


Pregunta 9: ¿La toma de decisiones es patrimonio exclusivo del personal jerárquico?

\begin{tabular}{|l|c||}
\hline \multicolumn{1}{|c|}{ Opinión de los Secretarios } & $\begin{array}{c}\text { Cantidad de Secretarios que } \\
\text { respondieron de esta manera }\end{array}$ \\
\hline \hline $\begin{array}{l}\text { Se observa eficacia en los diferentes agentes que tienen } \\
\text { responsabilidades asignadas compartidas }\end{array}$ & 5 \\
\hline \hline No, existen acuerdos previos a la toma de decisiones & 3 \\
\hline $\begin{array}{l}\text { Sí, pero se avanza hacia una democratización en la toma de } \\
\text { decisiones }\end{array}$ & 1 \\
\hline \hline Sí & 3 \\
\hline \hline
\end{tabular}

Pregunta 10: ¿Se delega autoridad? En caso afirmativo, ¿cuál es el criterio?

\begin{tabular}{|l|c||}
\hline \multicolumn{1}{|c|}{ Opinión de los Secretarios } & $\begin{array}{c}\text { Cantidad de Secretarios que } \\
\text { respondieron de esta manera }\end{array}$ \\
\hline $\begin{array}{l}\text { Existe delegación efectiva de responsabilidades en el cumplimiento } \\
\text { de las tareas docentes }\end{array}$ & 8 \\
\hline Se delega según las necesidades y circunstancias & 3 \\
\hline \hline No se delega la autoridad & 2 \\
\hline
\end{tabular}

Pregunta 11: ¿Existen relaciones interpersonales cooperativas?

\begin{tabular}{|l|c|}
\hline \multicolumn{1}{|c|}{ Opinión de los Secretarios } & $\begin{array}{c}\text { Cantidad de Secretarios que } \\
\text { respondieron de esta manera }\end{array}$ \\
\hline \hline Sí, optimizándose los recursos humanos disponibles & 8 \\
\hline \hline En algunos casos se dan, en otros es más difícil & 5 \\
\hline
\end{tabular}

\subsubsection{Análisis descriptivo}

La literatura sobre gestión educativa destacó en los últimos veinte años la importancia del trabajo en equipo en las escuelas. Mucho se argumentó sobre el rol de los directivos en la formación de los equipos de trabajo. Los investigadores observaron situaciones diferentes que han permitido pensar las herramientas no ya como imperativas - "hay" que trabajar en equipo- sino como recursos: en qué momento y con qué fin u objetivo le sirve a determinadas escuelas (urbana, en el límite urbano-subrubano o rural, para adolescentes o adultos) el trabajo en equipo. 
En esta investigación, algunos de esos colegios mostraron nuevas formas de gestión colegiada. Éstas implican acuerdos en los ejes centrales, delegación junto con reconocimiento de saberes, compromiso con la tarea, otorgamiento de poder y respeto por el trabajo del otro y junto con el otro. También incluyeron conocer los alcances y las limitaciones de los agentes educativos y demandaron un tiempo para conocer las instituciones e intercambiar experiencias a los efectos de saber con quiénes se puede trabajar para alcanzar los objetivos y con quiénes - - por diferentes motivos- ello torna difícil.

En otros establecimientos, de sus directivos se obtuvieron datos que aluden al "personalismo referencial". Un personalismo que les da sentido a las secuelas. Les otorga el sentido que los directores, los secretarios, los integrantes del gabinete psicopedagógico, los jefes de departamento, los profesores y los jefes de preceptores quieren para las escuelas: ofrecer una escuela en la que los alumnos puedan estudiar. El compromiso de los directores funciona como constructor del compromiso de los demás agentes de la escuela y —por extensión- de los actores del sistema educativo e -incluso- de los actores gubernamentales.

La tarea del gabinete psicopedagógico - de cuya existencia carecen varias escuelas de adolescentes ( $\mathrm{B}, \mathrm{C}, \mathrm{H}, \mathrm{I}$ y $\mathrm{J})$ y de adultos $\left(\mathrm{H}_{1}, \mathrm{~L}\right.$ y $\left.\mathrm{M}\right)$ incluidas en esta investigaciónimplica intentar comprender el proceso de aprendizaje en los educandos y en los educadores. Ello incluye la ideología de la comunidad educativa, la singularidad de la estructura escolar y sus objetivos particulares, dado que el propósito explicitado de las trece escuelas no sólo es impartir conocimientos sino contribuir a la formación integral de la persona.

El liderazgo y los equipos de trabajo, se hallan en función de la situación que enfrente la escuela en cada momento de su historia institucional y de los recursos y capacidades con que la misma cuente. En instituciones grandes - como las escuelas de adolescentes A, E, G e I y las de adultos L y M- la clave estaría en el ejercicio descentralizado de la dirección, el cual permite el trabajo en equipo con actores diferentes que aúnan saberes complementarios. Las demás —debido a su menor tamaño - tendrían dificultades para seguir adelante sin un liderazgo fuerte y comprometido aunque de ninguna manera hegemónico. Cuentan con una directora pero detrás funciona un equipo. Asimismo, el compromiso personal o colegiado resultaría siempre una condición fundamental para sostener el trabajo pedagógico y educativo en las trece escuelas. Relacionado con lo expuesto, los datos obtenidos permitirían afirmar que existe en todas ellas la preocupación constante y firme por alcanzar sus objetivos de corto, mediano y largo plazo. Por último, con relación a las preguntas formuladas en el cuestionario, todas fueron respondidas por los Directores de las trece escuelas. Sólo una directora ante la pregunta referida a las prioridades de las escuelas, no contestó. 
Seguidamente se tendrán en cuenta los porcentajes obtenidos en relación a los trece Directores, trece Secretarios y 102 Profesores (de egresados adolescentes y adultos) encuestados en este trabajo. Se han de comparar los resultados entre dichos agentes educativos, elegidos por la significativa función que cumplen en el proceso de enseñanzaaprendizaje. Se los tomó en cuenta al momento de responder a dos preguntas que los involucran profesionalmente: ¿Dónde está reconocido el derecho a la educación? y ¿Cómo evalúa la calidad educativa desde el retorno de la democracia (1983) hasta hoy? ${ }^{204}$ Respecto de la primera, es dable apreciar una diferencia de casi el doble de aciertos a favor de los Directores respecto de los Profesores (en relación a los Secretarios la brecha es menor) cuando se trata de opciones que reflejan normas de jerarquía superior, por debajo del texto supremo. Asimismo, de las 9 opciones contempladas en la pregunta, los Directores eligieron -en promedio- 3,61 opciones cada uno, los Secretarios 2,77 opciones en promedio cada uno y los Profesores 2,33. Se observa también aquí la primacía de los Directores sobre el resto.

En relación a la segunda pregunta los Directores y Secretarios, a excepción de los Profesores, eligieron una opción cada uno (trece en total, en ambos casos). De los extremos ("Excelente" y "Muy mala") sólo recibió dos adhesiones de Profesores la opción "Muy mala". Por otro lado, las opciones "Buena" y "Regular" atrajeron (con el 40,57\% y el 40,02\%, respectivamente) las opiniones mayoritarias de todos estos docentes al expresarse sobre la calidad educativa. Por último, nueve adhesiones de la opción "Otra/s (especificar)" de 140 (cifra total de las opciones elegidas) originaron de los Secretarios y los Profesores, como respuesta mayoritaria el siguiente texto: "algunas cosas me parecen buenas y otras no". En relación a lo expresado supra, véanse los Cuadros 1 y 2 y sus Gráficos 1 y 2 correspondientes.

204. Estas preguntas son las identificadas como 2 y 4, respectivamente, en los cuestionarios elaborados para Directores y Secretarios. Asimismo, son las preguntas 2 y 3, respectivamente, del confeccionado para Profesores de los egresados. Al respecto, véanse los Instrumentos de Recolección de Datos en los Anexos. 


\section{Porcentajes de algunos participantes en dos preguntas del cuestionario}

Cuadro 1

\begin{tabular}{|c|c|c|c|}
\hline Opciones & Directores & Secretarios & Profesores \\
\hline En uno o más Tratados Internacionales de Derechos Humanos con jerarquía constitucional & $9(69,23 \%)$ & $7(53,85 \%)$ & $35(34,31 \%)$ \\
\hline En una Ley Nacional & $10(76,92 \%)$ & $7(53,85 \%)$ & $36(35,29 \%)$ \\
\hline En la Constitución de la Provincia de Buenos Aires & $8(61,54 \%)$ & $6(46,15 \%)$ & $30(29,41 \%)$ \\
\hline En una Ordenanza Municipal del Partido de Junín & $0(0,00 \%)$ & $2(15,38 \%)$ & $2(1,96 \%)$ \\
\hline En todo lo anteriormente dicho & $0(0,00 \%)$ & $1(7,69 \%)$ & $21(20,59 \%)$ \\
\hline En nada de lo anteriormente dicho & $0(0,00 \%)$ & $0(0,00 \%)$ & $0(0,00 \%)$ \\
\hline Otro/s (especificar) & $0(0,00 \%)$ & $0(0,00 \%)$ & $3(2,94 \%)$ \\
\hline
\end{tabular}




\section{Gráfico 1: Porcentajes Totales}

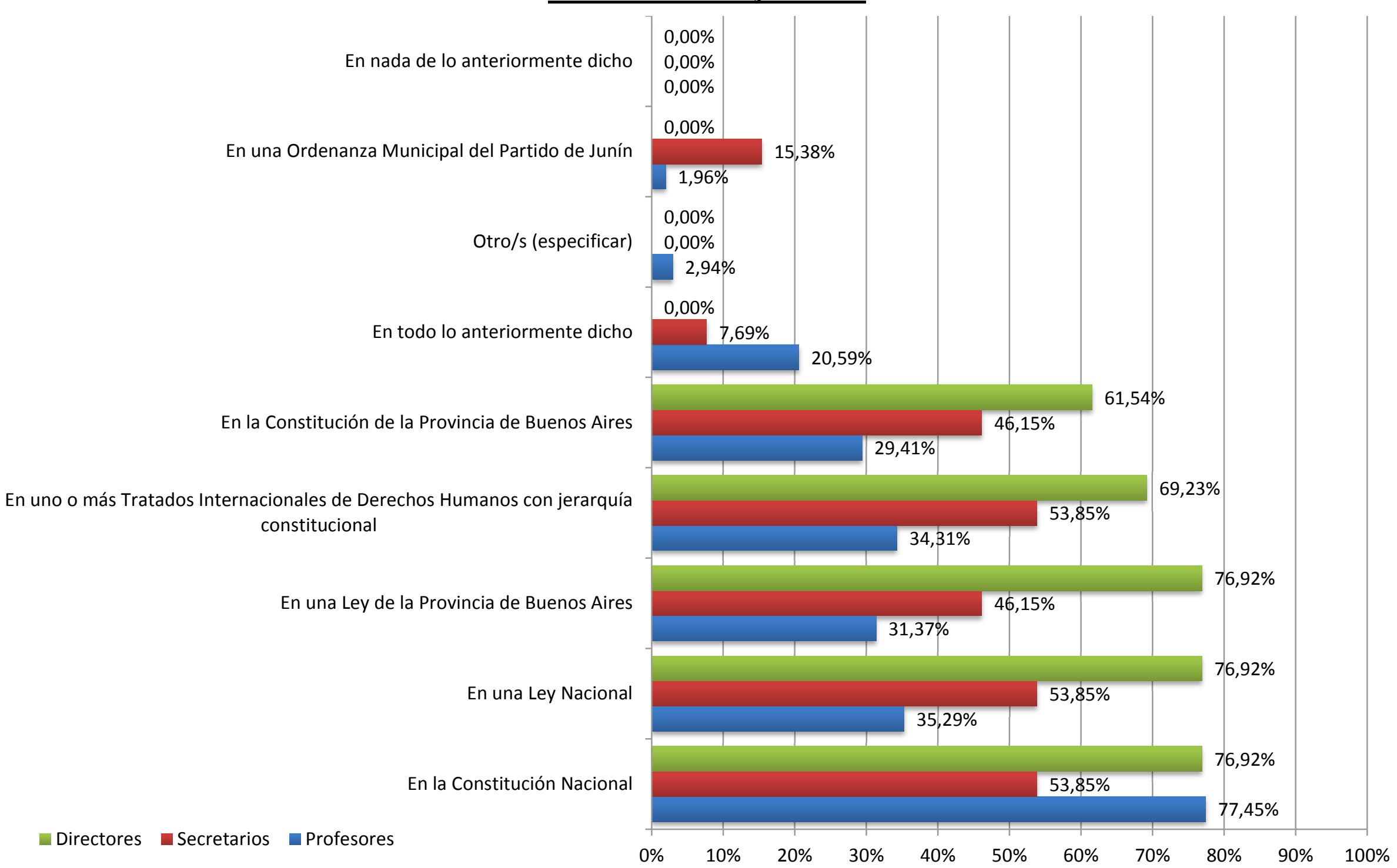


Cuadro 2

\begin{tabular}{|l|c|c||c||}
\hline \multicolumn{1}{|c|}{ Opciones } & Directores & Secretarios & Profesores \\
\hline \hline Excelente & $0(0,00 \%)$ & $0(0,00 \%)$ & $0(0,00 \%)$ \\
\hline Muy buena & $0(0,00 \%)$ & $0(0,00 \%)$ & $8(7,84 \%)$ \\
\hline \hline Buena & $7(53,85 \%)$ & $5(38,46 \%)$ & $30(29,41 \%)$ \\
\hline Indeciso/a & $0(0,00 \%)$ & $3(23,08 \%)$ & $13(12,75 \%)$ \\
\hline \hline Regular & $6(46,15 \%)$ & $4(30,77 \%)$ & $44(43,14 \%)$ \\
\hline \hline Mala & $0(0,00 \%)$ & $0(0,00 \%)$ & $9(8,82 \%)$ \\
\hline Muy mala & $0(0,00 \%)$ & $0(0,00 \%)$ & $2(1,96 \%)$ \\
\hline \hline Otra/s (especificar) & $0(0,00 \%)$ & $1(7,69 \%)$ & $8(7,84 \%)$ \\
\hline
\end{tabular}




\section{Porcentajes Totales}

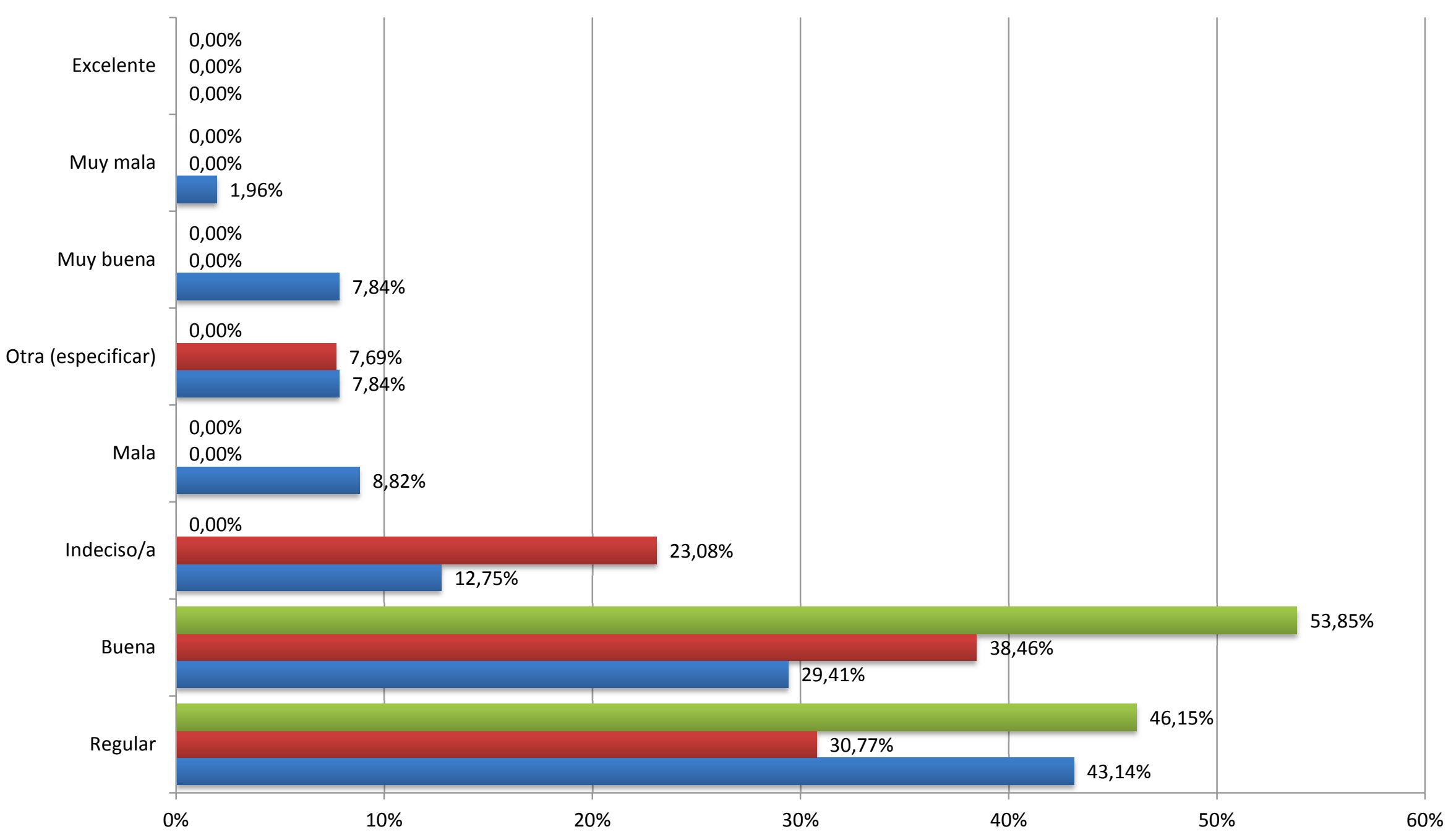

Directores Secretarios $\square$ Profesores 


\section{Enfoque Cualitativo}

Aquí se construyeron formas inclusivas para descubrir las múltiples visiones de los participantes (egresados, sus responsables, sus profesores, sus preceptores, directores, secretarios y bibliotecarios). El instrumento de recolección de los datos resultó ser el propio investigador, quien utilizó diversos métodos o técnicas, además de recolectar otros tipos de datos: lenguaje escrito, verbal y no verbal, conductas observables e imágenes. En todo momento se procuró minimizar la influencia que sobre los participantes y el ambiente pudieran ejercer las creencias, fundamentos o experiencias de vida del investigador asociados con el problema de estudio.

Muestreo, recolección y análisis de los datos fueron actividades casi paralelas. La muestra inicial no se modificó como tampoco el planteamiento del problema. El objetivo del proceso cualitativo no fue medir variables para llevar a cabo inferencias y análisis estadísticos - como en el enfoque cuantitativo- sino obtener datos (los cuales se convertirían en información) de personas, contextos y comunidades educativas en las formas de expresión de cada uno de ellos. Las herramientas utilizadas fueron — siguiendo el orden en que serán presentadas - la observación (para captar los ambientes y a sus agentes), el grupo de enfoque (lo que expresó y construyó el grupo) y los documentos (generados con finalidad oficial por un grupo de personas). 


\subsection{Observación}

No se trató de mera contemplación. Implicó adentrarse profundamente en situaciones sociales y mantener un papel activo, así como una reflexión permanente. Estar atento a los detalles, sucesos, eventos e interacciones. Debieron comprenderse los contextos sociales y culturales en los cuales ocurrían las experiencias humanas. La labor se centró en escuelas estatales de nivel medio del Distrito de Junín (provincia de Buenos Aires). Fue observado en ellas el ambiente físico: tamaño, arreglo espacial o distribución, señales y accesos. Además, el ambiente social y humano (generado en el ambiente físico): formas de organización en grupos y subgrupos y patrones de interacción o vinculación. También fue importante observar las actividades (acciones) individuales y colectivas. 


\subsubsection{Escuelas de adolescentes}

Se observaron en el período 2010-2012 los edificios de diez escuelas estatales mixtas para adolescentes (A, B, C, D, E, F, G, H, I y J), donde asistían estudiantes de $1^{\circ}, 2^{\circ}$ y $3^{\circ}$ Año del nivel medio. Todos los establecimientos están situados en el ejido urbano, salvo la escuela I ubicada en el límite entre las zonas urbana y suburbana a un costado de la ruta nacional $\mathrm{N}^{\mathrm{o}} 188$. Y la A, que funciona en una localidad distante 20 kilómetros. de la ciudad de Junín en una zona rural, a la que se accede mediante un camino pavimentado - de aproximadamente 1 kilómetro de extensión - luego de transitar dicha ruta. A propósito de esta zona, Axel Rivas (2010) ha escrito que entre las deudas que tiene el sistema educativo argentino con la educación rural se destaca, en primer lugar, la necesidad de extender la oferta del nivel inicial y -especialmente- de la secundaria. En 2001 - afirma este autor- en áreas urbanas el 89 por ciento de los adolescentes de doce a diecisiete años asistía a la escuela, mientras ese porcentaje bajaba al 72 por ciento en zonas rurales. En 2007 en todo el país los alumnos de escuelas rurales ascendían al 13 por ciento en el nivel primario y al 7 por ciento en el medio. Asimismo, en la educación de adultos se evidencia una gran disparidad: mientras el 16 por ciento de la población urbana tenía en 2001 primaria incompleta o ninguna educación, en el ámbito rural la proporción aumentaba al 39\% de los habitantes. ${ }^{205}$

A continuación la referencia se hará al asentamiento de las diez escuelas citadas. La B y la $\mathrm{C}$ se hallan a dos cuadras del centro de la ciudad de Junín, a ambos lados de una misma calle, una casi frente a la otra. Las escuelas D y E, a cinco cuadras del centro, ocupan espacios físicos contiguos al final de una de las principales avenidas. Próxima a la avenida de Circunvalación que marca el límite entre lo urbano y lo suburbano funciona la escuela F. En el sector sudoeste, muy alejada del centro, se erige la escuela G. Asimismo, cerca de la avenida de Circunvalación —en el sector noreste- está la escuela H. A una distancia de cuatrocientos metros de la Ruta Nacional $N^{0} 7$ está situada la escuela J. El acceso a las escuelas mencionadas — salvo la I — es directo y rápido, merced a la pavimentación.

Respecto de los metros cuadrados construidos en cada una y la señalización correspondiente, se destacan las escuelas B, D, E y F. Asimismo, la D y la F reciben no sólo a estudiantes del nivel medio, también del primario. Las escuelas D y E incluyen los niveles secundario y terciario (no universitario). Los establecimientos $\mathrm{F}$ y $\mathrm{H}$ se levantaron hace menos de veinte años. Por ende, existe una menor exigencia social para la mejora del aspecto físico de los mismos. Asimismo, el estado de muchas escuelas a que se hace referencia oscila de bueno a muy bueno. No obstante, la $\mathrm{C}$ (que ocupa instalaciones pertenecientes a otra hasta no hace mucho tiempo) muestra algunas falencias edilicias que en la escuela $\mathrm{J}$ son aún más

205. Rivas, Axel, Capítulo 4. “Cuestiones”, op. cit., página 142. 
notorias. La I se halla rodeada de una frondosa arboleda, observándose dificultades para acceder a la misma en las jornadas de lluvia, puesto que la separa de la ruta un camino de tierra (de aproximadamente doscientos metros) que se torna casi intransitable esos días. Tiene una oferta educativa de jornada completa - turnos matutino y vespertino- con varios servicios. En torno a la expansión de los comedores escolares, Axel Rivas (2010) asevera que es una tendencia que se afirma debido al creciente deterioro de las condiciones sociales: en 1997 el 11 por ciento de los niños que asistían a la educación básica en escuelas de gestión estatal recibían el servicio de almuerzo. Este indicador trepó al 21 por ciento en 2003 luego de la crisis económica de principio del siglo cuando la pobreza alcanzó niveles récord en el país y posteriormente siguió creciendo - a pesar de la recuperación económica- hasta situarse en 25 por ciento en 2007. Similares tendencias se observan en los demás servicios alimenticios que proveen las escuelas. El desayuno ("copa de leche") ha pasado de atender al 28 por ciento de los alumnos en 1997 al 46 por ciento en 2007 y la merienda ("servicio de refrigerio") ha crecido del 5 al 17 por ciento en idéntico periodo. Las jurisdicciones con gran población, como la Ciudad Autónoma de Buenos Aires y las provincias de Buenos Aires, Córdoba y Santa Fe, cuentan con una cobertura del servicio de almuerzo igual o mayor al promedio nacional. ${ }^{206}$ En definitiva, el ambiente físico comprensivo del tamaño, arreglo espacial o distribución, señales, accesos y sitios con funciones primordiales existentes en estos colegios del Distrito de Junín evidencian una realidad: resultó menos compleja su construcción (las escuelas D y E datan de más de 50 años) que lo necesario ahora para mantenerlas acorde a las exigencias actuales. Cabe mencionar la situación de la escuela $\mathrm{C}$, respecto de la cual se estaban adoptando las medidas pertinentes para solucionar algunos problemas (por ejemplo, la provisión de gas natural y el arreglo de los baños para alumnos). El accionar del Estado (en cualquiera de sus tres niveles) y el de las Cooperadoras (lo realizado por algunas de ellas fue muy importante en las décadas de 1980 y de 1990), siempre resulta imprescindible a fin de promover el bienestar de todos los integrantes de la comunidad educativa.

\subsubsection{Escuela D: desarrollo de una clase}

Esta escuela - ubicada a pocas cuadras del centro de la ciudad de Junín - fue elegida por muchos responsables de los egresados 2010 por la formación que otorga (del mismo modo lo hicieron otros responsables, en años anteriores, por idéntico motivo). En base a ello, se decidió realizar la observación de una clase de la materia Filosofía. Obtenido el permiso correspondiente, el investigador se desempeñó como observador no participante el miércoles 10 de noviembre de 2010, en horas de la mañana, en un curso mixto.

206. Rivas, Axel, Capítulo 3. “Cartografías”, op. cit., página 94. 
El grupo de $3^{\circ}$ Año (modalidad Ciencias Sociales) que se observó era - como casi todos los grupos de jóvenes que fueron tenidos en cuenta- bullicioso. Hablaban en voz muy alta y se decían cosas de un lado al otro de la calle. Se llamaban recíprocamente con palabras que las generaciones anteriores creían insultantes y que ellos convirtieron en afectuosas o respetuosas. Se palmeaban o se abrazaban. También había muchos sentados en el suelo o en los escalones de acceso al colegio. Cuando sonó el timbre de entrada —eran las 7,30 hs- la puerta quedó taponada por algunos alumnos allí parados que no se negaban a entrar pero parecía costarles mucho vencer la inercia para desplazarse. Ya dentro del colegio idéntica actitud pudo observarse en la entrada al aula para la clase de Filosofía. Lo hacían despaciosamente, conversando entre compañeros (algunos, con estudiantes de otros cursos). Dos alumnas luego de entrar solicitaron permiso al profesor - que ya estaba junto al escritorio situado en el frente y hacia la derecha del aula- para volver a salir porque habían olvidado decir o hacer algo. De a poco, todos se fueron sentando ante la mirada del docente que iba tomando en cuenta la asistencia, comprobando que todos los alumnos integrantes de la lista estaban presentes. Puso en marcha la clase concitando la atención del alumnado. Dispuso la realización de una tarea en pequeños grupos — dentro del aula- por lo que la participación de la mayoría fue activa. En general, los educandos se mostraron atentos y prestos al debate. Algunos tuvieron inconvenientes en la expresión de las ideas en forma oral o escrita. Eran conscientes de tal dificultad, pero no parecían preocuparse demasiado por ello. Incluso, unos pocos bromearon ante los errores propios y ajenos. Al final de la tarea, el docente expresó algunas reflexiones sobre lo trabajado e indicó una labor para la clase siguiente. Casi de inmediato se escuchó el timbre de salida, eran las 9,40 horas. Vale señalar que antes, de 8,30 a 8,40 horas, se había interrumpido la clase para salir al recreo.

\subsubsection{Escuela G: horarios}

En la escuela G, sobre cartulina azul en una pared de la Sala de Preceptores, pueden observarse esquemas referidos a algunos cursos ( $3^{\circ}$ Año en sus diferentes modalidades), donde constan los nombres y apellidos de los profesores, las materias que imparten y los horarios $^{207}$ correspondientes. A continuación se transcribirán textualmente (excepto la

207. El tiempo escolar es un fenómeno complejo. Las medidas formales consideran la cantidad de días y horas de clase e -incluso- la organización diaria del uso del tiempo, sin especificar las horas reales de clase, lo cual implicaría descontar los días sin clases (por diversas causas), el ausentismo docente y el propio de los estudiantes. A su vez, el análisis del tiempo de enseñanza puede ser complementado con otras variables, como la cantidad de alumnos por sección (en el nivel primario) o por división (en el medio) o la oferta de cargos docentes por escuela. Los distintos modelos pedagógicos implican una mayor o menor personalización de la enseñanza. En Rivas, Axel, Capítulo 2. "Comparaciones", op. cit., página 72. 
identificación de los educadores por ser irrelevante para esta investigación) y con posterioridad se efectuará su análisis:

$3^{\circ}$ Ciencias Naturales - Turno Mañana

\begin{tabular}{|c|c|c|c|}
\hline Día & Nro. & Materia & Horario de Clases \\
\hline \multirow{5}{*}{ Lunes } & 1 & Biología & De $7^{\frac{30}{2}}$ a $8^{\frac{30}{0}}$ horas \\
\hline & 2 & Proyecto de Investigación & De $8^{\frac{40}{a}}$ a $9^{40}$ horas \\
\hline & 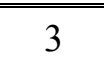 & Matemática & De $9^{\frac{50}{\underline{y}}}$ a $10^{\underline{50}}$ horas \\
\hline & 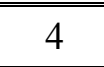 & Matemática & De 11 a 12 horas \\
\hline & 5 & Lengua & De 12 a 13 horas \\
\hline \multirow{5}{*}{ Martes } & 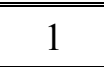 & Biotecnología & De $7^{\frac{30}{4}}$ a $8^{\underline{30}}$ horas \\
\hline & 2 & Biotecnología & De $8^{40}$ a $9^{40}$ horas \\
\hline & 3 & Lengua & De $9^{\frac{50}{0}}$ a $10^{50}$ horas \\
\hline & 4 & Lengua & De 11 a 12 horas \\
\hline & $\overline{5}$ & & De 12 a 13 horas \\
\hline \multirow{5}{*}{ Miércoles } & 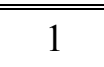 & Química Aplicada & De $7^{\frac{30}{3}}$ a $8^{30}$ horas \\
\hline & 2 & Química Aplicada & De $8^{40}$ a $9^{40}$ horas \\
\hline & 3 & Biofísica & De $9^{\frac{50}{2}}$ a $10^{50}$ horas \\
\hline & 4 & Biofísica & De 11 a 12 horas \\
\hline & 5 & & De 12 a 13 horas \\
\hline \multirow{5}{*}{ Jueves } & 1 & Biología & De $7^{\frac{30}{3}}$ a $8^{\underline{30}}$ horas \\
\hline & 2 & Biología & De $8^{40}$ a $9^{40}$ horas \\
\hline & 3 & Proyecto de Investigación & De $9^{\frac{50}{2}}$ a $10^{50}$ horas \\
\hline & 4 & Inglés & De 11 a 12 horas \\
\hline & 5 & Biotecnología & De 12 a 13 horas \\
\hline \multirow{6}{*}{ Viernes } & 1 & Cultura y Estética Contemporáneas & De $7^{\frac{30}{3}}$ a $8^{\frac{30}{\underline{y}}}$ horas \\
\hline & 2 & Cultura y Estética Contemporáneas & De $8^{40}$ a $9^{40}$ horas \\
\hline & 3 & Inglés & De $9^{50}$ a $10^{50}$ horas \\
\hline & 4 & Proyecto de Investigación & De 11 a 12 horas \\
\hline & 5 & & De 12 a 13 horas \\
\hline & & Educación Física & \\
\hline
\end{tabular}

Total: 10 materias 
$3^{\circ}$ EGEOR (Economía y Gestión de las Organizaciones) - Turno Mañana

\begin{tabular}{|c|c|c|c|}
\hline Día & Nro. & Materia & Horario de Clases \\
\hline \multirow{5}{*}{ Lunes } & 1 & Tecnologías de Gestión & De $7^{\frac{30}{2}}$ a $8^{\frac{30}{1}}$ horas \\
\hline & 2 & Lengua & De $8^{40}$ a $9^{40}$ horas \\
\hline & 3 & $\begin{array}{l}\text { Espacios Curriculares Institucionales (ECI): } \\
\text { Recursos Humanos }\end{array}$ & De $9^{\frac{50}{}}$ a $10^{50}$ horas \\
\hline & 4 & ECI: Recursos Humanos & De 11 a 12 horas \\
\hline & 5 & Biología & De 12 a 13 horas \\
\hline \multirow{5}{*}{ Martes } & 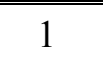 & ECI: Informes Contables & De $7^{30}$ a $8^{\underline{30}}$ horas \\
\hline & 2 & ECI: Informes Contables & De $8^{40}$ a $9^{40}$ horas \\
\hline & 3 & Inglés & De $9^{\frac{50}{3}}$ a $10^{\frac{50}{2}}$ horas \\
\hline & 4 & Inglés & De 11 a 12 horas \\
\hline & 5 & & De 12 a 13 horas \\
\hline \multirow{5}{*}{ Miércoles } & 1 & Economía & De $7^{\frac{30}{2}}$ a $8^{\frac{30}{0}}$ horas \\
\hline & 2 & Economía & De $8^{40}$ a $9^{40}$ horas \\
\hline & 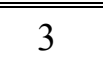 & "Cultura y Estética Contemporáneas & De $9^{\frac{50}{2}}$ a $10^{\underline{50}}$ horas \\
\hline & 4 & Cultura y Estética Contemporáneas & De 11 a 12 horas \\
\hline & 5 & & De 12 a 13 horas \\
\hline \multirow{5}{*}{ Jueves } & 1 & Tecnologías de Gestión & De $7^{\frac{30}{2}}$ a $8^{\frac{30}{-}}$ horas \\
\hline & 2 & Economía & De $8^{40}$ a $9^{40}$ horas \\
\hline & 3 & Lengua & De $9^{\frac{50}{2}}$ a $10^{\frac{50}{0}}$ horas \\
\hline & 4 & Lengua & De 11 a 12 horas \\
\hline & 5 & & De 12 a 13 horas \\
\hline \multirow{6}{*}{ Viernes } & 1 & ECI: Informes Contables & De $7^{\frac{30}{2}}$ a $8^{\frac{30}{0}}$ horas \\
\hline & 2 & Tecnologías de Gestión & De $8^{40}$ a $9^{40}$ horas \\
\hline & 3 & Biología & De $9^{\frac{50}{2}}$ a $10^{\frac{50}{6}}$ horas \\
\hline & 4 & Matemática & De 11 a 12 horas \\
\hline & 5 & Matemática & De 12 a 13 horas \\
\hline & & Educación Física & \\
\hline
\end{tabular}

Total: 10 materias 
$3^{\circ}$ HUSOC (Humanidades y Ciencias Sociales) — Turno Tarde

\begin{tabular}{|c|c|c|c|}
\hline Día & Nro. & Materia & Horario de Clases \\
\hline \multirow{5}{*}{ Lunes } & 1 & ECI: Recursos Humanos & De 13 a 14 horas \\
\hline & 2 & ECI: Recursos Humanos & De $14^{10}$ a $15^{\frac{10}{0}}$ horas \\
\hline & 3 & Proyecto de Investigación & De $15^{\frac{20}{20}}$ a $16^{\frac{20}{\underline{y}}}$ horas \\
\hline & 4 & Proyecto de Investigación & De $16^{30}$ a $17^{30}$ horas \\
\hline & 5 & & De $17^{\frac{30}{2}}$ a $18^{\frac{30}{-}}$ horas \\
\hline \multirow{5}{*}{ Martes } & 1 & ECI: Trabajo Social & De 13 a 14 horas \\
\hline & 2 & ECI: Trabajo Social & De $14^{10}$ a $15^{\frac{10}{0}}$ horas \\
\hline & 3 & Matemática & De $15^{\frac{20}{2}}$ a $16^{\underline{20}}$ horas \\
\hline & 4 & Matemática & De $16^{30}$ a $17^{30}$ horas \\
\hline & 5 & & De $17^{\frac{30}{2}}$ a $18^{\frac{30}{\underline{y}}}$ horas \\
\hline \multirow{5}{*}{ Miércoles } & 1 & Lengua Extranjera & De 13 a 14 horas \\
\hline & 2 & Lengua Extranjera & De $14^{10}$ a $15^{\frac{10}{0}}$ horas \\
\hline & 3 & Sociología & De $15^{20}$ a $16^{20}$ horas \\
\hline & 4 & Economía & De $16^{30}$ a $17^{30}$ horas \\
\hline & 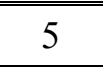 & Economía & De $17^{\frac{30}{20}}$ a $18^{\frac{30}{\underline{y}}}$ horas \\
\hline \multirow{5}{*}{ Jueves } & 1 & Proyecto de Investigación & De 13 a 14 horas \\
\hline & 2 & Lengua y Literatura & De $14^{10}$ a $15^{\frac{10}{0}}$ horas \\
\hline & 3 & Lengua y Literatura & De $15^{20}$ a $16^{20}$ horas \\
\hline & 4 & Biología & De $16^{30}$ a $17^{30}$ horas \\
\hline & 5 & Biología & De $17^{30}$ a $18^{30}$ horas \\
\hline \multirow{6}{*}{ Viernes } & 1 & Cultura y Estética Contemporáneas & De 13 a 14 horas \\
\hline & 2 & Cultura y Estética Contemporáneas & De $14^{\frac{10}{}}$ a $15^{\frac{10}{0}}$ horas \\
\hline & 3 & Sociología & De $15^{20}$ a $16^{20}$ horas \\
\hline & 4 & Sociología & De $16^{30}$ a $17^{30}$ horas \\
\hline & 5 & Lengua y Literatura & De $17^{\frac{30}{}}$ a $18^{\underline{30}}$ horas \\
\hline & & Educación Física & \\
\hline
\end{tabular}

Total: 11 materias

A partir de lo observado en los esquemas el análisis es el siguiente: la hora de clase es de sesenta minutos (que representa un módulo). En algunas asignaturas la carga horaria semanal es de dos módulos (que transcurren juntos o separados) o de tres módulos (dos juntos un día y el restante otro día o los tres módulos en tres días diferentes).

En $3^{\circ}$ Año de Ciencias Naturales y en $3^{\circ}$ Año de EGEOR se dictan veintidós clases semanales y en $3^{\circ}$ Año cuya modalidad es HUSOC son veintitrés clases por semana. En todos 
los casos debe agregarse la materia Educación Física, respecto de la cual los esquemas aludidos nada explicitan. Consecuencia de ello, por esta vía no puede saberse en qué días y horarios se imparte la misma.

En otro orden de ideas, en $3^{\circ}$ Año de HUSOC todos los profesores tienen a su cargo una sola materia. En los restantes cursos ocurre lo mismo, a excepción de la profesora que tiene a su cargo dos asignaturas ("Biofísica" y "Matemática") en la modalidad Ciencias Naturales y otra profesora que dicta dos materias ("ECI: Informes Contables" y "Tecnologías de Gestión") en la modalidad EGEOR.

Hay cuatro profesoras que enseñan en dos Terceros (HUSOC y EGEOR) y otra que también lo hace, pero en HUSOC y en Ciencias Naturales. Los demás docentes imparten sus clases sólo en una modalidad. Esta realidad motiva la siguiente reflexión: el sentido de pertenencia a la escuela $\mathrm{G}$ sería más fuerte en esos cinco docentes y ello podría quedar corroborado por lo siguiente: dos de ellos son profesores-tutores, observándose en ambos un muy bajo porcentaje de inasistencias.

Por lo demás, las mayores cargas horarias semanales (tres módulos) corresponden en Ciencias Naturales a: Biología, Lengua, Biotecnología y Proyecto de Investigación. En EGEOR, Tecnologías de Gestión, Lengua, ECI: Informes Contables y Economía. En HUSOC: Proyecto de Investigación, Sociología y Lengua y Literatura. La mayor carga horaria de las asignaturas citadas se condice con las características fundamentales de cada una de las modalidades. Asimismo en una materia - Biología, de EGEOR - no existía ningún profesor que estuviera impartiendo clases al tiempo de la recolección de datos (octubre de 2010). Se informó al investigador que la profesora que se estaba desempeñando había renunciado, que todavía no se había realizado el acto público para su otorgamiento a un educador y que el mismo tendría lugar en la Secretaría de Inspección, ubicada en pleno centro de la ciudad de Junín.

En este orden de ideas, téngase presente que el artículo $94 \mathrm{f}$. de la Ley de Educación de la provincia de Buenos Aires prescribe que - entre otras - los docentes tienen la obligación de "Proteger, promover y reconocer el conocimiento y ejercicio de los derechos de los niños, adolescentes, jóvenes, adultos $y$ adultos mayores que se encuentren bajo su responsabilidad, ...”.

En la escuela G también están distribuidos en un esquema los horarios de actividades del cuerpo directivo. La directora asiste los lunes, martes y viernes de $7^{\frac{30}{3}}$ a 12 horas; los miércoles de $16^{00}$ a $19^{\frac{30}{0}}$ horas y los jueves entre las 13 y las 18 horas. En total: veintidós horas semanales. La vicedirectora concurre los martes de 13 a 18 horas y los viernes de 18 a 22 horas. Total: nueve horas semanales. Y la secretaria cumple sus funciones los martes y jueves, desde las 14 horas (no consta la hora de finalización de las mismas). Asimismo, de 18 a 22 horas funciona la escuela $G_{1}$-de adultos - que comparte el edificio con la escuela $G$. A 
un lado el análisis referido a estos horarios (que se previó realizar pero la falta de información impide llevarlo a cabo pormenorizadamente), este aspecto de la organización administrativa de la escuela $\mathrm{G}$ se tomó también en cuenta en los colegios $\mathrm{H}$ e I donde pudo comprobarse fehacientemente que, no obstante la distribución horaria vigente para sus autoridades, en algunas horas de varios meses de 2010 y de 2011 ambos establecimientos quedaron acéfalos. Según pudo comprobarse, los profesores de más antigüedad en la docencia, presentes en esos momentos, habrían asumido todas las responsabilidades. Estas situaciones podrían haber derivado en harto problemáticas para esos docentes, inexpertos para resolver cualquier problema ajeno al desarrollo normal de las actividades escolares. No obstante, en oportunidades como las explicitadas, se evidenció la colaboración prestada a aquellos profesores por los demás agentes educativos presentes.

En tal orden de ideas, téngase presente que el artículo 94 c. y e. de la Ley de Educación de la provincia de Buenos Aires prescribe que - entre otras obligaciones- los docentes deben "Cumplir con los lineamientos de la política educativa provincial" y "Ejercer su trabajo de manera idónea y responsable", respectivamente.

\subsubsection{Escuelas de adultos}

Se observaron en 2010 y en 2011 los edificios de nueve escuelas mixtas para adultos $\left(A_{1}\right.$, $\left.\mathrm{F}_{1}, \mathrm{H}_{1}, \mathrm{~L}, \mathrm{~L}_{1}, \mathrm{~L}_{2}, \mathrm{~L}_{3}, \mathrm{~L}_{4} \mathrm{y} \mathrm{M}\right)$, todas de gestión pública, donde concurrían alumnos de $1^{\mathrm{o}}, 2^{\mathrm{o}} \mathrm{y}$ $3^{\circ}$ Año del nivel medio.

Las denominaciones $\mathrm{F}$ y $\mathrm{F}_{1}$ identifican, la primera a una escuela de adolescentes y la segunda -en el mismo edificio- a un colegio para adultos. Lo mismo sucede,

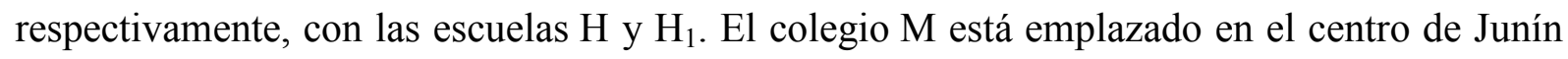
-frente a la principal plaza de la ciudad - siendo su construcción de hace muchos años. Las escuelas $\mathrm{L}, \mathrm{L}_{1}, \mathrm{~L}_{2}, \mathrm{~L}_{3}$ y $\mathrm{L}_{4}$ se encuentran en diferentes sectores urbanos - a distancias casi equidistantes entre sí todas ellas- y corresponden al Centro Educativo de Nivel Secundario (CENS) $N^{o}$ 200. En las nueve instituciones se imparten clases de 19 a 22 horas. En algunos días de la semana existen -alternativamente- pre y post horas. En el primer caso las actividades áulicas se llevan a cabo desde las $18^{\underline{25}}$ horas. En el segundo, las clases se extienden hasta las $22^{\frac{35}{}}$ horas. En las nueve escuelas funciona también —a la mañana y a la tarde- el nivel primario. Precisamente a este nivel pertenecen los edificios respectivos, salvo la escuela $\mathrm{H}_{1}$ (de adultos) que funciona en edificio propio.

Respecto del ambiente físico, algunos colegios $\left(\mathrm{L}, \mathrm{L}_{1}\right.$ y $\left.\mathrm{L}_{2}\right)$ muestran falencias que - si bien similares- son más notorias en otros $\left(\mathrm{L}_{4} \mathrm{y} \mathrm{M}\right)$. Asimismo, con relación a otras escuelas para adolescentes y adultos (en las que no se realizaron actividades para esta investigación), la mayoría consta de instalaciones apropiadas para su normal funcionamiento. 


\subsubsection{Modalidades en varias escuelas: materias que comprenden}

Se tendrá en cuenta Ciencias Naturales en las escuelas E, G y J (de adolescentes) y $\mathrm{M}_{1}$ y $\mathrm{M}_{2}$ (extensiones de la escuela $\mathrm{M}$ de adultos). Esta modalidad comprende las siguientes materias que aparecen ordenadas alfabéticamente:

\begin{tabular}{||l||}
\hline \multicolumn{1}{|c||}{ Colegio E } \\
\hline Biofísica \\
Biología \\
Cultura y Estética Contemporáneas \\
Educación Física \\
Histología \\
Inglés \\
Lengua y Literatura \\
Matemática \\
Proyecto de Investigación \\
Química Biológica \\
\hline \hline Total: 10 materias \\
\hline \hline
\end{tabular}

\begin{tabular}{|l||}
\hline \multicolumn{1}{|c||}{ Colegio G } \\
\hline \hline Biofísica \\
Biología \\
Biotecnología \\
Cultura y Estética Contemporáneas \\
Educación Física \\
Inglés \\
Lengua \\
Matemática \\
Proyecto de Investigación \\
Química Aplicada \\
\hline \hline Total: 10 materias \\
\hline
\end{tabular}

\begin{tabular}{|l||}
\hline \multicolumn{1}{|c|}{ Colegio J } \\
\hline \hline Biología \\
Cultura y Estética Contemporáneas \\
(ECI): Práctica Sanitaria \\
ECI: Primeros Auxilios \\
Educación Física \\
Inglés \\
Matemática \\
Prácticas del Lenguaje \\
Proyecto de Investigación \\
\\
\hline \hline Total: 9 materias \\
\hline
\end{tabular}

\begin{tabular}{|l||}
\hline \multicolumn{1}{|c|}{ Colegios $\mathbf{M}_{1} \mathbf{~} \mathbf{~} \mathbf{M}_{2}$} \\
\hline \hline Alimentos y Salud \\
Atención de la Salud \\
Educación para la Salud \\
Informática \\
Inglés \\
Lengua y Literatura \\
Matemática \\
Política de Educación Sanitaria \\
Problemática Social Contemporánea \\
Química \\
Sociología \\
\hline Total: 11 materias \\
\hline
\end{tabular}

Tomando en consideración lo expuesto se realiza el siguiente análisis: en las escuelas E, G y J las materias que incluye la modalidad son Biología, Cultura y Estética Contemporáneas, Educación Física, Inglés, Lengua (o Lengua y Literatura o Prácticas del Lenguaje), Matemática y Proyecto de Investigación. En total, siete asignaturas comunes. Biofísica se dicta en dos (la E y la G) de las tres escuelas; Química Aplicada se enseña solamente en la escuela G y Química Biológica se imparte únicamente en la escuela E. 
En adultos se analizan los establecimientos $\mathrm{M}_{1}$ y $\mathrm{M}_{2}$. Sus planes de estudio coinciden con los de los adolescentes sólo en cuatro materias: Inglés, Lengua y Literatura, Matemática y Química (si bien ésta no se enseña en la J). Asimismo, entre las escuelas de adolescentes, la J incluye una materia menos que las dos restantes y dos menos que las escuelas de adultos. La escuela $\mathbf{J}$ está situada en una zona habitada mayoritariamente por trabajadores dependientes y/o cuentapropistas que han conformado familias numerosas. Sus hijos manifiestan que si continuaran estudios superiores, inexorablemente también trabajarían. O 一n número mayoritario - trabajarían solamente. De manera que si sus trayectorias educativas finalizaran con el nivel medio, tendrían menos conocimientos que sus pares de otras instituciones, dada la menor cantidad de asignaturas que integran la modalidad en esa escuela. En las extensiones de la escuela M aparecen Informática y tres materias referidas a la salud. Aquélla no se observa en las otras escuelas y las tres restantes no aparecen en los demás colegios, salvo algunas con una denominación similar en la escuela $\mathrm{J}$.

Seguidamente se considerará la modalidad EGEOR en las escuelas C, F y G (de adolescentes) y M (de adultos), la cual incluye las siguientes asignaturas ordenadas alfabéticamente:

\begin{tabular}{|l||}
\hline \multicolumn{1}{|c|}{ Colegio C } \\
\hline \hline Abordaje Interdisciplinario de las Relaciones \\
Laborales \\
Biología \\
Cultura y Estética Contemporáneas \\
Dinámica Empresarial III \\
ECI: Estados Contables \\
Economía \\
Educación Física \\
Gestión Financiera, Bancaria y Seguros \\
Inglés \\
Lengua y Literatura \\
Matemática \\
SIC (Sistemas de Información Contable) \\
Tecnologías de Gestión \\
TTP (Trayectos Técnicos Profesionales) \\
Planeamiento y Evaluación de Proyecto \\
\hline \hline Total: 14 materias \\
\hline
\end{tabular}

\begin{tabular}{|l||}
\hline \multicolumn{1}{|c|}{ Colegio $\mathbf{F}$} \\
\hline \hline Biología \\
Cultura y Estética Contemporáneas \\
ECI: Empresa II \\
ECI: Estadística \\
Economía \\
Educación Física \\
Lengua Extranjera (Inglés) \\
Lengua y Literatura \\
Matemática \\
Tecnologías de Gestión \\
\\
\\
\hline \hline Total: 10 materias \\
\hline
\end{tabular}




\begin{tabular}{|l||}
\hline \multicolumn{1}{|c||}{ Colegio G } \\
\hline Biología \\
Cultura y Estética Contemporáneas \\
ECI: Informes Contables \\
ECI: Recursos Humanos \\
Economía \\
Educación Física \\
Inglés \\
Lengua \\
Matemática \\
Tecnologías de Gestión \\
\hline \hline Total: 10 materias \\
\hline
\end{tabular}

\begin{tabular}{|l||}
\hline \multicolumn{1}{|c|}{ Colegio M } \\
\hline Economía \\
Gestión Empresarial \\
Informática \\
Inglés \\
Legislación Impositiva \\
Lengua y Literatura \\
Matemática \\
Mercadotecnia \\
Problemática Social Contemporánea \\
Química \\
\hline \hline Total: 10 materias \\
\hline
\end{tabular}

Obsérvese la cantidad de materias que deben estudiar los adolescentes de la escuela C. Con semejante mosaico surge la pregunta de si les será posible aprender los contenidos de cada una con la profundidad que se debiera. Determinar las relaciones que esos educandos establecerán entre diferentes temas de las materias a enseñarse, así como conocer si darán más importancia a las asignaturas consideradas básicas, no constituyen motivos de investigación en esta tesis. En las escuelas C, F y G las materias que se dictan son: Biología, Cultura y Estética Contemporáneas, Economía, Educación Física, Lengua Extranjera (Inglés), Lengua (o Lengua y Literatura), Matemática y Tecnologías de Gestión. En total: ocho asignaturas comunes. Los ECI difieren y los TTP sólo aparecen en la escuela C.

En adultos —escuela $\mathrm{M}$ - el nombre de la modalidad es Gestión y Organización de las Empresas. Su plan de estudios sólo coincide con los de las escuelas de adolescentes en estas materias: Economía, Lengua Extranjera (Inglés), Lengua y Literatura y Matemática. La formación escolar no es, como puede apreciarse, exactamente la misma para todos los adolescentes y es mucho menor la que se alcanza entre los adultos.

A renglón seguido se considerará la modalidad HUSOC en las escuelas E y G (de adolescentes) y M (de adultos). Las siguientes son las asignaturas que comprende, ordenadas alfabéticamente: 


\begin{tabular}{|l||}
\hline \multicolumn{1}{|c||}{ Colegio E } \\
\hline \hline Biología \\
Cultura y Estética Contemporáneas \\
Economía \\
Educación Física \\
Lengua Extranjera (Inglés) \\
Lengua Nacional \\
Matemática \\
ECI: Orientación Vocacional \\
Proyecto de Investigación \\
Sociedad y Ciencia \\
Sociología \\
\hline \hline Total: 11 materias \\
\hline
\end{tabular}

\begin{tabular}{|l||}
\hline \multicolumn{1}{|c|}{ Colegio G } \\
\hline \hline Biología \\
Cultura y Estética Contemporáneas \\
ECI: Recursos Humanos \\
ECI: Trabajo Social \\
Economía \\
Educación Física \\
Lengua Extranjera (Inglés) \\
Lengua y Literatura \\
Matemática \\
Proyecto de Investigación \\
Sociología \\
\hline \hline Total: 11 materias \\
\hline
\end{tabular}

\begin{tabular}{|l||}
\hline \multicolumn{1}{|c||}{ Colegio M } \\
\hline \hline Comunicación y Medios \\
Filosofía \\
Informática \\
Lengua Extranjera (Inglés) \\
Lengua y Literatura \\
Matemática \\
Organizaciones Sociales \\
Problemática Social Contemporánea \\
Química \\
Recursos Humanos \\
\hline \hline Total: 10 materias \\
\hline \hline
\end{tabular}

Tomando en cuenta lo expresado se lleva a cabo el siguiente análisis: en las escuelas E y G las materias que se dictan son: Biología, Cultura y Estética Contemporáneas, Educación Física, Economía, Lengua Extranjera (Inglés), Lengua y Literatura (o Lengua Nacional), Matemática, Proyecto de Investigación y Sociología. En total, nueve asignaturas comunes. Algunas de ellas se imparten exclusivamente en una de las dos escuelas mencionadas. Aporta un dato relevante una asignatura de la escuela E denominada ECI: Orientación Vocacional. Por qué causa/s sólo se dicta en este colegio y únicamente en $3^{\circ}$ Año no es objetivo de esta investigación. Desde la misma (según palabras de la profesora) se aporta la idea referida a que Orientación Vocacional debiera impartirse en todos los colegios a partir de $2^{\circ}$ Año. La materia Informática se observa en adultos mas no en adolescentes. En adultos se analiza la escuela M. 
La modalidad coincide con la de los adolescentes sólo en estas materias: Lengua Extranjera (Inglés), Lengua y Literatura, Matemática y Recursos Humanos.

\subsubsection{Alumnos que egresan del nivel medio y finalizan (o no) el mismo}

Una realidad a la que debiera prestarse atención es conocer, una vez egresados, cuántos de esos estudiantes del Distrito de Junín finalizan el nivel medio. Asimismo, saber cuánto tiempo transcurre desde el egreso hasta que aprueban la/s materia/s que adeudan y cuáles son los promedios de notas más elevados en cada división. En esta investigación se realizaron actividades en veinticinco escuelas de adolescentes $y$ de adultos. Adquiridos los conocimientos de las modalidades, cursos y divisiones existentes en las mismas, se obtuvieron los datos correspondientes a los egresados 2010. En primer lugar, a modo de ejemplos, vaya lo acontecido en las escuelas $\mathrm{D}$ y $\mathrm{H}$ (adolescentes) y $\mathrm{H}_{1}$ (adultos). La primera fue elegida por el volumen de egresados - 129- de un total de 675 estudiantes que cursaron en ella en 2010. ${ }^{208}$ Aquéllos eran mayoritariamente de nivel socioeconómico medio. Los otros dos colegios fueron tomados en cuenta porque mostraban una realidad diferente a la expuesta en algunos aspectos. Sus matrículas pertenecían mayoritariamente al nivel socioeconómico bajo.

En la escuela D había cinco cursos de $3^{\circ}$ Año. En total, 129 egresados. El establecimiento está ubicado a cinco cuadras del centro de la ciudad de Junín. Véanse en el cuadro siguiente los porcentajes (bastante similares) de los egresados que no adeudan materias y de aquéllos que sí adeudan.

\begin{tabular}{|l||c||c||c|c|c|c||}
\hline & $\begin{array}{c}3^{\circ} \text { I } \\
\text { ADICO }\end{array}$ & $\begin{array}{c}3^{\circ} \text { I } \\
\text { Cs. Naturales }\end{array}$ & $\begin{array}{c}3^{\circ} \text { II } \\
\text { Cs. Naturales }\end{array}$ & $\begin{array}{c}3^{\circ} \text { I } \\
\text { HUSOC }\end{array}$ & $\begin{array}{c}3^{\circ} \text { II } \\
\text { HUSOC }\end{array}$ & Total \\
\hline Egresados & 29 & 29 & 20 & 24 & 27 & $129(100 \%)$ \\
\hline $\begin{array}{l}\text { No adeudan } \\
\text { materia/s }\end{array}$ & 19 & 10 & 9 & 14 & 16 & $68(48,83 \%)$ \\
\hline $\begin{array}{l}\text { Adeudan } \\
\text { materia/s }\end{array}$ & 10 & 19 & 11 & 10 & 11 & $61(51,17 \%)$ \\
\hline \hline
\end{tabular}

* Significa cualquiera de estas dos situaciones: 1) no adeudó materia alguna al finalizar el ciclo lectivo; 2) adeudó una o más materias y la/s aprobó en el turno Diciembre y/o Marzo.

${ }^{* *}$ Significa cualquiera de estas tres situaciones: 1) no se presentó a rendir la/s materia/s adeudada/s en los turnos Diciembre y Marzo; 2) fue desaprobado/a en los turnos Diciembre y Marzo; 3) por su promedio (aplazo) en la/s materia/s debió rendirla/s directamente en el turno Marzo y allí desaprobó o no se presentó.

208. En dicha escuela se produjo en 2011 un hecho no frecuente: egresó del nivel medio un varón con la alteración genética conocida como Síndrome de Down. 
De los 129 egresados fueron encuestados para esta investigación 93; es decir, el 72,09 por ciento. Dicha cifra comprende 21 de $3^{\circ}$ I ADICO, 17 de $3^{\circ}$ I Ciencias Naturales, 17 de $3^{\circ}$ II Ciencias Naturales, 20 de $3^{\circ}$ I HUSOC y 18 de $3^{\circ}$ II HUSOC. A todos ellos se les administró el cuestionario elaborado para tal fin. Los 93 participantes en la pregunta 2 “Cuántas horas diarias en promedio estudiás?”, dieron lugar a los siguientes resultados:

\begin{tabular}{|l||c||c|c||c|c||c||}
\hline Opciones & $\begin{array}{c}3^{\circ} \text { I } \\
\text { ADICO }\end{array}$ & $\begin{array}{c}3^{\circ} \text { I } \\
\text { Cs. Naturales }\end{array}$ & $\begin{array}{c}3^{\circ} \text { II } \\
\text { Cs. Naturales }\end{array}$ & $\begin{array}{c}3^{\circ} \text { I } \\
\text { HUSOC }\end{array}$ & $\begin{array}{c}3^{\circ} \text { II } \\
\text { HUSOC }\end{array}$ & Total \\
\hline Ninguna & 2 & 5 & 2 & 1 & 4 & 14 \\
\hline Entre 1 y 2 horas & 3 & 2 & 8 & 7 & 6 & 26 \\
\hline Más de 2 horas & 0 & 1 & 0 & 0 & 2 & 3 \\
\hline $\begin{array}{l}\text { Me basta con atender las explicaciones } \\
\text { del profesor en clase }\end{array}$ & 3 & 1 & 1 & 4 & 3 & 12 \\
\hline \hline Cuando hay examen todo lo necesario & 20 & 7 & 7 & 11 & 5 & 50 \\
\hline \hline Otra/s (especificar) & 0 & 1 & 0 & 0 & 0 & 1 \\
\hline
\end{tabular}

Nota: Véase en los Anexos esta pregunta insertada en el Instrumento de Recolección de Datos aplicado a los alumnos.

Adviértase que el 53,76 por ciento (50 alumnos) eligió la opción "Cuando hay examen todo lo necesario". Interesa también considerar el 27,95 por ciento (26 estudiantes) que optó por la respuesta "Entre 1 y 2 horas". Este último y el anterior porcentaje representan la conducta mayoritaria de los egresados, quienes estudian a diario una cantidad de tiempo determinada y concentran sus esfuerzos máximos cuando deben rendir exámenes.

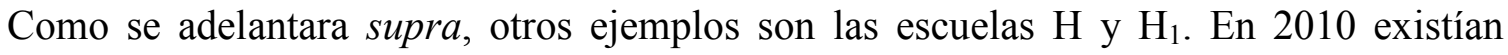
cuatro cursos del último año del nivel medio. En adolescentes, $3^{\circ}$ Año, División Única, con ocho egresados (siete encuestados) y $3^{\circ}$ Año, División Única con seis egresados (todos encuestados). En adultos, $3^{\circ}$ Año que tuvo seis egresados (ninguno encuestado) y $3^{\circ}$ Año con doce egresados (tres encuestados). En total egresaron treinta y dos estudiantes. De ellos fueron encuestados dieciséis; es decir, el 50 por ciento. En los dos cuadros siguientes, obsérvese que los adolescentes tienen menos dificultades que los adultos para aprobar las materias que adeudan: 
Adolescentes

\begin{tabular}{|l|c||c|}
\hline & $\begin{array}{c}3^{\text {o }} \text { (División Única) } \\
\text { Cs. Naturales }\end{array}$ & $\begin{array}{c}3^{\circ} \text { (División Única) } \\
\text { EGEOR }\end{array}$ \\
\hline \hline Egresados & 8 & 6 \\
\hline \hline No adeudan materia/s & 5 & $\begin{array}{l}\text { 6 (En el turno Diciembre aprobaron todos los } \\
\text { educandos que adeudaban alguna/s materia/s) }\end{array}$ \\
\hline \hline Adeudan materia/s & 3 & 0 \\
\hline
\end{tabular}

Adultos

\begin{tabular}{|l|c|c|}
\hline & $\begin{array}{c}3^{\text {o }} \text { A } \\
\text { Cs. Naturales }\end{array}$ & $\begin{array}{c}3^{\text {o }} \text { B } \\
\text { Producción de Bienes y Servicios }\end{array}$ \\
\hline Egresados & 12 & 6 \\
\hline \hline No adeudan materia/s & 8 & 4 \\
\hline \hline Adeudan materia/s & 4 & 4 \\
\hline
\end{tabular}

A continuación podrá observarse el cuadro donde aparecen veinticinco colegios con los datos referidos a los interrogantes planteados al comienzo de este acápite (3.1.4.). En el mismo figuran diecinueve escuelas de adolescentes y seis establecimientos de adultos. 
Egresados 2010 de 25 escuelas (ordenadas alfabéticamente)

\begin{tabular}{|c|c|c|c|c|c|c|c|c|c|}
\hline \multirow{2}{*}{ Escuela } & \multirow{2}{*}{ Modalidad } & \multirow{2}{*}{$\begin{array}{l}\text { Curso y } \\
\text { división }\end{array}$} & \multicolumn{3}{|c|}{ Egresaron (al 30/11/10) } & \multirow{2}{*}{ Finalizaron } & \multirow{2}{*}{$\begin{array}{c}\text { Egresaron } \\
\text { sin adeudar } \\
\text { materias }\end{array}$} & \multirow{2}{*}{$\begin{array}{l}\text { Adeudan } \\
\text { materias }\end{array}$} & \multirow{2}{*}{$\begin{array}{c}\text { Mejores } \\
\text { promedios }\end{array}$} \\
\hline & & & Total & Varones & Mujeres & & & & \\
\hline A (adolescentes) & EGEOR & $3^{\circ} \mathrm{I}$ & 13 & 6 & 7 & 9 & 3 & 4 & $9^{\underline{00}} ; 8^{\underline{86}} ; 8^{4 \underline{45}}$ \\
\hline $\mathrm{A}_{1}$ (adultos) & EGEOR & $3^{\circ} \mathrm{A}$ & 5 & 3 & 2 & 4 & 2 & 1 & $8^{\underline{86}} ; 8^{\underline{45}} ; 7^{\underline{93}}$ \\
\hline \multirow{3}{*}{$\begin{array}{c}\text { B } \\
\text { (adolescentes) }\end{array}$} & Electromecánica & $3^{\circ} \mathrm{I}$ & 22 & 21 & 1 & 15 & 6 & 7 & $9^{\underline{08}} ; 8^{\underline{75}} ; 8^{\underline{16}}$ \\
\hline & Automotores & $3^{\circ} \mathrm{II}$ & 9 & 9 & 0 & 7 & 3 & 2 & $8^{\underline{50}} ; 8^{\underline{33}} ; 8^{\underline{00}}$ \\
\hline & Electrónica & $3^{\circ} \mathrm{III}$ & 9 & 9 & 0 & 6 & 3 & 3 & $8^{\underline{33}} ; 8^{\underline{16}} ; 7^{\underline{50}}$ \\
\hline \multirow{2}{*}{$\begin{array}{c}\mathrm{B}_{1} \\
\text { (adultos) }\end{array}$} & BAOT & $3^{\circ} \mathrm{A}$ & 11 & 6 & 5 & 9 & 3 & 2 & $8^{\frac{69}{}} ; 8^{\frac{45}{2} ; 8^{00}}$ \\
\hline & M. Mayor de Obras & $3^{\circ} \mathrm{B}$ & 11 & 9 & 2 & 8 & 1 & 3 & $8^{\underline{86}} ; 8^{\underline{40}} ; 8^{\underline{00}}$ \\
\hline \multirow{2}{*}{$\begin{array}{c}\mathrm{C} \\
\text { (adolescentes) }\end{array}$} & BIES (Informática) & $3^{\circ} \mathrm{I}$ & 15 & 5 & 10 & 8 & 4 & 7 & $8^{\frac{82}{2}} 8^{\underline{23}} ; 7^{\underline{93}}$ \\
\hline & EGEOR & $3^{\circ} \mathrm{I}$ & 4 & 0 & 4 & 3 & 2 & 1 & $8^{\frac{60}{2}} ; 8^{\underline{50}} ; 8^{00}$ \\
\hline $\mathrm{C}_{1}$ (adultos) & BAOT & $3^{\circ} \mathrm{A}$ & 14 & 6 & 8 & 9 & 4 & 5 & $9^{\underline{30}} ; 8^{\underline{82}} ; 8^{\underline{10}}$ \\
\hline \multirow{5}{*}{$\begin{array}{c}\mathrm{D} \\
\text { (adolescentes) }\end{array}$} & Ciencias Naturales & $3^{\circ} \mathrm{I}$ & 29 & 12 & 17 & 10 & 7 & 19 & $9^{\underline{41}} ; 9^{\underline{00}} ; 8^{\underline{26}}$ \\
\hline & Ciencias Naturales & $3^{\circ} \mathrm{II}$ & 20 & 7 & 13 & 9 & 6 & 11 & $9^{\underline{20}} ; 9^{\underline{10}} ; 8^{\underline{86}}$ \\
\hline & HUSOC & $3^{\circ} \mathrm{I}$ & 24 & 10 & 14 & 14 & 9 & 10 & $9^{\frac{33}{3}} ; 9^{\underline{00}} ; 8^{\underline{16}}$ \\
\hline & HUSOC & $3^{\circ} \mathrm{II}$ & 27 & 14 & 13 & 16 & 8 & 11 & $8^{\frac{86}{2}} ; 8^{\underline{69}} ; 8^{\underline{26}}$ \\
\hline & ADICO & $3^{\circ} \mathrm{I}$ & 29 & 7 & 22 & 19 & 9 & 10 & $9^{900} ; 8^{45} ; 7^{93}$ \\
\hline
\end{tabular}




\begin{tabular}{|c|c|c|c|c|c|c|c|c|c|}
\hline \multirow{2}{*}{ Escuela } & \multirow{2}{*}{ Modalidad } & \multirow{2}{*}{$\begin{array}{l}\text { Curso y } \\
\text { división }\end{array}$} & \multicolumn{3}{|c|}{ Egresaron (al 30/11/10) } & \multirow{2}{*}{ Finalizaron } & \multirow{2}{*}{$\begin{array}{c}\text { Egresaron } \\
\text { sin adeudar } \\
\text { materias }\end{array}$} & \multirow{2}{*}{$\begin{array}{r}\text { Adeudan } \\
\text { materias }\end{array}$} & \multirow{2}{*}{$\begin{array}{c}\text { Mejores } \\
\text { promedios }\end{array}$} \\
\hline & & & Total & Varones & Mujeres & & & & \\
\hline \multirow{4}{*}{$\begin{array}{c}\mathrm{E} \\
\text { (adolescentes) }\end{array}$} & EGEOR & $3^{\circ} \mathrm{I}$ & 18 & 6 & 12 & 8 & 5 & 10 & $8^{\frac{69}{3}} ; 8^{\underline{16}} ; 7^{\underline{56}}$ \\
\hline & HUSOC & $3^{\circ} \mathrm{I}$ & 16 & 3 & 13 & 10 & 6 & 6 & $9^{20} ; 9^{\frac{10}{2}} ; 9^{\underline{05}}$ \\
\hline & Ciencias Naturales & $3^{\circ} \mathrm{I}$ & 10 & 6 & 4 & 7 & 2 & 3 & $8^{\underline{86}} ; 8^{\underline{45}} ; 8^{\underline{00}}$ \\
\hline & Ciencias Naturales & $3^{\circ} \mathrm{II}$ & 16 & 5 & 11 & 6 & 3 & 10 & $9^{3 \underline{33}} ; 8^{\underline{86}} ; 8^{\underline{26}}$ \\
\hline \multirow{5}{*}{$\begin{array}{c}\text { F } \\
\text { (adolescentes) }\end{array}$} & EGEOR & $3^{\circ} \mathrm{I}$ & 22 & 8 & 14 & 16 & 7 & 6 & $9^{\underline{00}} ; 8^{\underline{75}} ; 8^{\underline{50}}$ \\
\hline & EGEOR & $3^{\circ} \mathrm{II}$ & 34 & 15 & 19 & 30 & 23 & 4 & $9^{\underline{66}} ; 9^{\underline{63}} ; 9^{\underline{46}}$ \\
\hline & ADICO & $3^{\circ} \mathrm{I}$ & 28 & 10 & 18 & 20 & 10 & 8 & $9^{\frac{12}{2}} ; 9^{\frac{00}{2}} ; 8^{\underline{69}}$ \\
\hline & ADICO & $3^{\circ} \mathrm{II}$ & 17 & 7 & 10 & 5 & 3 & 12 & $8^{\underline{23}} ; 7^{\underline{93}} ; 7^{\underline{86}}$ \\
\hline & Ciencias Naturales & $3^{\circ} \mathrm{I}$ & 29 & 15 & 14 & 19 & 12 & 10 & $9^{\underline{08}} ; 9^{\underline{00}} ; 8^{\underline{60}}$ \\
\hline \multirow{2}{*}{$\begin{array}{c}\mathrm{F}_{1} \\
\text { (adultos) }\end{array}$} & Ciencias Sociales & $3^{\circ} \mathrm{A}$ & 42 & 20 & 22 & 30 & 10 & 12 & $8^{\frac{75}{2}} ; 8^{\underline{60}} ; 8^{\underline{00}}$ \\
\hline & Gestión y Administración & $3^{\circ} \mathrm{B}$ & 20 & 12 & 8 & 12 & 5 & 8 & $8^{\frac{69}{3}} ; 8^{\frac{16}{7}} ; 7^{\frac{86}{6}}$ \\
\hline $\begin{array}{l}\mathrm{F}_{1.1} \\
\text { (adultos) }\end{array}$ & $\begin{array}{l}\text { Gestión y Administración } \\
\text { (Anexo) }\end{array}$ & $3^{\circ} \mathrm{C}$ & 11 & 5 & 6 & 8 & 4 & 3 & $8^{\frac{75}{2}} ; 8^{\underline{60}} ; 7^{93}$ \\
\hline \multirow{3}{*}{$\begin{array}{c}\mathrm{G} \\
\text { (adolescentes) }\end{array}$} & HUSOC & $3^{\circ} \mathrm{U}$ & 9 & 1 & 8 & 6 & 3 & 3 & $8^{\underline{33}} ; 8^{\underline{24}} ; 7^{\underline{56}}$ \\
\hline & Ciencias Naturales & $3^{\circ} \mathrm{U}$ & 32 & 13 & 19 & 20 & 10 & 12 & $9^{\underline{33}} ; 9^{\underline{00}} ; 8^{\underline{86}}$ \\
\hline & EGEOR & $3^{\circ} \mathrm{U}$ & 17 & 7 & 10 & 14 & 8 & 3 & $8^{\frac{86}{2}} ; 8^{\frac{60}{2}} ; 8^{\underline{26}}$ \\
\hline $\mathrm{G}_{1}$ (adultos) & EGEOR & $3^{\circ} \mathrm{A}$ & 5 & 2 & 3 & 3 & 2 & 2 & $8^{45} ; 8^{\underline{26}} ; 7^{\underline{56}}$ \\
\hline
\end{tabular}




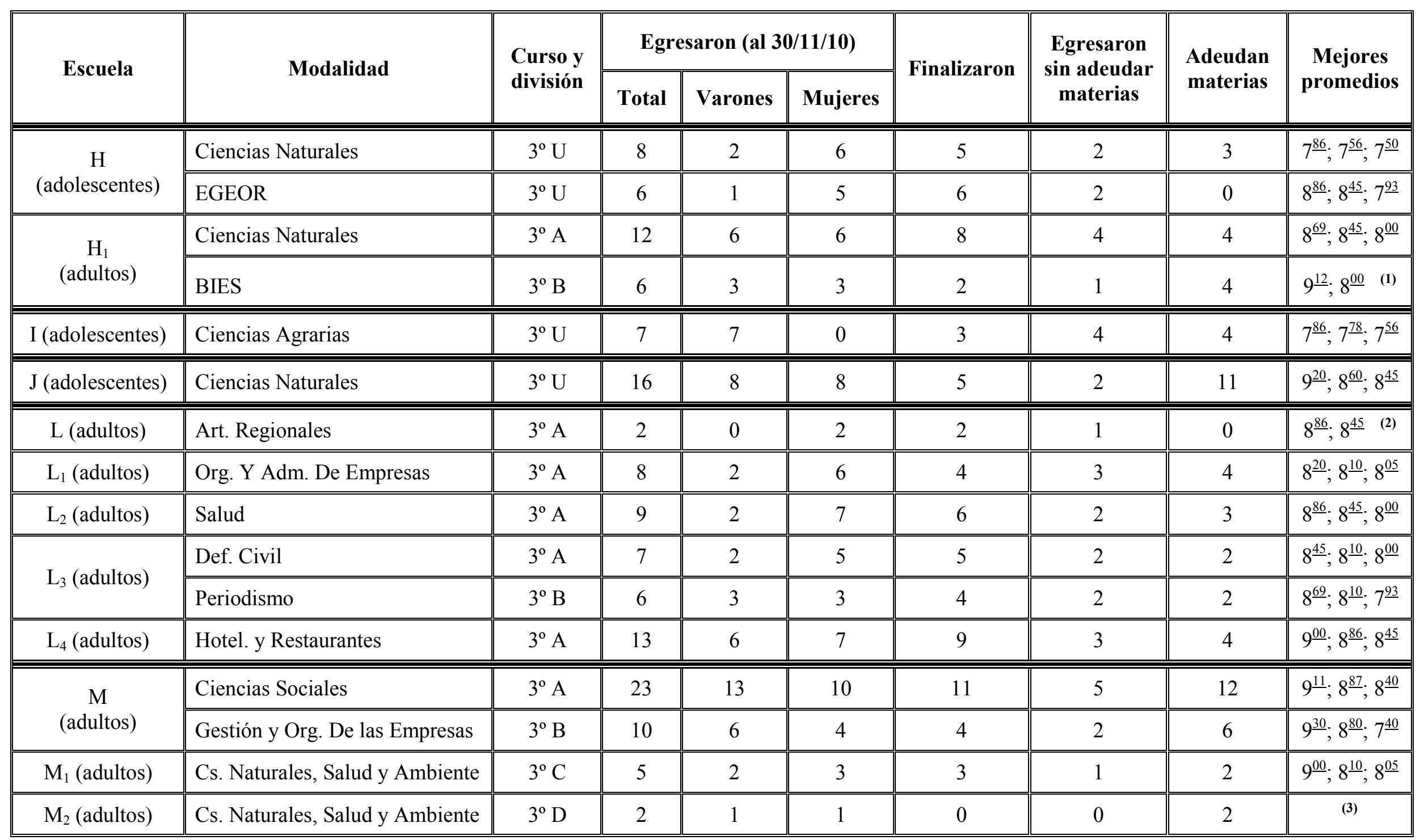

${ }^{(1)}$ El tercer promedio surgirá cuando finalicen los 4 egresados que adeudan materias. ${ }^{(2)} \mathrm{El}$ tercer promedio no existirá porque los egresados fueron 2.

${ }^{\text {(3) }}$ Sin información respecto de los mejores promedios porque ninguno de los 2 egresados finalizó. 


\subsubsection{El proceso de socialización escolar}

Para abordar los modos de gobierno en las escuelas medias estatales del Distrito de Junín resultó sugerente el desplazamiento de los sistemas disciplinarios de penalización a otros basados en la responsabilidad de los educandos. De los temas regulados por las disposiciones internas de los diez establecimientos de adolescentes y nueve de adultos, devienen reflexiones sobre el modo de conducción de cada uno y el tipo de subjetividades que se despliega en los mismos. Así, en relación a la vestimenta de los estudiantes la normativa vigente en ellos toma la forma de recomendación en cuanto a la utilización de ropa adecuada para las actividades escolares, cómoda, limpia y en buen estado de conservación. Se promueven subjetividades activas y responsables que puedan tomar decisiones y realizar elecciones que les permitan lograr la vestimenta adecuada y —al mismo tiempo- diferenciarse de los demás. El investigador pudo comprobar que en ninguna de las escuelas partícipes en este trabajo los egresados vestían guardapolvo.

En otro orden, las citadas escuelas llevan a cabo periódicamente - 2010 y 2011 no fueron la excepción - campañas informativas de carácter preventivo sobre alcoholismo, tabaquismo y otras sustancias que pueden causar daño a la salud. En tal sentido, varios directivos participantes manifestaron honda preocupación por el posible consumo de drogas ilegales dentro mismo de las escuelas o a pocos metros de ellas, comprometiéndose a adoptar las medidas que fuere menester.

A más de lo expresado, un instrumento escrito que regula la vida escolar es el Acuerdo Institucional de Convivencia. El mismo se inicia con una declaración de principios, basando su legitimidad en los procesos de reflexión colectiva que se llevaron a cabo oportunamente en las escuelas y de los cuales deriva. De dichas declaraciones de principios se desprenden varias consideraciones respecto de la concepción de la ley y del tipo de autoridad que se instituye. Ahora bien, la participación de todos en la elaboración de las normas, sobre la base de un diálogo fecundo, pareciera que devino en un distanciamiento de las figuras de autoridad tradicionales y de sus formas de definir y aplicar la ley. De los valores sustentados por tales documentos emanan los deberes y derechos de todos los integrantes del colegio en su condición de personas. Tal regulación pareciera develar una cierta horizontalidad en las relaciones interpersonales (respetar, ser tolerante, no discriminar y dar buen trato, entre otras). Se percibiría aquí un acortamiento de la brecha entre la cúspide y la base en las relaciones de autoridad en el colegio, que no implica la total horizontalidad. Las escuelas B, C, F, G, H, I y $\mathrm{J}$ (entre los adolescentes) y las escuelas $\mathrm{A}_{1}, \mathrm{H}_{1}, \mathrm{~L}, \mathrm{~L}_{1}, \mathrm{~L}_{2}, \mathrm{~L}_{3}, \mathrm{~L}_{4}$ y $\mathrm{M}$ (de adultos), son ejemplos innegables de lo expresado y como datos vayan los siguientes: un egresado de la escuela I afirmó que "la relación es de persona a persona, no tanto de profesor a alumno; es una cuestión de respeto mutuo" y agregaba que "las autoridades son jóvenes y eso nos da la posibilidad de forjar un vínculo”. El diálogo permitiría, entonces, la apertura del estudiante y la creación en él de una interioridad gobernable y autogobernable. Asimismo, otro egresado 
de la escuela I expresó: "siempre vienen; pasa algo y vienen todos a hablar. Tenés que hacer una especie de conferencia y bueno, nada, se quedan tranquilos con eso, con el diálogo". Del mismo modo se podría interpretar la aseveración de un tercer egresado de esa misma escuela: "hablan, primero que nada hablan con vos. Por qué lo hiciste, qué te pasó. Está mucho la cuestión de si te está pasando algo, si estás mal”. A través de estos tres adolescentes surge nítido que la indisciplina no sería interpretada actualmente como una transgresión sino como un problema de desajuste del estudiante (ya sea varón o mujer), ocasionado por contextos familiares que dan lugar a una baja autoestima. Este desajuste lo podría llevar a no insertarse en el colegio o a no sentirse cómodo en él e -incluso- a decidir abandonarlo.

Las escuelas A, D, E, F y $\mathrm{F}_{1}$ presentan una forma tradicional de las pedagogías disciplinarias, si bien es posible señalar algún indicio de inestabilidad de estas formas. Al no existir hoy las denominadas amonestaciones - como tipo de sanción ante los denominados actos de indisciplina - se acude en estas escuelas a la aplicación de inasistencias como manera de corregir actitudes inadecuadas. Según la mayor o menor entidad del acto ilícito cometido serán una, dos o más inasistencias que recaerán sobre el estudiante. A un lado el desconocimiento del Derecho que existe aquí (la inasistencia se computa ante la ausencia del alumno a clase, no por otra causa), la explicación de todas las autoridades fue la que sigue: "De esta manera se mantienen tranquilos; si no lo hacemos, algunos se vuelven inmanejables a veces".

Algunos docentes, identificados como claves para entender el funcionamiento de la disciplina escolar, son los preceptores. Según algunos estudiantes que egresaron en 2010, "los preceptores son quienes terminan decidiendo algunas cosas". Otros opinaron así: "Hay mucha burocracia, mucho reglamento; pero después se discute y muy difícilmente la cosa se ponga muy brava". Esta afirmación pareciera, a primera vista, oponerse a la rigidez de la normativa vigente.

En muchas ocasiones la opinión del preceptor sobre las actitudes de los alumnos en clase, durante los recreos e -incluso- allende la escuela, es de enorme valor para el análisis, la interpretación y la posterior toma de decisiones de otros docentes (integren el cuerpo directivo y/o tengan materias a su cargo). La información sobre aspectos de la personalidad del egresado, características de su grupo familiar, causas de inasistencias, rendimiento escolar, repitencia y vínculos afectivos son valiosos para los demás agentes educativos. En particular, se consideran aquí las palabras de la preceptora Mariel de la escuela F: "en esta escuela existen tres modalidades, EGEOR, Ciencias Naturales y ADICO. Ahora, no todos van a una o a otra porque allí están las materias que más les gusta. A veces, a algunos les va mal y se cambian de modalidad durante el mismo año. O repiten y eligen otra para el año siguiente. No sé qué ganan actuando así’”. 
A todo esto, la biblioteca -en las escuelas donde funciona, que son la mayoría- ha empezado a convertirse, si antes ya no lo era, en uno de los ámbitos preferidos de los educandos, entre ellos los egresados. En mucho contribuyó a ello la posibilidad de acceder a Internet a partir de la instalación de computadoras en las escuelas, varias de las cuales fueron elegidas para esta investigación. Los estudiantes llegan para buscar información y/o realizar trabajos indicados por los profesores. "Muchos menos se acercan para consultar libros", afirmaron los bibliotecarios, quienes destacaron el ambiente de respeto y cuasi silencio del lugar contrastando con lo que se vive muchas veces en el interior de las aulas. En tal sentido, varios profesores -especialmente del área de Comunicaciones- manifestaron lo positivo que puede resultar para el aprendizaje el aporte de la tecnología actual, aplicada ya en el aula ya en la biblioteca.

"Hay educadores que vienen con los egresados a realizar tareas aquí. Otros no vienen nunca. Y pensar que desde hace algunos años el material didáctico que nos envían desde los organismos de gobierno es muy bueno y está muy actualizado en todas las materias". Esta era la reflexión que dejaba la bibliotecaria Susana de la escuela D, compartida por otras de las escuelas de adolescentes y unas pocas bibliotecarias de los colegios de adultos (donde existen muy pocas bibliotecas).

Los Centros de Estudiantes -institucionalizados por la normativa específica- cumplen actividades cuya finalidad es la representación de los educandos en las circunstancias que prevén las disposiciones legales. Elaboran propuestas de variada naturaleza en pos del mantenimiento y la refacción del edificio escolar y también lo atinente al desarrollo de las capacidades integrales de todos los educandos. Asimismo, resultan importantes las conexiones que - a veces - se establecen entre los Centros de Estudiantes de adolescentes y los del nivel terciario. Un ejemplo de ello es el vínculo del Centro de Estudiantes de la escuela D con el del Instituto X (del que se egresa siendo profesor). Pudo comprobarse que sólo en pocas escuelas — de adolescentes como de adultos- estos Centros tienen alguna influencia significativa en la vida escolar, estando restringidos en su accionar por una o más causas. Por ende, aparecería así un obstáculo importante para el adecuado ejercicio de la vida en democracia. 


\subsection{Grupo de enfoque (focus group)}

Se utilizó este método de recolección de datos — cuya unidad de análisis es el grupo- el cual permitió comprobar de qué modo los preceptores de $3^{\circ}$ Año del nivel medio de las diecinueve escuelas participantes formaban un esquema o perspectiva de temáticas generales.

El formato de las sesiones resultó parecido al de una reunión de grupos de crecimiento en el desarrollo humano. Se trabajó también -mediante dicha técnica, denominada también sesiones en profundidad- con egresados, sus responsables, sus profesores, directores y secretarios. Reunidos los grupos, se trabajó en relación con los conceptos, experiencias, emociones, creencias, sucesos o temas que resultaban de interés en el planteamiento de la investigación. 


\subsubsection{La mirada de los preceptores}

Las diferentes sesiones de los grupos - doce en total, seis con preceptores de egresados adolescentes y seis con los de adultos - se llevaron a cabo en las Salas de Preceptores o en lugares habilitados al efecto (debido a refacciones que se estaban efectuando en algunas escuelas). Esos espacios físicos oscilaron entre muchos amplios y confortables y unos pocos que sólo presentaban las condiciones mínimas de aislamiento, silencio y comodidad. ${ }^{209}$ En las escuelas $\mathrm{G}, \mathrm{H}$ y $\mathrm{J}$ las sesiones se desarrollaron en un pequeño lugar que es compartido diariamente por preceptores y profesores, si bien no se presentaron dificultades durante las mismas.

Se trató desde el comienzo de generar un clima de confianza (rapport) con los participantes (mayoritariamente mujeres). Estuvieron presentes los preceptores de cada Tercero y pudieron observarse - entre otras particularidades - las siguientes: la escuela $\mathrm{F}$ tenía cinco cursos de alumnos del último año; tres de ellos cuyos egresados asistían a la mañana y dos donde concurrían a la tarde. La escuela D tenía cinco cursos y todos los educandos asistían en el turno matutino. En ella, un preceptor tenía dos cursos a su cargo, otro preceptor tenía otros dos donde y el tercero se encargaba del restante. Diferente situación fue de la escuela $\mathrm{J}$, donde había un solo curso de egresados con su preceptor por lo que el grupo de enfoque se constituyó -reconociéndose, en primer término, el carácter sesgado del mismo- con los preceptores de $1^{\circ}, 2^{\circ}$ y $3^{\circ}$ Año. En los dos primeros casos habían sido preceptores de estos egresados en esos años. Asimismo, dos preceptores vivieron durante 2010 situaciones particulares: uno lo era en la escuela $\mathrm{F}$ a la tarde y ejercía idéntico cargo en una escuela de gestión privada a la mañana. El otro se desempeñaba como preceptor en dos colegios (el $\mathrm{H}$, de adolescentes en horario matutino y el $\mathrm{H}_{1}$, de adultos en el nocturno) que comparten el mismo edificio.

En muchos cursos se hicieron necesarias varias sesiones debido a que se presentaban nuevas problemáticas que se consideraron importantes para este trabajo. A través de las mismas, las expresiones vertidas por estos agentes educativos denotaron: 1) conocimiento bueno o muy buen respecto de la personalidad de los egresados (para ello se nutren de los pareceres de sus antecesores); 2) elevado nivel de comprensión de las positividades y negatividades de aquéllos; 3) conocimiento suficiente de la importancia de su rol en la escuela; 4) mantienen un diálogo permanente y fluido con los responsables de los alumnos

209. En tal sentido, recuérdese que el artículo 93 o. de la Ley Provincial de Educación establece que los docentes de todo el sistema educativo tienen - entre otros- los derechos de "Desarrollar sus tareas en condiciones adecuadas de seguridad e higiene...". Quedan incluidos aquí —entre otros agentes educativos- los preceptores. 
(muchas veces con una paciencia que excede la que debería esperarse de ellos), 5) a veces tienen actitudes "paternalistas" no siempre beneficiosas para el egresado y 6) su labor no es siempre reconocida como se debiera por algunos de los restantes integrantes de la comunidad educativa.

En cuanto a la faz técnica referida a los grupos de enfoque, no se grabaron las sesiones porque se decidió perder, algún detalle (que en otra sesión se intentó recuperar) en pos de mantener la naturalidad e informalidad de lo interactuado. Las observaciones se registraron de inmediato, finalizadas las sesiones. Cuando las conversaciones se desviaron hacia temas que no eran de interés para esta investigación se las dejó fluir hasta que - sutilmente- se intervino con la finalidad de retomar las temáticas importantes. En todo momento se observó una actitud positiva de los participantes hacia el investigador y las sesiones en sí, las cuales se cumplieron - con la autorización de los directores de las escuelas- en los horarios que mediaban entre un recreo y otro o entre un turno y otro. Sólo cuatro preceptores (dos de escuelas de adolescentes y dos de adultos) estuvieron ausentes - por causas que, se informó justificaron oportunamente- en dos sesiones durante el período comprendido entre agosto y diciembre de 2010.

\subsubsection{Otras opiniones sobre la realidad educativa}

\subsubsection{Cómo ven los profesores a los egresados}

Falta de integración. Respecto de los profesores, las opiniones no fueron unánimes al definir a la escuela como un posible espacio fecundo para los educandos. La mayoría de ellos cree que la escuela es un espacio amigable y que sólo aquéllos que no logran integrarse o no dan con la escuela adecuada pueden sentir hostilidad. "Eso lo puede decir un educando que no se integra, un marginal" y "Por ahí no es la escuela justa, la que él necesita", son las expresiones más escuchadas de los educadores al hacer referencia a tales alumnos. Existe, en tal sentido, una expresión que adquirió relevancia entre los docentes con el paso del tiempo: "no se trata de que aquel alumno no es para tal escuela; en realidad, habría que decir que tal escuela no es para aquel alumno". En tal orden de ideas, la aparición de nuevas tecnologías, los cambios culturales y los procesos de comunicación global marcan desafíos para pensar la educación (por ende, la escuela) del futuro. Se calculó que entre 2005 y 2050 la proporción de habitantes de cinco a veinte años disminuirá (dada la baja tasa de natalidad) y pasará de representar el 34 por ciento al 24 por ciento de la población argentina. Dicha tendencia plantea un doble desafío: por un lado, la disminución de la población en edad escolar (de tres a diecisiete años) facilitará el uso de recursos para la universalización del nivel inicial y del secundario. Por otra parte, la población adulta aumentará considerablemente, lo cual implicará un elevado costo presupuestario en materia de jubilaciones. 
Hostilidad. La minoría de los docentes consultados por el investigador cree que la escuela puede ser hostil para los estudiantes debido a situaciones de discriminación, peleas y límites que tienen que respetar. "El que quiere venir a molestar, vos le ponés límites y sí, para él la escuela va a ser hostil", afirmó un profesor de la escuela H. Otro docente del colegio G agregó: "Discriminación, sí; donde estoy yo un chico que es boliviano el año pasado era terrible; estaba en primer año, pobrecito lo que sufría. Se resolvió el problema con la actuación del departamento de psicología y los grupos que discriminaban tuvieron que entender qué era convivir con otras personas".

Ayer y hoy. "La diferencia que hay ahora es que pelean cinco contra uno; en la época nuestra se agarraban a piñas uno contra uno. Es otro tipo de agresión y no hay nadie que ponga un límite", señalaron algunos profesores. Esta última aseveración respecto de la falta de límites originó —en los últimos diez años - la lógica preocupación en todo el sector docente de nuestro país (el Distrito de Junín incluido). “¿Qué está pasando aquí?” se preguntaron los miembros de las comunidades educativas. Pareciera que poner límites es malo per se. Si en la familia y en la escuela no se ponen los límites pertinentes, no cabe duda que no se están cumpliendo las funciones como se debiera. Esto es grave y tendrá efectos inimaginables para la vida de muchas personas. Pregúntese el lector qué sociedad —de antaño o actualsobrevivió sin el respeto a ciertos límites aunque más no sea mínimos, fueren ellos geográficos, legales, religiosos o morales. Los límites están en el propio ser humano -física e intelectualmente- así como en la ley misma y es la autoridad —en este trabajo son los responsables de los egresados, los profesores de éstos, sus preceptores y los cuerpos directivos- quien los impone a todos conforme a derecho, para vivir civilizadamente.

\subsubsection{Cómo ven los egresados a los profesores}

Falta de autoridad. Al tiempo que un bajo porcentaje de egresados expresó que con los profesores "está todo bien", la mayoría de ellos afirmó que la tirantez en el vínculo con los docentes se da por dos razones: una es la tendencia de muchos educadores a trasladar los asuntos de su vida privada (muchas veces, familiar) al ámbito del aula y la otra es el intento de generar complicidad con los alumnos. Así los roles se desdibujan, lo que causa fastidio en los adolescentes. Respecto de la primera razón, la pregunta es por qué causa/s muchos profesores de nivel medio utilizan sus clases para dialogar con los estudiantes (ora adolescentes ora adultos) sobre temas que no son los de la materia que imparten. Nadie se atreverá a afirmar - comentaba un grupo de docentes al que se consultó- que lo hacen porque desconocen el tema que deben desarrollar ese día. Se tenderá a pensar —aseveraba tal grupo de docentes - que el profesor busca que se lo escuche en su propia problemática ya que no puede (o no quiere) hacerlo en otro ámbito. Aquí hay algo cierto: la parte del sueldo correspondiente al día que actuó de esa manera no la ganó honestamente y esto es más grave 
aún en aquellos docentes donde esa conducta se repetía casi de continuo durante el ciclo lectivo 2010. Algunos docentes y alumnos afirmaron que la solución para esto es muy difícil. Otros, en cambio, señalaron que si algún directivo supervisase (controlase) las clases de esos profesores la realidad cambiaría indefectiblemente. Por lo demás, ningún docente consultado manifestó tener ese comportamiento en sus clases ni conocer a alguien que actuase de esa manera.

En lo que atañe a la segunda razón, la pregunta obligada es qué lleva a ciertos profesores al intento de generar una complicidad con los educandos. A un lado la explicación desde el punto de vista psicológico (si resultara procedente), lo real es que educadores y alumnos son las dos partes del proceso educativo (representan el enseñar y el aprender del derecho a la educación). No existen el uno sin el otro pero —esto también es irrefutable- ninguno debe confundir su status con el del otro.

Intolerancia. A muchos profesores los encuentran fastidiosos e intolerantes, lo cual provoca que el maltrato sea la manera habitual de relacionarse entre docentes y alumnos. "Es difícil la relación con los docentes. Se piensan que porque son profesores pueden hacer lo que quieren. Con el poder te aprietan y no es así”, afirmó una egresada de la escuela F.

Resulta interesante reflexionar aquí sobre la edad del profesor y su antigüedad en la docencia. Podrían tomarse ambos como datos significativos a los fines de conocer el por qué del cansancio que - a su vez- acarrearía el malhumor y la intolerancia. Cualquier educador joven y con pocos años (menos de cinco) en el ejercicio de la docencia puede estar malhumorado e intolerante, por lo que las circunstancias de la edad y años de docencia en algunos casos nada asegura. Por lo demás, no tiene justificación alguna el docente que, por respuestas deficientes de los educandos ante preguntas sobre contenidos de la asignatura, muestran -muchas veces - su malhumor e intolerancia. A todo esto, ningún docente consultado manifestó tener en sus clases ese comportamiento ni conocer a alguien que así actuase.

Cansancio. Muchos educandos perciben que para los profesores el colegio es más un espacio hostil que amigable. Los observan cansados y desbordados por la conducta transgresora o desobediente de los alumnos. En tal sentido reconocen cierta gratificación en demostrar rebeldía o burlarse de algunos docentes y preceptores. También reconocen que hay profesores que saben imponer su autoridad y lograr una relación respetuosa. "Todos sabemos a qué profesor molestar y a cuál no", dijo una egresada de la escuela A.

\subsubsection{Otros puntos de vista sobre la misma realidad}

Mayoritariamente, los directores creen que la participación de los responsables de los educandos en actividades organizadas por las escuelas ha disminuido en los últimos diez años. 
Además, aseguran que se preocupan poco sobre los contenidos que deben aprender sus hijos y menos aún si se trata de escuelas públicas. Otros directores, minoritariamente, se distinguen entre los que aseveran que los responsables se ocupan bastante y los que afirman que la preocupación por el desempeño escolar es mucha. En cuanto a la concurrencia de esos responsables a la escuela ante situaciones de conflicto o problemas de convivencia, casi todos los secretarios afirmaron que sólo asisten si se los notifica. En minoría, los secretarios sostuvieron que aquéllos concurren espontáneamente.

Desde los egresados la percepción de esta temática es bien diferente: la mayoría aseguró que los responsables se preocupan bastante o mucho por sus estudios. El resto señaló que recibe poca o muy poca ayuda en sus tareas escolares.

En general, los responsables de egresados (adolescentes y adultos) expresaron tres preocupaciones fundamentales: las pocas veces que son convocados desde la escuela a acercarse a ella, los problemas de conducción de los directivos por su bajo nivel de capacitación y las reiteradas inasistencias a clase por diversas causas (por ejemplo, huelga) de muchos profesores. En tal sentido, no existe una relación directa entre la cantidad de paros por año y el crecimiento del gasto educativo en atención al Producto Bruto Interno (PBI). Tampoco con el nivel salarial docente ni con el nivel de inversión educativa de las provincias. Buenos Aires es la que realiza el mayor esfuerzo financiero en educación y una de las que más aumentó los salarios docentes, pero tuvo un promedio de once paros por año entre 2002 y 2008, según datos oficiales. 


\subsection{Documentos}

Constituyen una fuente muy valiosa de datos cualitativos que colabora en el entendimiento del fenómeno central de estudio. En esta tesis se trabajo con documentos grupales obtenidos de algunas de las escuelas intervinientes: actas de calificaciones del turno Febrero/Marzo 2010, boletines de calificaciones de los egresados 2010, informes de jornadas institucionales llevadas a cabo en los colegios durante ese año y registros de asistencia a clase de alumnos y de profesores. En relación a este material se efectuaron los análisis pertinentes.

Ab initio, se solicitó formalmente la autorización de los Directores de las escuelas de gestión estatal (adolescentes y adultos) para obtener documentos grupales de contenido diverso. Se explicó a dichas autoridades el significado de los mismos y su vinculación con el planteamiento del problema. Los elementos proporcionados fueron elegidos por los Directores y tienen la ventaja de haber sido producidos por ellos y sus Secretarios (a unos y a otros, asimismo, se les aplicó el cuestionario pertinente). Además, todos ellos están escritos en los "lenguajes" que emplean tales directivos y usualmente son importantes para ellos y las instituciones que representan.

En primer lugar - puesto que se ha de seguir un orden cronológico- se efectuará el análisis de los datos pertinentes a la escuela $\mathrm{H} \mathrm{y}$ - sucesivamente- el correspondiente a los colegios F, G e I. 


\subsubsection{Escuela $H$}

En los Cuadros 1 y 2 siguientes podrán observarse los resultados de los exámenes de Febrero/Marzo de 2010 correspondientes a estudiantes de diferentes cursos de esta escuela. Mediante $\boldsymbol{A}, \boldsymbol{B}, \boldsymbol{C}$ y $\boldsymbol{D}$ se identifican los agrupamientos a que dieron lugar los mismos:

Cuadro 1

Febrero/Marzo 2010 - Comisiones Evaluadoras - Turno Matutino

\begin{tabular}{|c|c||c||c||c|}
\cline { 2 - 5 } \multicolumn{1}{c|}{} & $\mathbf{2}^{\mathbf{0}}$ & $\mathbf{3}^{\mathbf{0}}$ & $\mathbf{4}^{\mathbf{0}}$ & Totales \\
\hline $\boldsymbol{A}$ & 17 & 4 & 31 & $52(100 \%)$ \\
\hline $\boldsymbol{B}$ & 2 & 0 & 3 & $5(9,62 \%)$ \\
\hline $\boldsymbol{C}$ & 1 & 2 & 1 & $4(7,69 \%)$ \\
\hline $\boldsymbol{D}$ & 14 & 2 & 27 & $43(82,69 \%)$ \\
\hline
\end{tabular}

Notas: 1. $\boldsymbol{A}$ : Total de alumnos en condiciones de presentarse a rendir examen ante la Comisión Evaluadora. $\boldsymbol{B}$ : alumnos aprobados. $\boldsymbol{C}$ : alumnos desaprobados. $\boldsymbol{D}$ : alumnos ausentes. $\boldsymbol{A}=\boldsymbol{B}+\boldsymbol{C}+\boldsymbol{D}$.

2. El 17,31\% se presentó a rendir; es decir, $\boldsymbol{B}+\boldsymbol{C}$.

Cuadro 2

Febrero/Marzo 2010 - Comisiones Evaluadoras - Turno Vespertino

\begin{tabular}{|c|c||c|c|c|c||}
\cline { 2 - 6 } \multicolumn{1}{c|}{} & $\mathbf{2}^{\mathbf{0}}$ & $\mathbf{3}^{\mathbf{0}}$ & $\mathbf{4}^{\mathbf{0}} \mathbf{I}$ & $\mathbf{4}^{\mathbf{0}} \mathbf{I}$ & Totales \\
\hline $\boldsymbol{A}$ & 6 & 24 & 33 & 41 & $104(100 \%)$ \\
\hline $\boldsymbol{B}$ & 3 & 2 & 10 & 0 & $15(14,42 \%)$ \\
\hline $\boldsymbol{C}$ & 0 & 0 & 4 & 0 & $4(3,85 \%)$ \\
\hline $\boldsymbol{D}$ & 3 & 22 & 19 & 41 & $85(81,73 \%)$ \\
\hline
\end{tabular}

Notas: 1. $\boldsymbol{A}$ : Total de alumnos en condiciones de presentarse a rendir examen ante la Comisión Evaluadora. $\boldsymbol{B}$ : alumnos aprobados. $\boldsymbol{C}$ : alumnos desaprobados. $\boldsymbol{D}$ : alumnos ausentes. $\boldsymbol{A}=\boldsymbol{B}+\boldsymbol{C}+\boldsymbol{D}$.

2. El 18,27\% se presentó a rendir; es decir, $\boldsymbol{B}+\boldsymbol{C}$.

3. Se distingue en sombreado el elevado porcentaje de ausentes en ambos turnos $(82,69 \%$ y $81,73 \%)$. Es muy bajo también el porcentaje de aprobados $(9,62 \%$ y $14,42 \%)$.

En ambos Cuadros se han tomado en cuenta a educandos que -en 2010- cursaban $2^{\circ}$, $3^{\circ}$ y $4^{\circ}$ Año. Téngase presente que para culminar el nivel aún faltaban aprobar $5^{\circ}$ y $6^{\circ}$ Año. Ello acontecería en 2012, año en que dejó de tener vigencia el Nivel Polimodal.

En el Cuadro $3^{210}$ figura en primer lugar lo que atañe a Ciencias Naturales. Puede observarse cómo disminuye el número de estudiantes: veintiocho en $1^{\circ}$, doce en $2^{\circ}$ y nueve en

210. Véase dicho cuadro referido a tal modalidad en los Anexos (página 440). 
$3^{\circ}$ Año. Esta realidad muchos docentes la explicaron al investigador como un desgranamiento lógico que ocurre generalmente. Asimismo, en $1^{\circ}$ Año en dos de las once asignaturas (hoy denominadas espacios curriculares) no hay alumnos sin calificar. Esta cantidad se elevó a siete en $2^{\circ}$ Año. El informe institucional fue confeccionado por el cuerpo directivo de esta escuela al 11 de junio de 2010, no obstante lo cual aún había estudiantes sin notas. Las explicaciones dadas al investigador por los directivos y los profesores involucrados en esta realidad fueron varias.

En $3^{\circ}$ Año, uno de los nueve educandos aprobaba en ese momento las diez asignaturas; esto es el 11,11 por ciento del total. A fin de 2010 se observó que ocho de ellos egresaron (uno dejó de asistir por pase a otra escuela), muchos adeudando una o más asignaturas. Asimismo, datos obtenidos en ésta y en otras escuelas mostraron que el porcentaje de educandos que se presentó a rendir la/s materia/s fue muy bajo, ya en el turno Diciembre como en Febrero. Este comportamiento contradice el razonamiento de muchos docentes según el cual "es durante las vacaciones de verano cuando se dispone de más tiempo para estudiar, sin dejar de lado las actividades recreativas propias de la época". Esta realidad deficitaria al momento de tener que rendir lo adeudado se observó tanto en adolescentes como en adultos.

Asimismo, dos materias eran aprobadas por los nueves estudiantes. Con ocho aprobados aparecía Inglés, hecho no frecuente a estar por lo observado en otras escuelas (por ejemplo: A, B, D, H y M). Esto podría mostrar — de algún modo- la aptitud intelectual y la actitud hacia el aprendizaje del alumnado como también el aporte significativo del docente a dicha realidad. A todo esto, Educación Física es una de las asignaturas donde más desaprobados había. La posible falta de valoración de la misma por parte del estudiantado remitiría directamente a sus familias en cuanto transmisoras potenciales de informaciones, conocimientos y valores que hacen a la salud psicofísica de sus hijos. Relaciónese todo lo explicitado supra con el artículo $88 \mathrm{~d}$. de la Ley de Educación de la provincia de Buenos Aires, que establece como derecho de los alumnos (y correlativo deber de los docentes): "Ser evaluados en su desempeño y logros, conforme a criterios rigurosa y científicamente fundados, en todos los niveles, modalidades, ámbitos y orientaciones del sistema e informados al respecto".

En cuanto al material de la escuela $\mathrm{H}$, tal ítem podría tomarse en cuenta en relación a lo que acontece en el panorama nacional. En tal sentido, el estado de las escuelas y su equipamiento (independientemente de los niveles) son cuestiones que muchas veces dependen del punto de vista de su apreciación. Un análisis comparado permitiría ubicar estas discusiones en una perspectiva contextualizada, en la región latinoamericana. ${ }^{211}$ Por otro lado,

211. Las estadísticas de octubre de 2010 del relevamiento de la Organización de las Naciones Unidas para la Educación, la Ciencia y la Cultura (UNESCO) autorizan a efectuar varias lecturas. Por 
pudo comprobarse que en esta escuela existe un equipamiento que responde a las actuales necesidades de los docentes y de los educandos.

A renglón seguido se analizarán los datos del informe de calificaciones en la modalidad EGEOR producido por la misma escuela, que constan en el Cuadro 3 (continuación). ${ }^{212}$ Trátase del desempeño escolar de los egresados al 11 de junio de 2010. En esta investigación se aplicó el cuestionario a seis (del total de siete) egresados: un varón y cinco mujeres. El 57,14 por ciento; esto es, cuatro de los siete educandos (uno no finalizó el nivel) que aprobaba hasta aquí todas las asignaturas mostraría un curso con positividades y negatividades en cierto equilibrio. Por lo demás, una experiencia de fusión - similar a lo que sucede en la modalidad Ciencias Naturales - se da aquí con las materias Matemática, Inglés como también Lengua y Literatura, cuyos profesores las comparten en $2^{\circ}$ y en $3^{\circ}$ Año del Polimodal. En otro orden, las dificultades que debía enfrentar una de esas estudiantes, de 17 años, permiten visualizar la realidad de la alumna-madre: la protección y el cuidado de su bebé, las distancias desde su vivienda hasta la escuela y la guardería dificultan la asistencia a clase y - por ende- su rendimiento académico. Mirta Zaida Lobato (2008) asegura que en Argentina - como en otras partes del mundo- se produjo una gradual e inconfundible diferenciación y disociación de las esferas doméstica y política, trazando una línea divisoria - cierto que ideal- entre la familia, las instituciones y las prácticas políticas. ${ }^{213}$

Por lo demás, el equipamiento de esta escuela la ubica — como quedó dicho- en el nivel deseado para satisfacer las diferentes necesidades de la comunidad educativa. En tal sentido, su cuerpo directivo estimó que podría ser útil llevar a cabo un estudio semestral sobre el uso de todos los elementos tecnológicos puestos a disposición de educadores y de alumnos y su real incidencia en el logro de una mejor calidad educativa. En tal orden de ideas, recuérdese el artículo 88 e. de la Ley de Educación Provincial que prescribe como derecho del alumno: "Recibir el apoyo social, cultural y pedagógico necesario para garantizar la igualdad de oportunidades y posibilidades que le permitan completar la educación obligatoria...”.

Restaría observar cómo fue el desempeño de los egresados en la escuela $\mathrm{H}$, desde el inicio del ciclo lectivo 2010 hasta el 11 de junio de dicho año. A tal efecto se tomaron en

un lado, la gran mayoría de las escuelas argentinas reúne condiciones básicas para la enseñanza —en todos los rubros relevados- por encima del promedio de la región. Por otra parte, un 12 por ciento de ellas no cuenta con asientos suficientes y un 20,2 por ciento no tiene sanitarios en el número deseado para los alumnos. Así acontece también en las escuelas A, C, E, J, H, M, L y L4 del Distrito de Junín.

212. Véase dicho cuadro referido a esta modalidad en los Anexos (página 441).

213. Lobato, Mirta Zaida, Capítulo 2 "Madres obreras", en ¿Tienen derechos las mujeres? Política y Ciudadanía en la Argentina del siglo XX. Buenos Aires, Colección dirigida por José Nun, Capital Intelectual, 2008, página 10. 
consideración las mismas dos modalidades: Ciencias Naturales y EGEOR (y en idéntico orden). Agréguese que en esta investigación se aplicó el cuestionario a 7 (1 varón y 6 mujeres) de los 8 egresados pertenecientes a la primera de ellas. Respecto de EGEOR, 6 (1 varón y 5 mujeres) fueron los egresados (de un total de 7) a quienes se suministró el cuestionario pertinente. La ampliación de lo explicitado es este párrafo aparece en los Cuadros 4 y $5 .^{214}$

\subsubsection{Escuela $\mathbf{F}$}

A continuación se efectuará el análisis de los datos referidos a la asistencia de profesores por materia en $3^{\circ} \mathrm{I}$ de ADICO. En el Cuadro $6^{215}$ se contabilizaron 445 clases que debían haberse dictado desde el 15 de marzo de 2010 al 31 de agosto del mismo año. Se impartieron realmente 412, por lo que los ausentismos sumaron 33. Un promedio de 49 clases por asignatura teniendo en cuenta las 445. Asimismo, considerados todos los profesores de las nueve materias estuvo ausente el 7,42\% del total de clases previstas en dicho período. Implica que estuvo presente el $92,58 \%$. Los inspectores siempre destacaron en las reuniones llevadas a cabo en 2010 junto a directivos y a profesores lo necesario de la continuidad de las clases (tal lo informado por directivos de esta escuela al investigador). En otro orden, se observó el $36,66 \%$ de ausentismo por materia tomando en consideración las nueve asignaturas en las que se impartieron clases. No existió materia alguna donde no se registrasen inasistencias. La actitud de no faltar al dictado de clases - derivada del pensamiento sarmientino- hoy pareciera no existir y "quien la intente reflotar podría recibir como respuesta un gesto irónico de buena parte de sus colegas" (así lo manifestaron muchos de ellos). Respecto de Educación Física, no existía información. Esta situación fue explicada por tres egresados así: "parece que todavía no se designó profesor" y por algunas preceptoras con estas palabras: "ese es un tema de la directora, nosotras no sabemos nada".

Seguidamente se efectuará el análisis de los datos relativos a la asistencia de profesores por materia en $3^{\circ}$ II de ADICO. En el Cuadro $7^{216}$ se contabilizaron 457 clases que debieron haberse dictado desde el 15 de marzo de 2010 al 31 de agosto del mismo año. Un promedio de 50 clases por asignatura. Considerados todos los profesores, estuvo ausente el 9,63\% del total de clases previstas en dicho período. Implica que estuvo presente el 90,37\%. En tres materias no se registraron inasistencias de docentes a clase durante dicho período. Por lo demás, Matemática mostró el $42 \%$ de ausentismo. Esto significa que si no fue designado un

214. Véanse dichos cuadros en los Anexos (página 442).

215. Véase dicho cuadro referido a tal modalidad en los Anexos (página 446).

216. Véase dicho cuadro referido a tal modalidad en los Anexos (página 446). 
docente en reemplazo de quien estaba a cargo de la asignatura, casi la mitad de los contenidos no fueron desarrollados. Si un profesor sucedió al ausente habría que conocer en qué día del período lo hizo y cómo reaccionaron los alumnos frente al cambio. También cómo coordinaron ambos la tarea áulica, porque a veces el diálogo está presente entre los docentes y otras veces directamente no existe. Todo ello va en perjuicio de los alumnos, máxime si éstos pertenecen a sectores desfavorecidos (sean del Distrito de Junín o de cualquier otro del país). En otro orden de ideas, cabe repetir aquí —en relación a Educación Física- lo que se expresó supra respecto de $3^{\circ}$ I. Téngase presente, en relación a todo lo aseverado, el artículo 94 e. de la Ley de Educación Provincial que establece - entre otras - como obligaciones de los docentes: "Ejercer su trabajo de manera idónea y responsable".

Faltaría conocer cómo fueron los movimientos en la matrícula de educandos (particularmente de los cursos de egresados) que tuvieron lugar entre mayo y agosto de 2010. A tal efecto se confeccionó el Cuadro $8^{217}$. Asimismo, teniendo en cuenta los mismos quince cursos que se consideraron en el cuadro anterior, se brinda información respecto del ausentismo de profesores por curso en el Cuadro $9^{218}$.

\subsubsection{Escuela $G$}

Se analizaron también los aspectos esenciales del informe de la jornada institucional cumplida el 31 de agosto de 2010 en esta escuela. En esa oportunidad se convocó en forma conjunta a los docentes de la ESB (Escuela Secundaria Básica) y a los de la EES (Escuela de Educación Superior), dado que la problemática incumbía a ambas por igual.

En el informe de marras los docentes aludieron unánimemente a la apatía o falta de interés del alumnado, sin distinciones de modalidad o de curso. Trátase de un dato preocupante según los profesores de ésta y de otras escuelas. "Mientras tanto, desde las más importantes autoridades educativas nacionales y provinciales se insiste permanentemente en la inclusión con aprendizaje", señalaron varios docentes. Algo indudablemente justo, válido y posible "siempre que se logre probar la relación de causalidad según la cual: a mayor aprendizaje, mayor inclusión social", aseveraron otros. Asimismo, los problemas de inasistencia y de lectoescritura detectados en muchos egresados podrían deberse a varias causas: la familia, la televisión, el grupo de pares o los adultos significativos (entre otras), no descartándose combinaciones entre algunas o todas ellas. Tal lo afirmado por la totalidad de los educadores al investigador. Por otro lado, la familia apareció desdibujada en los diferentes

217. Véase dicho cuadro en los Anexos (página 447).

218. Véase dicho cuadro en los Anexos (página 448). 
cursos, como si su rol de educadora primaria ya no fuese tan fundamental para el desarrollo de las capacidades de los hijos.

En otro orden, los mismos docentes aseguraron que sus propuestas para mejorar y/o superar tal estado de cosas conducían a afirmar lo siguiente: "todas ellas son importantes, pero es de esperar que no permanezcan sólo en el papel y que tengan continuidad en el tiempo".

En relación a todo lo expresado supra, recuérdese que el artículo 91 b. de la Ley de Educación Provincial establece, entre otras, como obligaciones de los responsables de los alumnos, la de: "Asegurar la concurrencia de sus hijos o representados a los establecimientos escolares [...], salvo excepciones de salud o de orden legal que les impidan su asistencia periódica a la escuela".

\subsubsection{Escuela I}

A continuación se llevará a cabo el análisis de lo acontecido en la jornada institucional llevada a cabo el 31 de agosto de 2010 en su edificio ubicado a aproximadamente doscientos metros de uno de los límites urbano-suburbano de la ciudad de Junín. Cabe aclarar que no asistieron muchos docentes, concurriendo ese día a realizar la jornada prevista en la escuela donde tenían la mayor carga horaria. Por ende, estuvieron en los horarios de la mañana, tarde y noche, distribuidos en los colegios existentes en el Distrito de Junín.

A un lado la circunstancia señalada, la influencia de la escuela —más allá de cualquier debate sobre la educación actual en Argentina- parecería innegable con el paso de los años. Tal lo afirmado durante dicha jornada por los docentes reunidos en esta escuela al referirse a los cambios experimentados por los estudiantes desde $1^{\circ}$ hasta $3^{\circ}$ Año inclusive del Polimodal. "Los educandos que comenzaron el nivel medio no eran los mismos en lo orgánico, lo psicológico y lo moral que estos egresados de 2010”, opinaron coincidentemente. Diferentes personalidades adolescentes fueron adquiriendo, al tiempo que transcurrían los años, rasgos peculiares en la interacción familia-escuela-sociedad”, se afirmó. Empero, la realidad de este colegio se ve sesgada por la ausencia de algunos profesores de $3^{\circ}$ Año en la jornada de marras, tal como se mencionara supra. La información proporcionada al investigador también da cuenta de inasistencias de docentes ese día en otros colegios de nivel medio estatales. Si tales ausencias no se justificaron $-\mathrm{y}$ aún así- ello iría contra el conocimiento integral que debiera tener cada docente respecto de la escuela donde trabaja. Le impediría - asimismo - adquirir un sentido de pertenencia real a un colegio determinado, lo cual resulta fundamental para su desempeño profesional.

Los alumnos que iniciaron y egresaron de $3^{\circ}$ Año fueron siete (todos varones). Un octavo alumno asistió desde el 6 hasta el 17 de marzo de 2010 y pasó a otro colegio. En esta 
investigación fueron encuestados cinco de los siete educandos. El 42,85\% del alumnado finalizó $3^{\circ}$ Año y también el nivel medio puesto que no adeuda asignatura alguna, en tanto cuatro estudiantes aún adeudan materias. El porcentaje citado podría indicar que el primer objetivo para estos educandos fue lograr el egreso. En un tiempo posterior finalizarán o no la escuela secundaria. Entre ellos hay quienes piensan continuar estudios superiores, lo cual pone fecha de vencimiento a la culminación del nivel. Están — por otro lado- los que ansían o tienen hoy un trabajo determinado. Para ellos rendir la/s asignatura/s pendiente/s podría convertirse en un objetivo difícil y/o de largo plazo.

También se pudo observar el boletín de calificaciones de un estudiante que egresó de la escuela I. A continuación se consignarán los promedios finales de cada asignatura:

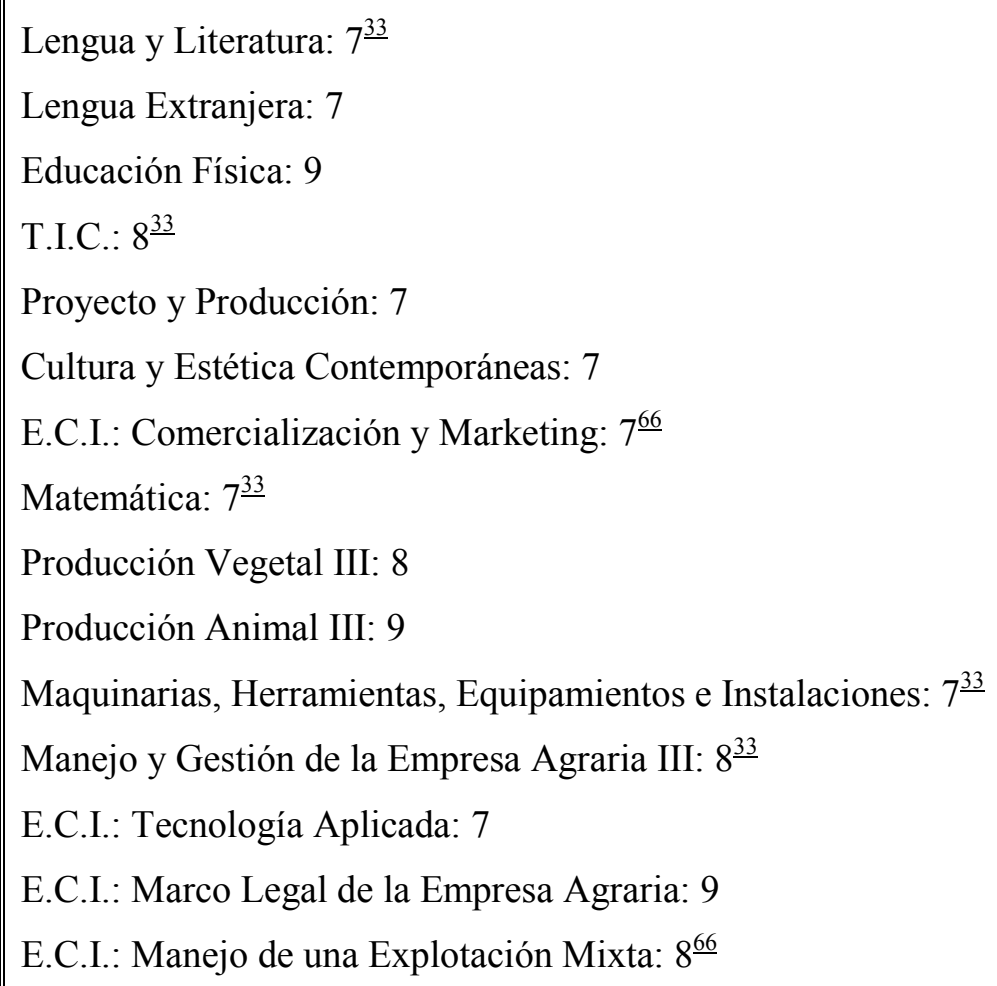

En total $117^{97}$ puntos obtenidos en 15 materias, lo que da como resultado el siguiente promedio: $7^{\frac{86}{}}$ (éste fue el mejor de $3^{\circ} \mathrm{Año}$ ). El segundo promedio fue $7^{78}$.

Dicho adolescente seguirá la carrera de Agronomía (atento la modalidad de la escuela) en la UNNOBA (Universidad Nacional del Noroeste de la Provincia de Buenos Aires), ubicada en la ciudad de Junín. Se aprecia su buen posicionamiento (con promedio 8 y aún más) en materias que pueden tener relación directa o indirecta con una o más de las que integran el Plan de Estudios de dicha carrera. Qué tan útiles serán los conocimientos adquiridos en esta escuela en relación por ejemplo, a Matemática (materia incluida en el Primer Año de 
Agronomía), ameritarían una investigación futura basada en las articulaciones entre el nivel medio y el superior (universitario).

Además, el investigador tuvo acceso al libro denominado Registro de alumnos. A partir de su lectura se confeccionó el siguiente cuadro:

\section{Desglose de los egresados 2010 de la escuela I}

\begin{tabular}{|c|c|c|}
\hline \multirow{2}{*}{$\begin{array}{l}\text { Alumno } 1 \\
\text { (18 años) }\end{array}$} & Padre: militar (suboficial) & \multirow{2}{*}{$\begin{array}{l}\text { Viven en inmediaciones de la } \\
\text { guarnición militar X (a más de } 5 \mathrm{~km} \text { de } \\
\text { la escuela) }\end{array}$} \\
\hline & Madre: ama de casa & \\
\hline \multirow{2}{*}{$\begin{array}{l}\text { Alumno } 2 \\
\text { (18 años) }\end{array}$} & $\begin{array}{l}\text { Padre: productor agropecuario (dueño de una } \\
\text { parcela de tierra menor a } 100 \text { hectáreas) }\end{array}$ & \multirow[t]{2}{*}{ Viven a $8 \mathrm{~km}$ de la escuela (zona rural) } \\
\hline & Madre: maestra & \\
\hline \multirow{2}{*}{$\begin{array}{l}\text { Alumno } 3 \\
\text { (19 años, } \\
\text { repitente) }\end{array}$} & $\begin{array}{l}\text { Padre: suboficial retirado de la Policía } \\
\text { Federal }\end{array}$ & \multirow{2}{*}{$\begin{array}{l}\text { Viven en inmediaciones del Bar } \\
\text { conocido como "Z" (en el Cuartel II, a } \\
10 \text { kilómetros de la escuela) }\end{array}$} \\
\hline & Madre: ama de casa & \\
\hline \multirow{2}{*}{$\begin{array}{l}\text { Alumno } 4 \\
\text { (18 años) }\end{array}$} & Padre: propietario de una pequeña empresa & \multirow{2}{*}{$\begin{array}{l}\text { Viven en la Avenida General San } \\
\text { Martín, a } 60 \text { cuadras de la escuela }\end{array}$} \\
\hline & Madre: ama de casa & \\
\hline \multirow[t]{2}{*}{$\begin{array}{l}\text { Alumno } 5 \\
\text { (17 años) }\end{array}$} & $\begin{array}{l}\text { Padre: empleado en relación de dependencia } \\
\text { en una empresa privada }\end{array}$ & \multirow{2}{*}{$\begin{array}{l}\text { Viven en el Cuartel II, a } 10 \text { kilómetros } \\
\text { de la escuela }\end{array}$} \\
\hline & Madre: empleada & \\
\hline \multirow{2}{*}{$\begin{array}{c}\text { Alumno } 6 \\
\text { (17 años) }\end{array}$} & $\begin{array}{l}\text { Padre: productor agropecuario (dueño de una } \\
\text { parcela de tierra menor a } 100 \text { hectáreas) }\end{array}$ & \multirow{2}{*}{$\begin{array}{l}\text { Viven en el barrio Unión Obreros de la } \\
\text { Construcción de la República } \\
\text { Argentina (UOCRA), a } 30 \text { cuadras de } \\
\text { la escuela. }\end{array}$} \\
\hline & Madre: ama de casa & \\
\hline $\begin{array}{l}\text { Alumno } 7 \\
\text { (17 años, } \\
\text { hermano } \\
\text { mellizo del } \\
\text { anterior) }\end{array}$ & $\begin{array}{l}\text { Padre y Madre: son los mismos que los del } \\
\text { Alumno } 6 .\end{array}$ & Ídem Alumno 6 \\
\hline
\end{tabular}

Respecto de las inasistencias de los egresados, éste es el análisis: 
El 2010 fue un año en el que — salvo los fines de semana denominados "largos" (con más de dos días) y algún feriado por una razón determinada- el ciclo lectivo tuvo un desarrollo normal en cuanto a días de clase previstos y efectivamente cumplidos. Por ende, todos los profesores pudieron - salvo alguna circunstancia especial y/o particulardesarrollar los contenidos de los diferentes espacios curriculares según hubieren planificado. Asimismo, datos de algunos informes tenidos en cuenta en esta investigación permitirían afirmar que las inasistencias de profesores ese año no incidieron en el desenvolvimiento escolar de los estudiantes. A un lado la calidad de la información proporcionada, surge la pregunta referida a cómo puede llegar a conocerse exactamente esa no incidencia.

Por lo demás, junio fue el mes de menor asistencia a clase ya que sólo lo hizo el 55,50\% de los egresados. El intenso frío - muchos días- y la lluvia - en algunos casos muy intensa- probablemente fueron causa de esta realidad. A ello debería sumarse la circunstancia de la distancia - muy significativa en algunos casos- entre la vivienda del estudiante y la escuela. A todo esto, el camino de acceso a la misma —desde la ruta nacional hasta el edificio propiamente dicho- es de tierra, por lo que en días de lluvia se torna intransitable. Asimismo, debe señalarse que entre los egresados habría alumnos que se desplazaban habitualmente en bicicleta y otros en ciclomotor para realizar el trayecto entre sus viviendas y la escuela.

A un lado las consecuencias legales de las ausencias injustificadas, ningún estudiante perdió la condición de regular y dos de ellos superaron el mes de inasistencias. Ambos alumnos están entre los 4 que adeudan materias, lo que aparecería como consecuencia probable de tantas ausencias. Por lo demás, no se tuvo conocimiento de que estuviesen enfermos y durante sus inasistencias nunca llegó a la escuela un certificado médico que acreditara alguna enfermedad. "Las causas de la no concurrencia a clase posiblemente hayan sido otras", reflexionaba la preceptora del curso en diálogo con el investigador. Podría relacionarse este dato con los resultados obtenidos del cuestionario aplicado a los egresados de esta escuela puesto que en la pregunta referida a qué harían una vez finalizado el nivel medio, ambos estudiantes eligieron la opción "trabajar solamente".

Una de las asignaturas que adeudan los 4 estudiantes es Matemática; las demás materias desaprobadas son diferentes entre todos ellos. A partir de aquí surge el interrogante de por qué Matemática es una asignatura adeudada por todos ellos. Para responder a ello podría efectuarse el siguiente análisis: en una institución secundaria —de adolescentes o de adultos - se presenta como dificultad el "ausentismo en la asignatura Matemática". Muchas veces este indicador se visualiza como un problema recurrente que admite estas reflexiones: "a los alumnos no les gusta dicha materia", "les resulta difícil y en tal institución escolar sucede esto desde siempre", se trata de un "problema histórico". Estas explicaciones conducen a una "naturalización" del hecho que no permite ver el problema real para abordarlo adecuadamente. Considérese que para romper una interpretación construida históricamente es 
necesario analizar el problema y contextualizarlo en el colegio. Tener datos que permitan obtener una respuesta adecuada sobre cuestiones como el porcentaje de ausentes por curso y por año, la relación existente entre estos datos y las calificaciones del alumnado, días de la semana que presentaron más inasistencias de los estudiantes, días del mes donde se observaron las mayores ausencias y teoría/s educativa/s aplicada por los docentes en el desarrollo de sus clases, entre otras. Si se tuviese en cuenta todo lo anterior, las respuestas a los interrogantes darán precisión sobre lo que preocupa a los docentes y permitirían realizar acciones de intervención eficaces.

Piénsese, en relación con todo lo expresado supra, que el contenido del artículo 89 c. y g. de la Ley de Educación Provincial establece, entre otras, como obligaciones de los alumnos: "Asistir a clase regularmente y con puntualidad", "respetar el proyecto institucional de la escuela y cumplir las normas de organización, convivencia y disciplina del establecimiento escolar". Respecto de la ausencias a clase de los egresados de esta escuela, véanse los Cuadros 1 y 2 siguientes:

Cuadro 1

Inasistencias de todos los egresados en 2010

\begin{tabular}{|l|c|l||}
\hline \multicolumn{1}{|c|}{ Mes } & Total & \multicolumn{1}{c||}{ Datos } \\
\hline \hline Marzo & $16(11,42 \%)$ & Todas injustificadas. Asistió a clase el $88,58 \%$ del alumnado \\
\hline \hline Abril & $12(23,60 \%)$ & Todas injustificadas. Asistió a clase el $76,40 \%$ del alumnado \\
\hline \hline Mayo & $12(19,10 \%)$ & 7 injustificadas. Asistió a clase el $80,90 \%$ del alumnado \\
\hline \hline Junio & $28(44,50 \%)$ & 2 injustificadas. Asistió a clase el $55,50 \%$ del alumnado \\
\hline Julio & $3(7,70 \%)$ & Todas injustificadas. Asistió a clase el $92,30 \%$ del alumnado \\
\hline \hline Agosto & $10(12,35 \%)$ & 8 injustificadas. Asistió a clase el $87,65 \%$ del alumnado \\
\hline \hline Septiembre & $18(19,60 \%)$ & 9 injustificadas. Asistió a clase el $80,40 \%$ del alumnado \\
\hline \hline Octubre & $19(23,90 \%)$ & 6 injustificadas. Asistió a clase el $76,10 \%$ del alumnado \\
\hline \hline Noviembre & $21(30,60 \%)$ & 8 injustificadas. Asistió a clase el $69,40 \%$ del alumnado \\
\hline \hline Diciembre & $6(10,10 \%)$ & 2 injustificadas. Asistió a clase el $89,90 \%$ del alumnado \\
\hline \hline Total: 145 inasistencias; 73 injustificadas, esto es el $50,34 \%$ \\
\hline
\end{tabular}




\begin{tabular}{|l|c|c||}
\hline \multicolumn{1}{|c|}{ Alumnos } & Inasistencias & $\begin{array}{c}\text { Inasistencias } \\
\text { injustificadas }\end{array}$ \\
\hline Alumno 1 & 17 & 14 \\
\hline Alumno 2 & 28 & 17 \\
\hline Alumno 3 & 39 & 22 \\
\hline Alumno 4 & 20 & 15 \\
\hline Alumno 5 & 27 & 15 \\
\hline Alumno 6 & 29 & 20 \\
\hline \hline Alumno 7 & 32 & 19 \\
\hline Alumno 8 & Dejó de asistir el 17/03/2010 & $\mathbf{1 2 2}(\mathbf{6 3 , 5 4 \% )}$ \\
\hline \hline Total: & $\mathbf{1 9 2}$ & \\
\hline
\end{tabular}

Nota: en sombreado la información referida a los dos egresados con más inasistencias (un varón y una mujer).

Obsérvese en el Cuadro 2 que más de la mitad de las inasistencias anuales de cada uno de los egresados no está justificada. Como derivación lógica, más de la mitad de las inasistencias anuales de todos ellos tampoco lo está. Esta realidad de hoy no fue siempre así. Ir a la escuela años atrás era vivido — en general - como algo placentero y de suma importancia para la vida presente y futura. Asistir pareciera haberse convertido - consecuencia de diversos factoresen un esfuerzo casi desmedido y en buena medida carente de sentido para el estudiantado (al menos, para buena parte de él). La "justificación" en los hechos de las inasistencias injustificadas haría responsables en primer lugar, al preceptor del curso, más allá de que esta situación sea injusta e inmoral en relación a aquellos estudiantes que no llegaron a tantas ausencias. Los responsables de los egresados podrían explicar también por qué suceden estas cosas.

En otro orden de ideas, el alumnado de este colegio asiste a clase de lunes a viernes, en horario matutino y vespertino. Las actividades áulicas se inician a las 7,30 horas y se extienden hasta el mediodía. A las 12,15 horas todos los educandos almuerzan lo elaborado por el personal de cocina o los alimentos que ellos hubiesen traído de sus hogares. A las $13 \mathrm{hs}$ se reinician las labores educativas hasta las 17,15 horas. Las materias primas para la realización del almuerzo son proporcionadas por un organismo escolar (estatal), existente a pocas cuadras del centro de la ciudad de Junín, al igual que los insumos utilizados para la merienda, la cual tiene lugar a las 15 hs. 


\section{Capítulo III RESULTADOS}

\section{Escrutinio empírico para aportar evidencia a favor de las subhipótesis}

\subsection{Escuela J}

Seguidamente se transcribirá lo que atañe a dicho establecimiento, elegido como caso paradigmático porque evidenció características esenciales que presenta la educación de nivel medio en el Distrito de Junín.

La escuela J está ubicada a cincuenta cuadras del centro de la ciudad de Junín. Desde el punto de vista edilicio es una construcción añeja — pensada sólo para satisfacer necesidades de la época en que se erigió- tal como acontece con varias de las escuelas del citado Distrito (de adolescentes o de adultos). Ha tenido - al igual que otras-modificaciones y refacciones, empero adolece de una infraestructura acorde con las necesidades e intereses de la comunidad educativa del sector social en el que está situada. Téngase presente que - mayoritariamenteson familias de trabajadores en relación de dependencia o cuentapropistas, de entre cuatro y diez integrantes cada una.

Las aulas son cinco y todas pequeñas por igual. Albergan a cursos de un máximo de veinte estudiantes. También son diminutas otras instalaciones destinadas -en algunos casos- a diferentes integrantes de la comunidad educativa (Sala de Preceptores, por ejemplo). Respecto del material didáctico — como mapas e instrumental tecnológico a ser utilizados en el desarrollo de las clases y computadoras para los alumnos- no existen en esta escuela, según comentaron preceptores de la misma y el propio investigador pudo comprobar. Sí se hallan, en un espacio reducido, unos pocos libros mayormente desactualizados —que nadie consulta, según informaron los directivos- pero no existe una biblioteca. Por lo demás, la tarea de higiene desarrollada por los auxiliares de limpieza es (tal como pudo observarse) aceptable y está bien coordinada por quienes trabajan en horario matutino y aquellos que lo hacen por la tarde. Puede ocurrir que no cuente - muchas veces - con todos los elementos de limpieza necesarios para cumplir su labor (así los manifestaron los propios auxiliares).

Por lo demás, la escuela está muy lejos de cualquier dependencia policial, lo cual torna harto difícil resolver el problema de la inseguridad. Por ejemplo: en los tres últimos años 
ingresaron a ella dos veces varios desconocidos causando diferentes daños, según comentaron varios integrantes de la comunidad educativa quienes también expresaron enfáticamente "ya no se puede más. Estamos cansados de estos delincuentes”. A todo esto, el presidente del Foro de Seguridad 1, Osvaldo Giapor, aseguró al investigador que los niveles delictivos en Junín permanecieron constantes en el período 2010-2011 y afirmó que "a diferencia de otras ciudades de la provincia de Buenos Aires, Junín sigue siendo una ciudad bien controlada”. En relación a los dispositivos instalados en la zona céntrica, el fomentista afirmó que el centro se merecía tener más seguridad y que el delito se fue yendo —últimamente- hacia los barrios.

\subsubsection{Egresados}

De los 16 egresados, la gran mayoría expresó que va a la escuela porque el título secundario le permitirá conseguir trabajo. Los restantes tienen expectativas de estudios superiores no universitarios - y se imaginan trabajando al mismo tiempo- a realizar en Junín o en otras ciudades, aunque no saben si ello será posible, fundamentalmente por la situación económica incierta que viven. En cambio, ninguno de los egresados de la escuela $\mathrm{F}$ (130 en total) piensa trabajar solamente. Tal lo que se aseverara - junto a otros datos- en 2.1.3.2. Ideas respecto del futuro, en la página 151. En otro orden de ideas, los temas que más frecuentemente aparecen en conversaciones con sus pares son la drogadicción y el deporte. El sueño “dorado" es que el deporte (básicamente los egresados de la escuela J practican fútbol) les brinde la oportunidad de pasar a la vida pública y así encontrar la solución a sus necesidades materiales. Para estos egresados de nivel socioeconómico bajo, que quisieran llegar a la Primera División del fútbol argentino, ser transferidos a un club extranjero aseguraría a toda la familia. La inflación, la corrupción y la religión no aparecen en esas conversaciones. Un solo educando se valió de Internet y de las actividades o espacios organizados por la escuela para tomar una decisión respecto de su futuro. Y casi todos tienen a la familia - en primer lugar - y a la escuela (junto a la radio y a la televisión) como fuentes para adquirir la información y el conocimiento. La percepción de los aportes de la formación escolar se aprecia nítidamente cuando muchos afirman que cursan el secundario para llegar a ser "alguien" en la vida.

A todo esto, las mayores dificultades en torno a la adquisición de conocimientos aparecieron en Matemática e Historia y no tanto en Lengua, donde sus realidades se asemejan -en cuanto a deficiencias - a las de educandos de otros colegios. Asimismo, estos egresados trabajan (siete de ellos en el sector informal), algunos en horarios rotativos lo cual complejiza sus asistencias a clase $\mathrm{y}$ - por ende- sus rendimientos educativos. Los siete trabajadores no están registrados como tales viéndose perjudicados por tal ilegalidad en diferentes aspectos. Aún existe otro daño para estos jóvenes: los adultos que les dan empleo de manera ilegal son 
los únicos responsables de ello por lo que el aprendizaje que tendrán de tal experiencia puede no ser el mejor para sus vidas futuras.

\subsubsection{Responsables}

De los diez egresados encuestados (los seis restantes estuvieron ausentes el día de la recolección de datos), cuatro no viven con ambos progenitores. Por diferentes causas, en las familias a que pertenecen los cuatro no existió la celebración del matrimonio civil. Si bien existirían idealmente treinta y dos responsables de los educandos, sólo cuatro contestaron el mismo: un padre y tres madres. Consultados los egresados respecto de si los cuestionarios habían llegado a sus padres (les fueron enviados por el investigador a sus domicilios a través de ellos) la opinión unánime fue que habían cumplido el pedido del mismo.

Se encuestó a tres padres que trabajan hoy día (el papá lo hace en una empresa privada y dos mamás por cuenta propia) y a una madre desocupada. La ruptura de los lazos sociales, especialmente significativa en los contextos urbano-marginales como el de esta escuela, tiene en la desocupación una de sus principales causas y sus consecuencias educativas son cruciales tal como se observó al hacerse referencia a los alumnos (Véase 1.1.1). Respecto de qué desean para sus hijos en el futuro, los responsables que trabajan actualmente anhelan que sean buenos trabajadores y que lleguen a ser buenos profesionales. Esto último - mencionado en segundo término- aparecería como más difícil de lograr según sus propios dichos. Ningún progenitor aludió a que constituyan una familia ni a que obtengan muchas ganancias materiales. Asimismo, seis de los diez egresados encuestados piensan estudiar y trabajar conjuntamente. Que ninguno de ellos imagine estudiar solamente evidencia la realidad económica familiar, donde estudiar sólo es posible si el propio trabajo del estudiante lo sustenta. Por lo demás, autoridades de esta escuela confirmaron al investigador que muchos responsables de los egresados no se ocupan fehacientemente (incluso, en algunos casos, ni mínimamente) de la trayectoria educativa de los mismos. Actitud que es repetida por un gran número de responsables de egresados (adolescentes y adultos) de escuelas donde se trabajó para esta investigación. En una mínima proporción los responsables sí se ocupan, tal como le fue confirmado al investigador por algunos cuerpos directivos.

\subsubsection{Profesores}

Consultadas seis profesoras del curso, la opción (o categoría) alumnos regulares —en cuanto a sus rendimientos- expresó la opinión mayoritaria. 
Esta es una escuela - receptiva de alumnos provenientes de uno de los sectores más desfavorecidos del Distrito- donde cabría aplicar en las clases la epistemología genética, ${ }^{219}$ tal y como se promueve hoy desde las más altas autoridades educativas nacionales y provinciales. Dicha teoría tiende a reconocer los saberes previos de los alumnos como un paso del aprendizaje y a considerar al docente como un facilitador de los conocimientos de aquéllos, logrados en un tiempo que es absolutamente personal. En relación a la epistemología genética, valga señalar que ninguna de las profesoras encuestadas manifestó que aplica esa teoría en sus clases. Por otro lado y respecto de todos docentes de $3^{\circ}$ Año de esta escuela, las inasistencias reiteradas de algunos de ellos desde septiembre de 2010 en adelante — por diferentes causas todas justificadas, según informó la secretaria— produjo alteraciones en el desarrollo de los contenidos de los diferentes espacios curriculares. Esta consecuencia fue señalada al investigador por varios integrantes de la comunidad educativa. En otro orden de ideas, utilizar el teléfono celular así como hablar — ambos comportamientos llevados a cabo cuando el profesor explica - representan, junto al ingreso y egreso del aula sin consentimiento del educador y la ofensa verbal entre los alumnos, las conductas inadecuadas más frecuentes, según las profesoras.

Por otro lado, la mitad de las docentes manifestó no estar de acuerdo ni en desacuerdo con las leyes de educación nacional y de la provincia de Buenos Aires. Pareciera indubitable la falta de compromiso real de estas profesoras. Asimismo, cinco de las seis profesoras lo son también en otros colegios por lo que el conocimiento de tales leyes se vuelve imperioso para una mejor comprensión de la realidad educativa. Tales docentes aparecen ancladas - por ende- en el mundo de su especialidad (la/s materia/s que tienen a su cargo). Esta realidad también se observó en las demás escuelas alcanzando a muchísimos docentes. La causa de esto podría ser, afirmaron varias directoras, una deficiente formación en los Profesorados, que muchas veces continúa con una ausencia de capacitación durante la vida activa del educador. En este sentido, cuanto mayor conocimiento de las normas — no sólo jurídicas - tengan los docentes, mayores posibilidades de guiar y/o de encauzar a sus educandos para prevenir y/o morigerar y/o solucionar conflictos. Por otro lado, los probables perjuicios de tal actitud se extenderían a todos los integrantes de la comunidad educativa (a los educandos, especialmente).

Cuatro de dichas profesoras afirmaron que, ante conductas inadecuadas del alumnado, suspenden la clase y empiezan todos a dialogar sobre aspectos del Acuerdo Institucional de Convivencia. Éstos, en tanto espacios de regulación de las relaciones vinculares, obligan a su

219. La epistemología genética es el "estudio de los mecanismos de evolución (crecimiento) de los conocimientos" y su objeto particular es "el estudio de los estadios sucesivos de una ciencia en función de su desarrollo". Battro, Antonio y Piaget, Jean en Diccionario de epistemología genética. Editor Proteo, Traducido por Floreal Mazía, 1971, página 354. 
efectivo cumplimiento a docentes, alumnos y a los demás integrantes de la comunidad educativa. Por otro lado y como sucede en varias escuelas, no existe en la $\mathrm{J}$ un gabinete psicopedagógico, hablar del trabajo de un gabinete psicopedagógico cuya existencia implica comprender el proceso de aprendizaje de los estudiantes, incluyendo la ideología de la comunidad educativa, la singularidad de la estructura escolar y la de sus objetivos particulares. El propósito central de la escuela no es solamente impartir conocimientos sino contribuir a la formación integral del individuo. En otro orden, en respuestas a otras preguntas del cuestionario, todas las profesoras mostraron un exacto conocimiento de a quiénes se les reconoce el derecho a la educación y que el mismo está consagrado en la Constitución Nacional. Sostuvieron mayoritariamente que los egresados de la escuela son regulares como estudiantes y adhirieron a la opción regular cuando aludieron a la calidad educativa en nuestro país desde 1983 a hoy. Todas utilizan Internet, libros, periódicos y revistas como fuentes para adquirir la información y el conocimiento, todas herramientas que - por olvido o desidia o ineptitud de alguien o de algunos- no existen aún hoy en esta escuela.

Cuatro del total de las participantes eligieron ser docentes por vocación, actitud que hasta hace algunos años despertaba respeto y admiración en la sociedad. En torno a esta cuestión, se desconoce si incide o no el componente vocacional en la personalidad de estas docentes y - por ende- en el desarrollo de sus actividades áulicas. En otro orden de ideas, todas coincidieron en atribuir a la actual crisis de valores fenómenos como el alcoholismo, la delincuencia, la drogadicción y la prostitución, en el Distrito. "Valores que ellas mismas están llamadas a sostener y a recrear en sus labores cotidianas", señalaron dos responsables de los egresados.

Una madre universitaria y otra con un título terciario no universitario son las que alcanzaron el mayor nivel educativo de todas las madres de las profesoras intervinientes. Otros responsables de dichas docentes no finalizaron el nivel terciario.

\subsection{Escuelas $D, J, M y L_{4}$}

A renglón seguido se tomarán en cuenta cuatro escuelas que — dados los resultados en ellas obtenidos - se estiman ejemplos significativos de lo que se procura demostrar.

Se eligieron dos de adolescentes (la D y la J) por sus diferentes ubicaciones (la primera a cinco cuadras del centro de la ciudad de Junín y la segunda a cincuenta cuadras del mismo). También fueron seleccionados dos establecimientos educativos de adultos ( $\left.\mathrm{M} \mathrm{y} \mathrm{L}_{4}\right)$ situados el primero a una cuadra del centro de dicha ciudad y el otro a treinta cuadras del mismo. En primer lugar obsérvese el siguiente cuadro: 


\begin{tabular}{||c||c|}
\hline Escuela & Egresados encuestados \\
\hline \hline $\mathrm{D}$ & 93 (en 5 cursos) \\
\hline \hline $\mathrm{J}$ & 10 (en 1 curso) \\
\hline \hline $\mathrm{M}$ & 14 (en 2 cursos) \\
\hline \hline $\mathrm{L}_{4}$ & 11 (en 1 curso) \\
\hline
\end{tabular}

Como se dijera en 3. Hipótesis ${ }^{220}$, a los efectos de una mayor operatividad se plantearon varias subhipótesis respecto de integrantes de las comunidades educativas. Así, en atención a los egresados surgió la subhipótesis 1: Las razones de asistencia a la escuela. Se solicitó a los participantes dar respuesta a las veintitrés preguntas del cuestionario, habiéndose realizado esa tarea en las diecinueve escuelas — diez de adolescentes y nueve de adultos- de la muestra. He aquí de los cuatro colegios mencionados los resultados que se consideran esenciales para los objetivos generales y específicos que se pretenden alcanzar:

Variable 1: "Razones de asistencia a la escuela"

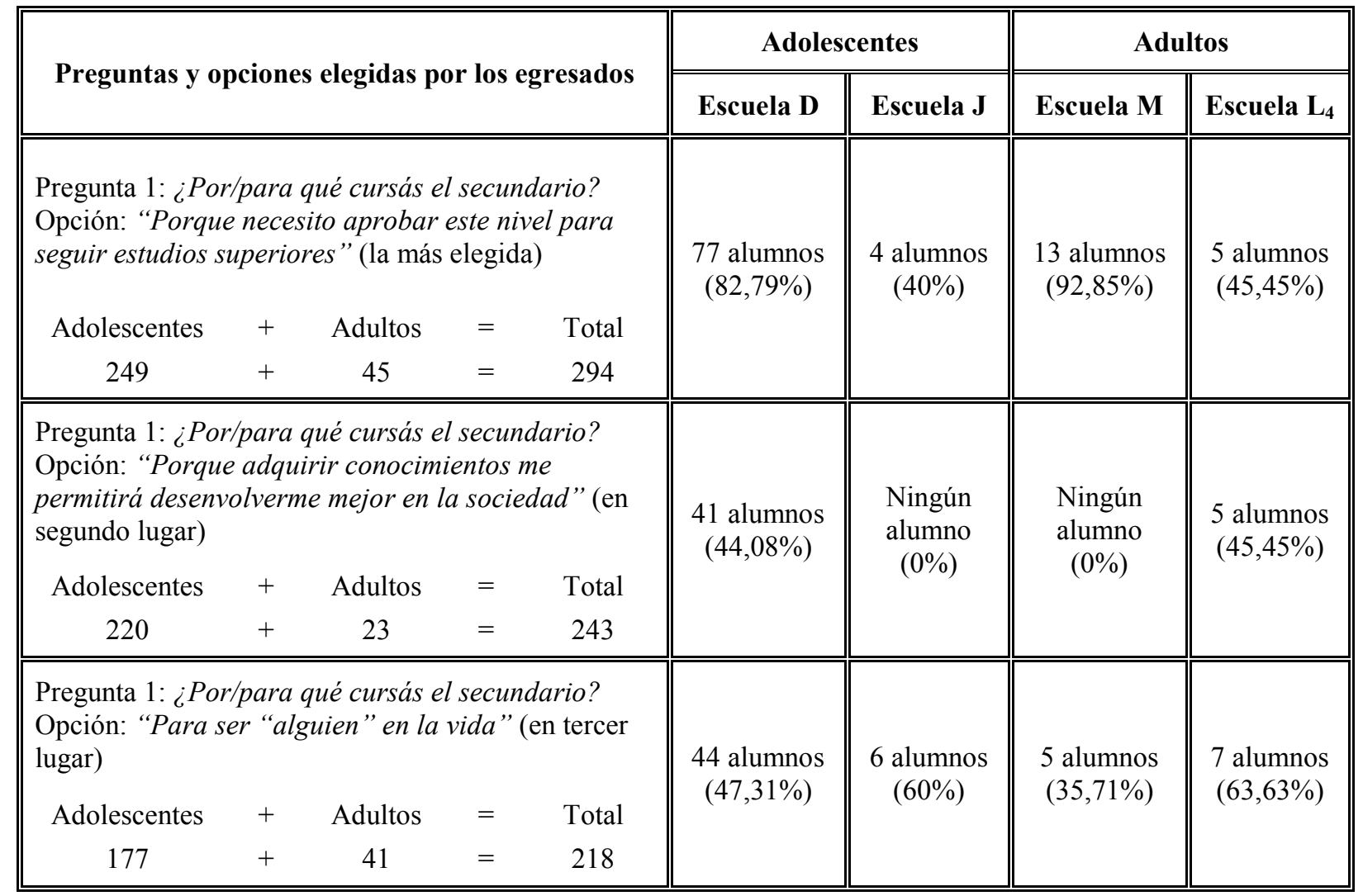

220. Al respecto, léase la página 9. 


\begin{tabular}{|c|c|c|c|c|c|c|c|c|}
\hline \multirow{2}{*}{\multicolumn{5}{|c|}{ Preguntas y opciones elegidas por los egresados }} & \multicolumn{2}{|c|}{ Adolescentes } & \multicolumn{2}{|c|}{ Adultos } \\
\hline & & & & & Escuela D & Escuela $\mathbf{J}$ & Escuela $\mathbf{M}$ & Escuela $\mathbf{L}_{4}$ \\
\hline \multicolumn{5}{|c|}{$\begin{array}{l}\text { Pregunta 1: ¿Por/para qué cursás el secundario? } \\
\text { Opción: "Porque el título secundario me permitirá } \\
\text { conseguir trabajo y así tener una vida digna y } \\
\text { respetable” (en cuarto lugar) }\end{array}$} & \multirow[t]{3}{*}{$\begin{array}{c}37 \text { alumnos } \\
(39,78 \%)\end{array}$} & \multirow[t]{3}{*}{$\begin{array}{l}8 \text { alumnos } \\
(80 \%)\end{array}$} & \multirow{3}{*}{$\begin{array}{l}5 \text { alumnos } \\
(35,71 \%)\end{array}$} & \multirow{3}{*}{$\begin{array}{c}4 \text { alumnos } \\
(36,36 \%)\end{array}$} \\
\hline Adolescentes & + & Adultos & & Total & & & & \\
\hline 160 & + & 35 & $=$ & 195 & & & & \\
\hline
\end{tabular}


Variable 2: "Percepción de aportes de la formación escolar"

\begin{tabular}{|c|c|c|c|c|c|c|c|}
\hline \multirow{2}{*}{\multicolumn{4}{|c|}{ Preguntas y opciones elegidas por los egresados }} & \multicolumn{2}{|c|}{ Adolescentes } & \multicolumn{2}{|c|}{ Adultos } \\
\hline & & & & Escuela D & Escuela $\mathbf{J}$ & Escuela M & Escuela $L_{4}$ \\
\hline \multicolumn{4}{|c|}{$\begin{array}{l}\text { Pregunta 2: ¿Cuántas horas diarias en promedio } \\
\text { estudiás? "Cuando hay examen todo lo necesario” (la } \\
\text { Opción: “Cuand } \\
\text { más elegida) }\end{array}$} & $\begin{array}{c}50 \text { alumnos } \\
(53,76 \%)\end{array}$ & $\begin{array}{c}4 \text { alumnos } \\
(40 \%)\end{array}$ & $\begin{array}{c}8 \text { alumnos } \\
(57,14 \%)\end{array}$ & $\begin{array}{c}10 \text { alumnos } \\
(90,90 \%)\end{array}$ \\
\hline \multicolumn{4}{|c|}{$\begin{array}{l}\text { Pregunta 3: ¿Cuál/cuáles de los siguientes servicios } \\
\text { que presta la biblioteca utilizaste durante 2010? } \\
\text { Opción: "Entré a consultar algún libro” (la más } \\
\text { elegida) }\end{array}$} & $\begin{array}{c}78 \text { alumnos } \\
(83,87 \%)\end{array}$ & $\begin{array}{l}\text { Ningún } \\
\text { alumno } \\
(0 \%)\end{array}$ & $\begin{array}{c}10 \text { alumnos } \\
(71,42 \%)\end{array}$ & $\begin{array}{l}\text { Ningún } \\
\text { alumno } \\
(0 \%)\end{array}$ \\
\hline \multicolumn{4}{|c|}{$\begin{array}{l}\text { Pregunta 4: ¿Qué opinás del Acuerdo Institucional de } \\
\text { Convivencia? } \\
\text { Opción: "Bueno” (la más elegida) }\end{array}$} & $\begin{array}{c}47 \text { alumnos } \\
(50,53 \%)\end{array}$ & $\begin{array}{l}2 \text { alumnos } \\
(20 \%)\end{array}$ & $\begin{array}{c}9 \text { alumnos } \\
(64,28 \%)\end{array}$ & $\begin{array}{c}6 \text { alumnos } \\
(54,54 \%)\end{array}$ \\
\hline \multicolumn{4}{|c|}{$\begin{array}{l}\text { Pregunta 5: ¿Cuál/cuáles son los temas que } \\
\text { frecuentemente aparecen en las conversaciones de } \\
\text { estudiantes como vos? } \\
\text { Opción: "Vida social” (la más elegida) }\end{array}$} & $\begin{array}{c}70 \text { alumnos } \\
(75,26 \%)\end{array}$ & $\begin{array}{l}2 \text { alumnos } \\
(20 \%)\end{array}$ & $\begin{array}{c}8 \text { alumnos } \\
(57,14 \%)\end{array}$ & $\begin{array}{c}8 \text { alumnos } \\
(72,72 \%)\end{array}$ \\
\hline \multicolumn{4}{|c|}{$\begin{array}{l}\text { Pregunta 6: “¿En qué actividades o espacios } \\
\text { organizados por la escuela participaste con la } \\
\text { finalidad de adoptar una decisión respecto de tu } \\
\text { futuro (estudio y/o trabajo)?” } \\
\text { Opción: "Búsqueda en Internet” (la más elegida) }\end{array}$} & $\begin{array}{c}37 \text { alumnos } \\
(39,78 \%)\end{array}$ & $\begin{array}{c}1 \text { alumno } \\
(10 \%)\end{array}$ & $\begin{array}{c}6 \text { alumnos } \\
(42,86 \%)\end{array}$ & $\begin{array}{c}3 \text { alumnos } \\
(27,27 \%)\end{array}$ \\
\hline \multicolumn{4}{|c|}{$\begin{array}{l}\text { Pregunta 7: “¿A qué se debió, finalmente, tu } \\
\text { decisión?” “ } \\
\text { Opción: “A gustos o preferencias propias" (la más } \\
\text { elegida) }\end{array}$} & $\begin{array}{c}78 \text { alumnos } \\
(83,87 \%)\end{array}$ & $\begin{array}{l}2 \text { alumnos } \\
(20 \%)\end{array}$ & $\begin{array}{c}11 \text { alumnos } \\
(78,57 \%)\end{array}$ & $\begin{array}{c}8 \text { alumnos } \\
(72,72 \%)\end{array}$ \\
\hline
\end{tabular}




\begin{tabular}{|c|c|c|c|c|c|c|c|}
\hline \multirow{2}{*}{\multicolumn{4}{|c|}{ Preguntas y opciones elegidas por los egresados }} & \multicolumn{2}{|c|}{ Adolescentes } & \multicolumn{2}{|c|}{ Adultos } \\
\hline & & & & Escuela D & Escuela J & Escuela $\mathrm{M}$ & Escuela $\mathbf{L}_{4}$ \\
\hline \multicolumn{4}{|c|}{$\begin{array}{l}\text { Pregunta 8: “¿De qué fuente te valés para adquirir la } \\
\text { información y el conocimiento?” } \\
\text { Opción: “Internet” (la más elegida) }\end{array}$} & $\begin{array}{c}71 \text { alumnos } \\
(76,34 \%)\end{array}$ & $\begin{array}{c}3 \text { alumnos } \\
(30 \%)\end{array}$ & $\begin{array}{c}10 \text { alumnos } \\
(71,42 \%)\end{array}$ & $\begin{array}{c}5 \text { alumnos } \\
(45,45 \%)\end{array}$ \\
\hline \multicolumn{4}{|c|}{$\begin{array}{l}\text { Pregunta 9: ¿De quién/es es la responsabilidad de } \\
\text { impartir la educación para todos los habitantes en } \\
\text { Argentina? } \\
\text { Opción: “Del Estado Nacional” (la más elegida) }\end{array}$} & $\begin{array}{c}89 \text { alumnos } \\
(95,69 \%)\end{array}$ & $\begin{array}{c}8 \text { alumnos } \\
(80 \%)\end{array}$ & $\begin{array}{c}14 \text { alumnos } \\
(100 \%)\end{array}$ & $\begin{array}{c}11 \text { alumnos } \\
(100 \%)\end{array}$ \\
\hline \multicolumn{4}{|c|}{$\begin{array}{l}\text { Pregunta 10: ¿Dónde está reconocido el derecho a la } \\
\text { educación? } \\
\text { Opción: "En la Constitución Nacional" (la más } \\
\text { elegida) }\end{array}$} & $\begin{array}{c}67 \text { alumnos } \\
(72,04 \%)\end{array}$ & $\begin{array}{l}7 \text { alumnos } \\
(70 \%)\end{array}$ & $\begin{array}{c}13 \text { alumnos } \\
(92,85 \%)\end{array}$ & $\begin{array}{c}7 \text { alumnos } \\
(63,63 \%)\end{array}$ \\
\hline
\end{tabular}

Variable 3: "Nivel de conocimientos adquiridos"

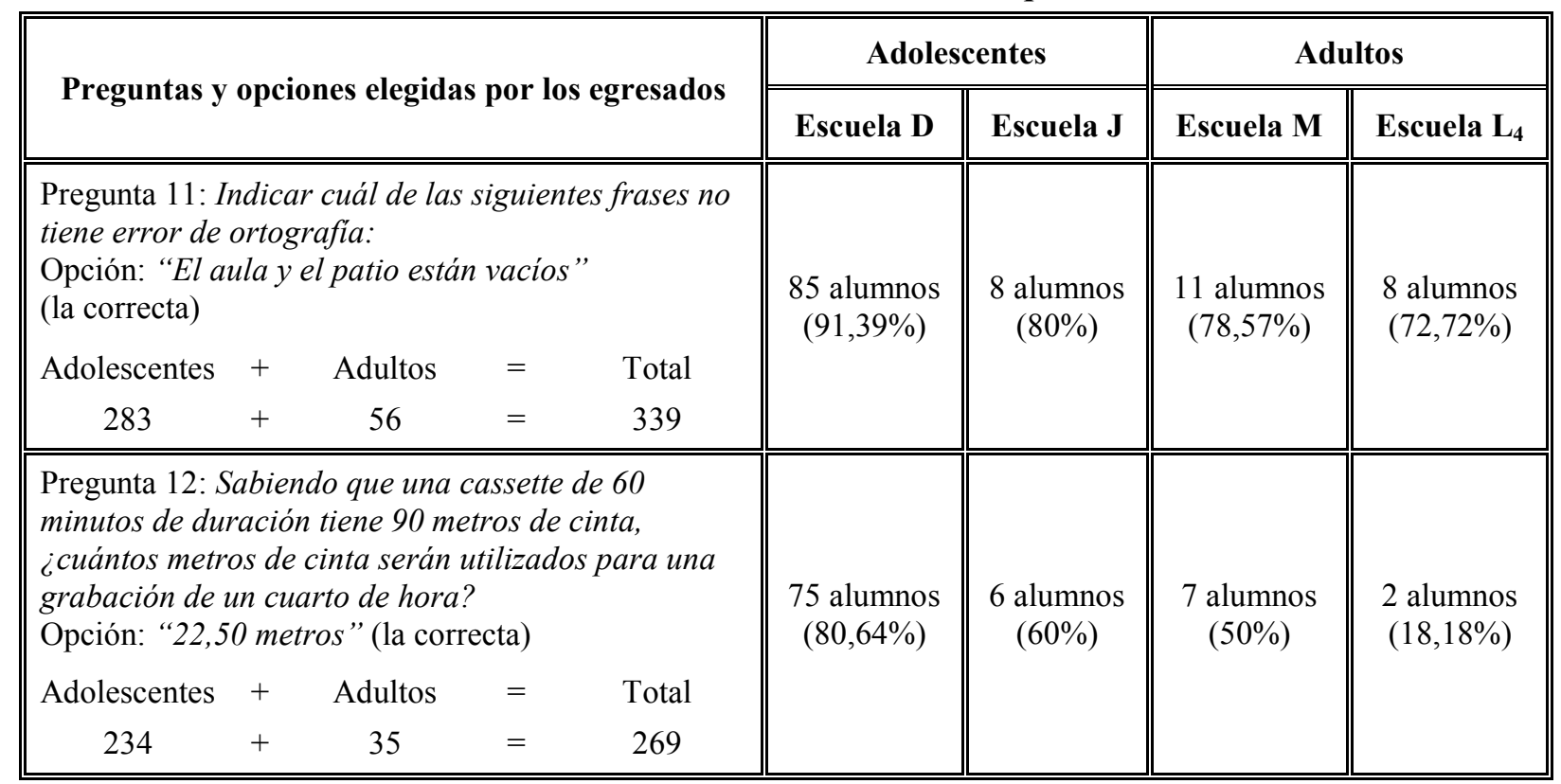




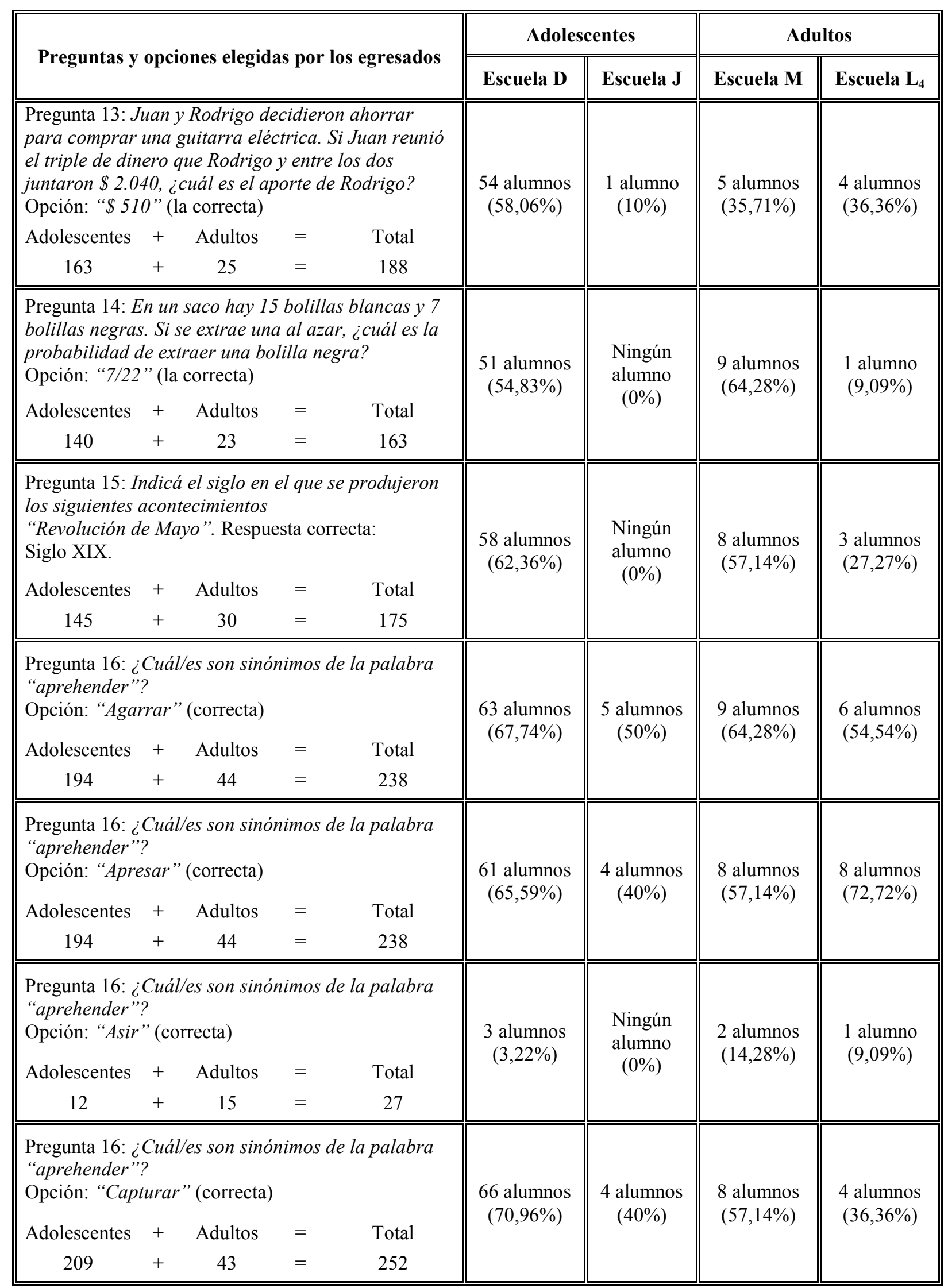




\begin{tabular}{|c|c|c|c|c|c|c|c|}
\hline \multirow{2}{*}{\multicolumn{4}{|c|}{ Preguntas y opciones elegidas por los egresados }} & \multicolumn{2}{|c|}{ Adolescentes } & \multicolumn{2}{|c|}{ Adultos } \\
\hline & & & & Escuela D & Escuela J & Escuela M & Escuela $\mathbf{L}_{4}$ \\
\hline \multicolumn{4}{|c|}{$\begin{array}{l}\text { Pregunta 17: ¿Cuál/es son sinónimos de la palabra } \\
\text { "investigar”? } \\
\text { Opción: "Buscar" (correcta) }\end{array}$} & $\begin{array}{c}82 \text { alumnos } \\
(88,17 \%)\end{array}$ & $\begin{array}{l}7 \text { alumnos } \\
(70 \%)\end{array}$ & $\begin{array}{c}13 \text { alumnos } \\
(92,85 \%)\end{array}$ & $\begin{array}{c}9 \text { alumnos } \\
(81,81 \%)\end{array}$ \\
\hline \multicolumn{4}{|c|}{$\begin{array}{l}\text { Pregunta 17: ¿Cuál/es son sinónimos de la palabra } \\
\text { "investigar”? } \\
\text { Opción: "Escrutar" (correcta) }\end{array}$} & $\begin{array}{c}6 \text { alumnos } \\
(6,45 \%)\end{array}$ & $\begin{array}{l}\text { Ningún } \\
\text { alumno } \\
(0 \%)\end{array}$ & $\begin{array}{l}1 \text { alumno } \\
(7,14 \%)\end{array}$ & $\begin{array}{l}\text { Ningún } \\
\text { alumno } \\
(0 \%)\end{array}$ \\
\hline \multicolumn{4}{|c|}{$\begin{array}{l}\text { Pregunta 17: ¿Cuál/es son sinónimos de la palabra } \\
\text { "investigar”? } \\
\text { Opción: "Examinar" (correcta) }\end{array}$} & $\begin{array}{c}78 \text { alumnos } \\
(83,87 \%)\end{array}$ & $\begin{array}{c}7 \text { alumnos } \\
(70 \%)\end{array}$ & $\begin{array}{c}10 \text { alumnos } \\
(71,42 \%)\end{array}$ & $\begin{array}{c}10 \text { alumnos } \\
(90,90 \%)\end{array}$ \\
\hline \multicolumn{4}{|c|}{$\begin{array}{l}\text { Pregunta 17: ¿Cuál/es son sinónimos de la palabra } \\
\text { "investigar”? } \\
\text { Opción: "Observar” (correcta) }\end{array}$} & $\begin{array}{c}54 \text { alumnos } \\
(58,06 \%)\end{array}$ & $\begin{array}{c}6 \text { alumnos } \\
(60 \%)\end{array}$ & $\begin{array}{c}12 \text { alumnos } \\
(85,71 \%)\end{array}$ & $\begin{array}{c}6 \text { alumnos } \\
(54,54 \%)\end{array}$ \\
\hline
\end{tabular}

Variable 4: "Orientaciones de futuro"

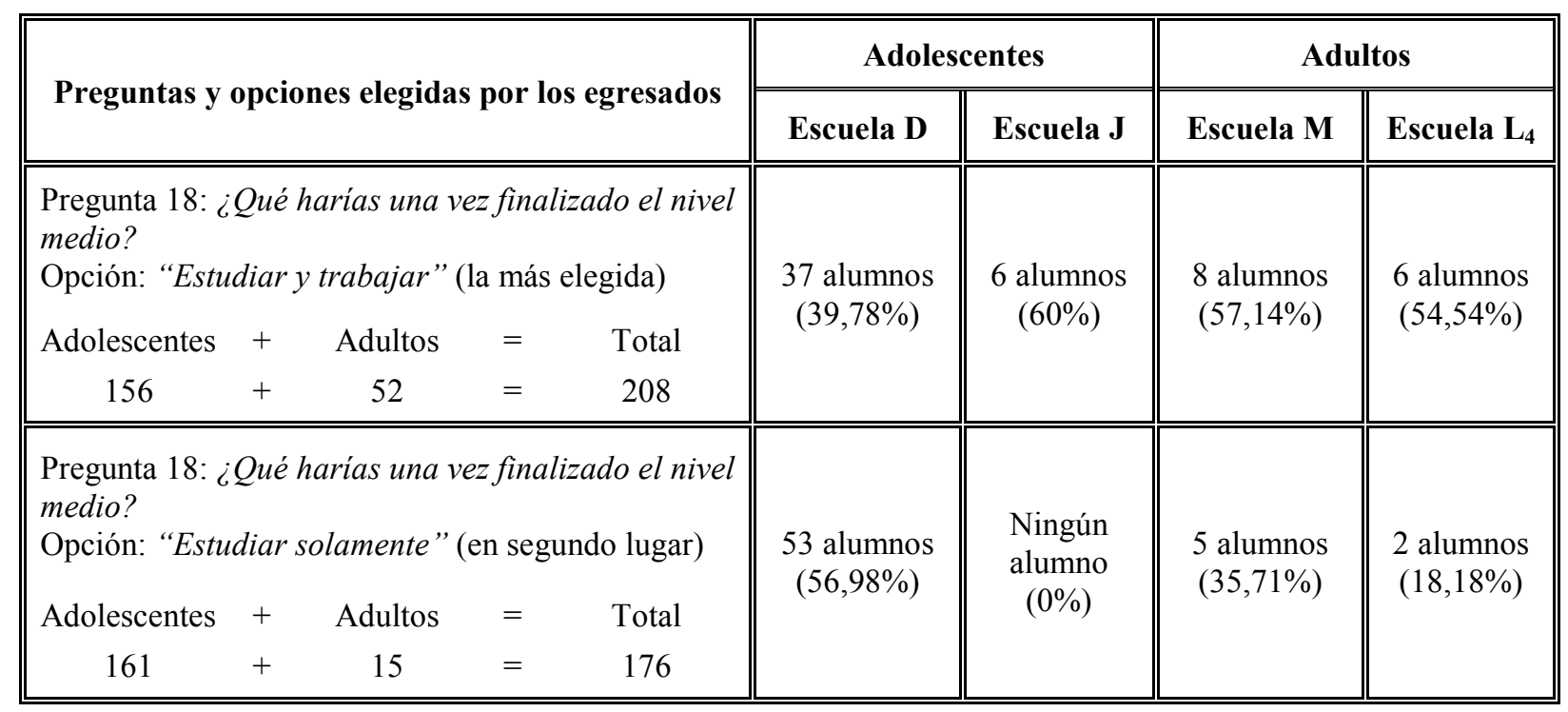




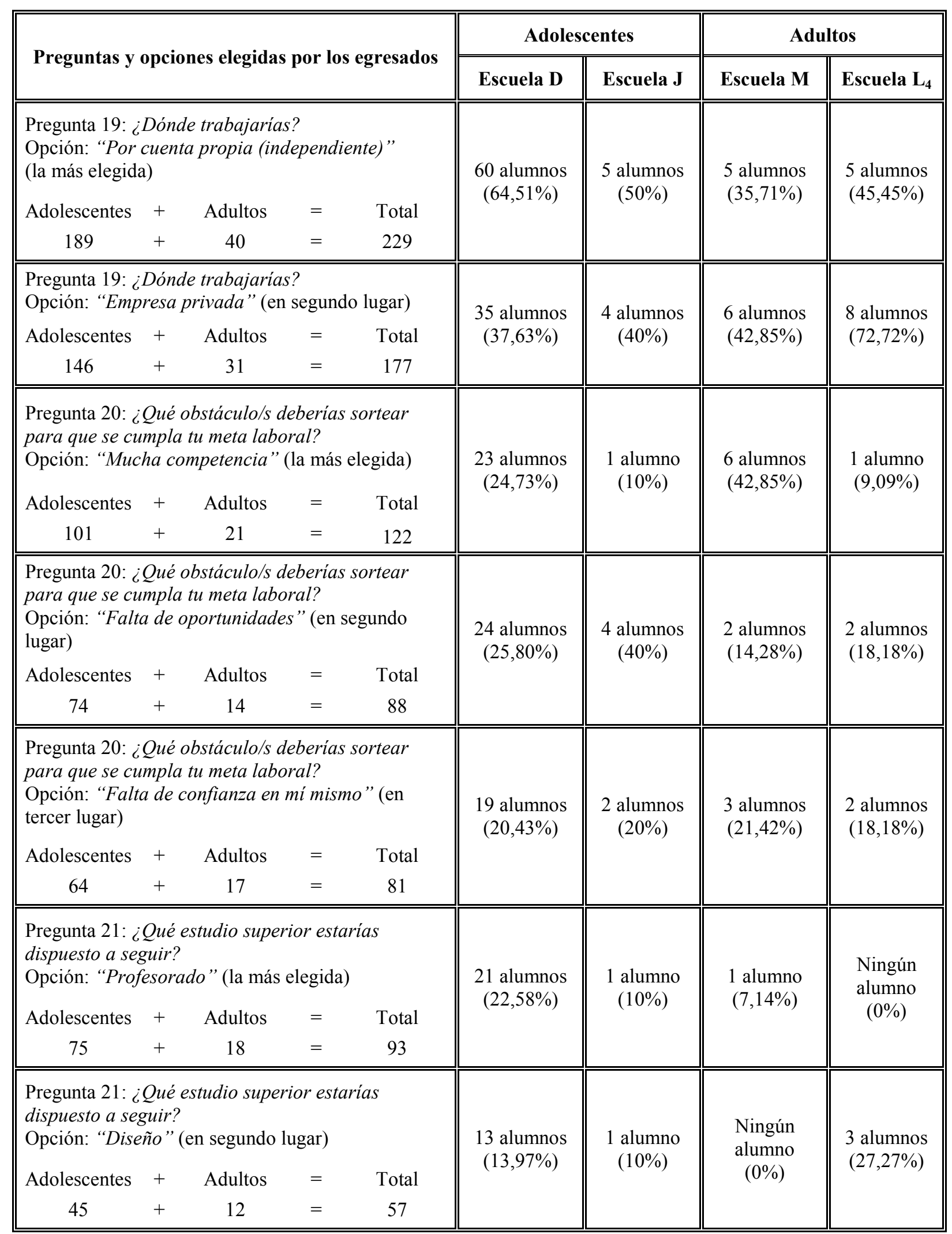




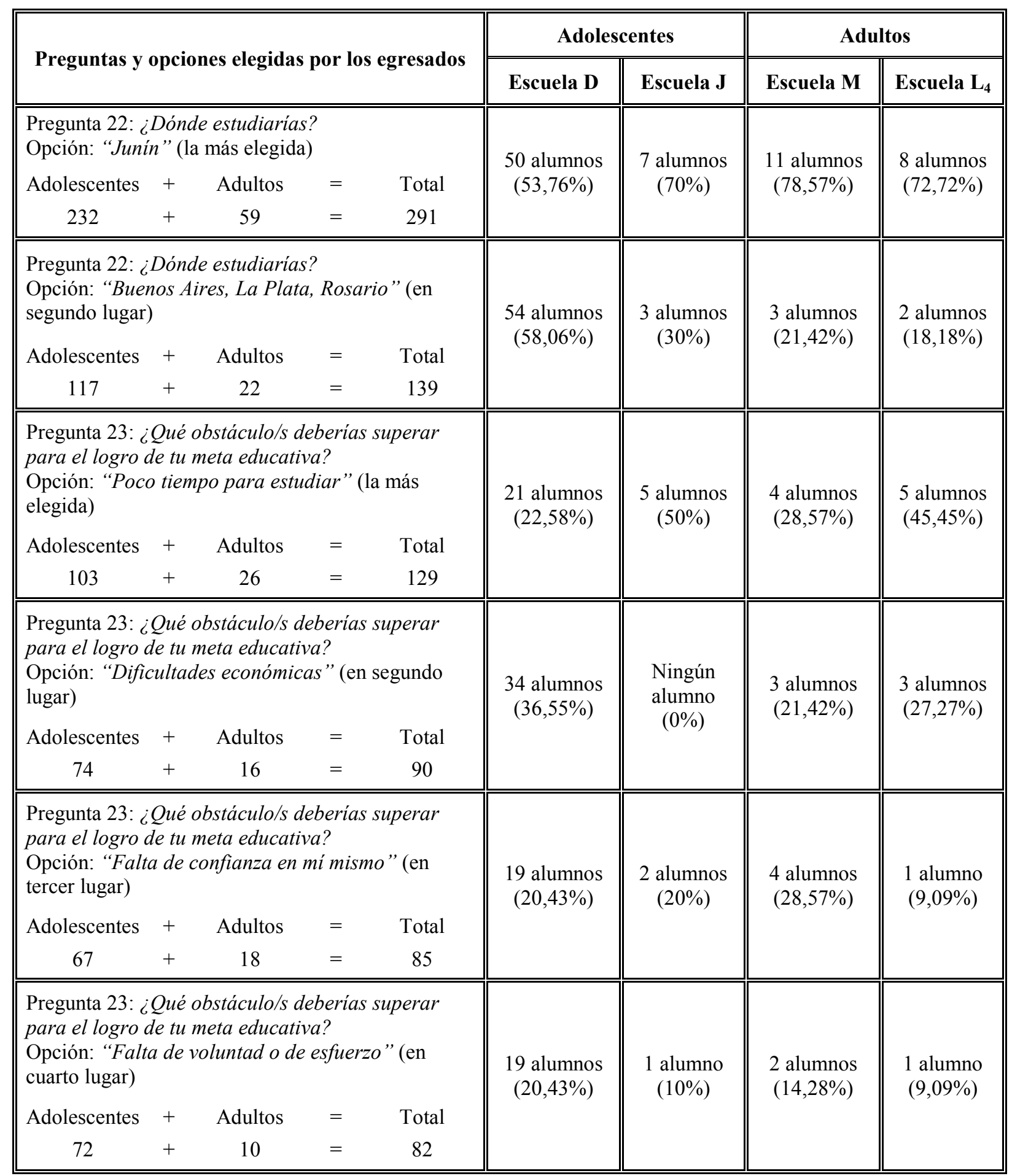

Nota: Respecto de la pregunta 1 (correspondiente a la variable 1) figuran las cuatro opciones más elegidas (de diez en total). Se estimó conveniente incluirlas porque representarían —en conjunto- el abanico de aspiraciones de los egresados pertenecientes a diferentes niveles socioeconómicos. Por otro lado, en relación a las nueve preguntas correspondientes a la variable 2 sólo aparece la opción más elegida en cada una de ellas por estimarse las más representativas de lo que se entendería como aportes de la formación escolar a egresados 2010. En atención a la variable 3 pueden observarse los aciertos de los egresados adolescentes y adultos a través de las siete preguntas formuladas (con cuatro opciones correctas en las dos últimas) en lo que podría considerarse un paneo de los conocimientos adquiridos en el nivel medio. Las seis preguntas pertenecientes a la variable 4 se 
reflejan a través de la opción más elegida y de otras en orden decreciente. La inclusión de estas últimas se justificaría atento a que en algunos casos estas opciones son tan significativas como las que le preceden y a que —en otros- la presencia de todas permitiría observar un panorama más completo de las orientaciones de futuro.

\subsubsection{Prueba de la subhipótesis 1 (Egresados)}

Variable 1: Razones de asistencia a la escuela

Se tomaron en cuenta aquí sólo aquellos datos referidos a la variable 1 que permitieron visualizar realidades incontrastables a los efectos de la prueba. Así, mientras la gran mayoría de los egresados adolescentes de la escuela D realizó el secundario como medio para el acceso a estudios superiores, en la escuela $\mathrm{J}$ menos de la mitad de sus educandos lo consideró de igual modo. Asimismo, casi el total de egresados adultos de la escuela $\mathrm{M}$ estimó el nivel medio como peldaño para continuar estudios de tercer nivel. En cambio, ese mismo propósito lo tuvo menos de la mitad de los estudiantes de la escuela $\mathrm{L}_{4}$.

En la escuela D menos de la mitad de los egresados pensó terminar el nivel medio para conseguir trabajo. En cambio, en la escuela J ésa fue la meta perseguida por la gran mayoría

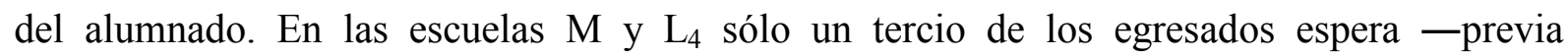
finalización del nivel medio- encontrar trabajo. Según propias manifestaciones, muchos de ellos ya lo tienen.

Variable 2: Percepción de aportes de la formación escolar

Se consideraron sólo aquellos datos relativos a la variable 2 que permitieron visualizar realidades incontrastables a los efectos de la prueba. Así, en las escuelas D y M, alrededor de tres cuartas partes de sus egresados ingresaron durante 2010 a consultar algún libro en la biblioteca. La de la escuela D tiene 12.000 volúmenes a disposición de las comunidades educativas de cuatro niveles de enseñanza: inicial, primario, secundario y terciario no universitario (Profesorados). El colegio M cuenta con 2000 volúmenes para el nivel secundario. En las escuelas $\mathrm{J} \mathrm{y} \mathrm{L}_{4}$ no existen bibliotecas con espacios físicos específicos y los libros que se encuentran en ellas a más de insuficientes están desactualizados.

Al tiempo que la mitad de los egresados de las escuelas $\mathrm{D}, \mathrm{M}$ y $\mathrm{L}_{4}$ opinó que los Acuerdos Institucionales de Convivencia son buenos, sólo menos de un tercio de los pertenecientes a la escuela $\mathrm{J}$ sostuvo lo mismo. En esta escuela, tal como lo manifestaron agentes educativos de la misma al investigador, las conductas inadecuadas del alumnado -egresados incluidos - son frecuentes adentro y en las inmediaciones del establecimiento.

Para la mayoría de los egresados de los colegios $\mathrm{D}$ y $\mathrm{L}_{4}$ - algo menos para los de la escuela $\mathrm{M}$ - las cuestiones de la vida social aparecieron como temas frecuentes en las conversaciones con sus pares. Representaron, en cambio, un porcentaje bajo entre los de la 
escuela $\mathrm{J}$, básicamente compenetrados en dos temas de permanente actualidad e importancia: el deporte y la drogadicción.

Para los egresados de las escuelas $\mathrm{D}, \mathrm{M}$ y $\mathrm{L}_{4}$ las decisiones respecto del futuro se debieron - fundamentalmente- a gustos o preferencias propias. Para los de la J los gustos o preferencias propias influyeron escasamente en tales decisiones. La influencia familiar y del grupo de compañeros/amigos fue manifiesta para ellos al momento de adoptarlas.

Variable 3: Nivel de conocimientos adquiridos

Se tuvieron en cuenta aquí sólo aquellos datos que atañen a la variable 3 que permitieron visualizar realidades incontrastables a los efectos de la prueba. Así, sin pretender que las preguntas 11 a 17 actuasen como examinadoras de los conocimientos de los egresados, tuvieron sí la finalidad de visualizar in situ algunos de sus perfiles. Poco más de la mitad del alumnado de las escuelas D y M contestó correctamente todas las preguntas formuladas, considerándolas en forma conjunta. Asimismo, hubieron porcentajes muy bajos en ambas escuelas en una opción de dos preguntas y uno cercano al cincuenta por ciento en la $\mathrm{M}$ al responderse a otra. En cambio, llegaron a poco más de un tercio de respuestas correctas los educandos de los colegios $\mathrm{J}_{\mathrm{y} \mathrm{L}}$. Los estudiantes de la escuela D superaron porcentualmente por más del doble los aciertos de los de la J, en algunas preguntas. Si se tomasen en cuenta las siete preguntas (11 a 17) relativas a esta variable (con todas sus opciones correctas) la diferencia a favor de la D se reduciría a menos del doble. Sólo en una pregunta de Lengua Nacional los egresados de la escuela $\mathrm{J}$ superaron en aciertos por muy poco porcentaje a los del colegio D. Los egresados de las escuelas $\mathrm{J}_{\text {y }} \mathrm{L}_{4}$ contestaron todos erróneamente algunas opciones de las preguntas formuladas. En la pregunta de Historia referida al siglo en que se produjo la Revolución de Mayo, ningún egresado de la escuela J respondió acertadamente.

\section{Variable 4: Orientaciones de futuro}

Se consideraron aquí sólo aquellos datos referidos a la variable 4 que posibilitaron visualizar realidades incontrastables a los efectos de la prueba. Así, estudiar y trabajar en forma conjunta y estudiar exclusivamente resultaron las dos opciones más elegidas —en ese orden- por los educandos de las cuatro escuelas, al ser consultados respecto de su futuro. Los de la escuela $\mathrm{J}$ eligieron la primera opción citada, alcanzando ésta aquí el mayor porcentaje entre todos los egresados. Ninguno de los estudiantes de la escuela $\mathrm{J}$ respondió que ha de estudiar solamente. Asimismo, bajos porcentajes de los educandos de todas estas escuelas expresaron mucha competencia, falta de oportunidades y falta de confianza en sí mismos, como obstáculos para alcanzar su meta laboral. Y fueron los de la escuela J quienes más se pronunciaron por la falta de oportunidades para alcanzar dicho objetivo. 
Un Profesorado o algunas de las especialidades de la carrera de Diseño son los estudios superiores más elegidos por todos los egresados. La gran mayoría de ellos pertenecientes a las escuelas J, M y L 4 estudiará en Junín. Los de la escuela D han decidido así: una mitad lo hará en Junín y la otra en ciudades como Buenos Aires, La Plata o Rosario. Por otro lado, un bajo porcentaje de estudiantes de las escuelas D y M señaló como obstáculo para alcanzar la meta educativa el poco tiempo para estudiar. En cambio, fueron la mitad los egresados de las escuelas $\mathrm{J}_{\text {y }} \mathrm{L}_{4}$ que afirmaron lo mismo y ello se debe a actividades laborales que cumplen diariamente.

Mediante una lectura comprehensiva de lo afirmado precedentemente - referido a las cuatro variables-se argumenta en favor de la subhipótesis 1: Las razones de asistencia a la escuela así como la percepción de aportes de la formación escolar son causas del nivel de conocimientos adquiridos y de las orientaciones de futuro de los egresados.

\subsubsection{Prueba de la subhipótesis 2 (Responsables)}

Oportunamente se solicitó a los responsables de egresados adolescentes y adultos dar respuesta a las trece preguntas del cuestionario, el cual debía llegar a los mismos de manos de sus hijos, a quienes les fueron entregados por el investigador en la escuela el día de la recolección de datos referidos a ellos. Para la prueba de la subhipótesis 2 se tendrán en cuenta aquí, en idéntico orden, las mismas escuelas ( $\mathrm{D}, \mathrm{J}, \mathrm{M}$ y $\mathrm{L}_{4}$ ) que en el caso de los egresados. En forma previa, obsérvese el cuadro siguiente:

\begin{tabular}{|c||l|c||}
\hline Escuela & \multicolumn{1}{|c|}{ Responsables encuestados } & Edad promedio \\
\hline \hline $\mathrm{D}$ & $45(17$ padres, 27 madres, y 1 tutora) & 41 años \\
\hline \hline $\mathrm{J}$ & 4 (1 padre y 3 madres) & 40 años \\
\hline $\mathrm{M}$ & $10(5$ padres, 4 madres y 1 tutora $)$ & 50 años \\
\hline \hline $\mathrm{L}_{4}$ & 2 madres & 41 años \\
\hline
\end{tabular}

Variable 1: Nivel de escolaridad alcanzado

Se atendió sólo a aquellos datos referidos a la variable 1 que posibilitaron visualizar realidades incontrastables a los efectos de la prueba. Así, de los sesenta y un responsables de egresados pertenecientes a las cuatro escuelas, un padre - de un egresado de la escuela Dfinalizó un posgrado. Además, seis padres llevaron a cabo estudios universitarios (cuatro los culminaron) y cinco madres realizaron idénticos estudios (dos los finalizaron). Los demás alcanzaron niveles educativos inferiores. Asimismo, dos abuelos paternos finalizaron estudios universitarios. Una abuela paterna y una abuela materna también los concluyeron. Un abuelo 
y una abuela paternos como también dos abuelos y dos abuelas maternos finalizaron estudios terciarios no universitarios. Dos abuelas maternas no culminaron sus estudios terciarios no universitarios. Los demás culminaron (o no) niveles educativos inferiores.

Por otro lado, en la escuela $\mathrm{J}$ los cuatro padres afirmaron tener estudios primarios finalizados. Una mamá de un egresado de dicha escuela, de 36 años, tiene a sus padres que culminaron el secundario. Los demás abuelos de los restantes egresados no alcanzaron ese nivel. Es visible el contraste entre las realidades de la escuela D y de la $\mathrm{J}$ en cuanto al nivel de escolaridad alcanzado por los responsables y los padres de éstos.

Variable 2: Inclusión en el mercado de trabajo

Aquí se consideraron sólo aquellos datos referidos a la variable 2 que permitieron apreciar realidades incontrastables a los efectos de la prueba. Así, de los cuarenta y cinco padres de la escuela D, cinco están desocupados. En la escuela $\mathrm{M}$, tres de los diez no trabajan; en la escuela $\mathrm{J}$ uno de los cuatro vive esa misma realidad y en la $\mathrm{L}_{4}$ ninguna de las dos madres está desocupada. Siete padres trabajan en algún organismo de gobierno y todos son de la escuela D. La tercerización de la economía se hace visible aquí: a las actividades de servicios públicos sólo acceden personas que reúnen determinadas cualidades y capacidades que abundan más en las escuelas D y M que en $\mathrm{J}_{\text {y L }}$.

Variable 3: Conocimiento de la realidad educativa y social

Se tomaron en cuenta aquí solamente aquellos datos referidos a la variable 3 que permitieron visualizar realidades incontrastables a los efectos de la prueba. Así, libros, periódicos, revistas, la familia y la escuela son las fuentes de que se valen mayoritariamente los responsables de los egresados de las escuelas $\mathrm{D}, \mathrm{M} \mathrm{y} \mathrm{L}_{4}$, para acceder al conocimiento y a la información. El mismo nivel alcanzó el uso de Internet entre los responsables de la escuela $\mathrm{D}$ al tiempo que un nivel muy bajo de Internet tuvo lugar en la escuela $\mathrm{J}$ y tal servicio no es utilizado afirmaron las madres de egresados de la escuela $\mathrm{L}_{4}$.

Respecto de fenómenos como el alcoholismo, la delincuencia, la drogadicción y la prostitución en el Distrito de Junín, existió casi coincidencia entre los responsables en atribuirlos a la falta de límites que se observa en los jóvenes y a la actual crisis de valores. El padre y una madre pertenecientes a la escuela $J$ afirmaron que tales fenómenos se deben a que "no aprendimos a votar" y estimaron que esta realidad podría cambiar cuando "algunos políticos piensen más en los problemas de la gente”. Esta última opinión fue poco compartida por responsables de las otras escuelas, quienes avizoraron el cambio de esta realidad a través de una mejor calidad educativa y/o mediante políticas sociales de prevención. Por lo demás, muy pocos de los sesenta y un responsables de egresados de las cuatro escuelas creen que 
estos flagelos existirán por siempre. Unánimemente entendieron que la responsabilidad de impartir la educación para todos los habitantes del país es del Estado Nacional. En otro orden de ideas, la gran mayoría de estos responsables tiene conocimiento que en la Constitución Nacional está reconocido el derecho a la educación. Sólo una madre de la escuela J expresó no saberlo y una madre de la $\mathrm{L}_{4}$ no contestó. Por lo demás, al evaluar la calidad educativa de 1983 a hoy, los responsables de los egresados de todas las escuelas ( $\mathrm{D}, \mathrm{J}, \mathrm{M}$ y $\mathrm{L}_{4}$ ) mayoritariamente expresaron que es buena. Desglosadas las opiniones correspondientes a la escuela J, el arco comprende desde "muy buena" hasta un padre y una madre que señalaron "falta más educación".

Variable 4: Elección de la escuela como estrategia familiar de vida

Fueron tenidos en cuenta aquí sólo aquellos datos referidos a la variable 4 que permitieron apreciar realidades incontrastables a los efectos de la prueba. Así, unánimemente los responsables admitieron que la comunicación entre padres e hijos es a veces fácil, a veces difícil. Dos progenitores de la escuela $\mathrm{J}$ afirmaron que la comunicación es muy fácil, opinión que fue escasamente compartida por sus pares de las escuelas D, M y L4. En lo que atañe a la comunicación escuela-familia, se observaron mayoritariamente buenas relaciones entre profesores y padres de egresados de las cuatro escuelas. Minoritariamente son excelentes, regulares o malas, a estar por la opinión de los responsables. Éstos expresan sus opiniones a las autoridades del colegio cuando son citados dado algún motivo o yendo espontáneamente por propia decisión al mismo. Los de la escuela $\mathrm{J}$ manifestaron que no hacen conocer sus inquietudes a las autoridades y que les gustaría comunicarse con ellas.

En cuanto al deseo de estos responsables para el futuro de sus hijos, mayoritariamente esperan que sean buenas personas y buenos trabajadores. Esto último fue primordial en los padres de la escuela $\mathrm{J}$, mientras que para los responsables de los egresados de las escuelas D y $\mathrm{M}$ el deseo radicó — también — en que sean buenos profesionales. En la D el máximo de elecciones recayó en que su hijo/a sea feliz. En otro orden, la elección de la escuela J para que estudien allí sus hijos se debió fundamentalmente a las madres, quienes adoptaron tal decisión porque la escuela está cerca de sus casas. En cambio, respecto del colegio M la elección recayó mayoritariamente en los hijos debido a los muy buenos comentarios que recibieron de ella. Lo mismo aconteció con la $\mathrm{L}_{4}$, siendo elegida por los hijos pero debido a que otros integrantes de la familia también habían estudiado en ella. Por último, en el caso de la escuela D fueron madres e hijos quienes optaron por dicho colegio - con menores intervenciones de los padres- puesto que están de acuerdo con su perfil institucional y se halla ubicado cerca de sus viviendas.

De una lectura comprehensiva de lo afirmado anteriormente - referido a las cuatro variables- se argumenta en favor de la subhipótesis 2: El nivel de escolaridad alcanzado 
junto a la inclusión en el mercado de trabajo y el conocimiento de la realidad educativa y social por parte de los responsables del alumno influyen en la elección de la escuela como estrategia familiar de vida.

\subsubsection{Prueba de la subhipótesis 3 (Profesores)}

Se tendrán en cuenta seguidamente las mismas cuatro escuelas, D, J, M y L4. En forma previa, obsérvese el siguiente cuadro:

\begin{tabular}{|c|c|}
\hline Escuela & Profesores encuestados \\
\hline \hline $\mathrm{D}$ & 7 (2 varones y 5 mujeres) \\
\hline \hline $\mathrm{J}$ & 6 profesoras \\
\hline $\mathrm{M}$ & 5 (1 varón y 4 mujeres) \\
\hline \hline $\mathrm{L}_{4}$ & 1 profesora \\
\hline
\end{tabular}

Variable 1: Conocimiento de la realidad educativa y social

Se tomaron en cuenta aquí sólo aquellos datos referidos a la variable 1 que permitieron visualizar realidades incontrastables a los efectos de la prueba. Así, todas las profesoras de las escuelas $\mathrm{J}_{\text {y }} \mathrm{L}_{4}$ reconocieron que tienen derecho a la educación todos los sujetos mencionados en las opciones de la pregunta correspondiente. ${ }^{221}$ Lo mismo sostuvo la mayoría de los docentes de las escuelas D y M. La minoría de educadores de estos últimos dos colegios respondió la pregunta en forma incompleta. También se observó unanimidad en las cuatro escuelas cuando los diecinueve docentes afirmaron que el derecho a la educación está reconocido en la Constitución Nacional.

Respecto de la calidad educativa de 1983 a hoy, los docentes tuvieron una opinión buena (la mayoría que ejerce en la escuela $\mathrm{D}$ y en la $\mathrm{M}$ ), regular (la mayoría en la $\mathrm{J}$ ) o mala (la profesora de la escuela $\mathrm{L}_{4}$ ). Tal diversidad de opiniones ameritaría un profundo debate, pues aquélla también se observó en las demás instituciones educativas del nivel. Asimismo, podría relacionarse la opinión vertida por la docente de la escuela $\mathrm{L}_{4}$ en el sentido de la mala calidad educativa de 1983 a hoy y la afirmación de que sus alumnos son todos de rendimiento bueno. Asimismo, todos estos educadores coincidieron en que fenómenos como el alcoholismo, la delincuencia, la drogadicción y la prostitución en el Distrito de Junín son atribuibles a la

221. Véase en los Anexos el instrumento de recolección de datos utilizado con los profesores. 
actual crisis de valores. Tal opinión puso énfasis en la educación para terminar con estos flagelos y en ella surgió nítida la responsabilidad de los docentes en la prevención.

En otro orden de ideas, sabido es que la clase media asalariada del sector público — que incluye a los docentes - gozó por largo tiempo de protección social. Diversos estudios en los últimos años han explicado el deterioro de dicha clase a causa del constreñimiento del Estado desde hace tres décadas. Estas transformaciones involucran hoy a los profesores en una trama compleja cual es que inmediatamente después de lograr el título buscan acumular módulos u horas cátedra a fin de obtener una remuneración que les permita satisfacer sus necesidades. También pueden complementar la actividad en el aula con el ejercicio de algún cargo en otra/s escuela/s.

Variable 2: Desempeño de la actividad docente

Aquí se tuvieron en cuenta sólo aquellos datos referidos a la variable 2 que permitieron visualizar realidades incontrastables a los efectos de la prueba. Así, la totalidad de los profesores de la escuela D lo son también en otras y algunos -incluso- en un Instituto de Profesorado en Junín. Lo mismo acontece con las profesoras que trabajan en la escuela J (una de ellas - asimismo - es Directora en otro colegio). Realidades similares se observan con los docentes de las escuelas $\mathrm{M} \mathrm{y} \mathrm{L}_{4}$. La identidad laboral de todos ellos se nutriría de diferentes experiencias que se llevan a cabo diariamente, en algunos casos en varios niveles educativos. Por otra parte, más de la mitad de los profesores de estas cuatro escuelas manifestó que -además- trabaja como preceptor o profesor en otro/s colegio/s. A veces se dan casos como el de un preceptor de la escuela E, turno mañana, de 7 a 12 hs, que luego es profesor en el colegio F - vespertino- de 15,15 a 17,15 hs y preceptor en la escuela $\mathrm{H}_{1}$-nocturno- de 18 a 22 hs. En total, 11 horas diarias de labor.

Asimismo, todos los educadores de las escuelas D, J, M y $\mathrm{L}_{4}$ aplican en sus clases una combinación de diferentes teorías o recursos educativos, pero ninguno utiliza la epistemología genética. Ésa es la teoría que las autoridades educativas nacionales, basándose en la normativa vigente, indican que debiera aplicarse en el desarrollo de la actividad áulica en el nivel medio.

Casi todos los profesores que trabajan en la escuela D estuvieron de acuerdo con las leyes nacional y provincial de educación. En tanto, la mayoría de los docentes de la escuela $\mathrm{M}$ se manifestó en desacuerdo con dichas normas. Las educadoras de la J no están de acuerdo ni en desacuerdo con ambas. La profesora de la $\mathrm{L}_{4}$ admitió no estar debidamente informada respecto de tales normas. Se evidenciaría, de esta manera, un variado panorama de impredecibles consecuencias educativas y — por extensión- sociales para, especialmente, los egresados debido a la incertidumbre en torno a la real aplicación de las disposiciones de ambas leyes. 
En otro orden, entre los progenitores de estos diecinueve docentes hay un padre y una madre con estudios universitarios finalizados, tres madres junto a un padre con terciario no universitario finalizado y un padre con terciario no universitario sin finalizar. Vale decir que de treinta y ocho padres de estos profesores, sólo seis alcanzaron a finalizar estudios superiores, lo cual indicaría el nivel socioeconómico medio o medio bajo del cual provienen estos educadores de hoy (realidad que también pudo comprobar el investigador entre los docentes de las restantes escuelas estatales intervinientes).

Entre todos estos docentes, la mayoría (en las escuelas $\mathrm{J}_{,} \mathrm{M}$ y $\mathrm{L}_{4}$ ) lo es por vocación. La mayor parte de los profesores de la escuela $\mathrm{D}$ nunca pensó ser docente pero un día cambió de opinión, al tiempo que algunos de ellos son docentes por vocación y/o pertenecen a una familia de docentes.

Por lo demás, libros, periódicos, revistas e Internet son las fuentes de que se valen para adquirir la información y el conocimiento todos los profesores de las escuelas $\mathrm{J}_{\text {, }} \mathrm{L}_{4}$ y M y la mayoría de los de la D.

Variable 3: Trayectoria de los estudiantes en su último año del nivel medio

Se consideraron aquí solamente aquellos datos referidos a la variable 3 que posibilitaron visualizar realidades incontrastables a los efectos de la prueba. Así, para los profesores de la escuela D sus alumnos tienen mayoritariamente muy buenos rendimientos. Algo análogo pero centralizado en los buenos, asevera la profesora de la escuela $\mathrm{L}_{4}$. También mayoría de muy buenos - con porcentajes similares- es lo señalado por los cinco educadores de la escuela M. La realidad fue diferente en la escuela J, pues allí predominaron los egresados considerados regulares a tenor de lo expresado por las seis docentes participantes. En otro orden de ideas, conversar o utilizar el teléfono celular en clase cuando el docente explica un tema son las conductas inadecuadas más observadas en las escuelas D y J, con una salvedad: el porcentaje de uso de los celulares es menor en la escuela $\mathrm{D}$ debido a un control más eficaz por parte de sus agentes educativos. Téngase presente que la cantidad de celulares de que disponían los egresados de ambas escuelas era, en relación al número de alumnos por curso, muy similar. Por otro lado, la ofensa verbal entre los propios educandos ocupó el escalón inmediato inferior en dichas conductas y la ofensa verbal de los alumnos hacia los educadores ocupó el último escalón dentro de tales conductas. Tal lo expresado por todos los profesores de las escuelas D, J, M y L4. El encauzamiento/finalización de las conductas inadecuadas se produce citando a la escuela a los padres de los alumnos involucrados cuando son reiteradas. Esto se lleva a cabo en todos estos colegios. Asimismo, en las escuelas J y M algunos docentes - ejerciendo la autoridad a que tienen derecho- suspenden momentáneamente la clase y empiezan a dialogar entre todos sobre aspectos del Acuerdo Institucional de Convivencia. 
Fue comentario entre algunos docentes de las escuelas $\mathrm{C}, \mathrm{G}$ y $\mathrm{J}$ que, si bien ocasionalmente, habían padecido algunas actitudes "inesperadas y fuera de lugar" (tal como las calificaron) de algunos de sus egresados al leerles las notas finales de sus asignaturas correspondientes al Segundo Trimestre de 2010. Incluso los responsables de dos de ellos - pertenecientes a las escuelas G y J- fueron al día siguiente a escuelas para reclamar por las notas, con insultos y amenazas hacia los educadores y otras autoridades. Así lo confirmaron las directoras de ambos colegios al investigador.

De una lectura comprehensiva de lo afirmado supra - referido a las tres variables - se argumenta en favor de la subhipótesis 3: El conocimiento de la realidad educativa y social junto al desempeño de su actividad docente inciden en la trayectoria de los estudiantes en su último año del nivel medio.

\subsubsection{Prueba de la subhipótesis 4 (Directores)}

Se tendrán en cuenta, al responder al cuestionario autoadministrado, las opiniones de trece Directores de las diecinueve escuelas de adolescentes y de adultos seleccionadas.

Variable 1: Conocimiento de la realidad educativa

Aquí se tomaron en cuenta sólo aquellos datos referidos a la variable 1 que permitieron apreciar realidades incontrastables a los efectos de la prueba. Así, todos los directores encuestados afirmaron la importancia de la Constitución Nacional, de los Tratados Internacionales de Derechos Humanos con jerarquía constitucional y de la Constitución de la Provincia de Buenos Aires - a más de otra normativa vigente- que reconocen el derecho a la educación para todos. Se manifestaron en su mayoría de acuerdo o muy de acuerdo con las leyes de Educación Nacional y de Educación Provincial vigentes. Asimismo, evaluaron la educación desde el retorno de la democracia hasta hoy como buena - mayoritariamente- y regular, para una minoría. En otro orden de ideas, un padre de estos trece directores alcanzó a finalizar los estudios terciarios (no universitarios). Los progenitores de los demás culminaron (o no) sus estudios primarios. Cabría reiterar en este aspecto lo ya aseverado en torno a los profesores respecto del nivel socioeconómico medio o medio bajo del que provienen estos directores.

Variable 2: Interrelaciones escuela-familia

Se tomaron en cuenta solamente aquellos datos que posibilitaron visualizar realidades incontrastables a los fines de la prueba. Los directores expresaron que existe una actitud de apertura de las escuelas para con todos los responsables de los educandos y se manifestaron prestos a escuchar sus opiniones e inquietudes. Saben que la realidad escolar es cambiante 
—posee su propia dinámica interna - porque el ser humano mismo lo es y actúan así a través del instrumental escolar de que disponen o — básicamente- "cara a cara" cuando se trata de comunidades educativas pequeñas. Algunos directores señalaron que -en ocasiones- los responsables no concurren a las citaciones efectuadas desde la escuela o lo hacen pero después no se observan respuestas positivas - ya de ellos, ya de los educandos - respecto de los acuerdos a que se había llegado en los encuentros con el cuerpo directivo.

Variable 3: Organización de las actividades educativas

Fueron tenidos en cuenta sólo aquellos datos que permitieron apreciar realidades incontrastables a los efectos de la prueba. Así, los directores mayoritariamente opinaron que son varias las tareas a desarrollarse en la escuela referidas a su organización con el fin de alcanzar los objetivos que la legislación vigente prevé. Aseguraron que los equipos de gestión (integrados por los cuerpos directivos y los jefes de Departamento) realizan una labor de cooperación significativa a través del desempeño de todos los agentes educativos en forma responsable. Destacaron, asimismo, el sentido de pertenencia — siempre deseable, aunque no todas las veces presente en el personal- y la transmisión de las informaciones siguiendo la vía jerárquica, como pilares de un trabajo en libertad en el que se da el exacto valor e importancia a cada uno de los integrantes de la comunidad educativa.

De una lectura comprehensiva de lo afirmado precedentemente -referido a las tres variables- se argumenta en favor de la subhipótesis 4: El conocimiento de la realidad educativa así como las interrelaciones escuela-familia determinan la organización de las actividades educativas.

\subsubsection{Prueba de la subhipótesis 5 (Secretarios)}

Se tendrán en cuenta aquí las aseveraciones de trece Secretarios de las diecinueve escuelas de adolescentes y de adultos participantes.

Variable 1: Conocimiento de la realidad educativa

Se consideraron aquí sólo aquellos datos referidos a la variable 1 que permitieron visualizar realidades incontrastables a los fines de la prueba. Así, todos los secretarios destacaron la importancia de la Constitución Nacional, de los Tratados Internacionales de Derechos Humanos con jerarquía constitucional y de la Constitución de la Provincia de Buenos Aires - a más de otra normativa vigente- que reconocen el derecho a la educación para todos. En su mayoría, están de acuerdo con las Leyes de Educación Nacional y de Educación Provincial vigentes. Además, consideraron a la educación desde 1983 a la fecha 
como buena -mayoritariamente- o regular (una menor cantidad). Una secretaria la consideró buena, pero sólo la educación de hace tres años a la fecha. Los padres de estos trece secretarios alcanzaron estudios secundarios - culminados y no- como máximo nivel de escolaridad. Reitérase aquí lo aseverado supra (respecto de los profesores y directores), en adhesión al nivel socioeconómico medio o medio bajo del cual provienen los secretarios.

\section{Variable 2: Interrelaciones escuela-medio}

Tomáronse en cuenta solamente los datos referidos a la variable 2, que permitieron visualizar realidades incontrastables a los efectos de la prueba. Así, todos los secretarios - de maneras en algo diferentes - destacaron las beneficiosas relaciones que tienen lugar - y que podrían intensificarse en el futuro- entre la escuela y la comunidad a la que pertenece la misma. El vínculo escuela-comunidad ha sido uno de los blancos de acción de las políticas de las reformas educativas, especialmente tematizadas en los programas ministeriales cuyos ejes se dirigen a actuar en y sobre la población urbana, urbana-suburbana y rural. ${ }^{222}$ Asimismo, enfatizaron que - de lo contrario - la escuela vería perturbado su funcionamiento en grado sumo. La secretaria de la escuela $\mathrm{F}$ destacó que la implementación en ésa de una emisora de radio facilita y potencia las relaciones entre la escuela y todos los miembros de la comunidad educativa. Asimismo, subrayó la importancia de las tareas desarrolladas en dicha escuela a los efectos de ayudar a colegios que se hallan en estado de vulnerabilidad social en el Distrito de Junín.

Variable 3: Organización de las actividades educativas

Se tomaron en cuenta aquí sólo aquellos datos referidos a la variable 3 que permitieron visualizar realidades incontrastables a los efectos de la prueba. Así, los secretarios coincidieron en que la toma de decisiones para el cumplimiento de la reglamentación vigente es patrimonio exclusivo del personal jerárquico. También sostuvieron —casi unánimemente- que se delega autoridad, pero según las necesidades y circunstancias, supervisándose posteriormente el desempeño del personal en quien se delegó. Por su lado, la secretaria de la escuela $\mathrm{F}$ indicó que en esa escuela no se delega autoridad, aspecto que ella misma considera debería abrirse a debate y conciliar las ideas que pudieren surgir al respecto. En cuanto a la división del trabajo escolar, todos los secretarios coincidieron en que tal división se observa diariamente en diferentes situaciones. Los secretarios de las escuelas $\mathrm{H} \mathrm{y}$

222. Grinberg, Silvia Mariela, "Capítulo III: La comunidad, nuevo locus de gobierno", op. cit., página 150 . 
$\mathrm{H}_{1}$ expresaron que tal aspecto organizativo está dispuesto en el Estatuto del Docente por lo que - subrayó - lo que debe hacerse es respetar lo establecido.

De una lectura comprehensiva de lo afirmado supra - referido a las tres variables- se argumenta en favor de la subhipótesis 5: El conocimiento de la realidad educativa así como las interrelaciones escuela-medio determinan la organización de las actividades educativas.

\section{Prueba de la Hipótesis General}

Se tuvieron en cuenta aquí sólo aquellos datos que posibilitaron visualizar realidades incontrastables a los fines de la prueba. Para comprobar la hipótesis general se consideraron ocho escuelas que - dados los resultados en ellas obtenidos- configuran ejemplos apropiados para lo que se procura demostrar. Se compararon cuatro escuelas de adolescentes (D, F, H y J) de esta manera: D con F y H con J. También se incluyeron cuatro escuelas de adultos $\left(\mathrm{F}_{1}, \mathrm{H}_{1}, \mathrm{~L}_{4}\right.$ y $\left.\mathrm{M}\right)$ cotejándolas de este modo: $\mathrm{F}_{1}$ con $\mathrm{M} \mathrm{y} \mathrm{H}_{1}$ con $\mathrm{L}_{4} \cdot{ }^{223}$ Se registraron las máximas similitudes y las máximas diferencias entre los datos obtenidos de todos estos colegios. Asimismo, se tomaron en cuenta siete preguntas (veintitrés es el total) del cuestionario autoadministrado para egresados (adolescentes y adultos): aquellas identificadas con los números $1,3,14,15,18,20$ y $23^{224}$ y las opciones de respuesta estimadas como más significativas. A continuación, obsérvense los siguientes cuadros 1 y 2 :

Cuadro 1

\begin{tabular}{|c|c|}
\hline Escuela & $\begin{array}{c}\text { Egresados adolescentes } \\
\text { encuestados }\end{array}$ \\
\hline \hline $\mathrm{D}$ & $93(5$ cursos $)$ \\
\hline \hline $\mathrm{F}$ & $110(5$ cursos $)$ \\
\hline $\mathrm{H}$ & $14(2$ cursos $)$ \\
\hline \hline $\mathrm{J}$ & $10(1$ curso $)$ \\
\hline \hline TOTAL: & $227(13$ cursos $)$ \\
\hline
\end{tabular}

Cuadro 2

\begin{tabular}{|c||c||}
\hline Escuela & $\begin{array}{c}\text { Egresados adultos } \\
\text { encuestados }\end{array}$ \\
\hline \hline $\mathrm{F}_{1}$ & $21(2$ cursos $)$ \\
\hline \hline $\mathrm{M}$ & $14(2$ cursos $)$ \\
\hline $\mathrm{H}_{1}$ & $3(1$ curso $)$ \\
\hline \hline $\mathrm{L}_{4}$ & $11(1$ curso $)$ \\
\hline TOTAL: & $49(6$ cursos $)$ \\
\hline
\end{tabular}

223. La existencia de cuatro grupos, dos de escuelas de adolescentes (D-F y H-J) y dos de adultos ( $\mathrm{F}_{1}-\mathrm{M}$ y $\left.\mathrm{H}_{1}-\mathrm{L}_{4}\right)$, obedeció a la similitud existente entre las escuelas integrantes de cada uno de ellos. La ubicación y características de las mismas, la cantidad de cursos y modalidades del último año del nivel y el número, edad y sexo de los egresados 2010 fueron algunas de las razones que determinaron la manera de agrupar a dichos establecimientos educativos.

224. Mediante la elección de estas preguntas y categorías de respuesta aparecen contempladas las cuatro variables de la subhipótesis 1 , considerada a modo de ejemplo. 
Ahora, obsérvense el cuadro 3 y su continuación a los efectos de cotejar los porcentajes obtenidos a tenor de lo aseverado supra: 
Cuadro 3

\begin{tabular}{|c|c|c|c|c|c|c|c|c|}
\hline $\begin{array}{l}\text { Preguntas y opciones elegidas } \\
\text { por los egresados }\end{array}$ & \multicolumn{4}{|c|}{ Escuelas de Adolescentes } & \multicolumn{4}{|c|}{ Escuelas de Adultos } \\
\hline $\begin{array}{l}\text { Pregunta 1: ¿Por/para qué cursás el secundario? } \\
\text { Opción: “Porque necesito aprobar este nivel } \\
\text { para seguir estudios superiores” (la más elegida) }\end{array}$ & $77(82,79 \%)$ & $87(79,09 \%)$ & $11(78,57 \%)$ & $4(40 \%)$ & $15(71,42 \%)$ & $13(92,85 \%)$ & $1(33,33 \%)$ & $5(45,45 \%)$ \\
\hline $\begin{array}{l}\text { Pregunta 1: ¿Por/para qué cursás el secundario? } \\
\text { Opción: "Para ser alguien en la vida”" }\end{array}$ & $44(47,31 \%)$ & $56(50,90 \%)$ & $11(78,57 \%)$ & $6(60 \%)$ & $11(52,38 \%)$ & $5(35,71 \%)$ & $1(33,33 \%)$ & $7(63,63 \%)$ \\
\hline $\begin{array}{l}\text { Pregunta 14: En un saco hay } 15 \text { bolillas blancas y } \\
7 \text { bolillas negras. Si se extrae una al azar, ¿cuál } \\
\text { es la probabilidad de extraer una bolilla negra? } \\
\text { Opción: "7/22” (respuesta correcta) }\end{array}$ & $51(54,83 \%)$ & $55(50 \%)$ & $2(14,28 \%)$ & $0(0 \%)$ & $6(28,57 \%)$ & $9(64,28 \%)$ & $1(33,33 \%)$ & $1(9,09 \%)$ \\
\hline $\begin{array}{l}\text { Pregunta 18: ¿Qué harías una vez finalizado el } \\
\text { nivel medio? } \\
\text { Opción: "Estudiar y trabajar” (la más elegida) }\end{array}$ & $37(39,78 \%)$ & $45(40,90 \%)$ & $7(50 \%)$ & $6(60 \%)$ & $14(66,66 \%)$ & $8(57,14 \%)$ & $3(100 \%)$ & $6(54,54 \%)$ \\
\hline $\begin{array}{l}\text { Pregunta 18: ¿Qué harías una vez finalizado el } \\
\text { nivel medio? } \\
\text { Opción: "Estudiar solamente” }\end{array}$ & $53(56,98 \%)$ & $66(60 \%)$ & $5(35,71 \%)$ & $0(0 \%)$ & $7(33,33 \%)$ & $5(35,71 \%)$ & $0(0 \%)$ & $2(18,18 \%)$ \\
\hline
\end{tabular}




\section{Cuadro 3 (continuación)}

\begin{tabular}{|c|c|c|c|c|c|c|c|c|}
\hline \multirow{2}{*}{$\begin{array}{c}\text { Preguntas y opciones elegidas } \\
\text { por los egresados }\end{array}$} & \multicolumn{4}{|c|}{ Escuelas de Adolescentes } & \multicolumn{4}{|c|}{ Escuelas de Adultos } \\
\hline & D & $\mathbf{F}$ & $\mathbf{H}$ & $\mathbf{J}$ & $\mathbf{F}_{1}$ & $\mathbf{M}$ & $\mathbf{H}_{1}$ & $\mathbf{L}_{4}$ \\
\hline $\begin{array}{l}\text { Pregunta 18: ¿Qué harías una vez finalizado el } \\
\text { nivel medio? } \\
\text { Opción: "Trabajar solamente” }\end{array}$ & $4(4,30 \%)$ & $0(0 \%)$ & $1(7,14 \%)$ & $3(30 \%)$ & $1(4,76 \%)$ & $0(0 \%)$ & $0(0 \%)$ & $2(18,18 \%)$ \\
\hline $\begin{array}{l}\text { Pregunta 20: ¿Qué obstáculo/s deberías sortear } \\
\text { para que se cumpla tu meta laboral? } \\
\text { Opción: "Mucha competencia” (la más elegida) }\end{array}$ & $23(24,73 \%)$ & $40(36,36 \%)$ & $2(14,28 \%)$ & $1(10 \%)$ & $5(23,80 \%)$ & $6(42,85 \%)$ & $0(0 \%)$ & $1(9,09 \%)$ \\
\hline $\begin{array}{l}\text { Pregunta } 20: \text { ¿Qué obstáculo/s deberías sortear } \\
\text { para que se cumpla tu meta laboral? } \\
\text { Opción: "Falta de oportunidades" }\end{array}$ & $24(25,80 \%)$ & $19(17,27 \%)$ & $5(35,71 \%)$ & $4(40 \%)$ & $5(23,80 \%)$ & $2(14,28 \%)$ & $1(33,33 \%)$ & $2(18,18 \%)$ \\
\hline $\begin{array}{l}\text { Pregunta 23: ¿Qué obstáculo/s deberías superar } \\
\text { para el logro de tu meta educativa? } \\
\text { Opción: "Poco tiempo para estudiar” (la más } \\
\text { elegida) }\end{array}$ & $21(22,58 \%)$ & $35(31,81 \%)$ & $7(50 \%)$ & $5(50 \%)$ & $5(23,80 \%)$ & $4(28,57 \%)$ & $0(0 \%)$ & $5(45,45 \%)$ \\
\hline $\begin{array}{l}\text { Pregunta 23: ¿Qué obstáculo/s deberías superar } \\
\text { para el logro de tu meta educativa? } \\
\text { Opción: "Otras responsabilidades u obligaciones } \\
\text { familiares" }\end{array}$ & $17(18,27 \%)$ & $70(63,63 \%)$ & $3(21,42 \%)$ & $3(30 \%)$ & $5(23,80 \%)$ & $3(21,42 \%)$ & $2(66,66 \%)$ & $1(9,09 \%)$ \\
\hline
\end{tabular}


Seguidamente se realizarán las apreciaciones correspondientes teniendo como base lo observado en el cuadro anterior:

Análisis referido a la pregunta 1: las escuelas D, F, F 1 y M están ubicadas a muy pocas cuadras del centro de la ciudad de Junín y los egresados que asisten a ellas admitieron —en su

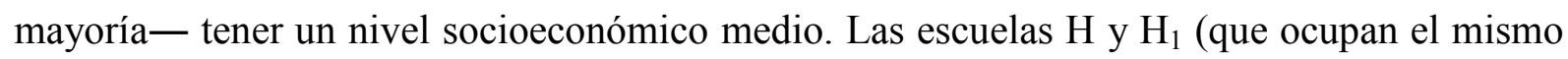
edificio), la $\mathrm{J}$ y la $\mathrm{L}_{4}$ están lejos o muy lejos del centro (la $\mathrm{L}_{4}$ a cuarenta y las restantes a cincuenta cuadras) y reciben a estudiantes de nivel socioeconómico medio bajo y bajo (éste mayoritariamente). Menos de la mitad de los egresados de las escuelas $\mathrm{J}_{1} \mathrm{H}_{1}$ y $\mathrm{L}_{4}$ piensan seguir estudios superiores. En cambio, los de los colegios D, F, F $1, \mathrm{H}_{1}$ y M eligieron dicha opción en su gran mayoría.

A excepción del colegio $\mathrm{H}$ la tendencia parecería ser que a mayor nivel socioeconómico de origen, mayor es el nivel educativo al que se aspira, siendo casi nulas o nulas las expectativas de trabajar conjuntamente si se está posicionado en el nivel socioeconómico medio. Por otro lado, son $\mathrm{H}, \mathrm{J} \mathrm{y} \mathrm{L}_{4}$ las que mostraron los mayores porcentajes de alumnos que valoran como fundamentales a las escuelas para adquirir su identidad personal (ser "alguien" en la vida). No constituirían para ellos tanto un paso previo - como sí para los egresados de los colegios D, F, H, F y M- sino que tienen un alto valor por sí mismas, en tanto que en $\mathrm{F}$ y $F_{1}$ esta postura corresponde a la mitad del estudiantado. Entre los egresados que cursaban el nivel medio para obtener el título necesario a efectos de alcanzar la meta educativa futura, el porcentaje por escuela varió sustancialmente, siendo muy elevado en $\mathrm{D}, \mathrm{F}, \mathrm{H}, \mathrm{F}_{1}$ y M pero se reduce a la mitad - y menos- en las tres escuelas restantes $\left(J, H_{1}\right.$ y $\left.L_{4}\right)$. La educación formal (a través de doce años) no resultaría suficiente aquí para internalizar el valor que representa en aquéllos que más lo necesitan a fin de superar las desventajas de origen. Desde esta diferencia inicial empezarían a proyectarse los diferentes status que cada uno de ellos ocuparía en la sociedad futura, los cuales estarían "reservados" de antemano.

Más de una vez el investigador escuchó preguntar en las escuelas $\mathrm{J}_{1} \mathrm{H}_{1}$ y $\mathrm{L}_{4}$ si alguno de sus egresados había decidido seguir estudios universitarios. La respuesta — proporcionada especialmente por preceptores - fue unánime: “desde hace veinte años a hoy (2010) no tenemos conocimiento de si algún egresado inició y/o terminó un Profesorado o la Universidad, en otra ciudad o en Junín mismo".

Análisis referido a la pregunta 18: más de la mitad de los egresados de las escuelas $\mathrm{D}$ y $\mathrm{F}$ estudiarían exclusivamente. Los de las demás escuelas que estudiarían solamente $\left(\mathrm{H}, \mathrm{F}_{1}\right.$ y M) representan -mayoritariamente - un tercio. Agréguese a ello este dato: en las escuelas $\mathrm{J}_{\text {y } \mathrm{H}_{1}}$ no existió ningún egresado que piense de ese modo (téngase presente que en la escuela $\mathrm{J}$ - de adolescentes - la mayoría de ellos trabajan). Aquí las ventajas relativas en el comienzo de sus trayectorias educativas son para los estudiantes de las escuelas $\mathrm{D}$ y F, quienes podrían llegar a la meta educativa con menos esfuerzos y una mayor capacitación e -inclusive - alcanzar 
niveles educativos superiores. En el mismo orden de ideas, aproximadamente la mitad de los egresados de los colegios $\mathrm{H}, \mathrm{J}, \mathrm{F}_{1}, \mathrm{M}$ y L $\mathrm{L}_{4}$ estudiarían y trabajarían (sólo en la escuela $\mathrm{H}_{1}$ se observa que la totalidad de los egresados hará así). Asimismo, un bajo porcentaje de egresados en cada uno de los colegios decidió trabajar solamente (únicamente en la $\mathrm{J}$ la cifra se elevó a un tercio de todos los egresados). Merced a la formación escolar que adquirirían los egresados de la escuela $\mathrm{J}$, se desprende que la oferta presentaría oficios y/o trabajos no especializados en su futuro. Por lo demás, no habría demasiada diferencia entre el nivel de escolaridad alcanzado por estos egresados y el de sus padres y abuelos. No existiría aquí la llamada movilidad social ascendente.

Análisis referido a las preguntas 20 y 23: el poco tiempo para estudiar constituiría el obstáculo más importante —en vista de la meta educativa futura- para la mitad de los egresados de las escuelas H y J. Casi tres cuartas partes de los egresados de los dos últimos colegios tienen a otras responsabilidades u obligaciones familiares como mayor obstáculo para alcanzar dicha meta. Sólo un tercio de los egresados de la escuela $F$ consideró un obstáculo el poco tiempo para estudiar, mientras que en la escuela $\mathrm{H}_{1}$ para sus egresados este obstáculo no existe. Asimismo, la mucha competencia es el obstáculo más significativo para alcanzar un trabajo futuro para los estudiantes de los colegios F y M. Un tercio de quienes culminan el nivel medio en las escuelas $\mathrm{H}, \mathrm{J}$ y $\mathrm{H}_{1}$ ven a la falta de oportunidades como su mayor obstáculo para obtener un trabajo futuro. Obsérvese la presencia de dificultades en la vida de estos estudiantes — adolescentes y adultos— que intentan lograr una mejor calidad de vida futura.

En torno al análisis de las respuestas a las preguntas 3, 14 y 15, los conocimientos demostrados por los adolescentes y los adultos permitirían individualizar la existencia de una línea cuyos extremos están lejanos. Así, las escuelas D, F, F 1 (si bien en la pregunta 14 no se llegó a un tercio de aciertos) y $\mathrm{M}$ mostraron que la mitad de sus egresados respondió acertadamente y en los colegios $\mathrm{H}, \mathrm{H}_{1}$ y L $\mathrm{L}_{4}$ se registraron porcentajes muy bajos de respuestas correctas. Con un dato que no se repitió: ningún egresado de la escuela J logró acierto alguno en ambas preguntas (la 14 sobre Matemática y la 15 de Historia). Precisamente en éste y en el colegio $\mathrm{L}_{4}$ (a los que se agregan otros) no existen bibliotecas (ni espacios físicos que se utilicen como tales), privándose a sus estudiantes del aporte que realiza el libro para la adquisición del conocimiento y la información con mira a intentar salir de la desfavorecida realidad en que están inmersos desde su nacimiento. Un servicio de biblioteca adecuado pudo observar el investigador en las escuelas D, F, H, F, $\mathrm{M} \mathrm{y} \mathrm{H}_{1}$.

De una lectura comprehensiva de lo aseverado supra, se argumenta a favor de la hipótesis general: una sociedad, como la perteneciente al Distrito de Junín, basada exclusivamente en el uso intensivo del conocimiento produce simultáneamente fenómenos de más igualdad y de más desigualdad, de mayor homogeneidad y de mayor fragmentación sociales. 


\section{CONCLUSIONES}

Durante décadas se afirmó que los procesos cuantitativo y cualitativo eran irreconciliables. Pero desde 1985 un número creciente de autores ha propuesto la unión de ambos enfoques. En esta tesis se coincide con dicha postura, dada la convicción que anima al investigador en el sentido que el enfoque mixto o multimodal es el que armoniza o se adapta mejor al planteamiento del problema. Por ende, se impulsa dicho enfoque, resaltando más las bondades que las limitaciones de los procesos cuantitativo y cualitativo. Esta concepción se fundamenta en que ambos procesos son posibles elecciones $\mathrm{u}$ opciones para afrontar problemas de investigación, más que paradigmas o posiciones epistemológicas. Por otro lado, la polarización de enfoques bloquea nuevos caminos para incluir, extender, revisar y reinventar las formas de conocimiento. Todo ello es contrario a la innovación en las ciencias, cualidad estimada esencial para este investigador. Asimismo, con el diseño de enfoque en paralelo se buscó convergencia y resultados complementarios, reconociendo que todavía tal enfoque, está en proceso de reflexión y desarrollo en todo el mundo.

En numerosos estudios se afirma que para percibir lo que está ocurriendo en el mundo es útil contrastar la realidad con lo sucedido a comienzos de la civilización industrial. Por entonces, una clase obrera que se incorporaba en grandes números al sistema productivo capitalista exigía idénticos derechos que las demás personas. Actualmente la exclusión constituye un testimonio de la crisis de la sociedad salarial a partir de la segunda posguerra. Millones de personas experimentan a diario el riesgo de ser declaradas inútiles y verse arrojadas a la precariedad y a la pobreza. En América Latina, la aplicación de políticas de ideología liberal, desde 1990 a la fecha, ha dado como resultado una mayor concentración de la riqueza, el aumento de la exclusión social, de la desocupación, de la informalidad y de la precariedad del empleo. Cierto es también que en el último decenio algunos países de la región han intentado - $-\mathrm{y}$ alcanzado relativamente en algunos casos - a través de políticas públicas pergeñadas en beneficio de los que menos tienen acortar, al menos, la profunda brecha social observable al interior de los mismos.

En este orden de ideas, preguntarse hoy por la importancia de la educación implica considerar las transformaciones que atraviesan las diferentes sociedades (latinoamericana, argentina, juninense) y dar cuenta de la especificidad que esos fenómenos tienen en las economías desarrolladas y en las emergentes. Ya nadie discute a la educación como factor para acceder a la igualdad de oportunidades y — a través de ello- propender al logro de una 
sociedad más justa. Empero, en Argentina los colegios no podrán atender las diferencias sociales si no se les destinan los recursos necesarios de orden humano y material.

Todos ellos demandan — según los especialistas en educación- poder de decisión y asistencia técnica en el marco de un modelo institucional (que pareciera no existir o que existe pero con graves deficiencias) diseñado para escuelas con mayor autonomía pedagógica, financiera y organizativa. Hoy se da un consenso entre esos especialistas acerca de que debería existir una oferta socialmente justa — a la que todos pudieran acceder - sin la cual no se puede lograr una educación de calidad para todos. Eso y no otra cosa es la justicia social a que hace referencia el artículo 75, inciso 19, párrafo $1^{\circ}$ de la Constitución Nacional, reforma de 1994. Esta demanda se observa actualmente en todo el país, dentro suyo en la provincia de Buenos Aires, e idéntica realidad se pudo comprobar en el Distrito de Junín en esta tesis. Una serie de circunstancias favorables o desfavorables — según los casos- acompañará en su trayectoria al educando. Familia, escuela y sociedad constituyen, tal como se probara, una tríada que, cual destino ineludible, dejará su impronta en esos jóvenes que realizarán sus sueños de progreso - y casi imperceptiblemente - se adaptarán a un tipo de vida no anhelado. En éstos últimos, un sentido conformista de la vida y la aceptación de la realidad "tal como es" y no como "podría ser" irán desvaneciendo aquellas ideas, de cuando cursaban el nivel medio, de un futuro mejor.

En atención a ello, esta investigación permitió identificar factores de estratificación que fragmentarían el universo de egresados secundarios del Distrito de Junín, tanto en adolescentes como en adultos. Repárese que cuando aquí se habla de fragmentación se alude a un modo de segregación que origina una distancia social específica entre quienes habitan los diferentes fragmentos. Habría, pues, dos grandes líneas que marcan las fronteras entre los distintos fragmentos: una estaría dada por el trabajo al que se aspira o simplemente el deseo de trabajar, sin expectativas de un trabajo determinado (aquí estarían incluidos los egresados adolescentes y adultos pertenecientes a los sectores desaventajados, clase media baja y baja, del Distrito). La otra sería el interés por alcanzar la meta educativa futura, estudiando exclusivamente o estudiando y trabajando al mismo tiempo (aquí se alinearían los egresados adolescentes y adultos que se consideran inmersos en la clase media). Asimismo, la forma en que los egresados se articularían con el espacio globalizado muestra también diferencias: para quienes visualizan un trabajo a futuro, su finalidad es acceder — a través de él一 a una vida digna (asocian esfuerzo productivo con dignidad, en clara referencia a la ética del trabajo) o ser alguien en la vida (adquirir identidad propia). Todos ellos estarían anclados al espacio y al tiempo de lo local. Por otro lado, quienes ansían la meta educativa se sienten mayoritariamente en libertad de desplazarse y movilizarse, eligiendo los escenarios más convenientes para su vida estudiantil. Para estos alumnos el espacio ha perdido sus cualidades restrictivas, haciendo un uso diario de la tecnología informática. Los derechos de que gozan en la democracia parecieran asegurar el marco desde el cual proyectarse. Sin embargo, una 
serie de condicionantes existentes llegan a convertirse en valladares insalvables para egresados desfavorecidos del nivel medio (adolescentes y adultos) del Distrito. Ello impedirá que se conviertan en ejes transformadores que actúen como instrumentos insustituibles para el progreso de todas las personas y alcanzar así una sociedad más justa.

Ahora bien, el modelo económico argentino está caracterizado por la concentración —estudios oficiales y privados desde 1990 a la fecha así lo confirman - siendo, por ende, un rasgo distintivo la desigualdad. En este contexto la educación no parece compensar suficientemente - no obstante sus esfuerzos - el efecto desigualador del mismo. Hoy día sin escuela media es muy difícil acceder al mercado de trabajo, pero egresar de ella ya no alcanza para garantizar un puesto digno en una actividad formal y - a veces - ni siquiera en el sector informal. Informes publicados por el Instituto Nacional de Estadística y Censos (INDEC) en 2010 y en 2011 dan cuenta que el número de argentinos desocupados entre quienes finalizaron el nivel medio en esos años era preocupante. Así, las intenciones de los gobiernos que pregonan la "inclusión con aprendizaje" se materializan en una educación de baja calidad para muchos y otra de alta calidad que se brinda a segmentos pequeños. Sabido es que la finalidad de una política de inclusión es enfrentar la segmentación y la exclusión social. Pero ello exige desandar un modelo económico de desarrollo, el cual requiere una escuela media de alta calidad; esto es, igualdad de oportunidades y posibilidades para todos sin discriminación alguna. Y agréguese: esto debe acontecer en cualquier lugar del país (el Distrito de Junín incluido). En este punto siempre debe recordarse que prejuicio y discriminación son cosas muy parecidas y que el primero deviene en la segunda. El prejuicio nace de la actitud de que determinadas personas son inferiores y deben ser consideradas con desprecio. Asimismo, la discriminación implica acción, casi siempre basada en reglas injustas. El Distrito de Junín no es ajeno a todo esto, a estar por lo comprobado.

Resultó significativo el vínculo establecido entre lo preceptuado en el artículo 75, inciso 19 , párrafo $3^{\circ}$ del texto supremo y los resultados de las actividades llevadas a cabo -ya en razón del proceso cuantitativo, ya del cualitativo- en las escuelas secundarias del Distrito. Como se afirmara en 3.1. El marco de la Constitución Nacional (página 34) "el hecho de que el docente enseñe no significa que el alumno aprenda (mucho o poco) lo que se pretende enseñarle". He aquí el núcleo hacia donde se dirige el contenido de las novedades introducidas por la reforma de 1994, que evidencian el interés del Estado nacional al desarrollar una política educativa que incluye a todos sus niveles. En ese momento, cuando el profesor enseña y el egresado aprende, confluyen de alguna manera (aunque no estén presentes) los demás integrantes de la comunidad educativa; esto es, directores, secretarios y responsables de los egresados, entre otros. Todos influyen en el marco de una sociedad globalizada en el proceso de enseñanza y aprendizaje. En este trabajo de investigación se ha abordado a la educación desde la perspectiva jurídica, poniéndose énfasis en el análisis de la normativa constitucional e infraconstitucional, evidenciándose la brecha existente entre la 
normativa y la realidad. En ese encuentro áulico único e irrepetible se transmiten y adquieren conocimientos, habilidades y actitudes que serán diferentes según se trate de egresados de clase media, media baja o baja. Por tal motivo se produce - en ausencia del valor solidaridad - la fragmentación del universo de egresados secundarios del Distrito.

Oportunamente se hipotetizó que una sociedad como la perteneciente dicho Distrito -cuyo marco es la sociedad bonaerense y, por extensión, Argentina toda- basada exclusivamente en el uso intensivo del conocimiento, produce simultáneamente fenómenos de más igualdad y de más desigualdad. En base a ello podrían constituirse dos bloques de establecimientos educativos claramente diferenciados: uno integrado por las escuelas D, F, F y M (al que, por la similitud de los resultados obtenidos, se agregan las siguientes: A, B, C, E y L) y otro que incluye a los colegios $\mathrm{H}, \mathrm{J}_{1} \mathrm{H}_{1}$ y $\mathrm{L}_{4}$ (a los que deben agregarse, merced a los similares resultados alcanzados, los identificados como $A_{1}, G, I, L_{1}, L_{2}$ y $L_{3}$ ). De la comparación entre ellos emergerían indubitables las igualdades y las desigualdades que existen al interior de cada bloque. Asimismo, del análisis de ambos bloques también devienen una mayor homogeneidad y una mayor diferenciación sociales (consecuencia de la fragmentación producida), cuyos protagonistas son las clases media, media baja y baja del mencionado Distrito. Téngase presente que la tendencia hacia la homogeneidad social en Argentina es considerada por diferentes especialistas como uno de los rasgos centrales del nuevo tipo societal, lo cual aparecería reflejado en las prácticas y estilos de vida de las diferentes clases sociales e ilustrado de manera paradigmática por las urbanizaciones privadas. En tal sentido, algunos de ellos consideran que se estaría yendo hacia la constitución de verdaderos enclaves fortificados que presentan una gran tendencia a la homogeneidad social y generacional. En el Distrito de Junín, salvo algún caso esporádico, no se advierte una tendencia a materializar dichos enclaves. Los resultados permitirían inferir que no existirían en ascenso una clase media baja y una clase media.

Ahora bien, en la conformación de los fenómenos a que se hizo referencia aparecería -en primer término- la ubicación de las escuelas en los diferentes barrios. Desde el centro de la ciudad de Junín hacia la periferia se pueden observar colegios que reciben alumnos casi exclusivamente del sector urbano al que pertenecen. A aproximadamente diez cuadras del centro se experimenta una realidad económica, social y cultural; a veinte cuadras otra diferente y a cincuenta cuadras una diametralmente opuesta — salvo excepciones - a la primera. Varían el edificio escolar, la clase o sector social al que pertenece la familia del egresado y el tipo de construcción de la vivienda en la que reside el estudiante. Todo va de mayor a menor valor económico, de mayores ventajas (por la propiedad de recursos de todo tipo) a menores o — dicho de otra manera - de menores a mayores dificultades. Asimismo, el Foro de Seguridad 1 del Distrito de marras aseveró este año - a través del periodismo- que dispone de informes según los cuales el delito se ha ido trasladando - casi totalmentedesde la zona céntrica hacia los barrios. A cincuenta cuadras del centro de la ciudad no 
existen dependencias policiales y a esa distancia están ubicadas varias escuelas que integraron la muestra en esta investigación. En los tres últimos años, los dos periódicos locales de mayor circulación reflejaron los ingresos de desconocidos a esos colegios, causando diferentes daños más de una vez en cada uno de ellos. De las diecinueve escuelas estatales de nivel medio (diez de adolescentes y nueve de adultos), el ambiente físico comprensivo del tamaño, arreglo espacial o distribución, señales, accesos y sitios, evidencia algo indubitable: fue menos dificultosa su construcción (dos escuelas existen desde hace más de cincuenta años) que todo lo necesario actualmente parar mantenerlas acorde a la realidad, salvo excepciones. Asimismo, la expansión de los comedores escolares muestra otro déficit social: los indicadores nacionales de los servicios de desayuno y almuerzo treparon desde 2003 a la fecha, no obstante el crecimiento económico experimentado por el país. El Distrito de Junín muestra idéntica realidad, puesto que ya son varias las escuelas de nivel medio para adolescentes que cuentan con ellos. Respecto de las modalidades implementadas y las materias que incluyen el panorama es diverso. La modalidad Ciencias Naturales existente en varias escuelas de adolescentes y de adultos no comprende las mismas materias en cada una de ellas (tampoco coincide la cantidad total de asignaturas por colegio). En la modalidad EGEOR son catorce las materias que se imparten en la escuela $\mathrm{C}$ y sólo diez en las restantes de adolescentes y de adultos.

A su turno - y es lo que más interesa destacar en la presente investigación- está la realidad del alumnado. Se constató que si pertenece a una familia de padres, por ejemplo profesionales o quizás pequeño o mediano empresario, casi con seguridad realizará estudios terciarios no universitarios o universitarios en Junín (si existe el profesorado o la carrera de su preferencia) o en alguna otra ciudad importante como Buenos Aires, La Plata, Rosario o Córdoba. Es decir, este egresado elegirá qué estudiar y el lugar donde estudiará (en casi todos los casos estudiará solamente). Si logra graduarse es probable que casi de inmediato tenga en Junín o en la ciudad donde estudió un lugar donde ejercer su profesión (en muchos casos por los vínculos sociales que fue generando su familia, surgidos del ejercicio de la profesión de su o sus padres). Como es dable observar, se trata de un derrotero con un principio y un fin conocidos (y prácticamente determinados) a priori. Esta es la realidad de ciertos egresados de clase media (muchos adolescentes y unos pocos adultos), varones y mujeres. Pero interesa también conocer qué sucederá con los demás, con aquéllos que provienen de familias de trabajadores (clase media baja o baja) y egresan del secundario con sólo deseos de conseguir un trabajo. Importa, asimismo, conocer si podrá cumplirse en estos alumnos aquello de que la educación es una herramienta formidable para la movilidad social ascendente. Habrá que pensar y debatir si realmente la culminación del nivel medio es un instrumento útil para aspirar a tal movilidad o deberán alcanzarse estudios superiores para lograr efectivamente la misma. A diferencia de los egresados de escuelas ubicadas en la zona céntrica (o a pocas cuadras de ella), los que asistían a colegios alejados de la misma en su mayoría trabajaban 
(varios en el sector informal). Algunos lo hacían en horarios rotativos, complejizándose así su rendimiento educativo. Para ellos, un futuro educativo es casi una quimera. Asimismo, deportes como el fútbol o el boxeo los motivan fuertemente, considerando a los mismos un camino viable para dar solución a sus necesidades materiales.

Por lo demás, no obstante que muchos políticos aludieron —en todo tiempo- a la educación como liberadora de los pueblos, según afirman hoy estudiosos del tema, históricamente la enseñanza ha servido para discriminar a unos grupos humanos frente a otros: a los hombres frente a las mujeres, a los pudientes frente a los menesterosos, a los burgueses frente a los obreros, a las castas superiores frente a las inferiores. De manera que universalizar la educación es una tarea que consistiría en terminar con tales manejos discriminadores. Universalizar la educación implicaría que todos los jóvenes de entre trece y dieciocho años en América Latina - por ende en Argentina y específicamente en el Distrito de Junín- lleven a cabo (y concluyan) la escuela secundaria. Sin excepciones, vivan donde vivan. Coetáneamente lograr calidad en el servicio educativo, particularmente en beneficio de los desfavorecidos (los que menos recursos económicos tienen). Para ello se requiere el compromiso de todos los agentes de la comunidad educativa, aspecto deficitario que en el presente trabajo se observó en un elevado porcentaje. Ha quedado probado fehacientemente lo que se afirmara en el planteamiento del problema. Allí se señaló que siempre será necesario exigir en cualquier país (Argentina incluida) más y mejor educación para todos, como reaseguro para la permanencia de sociedades libres.

En esta investigación participó la mayoría de los integrantes de la comunidad educativa a que pertenece cada escuela. La idea fue que el más amplio espectro posible de datos cuantitativos y cualitativos permitiría efectuar una interpretación más completa y -por ende- más ajustada al problema en estudio, vía convergencia y resultados complementarios. Intervinieron egresados adolescentes y adultos que mostraron diferentes realidades, observadas a través de sus respuestas ante la indagación referida al problema en estudio. Ya desde los atributos sociodemográficos tornan visibles las diferencias sociales que -en los casos extremos - serán casi imposibles de revertir. Dos ejemplos son los adolescentes que egresaban de la escuela $\mathrm{J}$ y los adultos que lo hacían de la $\mathrm{L}_{4}$. A mayor abundamiento, los datos de la investigación - a nivel nacional- que originó el libro La tragedia educativa de Guillermo Jaim Etcheverry podrían cotejarse con los obtenidos en esta tesis. Los porcentajes logrados aquí (que constan en 2.1.3.1. La importancia de educarse, página 132) son prácticamente los mismos que figuran respecto de una pregunta idéntica formulada en aquella investigación, efectuada en 1993. Tal coincidencia muestra inequívocamente la persistencia de dificultades en los educandos, más allá de las diferentes políticas educativas implementadas desde aquella fecha a hoy. Asimismo, cuando el cuestionario aplicado a los egresados estatales del Distrito de Junín incursionaba en el espacio curricular Historia, más de la mitad de los adolescentes desconoció la fecha en que se produjo la Revolución de Mayo (en 
la escuela $\mathrm{J}$ nadie acertó). En adultos, los porcentajes fueron similares a los de los adolescentes aunque el dato de la escuela J aquí no se repitió.

Desde hace veinticinco años, en la educación de los adolescentes se vienen experimentando cambios. Los alumnos ya no esperan de pie al costado de su banco para saludar cuando el profesor ingresa al aula. Algunos integrantes de las comunidades educativas expresaron que aquello era un signo de autoritarismo, otros manifestaron que es una de las expresiones en que se trasunta la pérdida de autoridad de los docentes.

En la educación de adultos, lo que estaba vigente hace veinticinco años hoy cambió fundamentalmente. Aquellos estudiantes tenían en 1988 cuarenta o más años y —a vecesalgunos compañeros de veinte (por entonces la mayoría de edad se alcanzaba a los veintiún años). Fácil resulta imaginar la escena de aquel entonces en el aula: silencio (indicio del respeto hacia el profesor, considerado autoridad), alumnos que no faltaban a clase - salvo excepciones- y estudiar todos los días a más de exámenes casi de continuo, con la flexibilidad necesaria justificada en las responsabilidades extra clase que todos ellos debían afrontar. La realidad actual es absolutamente distinta en muchos aspectos, según pudo comprobarse en esta investigación. Estudiantes adultos de entre dieciocho (edad en que se adquiere actualmente la mayoría) y veinticinco años, escasamente dispuestos al estudio por varias razones (entre ellas, por no haber adquirido el hábito). El profesor - para algunos de ellos- es una persona que sólo transmite conocimientos, casi nunca es un "modelo" a seguir. En general, estos educandos tienen más voluntad para el disfrute inmediato de algunos aspectos de la vida y menos idea del esfuerzo sostenido a realizar para obtener logros en el futuro. Aquella flexibilidad respecto de los adultos se volvió elasticidad casi total en los días que transcurren. Así, los apuntes de clase están hoy incompletos, sus inasistencias son reiteradas (cuando llueve la ausencia es, generalmente, total), los exámenes no abundan, las letras son casi ilegibles, muchas ortografías son deficientes, muchos sostienen que con asistir a clase es suficiente para aprobar (obtener el siete) y un pequeño porcentaje admite que consume sustancias tóxicas. Todo esto fue comprobado por el investigador en diálogos con profesores de los mismos y visando personalmente muchas carpetas en distintos momentos de los ciclos lectivos 2010 y 2011. No obstante lo dicho, la mayoría de los profesores aprueba - al culminar el ciclo lectivo- a estos egresados que - por otro lado - se ven beneficiados por una política educativa nacional que privilegia la inclusión (eso se afirma verbalmente y está en la normativa jurídica) sin respeto de la denominada calidad educativa.

Seguidamente, se hará una referencia sobre el núcleo familiar con ajuste a la realidad del Distrito de Junín. Aquí aparecen los responsables (padres, madres, tutores u otros) de los egresados 2010. Se trata de hombres y mujeres que oscilan entre cuarenta y cincuenta años, algunos de los cuales tenían durante la última Dictadura Militar la misma edad que sus hijos hoy, pero vivida en medio del horror. Las diferencias son esenciales entre aquellos años (1976-1983) y la democracia actual. El descreimiento por la política como tal o por los 
políticos, el desconocimiento del pasado argentino (y el de otros países latinoamericanos), su preocupación por temas aparentemente triviales o superficiales, la escasa o nula propensión al ahorro y el disfrute de la vida son el común denominador de estos jóvenes (adolescentes y adultos).

Ahora bien, en relación a los logros educativos alcanzados por dichos responsables, es nítida la diferencia a favor de quienes son responsables de egresados adolescentes respecto de aquéllos que lo son de adultos. Y lo mismo sucede cuando de idénticos logros se trata respecto de los abuelos de unos y de otros. Aceptando que esta cuestión -logros educativos - tuviera directa relación con la calidad de vida de las personas, surgiría aquí un dato incontrastable: el paso de los años devendría en una mayor conciencia del valor educación. Ello aparejó una mejor calidad educativa, la cual culminaba otrora en la mentada movilidad social ascendente (algo, por lo demás, harto difícil de comprobar que así suceda por estos días). Empero, ese mayor valor atribuido a la educación, no es tan así en la realidad. Tal afirmación surge del análisis e interpretación de los datos obtenidos tras aplicar los cuestionarios a los responsables de los egresados adolescentes y adultos. Vale subrayar que la mayoría de esos responsables de egresados expresó que la comunicación entre padres e hijos a veces es fácil y otras, difícil. Cabría recordar que de una comunicación fluida y sostenida entre unos y otros sería posible esperar mejores oportunidades de inserción social para los hijos, especialmente quienes pertenecen a los sectores más desaventajados (estas consecuencias apuntadas fueron mencionadas al investigador por la totalidad de los docentes participantes en esta investigación). Asimismo, autoridades de escuelas a que asisten egresados de los sectores más desaventajados confirmaron al investigador que muchos de los responsables no se ocupan de la trayectoria educativa de sus hijos.

Otro dato de interés es la elección del establecimiento escolar para que estudien sus hijos. Implica comprender la relación que existe entre la posición social de la familia, el perfil institucional de la escuela, la formación de los educandos y los diferentes campos probables de actividad para los egresados. Aquí la elección de la escuela por la proximidad respecto de la casa que se habita, postergó a la opción que aludía al perfil institucional del establecimiento. En otro orden, que sea un buen trabajador o un buen profesional (para los responsables de los egresados de la escuela $\mathrm{J}$ ), que constituya una familia o que sea feliz (para los responsables de los de la escuela $\mathrm{G}$ ) son los deseos respecto de sus hijos, evidenciándose así dos escalas axiológicas con sus diferencias. Que sea feliz fue la opción más elegida entre los responsables de los egresados adolescentes y que sea una buena persona lo fue entre los de los egresados adultos.

En otro orden de ideas, la opinión de casi la mitad de los profesores de todos los egresados, según la cual la calidad educativa de los mismos es regular —las demás opiniones oscilaron entre buena y mala, en porcentajes iguales- permitiría concluir cuán lejos está el ideal generalizado en la población argentina, consistente en una educación de alta calidad para 
todos. Respecto de las causas de esta realidad sucede lo que casi siempre: unos responsabilizan a otros y éstos a aquéllos, con lo cual nunca nada queda probado y todo sigue igual (o peor). Por ende, los resultados deficientes en la educación argentina se repiten permanentemente en diferentes lugares del país (la provincia de Buenos Aires incluida y - por consiguiente - el Distrito de Junín también). Como lógico desenlace, en pruebas de nivel internacional, los estudiantes argentinos de nivel medio han alcanzado, últimamente, resultados muy magros y se destacaron - negativamente - en el rubro actitudes inadecuadas en clase. Por otro lado, téngase presente lo siguiente: un bajo porcentaje de los responsables de todos los educadores de quienes egresan finalizó un estudio superior, lo cual permitiría identificar los valores que aquéllos transmitieron a sus hijos y que éstos, convertidos en los profesores de hoy, transmitirán en el aula.

Un aporte para comprender la realidad que viven muchos docentes es que poco más de la mitad de ellos afirmó que trabaja en más de una institución educativa (dando clases o cumpliendo otra función). Ello hace obvia su condición de asalariados del sector público (como así del privado) y descartaría la calificación de "profesionales" con que se los pretende identificar (al menos, desde el punto de vista económico). Son - sin eufemismosempleados en relación de dependencia, su empleador es el Estado (nacional, provincial o municipal) o alguna institución privada). Tienen bajo su responsabilidad una "materia prima" (el educando) sobre la que actúan para obtener un "producto final" (el egresado) que es absolutamente diferente a las denominadas mercancías. El egresado de la escuela secundaria es un producto, elaborado a través de los años que incluye el nivel medio, presto a incorporarse al mundo del trabajo (el cual es muy competitivo) en torno al cual rigen las leyes de oferta y demanda del mercado laboral. La otra opción que tiene es continuar estudios terciarios para - una vez concluidos los mismos - ser un producto que se incorporará a un mercado (que también es muy competitivo) donde rigen idénticas leyes. Esta es la realidad que le aguarda, dado el sistema capitalista que rige la vida económica de los argentinos.

Respecto del rol docente, téngase presente que -como se puso de manifiesto en esta investigación - aquéllos que tienen modelos positivos fuertes (en oposición a quienes construyen el suyo basándose en modelos negativos) cuentan con más posibilidades de desarrollar identidades docentes mejor preparadas para enfrentar los desafíos desde el inicio de la actividad. Estos modelos permitirían desarrollar ideas sobre lo que significa la enseñanza y también una identidad a futuro. Cómo me gustaría ser trabajando como profesor sería aquí la pregunta fundamental. De la manera en que estos profesores ejercieron su rol habría resultado la existencia de muchos estudiantes destacados en el contexto de una educación de regular o baja calidad (tal lo aseverado por poco más de la mitad de ellos).Que el mayor número de alumnos destacados se halle entre los adultos indicaría su mejor aprovechamiento del tiempo respecto de los adolescentes. A la vez, todos los profesores 
encuestados se preguntaron cómo podría darse una educación de alta calidad con mayoría de alumnos que tuviesen rendimientos elevados.

En otro orden de ideas, fenómenos como el alcoholismo, la delincuencia, la drogadicción y la prostitución en el Distrito de Junín son atribuidos por la inmensa mayoría de los docentes a la actual crisis de valores, a factores familiares y a la falta de límites que se observa en los jóvenes. La pregunta que surge es quién o quiénes originaron la crisis de valores que se vive hoy. Han sido los adultos actuales o los de antaño, pareciera. O tal vez los adolescentes de hoy, en alguna medida. En definitiva, en una sociedad donde nadie se hiciera responsable se producirían situaciones con prevalencia del conflicto, con los consiguientes perjuicios para todos, especialmente los sectores desaventajados (por caso, los del Distrito de Junín y - particularmente - los egresados del nivel medio de esos sectores). Vaya como ejemplo el siguiente: durante 2010 - y en 2011 también- el investigador observó en algunos colegios del Distrito citado discusiones y peleas entre varios estudiantes (mujeres y varones, muchos de ellos egresados), producidas en los patios en el horario de los recreos como así en la puerta de entrada de la escuela, al finalizar el día de clase. Situaciones que, desde hoy hacia atrás veinte o treinta años, era absolutamente anormal presenciar (en la reyerta intervenían sólo varones; hoy también se da entre mujeres). Préstese atención a las reflexiones de un profesor del último año del nivel medio, con veinte años de antigüedad en escuelas estatales de adolescentes. "Antes, estas cosas no pasaban, la violencia en la escuela prácticamente no existía. Ahora están los Acuerdos Institucionales de Convivencia y - sin embargo- cada tanto tenemos un hecho desagradable. O se pegan entre los alumnos o le pegan a algún profesor. Hace unos años, cuando nosotros actuábamos teníamos el respaldo de los padres; ahora tenemos que cuidarnos porque vienen ellos a la escuela y nos insultan o nos quieren pegar".

A renglón seguido otro dato significativo es que la idea educativa basada en el cognitivismo y el constructivismo (así se desprende de las normativas nacional y de la provincia de Buenos Aires vigentes) casi es desconocida. Por ende, no es aplicada por la gran mayoría de los docentes; incluso pudo constatarse que en una escuela ningún profesor la utiliza. Este comportamiento pasa desapercibido para las autoridades de cada colegio y también para otras de mayor jerarquía. Por lo expuesto, la generalidad de los profesores pareciera ubicarse "afuera" de la difícil situación educativa que ellos también protagonizan (y como principales actores). En este investigación se comprobó que la mitad de ellos no adopta posición alguna respecto de las características de las leyes nacional y bonaerense de educación (lo cual, de algún modo, es una postura), que la epistemología genética no es aplicada en prácticamente curso alguno, que la vocación por la docencia no está presente en varios profesores y que la mayoría se desempeña en varios cursos, inclusive están quienes poseen otro cargo. Estos datos ya los muestran como agentes educativos que debieran 
replantearse algunos aspectos del ejercicio del rol en mira a lo que todas las comunidades educativas persiguen: mejorar la calidad educativa de los argentinos.

A propósito de lo referenciado supra, el constructivismo piagetiano (2.3. El constructivismo, página 28) representa una nueva vía para abordar la enseñanza de las ciencias, no obstante la crítica a excesos en los procedimientos. Sus logros consisten en poner el acento en los alumnos como ejes de su propio proceso de aprendizaje y en el valor otorgado al descubrimiento y a la investigación como forma para construir el conocimiento. Por su lado, Pierre Bourdieu (2.2. La función de la escuela, página 26) asevera que en las sociedades divididas en clases los gobernantes ejercen un poder simbólico para imponer una definición del mundo afín con sus intereses. Así, la cultura dominante es producida en las escuelas al punto que el dominado toma parte en su propia opresión. Por otra parte, aquella orientación del constructivismo es el prisma que sustentó la realización de actividades referidas al presente trabajo. Pero el sistema educativo argentino - tal como se probarapresenta, en su faz organizativa, algunos caracteres que son incompatibles con dicha teoría educativa. Consecuencia de ello, las trayectorias educativas de los egresados del Distrito son disímiles según la tríada familia-escuela-sociedad (barrio) al que se pertenezca. A punto tal que los que viven en sectores desfavorecidos reproducirían al dominado a que alude Bourdieu, a tenor de la evidencia aportada a favor de las subhipótesis y de la hipótesis general formuladas en esta investigación.

Ahora bien, durante la década de 1990 diferentes gobiernos latinoamericanos aplicaron políticas de ajuste (que perjudicaron más a los desaventajados, al tiempo que beneficiaron a algunos sectores minoritarios) y de privatización que elevaron el número de pobres y llevaron los índices de desigualdad a niveles siderales. Dichas reformas generaron, empero, la ampliación de las oportunidades de acceso y permanencia de los más pobres en el sistema educativo. Este hecho se explicaría de dos maneras: por un lado, podría sospecharse que se trató de un acto de responsabilidad cívica de gobiernos que, aunque dejaron traslucir un desprecio por los derechos humanos y por la justicia social, ansiaban la escolarización del pueblo. Por otro, pudo deberse a una política de sumisión de los pobres al poder dominante, cuya finalidad era que cayeran en la trampa de creer que la escuela iba a liberarlos, cuando -en rigor- era la coartada perfecta para consumar su dominación. Consultados los directores pertenecientes a las diecinueve escuelas estatales de adolescentes y de adultos del Distrito de Junín, la respuesta mayoritaria estuvo dada en el sentido de responsabilizar a esos gobernantes por hacerles creer a los pobres que la educación era la llave que les permitiría abrir la puerta hacia el futuro, un futuro con calidad de vida. Pero la realidad no fue así y tampoco pareciera serlo en la actualidad, aseveraron tales directores.

A todo esto, el sistema educativo argentino muestra una división de tareas: el ministerio nacional gobierna "bajando" directivas que llegan a las máximas autoridades provinciales, las escuelas las implementan y los supervisores controlan. La autoridad retiene el poder y la 
responsabilidad, en tanto el compromiso de los implementadores se limita al cumplimiento de dichas directivas: el registro al día, la planificación completa y el guardapolvo (no en todos los colegios), entre otras. Inmersos en esa estructura verticalista, estos directores encuestados no creen (uno de ellos es la excepción) que los demás agentes educativos puedan alcanzar un verdadero compromiso. Por lo demás, la mayoría de estos directores se asume como los encargados de resguardar la estructura orgánica de la institución escolar, reconociendo que su función y competencia no son indeclinables (en este sentido, el investigador pudo observar durante varios días de 2010 y del 2011 cómo varios secretarios las asumían transitoriamente sin que - en esencia - nada se modificase en el funcionamiento de los colegios). Asimismo, téngase presente lo siguiente: los directores están muy de acuerdo o de acuerdo (casi por partes iguales) con las leyes nacional y provincial de educación y evalúan (también casi por partes iguales) como buena o regular la calidad educativa desde 1983 hasta hoy. Ahora bien, considerando todo lo anterior y uniendo esos datos aflora que algunos docentes se mostraron incoherentes en sus opiniones, porque si están muy de acuerdo con tales leyes, la calidad educativa no debería ser regular salvo que se admita que — no obstante ese marco legal favorable- la educación puede devenir regular por otras causas. De ser ello así, tornaría evidente algo que para los docentes es unánime: una cosa es la educación formal (la que está prescripta en la normativa vigente) y otra muy distinta es la educación real (la que se lleva a cabo todos los días en las escuelas).

Respecto de los trece secretarios encuestados, mayoritariamente admitieron que entre la escuela y el medio en el que está emplazada se dan relaciones de cooperación y de colaboración. Asimismo, manifestaron que en las comunidades educativas que ellos integran existe una actitud positiva ante los cambios internos y externos, si bien en un principio los mismos generan oposición entre los docentes. Lo llamativo - una cuestión no menor- es que las máximas autoridades educativas nacionales y - principalmente- provinciales cambien y/o modifiquen las disposiciones casi de continuo, impidiéndose de esa manera la total comprensión y el debido acatamiento de aquéllas (así lo reconoció la mayoría de los directores y secretarios). Respecto de las leyes nacional y de la provincia de Buenos Aires de educación, una buena cantidad de Secretarios no está de acuerdo ni en desacuerdo con ambas. La mayoría de ellos asume que su rol implica participar de la organización institucional de la escuela a través de la toma de decisiones en el marco de su competencia. De manera tal que, con todo lo señalado en esta tesis se aportaría evidencia empírica en favor de la hipótesis general, con fundamento en lo propio acontecido respecto de las subhipótesis.

Podría aplicarse una expresión vigente desde hace cincuenta años, la cual asevera que se vive una "situación de crisis". Siguiendo a aquéllos que aseguran que las crisis finalmente originan cambios, se deberían esperar los supuestos cambios que indefectiblemente vendrían. Surge el interrogante sobre si esos cambios alcanzarían a la educación. Y si es así, a quién o a quiénes beneficiarían. Dicho todo esto lo problemático es que, más allá de si Argentina continúa atada o no al modelo sarmientino de educación, parece haberse extinguido una idea 
común de progreso y de modernidad. También surge la inquietud de si será posible que llegue a ser una gran Nación y cuál sería —en esa realidad - el rol a desempeñar por la educación.

Esto no admite discusión: la educación hoy -como ayer- es un espacio de confrontación y de disputa, un territorio de lucha y de antagonismo. Aseverar que hay intereses en pugna, visiones y expectativas que se enfrentan, no significa sostener que en la educación los buenos están de un lado y los malos del otro. La educación no interesaría a todos de la misma forma (incluso, a algunos gobernantes nunca pareció interesarles). Y ése es el nudo del problema. Ponerse de acuerdo será una cuestión de poder o de diálogo profundo y respetuoso. En tal sentido, en Argentina las personas con menos recursos junto a sus organizaciones, los partidos políticos, los sindicatos y los movimientos sociales han avanzado significativamente en su lucha por satisfacer demandas sociales crecientes. Éstas, en el Estado de Derecho democrático, tendieron a traducirse en un amplio espectro de oportunidades de participación en espacios de los cuales antes estaban excluidas. Darles más y mejor educación a los pobres y a los indigentes (o a los desfavorecidos en general) es una decisión política que se construye sobre la base de una opción: un modelo de producción y de distribución que coloque a la justicia social en el centro de las prioridades.

Mejores escuelas para - especialmente- los humildes constituye un imperativo ético en la democracia actual que no deberían evadir los gobiernos argentinos futuros si pretenden diferenciarse positivamente de los anteriores y sentar las bases para la construcción de una sociedad más justa (ya sea en el ámbito urbano como en el rural, en las provincias o en la Nación).

Cuando la normativa vigente -entre otra, el artículo 75 , inciso 19 , párrafo $3^{\circ}$ del texto constitucional reformado en 1994- no se cumple, la finalidad misma de la educación desaparece y el perjuicio que de ello se sigue alcanza a todos pero - especialmente- a los más vulnerables. Entre ellos están —a la espera, como antaño- los egresados adolescentes y adultos del nivel medio de escuelas estatales pertenecientes a esos sectores del Distrito de Junín.

Por último, si el colegio secundario resultara un ámbito fundamental e insoslayable desde el cual emprender y acompañar la construcción de la futura sociedad argentina y -en ellala formación de las generaciones jóvenes del Distrito de Junín, se espera que esta investigación proporcione algunos lineamientos que puedan resultar útiles a la hora de diseñar nuevos contenidos, propuestas y políticas educativas para ese período de sus vidas. 


\section{LIMITACIONES}

Este acercamiento a la realidad del Distrito de Junín en el bienio 2010/2011 y su vínculo con procesos sociales más generales $-\mathrm{y}$, por ende, sus relaciones con la sociedad argentina toda- podría ser considerado un aporte a la profusa y variada bibliografía existente sobre un tema que atañe a todos en mira al futuro del país: la educación media.

Evaluar la validez de las conclusiones de esta tesis supone siempre un juicio humano incierto, por lo que nunca connotará un criterio absoluto sino que validez o invalidez tienen varios grados de certidumbre. Por ende, tales conclusiones podrían resultar tentativas o aproximadamente válidas.

Ahora bien, ¿en qué grado la causalidad de las relaciones establecidas aquí se desprende de las asociaciones observadas? Los análisis realizados han permitido estimar la magnitud de las relaciones observadas; no obstante surgen —en este sentido- dos preguntas:

1. ¿hasta qué nivel esta investigación establece que las causas hayan sido producto de la experiencia descubridora, del factor creativo y de la experiencia integradora, consecuencias de nuevas oportunidades y/o mejoras? y,

2. ¿hasta qué nivel se tuvieron en cuenta otros factores que pueden ser igualmente responsables de las relaciones observadas, ya sea como variables mediadoras, fomentando interrelaciones o meramente provocando relaciones espurias? Es decir: ¿se conocían todos los factores que podían afectar a las relaciones observadas?

Como habitualmente acontece en las Ciencias Sociales, donde existe la manipulación de variables y la asignación aleatoria de los sujetos propia de metodologías experimentales en esta investigación se han acumulado evidencias empíricas. Así, la validez de las conclusiones a que se arribó concierne a dos tipos de inferencias relacionadas: primero, la existencia o no de una relación entre variables y segundo, el grado de relación que existe entre las mismas. Es por ello que se debería evaluar la validez de las inferencias relativas a estos constructos, medidas en forma indirecta a través de la operacionalización de los cuestionarios elaborados. También debería plantearse hasta qué punto las conclusiones de esta investigación científica son generalizables a otros contextos, escuelas o momentos distintos a los reflejados aquí; es decir, aquello conocido como el grado de validez externa. 


\section{SUGERENCIAS}

Los resultados de esta investigación científica mostrarían que las instituciones educativas estatales de nivel medio del Distrito de Junín atraviesan un proceso de cuestionamiento, el cual estaría inmerso en uno más general, que abarca a los demás niveles en todo el país. Del mismo posiblemente surgirán cambios cuya dirección es hoy un interrogante para todos los miembros de las comunidades educativas. Las investigaciones futuras en cotejo con las ya existentes (entre ellas la presente) permitirían — de actuarse con cientificidad y éticavisualizar las líneas directrices de la educación que vendrá. En tal sentido, podría resultar importante el presente trabajo para una toma de conciencia respecto de la problemática. Toda discriminación está prohibida por la normativa vigente pero no desapareció de las relaciones interpersonales, deviniendo situaciones reprochables en el ámbito escolar, siendo los educandos de los sectores desfavorecidos quienes más la sufren. Así, la diferencia en la adquisición de información y conocimientos (tal como se probara en esta tesis) a favor de los egresados de algunas escuelas - no obstante tratarse de la misma modalidad- perjudica a los desfavorecidos. Asimismo, podría cotejarse dicha realidad con la profundidad que sería dable alcanzar respecto de los mismos, lo cual motivaría una línea de exploración futura. Otra investigación podría referirse a las características del sistema educativo bonaerense en tiempos de la última dictadura militar (cuando los responsables de estos egresados de hoy eran adolescentes) y sus diferencias con el de hoy en el marco de la democracia, haciendo hincapié en las relaciones intrafamiliares. Otra línea investigativa podría abrirse para conocer, en el Distrito citado, las causas de los mejores logros educativos de los responsables de estos egresados adolescentes comparados con los de los responsables de egresados adultos y su posible influencia en la internalización del valor de la educación en sus hijos. O bien, con los datos aquí registrados abordar el problema de la movilidad social ascendente o descendente, desde el retorno democrático en 1983 hasta la fecha en el Distrito de Junín. O investigar las articulaciones entre el nivel medio y el superior (terciario no universitario o universitario), tomando en consideración a estudiantes de los ámbitos urbano y rural, ya sea adolescentes o adultos o todos a la vez. Asimismo, se sugiere una investigación referida al ejercicio del rol docente y su influencia como modelo en la formación de la personalidad de los alumnos, teniendo a la vocación (cualidad de su personalidad) como variable a considerar, entre otras. $\mathrm{O}$ investigar las motivaciones de la elección de una segunda carrera como opción a seguir cuando los egresados deciden su futuro educativo. 
Otra sugerencia, a tenor de una demanda estudiantil cada vez más creciente, alude a la realización de una investigación que —en el marco de la formación escolar- considere los posibles beneficios de la existencia como asignatura obligatoria de "Orientación Vocacional u Ocupacional”. 


\section{BIBLIOGRAFÍA}

\section{Específica}

Abrile de Vollmer, María Inés. "Estrategias para superar las desigualdades y la fragmentación en el sistema educativo", en Tedesco, Juan Carlos (comp.), ¿Cómo superar la desigualdad y la fragmentación del sistema educativo argentino? Ministerio de Educación, Ciencia y Tecnología, Presidencia de la Nación, 2005.

Airbe Barandiaran, Ana; Medrano Samaniego, Concepción, y Palacios Navarro, Santiago. "E1 perfil de consumo televisivo en adolescentes, jóvenes y adultos: implicaciones para la educación" en Revista de Educación, 352. Universidad del País Vasco. Facultad de Filosofía y Ciencias de la Educación. Departamento de Psicología Evolutiva y de la Educación. Mayo-Agosto 2010.

Belossi, Mariana y Palacios de Caprio, María Alicia. La escuela media y los jóvenes socialmente desfavorecidos. Buenos Aires, Lugar, 2004.

Bidart Campos, Germán José. Tratado elemental de derecho constitucional argentino: La reforma constitucional de 1994, Tomo II. Buenos Aires, Ediar, 1995.

Bourdieu, Pierre. "La urgencia y el fast thinking”, en Sobre la televisión. Barcelona, Editorial Anagrama S.A., traducción de Thomas Kauf, 1997.

Brunner, José Joaquín y Tedesco, Juan Carlos. Las nuevas tecnologías y el futuro de la educación. Buenos Aires, Grupo Editor Septiembre, 2003.

Capella Riera, Jorge. La Educación. Un Enfoque Integral. Segunda edición, Lima, Editorial Cultura y Desarrollo, 1987.

Carandino, Edgardo. "La prueba Pisa y sus resultados sobre la educación argentina", La Voz, jueves 23 de junio de 2011. <http://www.lavoz.com.ar/opinion/prueba-pisa-susresultados-sobre-educacion-argentina $>$. Fecha de consulta: 10 de enero de 2013.

Carrier, Jean-Pierre. 2. "Los retos de los multimedia para la escuela", en Escuela y multimedia. Traducción de Tatiana Sule Fernández, Siglo XXI Editores, 2002.

Castorina, José Antonio. Cap. VII. "Los obstáculos epistemológicos en la constitución de la psicopedagogía”, en Problemas en psicología genética. Niño y Dávila Editores, 1989. 
Coll, César; Marchesi, Álvaro y Tedesco, Juan Carlos (coordinadores), Calidad, equidad y reformas en la enseñanza, en Gobierno y dirección de los sistemas educativos en América Latina. 1. ${ }^{\text {a }}$ reunión del grupo de expertos de la OEI sobre "Reformas educativas". Documento de trabajo interno. Ciudad de México, mayo 2007.

Confederación de Trabajadores de la Educación de la República Argentina (CTERA). Las reformas educativas en los países del Cono Sur. Ensayos \& Investigaciones del Laboratorio de Políticas Públicas - Buenos Aires, No 11, CLACSO, 2005.

Consejo Nacional de Televisión (CNTV), Encuesta Niños, Adolescentes y Televisión, Departamentos Estudios, Chile, septiembre de 2012.

Dussel, Inés. La producción de la exclusión en el aula: una revisión de la escuela moderna en América Latina. Granada, España, presentado en X Jornadas LOGSE. "La escuela y sus agentes ante la exclusión social”, 27-29 Marzo, 2000.

La escuela media argentina y los desafios de las metas 2021. Presentación V: Foro Latinoamericano de Educación Metas educativas 2021. Buenos Aires, Propuestas iberoamericanas y análisis nacional, Fundación Santillana-OEI, 2009.

Dussel, Inés, Montes, Nancy y Legarralde, Martín, Informe sobre Educación y Desarrollo para el proyecto Gestión XXI, PNUD 97/025, Ministerio de Economía de la Nación, agosto de 2006.

Etcheverry, Guillermo Jaim. La tragedia educativa. Buenos Aires, Educación y Pedagogía Series, Editor Fondo de Cultura Económica, 2007.

Giroux, Henry. Capítulo 3 "Reproducción, resistencia y acomodo en el proceso de escolarización”, en Teoría y resistencia en educación. Una pedagogía para la oposición. México, Siglo XXI Editores, 1997.

Gladsztein, Adriana (psicoanalista especialista en niños y adolescentes). "La deserción en las públicas quintuplica a la de las privadas”, Clarín, Sección Educación, 26 de junio de 2012.

González Ibáñez, Joaquín. Tratados Internacionales de Derechos Humanos y Principio de Legalidad. La quiebra de las obligaciones de los tratados internacionales en el ámbito del derecho a la educación, en Derechos humanos, relaciones internacionales y globalización. Bogotá, Grupo Editorial Ibáñez, 2006. 
Grinberg, Silvia Mariela. Educación y poder en el siglo XXI: gubernamentalidad y pedagogía en las sociedades de gerenciamiento. Madrid - Buenos Aires, Miño y Dávila Editores, 2008 .

Gvirtz, Silvina y Palamidessi, Mariano. El ABC de la tarea docente: Currículum y enseñanza. Ciudad Autónoma de Buenos Aires, Aique, Tercera edición, mayo de 2011.

Iaies, Gustavo. Capítulo VI. "Introducción de nuevas tecnologías: el caso Argentina", en Las nuevas tecnologías y el futuro de la educación. Buenos Aires, Septiembre Grupo Editor, 2003.

"Sin idea de futuro y progreso, no hay educación posible". Clarín (Tribuna). 24 de febrero de 2011.

Kant, Immanuel. Pedagogía. Akal Ediciones, 1983.

“La enseñanza secundaria sacó una mala calificación”, en Clarín (Sociedad: Educación), Buenos Aires, 4 de marzo de 2011.

López Espinosa, Gustavo y van Gelderen, Alfredo Manuel. La escuela argentina en transformación: ocho cuestiones y veintidós protagonistas. Aula XXI, Ediciones Santillana S.A., 1996.

Marchesi, Álvaro y Martín, Elena, Calidad de la enseñanza en tiempos de cambio, Madrid, Alianza, 1998.

Obiols, Guillermo y Di Segni Obiols, Silvia. Capítulo III "La crisis de la escuela secundaria”, en Adolescentes, posmodernidad y escuela, Buenos Aires, Ediciones Noveduc Libros, agosto 2008 .

Pineau, Pablo, Dussel, Inés y Caruso, Marcelo, 1 “Por qué triunfó la escuela? o la modernidad dijo: 'Esto es educación', y la escuela respondió: 'Yo me ocupo", en La escuela como máquina de educar: tres escritos sobre un proyecto de la modernidad. Buenos Aires, Paidós, 2001.

Puiggrós, Adriana. "Hacia un sistema educativo nacional, de base federal y democrática", en Tedesco, Juan Carlos (comp.), ¿Cómo superar la desigualdad y la fragmentación del sistema educativo argentino? Ministerio de Educación, Ciencia y Tecnología, Presidencia de la Nación, 2005.

Quiroga Lavié, Humberto, La Autonomía Universitaria. La Ley, Tomo B, 1987. 
Rivas, Axel. Radiografía de la educación argentina. Buenos Aires, Fundación CIPPEC, Fundación Arcor, Fundación Roberto Noble, 2010.

Rodino, Ana María. Educación para la vida en democracia: contenidos y orientaciones metodológicas, en Cuadernos Pedagógicos. Instituto Interamericano de Derechos Humanos (IIDH), 2002.

Savater, Fernando, El valor de educar. Barcelona, Editorial Ariel, Segunda edición, 1997.

Tamayo Valencia, Luis Alfonso, Tendencia de la pedagogía en Colombia, publicado por la Revista Educación y Ciencia. Bogotá, Colombia, 1991.

Tedesco, Juan Carlos. La educación en el marco del nuevo capitalismo, en Memorias del II Congreso Nacional de Educación Superior a Distancia. Medellín, Educación en la Globalización, 2000.

"Los pilares de la educación del futuro", en Debates de educación. Barcelona, Ponencia en línea, Fundación Jaume Bofill, 2003. <http://www.uoc.edu/dt/20367/index.html>. Fecha de consulta: 1/09/2011.

"La educación como clave para el desarrollo nacional". La Nación (Sección Educación), 25 de mayo de 2003.

Tenti Fanfani, Emilio. La escuela y la cuestión social. Ensayos de sociología de la educación. Buenos Aires, Siglo XIX, 2007.

Tiramonti, Guillermina. Incorporación y promoción de las mujeres en el circuito formal de educación nacional, en Desarrollo Económico, Vol. 35, Nº 138. Buenos Aires, IDES, Julio-septiembre, 1995.

(ed.) La trama de la desigualdad educativa: mutaciones recientes en la escuela media. Buenos Aires, FLACSO. Biblioteca del docente. Ediciones Manantial, 2004.

Tiramonti, Guillermina y Ziegler, Sandra. La educación de las elites. Aspiraciones, estrategias y oportunidades. Buenos Aires, Paidós, 2008.

Oficina Regional de Educación de la UNESCO para América Latina y el Caribe (OREALC/UNESCO). "El derecho a una educación de calidad para todos en América Latina y el Caribe", en Revista Electrónica Iberoamericana sobre Calidad, Eficacia y Cambio en Educación (REICE). Vol. 5 N 3 , Santiago, 2007. $<$ http://www.rinace.net/arts/vol5num3/art1_htm.htm $>$. Fecha de consulta: 1 de septiembre de 2011. 
Vanossi, Jorge Reinaldo. Universidad y Facultad de Derecho: sus problemas. Buenos Aires, Editorial Universitaria de Buenos Aires, 1989.

\section{De contexto}

Badeni, Gregorio. Tratado de Derecho Constitucional. Segunda edición actualizada y ampliada. La Ley, 2006, Tomo I.

Battro, Antonio y Piaget, Jean. Diccionario de epistemología genética. Editor Proteo. Traducido por Floreal Mazía, 1971.

Declaración de las Naciones Unidas sobre los derechos de los pueblos indígenas. Publicado por las Naciones Unidas. Marzo de 2008.

Dromi, Roberto y Menem, Eduardo. La Constitución reformada. Comentada, interpretada y concordada. Buenos Aires, Ediciones Ciudad Argentina, 1994.

Escudé, Carlos. "La transformación de las ecuaciones del realismo periférico en el siglo XXI", en Revista POSTData N ${ }^{\circ}$ 12, Agosto 2007.

Lobato, Mirta Zaida, "Los trabajadores en la era del progreso", Nueva Historia Argentina. Buenos Aires, Sudamericana, 2000, Tomo V.

¿Tienen derechos las mujeres? Politica y Ciudadanía en la Argentina del siglo XX. Buenos Aires, Colección dirigida por José Nun, Capital Intelectual, 2008.

Locke, John. Segundo tratado sobre el gobierno civil. Madrid, Alianza, traducción, prólogo y notas de Carlos Mellizo, 1991.

Piaget, Jean. Seis estudios de psicología. Volumen 2 de Colección Labor. Nueva Serie. Labor, Tercera Edición, 1994.

Quiroga Lavié, Humberto, Benedetti, Miguel Ángel y Cenicacelaya, María de las Nieves, Derecho Constitucional Argentino. Santa Fe-Buenos Aires, Rubinzal-Culzoni, 2001, Tomo I.

Toffler, Alvin. La tercera ola. Edición Décima, Madrid, Plaza y Janés, 1995.

Touraine, Alain. Un nuevo paradigma para comprender el mundo de hoy, Volumen 135 de Paidós Estado y sociedad, Editorial Paidós, 2005.

Zaid, Gabriel. El progreso improductivo. Océano, 1999. 


\section{De metodología}

Alcina Franch, José. Aprender a investigar. Métodos de trabajo para la redacción de tesis doctorales. Madrid, Compañía Literaria, 1994.

Botta, Mirta. Tesis, monografias e informes. Nuevas normas y técnicas d investigación y redacción. Buenos Aires, Biblos, 2002.

Cataldi, Zulma y Lage, Fernando J. Diseño y organización de tesis. Ciudad Autónoma de Buenos Aires, Nueva Librería, 2004.

Cea D'Ancona, María Ángeles. Metodología Cuantitativa. Estrategias y Técnicas de Investigación Social. Madrid, Editorial Síntesis, 1996.

Dei, H. Daniel. La tesis: cómo orientarse en su elaboración. Editorial Prometeo, 2006.

Eco, Umberto. Cómo se hace una tesis. Barcelona, Gedisa, 1998.

Gordillo, Agustín. El método en Derecho. Aprender, enseñar, escribir, crear, hacer. Civitas Ediciones, S.L., 2001.

Hernández Sampieri, Roberto, Fernández Collado, Carlos y Baptista Lucio, Pilar. Metodología de la investigación. México, Mc Graw Hill Interamericana, 2006.

Hughes, John; Utrilla De Neira, Mónica y Sharrock, Wes La filosofía de la investigación social. Fondo de Cultura Económica, 1999.

Mayntz, Renate; Holm, Kurt y Hübner, Meter. Capítulo 1, en Introducción a los métodos de la sociología empírica. Madrid, Alianza, 1993.

Mendicoa, Gloria Edel. Manual Teórico Práctico de Investigación Social. Apuntes preliminares. Buenos Aires, Segunda Edición, Espacio Editorial, 1998.

Sobre tesis y tesistas. Lecciones de enseñanza-aprendizaje. Buenos Aires, Segunda Edición. Espacio Editorial, 2003.

Parise, Agustín. La imperiosa remisión al Derecho Comparado en las investigaciones de carácter jurídico, en Revista Universitaria La Ley. Buenos Aires, 2002.

Prats, Joaquim. Técnicas y recursos para la elaboración de tesis doctorales: bibliografia y orientaciones metodológicas. Universitat de Barcelona. Departament de Didàctica de les Ciències Socials, 2004. 
Sabino, Carlos. Cómo hacer una tesis. Caracas, Editorial Panapo, 1994.

Samaja, Juan. Epistemología y Metodología. Elementos para una Teoría de la Investigación cientifica. Buenos Aires, EUDEBA, 2002.

Scavone, Graciela. Cómo se escribe una tesis. Buenos Aires, La Ley, 2002.

Sierra Bravo, Restituto. Tesis Doctorales y Trabajos de Investigación Científica. Madrid, Editorial Paraninfo, 1999.

Taborga, Huáscar. Cómo hacer una tesis. México D.F., Grijalbo, 1980.

Universidad Central de Venezuela. Manual para la elaboración de Tesis Doctorales, Trabajos de Grado y Trabajos Especiales. Primera edición según las observaciones realizadas en las V Jornadas de Autoevaluación del Centro de Estudios de Postgrado de la Facultad de Ciencias Jurídicas y Políticas (UCV), 2004.

Valles, Miguel. Técnicas cualitativas de Investigación Social. Síntesis Sociológica, Madrid, 1999.

\section{Consultada}

Acosta, Felicitas. "Escuelas medias y sectores populares: entre la eficacia y la ley, la moral y la cultura", en REICE. Revista Electrónica Iberoamericana sobre Calidad, Eficacia y Cambio en Educación, Vol. 4, №3. Madrid, España, Red Iberoamericana de Investigación sobre cambio y eficacia escolar, 2006.

Aguilar Hernández, Citlali y Schmelkes del Valle, Sylvia. "El estado de la enseñanza de la formación para la gestión y la política educativa en México", en Braslavsky, Cecilia y Acosta, Felicitas (orgs.), Estado de situación de la enseñanza de la gestión y la política educativa en América Latina. Buenos Aires, IIPE/UNESCO, 2001.

Agulla, Juan. Capítulo II: "El Estado: la integración de las sociedades nacionales". Capítulo VI: "La globalización: la agonía de las sociedades nacionales", en Globalización y agonía de las sociedades nacionales. Fundación Editorial de Belgrano, 1999.

Arendt, Hannah. Los orígenes del totalitarismo. Madrid, Taurus, 1998.

Austral, Rosario y Otero María Pía. Padres con la Escuela. Documento de circulación interna. Dirección de Investigación Educativa, Secretaría de Educación. (GCBA), 2002. 
Austral, Rosario, Dabenigno, Valeria, Goldenstein Jalif, Yamila, Iñigo, L. y Skoumal, G. Imágenes de futuros laborales. Horizontes sociales y personales de jóvenes escolarizados en el nivel medio de la Ciudad de Buenos Aires. Neuquén, IV Congreso Nacional y II Internacional de Investigación Educativa, Universidad Nacional del Comahue, 2007.

Austral, Rosario, Dabenigno, Valeria, Goldenstein Jalif, Yamila y otros. Valoraciones de la educación media y orientaciones de futuro. De estudiantes del último año de nivel medio de la Ciudad de Buenos Aires. Primer Informe. Informes de investigación de la Dirección de Investigación y Estadística del Ministerio de Educación del GCBA, 2009.

Baquero, Ricardo, Brisciol, Bárbara, Sburlatti, Santiago, Terigi, Flavio y Toscano, Ana G. Variaciones del Régimen Académico en Escuelas Medias con Población Vulnerable. Un Estudio de Casos en el Área Metropolitana de Buenos Aires, en REICE. Revista Iberoamericana sobre Calidad, Eficacia y Cambio en Educación. Volumen 7, Número 4, 2009.

Bauman, Zygmunt. Perspectivas para los nuevos pobres, en Modernidad líquida. México, Espiral, Universidad de Guadalajara, 2004.

Bidegain, Carlos M. Curso de Derecho Constitucional, Tomo II. Buenos Aires, AbeledoPerrot, 1995.

Biscaretti di Ruffia, Paolo. Introducción al Derecho Constitucional Comparado. México D.F., Fondo de Cultura Económica, 1996.

Boaventura de Sousa, Santos. Reinventar la democracia. Reinventar el Estado. CLACSO, 2006.

Bobbio, Norberto. El futuro de la democracia. Barcelona, Plaza y Janés, 1989. Liberalismo y democracia. México D.F., Fondo de Cultura Económica, 1989.

Borón, Atilio. Capítulo XI. "Filosofía política y crítica de la sociedad burguesa: el legado teórico de Karl Marx", en Borón, Atilio, La filosofía política moderna. De Hobbes a Marx. Ciudad Autónoma de Buenos Aires, Argentina, CLACSO, 2000.

Braslavsky, Cecilia La discriminación educativa en Argentina. Buenos Aires, FLACSO-Miño y Dávila, 1985. Autonomía y anomia en la educación pública argentina. Buenos Aires, FLACSO, 1993. Re-haciendo escuelas: hacia un nuevo paradigma en la educación latinoamericana. Buenos Aires, Santillana/Convenio Andrés Bello, 1999. 
Braslavsky, Cecilia y Acosta, Felicitas La formación en competencias para la gestión y la política educativa: un desafío para la educación superior en América Latina. En REICE. Revista Electrónica Iberoamericana sobre calidad, eficacia y cambio en Educación. Vol. 4, No 2e, 2006.

Braslavsky, Cecilia y Birgin, Alejandra. ¿Quiénes enseñan hoy en Argentina?, en Tiramonti, Guillermina et al., Las transformaciones de la educación en diez años de democracia. Buenos Aires, Tesis/Norma, 1995.

Braslavsky, Cecilia y Krawczyk, Nora. La escuela pública. Buenos Aires, Miño y Dávila, 1988.

Brunner, José Joaquín y Puryear, Jeff. Educación, equidad y competitividad económica en las Américas. Washington, Organización de los Estados Americanos (OEA), 1994.

Bunge, Mario A. Diccionario de filosofía. Editor Siglo XXI, $3^{\text {a }}$ edición, 2005.

Burdeau, Georges. La Democracia. Barcelona, Ariel, 1960.

Butelman, Ida (comp.) Pensando las instituciones. Sobre teorías y prácticas en educación. Editor Paidós, 1996.

Caillods, Françoise. ¿Aumentar la participación en la educación secundaria en América latina? Diversificación y equidad, en Braslavsky, Cecilia (org.), La educación secundaria. ¿Cambio o inmutabilidad? Buenos Aires, Santillana/IIPE/UNESCO, 2001.

Carnoy, Martín; Cosse, Gustavo y Martinez, Enrique. Las lecciones de la reforma educativa en el Cono Sur. Estudio comparativo de Argentina, Chile y Uruguay en la década de 1990. Ministerio de Educación de Argentina/Ministerio de Educación de Chile/ANEP Uruguay/Universidad de Stanford/BID, 2001.

Carré de Malberg, Raymond. Teoría General del Estado. México D.F., Fondo de Cultura Económica, 1948.

Casassus, Juan. Marcos conceptuales para el análisis de los cambios en la gestión de los sistemas educativos, en UNESCO, La gestión en busca del sujeto. Santiago de Chile, UNESCO, 1999.

Problemas de la gestión educativa en América Latina (la tensión entre los paradigmas de tipo A y el tipo B). Santiago de Chile, UNESCO, 2000. 
Chaui, Marilena. Capítulo IV. "Spinoza: poder y libertad”, en Borón, Atilio A., La filosofía política moderna. De Hobbes a Marx. Ciudad Autónoma de Buenos Aires, Argentina, CLACSO, 2000.

Chomsky, Noam. Neoliberalismo y globalización, Ediciones Universidad de la Frontera, 2009.

Claude, Richard. Derecho a la educación y educación para los derechos humanos, en SUR. Revista Internacional de Derechos Humanos. Revista semestral publicada en inglés, portugués y español por Sur - Red Universitaria de Derechos Humanos. Año 2. Número 2. Edición en Español, 2005.

Coll, César. La misión de la escuela y su articulación con otros escenarios educativos: reflexiones en torno al protagonismo y los límites de la educación escolar, en VI Congreso Nacional de Investigación Educativa. Conferencias Magistrales. México, Consejo Mexicano de Investigación Educativa, 2003.

Corrales, Javier. Aspectos politicos en la implementación de las reformas educativas. Santiago de Chile, PREAL, 1999.

Dabenigno, Valeria, Iñigo, Luisa y Skoumal, Gladys. Inserción ocupacional y continuidad educativa de los egresados recientes de escuelas con modalidad comercial de la Ciudad de Buenos Aires. Dirección de Investigación. Ministerio de Educación (GCBA), 2005.

Dalla Via, Alberto, Graña, Eduardo, Sisinni, Nicolás y Basterra, Marcela. Manual de teoría del Estado y del Gobierno. Buenos Aires, Fundación Editorial de Belgrano, Universidad de Belgrano, 1999.

De Mattos, Carlos. La descentralización, ¿una nueva panacea para enfrentar el subdesarrollo regional? Revista Paraguaya de Sociología, 26 (74), 1989.

Delors, Jacques. Capítulo 2. "De la cohesión social a la participación democrática", en La educación encierra un tesoro. Volumen 64 de Aula XXI, Comisión Internacional sobre la Educación para el Siglo XXI, UNESCO, Santillana, 1996.

Duverger, Maurice. Instituciones Politicas y Derecho Constitucional. Barcelona, Ariel, 1980. 
Del Cueto, Carla Muriel. Fragmentación social y nuevos modelos de socialización: estrategias educativas de las nuevas clases medias. Informe final del concurso: Fragmentación social y crisis política e institucional en América latina y el Caribe. Programa regional de becas, CLACSO, 2002.

Los únicos privilegiados. Estrategias educativas de las nuevas clases medias. Tesis de Maestría, Instituto de Altos Estudios Sociales, Universidad Nacional de General San Martín, 2003.

Di Gropello, Emanuela. Descentralización de la educación en América latina: un análisis comparativo. Serie Reformas de Política Pública 57. Santiago de Chile, CEPAL, 1987.

Dubet, François y Martuccelli, Danilo. En la escuela. Sociología de la experiencia escolar. Buenos Aires, Losada, 1997.

Durkheim, Émile. La Educación Moral. Madrid, Ediciones Morata, 2002.

Duschatzky, Silvia. La escuela como frontera. Reflexiones sobre la experiencia escolar de jóvenes de sectores populares. Buenos Aires, Paidós, 1999.

Dussel, Inés y Southwell, Myriam. ¿Qué y cuánto puede una escuela? Límites y posibilidades de la acción escolar, en Revista El monitor de la educación. $\mathrm{N}^{\mathrm{o}} 25.5^{\text {ta }}$ época. Ministerio de Educación. Presidencia de la Nación, 2010. www.me.gov.ar/monitor.

Eagleton, Ferry. Marx y la libertad. Santa Fe de Bogotá, Editorial Norma. Traducido por Germán Saavedra Soler, 1999.

Fayt, Carlos. Teoría de la Política en el Siglo XXI. La Política, el Poder y el Estado. La democratización de la democracia, La Ley. Buenos Aires, 2002.

Ferry, Giles. Pedagogía de la formación. Volumen 6 de Formación de Formadores: Serie Los Documentos. Facultad de Filosofía y Letras - Universidad de Buenos Aires. Novedades Educativas, 1997.

Friedrich, Carl. Teoría y realidad de la organización constitucional democrática. México D.F., Fondo de Cultura Económica, 1946.

La democracia como forma política y como forma de vida. Madrid, Tecnos, 1966.

Freire, Paulo Pedagogía del oprimido. Buenos Aires, Editorial Tierra Nueva y Siglo XXI Argentina Editores, 1970.

La educación permanente. Procedencia del original Universidad de Texas, 1980.

Pedagogía de la autonomía. Editorial Paz y Tierra S.A., 2004. 
Filmus, Daniel. La escuela media frente al mercado de trabajo: cada vez más necesaria, cada vez más insuficiente, en Braslavsky, Cecilia (ed.), La educación secundaria. ¿Cambio o inmutabilidad? Análisis y debate de procesos europeos y latinoamericanos contemporáneos. Buenos Aires, Santillana, 2001.

La reforma de la educación secundaria. Biblioteca virtual universal, 2003.

La función de la Escuela Media frente a la crisis del mercado de trabajo en Argentina. Ponencia pronunciada en el marco del Seminario Desafios de la Educación Secundaria en Francia y en los países del Cono Sur organizado por el Ministerio de Educación, Ciencia y Tecnología y la Embajada de Francia en la Argentina (Buenos Aires), 2003.

Filmus, Daniel; Miranda, Ana y Otero, Analía. La construcción de trayectorias laborales entre los jóvenes egresados de la escuela secundaria, en Jacinto, C. (coord.) ¿Educar para qué trabajo? Discutiendo rumbos en América Latina. Buenos Aires, La Crujía, MTSS, Ministerio de Educación, Ciencia y Tecnología, REDETIS, 2004.

Filmus, Daniel y Moragues, Mariana. ¿Para qué universalizar la educación media? en Tenti Fanfani, Emilio (ed), Educación media para todos. Los desafios de la democratización del acceso. Buenos Aires, Grupo Editor Altamira, 2003.

Gallart, María Antonia en colaboración con Cerrutti, M. y Moreno, M. La educación para el trabajo en el MERCOSUR. Situación y desafios. OEA, 1994.

La construcción social de la escuela media. Una aproximación institucional. Buenos Aires, La Crujía Ediciones, 2006.

García Canclini, Norberto. Diferentes, desiguales y desconectados. Mapas de la interculturalidad. Editorial Gedisa, 2004.

García Pelayo, Manuel. Derecho constitucional comparado. Madrid, Alianza, 1984.

Gargarella, Roberto. Nos los representantes. Buenos Aires, Crepp, 1995.

Geertz, Clifford. Los usos de la diversidad. Volumen 44 de Pensamiento contemporáneo. Universidad Autónoma de Barcelona, Ediciones Paidós, 1996.

Giddens, Anthony. Consecuencias de la Modernidad. Madrid, Alianza Universidad, 1994.

Gil, Beatriz y Tringaniello, Norma. El Secretario en una escuela bien pensada. Magisterio del Río de la Plata, Editorial y Distribuidora Lumen SRL, 2008.

Gómez, Albino. Sarmiento y la educación siglo XXI, en Revista Noticias, Buenos Aires, 19 de febrero de 2011. 
Hargreaves, Andy; Earl, Lorna y Ryan, Jim. Una educación para el cambio. Reinventar la educación de los adolescentes. Ediciones Octaedro SL, 1998.

Heller, Hermann. Teoría del Estado. México D.F., Fondo de Cultura Económica, 1992.

Herrnstein, Richard y Murray, Charles. The Bell Curve: Intelligence and Class Structure in American Life. Simon and Schuster, 1995.

Jacinto, Claudia. Los protagonistas de la expansión de la educación secundaria: mayor esfuerzo educativo, difícil inserción laboral, en Revista Anales de la Educación Común, Dirección Provincial de Planeamiento de la Dirección General de Cultura y Educación de la Provincia de Buenos Aires, 2006.

Kantor, Débora. La escuela media desde la perspectiva de los alumnos. Subsecretaría de Educación, Dirección General de Planeamiento, GCBA, 2000.

Kelsen, Hans. Teoría pura del derecho. Buenos Aires, EUDEBA, 1975.

Kessler, Gabriel La experiencia escolar fragmentada. Estudiantes y docentes en la escuela media en Buenos Aires. Universidad Nacional de General Sarmiento CONICET, IIPE UNESCO, 2002.

Lanza, Mariela. Unos 120 mil jóvenes debatieron sobre mejoras en el secundario. Parlamento Juvenil del Mercosur. Ministerio de Educación. Presidencia de la Nación, en Revista El monitor de la educación. $\quad \mathrm{N}^{\mathrm{o}} 28, \quad 5^{\circ}$ época, 2011. Disponible en: $<$ www.me.gov.ar/monitor>.

Lazzarini, José. Reafirmación de los partidos políticos. Anuario Jurídico IX, Instituto de Investigaciones Jurídicas. México D.F., U.N.A.M., 1982. Constitución de la Provincia de Buenos Aires. Buenos Aires, Astrea, 1994.

Lijphart, Arend. Las democracias contemporáneas. Barcelona, Ariel, 1961.

Loewenstein, Kart. Teoría de la Constitución. Barcelona, Ariel, 1983.

Lukács, Georg. El hombre y la democracia. Buenos Aires, Contrapunto S.A., 1985.

Martínez, Carlos y Roca, Leandro. Gratuidad y normatividad: un análisis desde la filosofía del derecho en torno a la gratuidad de la educación universitaria. Departamento de Desarrollo Docente de la Facultad de Derecho de la Universidad de Buenos Aires, 2009.

Melgoza Magaña, María Eugenia. (coordinadora) Adolescencia: espejo de la sociedad actual. Grupo Editorial Lumen, 2002. 
Melo Salcedo, Ileana. La participación política para construir una democracia a través del derecho fundamental a la educación en América Latina y el Caribe, en Derechos humanos, relaciones internacionales y globalización. Bogotá, Grupo Editorial Ibáñez, 2006

Miranda, Ana; Otero, Analía y Corica, Agustina. Tendencias en el tránsito entre la educación secundaria y el mundo del trabajo en el Gran Buenos Aires, Neuquén y Salta. Publicación en CD, $8^{\circ}$ Congreso Nacional de Estudios del Trabajo, organizado por la Asociación Argentina de Especialistas en Estudios del Trabajo, Buenos Aires, 8 al 10 de Agosto de 2007.

Nagel, Thomas. Igualdad y parcialidad. Buenos Aires, Paidós, 2000.

Nietzsche, Friedrich. Cinco conferencias. Barcelona, Tusquets. Traducción de Carlos Manzano, 2000.

Nino, Carlos. Fundamentos de Derecho General. Análisis filosófico, jurídico y politológico de la práctica constitucional. Buenos Aires, Editorial Astrea, 2000.

Nun, José. Democracia ¿Gobierno del pueblo o gobierno de los políticos? México D.F., Fondo de Cultura Económica, 2002.

Palamidessi, Mariano I. El currículum para la escuela primaria argentina: continuidades y cambios a lo largo de un siglo, en Terigi, Flavia (comp.), Diez miradas sobre la escuela primaria. Buenos Aires, Fundación OSDE/Siglo XXI, 2006.

Pérez Royo, Javier. Curso de Derecho Constitucional, Madrid-Barcelona, Marcial Pons, 1998.

Pineau, Pablo, Historia y política de la educación argentina. Buenos Aires, Ministerio de Educación de la Nación, 2010.

Puiggrós, Adriana, Imaginación y crisis en la educación latinoamericana. Rei Argentina S.A. Aique Grupo Editor S.A., Segunda edición, 1994.

Puiggrós, Adriana y Gagliano, Rafael (coord). La fábrica del conocimiento. Los saberes socialmente productivos en América Latina. Rosario, Homo Sapiens, 2004.

Ramos Pascua, José. La ética interna del Derecho. Democracia, derechos humanos y principios de justicia. Editorial Desclée de Brouwer S.A., 2007. 
Rawls, John. Teoría de la justicia. Editor Fondo de Cultura Económica, Segunda edición, 2006.

Riquelme, Graciela y Razquin, Paula. Mercado de trabajo y educación: el papel de la educación en el acceso al empleo, en Revista de Ciencias Sociales. Año 12. № 16. Departamento de Sociología. Facultad de Ciencias Sociales. Fundación de Cultura Universitaria. Montevideo. Uruguay. Noviembre, 1999.

Robert, Paul. La Educación en Finlandia: Los secretos de un éxito asombroso. Centro Virtual de Noticias (CVN), 2006.

Rousseau, Jean J. Contrato social. Madrid, Aguilar, 1973.

Sábato, Jorge F. La clase dominante en la Argentina moderna. Buenos Aires, Segunda edición, Colección CISEA, 1991.

Sánchez Viamonte, Carlos. El Poder Constituyente. Buenos Aires, Editorial Bibliográfica Argentina, 1957.

Sartori, Giovanni, Teoría de la Democracia. Madrid, Alianza, 1988. Elementos de Teoría Politica. Madrid, Alianza, 2007.

Schmitt, Carl. La defensa de la Constitución. Madrid, Tecnos, 1983. Teoría de la Constitución. Madrid, Alianza, 1992. Legalidad y legitimidad. Buenos Aires, Struhart \& Cía, 1994.

Sevane, José; Taddei, Emilio y Algranati, Carla. Las nuevas configuraciones de los movimientos populares en América Latina. Buenos Aires, CLACSO, 2006.

Sidicaro, Ricardo y Tenti Fanfani, Emilio. La Argentina de los jóvenes. Entre la indiferencia y la indignación. Buenos Aires, UNICEF / Losada, 1998.

Sieyes, Emmanuel. Escritos Políticos. México D.F., Fondo de Cultura Económica, 1993.

Svampa, Maristella y otros. Desde abajo. La transformación de las identidades sociales. Universidad Nacional de General Sarmiento, Editorial Biblos, 2000. Fragmentación espacial y procesos de integración social "hacia arriba”. Socialización, sociabilidad y ciudadanía. México, Espiral, Universidad de Guadalajara, 2004. 
Tedesco, Juan Carlos. Educar en la sociedad del conocimiento, Fondo de Cultura Económica de Argentina S.A., 2000.

Educación y hegemonía en el nuevo capitalismo: algunas notas e hipótesis de trabajo. En: Revista de Educación, número extraordinario, 2001.

Ley y pacto educativo: un análisis del caso argentino. En: Revista de Educación $N^{o} 344$, septiembre-diciembre 2007.

Gobierno y dirección de los sistemas educativos en América Latina. $1^{\text {a }}$ reunión del grupo de expertos de la OEI sobre "Reformas educativas". Documento de trabajo interno. Ciudad de México, mayo de 2007.

Opiniones sobre politica educativa (Reportajes). Buenos Aires, Ediciones Granica S.A., 2008 .

Terrén, Eduardo. Educación y empleo, en Fernandez Enguita, Mariano (comp), Sociología de las instituciones de educación secundaria. Barcelona, IICE, Horsori, 1997.

Touraine, Alain. ¿Qué es la democracia? México D.F., Fondo de Cultura Económica, 1994.

Vanossi, Jorge Reinaldo. Teoría Constitucional. Buenos Aires, Desalma, 1975. El Estado de Derecho en el Constitucionalismo Social. Buenos Aires, EUDEBA, 2000.

Várnagy, Tomás. Capítulo II. "El pensamiento político de John Locke y el surgimiento del liberalismo", en Borón, Atilio A., La filosofía política moderna. De Hobbes a Marx. Ciudad Autónoma de Buenos Aires, Argentina, CLACSO, 2000.

Veleda, Cecilia. Estrategias individuales y familiares en la elección de las instituciones de educación superior, en Kisilevsky, Marta y Veleda Cecilia, Dos estudios sobre el acceso a la educación superior en la Argentina. Buenos Aires, IIPE-UNESCO, 2002. Efectos segregatorios de la oferta educativa. El caso del conurbano bonaerense. Documento de Trabajo No 5, Centro de Implementación de Políticas Públicas para la Equidad y el Crecimiento (CIPPEC), 2005. 


\section{ANEXOS}

Constituyen la parte complementaria de esta tesis. Su incorporación está relacionada con aquellas consideraciones que se estiman necesarias a fin de aclarar y mejorar. Asimismo, responden a lo que se indicó en el cuerpo principal. Aquí se incluyeron cartas introductorias, cuestionarios y documentos. 


\section{Carta Introductoria}

Joven estudiante:

Estamos trabajando en una investigación que servirá para elaborar una tesis acerca de la educación media estatal en el Distrito de Junín. Los resultados de la misma serán útiles para conocer temas de actualidad importantes relacionados con la educación.

Quisiéramos pedir tu ayuda para que contestes algunas preguntas que no llevarán mucho tiempo. Tus respuestas serán confidenciales y anónimas.

Los educandos que fueron seleccionados para la investigación no se eligieron por su nombre sino al azar.

Las opiniones de todos los encuestados serán sumadas e incluidas en la tesis pero nunca se comunicarán datos individuales.

Te pedimos que contestes este cuestionario con la mayor sinceridad posible.

Lee las instrucciones cuidadosamente y, desde ya,

¡muchas gracias por tu colaboración! 


\section{Cuestionario (egresados)}

\section{Datos demográficos:}

Sexo:

Edad:

Nacionalidad:

Nivel socioeconómico (alto, medio o bajo):

Estado civil:

Barrio o zona donde vivís actualmente:

Actividad laboral que realizás:

¿hace cuánto tiempo?

¿desde qué edad?

¿Practicás algún deporte al menos una vez a la semana? ¿Cuál?

¿Qué año y modalidad cursás en 2010?

¿Repetiste algún año desde el primario (EGB) hasta hoy? ¿cuál/es?

En las preguntas 1 a 10 marcá la o las opciones elegidas con una cruz (X). Tus respuestas serán anónimas y absolutamente confidenciales.

1. ¿Por/para qué cursás el secundario?

Porque necesito aprobar este nivel para seguir estudios superiores

Para adquirir conocimientos que me sean útiles para el trabajo que estoy realizando

Porque el título secundario me permitirá conseguir trabajo y así tener una vida digna y respetable

Para ampliar mis conocimientos, para saber más

Porque adquirir conocimientos me permitirá desenvolverme mejor en la sociedad

Para ser "alguien" en la vida

Porque en la escuela la paso bien (tengo compañeros/amigos)

Para no estar en la calle

Porque en mi casa me dijeron "o estudiás o trabajás"

Otra/s (especificar) 
2. ¿Cuántas horas diarias estudiás?

\begin{tabular}{|c|}
\hline Ninguna \\
\hline Entre 1 y 2 horas \\
\hline Más de 2 horas \\
\hline Me basta con atender las explicaciones del profesor en clase \\
\hline Cuando hay examen todo lo necesario \\
\hline Otra/s (especificar) \\
\hline
\end{tabular}

3. ¿Cuál/cuáles de los siguientes servicios que presta la biblioteca utilizaste durante 2010 ?

Entré a consultar algún libro

Entré a consultar algún periódico

Entré a consultar alguna revista

Entré a hacer un trabajo

Entré a utilizar la computadora

Entré a estudiar

No entré

Otra/s (especificar)

4. ¿Qué opinás del Acuerdo Institucional de Convivencia?

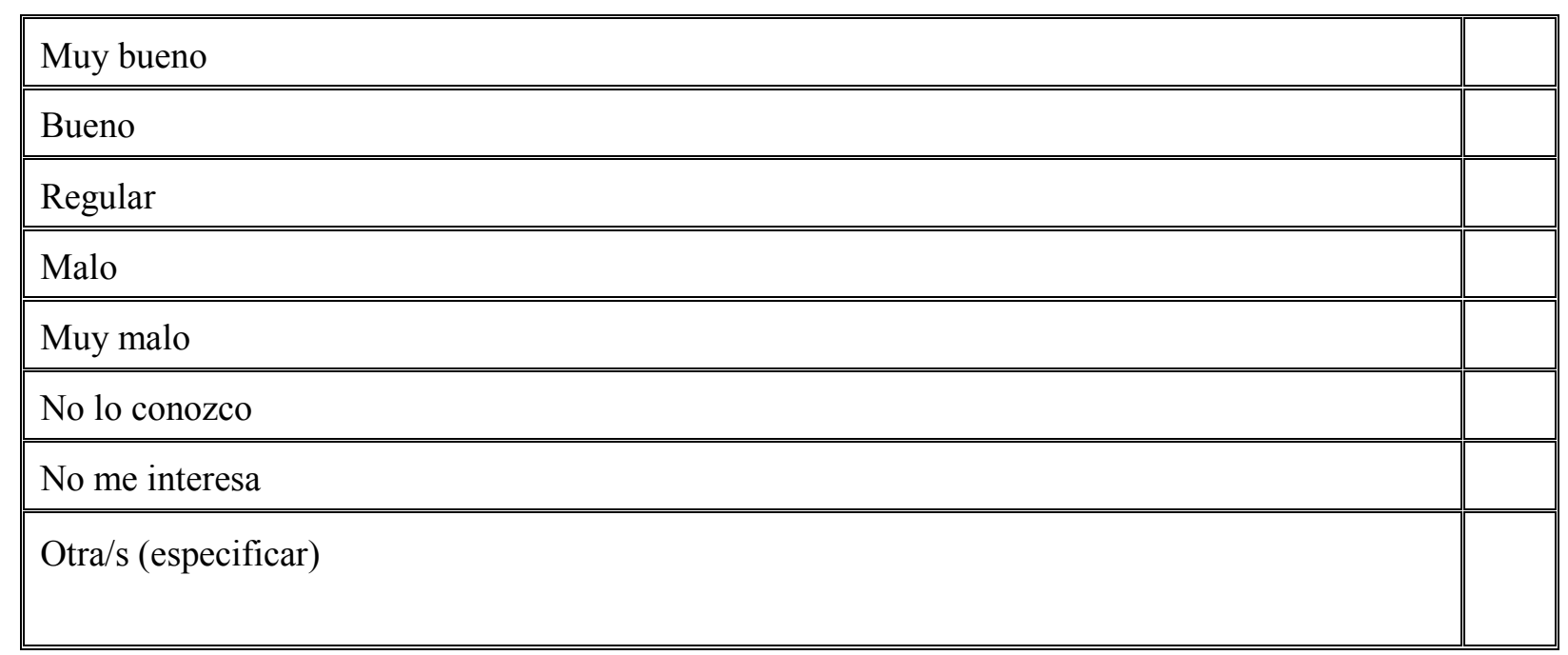


5. ¿Cuál/cuáles son los temas que frecuentemente aparecen en las conversaciones de los egresados?

\begin{tabular}{|c|}
\hline Corrupción \\
\hline Deportes \\
\hline Desempleo \\
\hline Drogadicción \\
\hline Inflación \\
\hline Inseguridad \\
\hline Pobreza \\
\hline Política \\
\hline Prostitución \\
\hline Religión \\
\hline Vida social \\
\hline Otra/s (especificar) \\
\hline
\end{tabular}

6. ¿En qué actividades o espacios organizados por la escuela participaste con la finalidad de adoptar una decisión respecto de tu futuro (estudio y/o trabajo)?

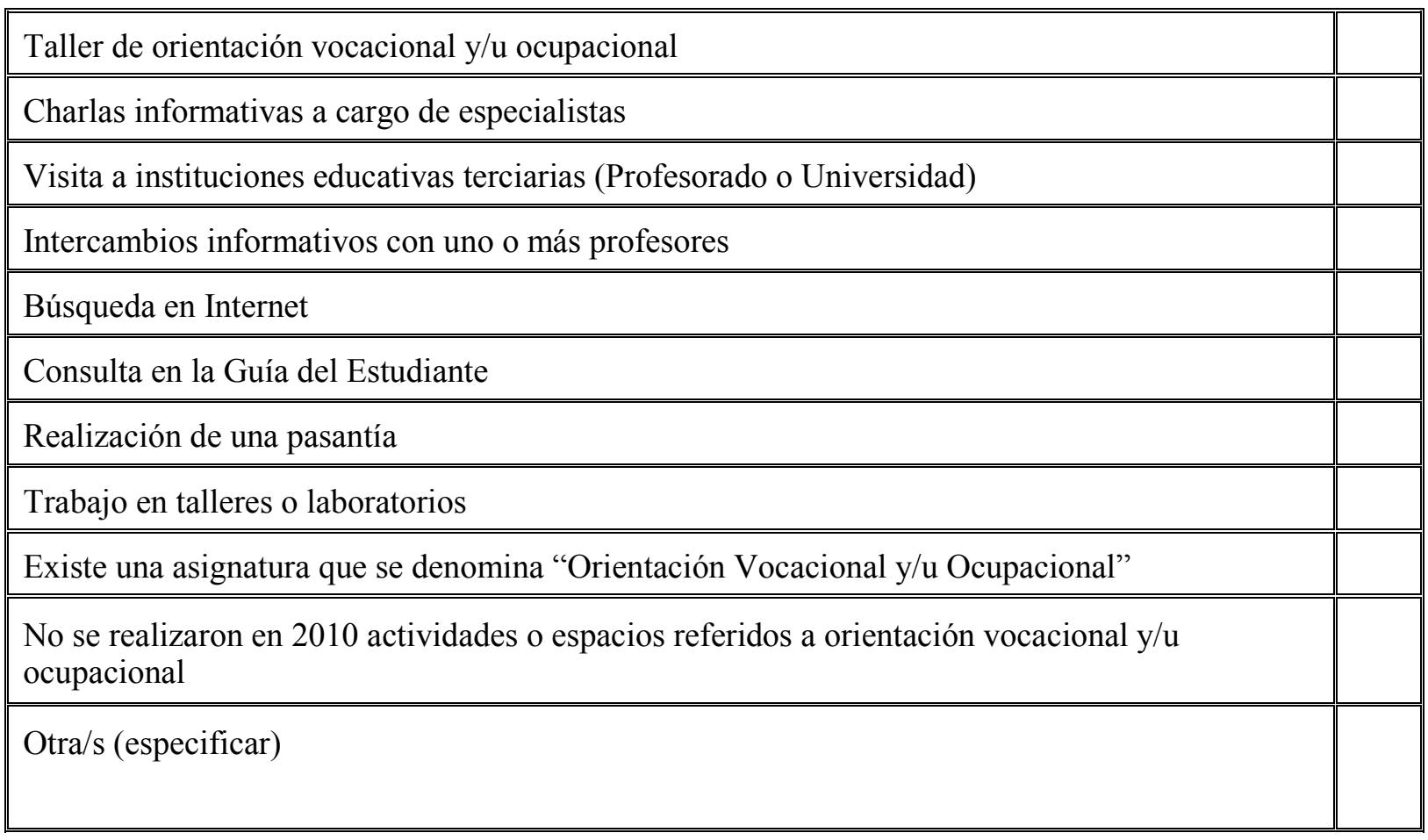


7. ¿A qué se debió, finalmente, tu decisión?

A las actividades o espacios que organizó la escuela

A las sugerencias del grupo familiar

A las conversaciones con el grupo de compañeros/amigos

A gustos o preferencias propias

Otra/s (especificar)

8. ¿De qué fuente te valés para adquirir la información y el conocimiento?

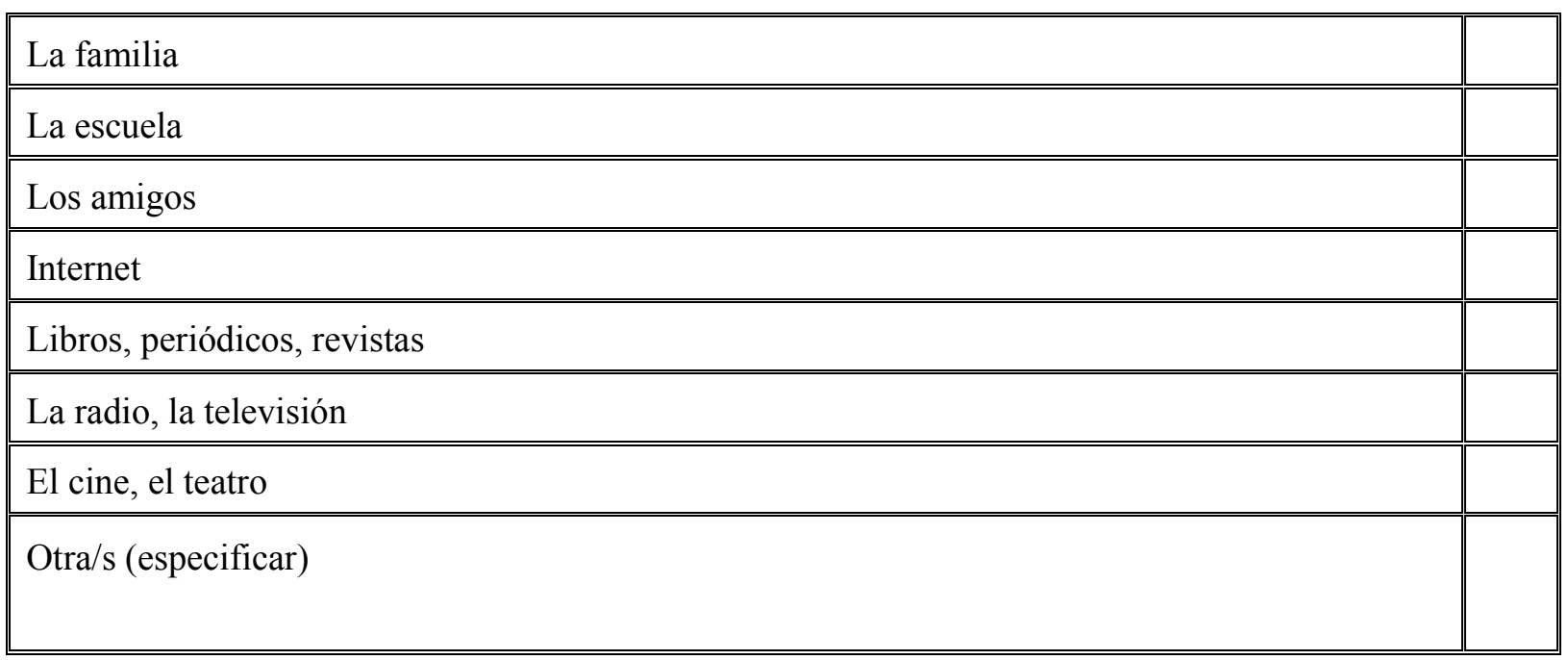

9. ¿De quién/es es la responsabilidad de impartir la educación para todos los habitantes en Argentina?

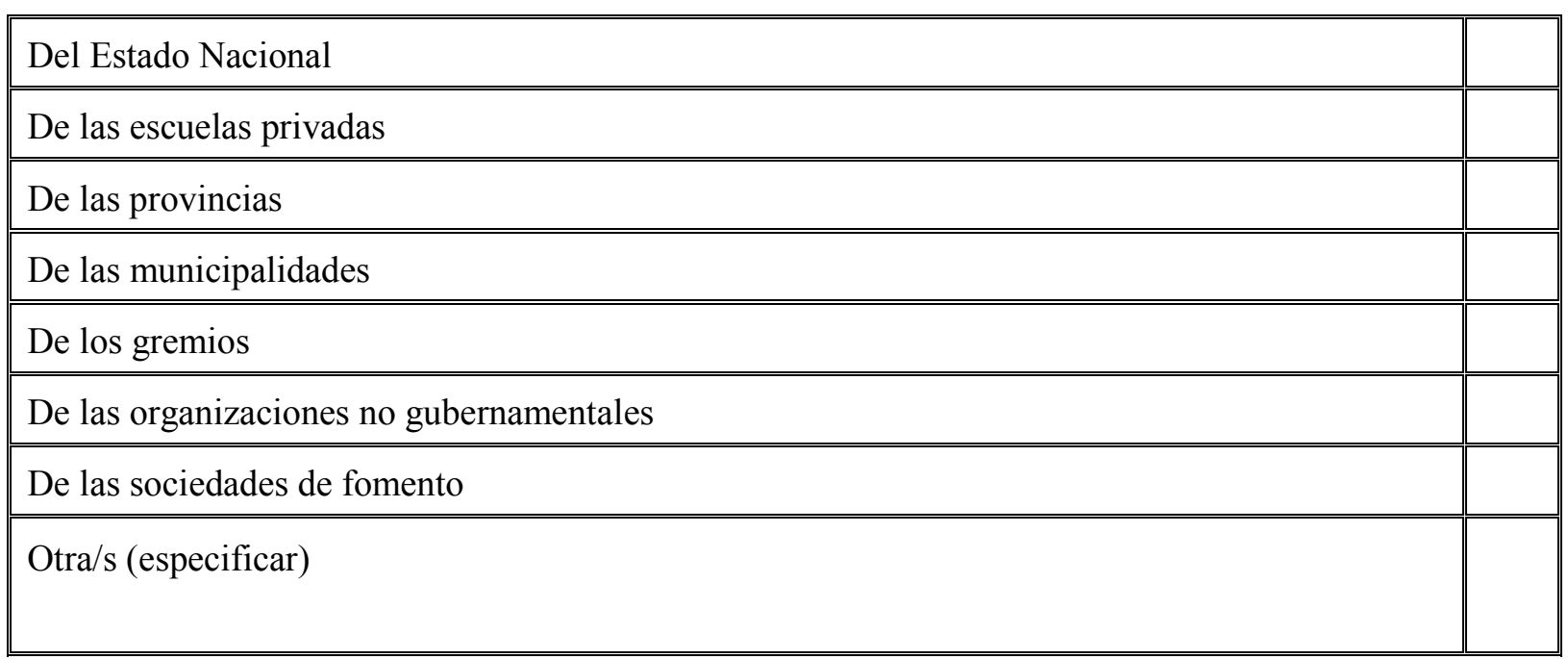


10. ¿Dónde está reconocido el derecho a la educación?

En la Constitución Nacional

En uno o más Tratados Internacionales de Derechos Humanos con jerarquía constitucional

En una Ley Nacional

En la Constitución de la Provincia de Buenos Aires

En una Ley de la Provincia de Buenos Aires

En una Ordenanza Municipal del Partido de Junín

En todo lo anteriormente dicho

En nada de lo anteriormente dicho

Otra/s (especificar)

En las preguntas 11 a 14 marcá la opción correcta con una cruz (X).

11. Indicar cuál de las siguientes frases no tiene error de ortografía:

El aula y el patio está vacío

El aula y el patio están vacías

El aula y el patio están vacíos

El aula y el patio está vacía

No sabe/No contesta

12. Sabiendo que una cassette de 60 minutos de duración tiene 90 metros de cinta, ¿cuántos metros de cinta serán utilizados para una grabación de un cuarto de hora?

\begin{tabular}{|l||l||}
\hline 0,375 metros & \\
\hline 6 metros & \\
\hline 22,50 metros & \\
\hline 360 metros & \\
\hline No sabe/No contesta & \\
\hline
\end{tabular}


13. Juan y Rodrigo decidieron ahorrar para comprar una guitarra eléctrica. Si Juan reunió el triple de dinero que Rodrigo y entre los dos juntaron $\$ 2.040$, ¿cuál es el aporte de Rodrigo?

\begin{tabular}{|l||l||}
\hline$\$ 1.530$ & \\
\hline$\$ 1.020$ & \\
\hline$\$ 680$ & \\
\hline No sabe/No contesta & \\
\hline \hline
\end{tabular}

14. En un saco hay 15 bolillas blancas y 7 bolillas negras. Si se extrae una al azar, ¿cuál es la probabilidad de extraer una bolilla negra?

\begin{tabular}{|l||l||}
\hline $7 / 15$ & \\
\hline $7 / 22$ & \\
\hline $22 / 7$ & \\
\hline $1 / 22$ & \\
\hline No sabe/No contesta & \\
\hline
\end{tabular}

15. Indicá el siglo en el que se produjeron los siguientes acontecimientos

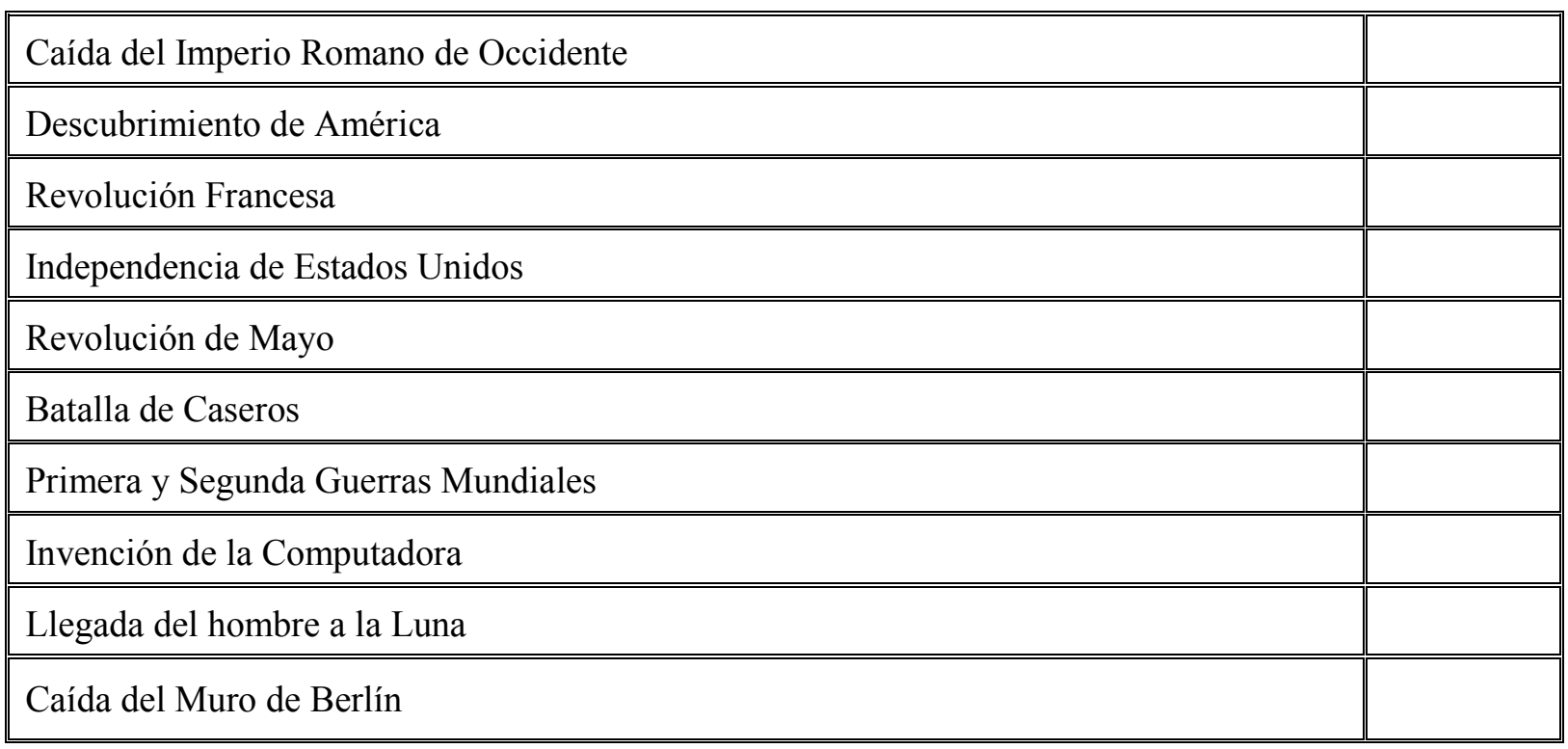


En las preguntas 16 a 23 marcá la o las opciones elegidas con una cruz (X).

16. ¿Cuál/es son sinónimos de la palabra "aprehender”?

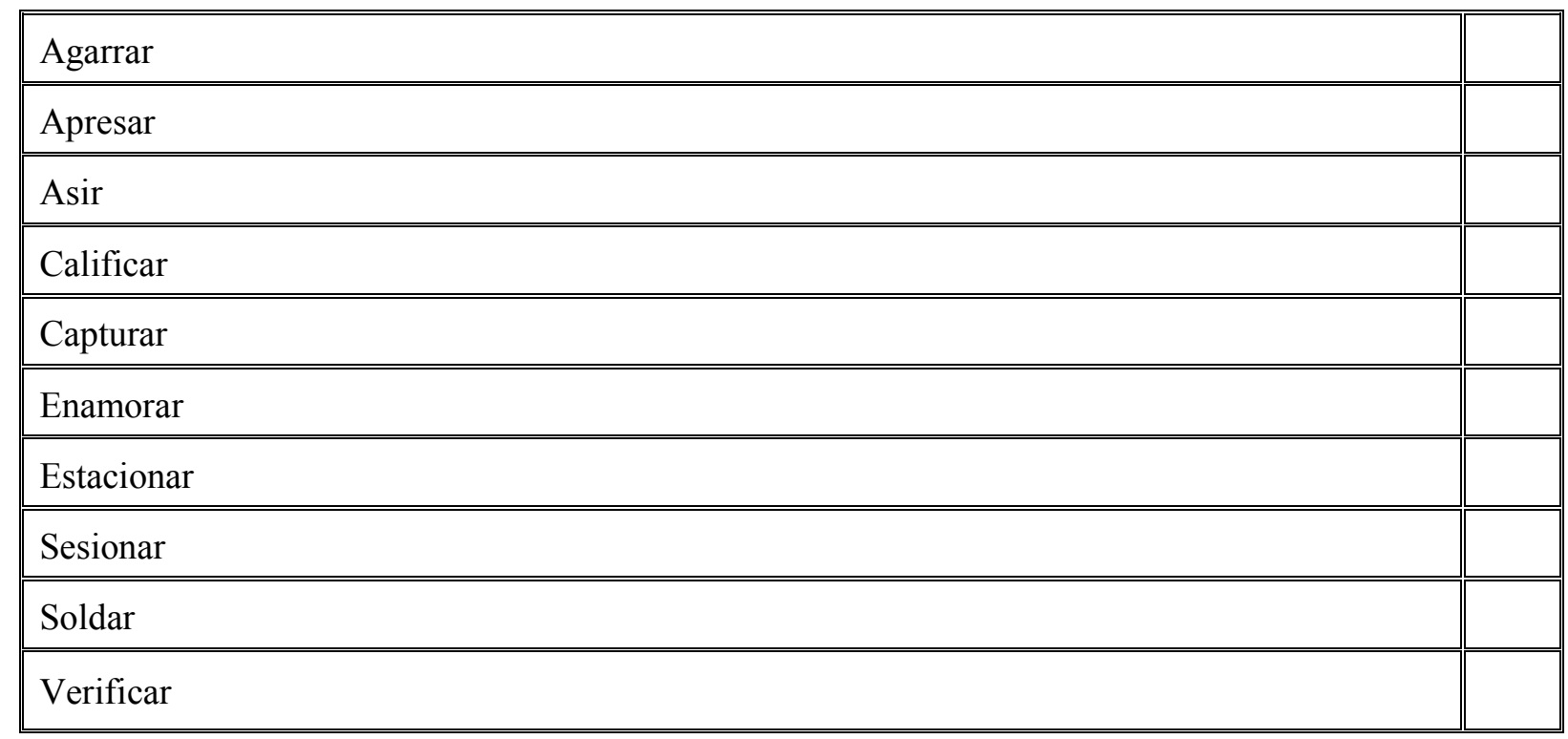

17. ¿Cuál/es son sinónimos de la palabra "investigar”?

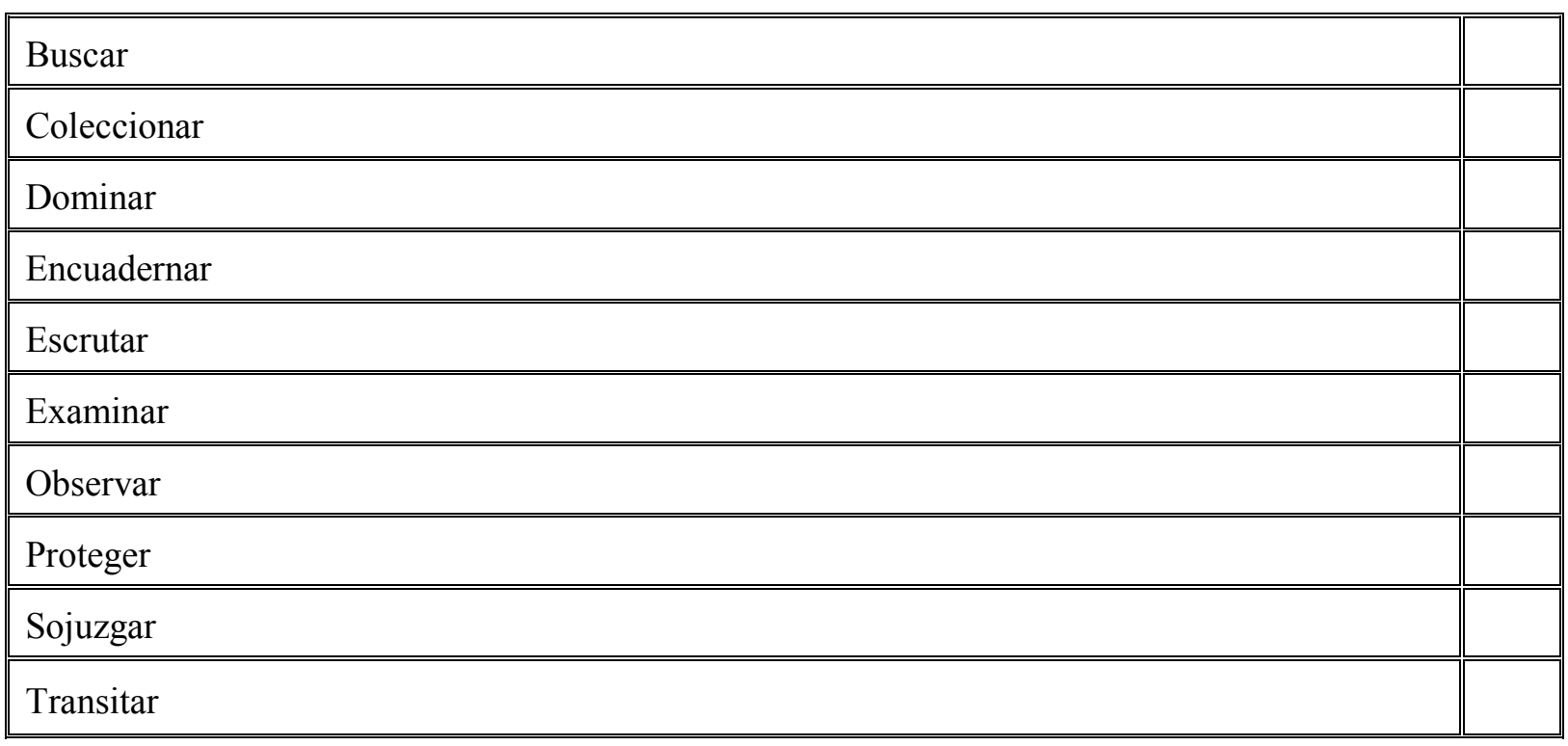


18. ¿Qué harías una vez finalizado el nivel medio?

\begin{tabular}{|l||l||}
\hline Estudiar y trabajar & \\
\hline \hline Estudiar solamente & \\
\hline \hline Trabajar solamente & \\
\hline Constituir una familia & \\
\hline Establecer relaciones de pareja & \\
\hline Hacer uso del tiempo libre & \\
\hline Adquirir algunos bienes materiales & \\
\hline Nunca pensé en metas u objetivos a futuro & \\
\hline Otro/s (especificar) & \\
\hline
\end{tabular}

19. ¿Dónde trabajarías?

Empresa privada

Gobierno

Por cuenta propia (independiente)

20. ¿Qué obstáculo/s deberías sortear para que se cumpla tu meta laboral?

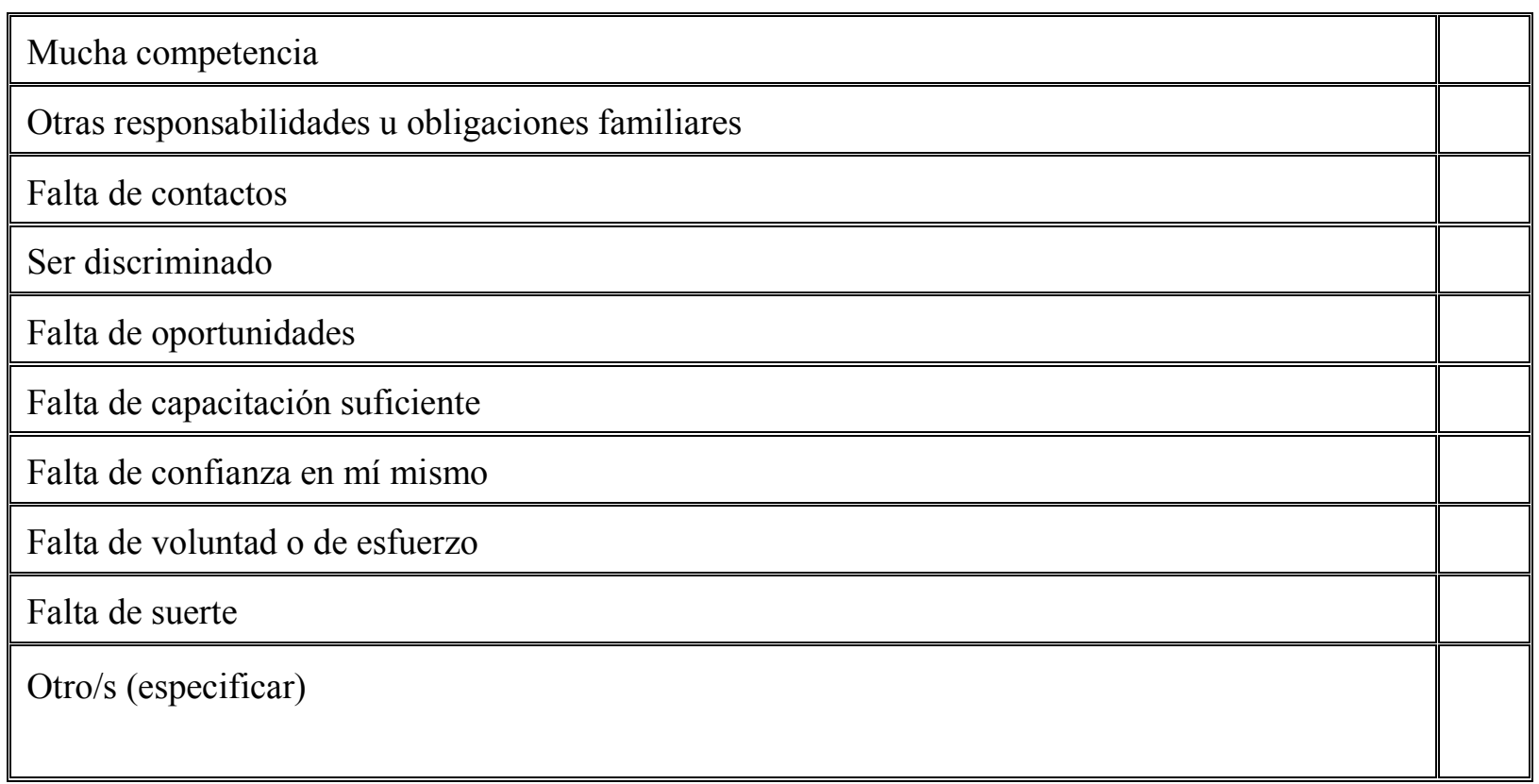


21. ¿Qué estudio superior estarías dispuesto/a a seguir?

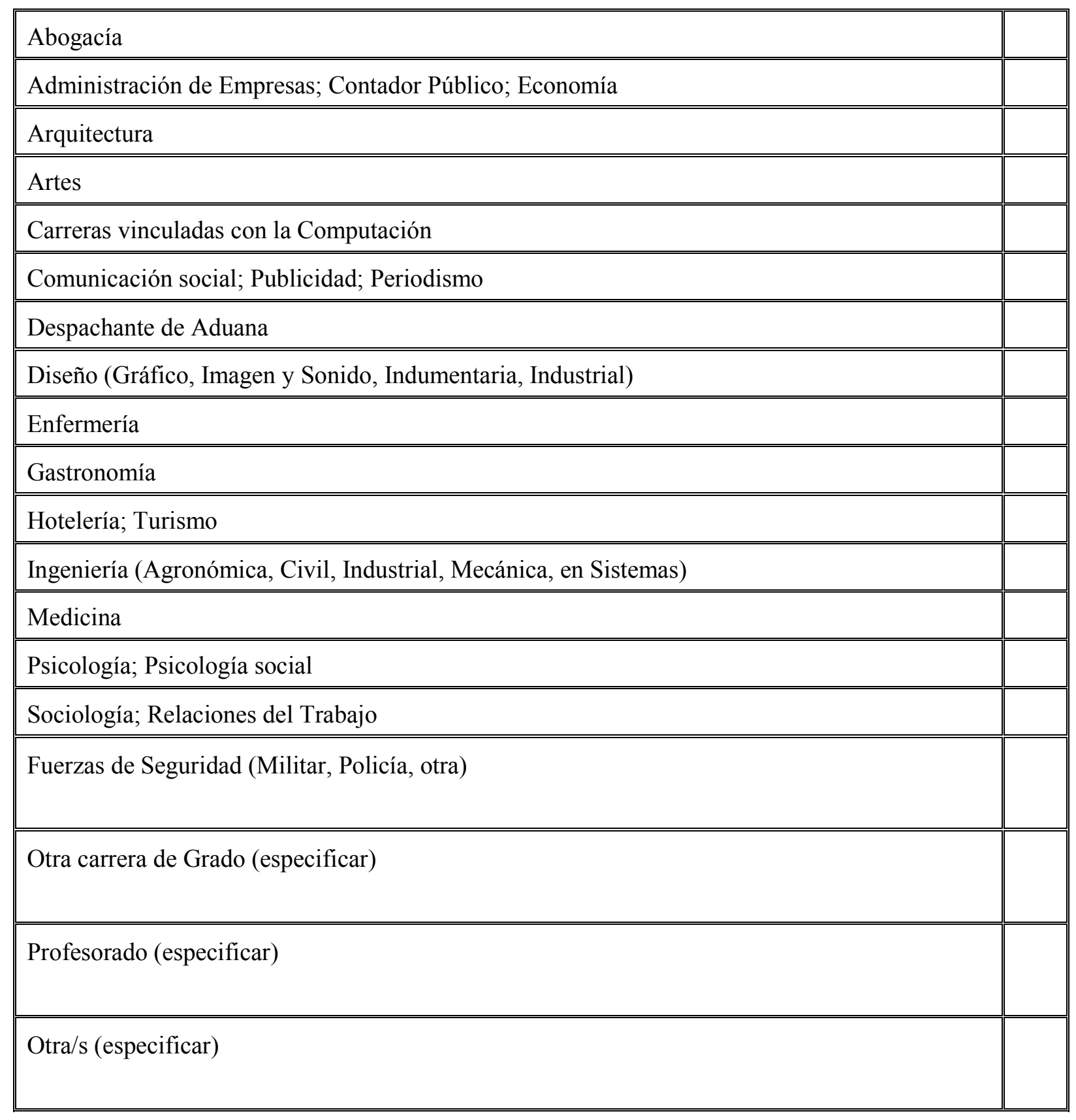

22. ¿Dónde estudiarías?

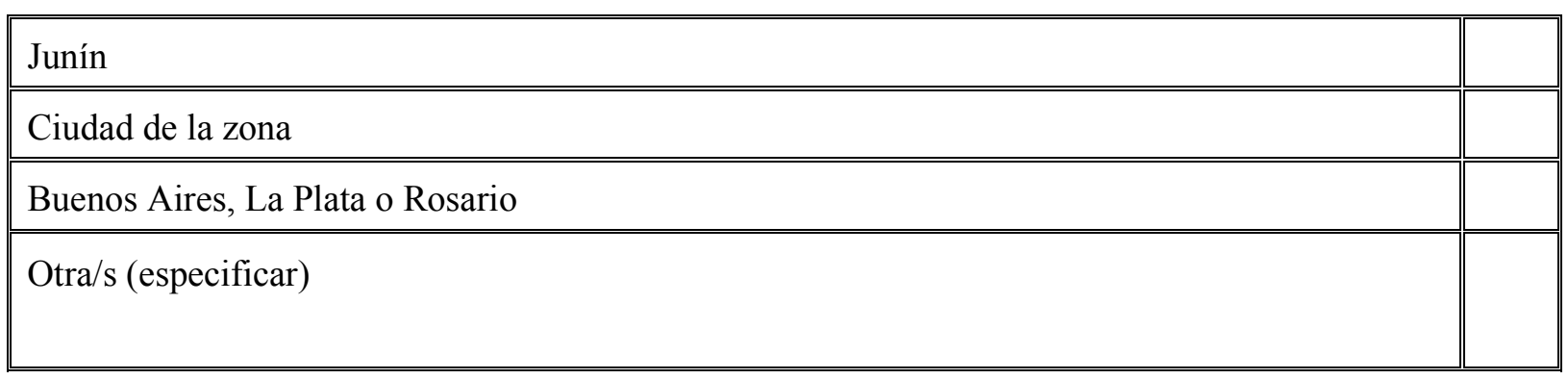


23. ¿Qué obstáculo/s deberías superar para el logro de tu meta educativa?

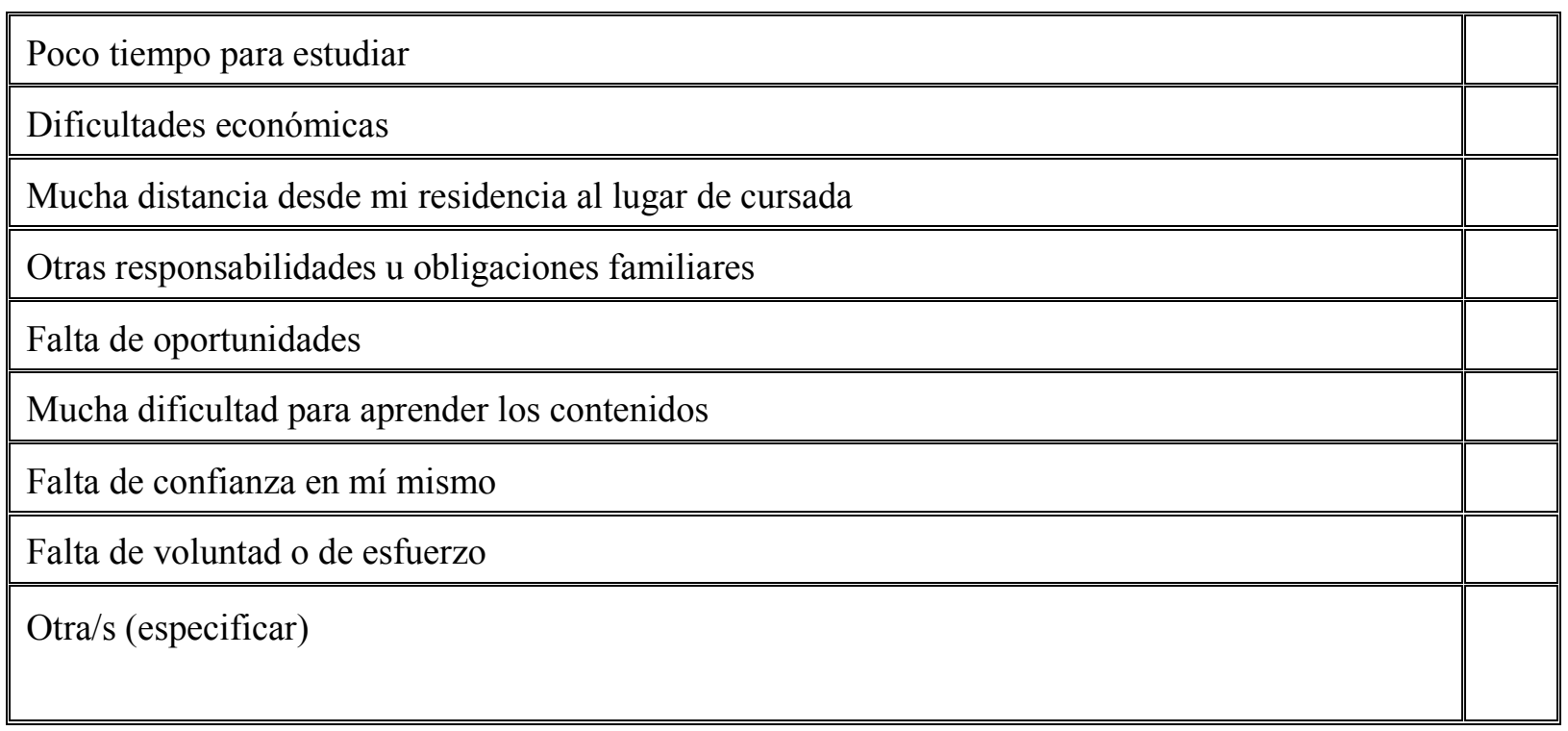




\section{Carta Introductoria}

Señor papá y/o señora mamá y/o tutor u otro:

Estamos trabajando en una investigación que servirá para elaborar una tesis acerca de la educación media estatal en el Distrito de Junín. Los resultados de la misma serán útiles para conocer temas de actualidad importantes relacionados con la educación.

Quisiéramos pedir su ayuda para que conteste algunas preguntas que no llevarán mucho tiempo. Sus respuestas serán confidenciales y anónimas.

Las opiniones de todos los encuestados serán sumadas e incluidas en la tesis pero nunca se comunicarán datos individuales.

Le pedimos que conteste este cuestionario con la mayor sinceridad posible.

Lea las instrucciones cuidadosamente y, desde ya,

¡muchas gracias por su colaboración! 


\section{Cuestionario (responsables)}

\begin{tabular}{|l||c|c||c||}
\cline { 2 - 4 } \multicolumn{1}{l|}{ Datos demográficos } & \multicolumn{1}{c|}{ Padre } & Madre & Tutor/Otro \\
\hline \hline Edad & & & \\
\hline \hline Estado civil & & & \\
\hline \hline Nacionalidad & & & \\
\hline $\begin{array}{l}\text { Nivel socioeconómico } \\
\text { (alto, medio o bajo) }\end{array}$ & & & \\
\hline $\begin{array}{l}\text { Barrio o zona donde } \\
\text { vive }\end{array}$ & & & \\
\hline \hline $\begin{array}{l}\text { Antigüedad en el lugar } \\
\text { actual de residencia }\end{array}$ & & & \\
\hline
\end{tabular}

En las preguntas 1 a 3 marque la o las opciones elegidas con una cruz (X). Sus respuestas serán anónimas y absolutamente confidenciales.

1. ¿Cuál es el máximo nivel educativo alcanzado por usted?

\begin{tabular}{|c|c|c|c|c|c|c|}
\hline & \multicolumn{2}{|c|}{ Padre } & \multicolumn{2}{|c|}{ Madre } & \multicolumn{2}{|c|}{ Tutor/Otro } \\
\hline & Finalizado & $\begin{array}{c}\text { No } \\
\text { Finalizado }\end{array}$ & Finalizado & $\begin{array}{c}\text { No } \\
\text { Finalizado }\end{array}$ & Finalizado & $\begin{array}{c}\text { No } \\
\text { Finalizado }\end{array}$ \\
\hline \multicolumn{7}{|l|}{ Primario } \\
\hline \multicolumn{7}{|l|}{ Secundario } \\
\hline \multicolumn{7}{|l|}{$\begin{array}{l}\text { Terciario } \\
\text { (no universitario) }\end{array}$} \\
\hline \multicolumn{7}{|l|}{ Universitario } \\
\hline \multicolumn{7}{|l|}{ Posgrado } \\
\hline \multicolumn{7}{|l|}{ Licenciatura } \\
\hline \multicolumn{7}{|l|}{ Doctorado } \\
\hline Otro/s (especificar) & & & & & & \\
\hline
\end{tabular}


2. ¿Cuál es el máximo nivel educativo alcanzado por su padre y/o madre o tutor/otro, es decir, los abuelos del egresado/a?

\begin{tabular}{|c|c|c|c|c|c|c|c|c|c|c|}
\hline & \multicolumn{2}{|c|}{$\begin{array}{l}\text { Abuelo } \\
\text { paterno }\end{array}$} & \multicolumn{2}{|c|}{$\begin{array}{l}\text { Abuela } \\
\text { paterna }\end{array}$} & \multicolumn{2}{|c|}{$\begin{array}{c}\text { Abuelo } \\
\text { materno }\end{array}$} & \multicolumn{2}{|c|}{$\begin{array}{c}\text { Abuela } \\
\text { materna }\end{array}$} & \multicolumn{2}{|c|}{$\begin{array}{l}\text { Padre y/o madre } \\
\text { de tutor u otro }\end{array}$} \\
\hline & F. & N.F. & F. & N.F. & F. & N.F. & F. & N.F. & F. & N.F. \\
\hline \multicolumn{11}{|l|}{ Primario } \\
\hline \multicolumn{11}{|l|}{ Secundario } \\
\hline \multicolumn{11}{|l|}{$\begin{array}{l}\text { Terciario (no } \\
\text { universitario) }\end{array}$} \\
\hline \multicolumn{11}{|l|}{ Universitario } \\
\hline \multicolumn{11}{|l|}{ Posgrado } \\
\hline \multicolumn{11}{|l|}{ Licenciatura } \\
\hline \multicolumn{11}{|l|}{ Doctorado } \\
\hline $\begin{array}{l}\text { Otro/s } \\
\text { (especificar) }\end{array}$ & & & & & & & & & & \\
\hline
\end{tabular}

F. $=$ Finalizado; N.F. $=$ No Finalizado

3. a. ¿Trabajó alguna vez?

\begin{tabular}{|l|l|l|l|}
\cline { 2 - 4 } \multicolumn{1}{l|}{} & Padre & Madre & Tutor/Otro \\
\hline Sí & & & \\
\hline \hline No & & & \\
\hline
\end{tabular}

b. ¿Dónde trabajó?

\begin{tabular}{|c|c|c|c|}
\hline & Padre & Madre & Tutor/Otro \\
\hline Empresa privada & & & \\
\hline Gobierno & & & \\
\hline Por cuenta propia (independiente) & & & \\
\hline
\end{tabular}

c. ¿Actualmente trabaja?

\begin{tabular}{|l|l|l||l|}
\cline { 2 - 4 } \multicolumn{1}{c|}{} & Padre & Madre & Tutor/Otro \\
\hline \hline Sí & & & \\
\hline No & & & \\
\hline
\end{tabular}


d. ¿Dónde trabaja?

\begin{tabular}{|l|l|l||l||}
\cline { 2 - 4 } \multicolumn{1}{c|}{} & Padre & Madre & Tutor/Otro \\
\hline \hline Empresa privada & & & \\
\hline \hline Gobierno & & & \\
\hline Por cuenta propia (independiente) & & & \\
\hline
\end{tabular}

En las preguntas 4 a 13 marque la o las opciones elegidas con una cruz (X).

4. ¿De qué fuente se vale para adquirir la información y el conocimiento?

\begin{tabular}{|c|c|c|c|}
\hline & Padre & Madre & Tutor/Otro \\
\hline \multicolumn{4}{|l|}{ La familia } \\
\hline \multicolumn{4}{|l|}{ La escuela } \\
\hline \multicolumn{4}{|l|}{ Los amigos } \\
\hline \multicolumn{4}{|l|}{ Internet } \\
\hline \multicolumn{4}{|c|}{ Libros, periódicos, revistas } \\
\hline \multicolumn{4}{|c|}{ La radio, la televisión } \\
\hline \multicolumn{4}{|l|}{ El cine, el teatro } \\
\hline Otra/s (especificar) & & & \\
\hline
\end{tabular}

5. a. ¿A qué atribuye fenómenos como el alcoholismo, la delincuencia, la drogadicción y la prostitución en el Distrito de Junín?

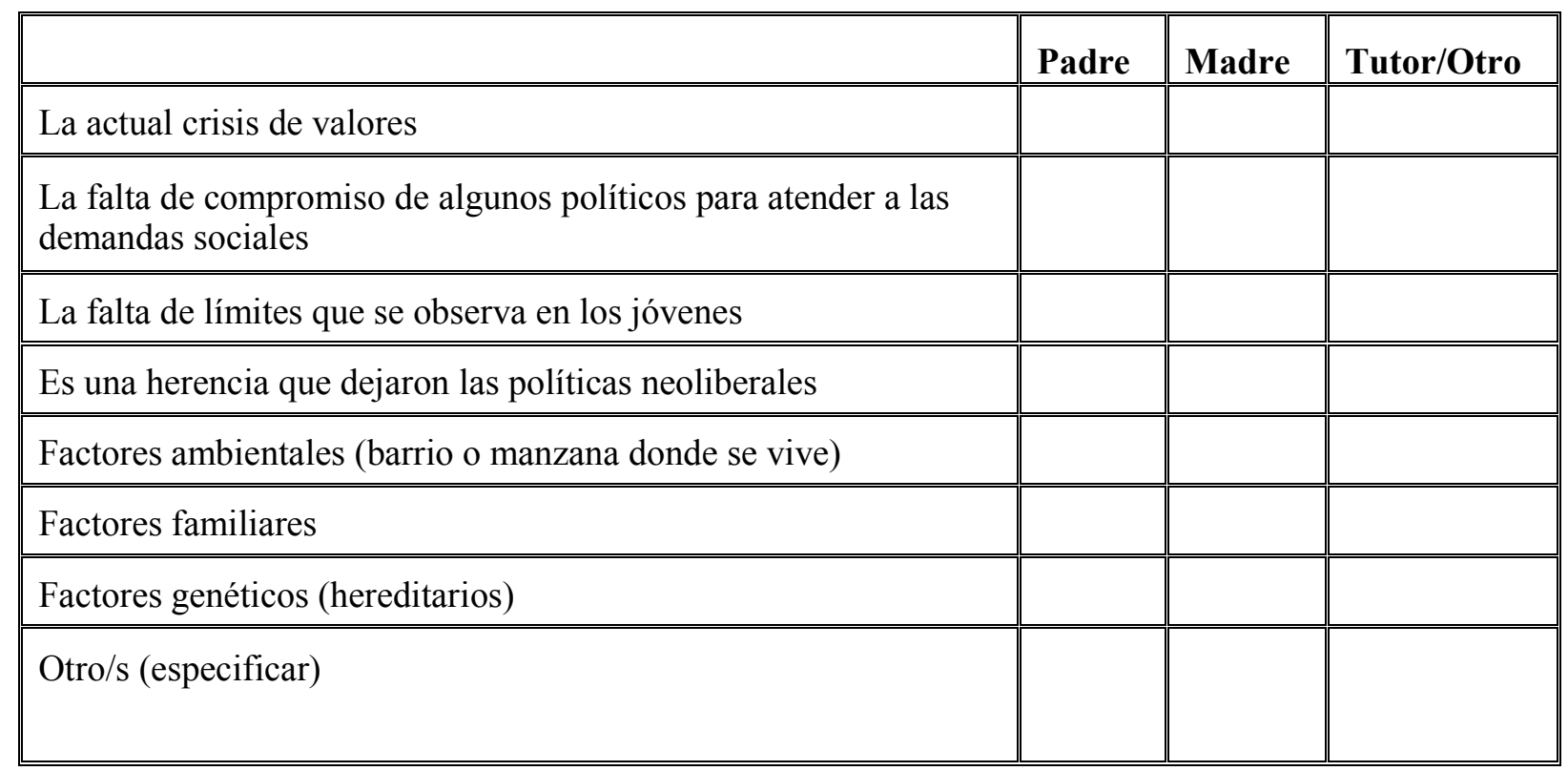


b. ¿Se puede cambiar esta realidad?

\begin{tabular}{|c|c|c|c|}
\hline & Padre & Madre & Tutor/Otro \\
\hline Sí. A través de políticas sociales de prevención & & & \\
\hline Sí. A través de una mejor calidad educativa & & & \\
\hline Sí. A través de un mejor servicio policial & & & \\
\hline Sí. A través de un mejor servicio de justicia & & & \\
\hline $\begin{array}{l}\text { Sí. Cuando algunos políticos piensen más en los problemas de la } \\
\text { gente }\end{array}$ & & & \\
\hline Sí. Desarrollando todos nosotros la capacidad de vivir juntos & & & \\
\hline No. Estos flagelos existieron siempre y siempre existirán & & & \\
\hline Otro/s (especificar) & & & \\
\hline
\end{tabular}

6. ¿De quién/es es la responsabilidad de impartir la educación para todos los habitantes en Argentina?

\begin{tabular}{|c|c|c|c|}
\hline & Padre & Madre & Tutor/Otro \\
\hline \multicolumn{4}{|l|}{ Del Estado Nacional } \\
\hline \multicolumn{4}{|c|}{ De las escuelas privadas } \\
\hline \multicolumn{4}{|l|}{ De las provincias } \\
\hline \multicolumn{4}{|c|}{ De las municipalidades } \\
\hline \multicolumn{4}{|l|}{ De los gremios } \\
\hline \multicolumn{4}{|c|}{ De las organizaciones no gubernamentales } \\
\hline \multicolumn{4}{|c|}{ De las sociedades de fomento } \\
\hline Otro/s (especificar) & & & \\
\hline
\end{tabular}


7. ¿Dónde está reconocido el derecho a la educación?

\begin{tabular}{|c|c|c|c|}
\hline & Padre & Madre & Tutor/Otro \\
\hline \multicolumn{4}{|c|}{ En la Constitución Nacional } \\
\hline \multicolumn{4}{|c|}{$\begin{array}{l}\text { En uno o más Tratados Internacionales de Derechos Humanos con } \\
\text { jerarquía constitucional }\end{array}$} \\
\hline \multicolumn{4}{|l|}{ En una Ley Nacional } \\
\hline \multicolumn{4}{|c|}{ En la Constitución de la Provincia de Buenos Aires } \\
\hline \multicolumn{4}{|c|}{ En una Ley de la Provincia de Buenos Aires } \\
\hline \multicolumn{4}{|c|}{ En una Ordenanza Municipal del Partido de Junín } \\
\hline \multicolumn{4}{|c|}{ En todo lo anteriormente dicho } \\
\hline \multicolumn{4}{|c|}{ En nada de lo anteriormente dicho } \\
\hline Otro/s (especificar) & & & \\
\hline
\end{tabular}

8. ¿Cómo evalúa la calidad educativa desde el retorno de la democracia (1983) hasta hoy?

\begin{tabular}{|l|l|l|l||}
\cline { 2 - 4 } \multicolumn{1}{c|}{} & Padre & Madre & Tutor/Otro \\
\hline Excelente & & & \\
\hline \hline Muy buena & & & \\
\hline Buena & & & \\
\hline Indeciso/a & & & \\
\hline \hline Regular & & & \\
\hline Mala & & & \\
\hline Muy mala & & & \\
\hline \hline Otra/s (especificar) & & & \\
\hline
\end{tabular}


9. ¿Cómo es actualmente la comunicación entre padres e hijos?

\begin{tabular}{|c|c|c|c|}
\hline & Padre & Madre & Tutor/Otro \\
\hline \multicolumn{4}{|l|}{ Muy fácil } \\
\hline \multicolumn{4}{|l|}{ Fácil } \\
\hline \multicolumn{4}{|c|}{ A veces fácil, a veces difícil } \\
\hline \multicolumn{4}{|l|}{ Difícil } \\
\hline \multicolumn{4}{|l|}{ Muy difícil } \\
\hline Otra/s (especificar) & & & \\
\hline
\end{tabular}

10. a. ¿Quién eligió la escuela a la que asiste su hijo/a?

\begin{tabular}{|l||l||}
\hline \hline Padre & \\
\hline \hline Madre & \\
\hline \hline Hijo/a & \\
\hline \hline Tutor/Otro & \\
\hline
\end{tabular}

b. ¿Por qué motivo?

\begin{tabular}{|c|c|c|c|c|}
\hline & Padre & Madre & Hijo/a & Tutor/Otro \\
\hline \multicolumn{5}{|c|}{$\begin{array}{l}\text { Es la que mejor lo/a prepara para continuar estudios } \\
\text { superiores }\end{array}$} \\
\hline \multicolumn{5}{|c|}{ Es una escuela exigente } \\
\hline \multicolumn{5}{|c|}{ Nos comentaron que es muy buena escuela } \\
\hline \multicolumn{5}{|c|}{ Porque estamos de acuerdo con el perfil institucional } \\
\hline \multicolumn{5}{|c|}{ Porque egresan capacitados para trabajar } \\
\hline \multicolumn{5}{|l|}{ Yo estudié en ella } \\
\hline \multicolumn{5}{|c|}{ Otro hijo/a también estudió en ella } \\
\hline \multicolumn{5}{|c|}{ Está ubicada cerca de mi/nuestra casa } \\
\hline \multicolumn{5}{|c|}{ No hay que pagar cuota } \\
\hline Otro/s (especificar) & & & & \\
\hline
\end{tabular}


11. ¿Qué desea para su hijo/a en el futuro?

\begin{tabular}{|c|c|c|c|}
\hline & Padre & Madre & Tutor/Otro \\
\hline \multicolumn{4}{|c|}{ Que sea un buen profesional } \\
\hline \multicolumn{4}{|c|}{ Que sea un buen trabajador } \\
\hline \multicolumn{4}{|c|}{ Que sea una buena persona } \\
\hline \multicolumn{4}{|c|}{ Que constituya una familia } \\
\hline \multicolumn{4}{|l|}{ Que sea feliz } \\
\hline \multicolumn{4}{|c|}{ Que gane mucho dinero } \\
\hline Otro/s (especificar) & & & \\
\hline
\end{tabular}

12. ¿Qué opinión le merecen los profesores de $3^{\circ}$ año de su hijo/a?

\begin{tabular}{|l|l|l|l||}
\hline & Padre & Madre & Tutor/Otro \\
\hline \hline Todos excelente & & & \\
\hline \hline Muchos excelente y algunos buena & & & \\
\hline Algunos excelente y muchos buena & & & \\
\hline Todos buena & & & \\
\hline Muchos buena y algunos mala & & & \\
\hline Algunos buena y muchos mala & & & \\
\hline \hline Todos regular & & & \\
\hline \hline Otra/s (especificar) & & & \\
\end{tabular}


13. ¿De qué manera hace conocer a las autoridades de la escuela sus inquietudes/opiniones sobre la marcha de la educación de su hijo/a?

\begin{tabular}{|l|l|l|l||}
\hline & Padre & Madre & Tutor/Otro \\
\hline \hline Cuando soy/somos citado/s desde la escuela por algún motivo & & & \\
\hline En las reuniones de padres con los directivos & & & \\
\hline \hline En las reuniones de padres con los profesores & & & \\
\hline \hline Yendo por mi/nuestra propia decisión a la escuela & & & \\
\hline De ninguna manera & & & \\
\hline Otra/s (especificar) & & & \\
& & & \\
\hline
\end{tabular}




\section{Carta Introductoria}

Señor/a Profesor/a del último año de escuela secundaria:

Estamos trabajando en una investigación que servirá para elaborar una tesis acerca de la educación media estatal en el Distrito de Junín. Los resultados de la misma serán útiles para conocer temas de actualidad importantes relacionados con la educación.

Quisiéramos pedir su ayuda para que conteste algunas preguntas que no llevarán mucho tiempo. Sus respuestas serán confidenciales y anónimas.

Las opiniones de todos los encuestados serán sumadas e incluidas en la tesis pero nunca se comunicarán datos individuales.

Le pedimos que conteste este cuestionario con la mayor sinceridad posible.

Lea las instrucciones cuidadosamente y, desde ya,

¡muchas gracias por su colaboración! 


\section{Cuestionario (profesores)}

\section{Datos demográficos:}

Sexo:

Edad:

Nacionalidad:

Nivel socioeconómico (alto, medio o bajo):

Estado civil:

Barrio o zona donde vive:

¿hace cuánto tiempo?

Antigüedad en la docencia:

¿Realiza alguna actividad física o deporte al menos una vez a la semana? ¿Cuál?

Marque la o las opciones elegidas con una cruz (X). Sus respuestas serán anónimas y absolutamente confidenciales:

1. ¿A quién/es se le/s reconoce el derecho a la educación?

\begin{tabular}{|l||l||}
\hline Ancianos & \\
\hline \hline Consumidores & \\
\hline Mujeres & \\
\hline Niños & \\
\hline Personas con discapacidad & \\
\hline Pueblos originarios & \\
\hline \hline Usuarios & \\
\hline \hline Todos & \\
\hline \hline Nadie & \\
\hline \hline Otro/s (especificar) & \\
\hline
\end{tabular}


2. ¿Dónde está reconocido el derecho a la educación?

En la Constitución Nacional

En uno o más Tratados Internacionales de Derechos Humanos con jerarquía constitucional

En una Ley Nacional

En la Constitución de la Provincia de Buenos Aires

En una Ley de la Provincia de Buenos Aires

En una Ordenanza Municipal del Partido de Junín

En todo lo anteriormente dicho

En nada de lo anteriormente dicho

Otro/s (especificar)

3. ¿Cómo evalúa la calidad educativa desde el retorno de la democracia (1983) hasta hoy?

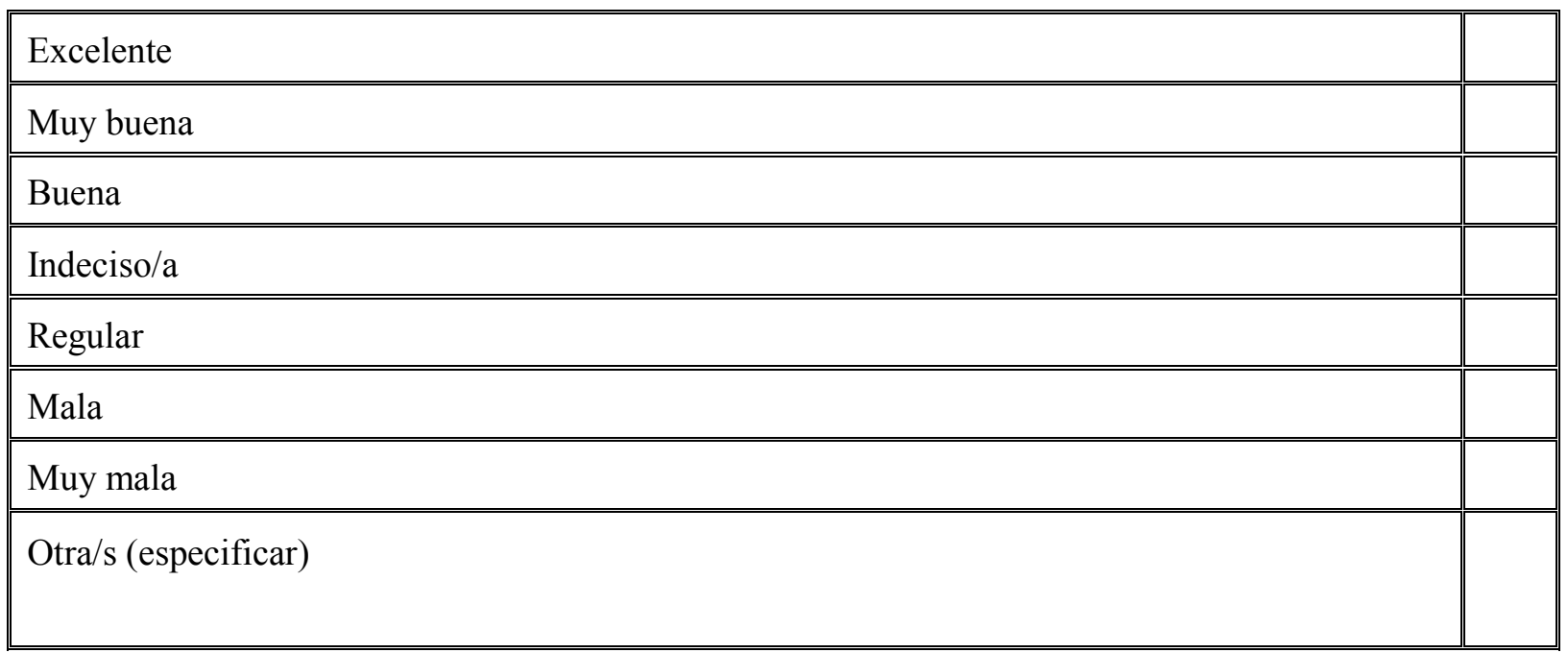


4. ¿A qué atribuye fenómenos como el alcoholismo, la delincuencia, la drogadicción y la prostitución en el Distrito de Junín?

La actual crisis de valores

La falta de compromiso de algunos políticos para atender a las demandas sociales

La falta de límites que se observa en los jóvenes

Es una herencia que dejaron las políticas neoliberales

Factores ambientales (barrio o manzana donde se vive)

Factores familiares

Factores genéticos (hereditarios)

Otro/s (especificar)

5. ¿Trabaja usted en alguna otra institución educativa?



6. ¿Qué tan de acuerdo se encuentra con lo dispuesto sobre la educación secundaria en las siguientes leyes?

\begin{tabular}{|c|c|c|}
\hline & $\begin{array}{c}\text { Ley de Educación } \\
\text { Nacional } N^{0} 26.206 / 06\end{array}$ & $\begin{array}{c}\text { Ley de Educación } \\
\text { Provincial } N^{0} 13.688 / 07\end{array}$ \\
\hline \multicolumn{3}{|l|}{ Muy de acuerdo } \\
\hline \multicolumn{3}{|l|}{ De acuerdo } \\
\hline \multicolumn{3}{|c|}{ Ni de acuerdo ni en desacuerdo } \\
\hline \multicolumn{3}{|l|}{ En desacuerdo } \\
\hline \multicolumn{3}{|l|}{ Muy en desacuerdo } \\
\hline \multicolumn{3}{|c|}{ No estoy debidamente informado/a } \\
\hline Otra/s (especificar) & & \\
\hline
\end{tabular}


7. ¿Cuál es el máximo nivel educativo alcanzado por su...?

\begin{tabular}{|c|c|c|c|c|c|c|}
\hline & \multicolumn{2}{|c|}{ Padre } & \multicolumn{2}{|c|}{ Madre } & \multicolumn{2}{|c|}{ Tutor/Otro } \\
\hline & Finalizado & $\begin{array}{c}\text { No } \\
\text { Finalizado }\end{array}$ & Finalizado & $\begin{array}{c}\text { No } \\
\text { Finalizado }\end{array}$ & Finalizado & $\begin{array}{c}\text { No } \\
\text { Finalizado }\end{array}$ \\
\hline \multicolumn{7}{|l|}{ Primario } \\
\hline \multicolumn{7}{|l|}{ Secundario } \\
\hline \multicolumn{7}{|l|}{$\begin{array}{l}\text { Terciario } \\
\text { (no universitario) }\end{array}$} \\
\hline \multicolumn{7}{|l|}{ Universitario } \\
\hline \multicolumn{7}{|l|}{ Posgrado } \\
\hline \multicolumn{7}{|l|}{ Licenciatura } \\
\hline \multicolumn{7}{|l|}{ Doctorado } \\
\hline Otro/s (especificar) & & & & & & \\
\hline
\end{tabular}

8. ¿Qué teoría/recurso educativa/o aplica en el desarrollo de las clases?

El de Emilia Ferreiro

Distinta, según las características del grupo de egresados

Distinta, según los diferentes temas de la asignatura

La conductista

La epistemología genética

La teoría del procesamiento de información

Una combinación de diferentes teorías

Otra/s (especificar) 
9. ¿Por qué causa/s eligió ser docente?

Desde mi infancia pensé ser docente

En el secundario algún/os profesor/es me aconsejaron que fuera docente

Me informaron que, como docente, iba a tener trabajo seguro

No podía irme a estudiar lo que deseaba a otro lugar

Pertenezco a una familia de docentes

Por vocación

Nunca pensé ser docente pero un día cambié de opinión

Otra/s (especificar)

10. ¿De qué fuente se vale para adquirir la información y el conocimiento?

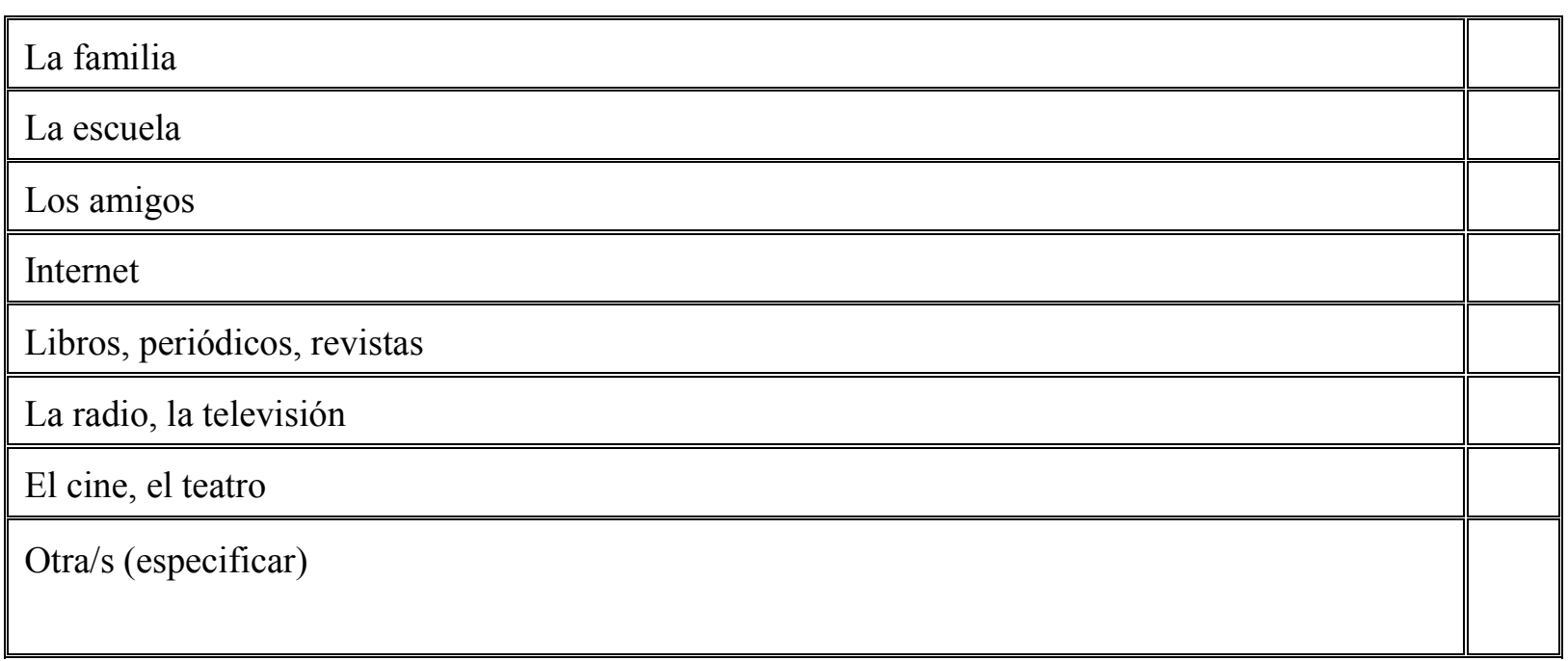

11. ¿Cómo considera que son como estudiantes los egresados de esta escuela? (Indique en porcentaje)

\begin{tabular}{|l||l||}
\hline Excelentes & \\
\hline Muy buenos & \\
\hline Buenos & \\
\hline Regulares & \\
\hline \hline Malos & \\
\hline
\end{tabular}


12. ¿Cuáles son las conductas inadecuadas del alumnado en clase?

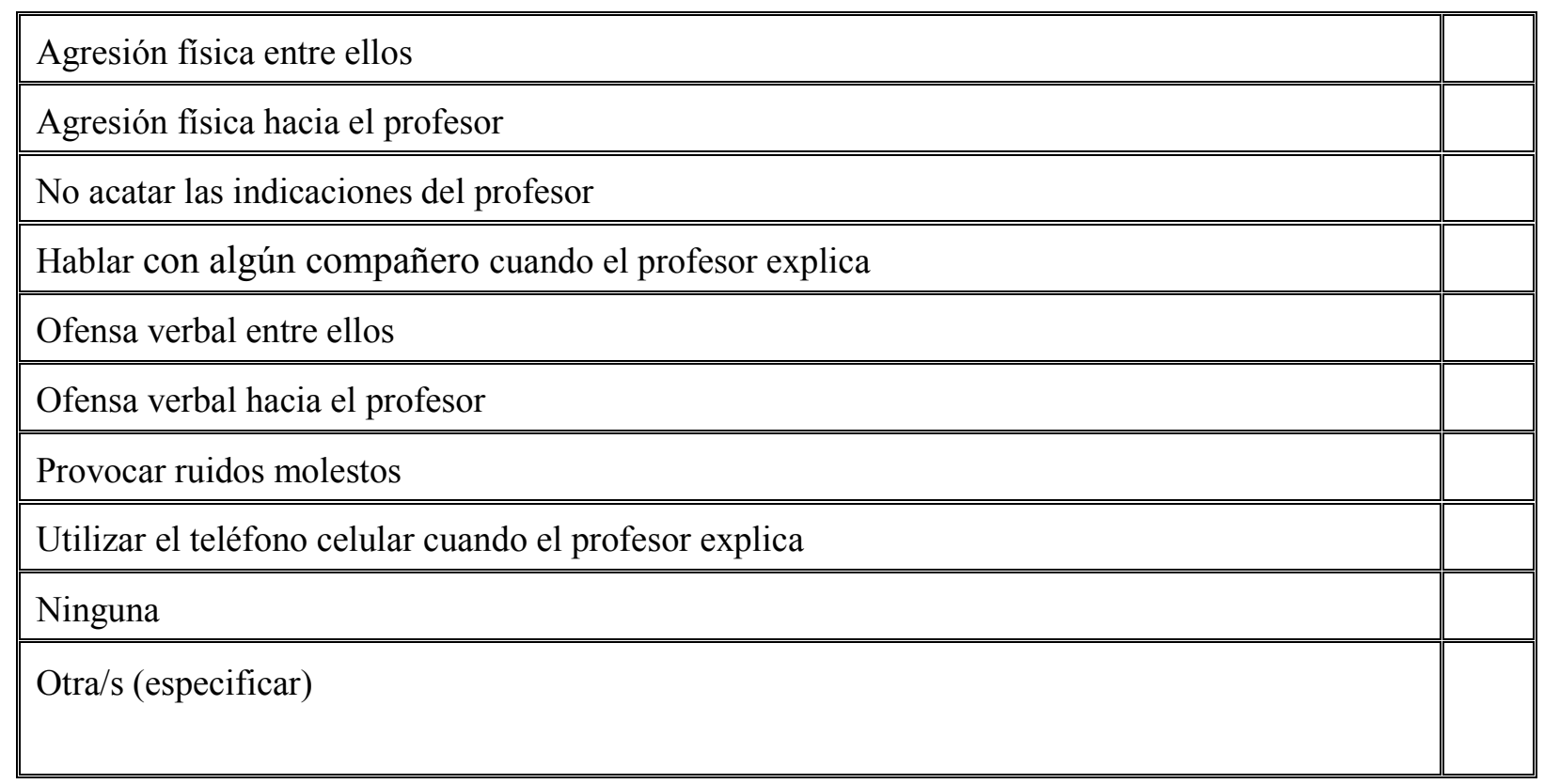

13. ¿Cómo encauza/pone fin a dichas conductas?

Hago venir al preceptor al aula y le comento lo sucedido

Hago venir al director al aula y le comento lo sucedido

Si no son muy perturbadoras, no intervengo

Si son perturbadoras corrijo al o a los responsables

Si son reiteradas cito en la escuela a los padres del o de los alumnos involucrados

Suspendo la clase y empezamos todos a dialogar sobre aspectos del Acuerdo de Convivencia

Suspendo la clase, pienso qué hacer y luego actúo

Otra/s (especificar) 


\section{Carta Introductoria}

Señor/a Director/a de escuela secundaria:

Estamos trabajando en una investigación que servirá para elaborar una tesis acerca de la educación media estatal en el Distrito de Junín. Los resultados de la misma serán útiles para conocer temas de actualidad importantes relacionados con la educación.

Quisiéramos pedir su ayuda para que conteste algunas preguntas que no llevarán mucho tiempo. Sus respuestas serán confidenciales y anónimas.

Las opiniones de todos los encuestados serán sumadas e incluidas en la tesis pero nunca se comunicarán datos individuales.

Le pedimos que conteste este cuestionario con la mayor sinceridad posible.

Lea las instrucciones cuidadosamente y, desde ya,

¡muchas gracias por su colaboración! 


\section{Cuestionario (directores)}

\section{Datos demográficos:}

Sexo:

Edad:

Nacionalidad:

Nivel socioeconómico (alto, medio o bajo):

Estado civil:

Barrio o zona donde vive:

Antigüedad en la docencia: ¿hace cuánto tiempo?

Antigüedad en el cargo actual:

¿Realiza alguna actividad física o deporte al menos una vez a la semana? ¿Cuál?

\section{Marque la o las opciones elegidas con una cruz (X). Sus respuestas serán anónimas y} absolutamente confidenciales.

1. El/la director/a de una escuela es:

La autoridad con funciones y competencias indeclinables

El coordinador natural de la institución educativa

El encargado de resguardar la estructura orgánica de la institución

Todo lo anteriormente dicho

Nada de lo anteriormente dicho

Otra/s (especificar)

2. ¿Dónde está reconocido el derecho a la educación?

En la Constitución Nacional

En uno o más Tratados Internacionales de Derechos Humanos con jerarquía constitucional

En una Ley Nacional

En la Constitución de la Provincia de Buenos Aires

En una Ley de la Provincia de Buenos Aires

En una Ordenanza Municipal del Partido de Junín

En todo lo anteriormente dicho

En nada de lo anteriormente dicho

Otro/s (especificar) 
3. ¿Qué tan de acuerdo se encuentra con lo dispuesto sobre la educación secundaria en las siguientes leyes?

\begin{tabular}{|c|c|c|}
\hline & $\begin{array}{c}\text { Ley de Educación } \\
\text { Nacional } N^{\circ} 26.206 / 06\end{array}$ & $\begin{array}{c}\text { Ley de Educación } \\
\text { Provincial } N^{\circ} \mathbf{1 3 . 6 8 8 / 0 7}\end{array}$ \\
\hline \multicolumn{3}{|l|}{ Muy de acuerdo } \\
\hline \multicolumn{3}{|l|}{ De acuerdo } \\
\hline \multicolumn{3}{|c|}{ Ni de acuerdo ni en desacuerdo } \\
\hline \multicolumn{3}{|l|}{ En desacuerdo } \\
\hline \multicolumn{3}{|l|}{ Muy en desacuerdo } \\
\hline \multicolumn{3}{|c|}{ No estoy debidamente informado/a } \\
\hline Otro/s (especificar) & & \\
\hline
\end{tabular}

4. ¿Cómo evalúa la calidad educativa desde el retorno de la democracia (1983) hasta hoy?

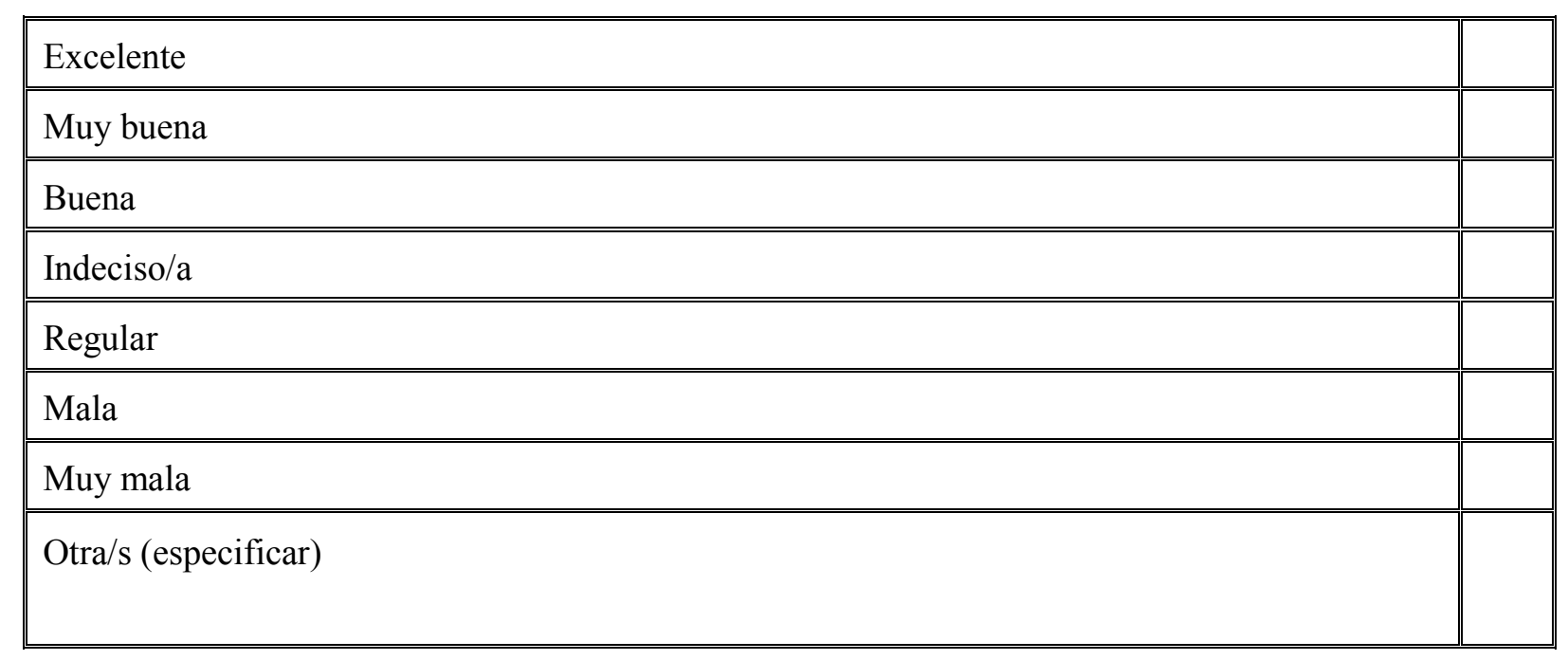


5. ¿Cuál es el máximo nivel educativo alcanzado por su...?

\begin{tabular}{|c|c|c|c|c|c|c|}
\hline & \multicolumn{2}{|c|}{ Padre } & \multicolumn{2}{|c|}{ Madre } & \multicolumn{2}{|c|}{ Tutor/Otro } \\
\hline & Finalizado & $\begin{array}{c}\text { No } \\
\text { Finalizado } \\
\end{array}$ & Finalizado & $\begin{array}{c}\text { No } \\
\text { Finalizado } \\
\end{array}$ & Finalizado & $\begin{array}{c}\text { No } \\
\text { Finalizado } \\
\end{array}$ \\
\hline Primario & & & & & & \\
\hline Secundario & & & & & & \\
\hline $\begin{array}{l}\text { Terciario } \\
\text { (no universitario) }\end{array}$ & & & & & & \\
\hline Universitario & & & & & & \\
\hline Posgrado & & & & & & \\
\hline Licenciatura & & & & & & \\
\hline Doctorado & & & & & & \\
\hline Otro/s (especificar) & & & & & & \\
\hline
\end{tabular}

En la escuela, lugar de encuentro de un grupo humano con funciones específicas, es necesario la organización del trabajo para el logro de objetivos con el máximo aprovechamiento de los recursos. Le solicitamos responda los siguientes interrogantes:

6. ¿Cómo se relaciona esta institución educativa con los responsables de los educandos que egresan en 2010 ?

7. ¿Cómo se llegó a confeccionar el Acuerdo Institucional de Convivencia?

8. ¿Cuáles son las prioridades de esta escuela? 
9. ¿Qué tareas hay que realizar en la escuela referidas a su organización?

10. ¿Quién/quiénes la/s lleva/n a cabo?

11. ¿Cómo se puede contribuir a ellas?

12. ¿Quién decide los pasos a seguir?

13. ¿Qué se decide? ¿Cuándo se decide?

14. ¿Quién informa a los demás? 
15. ¿A quién/es se informa? ¿Para qué se informa?

16. ¿Quién ayuda a quién?

17. ¿Cómo afecta el trabajo de uno a la tarea del otro? 


\section{Carta Introductoria}

Señor/a Secretario/a de escuela secundaria:

Estamos trabajando en una investigación que servirá para elaborar una tesis acerca de la educación media estatal en el Distrito de Junín. Los resultados de la misma serán útiles para conocer temas de actualidad importantes relacionados con la educación.

Quisiéramos pedir su ayuda para que conteste algunas preguntas que no llevarán mucho tiempo. Sus respuestas serán confidenciales y anónimas.

Las opiniones de todos los encuestados serán sumadas e incluidas en la tesis pero nunca se comunicarán datos individuales.

Le pedimos que conteste este cuestionario con la mayor sinceridad posible.

Lea las instrucciones cuidadosamente y, desde ya,

¡muchas gracias por su colaboración! 


\section{Cuestionario (secretarios)}

\section{Datos demográficos:}

Sexo:

Edad:

Nacionalidad:

Nivel socioeconómico (alto, medio o bajo):

Estado civil:

Barrio o zona donde vive:

¿hace cuánto tiempo?

Antigüedad en la docencia:

Antigüedad en el cargo actual:

¿Realiza alguna actividad física o deporte al menos una vez a la semana? ¿Cuál?

\section{Marque la o las opciones elegidas con una cruz (X). Sus respuestas serán anónimas y absolutamente confidenciales.}

1. El/la secretario/a de una escuela es aquella persona cuyo rol implica:

Asegurar canales de comunicación entre todos los actores de la institución y con los organismos con quienes se relacionan

Comprender la problemática del medio en que actúa y operar en razón de sus demandas y necesidades

Dar cuenta de los recursos humanos, materiales y financieros existentes

Intervenir en la elaboración y el control del proyecto educativo institucional

Observar y describir el trabajo, con el fin de proponer mecanismos para la mejor coordinación

Participar de la organización institucional

Tomar decisiones en el marco de su competencia y en el ejercicio legítimo de su autoridad

Todo lo anteriormente dicho

Nada de lo anteriormente dicho

Otro/s (especificar) 
2. ¿Dónde está reconocido el derecho a la educación?

En la Constitución Nacional

En uno o más Tratados Internacionales de Derechos Humanos con jerarquía constitucional

En una Ley Nacional

En la Constitución de la Provincia de Buenos Aires

En una Ley de la Provincia de Buenos Aires

En una Ordenanza Municipal del Partido de Junín

En todo lo anteriormente dicho

En nada de lo anteriormente dicho

Otro/s (especificar)

3. ¿Qué tan de acuerdo se encuentra con lo dispuesto sobre la educación secundaria en las siguientes leyes?

\begin{tabular}{|l|c||c||}
\cline { 2 - 3 } \multicolumn{1}{c|}{} & $\begin{array}{c}\text { Ley de Educación } \\
\text { Nacional } N^{\circ} 26.206 / 06\end{array}$ & $\begin{array}{c}\text { Ley de Educación } \\
\text { Provincial } N^{\circ} \text { 13.688/07 }\end{array}$ \\
\hline Muy de acuerdo & & \\
\hline \hline De acuerdo & & \\
\hline \hline Ni de acuerdo ni en desacuerdo & & \\
\hline \hline En desacuerdo & & \\
\hline \hline Muy en desacuerdo & & \\
\hline \hline No estoy debidamente informado/a & & \\
\hline \hline Otro/s (especificar) & & \\
\hline
\end{tabular}


4. ¿Cómo evalúa la calidad educativa desde el retorno de la democracia (1983) hasta hoy?

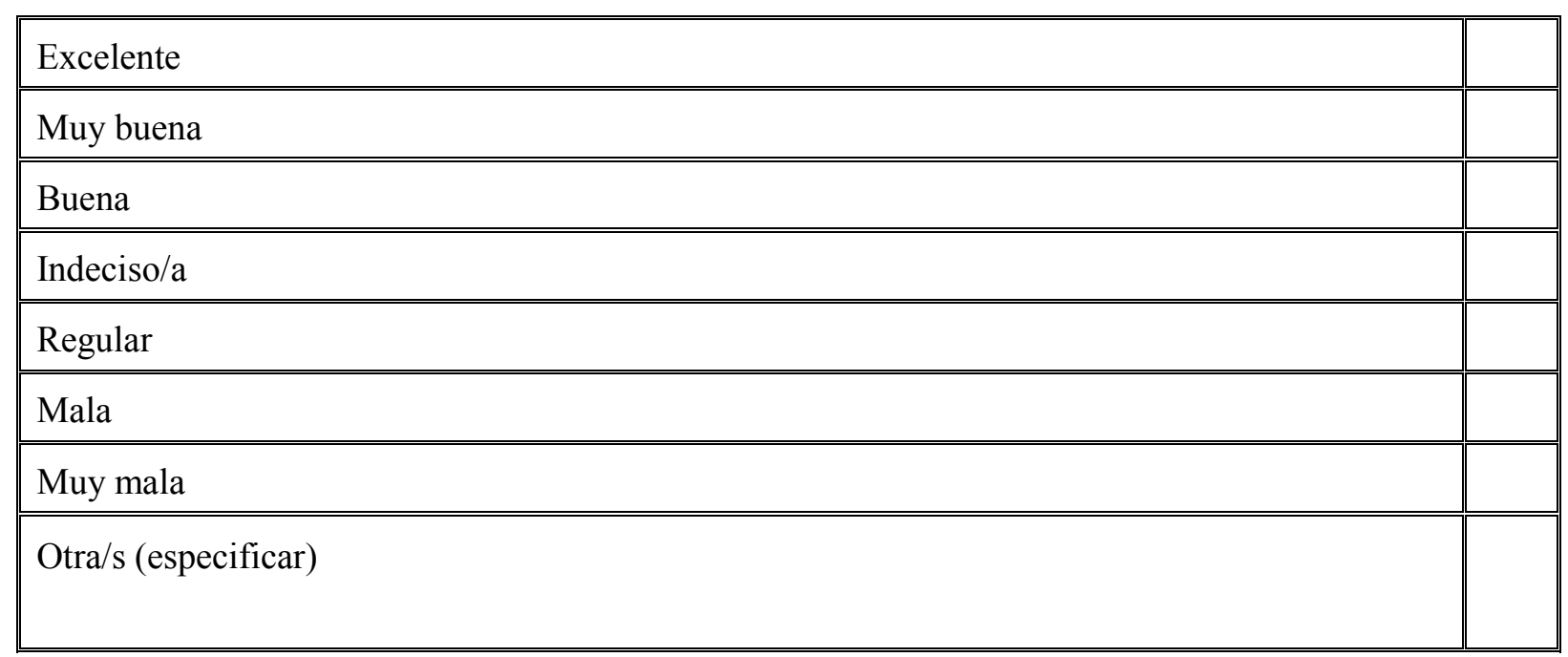

5. ¿Cuál es el máximo nivel educativo alcanzado por su:...?

\begin{tabular}{|c|c|c|c|c|c|c|}
\hline & \multicolumn{2}{|c|}{ Padre } & \multicolumn{2}{|c|}{ Madre } & \multicolumn{2}{|c|}{ Tutor/Otro } \\
\hline & Finalizado & $\begin{array}{c}\text { No } \\
\text { Finalizado }\end{array}$ & Finalizado & $\begin{array}{c}\text { No } \\
\text { Finalizado }\end{array}$ & Finalizado & $\begin{array}{c}\text { No } \\
\text { Finalizado }\end{array}$ \\
\hline \multicolumn{7}{|l|}{ Primario } \\
\hline \multicolumn{7}{|l|}{ Secundario } \\
\hline \multicolumn{7}{|l|}{$\begin{array}{l}\text { Terciario } \\
\text { (no universitario) }\end{array}$} \\
\hline \multicolumn{7}{|l|}{ Universitario } \\
\hline \multicolumn{7}{|l|}{ Posgrado } \\
\hline \multicolumn{7}{|l|}{ Licenciatura } \\
\hline \multicolumn{7}{|l|}{ Doctorado } \\
\hline Otro/s (especificar) & & & & & & \\
\hline
\end{tabular}

En la escuela, lugar de encuentro de un grupo humano con funciones específicas, es necesario la organización del trabajo para el logro de objetivos con el máximo aprovechamiento de los recursos. Le solicitamos responda los siguientes interrogantes: 
6. ¿Qué relación se da entre la escuela y el medio?

7. ¿Cuáles son las reacciones esperadas ante probables cambios?

8. ¿Hay división del trabajo?

9. ¿La toma de decisiones es patrimonio exclusivo del personal jerárquico?

10. ¿Se delega autoridad? En caso afirmativo, ¿cuál es el criterio?

11. ¿Existen relaciones interpersonales cooperativas? 
Dirección de Educación Secundaria - Región 14 - Distrito: Junín - Escuela H Modalidad: CIENCIAS NATURALES

Cuadro 3

Informe de Calificación: $1^{\circ}, 2^{\circ}$ y $3^{\circ}$ Año (P.I.C.) al 11/06/2010

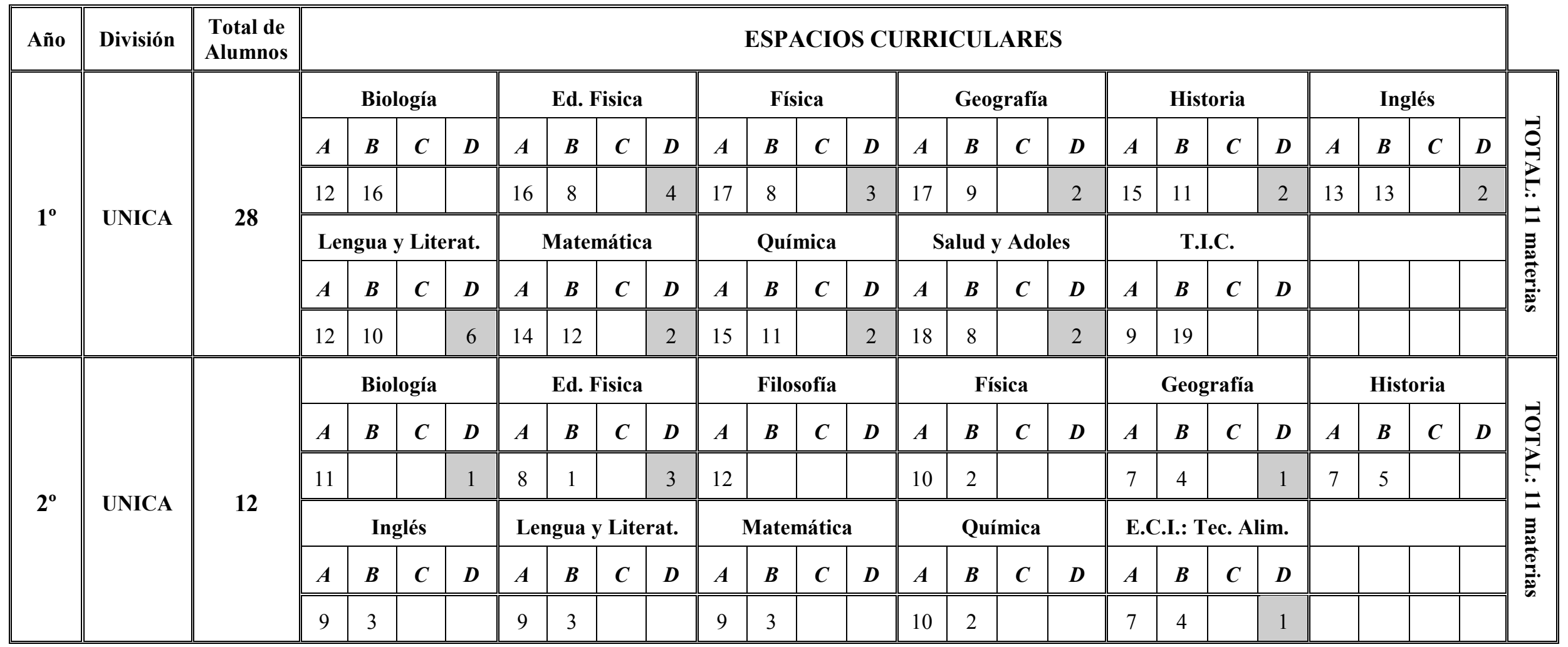


Cuadro 3 (continuación)

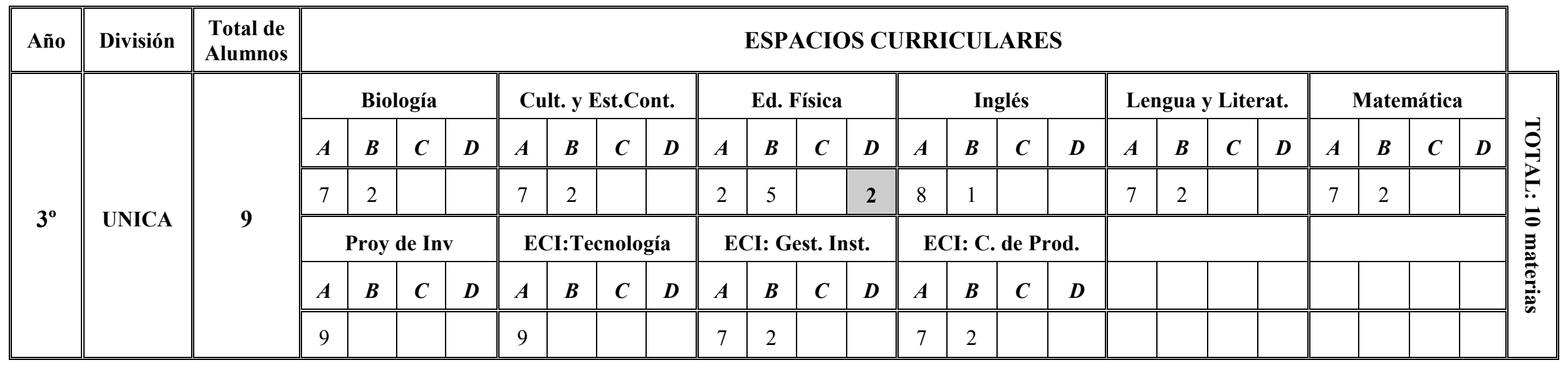

\section{Modalidad: EGEOR}

\section{Cuadro 3 (continuación)}

Informe de Calificación: $3^{\circ}$ Año al 11/06/2010

\begin{tabular}{|c|c|c|c|c|c|c|c|c|c|c|c|c|c|c|c|c|c|c|c|c|c|c|c|c|c|c|c|}
\hline Año & División & $\begin{array}{l}\text { Total de } \\
\text { Alumnos }\end{array}$ & \multicolumn{24}{|c|}{ ESPACIOS CURRICULARES } & \\
\hline \multirow{5}{*}{$\mathbf{3}^{\mathbf{0}}$} & \multirow{5}{*}{ UNICA } & \multirow{5}{*}{7} & \multicolumn{4}{|c|}{ Biología } & \multicolumn{4}{|c|}{ Cult. y Est.Cont. } & \multicolumn{4}{|c|}{ Economía } & \multicolumn{4}{|c|}{ Ed. Física } & \multicolumn{4}{|c|}{ Inglés } & \multicolumn{4}{|c|}{ Lengua y Literat. } & \\
\hline & & & $\boldsymbol{A}$ & $\boldsymbol{B}$ & C & $D$ & $A$ & $\boldsymbol{B}$ & $C$ & $D$ & $\boldsymbol{A}$ & $B$ & C & $D$ & $A$ & $\boldsymbol{B}$ & $C$ & $D$ & $\boldsymbol{A}$ & $B$ & $C$ & $D$ & $A$ & $B$ & $C$ & $D$ & 0 \\
\hline & & & 7 & & & & 7 & & & & 7 & & & & 6 & 1 & & & 6 & & & 1 & 7 & & & & $\dot{\theta}$ \\
\hline & & & \multicolumn{4}{|c|}{ Matemática } & \multicolumn{4}{|c|}{ Tec. de Gestión } & \multicolumn{4}{|c|}{ ECI: Tribut. } & \multicolumn{4}{|c|}{ ECI: Pca. Emp. } & & & & & & & & & $\stackrel{\vec{\partial}}{\partial}$ \\
\hline & & & 6 & 1 & & & 6 & 1 & & & 5 & 2 & & & 5 & 2 & & & & & & & & & & & \\
\hline
\end{tabular}

$\boldsymbol{A}$ : alumnos calificados con 7 a 10 puntos. $\boldsymbol{B}$ : alumnos calificados con 4 a 6 puntos. $\boldsymbol{C}$ : alumnos calificados con 1 a 3 puntos. $\boldsymbol{D}$ : alumnos sin calificar (en sombreado). La suma total $\boldsymbol{A}+\boldsymbol{B}+\boldsymbol{C}+\boldsymbol{D}$ debe coincidir con la columna Total de Alumnos 


\begin{tabular}{|c|c|}
\hline $\begin{array}{l}\text { Desempeño de alumnos } \\
\text { por materia }\end{array}$ & $\begin{array}{l}\text { Total de estudiantes a junio de } 2010,9 \text {. De ellos, } 1 \text { se exime en todas las } \\
\text { materias. Es decir, el } 11,11 \% \text { del total. Ningún alumno presenta } \\
\text { calificaciones debajo de } 4 \text { puntos. Si los } 9 \text { hubiesen sido calificados en las } \\
10 \text { asignaturas habría } 90 \text { notas. Hay sólo } 88 \text { debido a } 2 \text { estudiantes que no } \\
\text { fueron calificados en Educación Física. }\end{array}$ \\
\hline $\begin{array}{l}\text { Materias con mayor } \\
\text { número de alumnos } \\
\text { aprobados }\end{array}$ & $\begin{array}{l}\text { Proyecto de Investigación: } 9 . \\
\text { ECI: Tecnología: } 9 . \\
\text { Inglés: } 8 .\end{array}$ \\
\hline $\begin{array}{l}\text { Materias con mayor } \\
\text { número de alumnos } \\
\text { desaprobados }\end{array}$ & $\begin{array}{l}\text { Educación Física: } 5 \text {. } \\
\text { Hay } 6 \text { materias que presentan } 2 \text { alumnos desaprobados. Éstos no siempre } \\
\text { son los mismos en cada una de ellas. }\end{array}$ \\
\hline $\begin{array}{l}\text { Análisis de las } \\
\text { calificaciones de } \\
\text { diferentes años con el } \\
\text { mismo profesor }\end{array}$ & $\begin{array}{l}\text { En } 2^{\circ} \text { y en } 3^{\circ} \text { Año se comparten los profesores de Biología, Inglés, } \\
\text { Lengua y Literatura y Matemática, no observándose diferencias } \\
\text { significativas en las calificaciones de ambos grupos ni otras situaciones } \\
\text { que requieran intervención especial. }\end{array}$ \\
\hline $\begin{array}{l}\text { Cantidad de alumnos y } \\
\text { rendimiento por } \\
\text { materia }\end{array}$ & $\begin{array}{l}\text { Si bien la cantidad de educandos es reducida, hay cuatro materias (las } \\
\text { indicadas en el punto anterior) en las que el curso se fusiona con } 2^{\circ} \text { Año } \\
\text { (el número total se elevaría, entonces, a } 21 \text { ). Igualmente, el número de } \\
\text { alumnos no constituye una variable significativa para analizar el } \\
\text { rendimiento en las materias en cuanto a estudiantes aprobados. Si estas } \\
\text { asignaturas se dictaran para cada curso por separado, el rendimiento a } \\
\text { nivel cualitativo podría ser diferente. }\end{array}$ \\
\hline $\begin{array}{l}\text { Inasistencias y } \\
\text { calificaciones }\end{array}$ & $\begin{array}{l}\text { Si bien existen alumnos con inasistencias reiteradas, no siempre coinciden } \\
\text { con los que desaprueban la mayor cantidad de materias. Por otro lado, } \\
\text { existe una relación directa en el caso de Educación Física, que los } \\
\text { alumnos desaprueban ( } 5 \text { en total) por no asistir a las clases. }\end{array}$ \\
\hline $\begin{array}{l}\text { Desempeño escolar e } \\
\text { inasistencias de los } \\
\text { profesores }\end{array}$ & $\begin{array}{l}\text { Las inasistencias de los docentes no son relevantes y no inciden en el } \\
\text { desempeño escolar del alumno. }\end{array}$ \\
\hline $\begin{array}{l}\text { Análisis de las ausencias } \\
\text { a clase de los alumnos }\end{array}$ & $\begin{array}{l}\text { Respecto de los estudiantes con inasistencias reiteradas, el motivo de las } \\
\text { mismas se relaciona con cierta desorganización y conflictos familiares, a } \\
\text { la vez que se visualiza la ausencia de adultos que asuman sus roles en el } \\
\text { acompañamiento de la educación de sus hijos. Por otro lado, en el caso de } \\
\text { Educación Física la cuestión radicaría en una falta de valoración de la } \\
\text { materia. }\end{array}$ \\
\hline
\end{tabular}


Cuadro 4 (continuación)

\begin{tabular}{|l||l||}
\hline \hline $\begin{array}{l}\text { Conclusión del } \\
\text { ausentismo }\end{array}$ & $\begin{array}{l}\text { Falta de valoración de la educación como derecho y como bien cultural. } \\
\text { También se percibe en los educandos una interpretación errónea del } \\
\text { proceso de enseñanza y aprendizaje; es decir, no logran reconocer que } \\
\text { faltar a clase reiteradamente interfiere en dicho proceso, reduciéndolo a } \\
\text { completar las carpetas. Asimismo, se observa la ausencia de familias que } \\
\text { ejerzan sus roles, puesto que se observan estudiantes asumiendo } \\
\text { responsabilidades a temprana edad y la carencia de autoridad en las } \\
\text { familias que exija a sus hijos estudiar con responsabilidad. }\end{array}$ \\
\hline \hline $\begin{array}{l}\text { Análisis de estos datos } \\
\text { con la cantidad de clases } \\
\text { dictadas. Suspensión de } \\
\text { clases }\end{array}$ & $\begin{array}{l}\text { No constituye una variable significativa ya que no hubo suspensión de } \\
\text { clases. }\end{array}$ \\
\hline \hline $\begin{array}{l}\text { Equipamiento: análisis } \\
\text { del desempeño } \\
\text { académico con uso del } \\
\text { mismo }\end{array}$ & $\begin{array}{l}\text { La institución cuenta con una biblioteca de 2000 volúmenes, dos salas de } \\
\text { informática conectadas a Internet, laboratorio equipado y otros elementos } \\
\text { tecnológicos a disposición de los docentes y alumnos. }\end{array}$ \\
\hline
\end{tabular}




\begin{tabular}{|c|c|}
\hline $\begin{array}{l}\text { Desempeño de alumnos } \\
\text { por materia }\end{array}$ & $\begin{array}{l}\text { Total de estudiantes a junio de } 2010: 7 \text {. De ellos, } 4 \text { se eximen en todas las } \\
\text { materias. O sea, el } 57,14 \% \text { del total. } \\
\text { Ningún alumno presenta calificaciones debajo de } 4 \text { puntos. } \\
\text { Si los } 7 \text { hubiesen sido calificados en las } 10 \text { asignaturas habría } 70 \text { notas. } \\
\text { Sólo hay } 69 \text { debido a que un estudiante no fue calificado en Inglés. En } \\
\text { esta investigación fueron encuestados los } 6 \text { egresados: } 1 \text { varón y } 5 \\
\text { mujeres. }\end{array}$ \\
\hline $\begin{array}{l}\text { Materias con mayor } \\
\text { número de alumnos } \\
\text { aprobados }\end{array}$ & $\begin{array}{l}\text { Biología: } 7 . \\
\text { Cultura y Estética Contemporáneas: } 7 . \\
\text { Economía: } 7 . \\
\text { Lengua y Literatura: } 7 .\end{array}$ \\
\hline $\begin{array}{l}\text { Materias con mayor } \\
\text { número de alumnos } \\
\text { desaprobados }\end{array}$ & $\begin{array}{l}\text { ECI: Sistema tributario: } 2 . \\
\text { ECI: Práctica Empresarial: } 2 .\end{array}$ \\
\hline $\begin{array}{l}\text { Análisis de las } \\
\text { calificaciones de } \\
\text { diferentes años con el } \\
\text { mismo profesor }\end{array}$ & $\begin{array}{l}\text { En } 2^{\circ} \text { y en } 3^{\circ} \text { Año se comparten los docentes de Inglés, Lengua y } \\
\text { Literatura y Matemática, no apreciándose diferencias significativas en las } \\
\text { calificaciones de ambos grupos ni otras situaciones que requieran } \\
\text { intervención especial. }\end{array}$ \\
\hline $\begin{array}{l}\text { Cantidad de alumnos y } \\
\text { rendimiento por } \\
\text { materia }\end{array}$ & $\begin{array}{l}\text { Si bien la cantidad de estudiantes es reducida, hay tres materias (las } \\
\text { señaladas en el punto anterior) en las cuales el curso se fusiona con } 2^{\circ} \\
\text { Año (el número total se elevaría, pues, a 19). Igualmente, el número de } \\
\text { educandos no constituye una variable significativa para analizar el } \\
\text { rendimiento en las materias en cuanto a alumnos aprobados. Si estas } \\
\text { asignaturas se dictaran para cada curso por separado, el rendimiento a } \\
\text { nivel cualitativo podría ser diferente. }\end{array}$ \\
\hline $\begin{array}{l}\text { Inasistencias y } \\
\text { calificaciones }\end{array}$ & $\begin{array}{l}\text { Existen } 2 \text { alumnas que registran el mayor número de inasistencias. Una de } \\
\text { ellas presenta } 5 \text { asignaturas desaprobadas y la otra } 2 \text {. }\end{array}$ \\
\hline $\begin{array}{l}\text { Desempeño escolar e } \\
\text { inasistencias de los } \\
\text { profesores }\end{array}$ & $\begin{array}{l}\text { Las inasistencias de los docentes no son relevantes y no influyen en el } \\
\text { desempeño escolar del alumno. }\end{array}$ \\
\hline $\begin{array}{l}\text { Análisis de las ausencias } \\
\text { a clase de los alumnos }\end{array}$ & $\begin{array}{l}\text { Respecto de los estudiantes con inasistencias reiteradas, la causa de las } \\
\text { mismas se relaciona con cierta desorganización familiar, especialmente al } \\
\text { caso de en una alumna. El cuidado de su hijo (bebé) y la distancia que } \\
\text { existe desde su domicilio hasta la escuela y la guardería, obstaculizan su } \\
\text { rendimiento personal. }\end{array}$ \\
\hline $\begin{array}{l}\text { Conclusión del } \\
\text { ausentismo }\end{array}$ & $\begin{array}{l}\text { Falta de valoración de la educación como derecho y como bien cultural. } \\
\text { Ausencia de familias que ejerzan sus roles, puesto que se observan } \\
\text { estudiantes que asumen responsabilidades a temprana edad y carencia de } \\
\text { autoridad en las familias que exija a sus hijos estudiar con } \\
\text { responsabilidad. }\end{array}$ \\
\hline
\end{tabular}




\section{Cuadro 5 (continuación)}

Análisis de estos datos con la cantidad de clases dictadas.

No constituye una variable significativa ya que no hubo suspensión de Suspensión de clases

Equipamiento: análisis del desempeño académico con uso del clases.

mismo

En la institución existe una biblioteca con 2000 volúmenes, dos salas de informática conectadas a Internet, laboratorio equipado y otros elementos tecnológicos a disposición de los docentes y estudiantes. 
Cuadro 6

Escuela F - Asistencia de profesores por materia entre el 15/03/2010 y el 31/08/2010 - CURSO: $3^{\circ}$ I ADICO

\begin{tabular}{|c|c|c|c|}
\hline Materia & $\begin{array}{c}\text { Clases que debían } \\
\text { dictarse }\end{array}$ & $\begin{array}{l}\text { Clases que se } \\
\text { dictaron }\end{array}$ & Inasistencias \\
\hline Lengua & 77 & $74(96,10 \%)$ & $3(3,90 \%)$ \\
\hline Matemática & 88 & $81(92,05 \%)$ & $7(7,95 \%)$ \\
\hline Biología & 43 & $41(95,35 \%)$ & $2(4,65 \%)$ \\
\hline Físico-Química & 41 & $40(97,56 \%)$ & $1(2,44 \%)$ \\
\hline Historia & 41 & $36(87,80 \%)$ & $5(12,20 \%)$ \\
\hline Geografía & 34 & $31(91,18 \%)$ & $3(8,82 \%)$ \\
\hline Construcción de Ciudadanía & 40 & $36(90 \%)$ & $4(10 \%)$ \\
\hline Inglés & 38 & $33(86,84 \%)$ & $5(13,16 \%)$ \\
\hline Educación Artística & 43 & $40(93,02 \%)$ & $3(6,98 \%)$ \\
\hline Educación Física & Sin información & Sin información & Sin información \\
\hline TOTALES & $445(100 \%)$ & $412(92,58 \%)$ & $33(7,42 \%)$ \\
\hline
\end{tabular}

Cuadro 7

Escuela F - Asistencia de profesores por materia entre el 15/03/2010 y el 31/08/2010 - CURSO: $3^{\circ}$ II ADICO

\begin{tabular}{|c|c|c|c|}
\hline Materia & $\begin{array}{c}\text { Clases que debían } \\
\text { dictarse }\end{array}$ & $\begin{array}{l}\text { Clases que se } \\
\text { dictaron }\end{array}$ & Inasistencias \\
\hline Lengua & 85 & $81(95,3 \%)$ & $4(4,70 \%)$ \\
\hline Matemática & 72 & $42(58 \%)$ & $30(42 \%)$ \\
\hline Biología & 39 & $39(100 \%)$ & $0(0 \%)$ \\
\hline Físico-Química & 47 & $45(95,80 \%)$ & $2(4,20 \%)$ \\
\hline Historia & 45 & $43(95,60 \%)$ & $2(4,40 \%)$ \\
\hline Geografía & 45 & $41(91,20 \%)$ & $4(8,80 \%)$ \\
\hline Construcción de Ciudadanía & 42 & $42(100 \%)$ & $0(0 \%)$ \\
\hline Inglés & 36 & $34(94,50 \%)$ & $2(5,50 \%)$ \\
\hline Educación Artística & 46 & $46(100 \%)$ & $0(0 \%)$ \\
\hline Educación Física & Sin información & Sin información & Sin información \\
\hline TOTALES & $457(100 \%)$ & $413(90,37 \%)$ & $44(9,63 \%)$ \\
\hline
\end{tabular}


Cuadro 8 Escuela F - Movimientos de matrícula de alumnos - Marzo/Agosto de 2010

\begin{tabular}{|c|c|c|c|c|}
\hline Curso & Total Marzo & Egreso & Ingreso & Total Agosto \\
\hline $2^{\circ}$ I ADICO & 42 & 1 & 1 & 42 \\
\hline $2^{\circ}$ I Ciencias Naturales & 22 & 0 & 0 & 22 \\
\hline $2^{\circ}$ I EGEOR & 22 & 4 & 0 & 18 \\
\hline $2^{\circ} \mathrm{II} \mathrm{ADICO}$ & 23 & 0 & 0 & 23 \\
\hline $2^{\circ}$ II Ciencias Naturales & 24 & 0 & 0 & 24 \\
\hline $2^{\circ}$ II EGEOR & 22 & 2 & 0 & 20 \\
\hline $3^{\circ} \mathrm{I}$ ADICO & 28 & 0 & 0 & 28 \\
\hline $3^{\circ}$ I Ciencias Naturales & 30 & 1 & 0 & 29 \\
\hline $3^{\circ}$ I EGEOR & 22 & 0 & 0 & 22 \\
\hline $4^{\circ}$ I Comunicaciones & 28 & 2 & 2 & 28 \\
\hline $4^{\circ}$ I Ciencias Naturales & 32 & 1 & 1 & 32 \\
\hline $4^{\circ}$ I EGEOR & 18 & 6 & 1 & 13 \\
\hline $4^{\circ}$ II Comunicaciones & 26 & 3 & 0 & 23 \\
\hline $4^{\mathrm{o}}$ II Ciencias Naturales & 35 & 1 & 0 & 34 \\
\hline $4^{\circ}$ II EGEOR & 24 & 4 & 2 & 22 \\
\hline Totales & $398(100 \%)$ & $25(6,28 \%)$ & $7(1,75 \%)$ & $380(100 \%)$ \\
\hline
\end{tabular}

Notas: 1. El sombreado destaca la información obtenida respecto de los cursos y modalidades que interesan en esta investigación.

2. Cursos tenidos en cuenta: 15 , haciéndose hincapié en $3^{\circ}$ Año. 
Cuadro 9

Escuela F - Ausentismo de profesores por curso - Marzo/Agosto de 2010

\begin{tabular}{|l|c||c||}
\hline \multicolumn{1}{|c|}{ Curso } & Carga Horaria & Ausentismo \\
\hline \hline $2^{\circ}$ I ADICO & 561 & $63(11,23 \%)$ \\
\hline $2^{\circ}$ I Ciencias Naturales & 550 & $14(2,55 \%)$ \\
\hline \hline $2^{\circ}$ I EGEOR & 296 & $37(12,50 \%)$ \\
\hline \hline $2^{\circ}$ II ADICO & 526 & $50(9,51 \%)$ \\
\hline $2^{\circ}$ II Ciencias Naturales & 550 & $18(3,27 \%)$ \\
\hline \hline $2^{\circ}$ II EGEOR & 513 & $41(7,99 \%)$ \\
\hline \hline $3^{\circ}$ I ADICO & 316 & $58(18,35 \%)$ \\
\hline \hline $3^{\circ}$ I Ciencias Naturales & 438 & $34(7,76 \%)$ \\
\hline $3^{\circ}$ I EGEOR & 323 & $35(10,84 \%)$ \\
\hline $4^{\circ}$ I Comunicaciones & 547 & $43(7,86 \%)$ \\
\hline \hline $4^{\circ}$ I Ciencias Naturales & 513 & $15(2,92 \%)$ \\
\hline \hline $4^{\circ}$ I EGEOR & 488 & $49(10,04 \%)$ \\
\hline \hline $4^{\circ}$ II Comunicaciones & 561 & $21(3,74 \%)$ \\
\hline \hline $4^{\circ}$ II Ciencias Naturales & 513 & $41(7,99 \%)$ \\
\hline \hline $4^{\circ}$ II EGEOR & 481 & $(8,73 \%)$ \\
\hline \hline Porcentaje Total: 7,82\% ausentismo docente & & \\
\hline
\end{tabular}

Notas: 1. El sombreado destaca la información obtenida respecto de los cursos y modalidades que interesan en esta investigación.

2. Cursos tenidos en cuenta: 15 , poniéndose énfasis en $3^{\circ}$ Año. 